Ana Ribeiro Cassales

\title{
LIGNOPOLIURETANAS SINTETIZADAS A PARTIR DE LIGNINA KRAFT E ÓLEO DE MAMONA COM SIMULTÂNEA FORMAÇÃO DE FILMES
}

Tese apresentada ao Instituto de Química de São Carlos da Universidade de São Paulo como parte dos requisitos para a obtenção do Título de Doutora em Ciências.

Área de Concentração: Química Analítica e Inorgânica

Orientadora: Profa. Dra. Elisabete Frollini

SÃO CARLOS

2019 
Autorizoareproduçãoedivulgaçãototalouparcialdestetrabalho, porqualquermeio convencionalou eletrônico para fins de estudo e pesquisa, desdeque citada a fonte.

\section{Assinatura:}

\section{Data:}

\section{Cassales, Ana Ribeiro}

LignopoliuretanassintetizadasapartirdeLigninaKrafteóleodemamona com simultânea formação de filmes / Ana Ribeiro Cassales. —São Carlos, 2019.

$231 \mathrm{f}$.

Tese(DoutoradoemQuímicaAnalíticaeInorgânica)—InstitutodeQuímica de São Carlos / Universidade de São Paulo, 2019.

Orientadora: Profa. Dra. Elisabete Frollini

1.Poliuretanas. 2.Lignina Kraft.3.Óleode mamona.4.Filmes.5. Nanocompósitos. I. Título. 
Aqueles que me ensinaram a voar, meus pais, Antônio Augusto da Silva Cassales e Ana Maristela Ribeiro Cassales.

Aquele que me deu todo suporte, carinho e compreensão, meu marido, Marco Antônio Kunrath.

Aquela que me deu toda força. Meu coração fora do peito, minha filha, Bibiana Cassales Kunrath.

Dedico a vocês, meus amores, esta tese e o título de Doutora em Ciências. 



\section{Agradecimentos}

Primeiramente agradeço aos meus quatro pilares, meu pai Antônio Augusto, minha mãe Ana Maristela, meu marido Marco Antônio e minha filha Bibiana. Sem o apoio, ajuda, compreensão e a torcida de vocês eu não teria conseguido!

Também gostaria de agradecer a minha orientadora Prof. (a) Elisabete Frollini, pela orientação, dedicação, paciência, confiança e amizade ao longo destes anos. Obrigada pela contribuição na minha formação pessoal e profissional e pela oportunidade de desenvolver este trabalho;

Agradeço a Empresa Brasileira de Pesquisa Agropecuária (Embrapa) pela oportunidade de realização do doutorado, e em especial, as pessoas que fizeram com que essa capacitação fosse possível, meus queridos colegas e amigos da Embrapa Agroindústria Tropical: Morsyleide Rosa, Renato Carrhá, Cléa Figueiredo, Men de Sá Moreira, Lilian Chayn e meu chefe Gustavo Saavedra.

Agradeço as amizades que foram feitas ao longo desses anos através do convívio diário no laboratório, Dani, Érika, Joice, Robertas, Deyvid, Cláudia, Bianca, Thamiris, Lucas, Danilo, Déia, William, Felipe e em especial a Chica, Rachel, Lidi e Pati. Vocês foram essenciais!

Ao técnico Luiz Ramos. Muito obrigada pela dedicação na realização das análises térmicas e mecânicas;

A todos os funcionários da Central de Análises Químicas (CAQI), do Instituto de Química de São Carlos (IQSC) e da Universidade de São Paulo (USP/SC) que contribuíram de alguma forma para que esse trabalho fosse executado.

E por fim, o meu agradecimento à Universidade de São Paulo e ao Instituto de Química de São Carlos que se tornaram a minha segunda casa durante esses anos e aos órgãos de fomento à pesquisa, Coordenação de Aperfeiçoamento de Pessoal de Nível Superior (CAPES), Conselho Nacional de Desenvolvimento Científico e Tecnológico (CNPq) e Fundação de Amparo à Pesquisa do Estado de São Paulo (FAPESP), os quais permitiram e ainda permltem que as pesquisas do grupo de Materiais Macromoleculares e Fibras Lignocelulósicas (Macromolignocell) sejam feitas com excelência. 



\section{"Tudo que está no plano da realidade já foi sonho um dia." \\ (Leonardo da Vinci)}





\section{Resumo}

CASSALES, A. R. Lignopoliuretanas Sintetizadas a partir de Lignina Kraft e Óleo de Mamona com Simultânea Formação de Filmes. 2019. 231 f. Tese (Doutorado em Ciências) - Instituto de Química de São Carlos, Universidade de São Paulo, São Carlos, 2019.

O presente estudo teve como objetivo sintetizar poliuretanas (PUs) utilizando polióis derivados de fontes renováveis, como óleo de mamona (Castor Oil - CO), lignina Kraft previamente purificada (LK), e LK hidroxialquilada com glutaraldeído, LK-Glu, visando torná-la mais reativa frente a isocianatos de estrutura aromática (difenilmetano diisocianato polimérico - pMDI) e alifática (trímero de hexametileno diisocianato - tHDI), os quais foram usados na síntese das PUs. Destaca-se que ligninas têm sido usadas como poliol na síntese de PUs, mas não visando formação de filmes, como a abordagem deste estudo. Filmes lignopoliuretânicos foram formados simultaneamente as sínteses, na ausência de solvente e catalisador, na razão molar NCO/OH 1:1, usando pMDI, a 25, 50, 75 e $100{ }^{\circ} \mathrm{C}$, substituindo 10, 30 e 50 \% em massa de CO por LK (LignoPU CoLK10; LignoPU $_{\text {CoLK30; LignoPU }}$ CoLK50) ou LK-

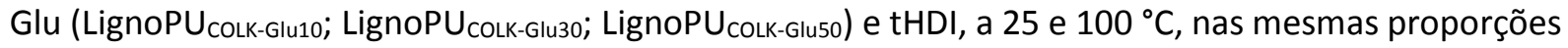
de LK (LignoPUH ${ }_{\text {CoLk10; }}$ LignoPUH CoLk30; LignoPUH $_{\text {CoLK50) }}$ ou LK-Glu (LignoPUH COLK-Glu10; LignoPUH $_{\text {CoLK-Glu30; }}$

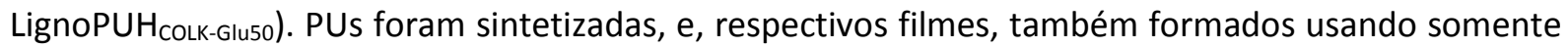
$\mathrm{CO}\left(\mathrm{PU}_{\mathrm{co}} ; \mathrm{PUH}_{\mathrm{CO}}\right)$ como poliol. Visando avaliar a influência nas propriedades dos filmes formados, sínteses foram realizadas na presença de nanocristais de celulose (CNCs) $(5,10$ e 12,5\% em massa) gerando os filmes LignoPUH ${ }_{\text {Colk50_100 }}$ (LignoPUH ${ }_{\text {Colk50_5\%CNC; LignoPUH }}$ Colk50_10\%CNC e LignoPUH CoLk50_12,5\%CNC) e LignoPUH $_{\text {CoLk-Glu50_100 (LignoPUH }}$ CoLk-Glu50_5\%CNC; LignoPUH

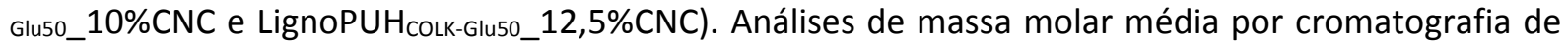
exclusão por tamanho (SEC) e ressonância magnética nuclear de Hidrogênio ( ${ }^{1} \mathrm{H}$ RMN) confirmaram a modificação química da LK pelo aumento na massa molar ponderal média (Mw, SEC) após a reação com glutaraldeído ( $L K=2331 \mathrm{~g} \mathrm{~mol}^{-1}$; $\mathrm{LK}-\mathrm{Glu}=4421 \mathrm{~g} \mathrm{~mol}^{-1}$, respectivamente) e aumento no teor de OH alifáticas na LK-Glu (LK=0,9 mmol g ${ }^{-1}$ e LK-Glu=2,4 mmol g ${ }^{-1},{ }^{1} \mathrm{H}$ RMN). A análise dinâmico-mecânica (DMA) mostrou o aparecimento de dois picos, relacionados a transições vítreas $\left(T_{\mathrm{g}}\right)$, indicando

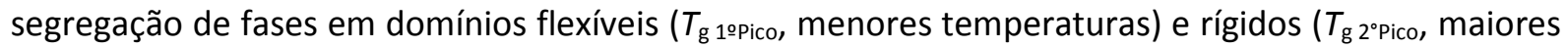
temperaturas) conforme o acréscimo de LK ou LK-Glu na composição tanto das LignoPUs quanto das LignoPUHs. Testes de tração indicaram que o uso de maior proporção de LK e LK-Glu (30 e 50 \%) levou a filmes com maior resistência à tração, que foi, no geral, superior nos filmes formados a partir de $\mathrm{CO}$ e LK-Glu, a $100^{\circ} \mathrm{C}$ (LignoPU COLK-Glu50 $_{\text {= }} 33 \mathrm{Mpa}$; LignoPUH COLK-Glu50 $_{\text {= }} 14 \mathrm{MPa}$ ). Os CNCs apresentaram uma ação efetiva como agentes de reforço, principalmente na matriz produzida com LK-Glu (Módulo de

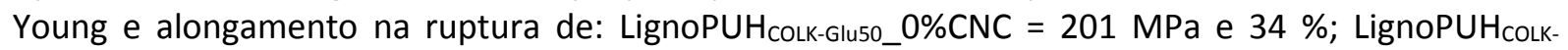
Glu50_12,5\%CNC = $441 \mathrm{MPa}$ e $22 \%$ ) em relação à preparada com LK (Módulo de Young e alongamento na ruptura de: LignoPUH ${ }_{\text {CoLk50_0\%CNC }=83 \mathrm{MPa} \text { e } 59 \% \text {; LignoPUH }}$ Colk50_12,5\%CNC $=132 \mathrm{MPa}$ e $37 \%$ ), provavelmente, por causa da maior reatividade dessa matriz. Destaca-se a ação do CO como agente dispersante não só de LK ou LK-Glu, mas também dos CNCs, viabilizando a interação entre todos os componentes do sistema. As metas pretendidas foram alcançadas, com a formação e caraterização de filmes lignopoliuretânicos diversos, com diferentes propriedades, os quais foram obtidos via rota que atende às expectativas referentes à sustentabilidade do processo.

Palavras-Chave: Poliuretanas; Lignina Kraft; Óleo de mamona; Filmes; Nanocompósitos. 


\section{Abstract}

CASSALES, A. R. Synthesized Lignopolyurethanes from Kraft Lignin and Castor Oil with simultaneous film formation. 2019. 231 f. Tese (Doutorado em Ciências) - Instituto de Química de São Carlos, Universidade de São Paulo, São Carlos, 2019.

The present study aimed to synthesize polyurethanes (PUs) using polyols derived from renewable sources such as castor oil (CO), previously purified Kraft lignin (KL), and KL hydroxyalkylated using glutaraldehyde, LK-Glu, in order to get a product more reactive towards the aromatic (polymeric diphenylmethane diisocyanate - pMDI) and aliphatic (trimer of hexamethylene diisocyanate - tHDI) isocyanates, which were used in the synthesis of the PUs. Lignins have been used as polyols in PUs synthesis, but not aiming at film formation, as the approach of this study. Lignopolyurethanic films were formed simultaneously to the syntheses, in the absence of solvent and catalyst, at the 1:1 $\mathrm{NCO} / \mathrm{OH}$ molar ratio, using $\mathrm{pMDI}$, at $25,50,75$ and $100{ }^{\circ} \mathrm{C}$, replacing 10,30 and $50 \mathrm{wt} \%$ of CO by LK

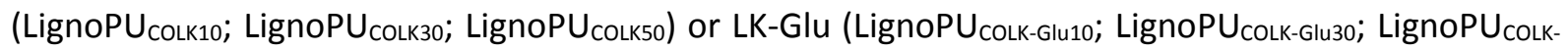
Gluso) and tHDI, at 25 and $100{ }^{\circ} \mathrm{C}$, in the same proportions as LK (LignoPUH ${ }_{\text {Colk10; LignoPUH }}$ colkз;

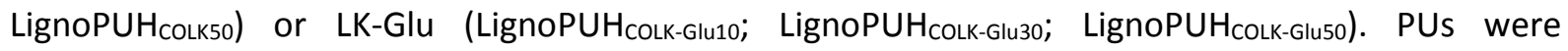
synthesized, and their films were also formed using only $\mathrm{CO}\left(\mathrm{PU}_{\mathrm{CO}} ; \mathrm{PUH}_{\mathrm{CO}}\right)$ as polyol. In order to evaluate the influence on the properties of the formed films, syntheses were performed in the presence of cellulose nanocrystals (CNCs) $(5,10$ and $12.5 \mathrm{wt} \%)$ generating the films LignoPUH CoLk50_100 $_{10}$ (LignoPUH ${ }_{\text {CoLk50_5\%CNC; LignoPUH }}$ Colk50_10\%CNC and LignoPUH ${ }_{\text {Colk50_12,5\%CNC) and LignoPUH }}$ colk-

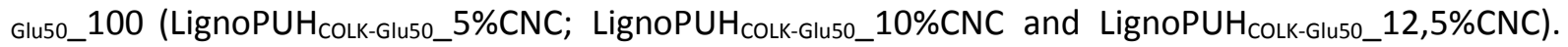
Average molar mass (Size Exclusion Chromatography, SEC) and Nuclear Magnetic Resonance ( ${ }^{1} \mathrm{H}$ NMR) analyzes confirmed the chemical modification of LK by the increase in the average molar mass ( $\mathrm{Mw}$, SEC) after reaction with glutaraldehyde (LK $=2331 \mathrm{~g} \mathrm{~mol}^{-1}$; LK-Glu $\left.=4421 \mathrm{~g} \mathrm{~mol}^{-1}\right)$ and increase in aliphatic $\mathrm{OH}$ content in LK-Glu (LK $=0.9 \mathrm{mmol} \mathrm{g}^{-1}$ and LK-Glu $=2.4 \mathrm{mmol} \mathrm{g}^{-1},{ }^{1} \mathrm{H}$ NMR). Dynamic Mechanical Analysis (DMA) showed two peaks related to glass transitions $\left(T_{\mathrm{g}}\right)$, indicating phase segregation in flexible ( $T_{\mathrm{g}}$ 1stpeak, lower temperatures) and rigid ( $T_{\mathrm{g}}$ 2ndPeak, higher temperatures) domains, as LK or LK-Glu increased in the composition of both LignoPUs and LignoPUHs. Tensile tests indicated that the use of a higher proportion of LK and LK-Glu (30 and 50\%) led to films with higher tensile strength, which was higher in films formed from CO and LK-Glu at $100^{\circ} \mathrm{C}$ (LignoPU COLK-Gluso $=33$ Mpa; LignoPUH ${ }_{\text {CoLk-Glu50 }}=14 \mathrm{Mpa}$ ). CNCs showed an effective action as reinforcing agents, mainly in the matrix formed from LK-Glu (Young's modulus and elongation at break of: LignoPUH COLK-Glu50_0\% $_{0}$

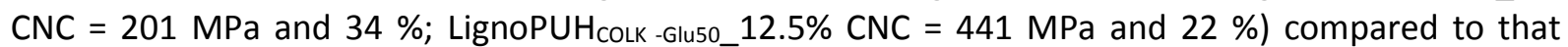

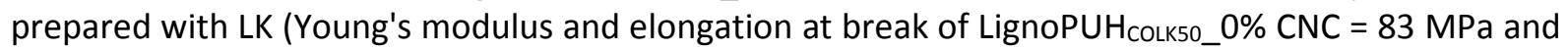
$59 \%$; LignoPUH ${ }_{\text {CoLk50_ }} 12.5 \% \mathrm{CNC}=132 \mathrm{MPa}$ and $37 \%$ ), probably due to higher reactivity of this matrix. It can be highlighted the action of $\mathrm{CO}$ as a dispersing agent not only of LK or LK-Glu but also of CNCs, enabling the interaction between all system components. The intended goals were achieved with the formation and characterization of various lignopolyurethanic films with useful properties, which were obtained via a route that meets the expectations regarding the sustainability of the process.

Keywords: Polyurethanes; Kraft Lignin; Castor oil; Films; nanocomposites. 



\section{Lista de Figuras}

Figura 1 - Representação de reação que leva às poliuretanas.

Figura 2 - Reação que leva à formação de poliuretana de estrutura (a) linear, (b) ramificada e (c) reticulada.

Figura 3- Representação esquemática de um polímero poliuretânico: (a) termoplástico (sem ligações cruzadas), (b) elastomérico (com baixo grau de ligações cruzadas) e (c) termorrígido (com alto grau de

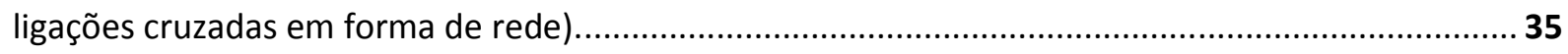

Figura 4 - Representação da reação que leva à formação de isocianatos. ...........................................35

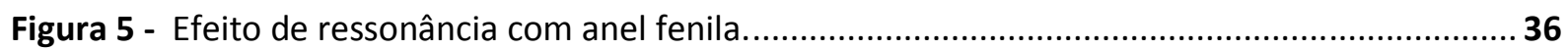

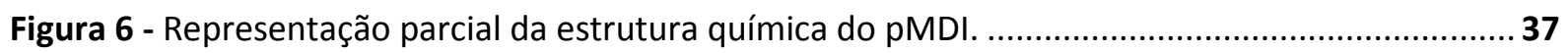

Figura 7 - Reações típicas do grupo isocianato com diferentes reagentes. Letra A: Formação de uretana; Letra B: Formação de uréia; Letra C: Formação de aminas (Espuma); Letra D: Formação de uréia; Letra E: Formação de biureto; Letra F: Formação de alofanato; Letra G: Formação de uretidiona; Letra H: Formação de isocianurato; Letras I e J: Produtos da decomposição dos isocianatos............................37

Figura 8 - Fórmula estrutural do trímero de HDI (tHDI) composto por anel isocianurato.....................39 Figura 9 - Ácidos graxos presentes no CO: (a) triglicerídeo do ácido ricinoléico; (b) ácido oleico e (c)

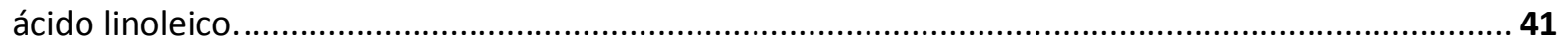

Figura 10 - Representação esquemática da estrutura da biomassa lignocelulósica............................. 43

Figura 11 - Representação parcial da estrutura molecular da celulose...........................................43

Figura 12 - (a) Estrutura da lignina proposta por ADLER (1977) e (b) Representação esquemática das unidades estruturais da lignina.

Figura 13 - Mecanismo de reação evidenciando a quebra da ligação éter na lignina Kraft na presença do íon hidrosulfeto (HS-).

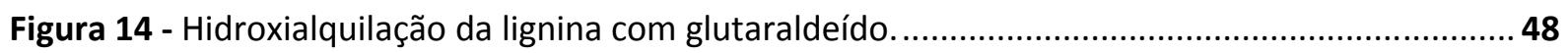

Figura 15 - Representação esquemática da produção de CNCs..........................................................49

Figura 16 - Número de trabalhos publicados e indexados na base de dados Science Direct envolvendo os termos "film; bio-based and polyurethane" nos últimos 10 anos...............................................51

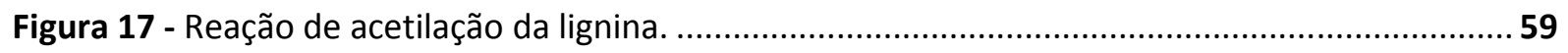

Figura 18 - Diagrama dà síntese das LignoPUs com simultânea formação de filmes. ..........................61

Figura 19 - Processo Kraft - Reação íons hidrossulfeto (HS-) com lignina na formação de compostos

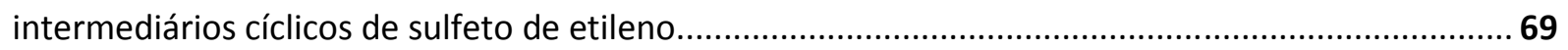

Figura 20 - Reação de repolimerização da lignina Kraft com intermediários metileno quinona...........70

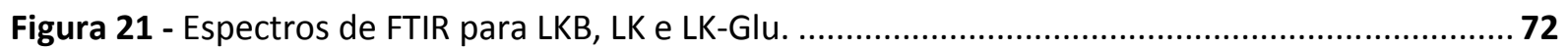

Figura 22 - Espectros de 1H RMN da (a) LK- acetilada e (b) LK-Glu - acetilada (Solvente CDCl3, 256 varreduras).

Figura 23 - Mecanismo de reação evidenciando a clivagem da ligação éter na lignina Kraft na presença

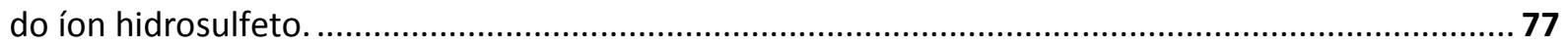

Figura 24 - Curvas de (a) TGA e (b) DTG da LKB, LK e LK-Glu em nitrogênio, vazão de $20 \mathrm{~mL} \mathrm{~min}^{-1}$ e razão

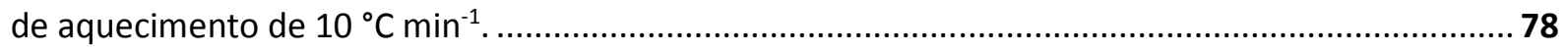

Figura 25 - Espectros FTIR das misturas reacionais imediatamente após deposição na placa (CO, LK ou LK-Glu e pMDI) e dos filmes formados, na região de 4000 a $1620 \mathrm{~cm}^{-1}$. ......................................... 81

Figura 26 - Micrografias eletrônicas de varredura da superfície dos filmes $\mathrm{PU}_{\mathrm{co}}$, LignoPU $\mathrm{U}_{\text {cokk30 e }}$

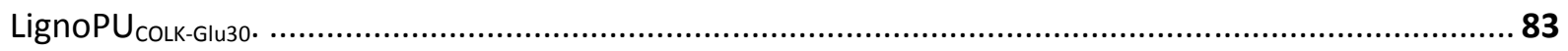

Figura 27 - Micrografias eletrônicas de varredura da criofratura dos filmes poliuretânicos formados simultaneamente à síntese realizada a partir de CO, LK ou LK-Glu e pMDI. .84 
Figura 28 - Curvas de TGA (a) e (b) e DTG (c) e (d) dos filmes poliuretânicos preparados simultaneamente à síntese a partir de CO, LK ou LK-Glu e pMDI em atmosfera de N2, vazão de $50 \mathrm{~mL}$

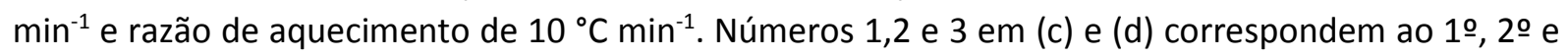
3 o evento, respectivamente.

Figura 29 - Difratogramas de raios X para os filmes poliuretânicos preparados simultaneamente à síntese realizada a partir de CO, LK ou LK-Glu e pMDI.

Figura 30 - (a) Taxa de Intumescimento (S\%) dos filmes formados e (b) Soluções de DMF após realização do teste de intumescimento, sendo: (1) PU $\mathrm{PO}_{\text {CO }}$ (2) LignoPU CoLK10; (3) LignoPU $_{\text {CoLK-Glu10; (4) LignoPU }}$ CoLK30;

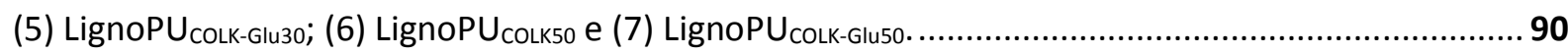

Figura 31 - Ângulo de avanço, AA e Ângulo de recuo, AR para os filmes poliuretânicos preparados simultaneamente à síntese realizada a partir de LK ou LK-Glu, CO e pMDI.

Figura 32 - Curvas de (a) Tan- $\delta$ para os filmes poliuretânicos ( $P U_{\text {Co, LignoPU }}$ colk10, LignoPU ${ }_{\text {colk30, }}$

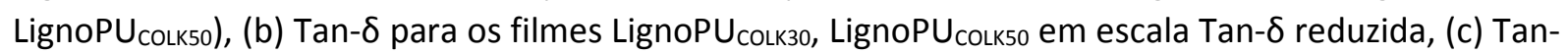

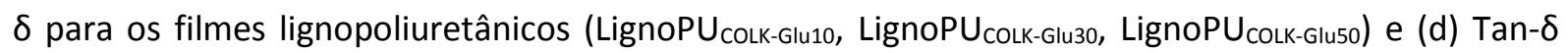
para os filmes LignoPU CoLK-Glu3o, LignoPU $_{\text {colk-Glu50 }}$ em escala Tan- $\delta$-reduzida.

Figura 33 - Módulo de armazenamento ( $\left.E^{\prime}\right)$ para os filmes poliuretânicos formados simultaneamente à síntese realizada a partir de CO, LK ou LK-Glu e pMDI nas temperaturas de -75 e $25^{\circ} \mathrm{C}$.

Figura 34 - (a) Resistência a ruptura, (b) módulo de Young e (c) alongamento na dos filmes poliuretânicos formados simultaneamente à síntese realizada a partir de CO, LK ou LK-Glu e pMDI. 99 Figura 35 - Reação de formação do grupo alofanato. 105

Figura 36 - Micrografias eletrônicas de varredura da criofratura dos filmes lignopoliuretânicos preparados simultaneamente à síntese realizada a partir de CO, LK ou LK-Glu (30 e 50 \%) e pMDI a 25 e $100^{\circ} \mathrm{C}$. 106

Figura 37 - Difratogramas de raios X para os filmes lignopoliuretânicos: (a) LignoPU LignoPU COLK-Glu30; $_{\text {(c) LignoPU }}$ COLK50 e (d) LignoPU $_{\text {COLK-Glu50, }}$ produzidos em diferentes temperaturas (25, 50,75 e $\left.100^{\circ} \mathrm{C}\right)$. 109

Figura 38 - Taxa de Intumescimento $(\mathrm{S} \%)$ dos filmes formados simultaneamente à síntese realizada a partir de (a) $30 \%$ de LK e LK-Glu e (b) 50\% de LK e LK-Glu nas temperaturas de 25, 50, 75 e $100{ }^{\circ} \mathrm{C}$,

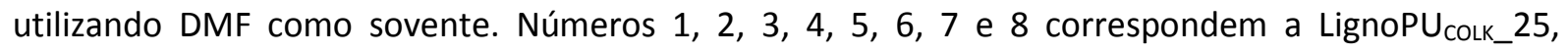
LignoPU COLK-Glu_25, LignoPU $_{\text {CoLk_50, LignoPU }}$ CoLk-Glu_50, LignoPU COLK_75, LignoPU $_{\text {COLK-Glu_75, }}$

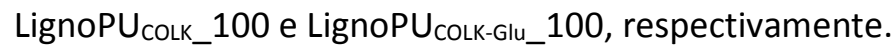

111

Figura 39 - AA e AR para os filmes LignoPU COLK-Glu30, LignoPU $_{\text {Colk-Glu50, LignoPU }}$ CoLk30 e LignoPU $_{\text {CoLk50 }}$ preparados à (a) $50^{\circ} \mathrm{C}$, (b) $75^{\circ} \mathrm{Ce} \mathrm{(c)} 100^{\circ} \mathrm{C}$. 113 Figura 40 - Curvas Tan- $\delta$ para os filmes formados simultaneamente à síntese realizada a partir de (a) $30 \%$ de LK e (b) $30 \%$ de LK-Glu nas temperaturas de $25,50,75$ e $100{ }^{\circ} \mathrm{C}$.

Figura 41 - Curvas Tan- $\delta$ para os filmes formados simultaneamente à síntese realizada a partir de (a) $50 \%$ de LK e (b) $50 \%$ de LK-Glu nas temperaturas de $25,50,75$ e $100^{\circ} \mathrm{C} .$.

Figura 42 - Módulo de Armazenamento $\left(E^{\prime}\right)$ a $25^{\circ} \mathrm{C}$ dos filmes formados simultaneamente à síntese realizada a partir de (a) $30 \%$ de LK e LK-Glu e (b) 50 \% de LK e LK-Glu nas temperaturas de 50, 75 e 100 ${ }^{\circ} \mathrm{C}$.

117

Figura 43 - (a) Resistência a ruptura, (b) módulo de Young e (c) alongamento na ruptura dos filmes formados simultaneamente à síntese realizada a partir de $30 \%$ de LK e LK-Glu nas temperaturas de 25 , 50, 75 e $100^{\circ} \mathrm{C}$.

Figura 44 - (a) Resistência a ruptura, (b) módulo de Young e (c) alongamento na ruptura dos filmes formados simultaneamente à síntese realizada a partir de $50 \%$ de LK e LK-Glu nas temperaturas de 25, 50,75 e $100^{\circ} \mathrm{C}$.

Figura 45 - Diagrama da metodologia de síntese das lignopoliuretanas usadas para preparar filmes. 
Figura 46 - Espectros FTIR das misturas reacionais imediatamente após deposição na placa (CO, LK ou LK-Glu e tHDI) e dos filmes formados na região de 4000 a $1600 \mathrm{~cm}^{-1}$.

Figura 47 - Micrografias eletrônicas de varredura da superfície dos filmes $\mathrm{PUH}_{\mathrm{CO}}$, LignoPUH $\mathrm{H}_{\text {CokK50 }} \mathrm{e}$

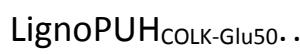
135

Figura 48 - Micrografias eletrônicas de varredura da criofratura dos filmes poliuretânicos preparados simultaneamente à síntese realizada a partir de CO, LK ou LK-Glu e tHDI.

136

Figura 49- Curvas de TGA (a) e (b) e DTG (c) e (d) dos filmes poliuretânicos formados simultaneamente à síntese realizada a partir de CO, LK ou LK-Glu e tHDI em atmosfera de $\mathrm{N}_{2}$, vazão de $50 \mathrm{~mL} \mathrm{~min}^{-1} \mathrm{e}$ razão de aquecimento de $10^{\circ} \mathrm{C} \mathrm{min}^{-1}$. Números 1 e 2 em (c) e (d) correspondem ao $1^{\circ}$ e $2^{\circ}$ evento, respectivamente.

Figura 50 - Difratogramas de raios $X$ para os filmes poliuretânicos formados simultaneamente à síntese realizada a partir de CO, LK ou LK-Glu e tHDI.

Figura 51 - (a) Taxa de Intumescimento ( $\mathrm{S} \%$ ) dos filmes preparados e (b) Soluções de DMF após

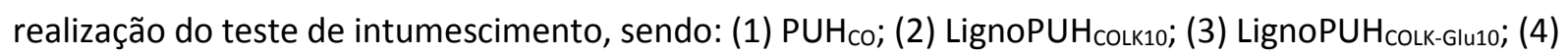

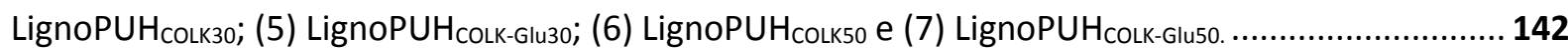

Figura 52 - AA e AR para os filmes lignopoliuretânicos preparados simultaneamente à síntese realizada a partir de CO, LK ou LK-Glu e tHDI.

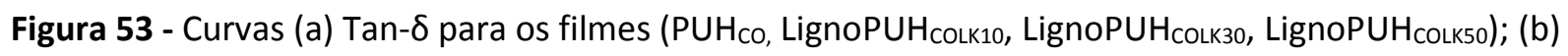
Tan- $\delta$ para os filmes apresentados em (a) escala reduzida; (c) Tan- $\delta$ para os filmes lignopoliuretânicos

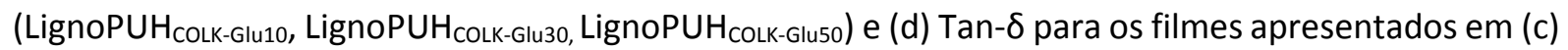
em escala reduzida.

146

Figura 54 - Módulo de armazenamento $\left(E^{\prime}\right)$ a $25{ }^{\circ} \mathrm{C}$ para os filmes poliuretânicos formados simultaneamente à síntese realizada a partir de CO, LK ou LK-Glu e tHDI. 148

Figura 55 - (a) Resistência à ruptura, (b) módulo de Young e (c) alongamento na ruptura dos filmes poliuretânicos formados simultaneamente à síntese realizada a partir de CO, LK ou LK-Glu e tHDI. 151 Figura 56 - Micrografias eletrônicas de varredura da criofratura dos filmes lignopoliuretânicos formados simultaneamente as sínteses ocorridas a partir de CO, 30 e 50 \% de LK ou LK-Glu, e tHDI, a 25 e $100{ }^{\circ} \mathrm{C}$. 158

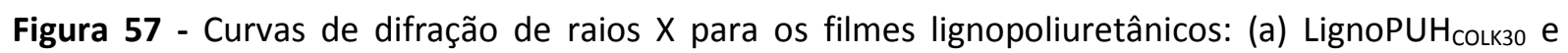

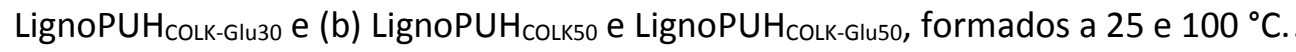
160 Figura 58 - Taxa de Intumescimento $(\mathrm{S} \%)$ dos filmes formados simultaneamente à síntese a partir de: (a) CO, $30 \%$ de LK ou LK-Glu e tHDI a 25 e $100{ }^{\circ} \mathrm{C}$ e fotos das soluções de DMF após realização do teste de intumescimento, sendo: (1) LignoPUH ${ }_{\text {CoLk30_25; (2) LignoPUH }}$ CoLK30_100; (3) LignoPUH $_{\text {CoLK-Glu30_25; }}$

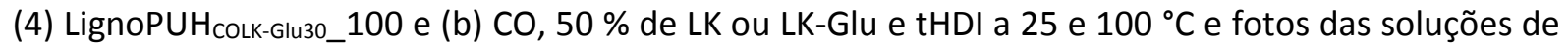
DMF após realização do teste de intumescimento, sendo: (1) LignoPUH Colk50_25; $_{2}$ LignoPUH ${ }_{\text {Colk50_100; (3) LignoPUH }}$ Colk-Glu50_25; (4) LignoPUH ${ }_{\text {colk-Glu50_100. }}$

Figura 59 - AA e AR para os filmes lignopoliuretânicos preparados simultaneamente à síntese realizada a partir de CO, LK ou LK-Glu e tHDI em diferentes temperaturas.

Figura 60 - Curvas (a) Tan- $\delta$ para os filmes formados simultaneamente à síntese realizada a partir de $30 \%$ de LK e LK-Glu a 25 e $100{ }^{\circ} \mathrm{C}$ (b) Tan- $\delta$ para os filmes de (a) em escala Tan- $\delta$ reduzida; (c) Tan- $\delta$ para os filmes formados simultaneamente à síntese realizada a partir de $50 \%$ de LK e LK-Glu a 25 e $100^{\circ} \mathrm{C}$ e (d) Tan- $\delta$ para os filmes de (c) em escala Tan- $\delta$ reduzida.

Figura $61-E^{\prime}\left(25^{\circ} \mathrm{C}\right)$ dos filmes formados simultaneamente à síntese realizada a partir de: (a) $30 \%$ de LK e LK-Glu e (b) $50 \%$ de LK e LK-Glu nas temperaturas de 25 e $100{ }^{\circ} \mathrm{C}$. . 167

Figura 62 - (a) Resistência a ruptura, (b) módulo de Young e (c) alongamento na ruptura dos filmes formados simultaneamente à síntese realizada a partir de $30 \%$ de LK e LK-Glu a 25 e $100{ }^{\circ} \mathrm{C}$. 170 
Figura 63 - (a) Resistência a ruptura, (b) módulo de Young e (c) alongamento na ruptura dos filmes dos filmes formados simultaneamente à síntese realizada a partir de $50 \%$ de LK e LK-Glu a 25 e $100{ }^{\circ} \mathrm{C}$.

Figura 64 - Diagrama da metodologia de síntese das LignoPUHs sintetizadas utilizando tHDI como isocianato e CNCs como agente de reforço e usadas para preparar filmes.

Figura 65 - Micrografias eletrônicas de varredura da superfície dos filmes formados simultaneamente à síntese realizada a partir de CO, $50 \%$ LK ou LK-Glu e tHDI sem e com a presença de $10 \%$ de CNCs.

Figura 66 - Micrografias eletrônicas de varredura das criofraturas dos filmes formados simultaneamente à síntese realizada a partir de CO, 50 \% LK ou LK-Glu e tHDI sem e com a presença de CNC's.

Figura 67 - Curvas de TGA (a) e (b) e DTG (c) e (d) dos filmes lignopoliuretânicos (CO, LK ou LK-Glu e

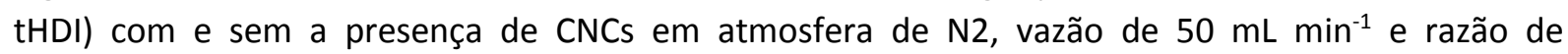
aquecimento de $10{ }^{\circ} \mathrm{C} \mathrm{min}^{-1}$. Números 1 e 2 em (c) e (d) correspondem ao $1^{\circ}$ e $2^{\circ}$ evento, respectivamente. 185

Figura 68 - Curvas de difração de raios X para CNC; para os filmes lignopoliuretânicos preparados simultaneamente à síntese realizada utilizando (a) LK e (b) LK-Glu como polióis, tHDI como isocianato na presença ou não de 5, 10 e $12,5 \%$ de CNCs.

Figura 69 - (a) S\% dos filmes lignopoliuretânicos (CO, LK ou LK-Glu e tHDI) com e sem a presença de CNCs e (b) fotos das soluções de DMF após realização do teste de intumescimento, sendo: (1) LignoPUH ${ }_{\text {CoLk50_0\%CNC; (2) LignoPUH }}$ Colk-Glu50_0\%CNC; (3) LignoPUH ${ }_{\text {Colk50_5\%CNC; (4) LignoPUH }}$ colkGlu50_5\%CNC; (5) LignoPUH ${ }_{\text {CoLk50_10\%CNC; }}$ (6) LignoPUH CoLK-Glu50_10\%CNC; $_{1}$ (7)

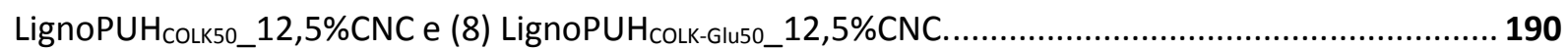
Figura 70 - AA e AR para os filmes lignopoliuretânicos (CO, LK ou LK-Glu e tHDI) com e sem a presença de CNCs.

Figura 71 - Regiões hidrofílicas e hidrofóbicas da molécula de celulose. 192

Figura 72 - Curvas Tan- $\delta$ para os filmes lignopoliuretânicos formados simultaneamente à síntese a partir de CO, (a) LK e (b) LK-Glu e tHDI, na presença de 5, 10 e 12,5\% de CNCs e para os filmes sem CNCs $(0 \% \mathrm{CNC})$.

Figura 73 - E' $\left(25^{\circ} \mathrm{C}\right)$ dos filmes lignopoliuretânicos (CO, LK ou LK-Glu e tHDI) com e sem a presença de CNCs. 195

Figura 74 - (a) Resistência a ruptura, (b) módulo de Young e (c) alongamento na ruptura dos filmes lignopoliuretânicos (CO, LK ou LK-Glu e tHDI) com e sem a presença de CNCs. 


\section{Lista de Tabelas}

Tabela 1 - Teores de umidade, cinzas, açúcares, análise elementar, Mw, Mw/Mn e lignina Klason para LKB, LK e LK-Glu

Tabela 2 - Principais bandas observadas para LKB, LK e LK-Glu............................................... 72

Tabela 3 - Picos presentes no espectro de ${ }^{1} \mathrm{H}$ RMN para lignina e possíveis atribuições ....................75

Tabela 4 - Comparação entre os teores de OH alifáticas, OH aromáticas e OH totais de LK e LK-Glu utilizadas neste estudo com outras ligninas Kraft derivadas de madeiras duras .............................76

Tabela 5 - Temperaturas dos eventos térmicos e massa residual encontrados para LKB, LK e LK-Glu em atmosfera de $\mathrm{N}_{2}$

78

Tabela 6 - Temperaturas dos eventos térmicos e massa residual encontrados nos filmes poliuretânicos formados simultaneamente à síntese realizada a partir de CO, LK ou LK-Glu e pMDI em atmosfera de $\mathrm{N}_{2}$ 86

Tabela 7 - Índice de cristalinidade ( $\mathrm{ICr}$ ) dos filmes poliuretânicos preparados simultaneamente à síntese realizada a partir de CO, LK ou LK-Glu e pMDI. 88

Tabela 8 - $T_{\mathrm{g}}$ (pico Tan- $\delta$ ) para os filmes poliuretânicos formados simultaneamente à síntese realizada a partir de CO, LK ou LK-Glu e pMDI..... 95

Tabela 9 - Temperaturas dos eventos térmicos e massa residual encontrados para os filmes

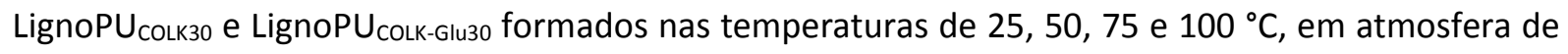
$\mathrm{N}_{2}$ 107

Tabela 10 - Temperaturas dos eventos térmicos e massa residual encontrados para os filmes LignoPU $\mathrm{COLK50}_{\text {e LignoPU }}$ CoLk-Glu50 formados nas temperaturas de $25,50,75$ e $100{ }^{\circ} \mathrm{C}$, em atmosfera de

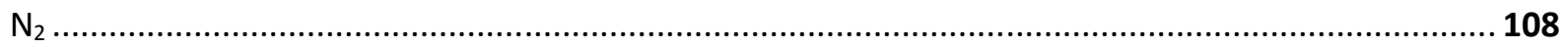

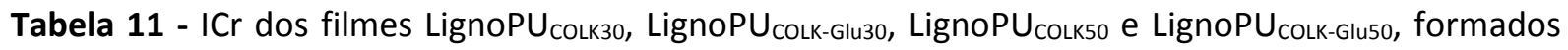
em diferentes temperaturas $\left(25,50,75\right.$ e $\left.100^{\circ} \mathrm{C}\right)$. 110

Tabela 12 - $T_{\mathrm{g}} \mathrm{s}$ (pico Tan- $\delta$ ) para os filmes formados simultaneamente as sínteses realizadas a partir de $30 \%$ de LK ou LK-Glu nas temperaturas de $25,50,75$ e $100{ }^{\circ} \mathrm{C}$.

Tabela 13 - $T_{\mathrm{g}} \mathrm{s}$ (pico Tan- $\delta$ ) para filmes formados simultaneamente à síntese realizada a partir de $50 \%$ de LK ou LK-Glu nas temperaturas de $25,50,75$ e $100{ }^{\circ} \mathrm{C}$.

Tabela 14 - Temperaturas dos eventos térmicos e massa residual encontrados para os filmes poliuretânicos formados simultaneamente à síntese realizada a partir de CO, LK ou LK-Glu e tHDI em atmosfera de $\mathrm{N}_{2}$

138

Tabela 15 - Índice de cristalinidade ( $\mathrm{ICr}$ ) dos filmes poliuretânicos formados simultaneamente à síntese realizada a partir de CO, LK ou LK-Glu e tHDI.

Tabela 16 - Valores de $T_{\mathrm{g}}$ (pico Tan- $\delta$ ) para os filmes poliuretânicos formados simultaneamente à síntese realizada a partir de CO, LK ou LK-Glu e tHDI.

Tabela 17 - Comparação dos resultados do Análise de propriedades de Tração dos filmes preparados simultaneamente à síntese realizada a partir de pMDI e tHDI a $25^{\circ} \mathrm{C}$

154

Tabela 18 - Temperaturas e perdas de massa observadas nos filmes LignoPUH CoLk30_25; LignoPUH $_{\text {CoLk- }}$ Glu30_25; LignoPUH ${ }_{\text {CoLk30_100 e LignoPUH }}$ CoLk-Glu30_100 em atmosfera de $\mathrm{N}_{2}$ 159

Tabela 19 - Temperaturas e perdas de massa observadas nos filmes LignoPUH CoLK50_25; LignoPUH $_{\text {CoLK- }}$ Glu50_25; LignoPUH ${ }_{\text {CoLk50_100 e LignoPUH }}$ CoLk-Glu50_100 em atmosfera de $\mathrm{N}_{2}$.... 159

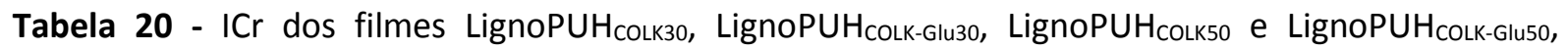
produzidos a 25 e $100{ }^{\circ} \mathrm{C}$.

Tabela 21 - Valores de $T_{\mathrm{g}}$ (pico Tan- $\delta$ ) para os filmes formados simultaneamente à síntese realizada a partir de 30 e $50 \%$ de LK ou LK-Glu e tHDI a 25 e $100{ }^{\circ} \mathrm{C}$. 
Tabela 22 - Comparação dos resultados da Análise de propriedades de Tração dos filmes formados simultaneamente à síntese realizada a partir de pMDI e tHDI a 25 e $100^{\circ} \mathrm{C}$

Tabela 23 - Temperaturas e perdas de massa observadas nos filmes lignopoliuretânicos (CO, LK ou LKGlu e tHDI) com e sem a presença de CNCs em atmosfera de $\mathrm{N}_{2}$.

Tabela 24 - ICr (\%)dos filmes lignopoliuretânicos (CO, LK ou LK-Glu e tHDI) com e sem a presença de CNCs.

Tabela 25 - $T_{\mathrm{g}} \mathrm{s}$ (pico Tan- $\delta$ ) para os filmes lignopoliuretânicos (CO, LK ou LK-Glu e tHDI) com e sem a presença de CNCs. 


\section{Lista de Abreviaturas, Siglas e Símbolos}

- $\% S$ - Taxa de inchamento

- AA - Ângulo de contato de avanço

- AC - Ângulo de contato

- AR - Ângulo de contato de recuo

- CNCs - Nanocristais de celulose, do inglês "cellulose nanocrystals"

- CO - Óleo de mamona, do inglês "castor oil"

- DMA - Análise Dinâmico-mecânica

- DRX - Difração de Raios X

- E' - Módulo de Armazenamento

- E" - Módulo de Perda

- FTIR - Espectroscopia na Região do Infra-vermelho com transformada de Fourier

- $\mathbf{H}^{1}$ RMN - Ressonância Magnética Nuclear de Hidrogênio

- HPLC - Cromatografia líquida de alta Eficiência, do inglês "High Liquid Performance Chromatography"

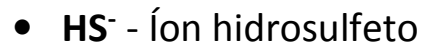

- Ic- Índice de cristalinidade

- LK - Lignina Kraft Purificada

- LKB - Lignina Kraft Bruta

- LK-Glu - Lignina Kraft hidroxialquilada com Glutaraldeído

- MEV - Microscopia Eletrônica de Varredura

- Mn - Massa molar numérica média

- Mw - Massa molar ponderal média

- $\mathrm{MW} / \mathrm{Mn}$ - Polidispersividade

- NCO - Grupos isocianato

- $\mathbf{O H}$ - Grupos hidroxila

- PE - Ponto de ebulição

- $\mathbf{p M D I}$ - Difenilmetano diisocianato polimérico

- PUs - Poliuretanas

- SEC - Cromatografia de Exclusão por tamanho, do inglês "Size Exclusion Chromatography"

- Tan- $\delta$ - Tan delta, Tan- $\delta=E^{\prime \prime} / E^{\prime}$

- $\boldsymbol{T}_{\mathbf{g}}$ - Temperatura de transição vítrea

- TGA - Termogravimetria

- DTG - Termogravimetria derivativa

- tHDI - Trímero de Hexametileno diisocianato

- $T_{\text {onset }}$ - Temperatura inicial de decomposição

- $T_{\text {máx }}$ - Temperatura em que a velocidade de perda de massa é máxima 


\section{Sumário}

Contextualização da pesquisa desenvolvida................................................... 27

Revisão Bibliográfica..................................................................................... 31

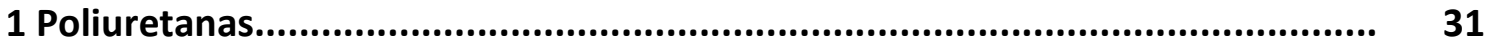

1.1 Tipos de Poliuretanas................................................................................... 33

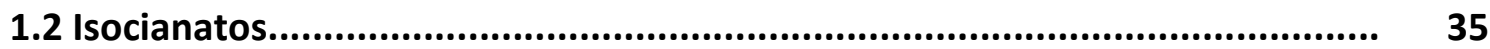

1.2.1 Tipos de Isocianatos................................................................................... 36

1.2.2 Reações de Isocianatos.............................................................................. 37

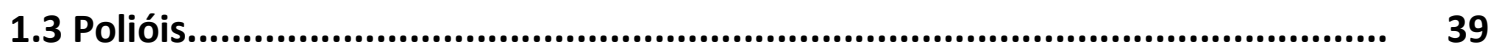

1.3.1 Óleo de Mamona................................................................................. 40

1.3.1.1 Uso do Óleo de Mamona na Síntese de PUs................................................ 41

1.3.2 Biomassa Lignocelulósica................................................................... 42

1.3.2.1 Lignina: Processos de Extração.................................................................... 44

1.3.2.2 Uso de Lignina como macromonômero na Síntese de PUs........................... 46

1.3.2.3 Hidroxialquilação.................................................................................. 4

1.4 Reforço de PUs com nanocristais de celulose (CNCs) .................................... 48

1.5 Filmes Poliuretânicos................................................................................ 49

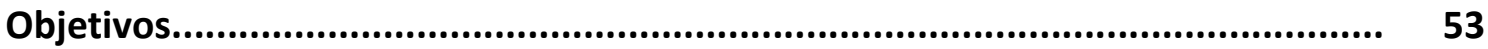

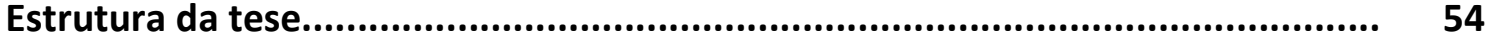

Capítulo 1: Filmes poliuretânicos formados simultaneamente as sínteses realizadas a partir de Óleo de mamona, Lignina Kraft/Lignina Kraft modificada com Glutaraldeído e Difenilmetano diisocianato polimérico............................... 55

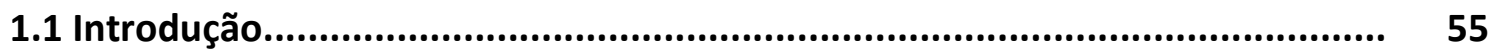

1.2 Materiais e Métodos.............................................................................. 56

1.2.1 Purificação da Lignina Kraft...................................................................... 56

1.2.2 Caracterização físico-química da Lignina Kraft.......................................... 56

1.2.2.1 Teor de Lignina Klason........................................................................... 56

1.2.2.2 Teor de Umidade e Cinzas........................................................................ 57

1.2.2.3 Teor de Açúcares.................................................................................... 57

1.2.2.4 Análise Elementar.............................................................................. 57

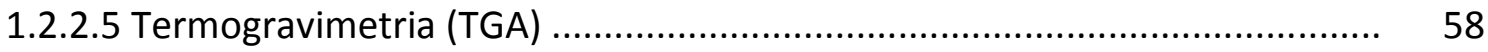


1.2.2.6 Espectroscopia na região do Infravermelho com Transformada de Fourier (FTIR)

1.2.2.7 Ressonância Magnética Nuclear de ${ }^{1} \mathrm{H}\left(\mathrm{RMN}^{1} \mathrm{H}\right)$........................................ 58

1.2.2.8 Determinação da Massa Molar Média.......................................................... $\quad 59$

1.2.3 Hidroxialquilação da Lignina Kraft: Reação com glutaraldeído..................... 59

1.2.3.1 Caracterização físico-química da Lignina Kraft Modificada com Glutaraldeído (LK-Glu) .................................................................................. 60

1.2.4 Síntese das Lignopoliuretanas com simultânea formação de filmes............. 60

1.2.4.1 Espectroscopia na região do Infravermelho com Transformada de Fourier (FTIR)

1.2.5 Caracterização dos Filmes Lignopoliuretânicos formados simultaneamente as sínteses a partir de CO, LK ou LK-Glu e pMDI.................................................. 63

1.2.5.1 Microscopia Eletrônica de Varredura (MEV) .............................................. 63

1.2.5.2 Termogravimetria (TGA) ................................................................... 64

1.2.5.3 Análise por Difração de raios X (DRX) …....................................................... 64

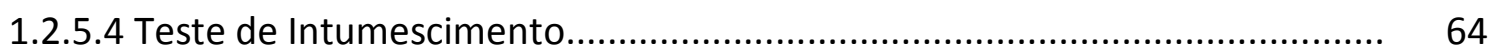

1.2.5.5 Análise Dinâmico-Mecânica (DMA) ............................................................ 65

1.2.5.6 Análise de propriedades de Tração ….......................................................... 65

1.2.5.7 Análise de Ângulo de Contato.............................................................. 65

1.2.6 Avaliação da Influência da temperatura nas sínteses das LignoPUs sobre as propriedades dos filmes lignopoliuretânicos formados, utilizando CO, LK ou LKGlu como polióis e pMDI como isocianato........................................................... 66

1.3 Resultados e Discussão.......................................................................... 66

1.3.1 Caracterização da Lignina Kraft Bruta (LKB), Lignina Kraft purificada (LK) e Lignina Kraft modificada com Glutaraldeído (LK-Glu) ........................................ 66

1.3.1.1 Espectroscopia na região do Infravermelho com Transformada de Fourier... 71

1.3.1.2 Ressonância Magnética Nuclear de ${ }^{1} \mathrm{H}$................................................... 73

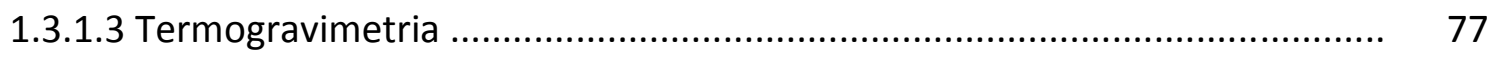

1.3.2 Filmes Poliuretânicos formados em sínteses ocorridas a partir de CO e LK

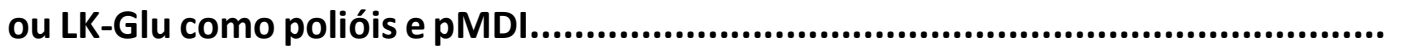


1.3.2.1 Espectroscopia na região do Infravermelho com Transformada de Fourier.

1.3.2.2 Microscopia Eletrônica de Varredura......................................................... 83

1.3.2.3 Termogravimetria ............................................................................ 85

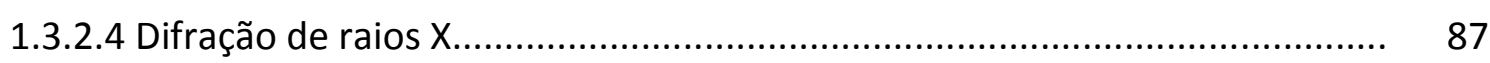

1.3.2.5 Teste de Intumescimento.................................................................. 89

1.3.2.6 Ângulo de contato........................................................................... 91

1.3.2.7 Análise Dinâmico-Mecânica ................................................................... 93

1.3.2.8 Propriedades de Tração ........................................................................... 99

1.3.3 Avaliação da influência da temperatura na síntese das LignoPUs sobre as propriedades dos filmes lignopoliuretânicos formados a partir de CO, LK ou LKGlu como polióis e pMDI como isocianato................................................... 103

1.3.3.1 Espectroscopia na região do Infravermelho com Transformada de Fourier.

1.3.3.2 Microscopia Eletrônica de Varredura......................................................... 105

1.3.3.3. Termogravimetria ............................................................................. 107

1.3.3.4 Difração de raios X................................................................................ 108

1.3.3.5 Teste de Intumescimento....................................................................... $\quad 110$

1.3.3.6 Ângulo de Contato........................................................................... 112

1.3.3.7 Análise Dinâmico-Mecânica................................................................. 114

1.3.3.8 Propriedades de Tração ............................................................................... 118

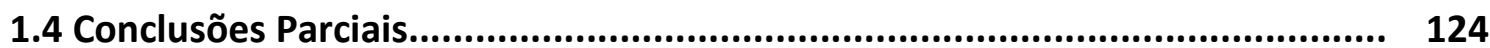

Capítulo 2: Filmes poliuretânicos formados simultaneamente as sínteses realizadas a partir de Óleo de mamona, Lignina Kraft/Lignina Kraft modificada com Glutaraldeído e Trímero de Hexametileno Diisocianato.............................. 127

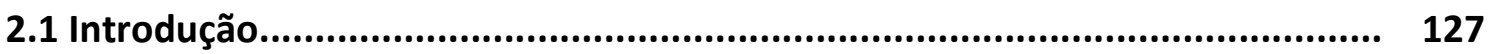

2.2 Materiais e Métodos............................................................................. 128

2.2.1 Síntese das Lignopoliuretanas usadas para preparar filmes ....................... 128

2.2.1.1 Espectroscopia na região do infravermelho com Transformada de Fourier... $\quad 130$

2.2.2 Caracterização dos Filmes Poliuretânicos formados simultaneamente as sínteses realizadas a partir de CO, LK ou LK-Glu e tHDI....................................... 130 
2.2.2.1 Microscopia Eletrônica de Varredura

2.2.2.2 Termogravimetria ........................................................................ 130

2.2.2.3 Difração de raios X................................................................................ 131

2.2.2.4 Teste de Intumescimento.................................................................... 131

2.2.2.5 Análise Dinâmico-Mecânica .................................................................. 131

2.2.2.6 Análise de propriedades de Tração .......................................................... 131

2.2.2.7 Análise de Ângulo de Contato................................................................. 131

2.2.3 Avaliação da Influência da temperatura da reação de síntese das LignoPUHs sobre as propriedades dos filmes lignopoliuretânicos formados utilizando CO, LK ou LK-Glu como polióis e tHDI como isocianato................................................ 131

2.3 Resultados e Discussão....................................................................... 132

2.3.1 Filmes Poliuretânicos formados simultaneamente as sínteses realizadas a partir de CO, LK ou LK-Glu como polióis, e tHDI como isocianato......................... 132

2.3.1.1 Espectroscopia na região do infravermelho com Transformada de Fourier... 132

2.3.1.2 Microscopia Eletrônica de Varredura ....................................................... 135

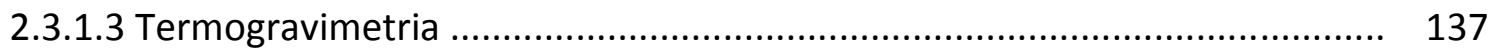

2.3.1.4 Difração de raios X............................................................................... $\quad 140$

2.3.1.5 Teste de Intumescimento................................................................. 142

2.3.1.6 Ângulo de Contato.......................................................................... 144

2.3.1.7 Análise Dinâmico-Mecânica ................................................................ $\quad 145$

2.3.1.8 Propriedades de Tração ............................................................................... $\quad 150$

2.3.2 Avaliação da Influência da temperatura na reação de síntese das LignoPUHs sobre as propriedades dos filmes lignopoliuretânicos formados utilizando CO, LK ou LK-Glu como polióis e tHDI como isocianato.............................................. 156

2.3.2.1 Espectroscopia na região do infravermelho com Transformada de Fourier... 156

2.3.2.2 Microscopia Eletrônica de Varredura ...................................................... 157

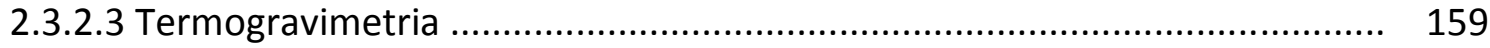

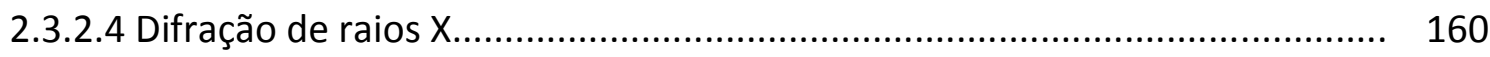

2.3.2.5 Teste de Intumescimento................................................................. 161

2.3.2.6 Ângulo de Contato................................................................................... 163

2.3.2.7 Análise Dinâmico Mecânica......................................................................... 164 


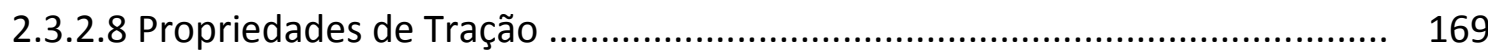

2.4 Conclusões Parciais....................................................................... 175

Capítulo 3: Filmes Poliuretânicos obtidos simultaneamente as sínteses realizadas a partir de Óleo de mamona, e Lignina Kraft modificada com glutaraldeído ou não: adição de celulose nanocristalina.......................................................... 177

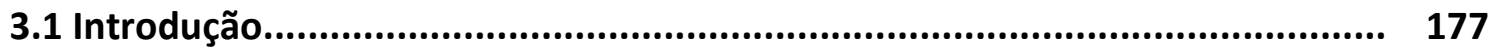

3.2 Materiais e Métodos........................................................................... 178

3.2.1 Síntese das LignoPUHs usadas para preparar simultaneamente filmes tendo como reagentes CO, LK ou LK-Glu, tHDI e CNCs como agente de reforço ..... 178

3.2.1.1 Espectroscopia na região do infravermelho com Transformada de Fourier . 180

3.2.2 Caracterização dos Filmes Lignopoliuretânicos obtidos a partir de PUs sintetizadas tendo como polióis CO e LK ou LK-Glu e tHDI como isocianato na

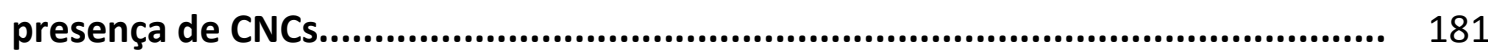

3.2.2.1 Microscopia Eletrônica de Varredura ...................................................... 181

3.2.2.2 Termogravimetria ........................................................................... 181

3.2.2.3 Difração de raios X............................................................................... 181

3.2.2.4 Teste de Intumescimento.................................................................... 181

3.2.2.5 Análise Dinâmico Mecânica .................................................................... 181

3.2.2.6 Análise de propriedades de Tração ......................................................... 181

3.2.2.7 Análise de Ângulo de Contato.............................................................. 182

3.3 Resultados e Discussão......................................................................... 182

3.3.1 Espectroscopia na região do infravermelho com Transformada de Fourier... 182

3.3.2 Microscopia Eletrônica de Varredura ................................................... 183

3.3.3 Termogravimetria .......................................................................... $\quad 184$

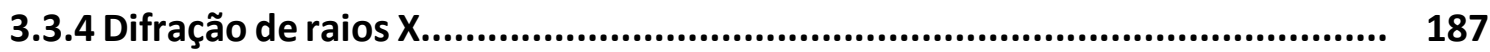

3.3.5 Teste de Intumescimento................................................................. 189

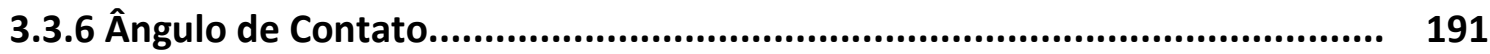

3.3.7 Análise Dinâmico Mecânica .................................................................. 193

3.3.8 Propriedades de Tração ......................................................................... 197

3.4 Conclusões Parciais.................................................................................... 200

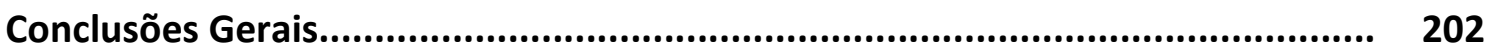


APÊNDICE A - Cromatogramas de distribuição de massa molar da (a) Lignina Kraft Bruta Acetilada (LKB); (b) Lignina Kraft Purificada Acetilada (LK) e (c) Lignina Kraft Modificada com Glutaraldeído Acetilada (LK-Glu) 220

APÊNDICE B - Espectros de FTIR para Lignina Kraft Purificada não Acetilada (LK), Lignina Kraft Purificada Acetilada (LK acetilada) e Lignina Kraft Modificada com Glutaraldeído e Acetilada (LK-Glu acetilada) na região de 4000 a $400 \mathrm{~cm}^{-1}$ 221

APÊNDICE C - Espectros de FTIR para os filmes PU Co, LignoPU $_{\text {Colk30 e LignoPU }}$ Colk-Gluzo na região de 4000 a $650 \mathrm{~cm}^{-1}$ e Tabela apresentando as principais bandas de transmissão observadas nos respectivos filmes.

APÊNDICE D - Espectros FTIR das misturas reacionais imediatamente após deposição na placa (CO, 30 e 50\% de LK ou LK-Glu e pMDI) e para os filmes formados, na região de 4000 a $1550 \mathrm{~cm}^{-1}$. Temperaturas avaliadas: 50,75 e $100^{\circ} \mathrm{C}$.

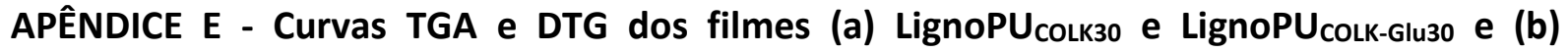

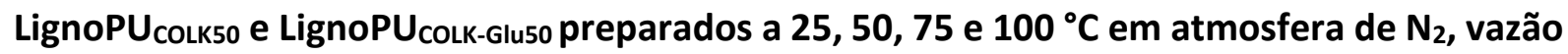
de $50 \mathrm{~mL} \min ^{-1}$ e razão de aquecimento de $10 \quad{ }^{\circ} \mathrm{C} \min ^{-}$ 1 .225

APÊNDICE F - Espectros de FTIR para os filmes PUH Co, LignoPUH $_{\text {colk30 e LignoPUH }}$ CoLk-Gluzo na região de 4000 a $650 \mathrm{~cm}^{-1}$ e Tabela apresentando as principais bandas de transmissão observadas nos respectivos filmes. 227

APÊNDICE G - Espectros FTIR das misturas reacionais imediatamente após deposição na placa (CO, LK ou LK-Glu e tHDI) e para os filmes formados, na região de 4000 a $1600 \mathrm{~cm}^{-}$ 1 
APÊNDICE H - Curvas TGA e DTG dos filmes (a) LignoPUH Colk30 e LignoPUH $_{\text {Colk-Glu3o e (b) }}$

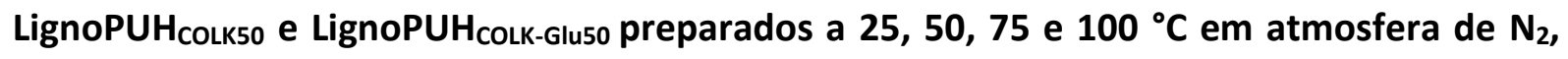
vazão de $50 \mathrm{~mL} \mathrm{~min}^{-1}$ e razão de aquecimento de $10^{\circ} \mathrm{C} \mathrm{min}^{-1}$ 229

APÊNDICE I - Espectros FTIR das misturas reacionais imediatamente após deposição na placa (CO, $50 \%$ LK ou LK-Glu e tHDI) na presença ou não de CNCs e para os filmes formados, na região de 4000 a $1550 \mathrm{~cm}^{-1}$. .230

APÊNDICE J - Curvas TGA e dTG dos CNCs em atmosfera de $\mathrm{N}_{2}$, vazão de $50 \mathrm{~mL} \mathrm{~min}^{-1}$ e razão de aquecimento de $10^{\circ} \mathrm{C} \mathrm{min}^{-1}$. .231 



\section{Contextual ização da pesquisa desenvolvida}

Entre as inúmeras possibilidades de agregação de valor à biomassa residual e aos subprodutos da agroindústria, destaca-se o desenvolvimento de filmes poliméricos baseados em materiais de origem renovável. Em 2017, cerca de 2 milhões de toneladas de biopolímeros foram produzidos no mundo, sendo que quase $60 \%$ dessa produção foi destinada à aplicação em embalagens, o maior e ainda crescente mercado dos biopolímeros (NIAOUNAKIS, 2019).

Poliuretanas (PUs) podem ser encontrados no formato de espumas, materiais moldados e filmes, por exemplo. Os filmes poliuretânicos correspondem a um segmento importante na produção mundial de PUs, sendo superado apenas pela produção de espumas (GRAND VIEW RESEARCH, 2019)ํ. A grande vantagem dos filmes poliuretânicos em relação aos outros polímeros corresponde a diversificação de propriedades que o material pode apresentar. Dependendodo filme poliuretânico, ele pode apresentar maior resistência a solicitações mecânicas e à abrasão do que filmes produzidos a partir de outros polímeros, como, polietileno (PE) e policloreto de vinila (PVC), bem como maior resistência química do que filmes de neoprene, por exemplo (AMERICAN POLYFILM, 2019)². Além disso, filmes poliuretânicos usualmente são biocompatíveis, o que faz com que sejam bastante aplicados na área médica (BARRIONI et al., 2015). Também podem ser aplicados em outras áreas, como a industrial, esportiva, alimentícia, entre outras, através de produtos como embalagens, curativos, adesivos, revestimentos elásticos ou rígidos, entre outros. Apesar das espumas flexíveis serem o maior segmento em produção das PUs, o mercado mundial de filmes poliuretânicos termoplásticos (Thermoplastic Polyurethane - TPU) em 2018 foi avaliado em 361,8 milhões de dólares com projeções de expansões para os próximos anos (GRAND VIEW RESEARCH, 2019) ${ }^{3}$.

\footnotetext{
1 Disponível em: www.grandviewresearch.com/industry-analysis/polyurethane-pu-market, acesso em 12/08/2019.

2 Disponível em: www.americanpolyfilm.com/about-american-polyfilm-polyurethane-manufacturer, acesso em: 10/11/2019.

3 Disponível em: https://www.grandviewresearch.com/industry-analysis/tpu-films-industry, acesso em: $\underline{11 / 11 / 19 .}$
} 
A síntese de PUs convencionais envolve geralmente a utilização de polióis e poliisocianatos que são oriundos do petróleo. Entretanto além do petróleo ser uma matériaprima não renovável, o processo de extração e refino do mesmo causam danos ao meio ambiente, e a não biodegradabilidade de seus subprodutos requerem disposição adequada no final de sua vida útil, fazendo com que essa fonte não seja sustentável do ponto de vista ambiental (MOHANTY et al., 2005).

Polímeros derivados de materiais renováveis, como os óleos vegetais e os lignocelulósicos, especialmente os resíduos e subprodutos agroindustriais, ganham a atenção de governantes, indústrias e instituições de pesquisa no mundo todo, devido a características como biocompatibilidade, sustentabilidade, e em alguns casos biodegradabilidade, comparativamente aos polímeros derivados de fontes fósseis (LI; RAGAUSKAS, 2012).

O óleo de mamona é um óleo vegetal bastante utilizado na síntese de PUs, inclusive em escala industrial, em função da presença de hidroxilas em sua estrutura, passíveis de reação com os grupos NCO dos isocianatos (Ll et al., 2015).

A lignina é um componente da biomassa lignocelulósica, juntamente com a celulose e hemiceluloses, e um importante subproduto da indústria de celulose e de biocombustíveis. São produzidas por ano mais de 1,5 milhão de toneladas de lignina, e apenas $2 \%$ da produção mundial são reaproveitadas para usos comerciais, o resto é queimado para gerar energia (GADHAVE et al., 2018; YANG et al., 2018). A lignina vem sendo estudada por diversos grupos de pesquisa (ARSHANITSA et al., 2016; GHADAVE et al., 2018; VALE et al., 2019), incluindo o grupo de Materiais Macromoleculares e Fibras Lignocelulósicas - MacromoLignocell, onde foi desenvolvidoo presente estudo, como substituta parcial ou total de álcoois derivados do petróleo na síntese de poliuretanas (RAMIRES et al., 2013; DE OLIVEIRA et al., 2015). A lignina é uma fonte de carbono renovável e abundante, possui estrutura que permite aplicação em uma gama de reações químicas, sendo uma macromolécula com biodegradabilidade intrínseca, o que pode contribuir para com a biodegradabilidade dos materiais em cuja síntese for usada como reagente (LI et al., 2003).

A disponibilidade dos grupos $\mathrm{OH}$ presentes na estrutura química da lignina pode aumentar via modificação química, facilitando assim a reação com os grupos NCO dos isocianatos. Por exemplo, pode-se citar a modificação química da lignina através de reação de hidroxialquilação com glutaraldeído (LAURICHESSE; AVEROUS, 2014). O glutaraldeído, um aldeído que pode ser obtido de fontes naturais, pode inserir segmentos alifáticos hidroxilados 
de até cinco carbonos na estrutura da cadeia rígida aromática da lignina, os quais provavelmente contribuirão para tornar as hidroxilas da lignina menos impedidas estericamente.

Dependendo da aplicação da PU, aumento da estabilidade térmica e melhorias nas propriedades mecânicas e de barreira são necessárias para um melhor desempenho do material. Uma alternativa que vem sendo amplamente estudada é a incorporação de nanocristais de celulose (CNCs) em matrizes poliméricas, incluindo poliuretânicas, uma vez que os CNCs podem atuar como reforço, melhorando suas propriedades físico-químicas (AUAD et al., 2008; RUEDA et al., 2013; PARK et al., 2013; LOPES et al., 2016; BUFFA et al., 2018; LEl et al., 2019).

Sendo assim, PUs foram sintetizadas, simultaneamente à formação de filmes, na ausência de solvente, utilizando como polióis matérias-primas renováveis, tais como óleo de mamona, lignina Kraft e lignina Kraft modificada com glutaraldeído.

A junção de lignina e óleo de mamona para atuarem como polióis na síntese de PUs sem a utilização de solventes orgânicos é uma abordagem interessante, uma vez que, o óleo além de conferir caráter elastomérico às PUs, atua como agente dispersante da lignina e reforços, a exemplo dos CNCs, nas PUs. Essa estratégia é importante do ponto de vista ambiental e não explorada para aplicação em filmes na literatura.

Em uma busca na base de dados "Web of Science" com os termos: lignin; castor oil; polyurethane; films, são encontrados apenas 5 artigos publicados nos últimos 10 anos e quando os termos utilizados são: Kraft lignin; castor oil; polyurethane; films, nenhum trabalho foi publicado desde 2009. Além do baixo número de artigos relacionados a esses termos, a abordagem utilizada pelos mesmos se diferencia em diversos aspectos (como o uso de solvente, temperatura, modificações químicas nas matérias-primas, entre outros) do que foi feito nesse trabalho, destacando seu ineditismo.

A utilização da combinação de lignina modificada quimicamente via reação de hidroxialquilação com glutaraldeído com óleo de mamona também é uma estratégia pioneira na síntese de filmes lignopoliuretânicos, até onde se tem conhecimento. Dessa forma, esse estudo pavimenta o caminho para ampliar o uso de ligninas em PUs, pois a aplicação em filmes praticamente não é explorada, e os filmes obtidos possuem um grande campo de aplicação, como em revestimentos de materiais e superfícies. 
Neste estudo foram explorados dois tipos de isocianatos, um de estrutura aromática (difenilmetano diisocianato polimérico - pMDI) e outro alifática (trímero de hexametileno diisocianato - tHDI) na síntese das lignopoliuretânas, com o objetivo de avaliar a influência da estrutura química do isocianato nas propriedadesdos filmes formados simultaneamente as sínteses.

CNCs foram adicionados à mistura reacional em algumas sínteses, selecionadas a partir dos resultados obtidos, visando avaliar possível impacto delas nas propriedades dos filmes formados. Essa abordagem, até onde se sabe, também não tem precedentes na literatura. 


\section{Revisão Bibliográfica}

\section{Poliuretanas}

Poliuretanas (PUs) correspondem a uma classe de polímeros caracterizados pela presença de grupos uretana em sua cadeia principal, os quais são formados pela reação entre reagentes que contém grupos hidroxila $(\mathrm{OH})$ e isocianato (NCO), ambos com funcionalidade igual ou superior a dois (PASCAULT et al., 2002). A Figura 1 mostra a representação da reação de formação das PUs, em que um centro nucleofílico ligado a um átomo de hidrogênio (nesse caso, o oxigênio do grupo $\mathrm{OH}$ do etilenoglicol) ataca o carbono eletrofílico do grupo $\mathrm{N}=\mathrm{C}=\mathrm{O}$ do isocianato e o átomo de hidrogênio é abstraído, ligando-se ao átomo de nitrogênio, formando a ligação uretânica, ou ligação carbamato (VILAR, 2002).

Figura 1 - Representação de reação que leva às poliuretanas.

n

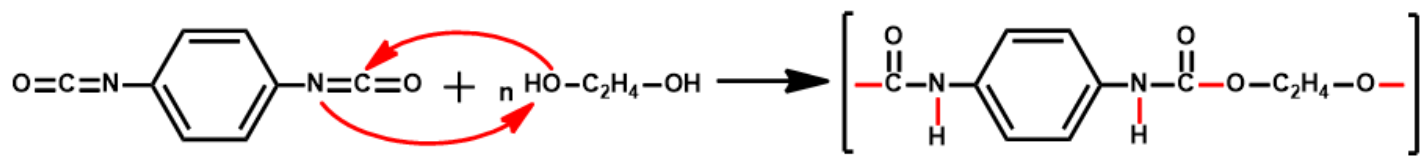

Diisocianato de Parafenileno

Etilenoglicol

Poliuretana

Fonte: Adaptado de PASCAULT et al., 2002.

As PUs são especialmente importantes em função da sua grande versatilidade em termos de propriedades físicas e químicas. Estes polímeros podem ser encontrados na forma de espumas flexíveis ou rígidas, como materiais moldados (mangueiras, rodízios), tintas e filmes (VILAR, 2002).

Em razão das diferentes aplicações que possuem, PUs estão sempre em contínuo aumento de demanda no mercado mundial. Em 2018, o mercado mundial das poliuretanas movimentou cerca de 65,5 bilhões de dólares (GRAND VIEW RESEARCH, 2019) ${ }^{4}$. A produção global de produtos baseados em PUs estimada no ano de 2017 foi de aproximadamente 23,4 milhões de toneladas em volume de PUs (AUSTIN; HICKS, 2017). Nos últimos anos, uma grande demanda das indústrias de bens de consumo tem alavancado a produção de PUs no

\footnotetext{
4 Disponível em: www.grandviewresearch.com/industry-analysis/polyurethane-pu-market, acesso em
} $12 / 08 / 2019$. 
mundo (MOON et al., 2019). As projeções para esse mercado são de que até 2021 haja um crescimento na produção mundial, podendo atingir até 26,5 milhões de toneladas em volume de poliuretanas no mundo (STATISTA, 2019) ${ }^{5}$, o que evidencia a importância dessa classe de polímeros na economia mundial.

A região denominada APAC (Asia-Pacífic) é a maior produtora de PUs no mundo, contabilizando $48,1 \%$ do volume total do mercado em 2018. Países como a China e a Índia têm destaque nessa produção, em função de grandes indústrias produtoras de PUs estarem mudando suas bases de produção para esses países emergentes. A Europa é considerada o segundo maior mercado em PUs seguida dos Estados Unidos (EUA), devido sua grande demanda por produtos de diversos setores, como o automobilístico, de móveis, de embalagens e de construção (GRAND VIEW RESEARCH, 2019) ${ }^{6}$.

No Brasil, a produção estimada de PUs foi de 620 mil toneladas ao ano, em 2018, sendo que no ranking mundial, o Brasil ocupa o $8^{\circ}$ lugar em faturamento, com o montante de 112 milhões de dólares (FLEXíVEL TECNOLOGIAS EM POLIURETANO, 2018)7.

O segmento de espumas flexíveis de PUs dominou a produção do mercado em 2018, em vista da sua aplicação em móveis (colchões, sofás, travesseiros, entre outros). Em seguida vem a produção de espumas rígidas, filmes, elastômeros, entre outros. O setor de construção ainda é o que mais demanda PUs. 28,5\% da receita do mercado mundial de PUs em 2018 veio desse setor. Além da construção, o setor de móveis e interiores, eletrodomésticos, automóveis, solas de sapato, embalagens, entre outras aplicações mais específicas constituem o cenário da produção de PUs (GRAND VIEW RESEARCH, 2019) ${ }^{8}$. Essa variedade de produtos só pode ser possível em função das diferentes formas e componentes que podem ser utilizados na manufatura de PUs.

\footnotetext{
5 Disponível em: https://www.statista.com/statistics/720341/global-polyurethane-market-size-forecast/, acesso em 12/08/2019.

6 Disponível em: https://www.grandviewresearch.com/industry-analysis/polyurethane-pu-market, acesso em 12/08/2019.

7 Disponível em: https://flexivelpu.com.br/blog/o-mercado-brasileiro-do-poliuretano/, acesso em 23/08/2019. Texto publicado em 23/01/2018.

8 Disponível em: https://www.grandviewresearch.com/industry-analysis/polyurethane-pu-market, acesso em $12 / 08 / 2019$.
} 


\subsection{Tipos de Poliuretanas}

A estrutura química das cadeias de PUs usualmente é formada por segmentos rígidos e flexíveis. Os segmentos rígidos têm menor habilidade para rotação em torno das ligações simples presentes nos mesmos e, portanto, menor capacidade para transições conformacionais, como ocorre devido à presença de anéis aromáticos oriundos de isocianatos usados como reagentes. Nos segmentos flexíveis é maior a habilidade de rotações em torno das ligações simples presentes e, portanto, maior capacidade para transições conformacionais, como nos segmentos lineares com poucas ou nenhuma ramificação, geralmente provenientes dos polióis. A porção rígida da estrutura química da PU irá conferir aos materiais dureza, resistência às solicitações mecânicas e maior estabilidade térmica, enquanto a porção flexível irá conferir elasticidade, devido à alta mobilidade dos segmentos, (Figura 2) (KROL, 2007).

A reação de dióis com di-isocianatos leva à formação de poliuretanas lineares (Figura 2 a). Se for utilizado um poliol, ou um poli-isocianato na reação, ocorrerá a formação de ramificações (Figura 2 b) e, eventualmente, a formação de reticulações (Figura 2 c). A quantidade de reticulações de um determinado polímero dependerá da quantidade de reagentes envolvidos que possuam funcionalidade maior que 2 (VILAR, 2002). Além da funcionalidade dos reagentes envolvidos (poliol e isocianato), a proporção entre eles também resultará em estruturas e características diferenciadas. As propriedades desejadas nos produtos finais definem as proporções de poliol e isocianato (VILAR, 2002). Para PUs sintetizadas em uma única etapa, ou seja, em que todos os reagentes são misturados simultaneamente, utiliza-se a razão $\mathrm{NCO}: \mathrm{OH}$ igual a 1, para que todos os grupos isocianato reajam com as hidroxilas disponíveis. A quantidade dos reagentes dependerá do número de grupos $\mathrm{OH}$ e NCO disponíveis nos reagentes. 
Figura 2 - Reação que leva à formação de poliuretana de estrutura (a) linear, (b) ramificada e (c) reticulada.

(a)
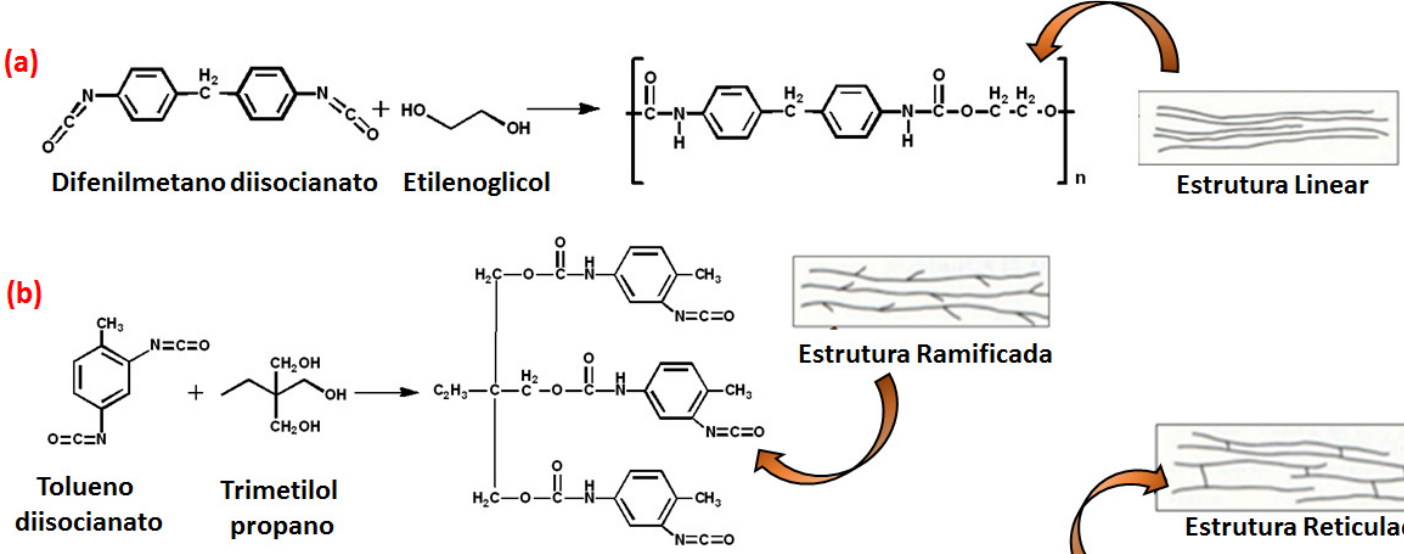

(c)

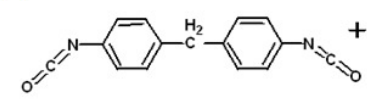

Difenilmetano diisocianato
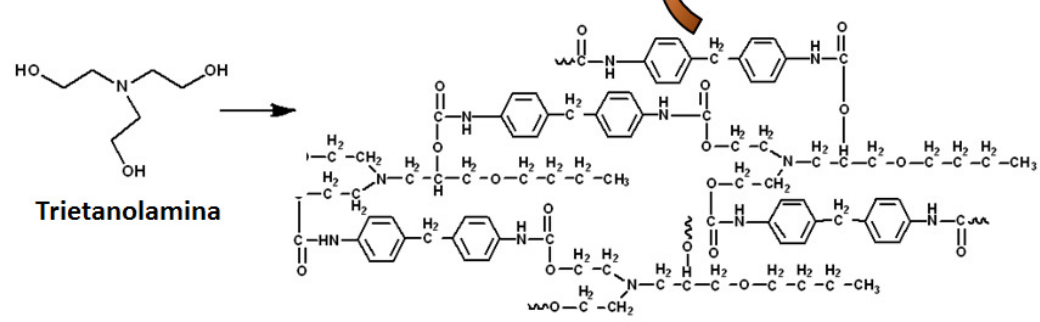

Fonte: Autoria própria.

As diferentes estruturas químicas e, consequentemente, as diferentes propriedades apresentadas pelas PUs, irão classificá-las em PUs termoplásticas, termorrígidas ou elastoméricas. PUs termoplásticas possuem cadeias lineares ou ramificadas, e podem ser fundidas posteriormente à suà síntese. As PUs termorrígidas possuem ligações cruzadas (reticulações) nas respectivas estruturas, o que irá afetar diretamente as propriedades mecânicas da PU, pois ligações cruzadas restringem a mobilidade dos segmentos entre estas ligações (Figura 3 a e 3c). Desta forma, posteriores aquecimentos não mais alteram seu estado físico, ou seja, a PU não amolece mais, tornando-se infusível e insolúvel (YILGOR et al., 2015). Por fim, PUs com propriedades elastoméricas possuem estruturas segmentadas, usualmente constituídas por longas cadeias flexíveis (provenientes dos polióis) unidas por segmentos em que anéis aromáticos rígidos estão presentes, com uma baixa densidade de ligações cruzadas (Figura 3 b) (YILGOR et al., 2015). 
Figura 3- Representação esquemática de um polímero poliuretânico: (a) termoplástico (sem ligações cruzadas), (b) elastomérico (com baixo grau de ligações cruzadas) e (c) termorrígido (com alto grau de ligações cruzadas em forma de rede).

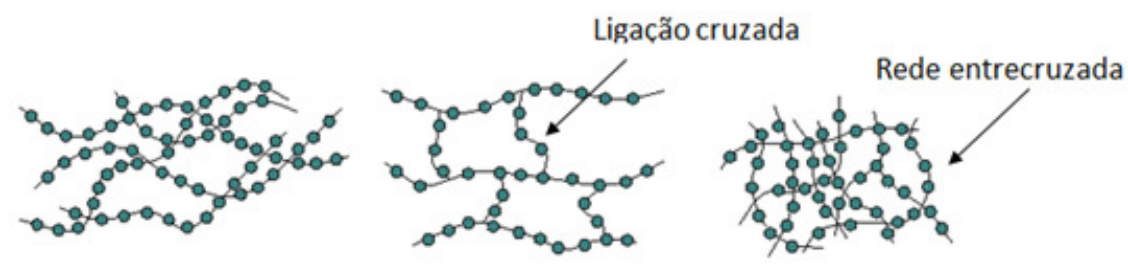

(a)

(b)

(c)

Fonte: DESIGN TECHNOLOGY, 2019².

As propriedades físicas e mecânicas dos materiais preparados a partir de PUs elastoméricas podem ser explicadas em termos da presença de domínios rígidos dispersos em uma matriz de domínios flexíveis (SZYCHER, 1999). As propriedades elásticas, como o módulo de elasticidade, podem ser mantidas comparativamente ao polímero não entrecruzado, mas haverá aumento em propriedades como a de resistência à fluência, o que explica o grande poder de deformação e recuperação das PUs elastoméricas (VILAR, 2002).

Existem disponíveis no mercado, uma grande variedade de isocianatos e polióis para à síntese de PUs, possibilitando a obtenção de PUs com as características desejadas para determinada aplicação de interesse, sejam elas termorrígidas, termoplásticas ou elastoméricas.

\subsection{Isocianatos}

O processo industrial de obtenção de isocianatos mais importante envolve a reação de aminas primárias com fosgênio, seguida de desidrohalogenação, Figura 4 (VILAR, 2002; LI et al., 2015).

Figura 4 - Representação da reação que leva à formação de isocianatos.

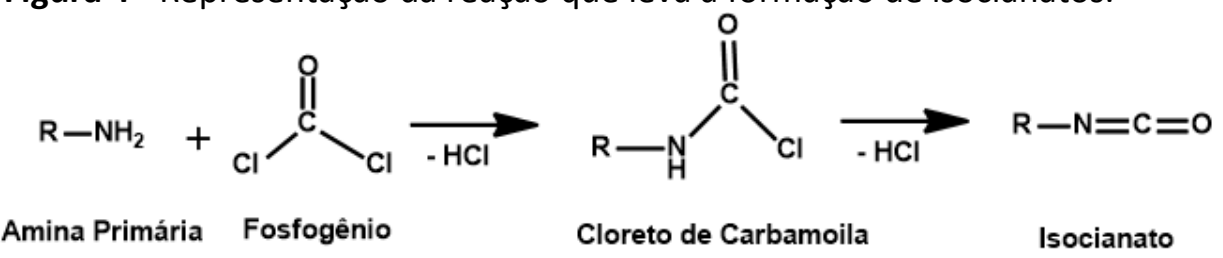

Fonte: Adaptado de Ll et al., 2015.

\footnotetext{
${ }^{9}$ Disponível em: https://www.designkmg.weebly.com/plastics.html, acesso em 13/08/2019.
} 
Diversos estudos reportam sínteses de isocianatos a partir de fontes naturais (CALLE et al., 2016; CORNILLE et al., 2017; DOLEY; DOLUI, 2018). No entanto, as etapas e reagentes que são utilizados até a obtenção dos isocianatos tornam questionável a valia dos processos e utilização dos mesmos.

\subsubsection{Tipos de Isocianatos}

Os isocianatos usados em síntese de PUs podem ser alifáticos ou aromáticos, sendo os aromáticos mais reativos que os alifáticos, devido ao efeito de ressonância que ocorre com o anel fenila (Figura 5), o que aumenta o caráter eletrofílico do carbono do grupo isocianato, tornando esse grupo mais reativo (SZYCHER, 1999).

Figura 5 - Efeito de ressonância com anel fenila.

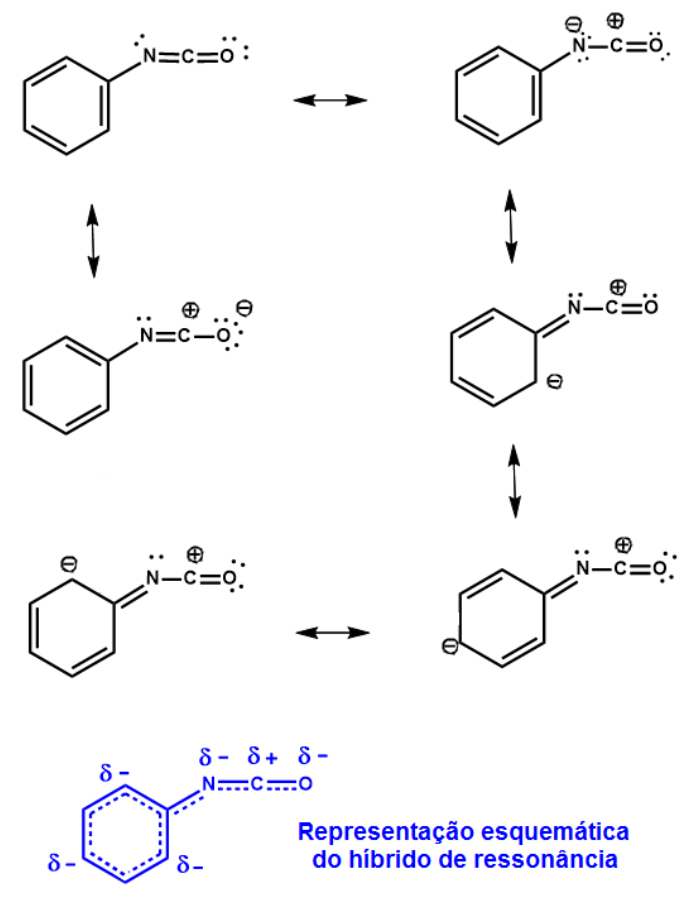

Fonte: Autoria própria.

Entre os isocianatos aromáticos, o difenilmetano diisocianato (MDI) e o tolueno diisocianato (TDI) são os mais usados, correspondendo, juntos, a cerca de $90 \%$ do mercado mundial de isocianatos (ALLPORT et al., 2003). Esses isocianatos costumam ser encontrados no mercado como uma mistura de isômeros, sendo a mistura de MDI, cuja funcionalidade vai de 2,5 a 3, conhecida como MDI cru, ou MDI polimérico (pMDI) (Figura 6). Quanto maior a funcionalidade nos isocianatos, maior a rigidez da PU. 
Figura 6 - Representação parcial da estrutura química do pMDI.

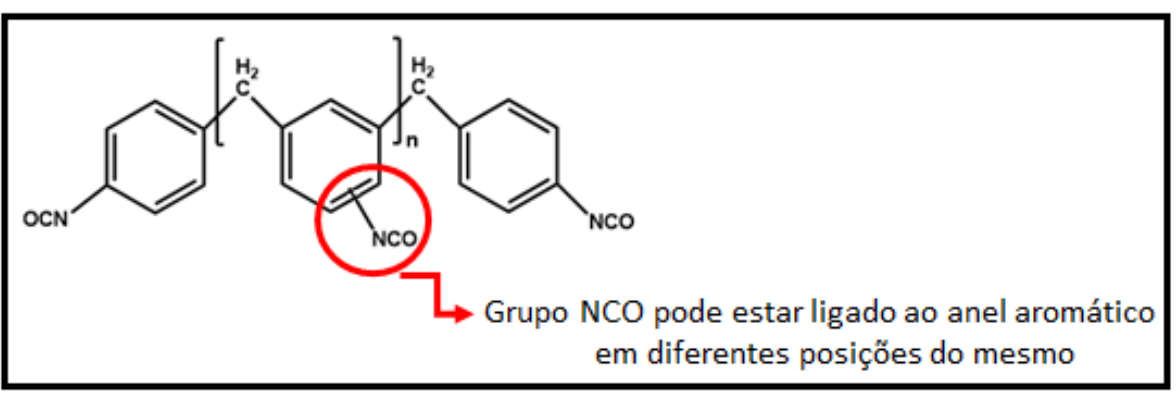

Fonte: Autoria própria.

O efeito estérico também tem impacto na reatividade dos isocianatos. Os isômeros em que o grupo NCO se encontra na posição para são mais reativos que os que os tem na posição orto. Sendo assim, o isômero mais reativo do pMDI, por exemplo, é o 4,4 MDI, seguido do 4,2 MDI e por último o 2,2 MDI.

\subsubsection{Reações de Isocianatos}

As principais reações dos isocianatos envolvem reações do grupo com compostos contendo hidrogênio ativo, e auto polimerização do grupo (Figura 7).

Figura 7 - Reações típicas do grupo isocianato com diferentes reagentes. Letra A: Formação de uretana; Letra B: Formação de uréia; Letra C: Formação de aminas (Espuma); Letra D: Formação de uréia; Letra E: Formação de biureto; Letra F: Formação de alofanato; Letra G: Formação de uretidiona; Letra H: Formação de isocianurato; Letras I e J: Produtos da decomposição dos isocianatos.

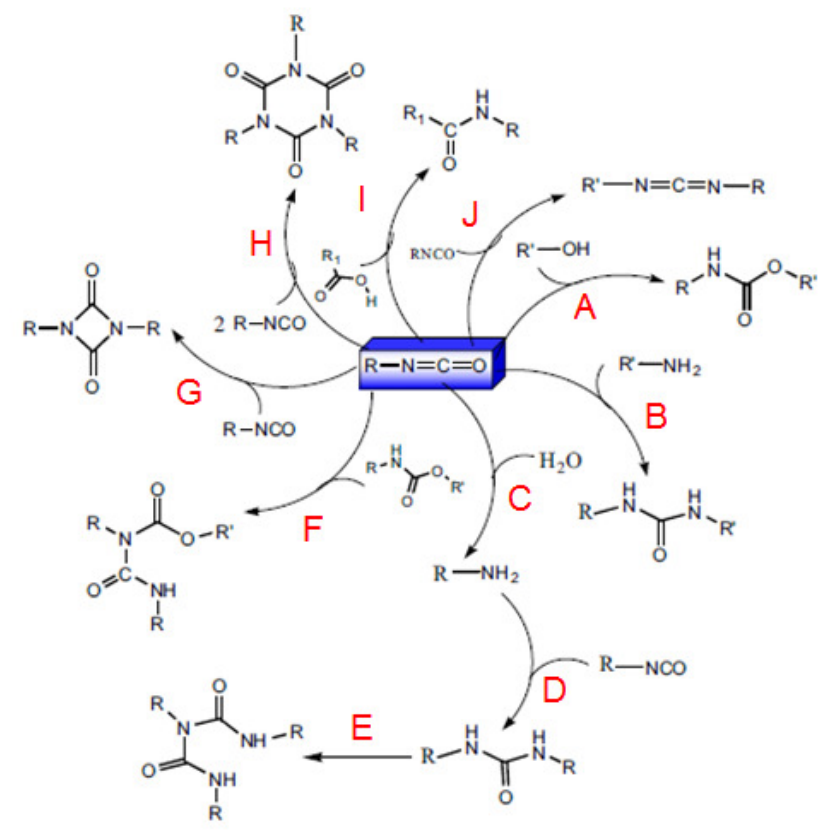

Fonte: CHATTOPADHYAY; RAJU, 2007. 
A reação de isocianatos com o grupo $\mathrm{OH}$ leva à formação de uretanas (Figura 7, A), já com aminas $\left(\mathrm{NH}_{2}\right)$, a reação leva à formação de uréias (Figura 7, B). A reação do grupo NCO com água, inicialmente leva à formação do composto instável, ácido carbâmico, que rapidamente se decompõe e produz amina (Figura 7, C). A amina é um reagente nucleofílico que pode reagir com grupos isocianato, como mencionado, e gerar uréias, (Figura 7, D) que por sua vez podem reagir com novamente com grupos isocianatos e produzir biuretos (Figura 7, E). Similarmente, os isocianatos podem regair com uretanas e produzir alofanatos (Figura 7, F) (CHATTOPADHYAY; RAJU, 2007). As reações E e F na Figura 7, são chamadas reações secundárias e ocorrem em menor extensão que as primárias (Figura 7, A, B e C). Normalmente as reações que levam à formação de biuretos e alofanatos dependem de condições específicas para ocorrer, como temperatura, umidade, tipo e proporção de isocianato utilizado (DUSEK; SPIRKOVA, 1990; DUSEK et al., 1990).

A auto-polimerização do grupo isocianato resulta na formação de anéis de uretidiona, um dímero, (Figura 7, G), assim como do trímero, isocianurato (Figura 7, H). A reações I e J na Figura 7, se referem a decomposição de isocianatos, que ocorrem principalmente em altas temperaturas (LEVCHIK; WEIL, 2004).

Em geral, os monômeros de diisocianatos costumam apresentar alta toxicidade, reatividade e volatilidade. A substituição dos monômeros voláteis por oligômeros de maior massa molar ou derivados é uma alternativa. Assim surgiram os chamados isocianatos em blocos, os dímeros (uretdiona) e trímeros (isocianuratos) de isocianatos (Figura 7, G e H), para dar aumentar a pressão de vapor dos isocianatos e conferir maior estabilidade as reações (HU et al., 2016).

Entre todos oligômeros, o isocianurato é o mais estável, em função da formação da estrutura em forma de anel, e que confere maior resistência térmica as PUs (CHALLA, 1993). A indústria tem investido cada vez mais na obtenção de isocianuratos derivados de isocianatos alifáticos (Figura 8), em especial o HDI, formando um trímero de HDI (tHDI) ligado por anel isocianurato, para aumentar sua funcionalidade e aprimorar as propriedades ópticas, químicas e térmicas em adesivos e embalagens (DRIEST et al., 2017). 
Figura 8 - Fórmula estrutural do trímero de HDI (tHDI) composto por anel isocianurato.

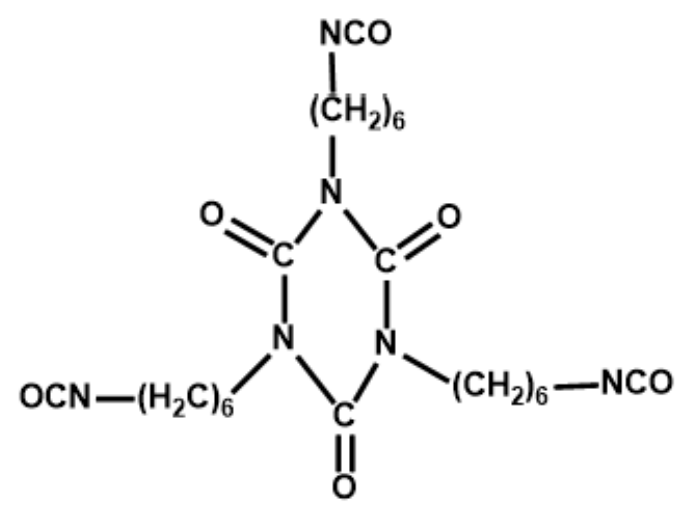

Fonte: Adaptado de DRIEST et al., 2017.

Neste estudo foram utilizados tanto isocianato do tipo aromático, difenilmetano diisocianato polimérico (pMDI, Figura 6), quanto alifático, trímero de hexametileno diisocianato (tHDI, Figura 8) na síntese das lignopoliuretanas.

\subsection{Polióis}

Diferentes tipos de polióis são utilizados na produção industrial das PUs, os quais apresentam diferentes funcionalidades, comprimentos de cadeia (massa molar) e reatividades, levando à formação de PUs com diferentes propriedades, tais como densidade, dureza, elasticidade, resistência térmica e química.

Dióis de baixa massa molar como glicerol e dietilenoglicol (DEG) levam a PUs com curtos segmentos oriundos dos mesmos, e a um maior número de grupos uretano na cadeia, originando materiais mais rígidos (LI et al., 2015).

Polióis com alta massa molar resultam em PUs com menos ligações uretânicas nas suas cadeias e mais segmentos flexíveis. Polióis de longas cadeias e baixa funcionalidade $(1,8-3)$ levam à formação de PUs com características elastoméricas, enquanto cadeias longas de polióis com alta funcionalidade (maior que 3), levam à formação de PUs mais rígidas e eventualmente entrecruzadas (CHATTOPADHYAY; RAJU, 2007). Exemplos desses polióis são os chamados polióis poliméricos como os do tipo poliéter ou poliéster. Esses são os principais polióis usados na síntese das PUs na indústria. Polietileno glicol (PEG) e polipropileno glicol (PPG) são exemplos de polióis poliéteres e policaprolactonas (PCL) e poliadipatos (PA) são exemplos de polióis do tipo poliéster (SZYCHER, 1999). 
Geralmente, os polióis e isocianatos envolvidos na síntese industrial das PUs são oriundos de precursores derivados do petróleo, os quais impactam negativamente o meio ambiente, pelo fato de o petróleo não ser uma fonte renovável, pelo impacto que sua extração causa na natureza, e pela não biodegradabilidade da maioria dos seus derivados (LI; RAGAUSKAS, 2012). Nesse contexto, o uso de reagentes de origem renovável na síntese das PUs atende às expectativas ambientais (ROSTRUP-NIELSEN, 2005).

Fontes renováveis como os óleos vegetais, as proteínas vegetais e a biomassa lignocelulósica vêm sendo consideradas como fonte de reagentes para à síntese das PUs (Ll et al., 2015). Como citado anteriormente, alguns estudos abordaram a substituição dos isocianatos convencionais, por oriundos de fontes renováveis (CALLE et al., 2016; CORNILLE et al., 2017; DOLEY; DOLUI, 2018), porém as rotas de obtenção desses produtos possuem limitações, como a necessidade de catalisadores eficientes para sintetizá-los em condições reacionais mais brandas (GUAN et al., 2011). Na literatura, a grande maioria dos estudos se refere a substituição dos polióis de origem petroquímica por matérias-primas oriundas de fontes renováveis, como óleo de mamona (TROVATI et al., 2019; LIANG et al., 2019), de soja (CZIONKA et al., 2018), de canola (KARIMI et al., 2017), glicerol bruto (CARRIÇO et al., 2016; GAMA et al., 2018), lignina (FERNANDEZ et al., 2017; JANG et al., 2018).

Neste estudo, óleo de mamona e lignina foram utilizadas em substituição aos polióis obtidos de fontes fósseis na síntese de PUs.

\subsection{1 Óleo de Mamona}

Os óleos vegetais são matérias primas obtidas de fontes renováveis e podem gerar polióis para à síntese de PUs (RISTIC et al., 2012). Na maioria dos casos, em função da ausência de hidroxilas em sua estrutura, alguns tipos de óleos vegetais necessitam passar por reações antes de serem usados na síntese de PUs, tais como, epoxidação, ozonólise, hidroformilação e transesterificação. Dependendo da reação e do óleo vegetal usado, são obtidos polióis derivados de óleos vegetais com diferentes estruturas e propriedades, de acordo com as diferentes aplicações pretendidas (HU et al., 2014).

O óleo de mamona (Castor Oil, $\mathrm{CO}$ ), se diferencia da maioria dos óleos vegetais pelo fato de seu principal componente possuir em sua estrutura hidroxilas (Figura 9), eliminando a necessidade de modificações químicas para uso como polióis na síntese de poliuretanas (Ll et 
al., 2015). O CO, oriundo da planta Ricinus communis (mamona) é constituído principalmente pelo triglicerídeo do ácido graxo ricinoleico (em torno de $90 \%$ ), o qual é constituído por cadeias com dezoito carbonos, uma insaturação e um grupo hidroxila no carbono 12 (Figura 9 a). O restante da composição do CO corresponde a ácidos oleicos e linoleicos (Figura 9 b e c) (OGUNNIYI E FAKAYEJO, 1996). A produção mundial de óleo de mamona em 2016 foi de aproximadamente 1,6 milhões de toneladas, responsáveis pelo faturamento de cerca de 2 bilhões de dólares (DIMIAN et al., 2019). A Índia é o maior produtor mundial de CO, com uma produção de 860,2 mil toneladas no ano de 2016 , sendo que nesse ano o segundo colocado foi o Brasil, que produziu aproximadamente 76 mil toneladas no ano (CASTOR OIL, 2016) ${ }^{10}$.

Figura 9 - Ácidos graxos presentes no CO: (a) triglicerídeo do ácido ricinoléico; (b) ácido oleico e (c) ácido linoleico.

(a)

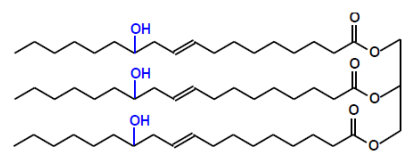

(b)

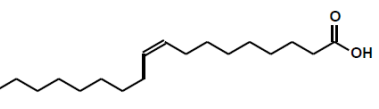

(c)

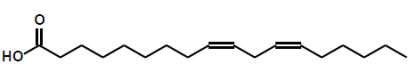

Fonte: Adaptado de Ll et al., 2015.

\subsubsection{Uso do Óleo de Mamona na Síntese de PUs}

O interesse na utilização de CO na síntese de PUs se dá em função principalmente da estrutura química de seu principal componente, o ácido ricinoleíco, Figura 9 (AZEVEDO, et al., 2011; TROVATI, et al., 2010). Longas cadeias lineares e apolares conferem hidrofobicidade à estrutura dos triglicerídeos e isso faz com que o CO dê origem a PUs com propriedades como resistência a água e flexibilidade, por exemplo. No Brasil, diversos estudos utilizando CO como poliol na síntese de PUs têm sido reportados desde à década de 90, sendo parte deles com foco no uso em regeneração óssea, devido a propriedade de biocompatibilidade apresentada por PUs derivada de CO (IGNACIO et al., 1996; CHIERICE et al, 1997; MALMONGE et al., 2005; KANDA et al., 2008).

Modificações químicas do $\mathrm{CO}$, como a transesterificação dos grupos éster do $\mathrm{CO}$ e a alcoxilação dos grupos hidroxila do CO podem aumentar o número de hidroxilas disponíveis ou inserir estes grupos em cadeias laterais, diversificando desta forma a estrutura dos polióis

\footnotetext{
10 Disponível em: http://www.castoroil.in/downloads/PreviewofComprehensiveCastorOilReport.pdf, acesso em 23/08/2019.
} 
oriundos de CO que podem ser usados na síntese de PUs (PFISTER et al., 2011). Algumas indústrias produtoras de PUs (BASF, Alberdingk Boley, ACTEGA) se valem dessas modificações ou utilizam o CO na sua forma natural para sintetizar PUs, tornando a utilização dessa fonte renovável uma realidade, devido não só ao apelo ambiental trazido pela utilização do CO, único poliol disponível comercialmente tal como extraído, mas também devido as boas propriedades químicas e mecânicas que essas poliuretanas apresentam em determinadas aplicações (MUTLU E MEIER, 2010).

Vários estudos têm sido relatados sobre o uso de CO na síntese de PUs para as mais diversas aplicações, as quais incluem matrizes em compósito e nanocompósitos (CORDERO et al., 2015; DAS et al., 2017; WANG et al., 2019), revestimentos e adesivos (MOGADHAM et al., 2016; AKRAM et al., 2017; SANTAN et al., 2018), entre outros.

Neste estudo, CO não modificado quimicamente foi utilizado como poliol na síntese das lignopoliuretanas.

\subsubsection{Biomassa Lignocelulósica}

Resíduos oriundos de agroindústrias e matéria orgânica proveniente diretamente de fontes vegetais, ou resultantes de seu processamento, podem gerar biomassa lignocelulósica. Os principais constituintes da parede celular dessa biomassa são a lignina, a celulose e hemiceluloses. A celulose se organiza helicoidalmente em microfibrilas, as quais são envolvidas por hemiceluloses, ligando-se uma a outra através de ligações hidrogênio e a lignina, uma matriz amorfa, permeia essas estruturas ligando-se às hemiceluloses por meio de ligações covalentes (Figura 10) (KALIA et al., 2013). O papel das hemiceluloses é o de compatibilizar a lignina e a celulose, estabilizando assim a parede celular (WYMAN et al., 2005). 
Figura 10 - Representação esquemática da estrutura da biomassa lignocelulósica.

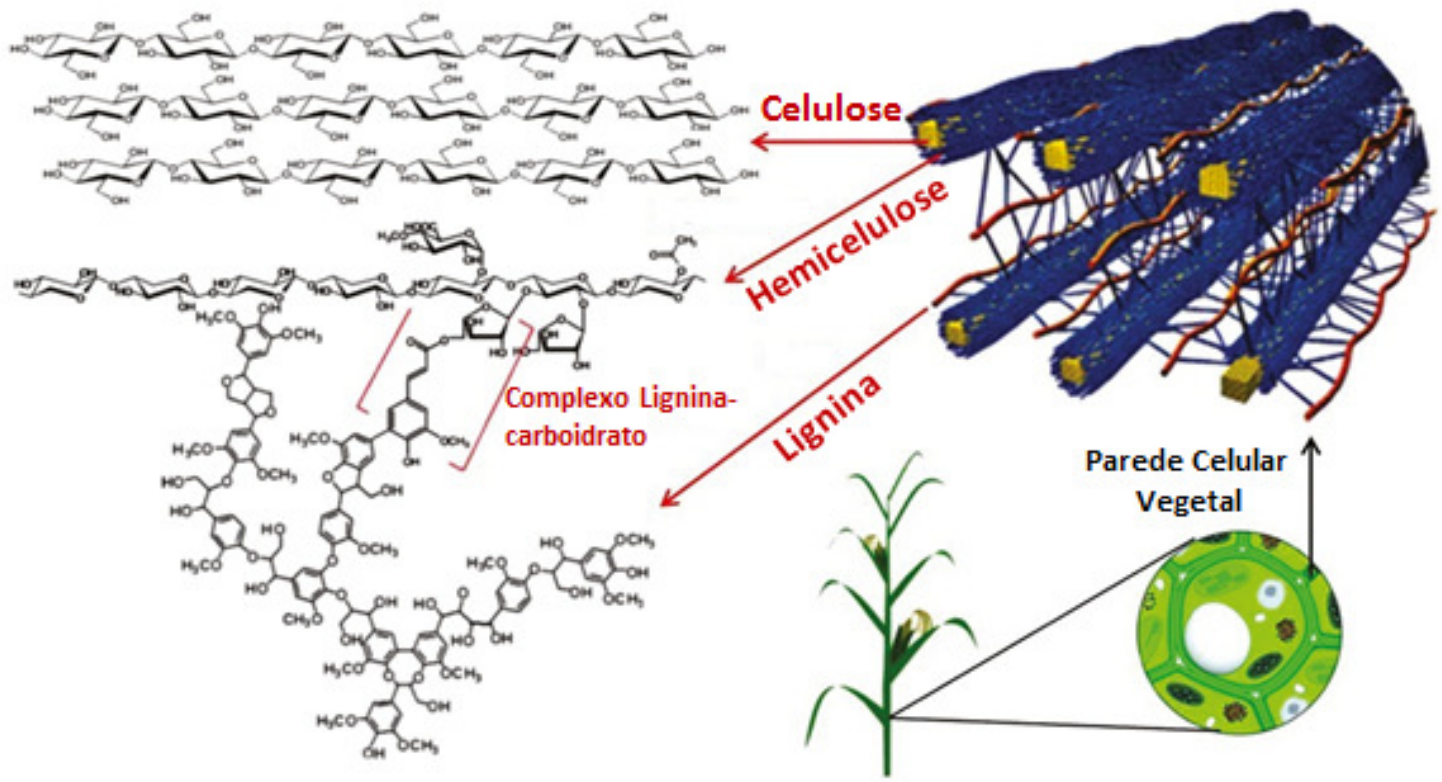

Fonte: Adaptado de KONDO, 1997.

A celulose e as hemiceluloses são polissacarídeos. A celulose é o principal componente estrutural das plantas e consiste em um homopolímero linear contendo unidades de glicose $\left(\mathrm{C}_{6} \mathrm{H}_{12} \mathrm{O}_{6}\right)$, sendo sua unidade repetitiva um dímero de glicose, a celobiose. Cada celobiose é composta por duas unidades repetitivas chamadas unidades anidroglicosídicas (UAG; $\mathrm{C}_{6} \mathrm{H}_{10} \mathrm{O}_{5}$ ) unidas por ligações glicosídicas do tipo $\beta-(1 \rightarrow 4)$, com ângulos de $180^{\circ}$ (Figura 11) (MOON et al., 2011).

Figura 11 - Representação parcial da estrutura molecular da celulose.

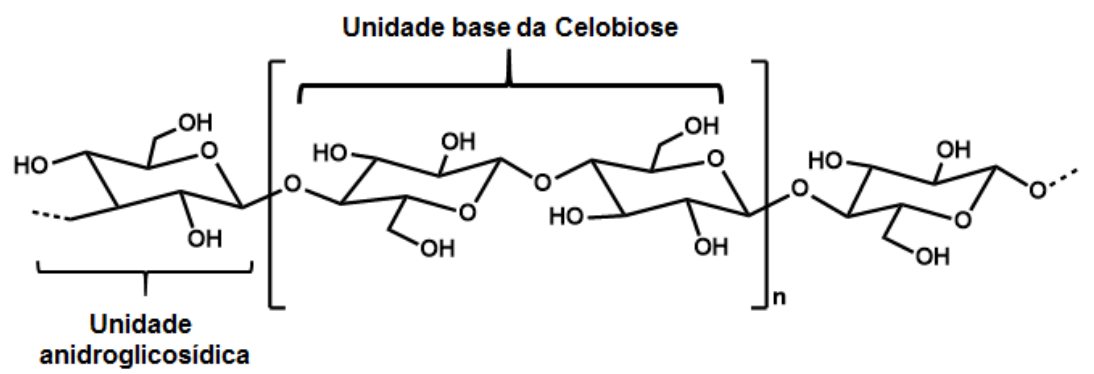

Adaptado de KLEMM et al., 1998.

As hemiceluloses correspondem a heteropolímeros ramificados, constituídos por pentoses e hexoses, como xilose, arabinose, glicose, manose e galactose e sua massa molar média é até cem vezes menor que a da celulose, sendo sua estrutura mais susceptível a 
hidrólise, uma vez que se situa nos domínios não cristalinos e tem menor grau de polimerização que a celulose (FENGEL; WEGENER, 1989; ACHA et al., 2009).

A lignina é uma macromolécula polifenólica complexa que é encontrada na parede celular de plantas, conferindo rigidez às mesmas (FENGEL; WEGENER, 1989) (Figura 12 a). Os principais precursores da lignina são três unidades fenilpropânicas, derivadas dos álcoois $p$ cumarílico, coniferílico e sinapílico (DOHERTY et al., 2011) (Figura 12 b). Sua estrutura e propriedades dependem do tipo de planta, condições de crescimento da mesma e método de extração da lignina (CANETTI; BERTINI, 2007; NOTLEY; NORGREN, 2010).

Figura 12 - (a) Estrutura da lignina proposta por ADLER (1977) e (b) Representação esquemática das unidades estruturais da lignina.

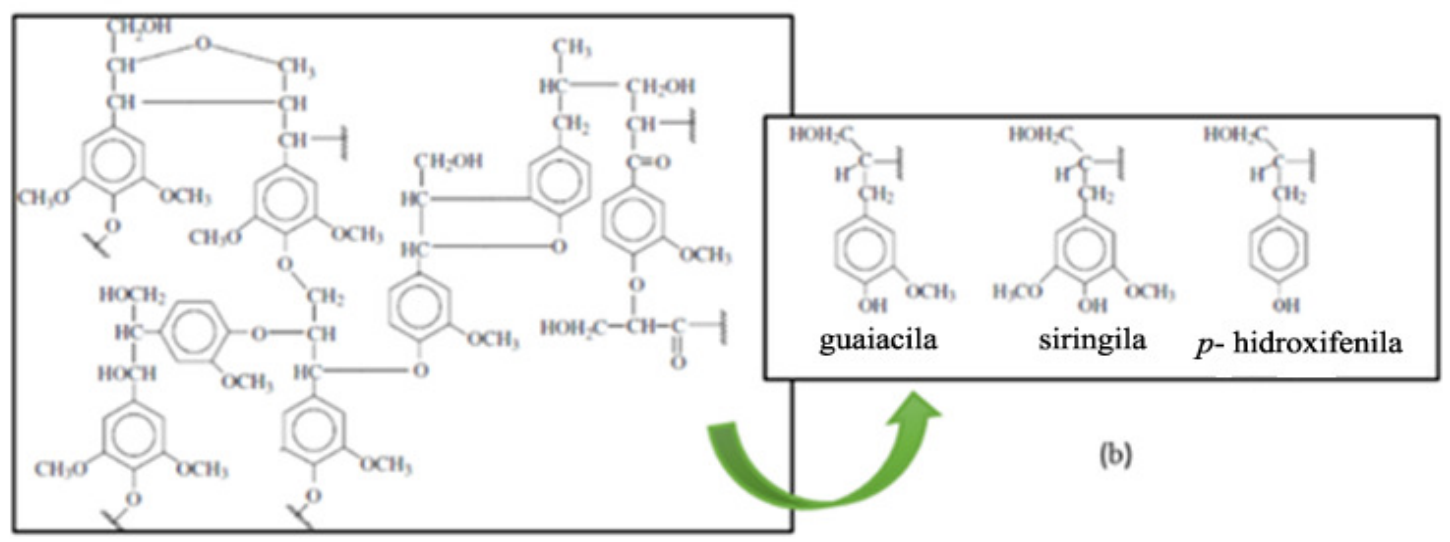

(a)

Fonte: Adaptado de ADLER, 1977.

Estima-se que, a indústria gere cerca de 1,5-1,8 bilhões de toneladas de lignina anualmente no mundo, sendo que aplicações comerciais (aditivos, adesivos, surfactantes ou dispersantes) consomem cerca de $2 \%$ dessa produção, e o restante é principalmente utilizado na geração de energia das próprias plantas industriais (GADHAVE et al., 2018; YANG et al., 2018).

\subsubsection{Lignina: Processos de Extração}

Os principais processos industriais de extração de lignina são organossolve, sulfito, soda e Kraft. O processo organossolve envolve a utilização de solventes orgânicos e ácidos, como etanol (processo etanossolve) e ácido acético (processo acetossolve), na extração da lignina. Esse processo gera ligninas livres de enxofre, com maior funcionalidade e estrutura química 
mais próximas da nativa. Todavia, os altos custos e a baixa qualidade da polpa celulósica não tornam esse processo tão atrativo para indústria comparativamente aos outros (DUWAL; LAWOCO, 2014).

O processo sulfito é o processo que gera os chamados lignossulfonatos. Nele, grandes quantidades de enxofre são incorporadas na lignina na forma de grupos $\mathrm{SO}_{3}^{-}$, tornando essa lignina um polieletrólito aniônico solúvel em água. Os lignossulfonatos são considerados o tipo de lignina mais importante comercialmente (maior valor agregado) e devido suas propriedades surfactantes, são muito utilizados pela indústria como dispersantes e redutores de viscosidade, por exemplo (LORA, 2008).

No processo soda a lignina é extraída pela ação de uma solução alcalina em condições semelhantes à do processo Kraft, porém sem a presença de enxofre. A ausência do enxofre torna esse processo menos eficiente que o Kraft para indústria de polpas celulósicas. Normalmente ele é aplicado em fibras, bagaços e palhas.

O principal processo industrial de extração da lignina é a polpação Kraft (deslignificação), amplamente utilizada na produção de papel e celulose. Cerca de $60 \%$ da lignina produzida no mundo é gerada através desse processo, o qual utiliza uma mistura de reagentes incluindo hidróxido de sódio $(\mathrm{NaOH})$ e sulfito de sódio $\left(\mathrm{Na}_{2} \mathrm{~S}\right)$ para deslignificar fibras de madeira (SANNIGRAHI et al., 2010). A maior eficiência desse processo em relação ao soda é decorrente do fato que em estruturas fenólicas, como a lignina, a clivagem da ligação éter no carbono beta da mesma é facilitada pela presença dos íons hidrosulfetos (HS), que são melhores nucleófilos que os grupos $\mathrm{OH}^{-}$, levando a uma extensiva despolimerização da macromolécula, e a consequente solubilização em meio alcalino (Figura 13). 
Figura 13 - Mecanismo de reação evidenciando a quebra da ligação éter na lignina Kraft na presença do íon hidrosulfeto (HS-).
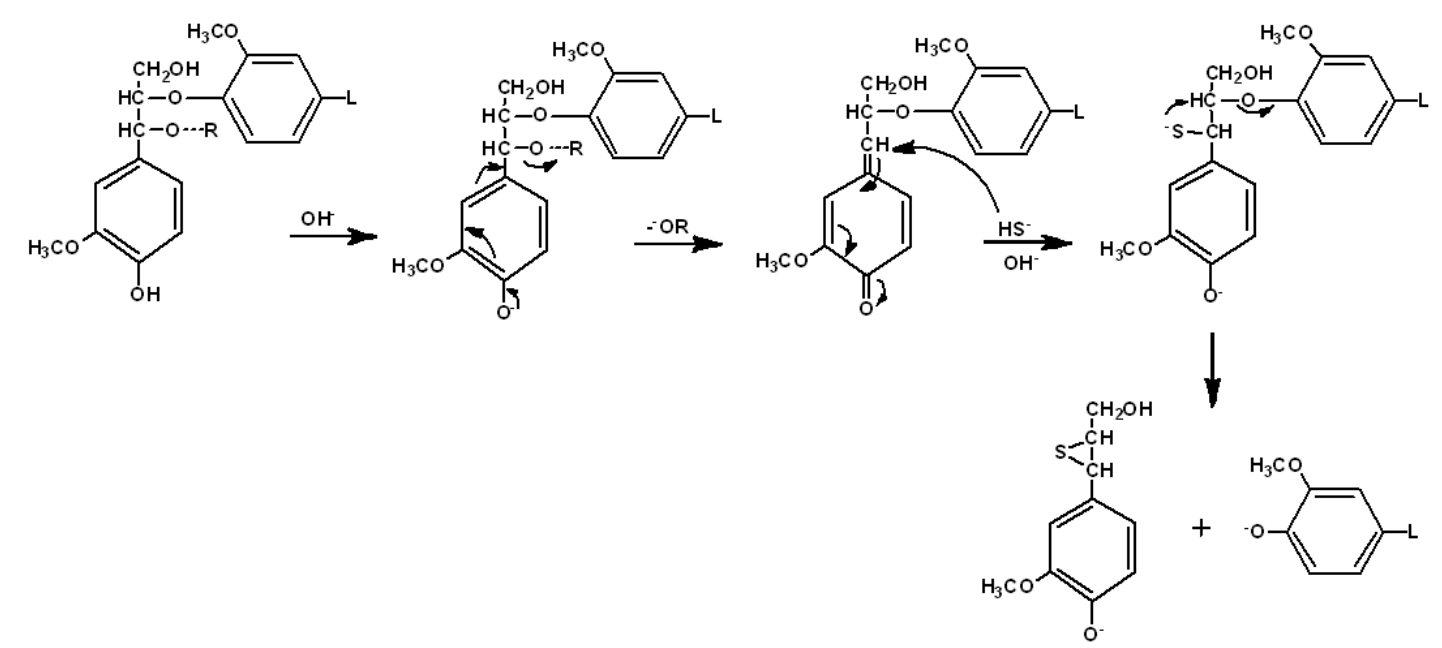

Fonte: Adaptado de SJOSTROM, 1993.

Segundo o ILI (2019) ${ }^{11}$ (International Lignin Institute) são produzidas 100 milhões de toneladas de lignina Kraft por ano e aproximadamente metade não é comercializada. O baixo valor e a abundância da lignina Kraft faz dela uma matéria-prima atrativa para diversas pesquisas em diferentes segmentos, como é o caso dos novos materiais poliméricos que podem agregar maior valor para esta macromolécula de origem natural (FARIS et al., 2017; TRIBOT et al., 2019).

\subsubsection{Uso de Lignina como macromonômero na Síntese de PUs}

A utilização de ligninas como um macromonômero na síntese de lignopoliuretanas vem sendo estudada por diversos grupos, incluindo o grupo de Materiais Macromoleculares e Fibras Lignocelulósicas - MacromoLignocell, devido à presença de hidroxilas alcoólicas que possibilitam a substituição parcial ou total de dióis ou polióis oriundos do petróleo, comumente utilizados na síntese de poliuretanas convencionais (RAMIRES et al., 2013; DE OLIVEIRA et al., 2015; ARSHANITSA et al., 2016; GHADAVE et al., 2018; VALE et al., 2019). Para que a lignina seja usada como reagente na síntese de PUs, uma etapa prévia de purificação da lignina pode ser necessária, uma vez que ligninas comerciais costumam conter impurezas, como açúcares remanescentes do processo de polpação e compostos inorgânicos,

\footnotetext{
${ }^{11}$ Disponível em: http://www.ili-lignin.com/aboutlignin.php, acesso em 15/08/2019.
} 
cuja presença pode levar a uma redução no rendimento da conversão química da lignina, podendo haver a formação de produtos indesejáveis (VISHTAL; KRASLAWSKI, 2011).

A reação de obtenção das poliuretanas usando ligninas como poliol pode ocorrer com ligninas que passaram por modificação química com o objetivo de, por exemplo, aumentar a disponibilidade dos grupos $\mathrm{OH}$ facilitando assim a reação com os grupos isocianato (ZHANG et al., 2015; ARSHANITSA et al., 2016; FERNANDEZ et al., 2017; GOLISZEK et al., 2019). Nesse sentido, existem algumas abordagens que envolvem a modificação dos grupos $\mathrm{OH}$ existentes na lignina (fenolação, eterificação - oxipropilação, entre outros) e as que envolvem a criação de novos sítios químicos ativos, utilizando, por exemplo, a estrutura dos anéis aromáticos da lignina (hidroxialquilação) (LAURICHESSE; AVEROUS, 2014).

Outra estratégia bastante utilizada parà síntese de PUs é a mistura da lignina com outros polióis, que podem ser oriundos do petróleo, como poli (etileno glicol) (PEG), ou de fontes renováveis como o óleo de soja (LUO et al., 2018) ou óleo de mamona (SADEGHIFAR et al., 2012; VOLKOVA et al., 2013; TAVARES et al., 2016; LIANG et al., 2019).

Em estudos realizados pelo grupo Macromolignocell sobre compósitos, lignopoliuretanas, posteriormente reforçadas com fibras lignocelulósicas, foram sintetizadas utilizando derivados de lignina (lignossulfonato de sódio) modificados (oxipropilados) ou não, em combinação com o óleo de mamona (RAMIRES et al., 2013; DE OLIVEIRA et al., 2015). Outra abordagem que foi utilizada neste estudo, correspondeu a hidroxialquilação da lignina via reação de seus sítios ativos reativos livres com aldeídos. Em estudo conduzido por DE OLIVEIRA (2014), lignossulfonato de sódio hidroxialquilado com glutaraldeído foi utilizado na síntese de compósitos de matriz lignopoliuretânica reforçadas por fibras de sisal.

\subsubsection{Hidroxialquilação}

A hidroxialquilação tem como objetivo criar novos sítios químicos ativos e consequentemente aumentar a reatividade de compostos fenólicos, como a lignina (LAURICHESSE; AVEROUS, 2014).

A reação de hidroxialquilação de ligninas consiste em reagir lignina com um aldeído, como o glutaraldeído, que pode ser obtido de fontes naturais, para introduzir hidroxilas alifáticas nas posições menos impedidas dos anéis aromáticos (Figura 14). 
Figura 14 - Hidroxialquilação da lignina com glutaraldeído.<smiles>COc1cc(C)cc(C(O)CCCC(O)c2cc(C)cc(C)c2O)c1O</smiles>

Fonte: Autoria própria.

Nas hidroxilas fenólicas, a ressonância com o anel aromático diminui o caráter nucleofílico do oxigênio, tornando as hidroxilas fenólicas menos reativas que as alifáticas. Além disto, as hidroxilas alifáticas são menos impedidas estéricamente que as fenólicas o que contribui para o aumento da reatividade da lignina frente aos grupos isocianato (NCO) na síntese de PUs.

No presente trabalho é reportada a modificação da lignina Kraft com glutaraldeído, em meio básico, para posterior utilização como poliol na síntese de filmes lignopoliuretânicos, sendo que esta abordagem até o momento não foi reportada na literatura, até onde se tenha conhecimento.

\subsection{Reforço de PUs com nanocristais de celulose (CNCs)}

Uma estratégia utilizada para melhorar as propriedades de materiais poliméricos é a utilização de reforços, como nanocristais de celulose (celulose nanocrystals, CNCs) (VALLEJOS, et al., 2012).

Os CNCs podem ser isolados, principalmente, via processo de hidrólise ácida, tanto de cadeias presentes na região cristalina quanto não cristalina de fibras vegetais (Figura 15) (SHARMA et al., 2018). Os CNCs são nanomateriais com alto grau de cristalinidade, com formato de agulha, haste ou "whisker" ("bigode") que apresentam espessuras no intervalo de 3-5 nm e comprimento na faixa de 50-500 nm (ELAZZOUZI-HAFRAOUI et al., 2008). 
Figura 15 - Representação esquemática da produção de CNCs.

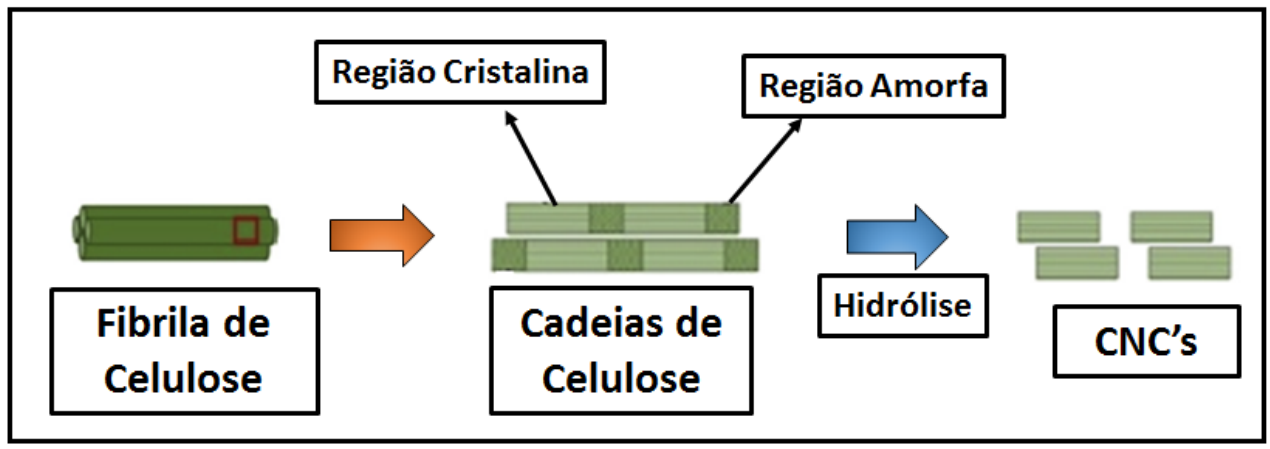

Fonte: Adaptado de PHANTHONG et al., 2018.

Diversos estudos relataram a incorporação de CNCs em matrizes poliuretânicas (AUAD et al., 2008; RUEDA et al., 2013; PARK et al., 2013; LOPES et al., 2016; BUFFA et al., 2018; LEI et al., 2019). Porém, uma boa dispersão dos CNCs é fundamental para se ter um real ganho em propriedades. A nanocelulose, em função da forte interação entre seus nanocristais, tende a se aglomerar, dificultando sua dispersão em matrizes poliméricas (LI; RAGAUSKAS, 2012).

Dessa forma, é interessante utilizar diferentes técnicas e agentes dispersantes que auxiliem na dispersão dos CNCs e garantam um reforço efetivo no material. Em estudo realizado por CASTRO et al. (2015), CO sem nenhuma modificação prévia foi utilizado como agente dispersante de CNCs obtidos de curauá, e usados em filmes baseados em "biopolietileno". Outra alternativa é a utilização de modificações químicas que podem ser feitas nas matrizes poliméricas (SETHI et al., 2017) ou na superfície dos CNCs (TIAN et al., 2019; AUCLAIR et al., 2018). Exemplos de modificações químicas realizadas nos CNCs são: oxidação, esterificação, graftização de polímeros, silanização, entre outros (ISLAM et al., 2013).

No presente trabalho foram utilizados CNCs não modificados quimicamente, visando avaliar a possível atuação dos mesmos como agentes de reforço de filmes lignopoliuretânicos.

\subsection{Filmes Poliuretânicos}

Os filmes poliuretânicos possuem propriedades únicas para prevenir danos causados por impacto, erosão, abrasão, penetração de fluidos, entre outros (RUEDA et al., 2013). Isso faz com que esses materiais possam ser utilizados na manufatura de inúmeros produtos em 
diferentes áreas, com novos usos sendo descobertos a cada dia. Eles podem ser usados na área industrial, como forro de tanques de combustíveis, adesivos, revestimentos para esteiras, proteção de painéis, aventais para áreas sujas, entre outros. Também podem ser utilizados na área médica, como curativos respiráveis, luvas cirúrgicas, bolsas de sangue e colostomia. $\mathrm{Na}$ área esportiva, filmes poliuretânicos podem ser encontrados em produtos como velas, laminados para paraquedas, mochilas, barracas, equipamentos de mergulho, entre outros. Além de outras aplicações mais gerais, tais como bolsas para silagem, filmes retardantes de chamas, embalagens especiais para alimentos, dentre outros.

Filmes poliuretânicos, especialmente os utilizados como revestimentos, podem ser termoplásticos ou termorrígidos. Os termoplásticos podem conter estrutura segmentada em domínios flexíveis e rígidos. Isso ocorre devido as diferentes propriedades das fases que levam a uma incompatibilidade intrínseca entre os segmentos flexíveis e rígidos. Nos domínios rígidos, pode ocorrer a formação de ligações hidrogênio entre os grupos carbonila e amino das ligações uretânicas adjacentes, induzindo a aglomeração de domínios rígidos ordenados, enquanto os domínios flexíveis costumam se organizar em domínios não ordenados (SEYMOR; COOPER, 1974). Os domínios rígidos em PUs termoplásticas segmentadas atuam como um reforço, ou, uma ligação cruzada do tipo físico, restringindo o movimento das cadeias dos domínios flexíveis.

As propriedades dos filmes poliuretânicos termoplásticos dependem de fatores como tamanho e composição dos domínios rígidos e flexíveis, assim como da distribuição das sequências dos segmentos. Em geral, à temperatura ambiente, os segmentos flexíveis encontram-se acima da temperatura de transição vítrea $\left(T_{\mathrm{g}}\right)$, ocorrendo, portanto, rotações em torno de ligações simples sequenciais, o que leva a movimentação do segmento, podendo conferir propriedades elastoméricas a esse polímero. Por outro lado, os domínios rígidos, à temperatura ambiente, se encontram abaixo de sua $T_{\mathrm{g}}$ e conferem estabilidade dimensional, além de contribuir para altos módulos e resistência à tração (KOUTSKY et al., 1970).

Os filmes poliuretânicos termorrígidos por sua vez apresentam entrecruzamentos do tipo químico, ou seja, ligações covalentes entre os segmentos, que geralmente se formam devido à utilização de altas temperaturas, pressão, mudanças de $\mathrm{pH}$, irradiação e normalmente, agentes de entrecruzamento. Outros fatores como uso de polióis e isocianatos com alta funcionalidade ( 3 e 2, respectivamente) e proporção NCO/OH maior que 1 também contribuem para formação de entrecruzamento (CHATTOPADHYAY; RAJU, et al., 2007). 
O entrecruzamento existente em termorrígidos, leva à formação de filmes poliuretânicos que apresentam maiores valores de $T_{g}$, e maior resistência à tração, abrasão, ácidos, álcalis e solventes, comparativamente aos filmes poliuretânicos termoplásticos. Entretanto, não podem ser reciclados, diferentemente dos termoplásticos (CHATTOPADHYAY; RAJU, et al., 2007).

Um tipo de entrecruzamento que pode ocorrer no decorrer dà síntese de filmes poliuretânicos são as ligações alofanato, que como mencionado, podem surgir quando algumas condições específicas, como o uso de catalisador, excesso de isocianato e altas temperaturas, são utilizadas (KONTOU et al., 1990).

Durante o desenvolvimento de novos filmes poliuretânicos, a proporção e tipo de matérias-primas utilizadas devem ser selecionadas de acordo com o local de aplicação final do filme. O desafio das indústrias é manter ou melhorar as propriedades desses filmes a um custo razoável, e simultaneamente atender à necessidade por materiais ambientalmente compatíveis (CHATTOPADHYAY; RAJU, et al., 2007).

A preparação de filmes poliuretânicos baseados em recursos renováveis vem aumentando nos últimos anos. Utilizando os termos "film; bio-based and polyurethane" na base de dados Science Direct, foi possível observar que do ano de 2009 para 2019, houve um crescimento de mais de $80 \%$ no número de trabalhos de pesquisa publicados relacionados com esses termos (Figura 16), o que evidencia a relevância e crescimento pela busca de materiais bio-baseados no âmbito dos filmes poliuretânicos.

Figura 16 - Número de trabalhos publicados e indexados na base de dados Science Direct envolvendo os termos "film; bio-based and polyurethane" nos últimos 10 anos.

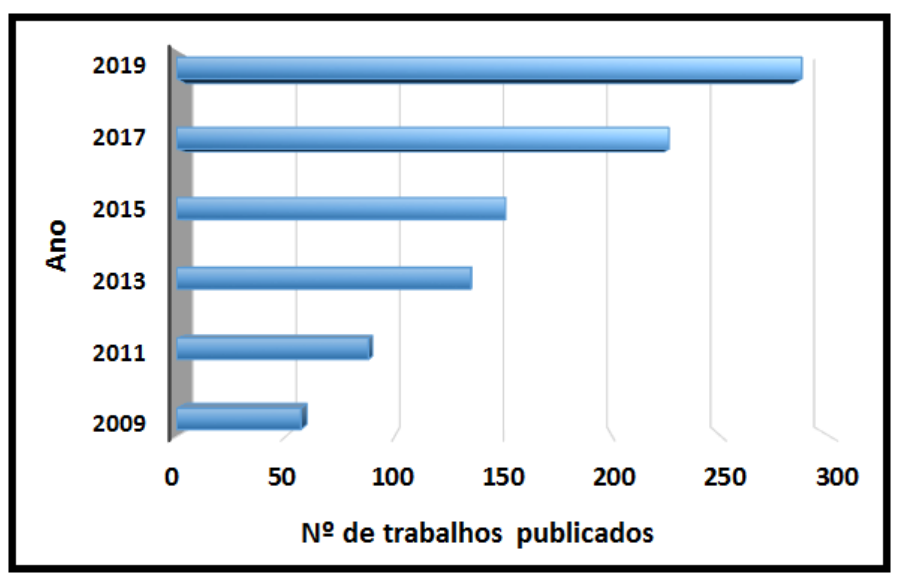

Fonte: Autoria própria. 
Óleos vegetais correspondem ao tipo de matéria-prima de origem renovável mais explorada na produção de filmes poliuretânicos em substituição aos polióis e isocianatos derivados do petróleo, isso porque os mesmos possuem grupos funcionais e tipos de ligações químicas passíveis de conversões químicas que insiram ou aumentem o teor de hidroxilas em sua estrutura, estabilidade química e física, baixa toxicidade, biodegradabilidade e flexibilidade (NOREEN et al., 2016). Óleos de diferentes plantas vêm sendo investigados na produção de filmes poliuretânicos para os mais diversos fins. Alguns exemplos são o óleo de canola (KONG et al., 2012), soja (ISMAIL et al., 2011; ACIK et al., 2018), mamona (SU et al., 2019; SARDARI et al., 2019), algodão (GAIKWAD et al., 2015; PATIL et al., 2017).

Os componentes de materiais lignocelulósicos (celulose, hemicelulose e lignina) também podem ser utilizados como matéria-prima de origem renovável na síntese de filmes poliuretânicos, entretanto, sua exploração é mais limitada que o dos óleos vegetais para esse fim (NOREEN et al., 2016). A Lignina, em especial, vem sendo explorada em alguns estudos para ser utilizada como poliol na síntese de filmes poliuretânicos com propriedades únicas e menos agressivos ao meio ambiente. Por ser um macromonômero essencialmente aromático, geralmente, o uso da lignina como poliol na produção de filmes poliuretânicos se dá em conjunto com outro tipo de poliol, como os próprios óleos vegetais (ZHANG et al., 2019; JANG et al., 2018).

Nesse contexto, o presente trabalho visou à formação de filmes simultaneamente as sínteses de poliuretanas, utilizando polióis de origem renovável como o componente do óleo de mamona, a lignina Kraft, e a lignina Kraft modificada quimicamente, assim como, isocianatos aromático e alifático, na ausência de solvente e catalisador. 


\section{Objetivos}

Geral

Síntese e caracterização de poliuretanas utilizando matérias-primas de origem renováveis, como o óleo de mamona e lignina, com formação simultânea de filmes lignopoliuretânicos.

\section{Específicos}

*Usar isocianatos de estrutura aromática e alifática, temperaturas ambiente e acima desta, visando avaliar a influência destes parâmetros nas sínteses e nas propriedades dos filmes lignopoliuretânicos formados;

* Modificar quimicamente a lignina, reagindo-a com glutaraldeído, com o intuito de aumentar a reatividade da mesma frente aos isocianatos;

*Avaliar a influência da presença de nanocristais de celulose nas propriedades dos filmes lignopoliuretânicos. 


\section{Estrutura da Tese}

Com o objetivo de facilitar a leitura desta tese, esta foi estruturada em capítulos a partir deste ponto. Cada capítulo tem como objetivo abordar os diferentes aspectos envolvidos na síntese das lignopoliuretanas com simultânea formação de filmes. Cada capítulo apresenta uma breve introdução referente ao que foi realizado em cada etapa, a descrição da parte experimental, os resultados obtidos e discutidos, e a conclusão parcial com relação ao que foi apresentado, conforme descrito a seguir:
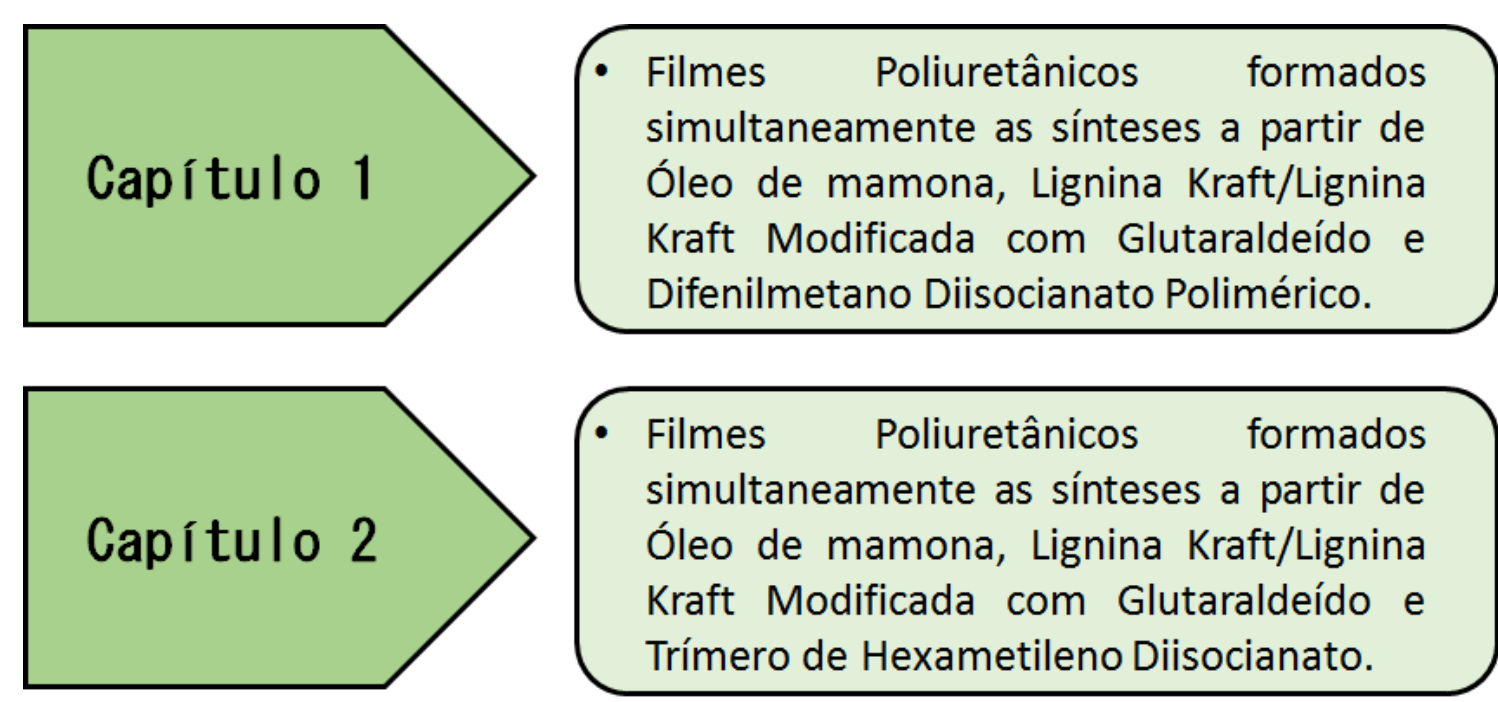

\section{- Filmes foliuretânicos formados} simultaneamente as sínteses a partir de Óleo de mamona, Lignina Kraft/Lignina Kraft Modificada com Glutaraldeído e Trímero de Hexametileno Diisocianato.

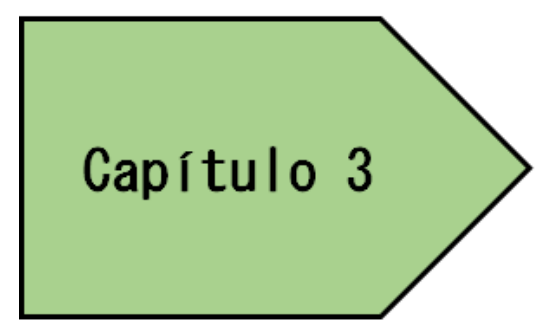
- Filmes
Poliuretânicos
obtidos simultaneamente as sínteses realizadas a partir de Óleo de mamona e Lignina Kraft Modificada com Glutaraldeído ou não: adição de nanocristais de celulose 


\section{Capítulo 1: Filmes poliuretânicos formados simultaneamente as sínteses realizadas a partir de óleo de mamona, Lignina Kraft/Lignina Kraft modificada com Glutaraldeído e Difeni Imetano di isocianato polimérico}

\subsection{Introdução}

Neste capítulo será relatada a caracterização química da lignina Kraft recebida da indústria Suzano Papel e Celulose, a partir daqui chamada de lignina Kraft bruta (LKB), e após sua purificação, denominada lignina Kraft purificada (LK). Também será descrita a modificação química (hidroxialquilação) realizada na LK, utilizando glutaraldeído como reagente (LK-Glu) e sua respectiva caracterização.

Adicionalmente, será relatada à síntese de poliuretanas (PUs) com simultânea formação de filmes utilizando como reagentes: óleo de mamona (CO), LK ou LK-Glu e isocianato de estrutura aromática, ou seja, o difenilmetano diisocianato polimérico (pMDI). Também será descrito o impacto sobre as propriedades dos filmes formados quando a temperatura da reação passa da ambiente para temperaturas acima desta.

Considera-se que a busca por materiais poliméricos obtidos a partir de alto teor de matérias-primas de origem renovável será constante. Essa pesquisa tem esta premissa como fundamento e, até onde chega nosso conhecimento, a metodologia de síntese com simultânea formação de filmes lignopoliuretânicos, à temperatura ambiente e acima desta, na ausência de solvente e catalisador, usando lignina Kraft e óleo de mamona como polióis e pMDI como isocianato, é sem precedentes. Este estudo também é considerado pioneiro no que concerne à obtenção de filmes lignopoliuretânicos a partir de lignina Kraft modificada via reação de hidroxialquilação com glutaraldeído. 


\subsection{Materiais e Métodos}

A Lignina Kraft utilizada foi gentilmente cedida pela indústria Suzano Papel e Celulose (Limeira-SP), que utiliza madeira oriunda do Eucalipto (Eucalyptus) como matéria-prima para seu processo de polpação Kraft. O difenilmetano diisocianato polimérico (pMDI) Desmodur VP PU 0129M utilizado na síntese dos filmes foi gentilmente cedido pela indústria Covestro (São Paulo-SP). A solução aquosa de glutaraldeído 50 \% foi adquirida da marca Exodo e o óleo de mamona (Castor Oil - CO) foi adquirido da Azevedo Indústria e Comércio de Óleos Ltda (Itupeva-SP).

\subsubsection{Purificação da Lignina Kraft}

A LKB foi submetida a uma purificação com água destilada, razão soluto/solvente 1:10, a $70^{\circ} \mathrm{C}$, por $1 \mathrm{~h}$ e posterior secagem em estufa de circulação de ar a $105^{\circ} \mathrm{C}$, até massa constante.

\subsubsection{Caracterização físico-química da Lignina Kraft}

A LKB e a LK foram caracterizadas quanto a: teor de lignina Klason, teor de umidade, teor de cinzas, teor de açúcares, análise elementar de carbono, hidrogênio, nitrogênio e enxofre, Termogravimetria (TGA), Espectroscopia na região do Infravermelho com Transformada de Fourier (FTIR) e Massa Molar Média por cromatografia de Exclusão por Tamanho (SEC). Para LK, também foi avaliada a Ressonância Magnética Nuclear de Hidrogênio $\left({ }^{1} \mathrm{H}\right.$ RMN).

\subsubsection{Teor de Lignina Klason}

Esta análise foi baseada na norma TAPPI T222 om-22, e fundamenta-se no uso de ácido sulfúrico (72\%) para separação da lignina dos polissacarídeos que podem ser extraídos juntamente com a lignina no processo Kraft, após hidrólise dos mesmos. A análise foi realizada em triplicata.

Para quantificação do teor de lignina Klason insolúvel em meio ácido pesou-se cerca de 1,0 g amostra, colocou-se em um erlenmeyer de $250 \mathrm{~mL}$ com 15,0 mL de ácido sulfúrico $72 \%$, e deixou-se sob agitação mecânica por $2 \mathrm{~h}$, à temperatura ambiente. Em seguida, transferiuse para um balão de $1000 \mathrm{~mL}$ adicionando-se $560 \mathrm{~mL}$ de água, seguido de refluxo por $4 \mathrm{~h}$. 
Filtrou-se a lignina insolúvel obtida em funil de vidro sinterizado ASTM tipo C ou 4 (previamente tarado), lavando-se várias vezes com água. A lignina insolúvel foi então seca em estufa a $105^{\circ} \mathrm{C}$ até massa constante.

Para quantificação do teor de lignina Klason solúvel em meio ácido o filtrado obtido da lignina Klason insolúvel foi analisado através de espectroscopia na região de ultravioleta (UV), em espectrofotômetro UV-Visível, marca Shimadzu, modelo UV-1800 (Japão), sendo determinadas as absorbâncias nos comprimentos de onda de 280 e 215 nm, (GOLDSCHMID, 1971). As amostras foram diluídas com ácido sulfúrico $3 \%$ até que o valor de absorbância fosse menor que 1.

O teor de lignina Klason total foi obtido pela soma dos teores de lignina Klason insolúvel e solúvel em meio ácido.

\subsubsection{Teor de Umidade e Cinzas}

O teor de umidade foi avaliado seguindo o protocolo da ABNT NBR NM ISO 287, enquanto o teor de cinzas foi feito seguindo as normas da TAPPI 412 om-93. As análises foram realizadas em triplicata.

\subsubsection{Teor de Açúcares}

Os teores de glicose e xilose foram obtidos pela análise da solução obtida após hidrólise da lignina com ácido sulfúrico (72\%), usando um cromatógrafo líquido de alta eficiência (HPLC), modelo HP-SEC, marca Shimadzu (Japão). O detector utilizado foi o índice de refração (RID, modelo 20A, Shimadzu), e a coluna utilizada foi a Aminex HPX 87H (300 mm $x 7,8 \mathrm{~mm}$, marca BIO RAD). O eluente utilizado foi uma solução de ácido sulfúrico (0,005 mol $\left.\mathrm{L}^{-1}\right)$, à $45^{\circ} \mathrm{C}$, com vazão de $0,6 \mathrm{ml} \mathrm{min}^{-1}$. Os padrões utilizados foram celobiose, D-glicose (Sigma-Aldrich), D-xilose (Sigma-Aldrich), L-arabinose (Sigma-Aldrich), ácido acético (49-51 $\%$, Sigma-Aldrich), todos de grau cromatográfico. A análise foi realizada em triplicata.

\subsubsection{Análise Elementar}

Os teores de carbono, hidrogênio, nitrogênio e enxofre foram determinados utilizando um equipamento EA 1108 - CHNS-O, marca Fisons Instruments (Inglaterra). Cerca de 1 mg das amostras foram pesadas em cápsulas de estanho $(3,2 \times 4 \mathrm{~mm})$ e inseridas no analisador 
elementar a $1020^{\circ} \mathrm{C}$. Em seguida, $\mathrm{O}_{2}$ (puro) foi injetado e a temperatura do forno foi elevada para $1800^{\circ} \mathrm{C}$, garantindo a combustão completa da amostra. Os gases originados na queima foram analisados em detector de condutividade térmica (TCD). As análises foram realizadas no Departamento de Química da Universidade Federal de São Carlos (UFSCAR).

\subsubsection{Termogravimetria (TGA)}

As perdas de massa das amostras foram avaliadas usando um equipamento TGA-50 da Shimadzu (Japão). Aproximadamente $8 \mathrm{mg}$ das amostras foram colocadas em um portaamostra de platina e aquecidas de 25 até $800^{\circ} \mathrm{C}$, a uma razão de aquecimento de $10{ }^{\circ} \mathrm{C} \mathrm{min}-1$, e sob atmosfera de nitrogênio com vazão de $20 \mathrm{~mL} \mathrm{~min}^{-1}$.

\subsubsection{Espectroscopia na região do infravermelho com Transformada de Fourier (FTIR)}

As amostras foram previamente secas em estufa a $105^{\circ} \mathrm{C}$ por $12 \mathrm{~h}$ e pulverizadas com $\mathrm{KBr}$ grau espectroscópico previamente seco em estufa a $105{ }^{\circ} \mathrm{C}$ na proporção de $1 \mathrm{mg}$ de amostra para $100 \mathrm{mg}$ de $\mathrm{KBr}$. As misturas resultantes foram prensadas em formato de pastilha. A análise de todas as amostras foi realizada em espectrofotômetro de infravermelho Shimadzu, modelo IRAffinity-1 com transformada de Fourier na região espectral entre 4000 a $400 \mathrm{~cm}^{-1}$, com resolução de $4 \mathrm{~cm}^{-1}$ e acúmulo de 32 varreduras.

\subsubsection{Ressonância Magnética Nuclear de ${ }^{1} \mathrm{H}\left(\operatorname{RMN}^{1} \mathrm{H}\right)$}

Essa técnica foi usada para a quantificação dos grupos hidroxilas presentes na LK (GONÇALVES et al., 2000). A análise de $\mathrm{RMN}^{1} \mathrm{H}$ requisitou a acetilação prévia da amostra a fim de minimizar a agregação decorrente das interações intermoleculares envolvendo grupos hidroxila. Além disso, a acetilação da lignina permite diferenciar com maior facilidade os grupos hidroxilas alifáticos e aromáticos, uma vez que os sinais de prótons de grupos hidroxilas não são observáveis no espectro, mas os sinais dos grupos acetila são detectados. Para acetilação da lignina Kraft uma mistura de piridina/anidrido acético (1:1 v/v), durante 24 h, 60 ${ }^{\circ} \mathrm{C}$ (Figura 17). Em seguida, fez-se reagir o anidrido acético (não reagido) com metanol (50 mL) durante $3 \mathrm{~h}$ em refluxo, $80^{\circ} \mathrm{C}$. $\mathrm{O}$ acetato de metila formado nesta reação foi rotaevaporado. A piridina foi evaporada por co-destilação com tolueno $(2 \times 10 \mathrm{~mL})$. 0 tolueno foi eliminado 
por co-destilação com metanol. O metanol foi evaporado, e o sólido foi seco em estufa e mantido em dessecador (HOAREAU, 2006).

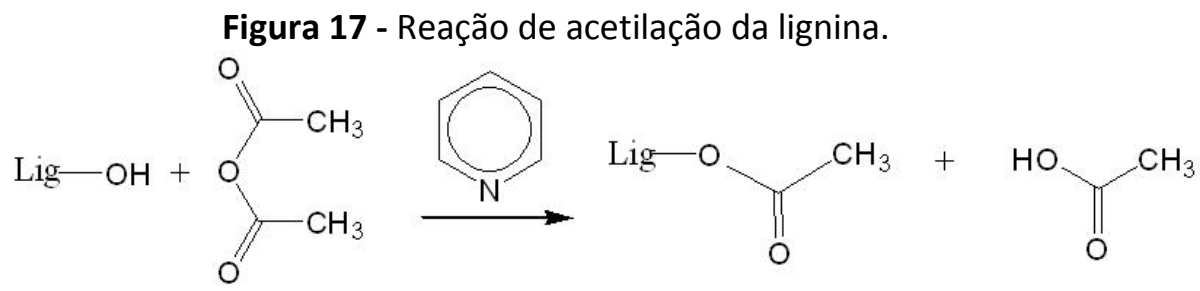

Fonte: Autoria própria

O espectro de $\mathrm{H}^{1} \mathrm{RMN}$ da LK acetilada foi registrado no aparelho da Agilent Technologies 400/54 Premium Shielded a $25{ }^{\circ} \mathrm{C}$, utilizando tubos de $5 \mathrm{~mm}$ e $\mathrm{CDCl}_{3}$ como solvente, 256 varreduras. Os deslocamentos químicos foram referenciados ao sinal residual do $\mathrm{CDCl}_{3} \mathrm{em}$ $\delta=7,26 \mathrm{ppm}$.

\subsubsection{Determinação da Massa Molar Média}

Esta técnica foi usada para a determinação da massa molar média de LK e LKB. Assim como na análise de $\mathrm{RMN}$ de ${ }^{1} \mathrm{H}$, a acetilação das amostras foi necessária para minimizar efeitos de agregação, assim como para torná-la totalmente solúvel no eluente utilizado, o THF (tetrahidrofurano). Para essa análise utilizou-se um cromatógrafo líquido HP-SEC, da marca Shimadzu, equipado com bomba (modelo LC-10 AD) e detector espectrofotométrico UVvisível (254 nm). Foram utilizadas uma pré-coluna PL-gel + 3 colunas em série Plgel 500A + $103 \mathrm{~A}+104 \mathrm{~A}$. O eluente foi THF grau HPLC com vazão de $1 \mathrm{~mL} \mathrm{~min}^{-1}$ à $35^{\circ} \mathrm{C}$ e a curva de calibração foi feita com padrões de poliestireno, com os seguintes valores de massa molar ponderal (Mw): 770.000, 435.000, 330.000, 66.000, 30.300, 22.000, 11.600, 7.000, 3.250, $2.450,1.700,1.060,580$ e $106 \mathrm{~g} \mathrm{~mol}^{-1}$.

\subsubsection{Hidroxialquilação da Lignina Kraft: Reação com glutaraldeído}

A modificação descrita a seguir foi baseada em estudos anteriores em que lignosulfonato de sódio foi modificado com aldeídos visando a preparação de resinas do tipo fenólica (DA SILVA et al., 2013). Os reagentes, lignina Kraft previamente purificada (LK), glutaraldeído (Glu) e $\mathrm{KOH}$ foram adicionados na razão 1:2:0,075, respectivamente, em massa. Em um balão de reação contendo o glutaraldeído, foi adicionado gradativamente a LK, sendo 
o sistema mantido sob agitação mecânica por 15 min para solubilização máxima da LK. Em seguida, KOH foi adicionado, mantendo a agitação da mistura por 40 min. Após este período, o pH foi medido para confirmação do meio básico ( $\mathrm{pH}$ entre 9 e 10). Em seguida, a temperatura foi elevada a $70{ }^{\circ} \mathrm{C}$ e mantida por $1 \mathrm{~h}$. Na sequência, a temperatura foi elevada até $95^{\circ} \mathrm{C}$ e mantida por $2 \mathrm{~h}$. Ao final deste período, o sistema foi resfriado e o pH foi ajustado para 5 com solução de $\mathrm{HCl} 10 \%$. Após este ajuste, tolueno foi adicionado ao meio (1:1 v/v) e a agitação foi mantida por $2 \mathrm{~h}$, com o intuito de precipitar a lignina modificada (LK-Glu). A LKGlu foi filtrada em papel filtro, lavada exaustivamente com água destilada para eliminar reagentes residuais eventualmente presentes, e seca em estufa, com rampa de temperatura inicialmente de $40{ }^{\circ} \mathrm{C}$ por $24 \mathrm{~h}, 80^{\circ} \mathrm{C}$ por $12 \mathrm{~h}$ e ao final $105^{\circ} \mathrm{C}$ até atingir massa constante.

\subsubsection{Caracterização físico-química da Lignina Kraft Modificada com Glutaraldeído (LK-Glu)}

Na caracterização da LK-Glu foram feitas as mesmas análises realizadas para LK: análise do teor de umidade, cinzas e açúcares, análise elementar de carbono, hidrogênio, nitrogênio e enxofre, TGA, FTIR, SEC e ${ }^{1} \mathrm{H}$ RMN. As metodologias utilizadas nessas análises foram iguais às descritas para LK no Item 1.2.2.

\subsubsection{Síntese das Lignopoliuretanas com simultânea formação de filmes}

Após ampla exploração de condições, as lignopoliuretanas (LignoPUs) foram sintetizadas utilizando CO e LK ou LK-Glu como polióis e pMDI como isocianato, conforme a metodologia apresentada no diagrama da Figura 18. 
Figura 18 - Diagrama dà síntese das LignoPUs com simultânea formação de filmes.

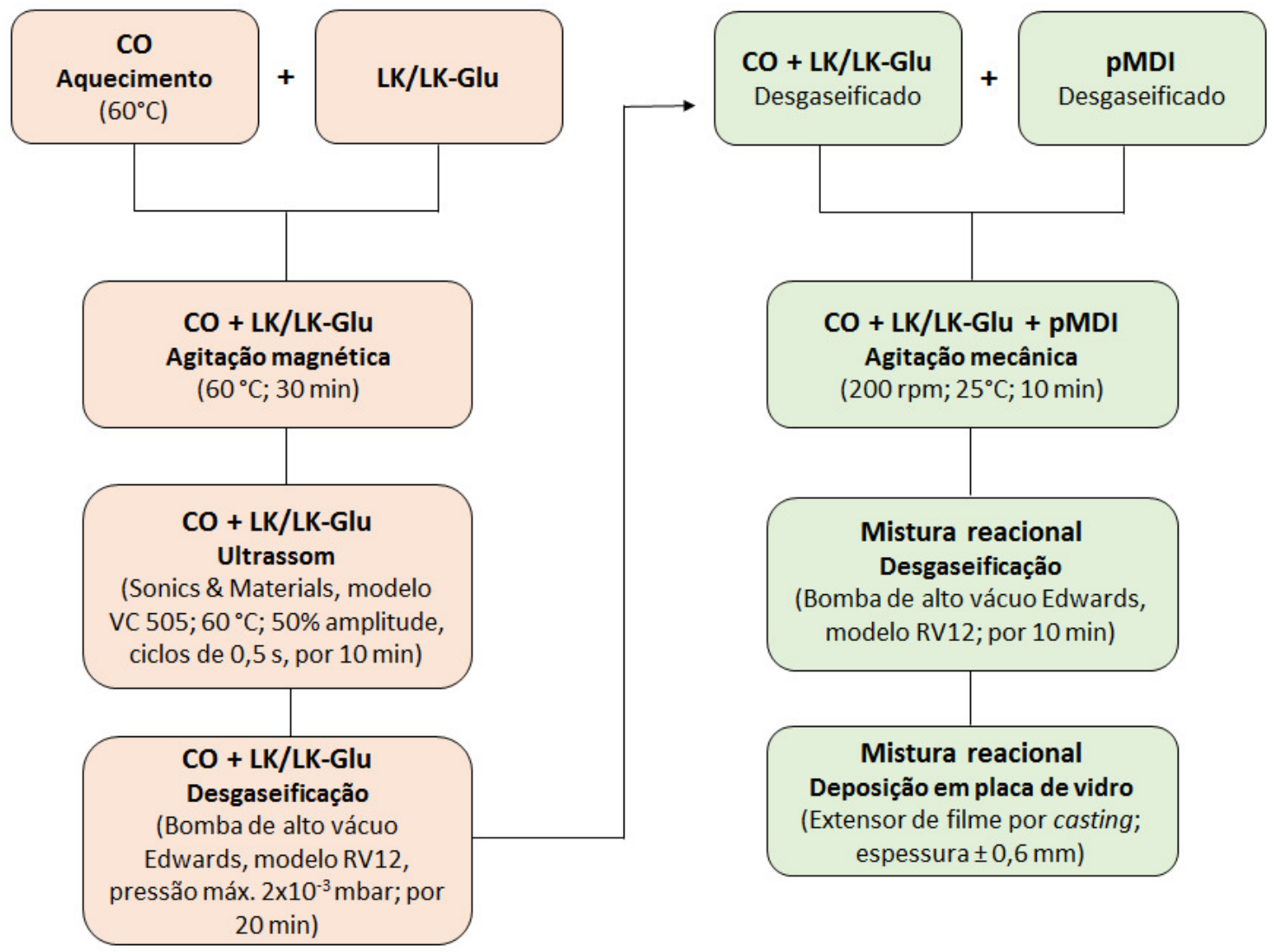

A placa de vidro em que a mistura reacional foi espalhada foi colocada em uma sala com temperatura de $(25 \pm 2){ }^{\circ} \mathrm{C}$ e umidade controlada (40\%), para dar prosseguimento a reação de polimerização da poliuretana, em condições adequadas para simultânea formação de filmes. O filme foi retirado da placa após o espectro FTIR indicou total consumo de pMDI, e armazenado em dessecador com sílica, sob vácuo, para análises posteriores.

Uma reação usando somente CO como poliol foi realizada, seguindo a mesma metodologia descrita para aquela em que CO e LK foram usados. O filme formado foi utilizado para avaliar como a introdução da lignina na formulação impacta as propriedades do material. Assim, as propriedades dos filmes formados a partir de CO e LK ou LK-Glu foram comparadas as do filme em que apenas CO foi utilizado.

No Quadro 1 encontra-se a formulação, proporção dos reagentes e a razão $\mathrm{NCO} / \mathrm{OH}$ utilizada na síntese de cada filme, bem como o código utilizado para cada um deles. Após testes preliminares, constatou-se que a presença de no mínimo $50 \%$ de CO é indispensável para dispersar a lignina no meio reacional. 
QUADRO 1 - Condições de reação das LignoPUs

\begin{tabular}{|c|c|c|}
\hline Materiais & $\begin{array}{c}\text { Formulação e } \\
\text { Proporção dos } \\
\text { reagentes }\end{array}$ & Código \\
\hline Filme Poliuretânico & $\begin{array}{c}\text { CO/pMDI } \\
\text { Razão 2,9 : } 1\end{array}$ & $\mathbf{P U}_{\mathrm{co}}$ \\
\hline \multirow{3}{*}{$\begin{array}{c}\text { Filmes } \\
\text { Lignopoliuretânicos } \\
\text { (LK) }\end{array}$} & $\begin{array}{l}\text { CO/LK10\%/pMDI } \\
\text { Razão 2,6: 0,2 : } 1\end{array}$ & LignoPU \\
\hline & $\begin{array}{l}\text { CO/LK30\%/pMDI } \\
\text { Razão } 2: 0,6: 1\end{array}$ & LignoPU Соцкзо \\
\hline & $\begin{array}{c}\text { CO/LK50\%/pMDI } \\
\text { Razão 1,45: 0,96: } 1\end{array}$ & LignoPU \\
\hline \multirow{3}{*}{$\begin{array}{l}\text { Filmes } \\
\text { Lignopoliuretânicos } \\
\text { (LK-Glu) }\end{array}$} & $\begin{array}{c}\text { CO/LK-Glu10\%/pMDI } \\
\text { Razão } 2,5: 0,2: 1 \\
\end{array}$ & LignoPU $U_{\text {CoLK-Glu10 }}$ \\
\hline & $\begin{array}{c}\text { CO/LK-Glu30\%/pMDI } \\
\text { Razão 1,8 : 0,5 : } 1 \\
\end{array}$ & LignoPU \\
\hline & $\begin{array}{l}\text { CO/LK-Glu50\%/pMDI } \\
\text { Razão 1,2 : 0,8: } 1\end{array}$ & LignoPU $U_{\text {COLK-Glu50 }}$ \\
\hline
\end{tabular}

A razão molar $\mathrm{NCO} / \mathrm{OH}=1: 1$ foi mantida para todos os filmes, a qual, assim como a razão em massa dos reagentes, foram calculadas considerando os seguintes fatores:

a)

\begin{tabular}{cccc}
\hline Isocianato & $\begin{array}{c}\text { Teor de grupos NCO } \\
\text { (Informado pelo } \\
\text { fabricante) }\end{array}$ & $\begin{array}{c}\text { Massa de NCO } \\
\text { presente em 1 } \\
\text { mol pMDI }\end{array}$ & $\begin{array}{c}\text { Mols de NCO } \\
\text { por mol de } \\
\text { pMDI }\end{array}$ \\
\hline $\begin{array}{c}\text { pMDI Desmodur VP } \\
\text { PU 0129M }\end{array}$ & $33,6 \%$ & $250 \mathrm{~g}$ & 2 \\
\hline
\end{tabular}

b) $\quad \mathrm{Na}$ análise de $\mathrm{RMN}^{1} \mathrm{H}$ (ver Item 1.3.1.2), foram detectados aproximadamente $4,1 \mathrm{mmol} \mathrm{OH} \mathrm{g}^{-1}$ na lignina Kraft não modificada (LK);

c) $\quad \mathrm{Na}$ análise de $\mathrm{RMN}^{1} \mathrm{H}$ (ver Item 1.3.1.2), foram detectados aproximadamente $5,8 \mathrm{mmol} \mathrm{OH} \mathrm{g}^{-1}$ na lignina Kraft modificada (LK-Glu);

d) O índice de hidroxila do CO é de $155 \mathrm{mg} \mathrm{KOH} \mathrm{g}^{-1}$ (dado retirado da ficha técnica do óleo) e $\mathrm{Mn} \cong 980 \mathrm{~g} \mathrm{~mol}^{-1}$.

A massa molar numérica do CO foi calculada a partir da Equação 1 (IONESCU, 2005):

$$
O H \#=\frac{f .5600}{M n} \quad \text { (Eq. 1) }
$$


Em que:

$\mathrm{OH \#} \mathrm{=} \mathrm{índice} \mathrm{ou} \mathrm{número} \mathrm{de} \mathrm{hidroxila} \mathrm{de} \mathrm{poliol} \mathrm{em} \mathrm{mg} \mathrm{de} \mathrm{KOH} \mathrm{g}^{-1}$

$\mathrm{Mn}=$ massa molar numérica média $\left(\mathrm{g} \mathrm{mol}^{-1}\right)$

$\mathrm{f}=$ funcionalidade, número de grupos $\mathrm{OH}$ por mol

5600 = massa equivalente de $\mathrm{KOH}$, em miligramas

Através do índice de hidroxila do $\mathrm{CO}, 155 \mathrm{mg} \mathrm{KOH} \mathrm{g}^{-1}$, e da funcionalidade 2,7 (CUNHA et al., 2004), chegou-se à massa molar do $\mathrm{CO}, \mathrm{Mn}=977,22 \mathrm{~g} \mathrm{~mol}^{-1}$. Assim, a cada 977,22 $\mathrm{g}$ de CO tem-se 2,7 mols de hidroxilas.

Dessa forma, os mols de OH existentes na massa utilizada de CO e da LK e LK-Glu foram relacionados na razão 1:1 aos mols de NCO do pMDI, obtendo-se assim a massa em gramas de pMDI necessárias para reação.

\subsubsection{Espectroscopia na região do infravermelho com Transformada de Fourier (FTIR)}

Imediatamente após a deposição da mistura reacional na placa de vidro foi retirada uma alíquota para análise (0h), e em períodos sequentes após a deposição do filme. A amostra referente ao tempo Oh foi analisada por deposição sobre pastilha de silício, devido a praticidade de espalhar o material sobre a pastilha. Os outros espectros foram obtidos no modo de Reflectância Total Atenuada (ATR) na região espectral entre 4000 a $650 \mathrm{~cm}^{-1}$, com resolução de $4 \mathrm{~cm}^{-1}$ e acúmulo de 32 varreduras.

\subsubsection{Caracterização dos Filmes Poliuretânicos formados simultaneamente as sínteses a partir de CO, LK ou LK-Glu e pMDI}

Os filmes obtidos simultaneamente as sínteses foram caracterizados pelas seguintes técnicas: Microscopia Eletrônica de Varredura (MEV); FTIR (descrito no Item 1.2.4.1); TGA; Difração de Raios X (DRX); Teste de Intumescimento; Análise Dinâmico-Mecânica (DMA); Ensaio de Resistência a Tração e Análise de ângulo de contato.

\subsubsection{Microscopia Eletrônica de Varredura (MEV)}

A superfície e a secção transversal (criofraturada) dos filmes foram analisadas utilizando-se um Microscópio Eletrônico de Varredura da marca Zeiss-Leica (Alemanha), modelo 440, aceleração de elétrons de $20 \mathrm{kV}$. As amostras foram coladas em porta-amostra 
de alumínio usando fita de carbono, e revestidas com uma fina camada de ouro $(20 \mu \mathrm{m})$ com o auxílio de um metalizador, marca BAL-TEC, modelo MED 020 (Liechtenstein).

\subsubsection{Termogravimetria (TGA)}

A estabilidade térmica dos filmes foi avaliada após o final da reação de polimerização, usando uma termobalança TGA-50 da Shimadzu (Japão). A amostra (aproximadamente $8 \mathrm{mg}$ ) foi colocada em um porta-amostra de platina e aquecida de $25^{\circ} \mathrm{C}$ até $900{ }^{\circ} \mathrm{C}$ a uma razão de aquecimento de $10^{\circ} \mathrm{C} \mathrm{min}^{-1}$, sob atmosfera de nitrogênio com vazão de $50 \mathrm{~mL} \mathrm{~min}^{-1}$.

\subsubsection{Análise por Difração de raios X (DRX)}

O grau de cristalinidade dos filmes foi analisado por difratometria de raios $\mathrm{X}$, usando um difratômetro de raios $X$ da marca Bruker (EUA), modelo D8 Advance equipado com um detector LynxEye e software DIFFRAC.EVA V4. As análises foram realizadas no intervalo de 2 Theta de 0 a 60 com um passo de 0,02 graus e tempo de irradiação de 0,5 s por passo. A quantificação do grau de cristalinidade foi baseada na intensidade relativa de picos específicos e da região não cristalina (KIM et al., 2016; ALEXANDER, 1969). O grau de cristalinidade foi calculado através das equações 2 e 3.

$$
\begin{aligned}
& \% \text { Amorficidade }=\frac{\text { Área total-Área do pico }}{\text { Área total }} * 100 \\
& \% \text { Cristalinidade }=100-\% \text { Amorficidade }
\end{aligned}
$$

\subsubsection{Teste de Intumescimento}

Três amostras de cada filme com dimensões de $5 \mathrm{~mm}$ de largura x $5 \mathrm{~mm}$ comprimento, previamente pesadas, foram imersas em recipientes contendo $20 \mathrm{~mL}$ de dimetilformamida (DMF) como solvente, selecionado por ser um solvente polar aprótico com afinidade pelos grupos polares presentes nas estruturas químicas dos componentes dos filmes, a $25{ }^{\circ} \mathrm{C}$ (THRING et al., 2004). Após 5 dias, os filmes foram retirados do solvente, e o excesso do mesmo foi retirado da superfície dos filmes com o auxílio de papel toalha, sendo os filmes pesados novamente.

A taxa de intumescimento (S\%) foi calculada através da equação 4 (JIA et al., 2015): 


$$
S \%=\left[\frac{W-W_{0}}{W_{0}}\right] \times 100 \quad \text { (Eq. 4) }
$$

Sendo $W$ = massa do polímero inchado $(\mathrm{g})$ e $W_{0}=$ massa do polímero seco $(\mathrm{g})$.

\subsubsection{Análise Dinâmico-Mecânica (DMA)}

O comportamento dinâmico-mecânico dos filmes foi avaliado utilizando um módulo DMA Thermal Analyzer, modelo Q800 (TA Instruments, EUA). As análises foram realizadas utilizando a garra de tensão para filmes. As dimensões dos corpos de prova foram 6,4 $\mathrm{mm}$ de largura $\times 5 \mathrm{~mm}$ de comprimento (distância entre as garras) x 0,65 mm de espessura. Os filmes foram previamente condicionados por 7 dias em dessecador com solução de $\mathrm{MgCl}_{2}$ (umidade relativa 33,3 \%). As condições experimentais foram: amplitude de oscilação de $20 \mu \mathrm{m}$, précarga de 0,01 Newton, $1 \mathrm{~Hz}$ de frequência, aquecimento de $-100{ }^{\circ} \mathrm{C}$ até $240{ }^{\circ} \mathrm{C}$, em uma taxa de aquecimento de $3{ }^{\circ} \mathrm{C} \mathrm{min}^{-1}$. As análises foram feitas em triplicata.

\subsubsection{Análise de propriedades de Tração}

Os ensaios foram realizados em um módulo DMA Thermal Analyzer, modelo Q800 (TA Instruments, EUA). Os filmes foram previamente condicionados por 7 dias em dessecador com solução de $\mathrm{MgCl}_{2}$ (umidade relativa 33,33\%). As dimensões dos corpos de prova dos filmes

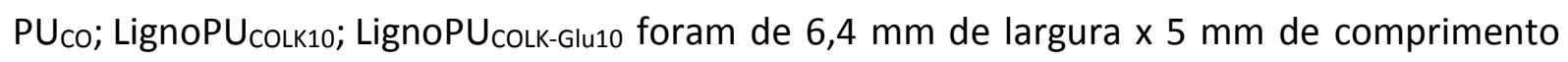
(distância entre as garras) × 0,65 mm de espessura.

Em função do não rompimento dos filmes formados a partir das PUs sintetizadas com 30 e 50\% de LK e LK-Glu (LignoPU ${ }_{\text {CoLk30; LignoPU }}$ CoLK50; LignoPU $_{\text {COLK-Glu30; LignoPU }}$ COLK-Glu50) nas dimensões citadas previamente, as dimensões dos corpos de prova desses filmes foram 1,5 $\mathrm{mm} \times 5 \mathrm{~mm} \times 0,66 \mathrm{~mm}$.

Os experimentos foram realizados em modo de tensão, utilizando a garra de tensão para filmes. As condições experimentais foram: rampa de força de $1 \mathrm{~N} \mathrm{~min}^{-1}$ até $18 \mathrm{~N}$, pré-carga de 0,001 N. Para cada amostra, as análises foram repetidas 6 vezes.

\section{2.5.7 Análise de Ângulo de Contato}

O ângulo de contato dinâmico entre a gota de água deionizada e a superfície dos filmes foi medido, a $25^{\circ} \mathrm{C}$, utilizando-se o goniômetro CAM 200 da KSV Instruments (Helsinque, 
Finlândia), equipado com um software de análise de imagem CAM 2008. Uma gota de água deionizada (aproximadamente $5 \mu \mathrm{L}$ ) foi depositada na superfície dos filmes $(1 \mathrm{~cm} \times 1 \mathrm{~cm})$ que estavam fixados em uma lamínula de vidro. Os ângulos de contato, para ambos os lados da gota, foram calculados em função do tempo após $1 \mathrm{~s}$ de contato entre a gota e o substrato. Assim, em cada cálculo do ângulo de contato foram realizadas 200 medidas, coletadas individualmente a cada $1 \mathrm{~s}$ de intervalo.

\subsubsection{Avaliação da Influência da temperatura nas sínteses das LignoPUs sobre as propriedades dos filmes formados, utilizando CO, LK ou LK- Glu como polióis e pMDI como isocianato}

Com o intuito de avaliar o impacto nas propriedades dos filmes obtidos, diferentes temperaturas acima da ambiente foram consideradas durante a polimerização das LignoPUs sintetizadas usando 30 e $50 \%$ de LK e LK-Glu, respectivamente. Estas porcentagens foram selecionadas a partir das propriedades observadas para os filmes formados concomitantemente às reações ocorridas à temperatura ambiente.

Após o espalhamento das misturas reacionais nas placas de vidro, as mesmas foram colocadas em estufa, marca Quimis (Brasil), nas temperaturas de 50, 75 e $100{ }^{\circ} \mathrm{C}$, e o procedimento e caracterizações posteriores seguiram o descrito nos itens 1.2.4 e 1.2.5.

\subsection{Resultados e Discussão}

\subsubsection{Caracterização da Lignina Kraft Bruta (LKB), Lignina Kraft purificada (LK) e Lignina Kraft modificada com Glutaraldeído (LK-Glu)}

Com o objetivo de retirar contaminantes oriundos do processo industrial, como açúcares e compostos inorgânicos, a lignina Kraft recebida (LKB) passou por uma prévia purificação (LK) para posteriormente ser utilizada na síntese de PUs com concomitante formação de filmes.

A LK foi também modificada com glutaraldeído (LK-Glu) com o objetivo de aumentar o número de sítios ativos da mesma frente a reação de síntese das lignopoliuretanas.

A Tabela 1 mostra os valores de umidade, cinzas, açúcares e lignina Klason da LK, LKB e LK-Glu, bem como a massa molar ponderal média $(\mathrm{Mw})$, polidispersividade $(\mathrm{Mw} / \mathrm{Mn})$ e composição centesimal de carbono, hidrogênio, nitrogênio, oxigênio e enxofre. 
Outros procedimentos para purificação da LKB foram avaliados, como lavagem com $\mathrm{NaOH}$ e posterior precipitação com $\mathrm{HCl}$, e lavagem com uma mistura de ciclohexano e etanol, todavia o procedimento que envolveu menos etapas, portanto menor custo, e que levou a um resultado tão satisfatório como os demais, foi a lavagem com água destilada à $70^{\circ} \mathrm{C}$, sob agitação mecânica, por $1 \mathrm{~h}$. Esse tratamento elevou a porcentagem de lignina Klason total em $5,7 \%$ comparado ao teor da LKB (Tabela 1 ).

Tabela 1 - Teores de umidade, cinzas, açúcares, análise elementar, Mw, Mw/Mn e lignina Klason para LKB, LK e LK-Glu

\begin{tabular}{cccc}
\hline Análise & LKB & LK & LK-Glu \\
\hline Umidade (\%) & $7,8 \pm 0,6$ & $3,8 \pm 0,2$ & $4,3 \pm 0,4$ \\
Cinzas (\%) & $1,8 \pm 0,1$ & $0,12 \pm 0,09$ & $0,10 \pm 0,05$ \\
C (\%) & 56,3 & 61,3 & 62,7 \\
H (\%) & 5,1 & 5,6 & 7,2 \\
N (\%) & 0,7 & 0,7 & 0 \\
S (\%) & 2,5 & 1,8 & 0,7 \\
O* (\%) & 33,5 & 30,4 & 29,2 \\
Glicose (\%) & $3,000 \pm 0,064$ & $2,700 \pm 0,004$ & ND** \\
Xilose (\%) & $2,600 \pm 0,005$ & $2,280 \pm 0,002$ & ND** \\
Açúcares totais (\%) & $5,600 \pm 0,005$ & $4,980 \pm 0,003$ & ND** \\
Lignina Klason Solúvel & $8,3 \pm 0,2$ & $9,0 \pm 0,8$ & $87 \pm 3$ \\
Lignina Klason Insolúvel & $80 \pm 2$ & $85 \pm 1$ & $96 \pm 2$ \\
Lignina Klason Total & $88 \pm 2$ & $94 \pm 1$ & 4421 \\
Mw (g mol ${ }^{-1}$ )*** & 1322 & 2331 & 4,0 \\
Mw/Mn*** & 1,5 & 2,0 & \\
\hline
\end{tabular}

* Determinação feita pela diferença após correção do valor das cinzas

**Não detectado

$* * *$ Ligninas acetiladas

As principais impurezas encontradas em ligninas técnicas comerciais, como a Kraft, são cinzas e resíduos de carboidratos (CATETO et al., 2008). As cinzas na lignina Kraft podem estar relacionadas com o teor de sódio, oriundo do processo de polpação (SANTOS et al., 2014). O percentual de cinzas encontrado para $\operatorname{LKB}(1,8 \pm 0,1 \%$, Tabela 1$)$ foi um pouco abaixo ao encontrado em outros estudos, em torno de 2-4\% (WON; KIM, 2015; GILLESPIE et al., 2013). 
Após o tratamento da LKB, o percentual de cinzas da mesma diminuiu para aproximadamente $0,10 \pm 0,05 \%$, o que é importante para algumas aplicações de alto valor agregado que requerem baixos teores de cinzas, como na síntese de polímeros (ROBERTS; KHAN, 1996).

As condições alcalinas do processo Kraft promovem a quebra de ligações da protolignina, ou seja, da lignina "in situ", ligada ao tecido da planta, além da dissolução de fragmentos de lignina e subsequente recondensação. Todavia, nem todas as ligações do complexo lignina-carboidrato são rompidas, resultando em açúcares residuais nas ligninas isoladas por processos alcalinos (CONSTANT et al., 2016). Além disso, carboidratos podem ficar "presos", ou seja, não ligados covalentemente a lignina, mas podem ser arrastados durante a etapa de precipitação e secagem da mesma (HUIJGEN et al., 2014). Na análise de HPLC, apenas glicose e xilose foram detectados nas ligninas avaliadas. A LKB apresentou 5,600 $\pm 0,005 \%$ de açúcares residuais e após a purificação este percentual reduziu para cerca de 5 $\%$ (Tabela 1). Esse valor é superior ao encontrado em trabalhos desenvolvidos por GORDOBIL ET AL. (2015) (3,4 \% de açúcares totais) e Constant et al. (2016) (1,4 \% de açúcares residuais) para ligninas Kraft extraídas de madeiras duras, por exemplo. Diferenças nestes valores são comuns em decorrência da variabilidade do tipo de matéria-prima e das condições usadas na polpação Kraft (DEHNE et al., 2016). A presença de açúcares na LK não corresponde a uma limitação, pois os grupos hidroxila presentes nas respectivas estruturas químicas permitem a atuação como polióis na síntese das PUs, incorporando-se à estrutura química das mesmas (WU et al., 2007; RIAZ et al., 2016).

Os valores de enxofre encontrados para lignina Kraft reportados na literatura encontram-se entre 1-2 \% (GORDOBIL et al., 2016), e os valores encontrados neste estudo para LKB foram ligeiramente superiores $(2,5 \%$, Tabela 1$)$. Pode ter contribuído para esse resultado, o fato de o processo Kraft utilizar sulfito de sódio $\left(\mathrm{Na}_{2} \mathrm{~S}\right)$ para deslignificar a madeira, e nesse caso, íons hidrossulfeto $\left(\mathrm{HS}^{-}\right)$, provenientes do $\mathrm{Na}_{2} \mathrm{~S}$, reagem com sítios reacionais da lignina formando compostos do tipo benzil mercaptano, os quais podem se rearranjar formando intermediários cíclicos de sulfeto de etileno $\left(\mathrm{C}_{2} \mathrm{H}_{4} \mathrm{~S}\right)$ (Figura 19) (GIERER; SMEDMAN, 1965). Ainda, durante o processo de precipitação da lignina Kraft, ácido sulfúrico é utilizado como licor de lavagem acidificado ( $\mathrm{pH}$ entre 2,5 e 4,0) com o objetivo de ressuspender a lignina para posterior filtração e lavá-la para retirada de sódio e cinzas da mesma (OHMAN, 2006). Essa é uma das etapas do processo LignoBoost, usado pela empresa Suzano, fornecedora da lignina Kraft usada, para precipitação da lignina (NALI et al., 2016). 
Isso pode ter deixado enxofre residual na lignina Kraft, o qual pode ser retirado em cerca de 28,6 \% após a purificação com água e 62,6 \% após reação de modificação com glutaraldeído (Tabela 1), melhorando as características dessa lignina para posterior aplicação na síntese de PUs.

Figura 19 - Processo Kraft - Reação íons hidrossulfeto (HS-) com lignina na formação de compostos intermediários cíclicos de sulfeto de etileno.

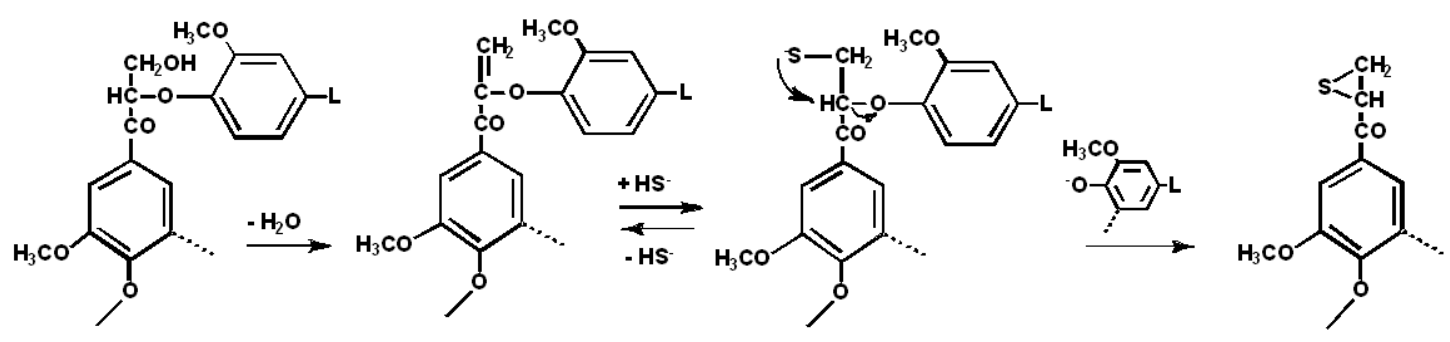

Fonte: Adaptado de GIEGER; SIEDMAN, 1965.

A cromatografia de exclusão por tamanho foi utilizada para avaliar a $\mathrm{Mw}$ e $\mathrm{Mw} / \mathrm{Mn}$ de LKB, LK e LK-Glu acetiladas. Os respectivos cromatogramas SEC encontram-se no Apêndice A. Conforme mencionado na parte experimental (Item 1.2.2.7) LKB, LK e a LK-Glu foram acetiladas previamente a realização das análises de ${ }^{1} \mathrm{H}$ RMN e SEC. Para a análise de SEC, essa acetilação é importante porque facilita a dissolução da lignina no eluente de análise, ou seja, THF. Além disso, a acetilação dificulta a agregação das macromoléculas através de interações intermoleculares entre grupos hidroxila, levando a cromatogramas que melhor refletem a massa molar média das macromoléculas, ou seja, não agregadas. Os espectros na região de infravermelho da LKB, LK e LK-Glu antes de serem acetiladas e após a reação de acetilação são mostrados no Apêndice $B$.

Fatores como natureza da matéria-prima, e principalmente, processo de extração, impactam a massa molar média da lignina, por isso existe uma grande diversidade de resultados reportados na literatura (NEVÁREZ et al., 2011). Para ligninas do tipo Kraft são esperados valores de massa molar média semelhantes ou até maiores ao encontrado neste estudo, pois em condições alcalinas, como no processo Kraft, reações de repolimerização podem ocorrer, aumentando o Mw das ligninas. Nesse caso, alguns grupos alfa-hidroxila da lignina formam intermediários metileno quinona que facilmente reagem com outros fragmentos de lignina, resultando em ligações metileno álcali estáveis (Figura 20) (ISHIZU et 
al., 1958; VAN DER KLASHORST, 1989), o que leva a macromoléculas de maior massa molar média.

Figura 20 - Reação de repolimerização da lignina Kraft com intermediários metileno quinona.
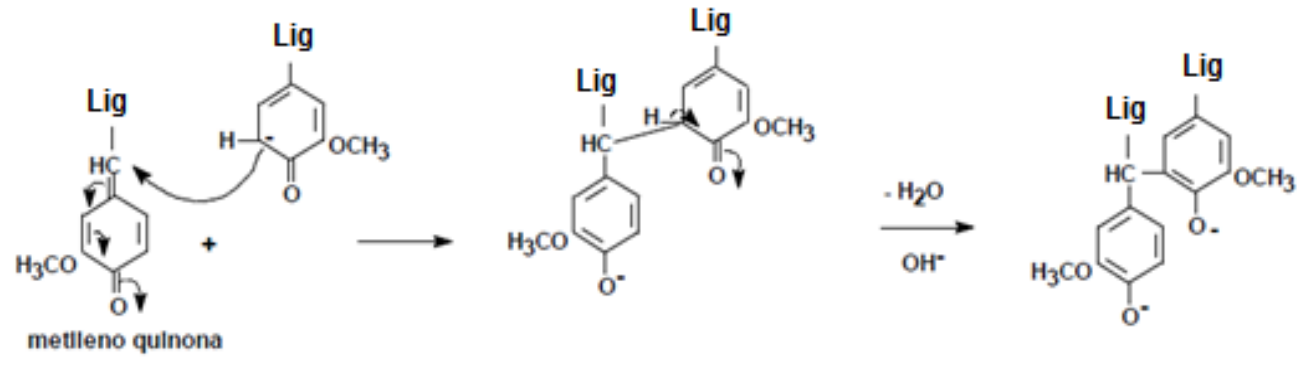

Fonte: Adaptado de SJOSTROM, 1993.

Em trabalho publicado por GORDOBIL et al. (2016) os valores de Mw e Mw/Mn para lignina Kraft acetilada de eucalipto foram $2653 \mathrm{~g} \mathrm{~mol}^{-1}$ e 2,5, respectivamente. As condições de análise envolviam dimetilformamida (DMF) como solvente e poliestireno como padrão. Já para LOURENÇON et al. (2015) os valores obtidos para esses parâmetros em amostra de lignina Kraft acetilada, também proveniente de eucalipto, foram de 3890 e 14,8. Nesse caso, foi utilizado THF como solvente e poliestireno como padrão, assim como no presente estudo.

O aumento observado no Mw de LK em relação a LKB pode ser atribuído a eliminação de moléculas de baixa massa molar na etapa de purificação. Com relação aos valores de massa molar média obtidas para a LK-Glu, foi possível observar um aumento significativo nos valores de $\mathrm{Mw}$ e $\mathrm{Mw} / \mathrm{Mn}$ em relação à LK (Tabela 1). Esse aumento pode estar relacionado com a reação entre as hidroxilas alifáticas introduzidas pela modificação com o glutaraldeído, com outras duas moléculas de lignina, introduzindo um segmento hidrocarbônico (Figura 14), e levando a formação de uma macromolécula com maior massa molar média (DE OLIVEIRA, 2014). A agregação entre as macromoléculas foi extremamente dificultada pela acetilação dos grupos hidroxila, porém, como observado nos espectros das ligninas acetiladas (Apêndice B), apesar de haver aumento na intensidade da banda referente aos grupamentos carbonilas (1636-1760 cm $\left.\mathrm{cm}^{-1}\right)$, a presença da vibração axial das hidroxilas $\left(3300-3500 \mathrm{~cm}^{-1}\right)$ nas ligninas acetiladas evidencia que essa acetilação não foi completa, e agregação de moléculas em reduzidíssima extensão pode ter ocorrido (D'ALMEIDA et al., 2005).

Com relação aos percentuais de carbono e hidrogênio encontrados, foi possível observar um aumento dos mesmos na LK em relação à LKB e na LK-Glu em relação a LK. Este aumento 
era esperado, tanto na etapa de purificação, que elevaria esses teores em função da retirada de contaminantes inorgânicos, quanto na etapa de modificação da lignina, uma vez que o glutaraldeído $\left(\mathrm{C}_{5} \mathrm{H}_{8} \mathrm{O}_{2}\right)$, utilizado para modificar a lignina é composto por carbono (C), hidrogênio $(H)$ e oxigênio (O), o que leva a aumento nos teores de carbono e hidrogênio bem como a massa molar média e no teor de OH na lignina (DE OLIVEIRA, 2014) (Figura 14).

Diferentemente dos teores de $\mathrm{C}$ e $\mathrm{H}$, que aumentaram após a modificação da lignina com glutaraldeído, o teor de oxigênio (O) apresentou uma redução de LK para LK-Glu (Tabela 1). Considerando que açúcares não foram detectados em LK-Glu, esta variação pode ser decorrente da eliminação de açúcares residuais na LK-Glu.

A partir destes resultados, foi possível obter uma fórmula mínima para LK e para LK-Glu, são elas: $\mathbf{C}_{\mathbf{2}, 69} \mathrm{H}_{\mathbf{2}, 95} \mathrm{O}_{\mathbf{1}}$ e $\mathbf{C}_{\mathbf{2}, \mathbf{8} 6} \mathbf{H}_{\mathbf{3}, 93} \mathbf{O}_{\mathbf{1}}$ (para efeitos de cálculos os valores de Nitrogênio e Enxofre não foram considerados). Nesse cálculo, o percentual dos elementos (C, $\mathrm{H}$ e O) foi relacionado com a massa molar de cada elemento, resultando no número de mols presentes em cada percentual. Os mols de cada elemento foram divididos pelo menor número de mols encontrado (nesse caso, do oxigênio), gerando assim as fórmulas mínimas citadas. Deve-se salientar que as porcentagens de C, H e O também são resultantes dos açúcares presentes nas ligninas avaliadas, assim, as fórmulas mínimas geradas representam uma aproximação.

As fórmulas mínimas, em conjunto com os demais resultados apresentados no Item 1.3.1.2, foram utilizadas para estimar o número de hidroxilas presentes na estrutura das ligninas LK e LK-Glu.

\subsubsection{Espectroscopia na região do Infravermelho com Transformada de Fourier}

Os espectros na região de infravermelho das amostras de LKB, LK e LK-Glu estão apresentados na Figura 21. 
Figura 21 - Espectros de FTIR para LKB, LK e LK-Glu.

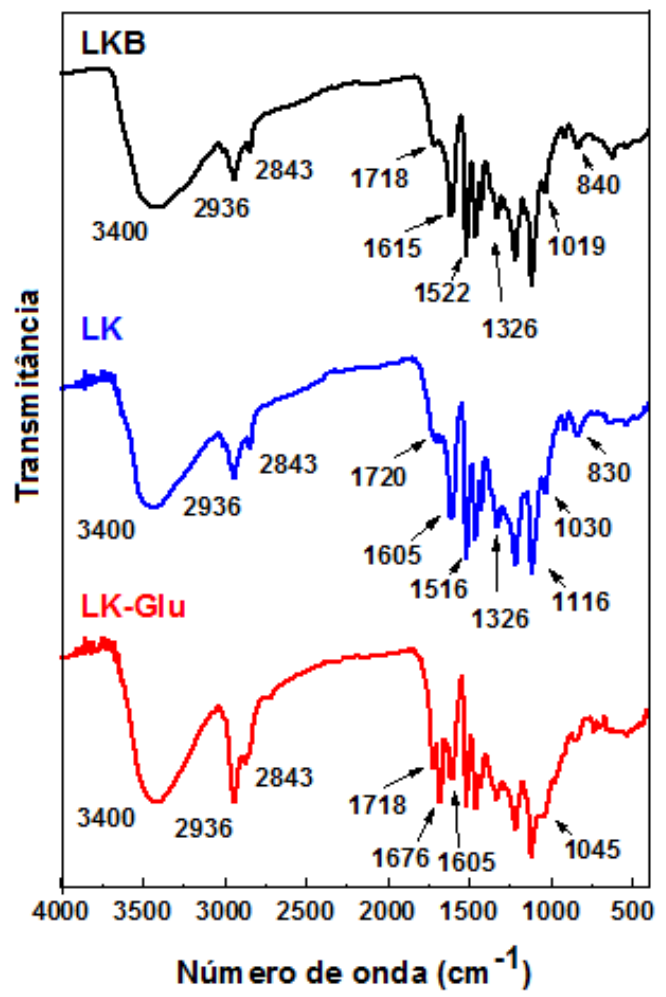

Os três espectros revelam as típicas bandas para lignina, como as deformações axiais O$\mathrm{H}$ associadas aos grupos hidroxila $\left(3400 \mathrm{~cm}^{-1}\right)$, as deformações axiais $\mathrm{C}-\mathrm{H}$ das cadeias alifáticas $\mathrm{CH}_{2}$ e $\mathrm{CH}_{3}$ (2936-2843 cm $\mathrm{cm}^{-1}$ ), e as várias vibrações do esqueleto dos anéis aromáticos (1609$1511 \mathrm{~cm}^{-1}$ ) (EL MANSOURI; SALVADO, 2006). Na Tabela 2 estão representadas as principais bandas observadas nos espectros na região do infravermelho para lignina Kraft.

Tabela 2 - Principais bandas observadas para LKB, LK e LK-Glu

\begin{tabular}{cl}
\hline № de onda $\left(\mathbf{c m}^{-\mathbf{1}}\right)$ & \multicolumn{1}{c}{ Possíveis Atribuições } \\
\hline 3400 & Deformação axial O-H em lignina \\
\hline 2936 & Deformação axial C-H em grupos metileno assimétrica \\
\hline 2843 & Deformação axial C-H em grupos metileno simétrica \\
\hline $1720-1718$ & Deformação axial dos grupos carbonila conjugados \\
\hline 1676 & Deformação axial dos grupos carbonila não conjugados \\
\hline $1615-1605$ & Vibração C-H de anel aromático \\
\hline 1516 & Vibração C-H de anel aromático \\
\hline 1465 & Estiramento C-O em lignina \\
\hline 1366 & $\begin{array}{l}\text { Vibração de deformação assimétrica da ligação C-H em } \mathrm{CH}_{3} \\
\text { de grupos metoxilas }\end{array}$ \\
\hline 1326 & Vibração de anel siringila \\
\hline 1205 & Estiramento C-C e C-O em anel guaiacila \\
\hline
\end{tabular}




\begin{tabular}{cl}
\hline \multirow{2}{*}{1116} & $\begin{array}{l}\text { Deformação de vibrações de ligações C-H em anel } \\
\text { aromático tipo guaiacila e siringila e deformação de } \\
\text { vibração de ligação C-O em álcool primário }\end{array}$ \\
\hline \multirow{3}{*}{$1019-1045$} & $\begin{array}{l}\text { Deformação de vibrações de ligações C-H em anel } \\
\text { aromático (guaiacila > siringila) e deformação de vibração } \\
\text { de ligação C-O em álcool primário e éter alifático }\end{array}$ \\
\hline 830 & Vibração C-H na posição 2 e 6 de anel guaiacila \\
\hline
\end{tabular}

Fonte: GARCIA et al., 2009; SUN et al., 2012; EL MANSOURI; SALVADO, 2006.

Ligninas derivadas de madeiras duras apresentam diferentes quantidades de unidades guaiacila e siringila, enquanto madeiras menos duras apresentam uma estrutura constituída principalmente por unidades guaiacila com pequenas quantidades de siringila e apenas traços de unidades p-hidroxifenila (BOERIU et al., 2004; DENCE, 1992). A lignina Kraft usada no presente estudo é oriunda de madeira dura (Eucalipto), portanto observam-se bandas típicas das unidades siringila e guaiacila $\left(1326,1116,1030\right.$ e $\left.830 \mathrm{~cm}^{-1}\right)$. A presença de banda característica de unidades guaiacila mostra que a lignina Kraft possui sítios ativos para reações de polimerização, uma vez que são mais reativas, por possuírem as posições C-3 e C-5 do anel aromático livres para reagir com grupos OH (MOUBARIK et al., 2013).

Com relação a LK-Glu, tem-se que a modificação com glutaraldeído pode inserir cadeias hidrocarbônicas e grupos hidroxila na lignina (SILVA et al., 2010; DE OLIVEIRA, 2014). Estes grupos e estruturas não diferem daqueles já presentes na estrutura da lignina, contudo podese observar a intensificação de algumas bandas, como as referentes a deformações axiais C-H das cadeias alifáticas (2936 e $\left.2843 \mathrm{~cm}^{-1}\right)$.

\subsubsection{Ressonância Magnética Nuclear de ${ }^{1} \mathrm{H}$}

A espectroscopia de ressonância magnética nuclear (RMN) de prótons $\left({ }^{1} \mathrm{H}\right)$ é uma técnica utilizada no estudo de ligninas tanto em nível qualitativo como quantitativo (FAIX et al., 1992). Os diferentes prótons presentes na lignina podem ser utilizados para quantificar os numerosos elementos estruturais dessa macromolécula. Para isso, conforme mencionado no Item 1.2.2.7 LK e LK-Glu foram acetiladas previamente. A acetilação das amostras de lignina para análise de ${ }^{1} \mathrm{H}$ RMN é necessária porque além da presença do grupo éster facilitar a dissolução no meio, os sinais dos prótons dos grupos hidroxila podem não ser observados no espectro de ${ }^{1} \mathrm{H}$ RMN obtido no solvente $\mathrm{CDCl}_{3}$, todavia, os sinais dos prótons dos grupos acetato introduzidos podem ser detectados e associados às hidroxilas aromáticas e alifáticas. 
A Figura 22 apresenta o espectro de ${ }^{1} \mathrm{H}$ da LK e LK-Glu acetiladas. Na Tabela 3 são apresentadas as possíveis atribuições dos picos presentes no espectro de $\mathrm{RMN}$ de ${ }^{1} \mathrm{H}$ das respectivas ligninas (Figura 22).

Figura 22 - Espectros de 1H RMN da (a) LK- acetilada e (b) LK-Glu - acetilada (Solvente CDCl3, 256 varreduras).

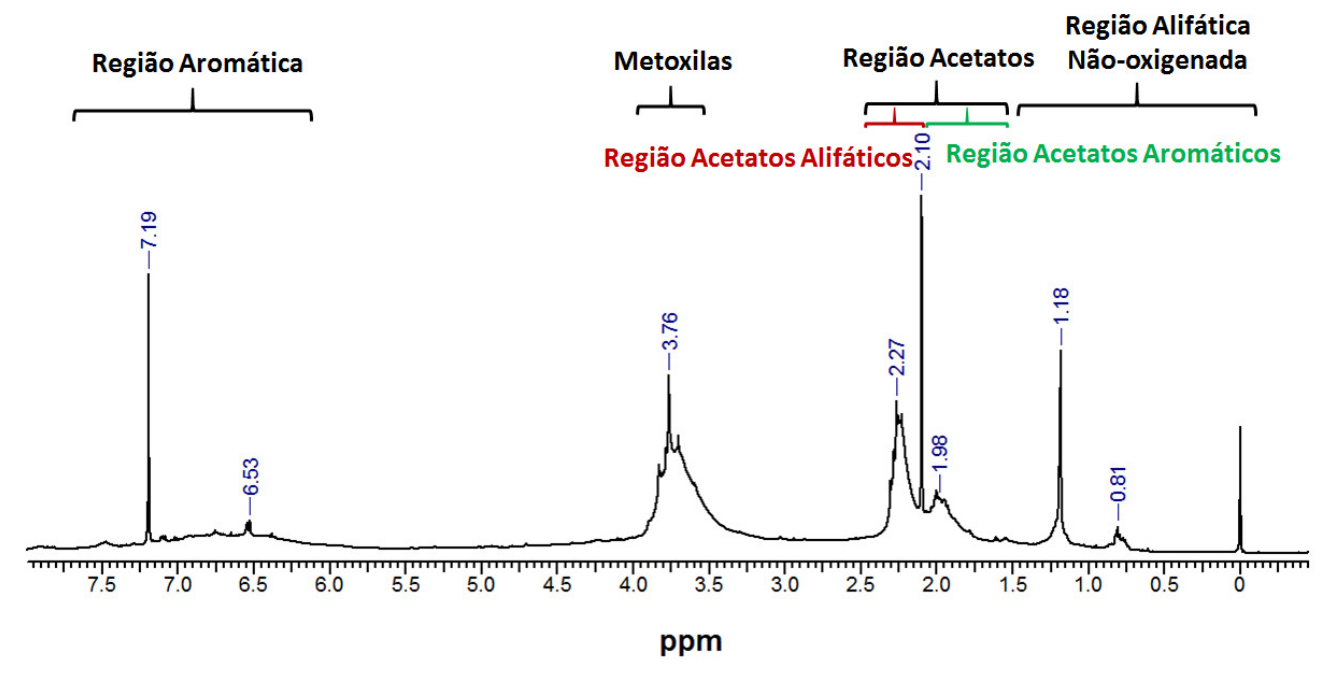

(a)

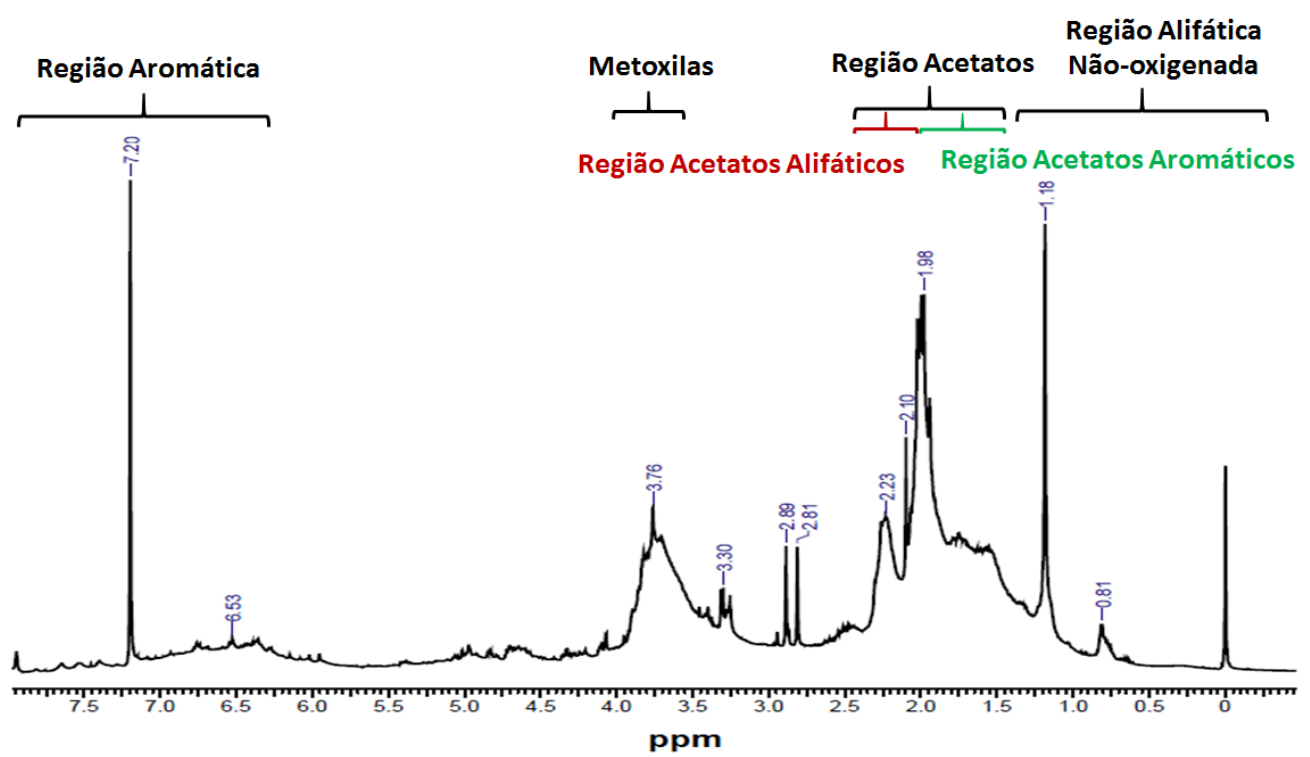

(b) 
Tabela 3 - Picos presentes no espectro de ${ }^{1} \mathrm{H}$ RMN para lignina e possíveis atribuições

Deslocamentos Químicos (ppm)

$6,25-7,90$

$5,75-6,25$

$5,20-5,80$

$3,55-3,95$

$2,20-2,50$

$1,60-2,20$

$<1,60$
Possíveis Atribuições

Região aromática

$\mathrm{H} \alpha$ em unidades $\beta-\mathrm{O}-4$ e prótons etilênicos

$\mathrm{H} \alpha$ em bezil-aril éteres

Metoxilas

Região de acetatos aromáticos

Região de acetatos alifáticos

Região alifática não oxigenada

Fonte: FAIX et al., 1992; GONÇALVES et al., 2000; DA SILVA, 2011.

O pico em 3,76 ppm corresponde aos prótons dos grupos metoxila, e os picos entre 6,2 e 7,2 ppm são referentes aos prótons aromáticos da lignina. Nas amostras de lignina Kraft analisadas, em 2,0 ppm é observado o pico dos acetatos alifáticos, e entre 2,1 e 2,2 o pico dos acetatos aromáticos. Estes picos estão relacionados, respectivamente, às hidroxilas alifáticas e aromáticas, que estão presentes na lignina antes da acetilação e que foram substituídas pelos grupos acetatos que puderam ser identificados no espectro de $\mathrm{RMN}{ }^{1} \mathrm{H}$.

Comparando os espectros da LK (Figura 22 a) e da LK-Glu (Figura 22 b) é possível verificar que os sinais principais estão presentes nos dois espectros. A diferença está no pico referente aos acetatos alifáticos $(1,60-2,10 \mathrm{ppm})$ que se mostrou mais largo na LK-Glu do que na LK, indicando a introdução de grupos $\mathrm{OH}$ alifáticos nessa estrutura (Figura 22).

Considerando a fórmula mínima obtida pela análise elementar das ligninas (LK = $\mathbf{C}_{2,69} \mathrm{H}_{2,95} \mathrm{O}_{1}$ e LK-Glu $=\mathbf{C}_{2,86} \mathrm{H}_{3,93} \mathrm{O}_{1}$ ) e a integração dos sinais de hidrogênio do espectro do ${ }^{1} \mathrm{H}$ RMN, foi possível determinar o conteúdo de metoxilas, gerando a fórmula que tem como base as possíveis unidades $\mathrm{C} 9$ presentes na lignina: $\mathrm{LK}=\mathbf{C}_{9} \mathbf{H}_{10,15} \mathbf{O}_{1,51}\left(\mathbf{O C H}_{3}\right)_{2,93}($ Massa Molar $=$ $233,14 \mathrm{~g} / \mathrm{mol}$ ) e LK-Glu $=\mathbf{C}_{9} \mathrm{H}_{13,6} \mathbf{O}_{1,18}\left(\mathbf{O C H}_{3}\right)_{3,03}$ (Massa Molar $=234,44 \mathrm{~g} / \mathrm{mol}$ ). Em seguida, as áreas obtidas pela integração da região dos acetatos aromáticos e alifáticos foram relacionadas à área total da integração dos sinais de hidrogênio do espectro do ${ }^{1} \mathrm{H}$ RMN e a fórmula C9 da LK e LK-Glu (GONÇALVES et al., 2000), resultando nas concentrações de hidroxilas reportadas na Tabela 4, em que são reportados também valores de outras ligninas Kraft derivadas de madeiras duras encontradas na literatura. 
Tabela 4 - Comparação entre os teores de $\mathrm{OH}$ alifáticas, $\mathrm{OH}$ aromáticas e $\mathrm{OH}$ totais de LK e LK-Glu utilizadas neste estudo com outras ligninas Kraft derivadas de madeiras duras

\begin{tabular}{ccccc}
\hline Lignina & $\begin{array}{c}\text { OH alifáticas } \\
\left(\mathbf{m m o l ~ g}^{-1}\right)\end{array}$ & $\begin{array}{c}\text { OH aromáticas } \\
\left(\mathbf{m m o l ~ g}^{-1}\right)\end{array}$ & $\begin{array}{c}\text { OH total } \\
\left(\mathbf{m m o l ~ g ~}^{-1}\right)\end{array}$ & $\begin{array}{c}\text { Método de } \\
\text { análise }\end{array}$ \\
\hline $\begin{array}{c}\text { LK } \\
\text { (Este estudo) } \\
\text { LK-Glu }\end{array}$ & 0,9 & 3,2 & 4,1 & ${ }^{1} \mathrm{H}$ RMN \\
$\begin{array}{c}\text { (Este estudo) } \\
\text { LK }\end{array}$ & 2,4 & 3,4 & 5,8 & ${ }^{1} \mathrm{H}$ RMN \\
$\begin{array}{c}\text { (GORDOBIL et al., 2016) } \\
\quad \text { LK }\end{array}$ & 1,2 & 2,7 & 3,9 & ${ }^{31} \mathrm{P} \mathrm{RMN}$ \\
$\begin{array}{c}\text { (DEHNE et al., 2016) } \\
\text { LK }\end{array}$ & 1,5 & 3,2 & 4,7 & ${ }^{31} \mathrm{P} \mathrm{RMN}$ \\
(TEJADO et al., 2007) & $\mathrm{NI*}$ & $\mathrm{NI}$ & 6,5 & ${ }^{1} \mathrm{H}$ RMN \\
\hline
\end{tabular}

*NI- Não Informado pelo autor

A lignina utilizada parà síntese de polímeros deve possuir muitos sítios ativos para reação. No caso dà síntese de $\mathrm{PUs}$, isso se refere a número de $\mathrm{OH}$ disponível para reagir com os grupos isocianato. Na tabela 4 pode-se observar que o valor de $\mathrm{OH}$ total $\left(4,1 \mathrm{mmol} \mathrm{g} \mathrm{g}^{-1}\right)$ encontrado para lignina Kraft neste estudo é próximo ao encontrado por GORDOBIL et al. (2016) $\left(3,9 \mathrm{mmol} \mathrm{g}^{-1}\right)$ e DEHNE et al. (2016) $\left(4,7 \mathrm{mmol} \mathrm{g}^{-1}\right)$, todavia se distancia do relatado por TEJADO et al. (2007) $\left(6,5 \mathrm{mmol} \mathrm{g}^{-1}\right)$. Essas diferenças entre valores encontradas na literatura são comuns, devido a heterogeneidade da estrutura da lignina. Fatores como matéria-prima, nesse caso tipo de madeira dura, condições de extração e condições de análise impactam significativamente no resultado obtido (CONSTANT et al., 2016). Ressalta-se que, assim como nos outros estudos citados, o teor de $\mathrm{OH}$ aromática mostrou-se superior ao de $\mathrm{OH}$ alifática. Isto pode ser explicado pelas condições severas aplicadas durante a polpação Kraft, aliado a presença de íons hidrosulfeto $\left(\mathrm{SH}^{-}\right)$, que levam a quebra das ligações éter no carbono beta que ligam os anéis aromáticos, resultando em um aumento na concentração de hidroxilas fenólicas (Figura 23) (DUVAL; LAWOCO, 2014). 
Figura 23 - Mecanismo de reação evidenciando a clivagem da ligação éter na lignina Kraft na presença do íon hidrosulfeto.
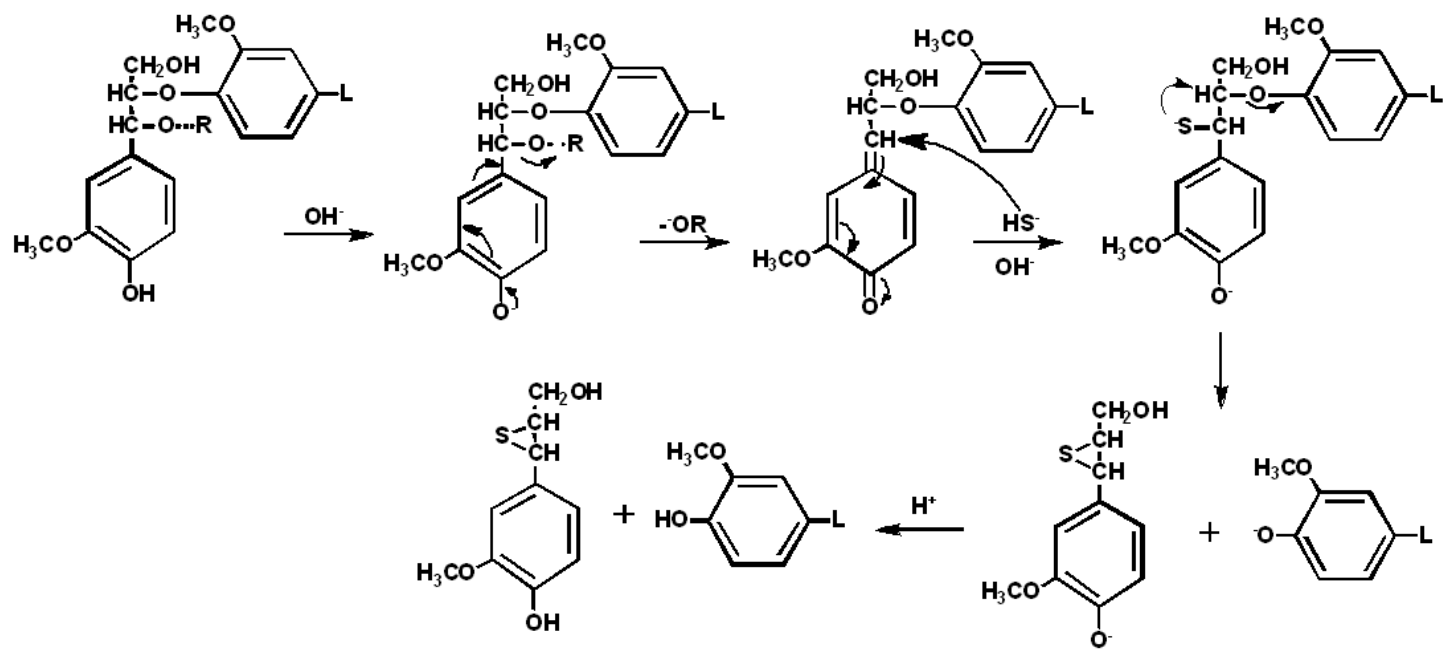

Fonte: Adaptado de SJOSTROM, 1993.

A reação de LK com glutaraldeído provocou um aumento na concentração de hidroxilas alifáticas, elevando este valor de 0,9 para $2,4 \mathrm{mmol} \mathrm{g}^{-1}$ de $\mathrm{OH}$ alifáticas. Com relação as hidroxilas aromáticas, o valor se manteve praticamente o mesmo, Tabela 4.

É importante ressaltar que até onde se tenha conhecimento, o uso de glutaraldeído na modificação de lignina Kraft, foi uma abordagem inédita no que se refere ao uso da mesma na síntese de lignopoliuretanas.

\subsubsection{Termogravimetria}

Na Figura 24 são apresentadas as curvas TGA e DTG da LKB, LK e da LK-Glu. A decomposição térmica da lignina, sob atmosfera inerte, ocorre em uma ampla faixa de temperatura resultando em cerca de 30 a $50 \%$ de produto carbonizado e uma elevada proporção de voláteis de baixa massa molar, a exemplo de compostos fenólicos como guaiacol e siringol (JAKAB et al., 1993; SHEN et al., 2010). 
Figura 24 - Curvas de (a) TGA e (b) DTG da LKB, LK e LK-Glu em nitrogênio, vazão de $20 \mathrm{~mL} \mathrm{~min}^{-1} \mathrm{e}$ razão de aquecimento de $10{ }^{\circ} \mathrm{C} \mathrm{min}^{-1}$.

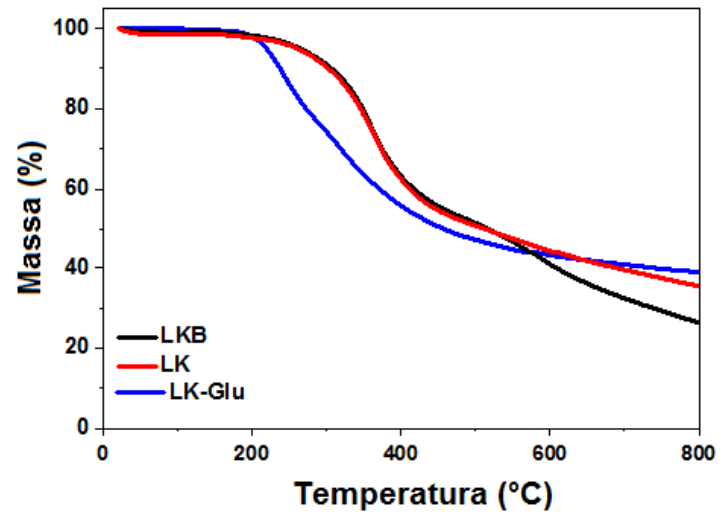

(a)

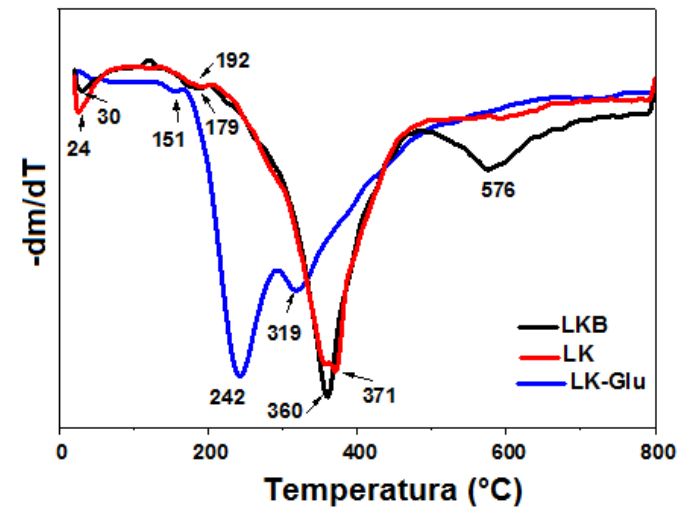

(b)

A Tabela 5 apresenta os eventos térmicos, bem como a massa residual encontrada para as amostras de LKB, LK e LK-Glu na análise de TGA/DTG em atmosfera inerte.

Tabela 5 - Temperaturas dos eventos térmicos e massa residual encontrados para LKB, LK e LK-Glu em atmosfera de $\mathrm{N}_{2}$

\begin{tabular}{ccccccc}
\hline Lignina & $\begin{array}{c}\text { Evento 1 } \\
\left(\mathbf{1 4 5 - 2 0 5}{ }^{\circ} \mathrm{C}\right)\end{array}$ & $\begin{array}{c}\text { Evento 2 } \\
\left(\mathbf{2 0 5 - 4 9 0}{ }^{\circ} \mathrm{C}\right)\end{array}$ & $\begin{array}{c}\text { Evento 3 } \\
\left(\mathbf{4 9 0 - 6 9 0}{ }^{\circ} \mathrm{C}\right)\end{array}$ & $\begin{array}{c}\text { Resíduo } \\
\left(\mathbf{8 0 0}{ }^{\circ} \mathrm{C}\right)\end{array}$ \\
\cline { 2 - 7 } & $T_{\text {Máx }}\left({ }^{\circ} \mathrm{C}\right)$ & $T_{\text {onset }}\left({ }^{\circ} \mathrm{C}\right)$ & $T_{\text {Máx1 }}\left({ }^{\circ} \mathrm{C}\right)$ & $T_{\text {Máx2 }}\left({ }^{\circ} \mathrm{C}\right)$ & $T_{\text {Máx }}\left({ }^{\circ} \mathrm{C}\right)$ & Massa $(\%)$ \\
\hline LKB & 179 & 298 & 360 & -- & 576 & 26 \\
LK & 192 & 288 & 356 & 371 & -- & 36 \\
LK-Glu & 151 & 205 & 242 & 319 & -- & 39 \\
\hline
\end{tabular}

O primeiro evento (pico de baixa intensidade), ocorreu na faixa de 145 a $205^{\circ} \mathrm{C}$, em todas ligninas analisadas. A perda de massa referente a esse evento foi de $2,5 \%$ e $2,3 \%$ para LKB e LK, respectivamente, sendo que a temperatura em que a velocidade de perda de massa é máxima foi de 179 e $192{ }^{\circ} \mathrm{C}$, respectivamente (Figura 24 b). Essa perda pode estar relacionada principalmente à presença de hemiceluloses ligadas a lignina, uma vez que na literatura, são relatadas temperaturas em torno de $235{ }^{\circ} \mathrm{C}$ para a decomposição de hemiceluloses (RAMIRES, 2010; TOLEDANO et al., 2015). Conforme mencionado (Item 1.3.1), açúcares foram detectados na análise cromatográfica de LKB e LK (5,5 \% e 5,0 \%, respectivamente), os quais correspondem principalmente a açúcares provenientes de hemiceluloses. Outros autores associaram esse evento a presença de moléculas de baixa massa molar, solvente ou grupos sulfato que provém do processo de precipitação da lignina usando ácido sulfúrico (LOURENÇON et al., 2015; HU et al., 2013), e são citadas temperaturas em que a velocidade de perda de massa é máxima em torno de 150 a $180{ }^{\circ} \mathrm{C}$. Conforme 
observado no Item 1.3.1, tanto LKB quanto LK também apresentaram enxofre em sua composição (2,5 \% e 1,8 \%, respectivamente), o que pode ter contribuído para o aumento na intensidade desse segundo evento. Para LK-Glu, a temperatura em que a velocidade de perda de massa é máxima foi de $151{ }^{\circ} \mathrm{C}$ e a perda de massa referente a esse evento foi de apenas 0,3\%, ou seja, inferior ao observado em LK (Figura 24 a, Tabela 5). Esse resultado é corroborado pelos resultados encontrados na Tabela 1 do Item 1.3.1, que mostram a ausência de açúcares residuais na LK-Glu e um percentual de enxofre inferior $(0,7 \%)$ ao encontrado na $\operatorname{LKB}(2,5 \%)$ e LK $(1,8 \%)$.

O evento em que ocorrereu a maior perda de massa $(45,6,46,4$ e $57,3 \%$ para LKB, LK e LK-Glu, respectivamente, Figura 24 b) está associado à decomposição térmica da lignina, em que inicialmente ocorre a quebra das ligações éter entre as unidades aromáticas e logo após a quebra de ligações das cadeias alifáticas (LAURICHESSE; AVÉROUS, 2014; MONTEIL-RIVERA et al., 2013; ZHAO et al., 2009).

O perfil de decomposição térmica apresentado pela LKB foi semelhante ao obtido para LK para esse evento, entretanto a LK-Glu apresentou diferenças em relação às outras ligninas (Figura 24 a). Para LK, houve o aparecimento de dois picos muito próximos, em 356 e $371{ }^{\circ} \mathrm{C}$. Para a LK-Glu foram observados dois picos intensos e separados, em 242 e $319{ }^{\circ} \mathrm{C}$. As curvas TGA de LKB, LK e LK-Glu (Figura 24 a) indicam a temperatura inicial de decomposição ( $T_{\text {onset }}$ ) das mesmas, 298, 288 e $205{ }^{\circ} \mathrm{C}$, respectivamente. A introdução de cadeias alifáticas hidroxiladas em LK-Glu deslocou o início da decomposição para temperaturas menores, embora ainda em um alto valor.

Sob atmosfera de $\mathrm{N}_{2}$ LKB, a LK e a LK-Glu apresentaram um percentual de massa residual de aproximadamente 26, 36 e $39 \%$, respectivamente (Figura 24 a). Esse resíduo refere-se principalmente a formação de carvão vegetal e uma alta fração de compostos aromáticos (BARTKOWIAK; ZAKRZEWSKI, 2004; VELDEN et al., 2010). Na literatura são reportadas massa residuais, sob atmosfera de $\mathrm{N}_{2}$, para lignina Kraft acima de $40 \%$ (GORDOBIL et al., 2016).

\subsubsection{Filmes Poliuretânicos formados em sínteses ocorridas a partir de CO, LK ou LK-Glu como polióis e pMDI}

Após diversos testes preliminares, os filmes lignopoliuretânicos (LignoPU

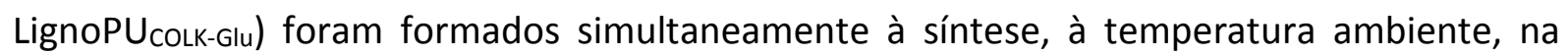


ausência de solventes, na razão molar NCO/OH 1:1, substituindo 10, 30 e 50 \% de CO por LK ou LK-Glu.

É importante salientar que apesar de o glutaraldeído livre apresentar toxicidade (TAKIGAWA; ENDO, 2006), o mesmo é consumido na reação de hidroxialquilação da lignina, sendo este produto lavado exaustivamente antes da etapa de secagem, para eliminação de eventuais reagentes residuais. Testes preliminares de biocompatibilidade foram realizados (resultados não mostrados), e o filme formado a partir de 50 \% de LK-Glu não demonstrou citotoxicidade em relação às células avaliadas (fibroblastos humanos presentes na pele).

As propriedades dos filmes foram avaliadas pelas técnicas de FTIR, MEV, TGA, DRX, Teste de intumescimento, DMA, Ensaio de Tração e análise de ângulo de contato.

\subsubsection{Espectroscopia na região do Infravermelho com Transformada de Fourrier}

A Figura 25 mostra os espectros na região do infravermelho para as misturas reacionais (CO, LK ou LK-Glu e pMDI) imediatamente após a deposição na placa, e para o filme formado. A região de infravermelho apresentada vai de 4000 a $1620 \mathrm{~cm}^{-1}$ para melhor observação das principais regiões com as bandas características de PUs, ou seja, a $3050-3720 \mathrm{~cm}^{-1}$, referente à região da vibração de estiramento $\mathrm{N}-\mathrm{H}$; a $2800-3000 \mathrm{~cm}^{-1}$, referente a região de vibração de estiramento $\mathrm{C}-\mathrm{H}$ e a $1665-1780 \mathrm{~cm}^{-1}$, referente a vibração de estiramento da carbonila $(\mathrm{C}=\mathrm{O})$ em uretanas (amida I) (GURUNATHAN et al., 2015). 
Figura 25 - Espectros FTIR das misturas reacionais imediatamente após deposição na placa (CO, LK ou LK-Glu e pMDI) e dos filmes formados, na região de 4000 a $1620 \mathrm{~cm}^{-1}$.
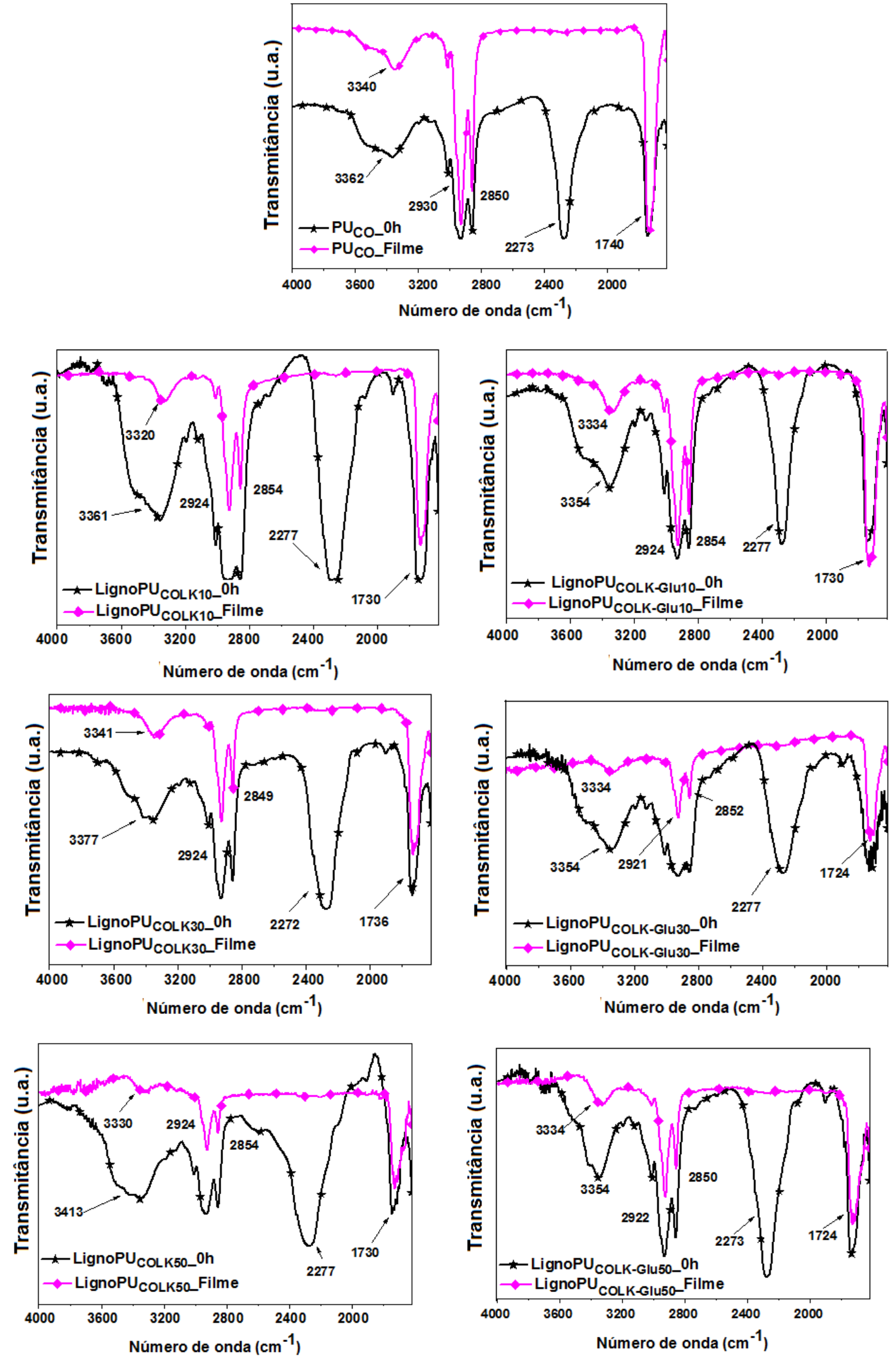
Os espectros da Figura 25 mostram que após a mistura dos reagentes (CO, LK ou LK-Glu e pMDI) e depósito na placa, nomeado como tempo $0 \mathrm{~h}$, a banda referente ao grupo isocianato (NCO) $\left(2277-2272 \mathrm{~cm}^{-1}\right)$, proveniente do pMDI, era intensa, não sendo mais observada no espectro do filme, indicando que todo isocianato reagiu com as hidroxilas do CO, LK ou LKGlu. A banda em aproximadamente $3413-3354 \mathrm{~cm}^{-1}$ também mostrou-se intensa no tempo Oh, devido à presença dos grupos $\mathrm{OH}$ provenientes do CO, LK ou LK-Glu (Figura 25). Porém a intensidade dessa banda no filme diminuiu consideravelmente, e pode ser atribuída a vibração de estiramento da ligação $\mathrm{N}-\mathrm{H}$ do grupo uretana (-O-CO-NH-) em aproximadamente 3341$3320 \mathrm{~cm}^{-1}$, e às hidroxilas aromáticas de LK ou LK-Glu, que são menos reativas que as alifáticas.

Através da análise dos espectros FTIR foi observado que aumentou o tempo necessário para o filme formado não apresentar a banda referente ao grupo isocianato conforme aumentou a concentração de LK (LignoPU ${\text { CoLk10 }=3 \text { dias; LignoPU } \text { CoLK30 }=7 \text { dias e LignoPU }}_{\text {coLk50 }}$ $=10$ dias) ou de LK-Glu (LignoPU CoLK-Glu10 $=2$ dias; LignoPU CoLK-Glu30 $=5$ dias e LignoPU CoLK-Glu50 = 8 dias), comparativamente a reação em que somente CO foi usado (PUco, 2 dias). Esse aumento no tempo pode ser atribuído a um maior impedimento estérico das hidroxilas presentes na lignina, o que retardaria a reação das mesmas com os grupos isocianato do pMDI (CHENG et al., 2012).

Entretanto, os filmes formados a partir de LK-Glu apresentaram menor tempo de polimerização em relação aos preparados com LK. Isso ocorreu, provavelmente, porque LKGlu possui maior número de $\mathrm{OH}$ alifáticas em sua estrutura que $\mathrm{LK}$, portanto, $\mathrm{OH}$ mais reativas e menos impedidas estericamente. Esse resultado mostra que a modificação química realizada na LK-Glu (reação de hidroxialquilação) atingiu o objetivo de aumentar a reatividade da lignina frente ao isocianato.

É preciso destacar que em um processo de obtenção de filmes via casting de soluções, primeiro é preciso sintetizar o polímero, o qual deve ser não entrecruzado, para viabilizar dissolução, e depois encontrar um solvente que dissolva o polímero sintetizado. Para PUs, em geral, esses solventes são orgânicos apróticos, de alto ponto de ebulição, como DMF (Ponto de ebulição $-\mathrm{PE}=153^{\circ} \mathrm{C}$; ALI et al., 2014), dimetilacetamida (DMAc; PE = $165^{\circ} \mathrm{C}$; LUONG et al., 2016) e 1,4 Dioxano (PE = $101^{\circ} \mathrm{C}$; JIA et al., 2015). A vaporização desses solventes é lenta, o que aumenta o tempo de obtenção de filmes. Adicionalmente, aumenta o custo, e reduz o aspecto de sustentabilidade do processo. 
De modo geral, os filmes $\mathrm{PU}_{\mathrm{CO}}$, LignoPU $\mathrm{COLK}_{\text {e LignoPU }} \mathrm{COLK}_{\text {-Glu }}$ apresentaram as mesmas bandas de transmissão (Apêndice $C$ ). Frequentemente, a inserção de lignina em PUs desloca bandas na região próxima a $1700 \mathrm{~cm}^{-1}$, as quais representam carbonilas interagindo via ligações hidrogênio em domínios ordenados cristalinos, para números de onda maiores, referentes à carbonilas interagindo via ligações hidrogênio, mas em domínios não cristalinos e/ou carbonilas não envolvidas com ligação hidrogênio, na estrutura da PU (TAVARES et al., 2016; DE OLIVEIRA et al., 2015; ZHANG et al., 2015). Todavia esse efeito não foi observado nos filmes obtidos, pois os números de onda observados para a banda referente ao estiramento dos grupos carbonila da ligação uretânica ( $\mathrm{NH}-\mathrm{CO}-\mathrm{O})$ nos filmes $\mathrm{PU}_{\mathrm{CO}}$,

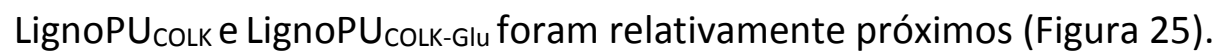

Como esperado, todas as bandas presentes no filme LignoPU $U_{\text {CoLk }}$ estão presentes no

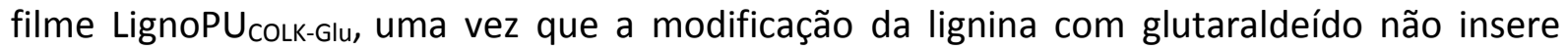
grupos diferentes aos já presentes na estrutura da lignina (Item 1.3.1).

\subsubsection{Microscopia Eletrônica de Varredura}

A análise de microscopia eletrônica por varredura foi feita com o objetivo de avaliar a morfologia da superfície (Figura 26) e da secção transversal (criofraturada) dos filmes (Figura 27).

A morfologia da superfície dos filmes foi semelhante para todos os filmes produzidos (Figura 26). Em todos eles, a superfície se mostrou homogênea e sem a presença de bolhas ou sulcos. Dessa forma, a Figura 26, mostra como exemplo a superfície do filme formado na síntese em que apenas CO foi usado como poliol (PU $\left.\mathrm{CO}_{\mathrm{CO}}\right), 30$ \% de LK (LignoPU $\mathrm{COLK30}_{0}$ e LK-Glu

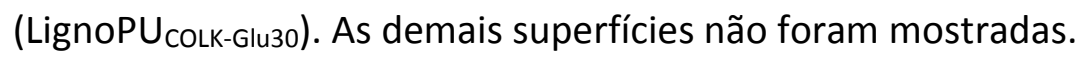

Figura 26 - Micrografias eletrônicas de varredura da superfície dos filmes $P U_{C O}$, LignoPU $U_{\text {CoLk30 }}$ e

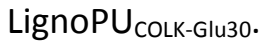
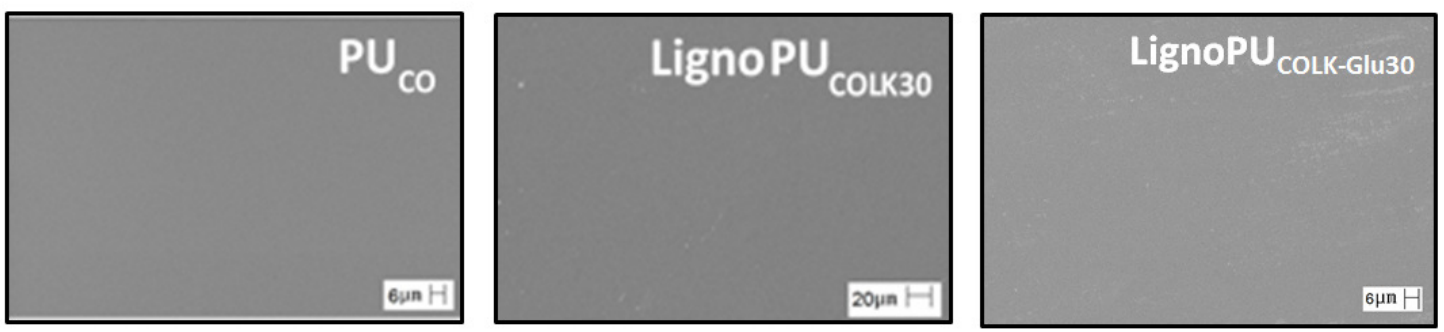
Já as micrografias das criofraturas dos filmes, mostradas na Figura 27, evidenciam uma mudança na morfologia dos mesmos à medida que aumenta a porcentagem de LK ou LK-Glu usada como poliol na síntese do PU.

Figura 27 - Micrografias eletrônicas de varredura da criofratura dos filmes poliuretânicos formados simultaneamente à síntese realizada a partir de CO, LK ou LK-Glu e pMDI.

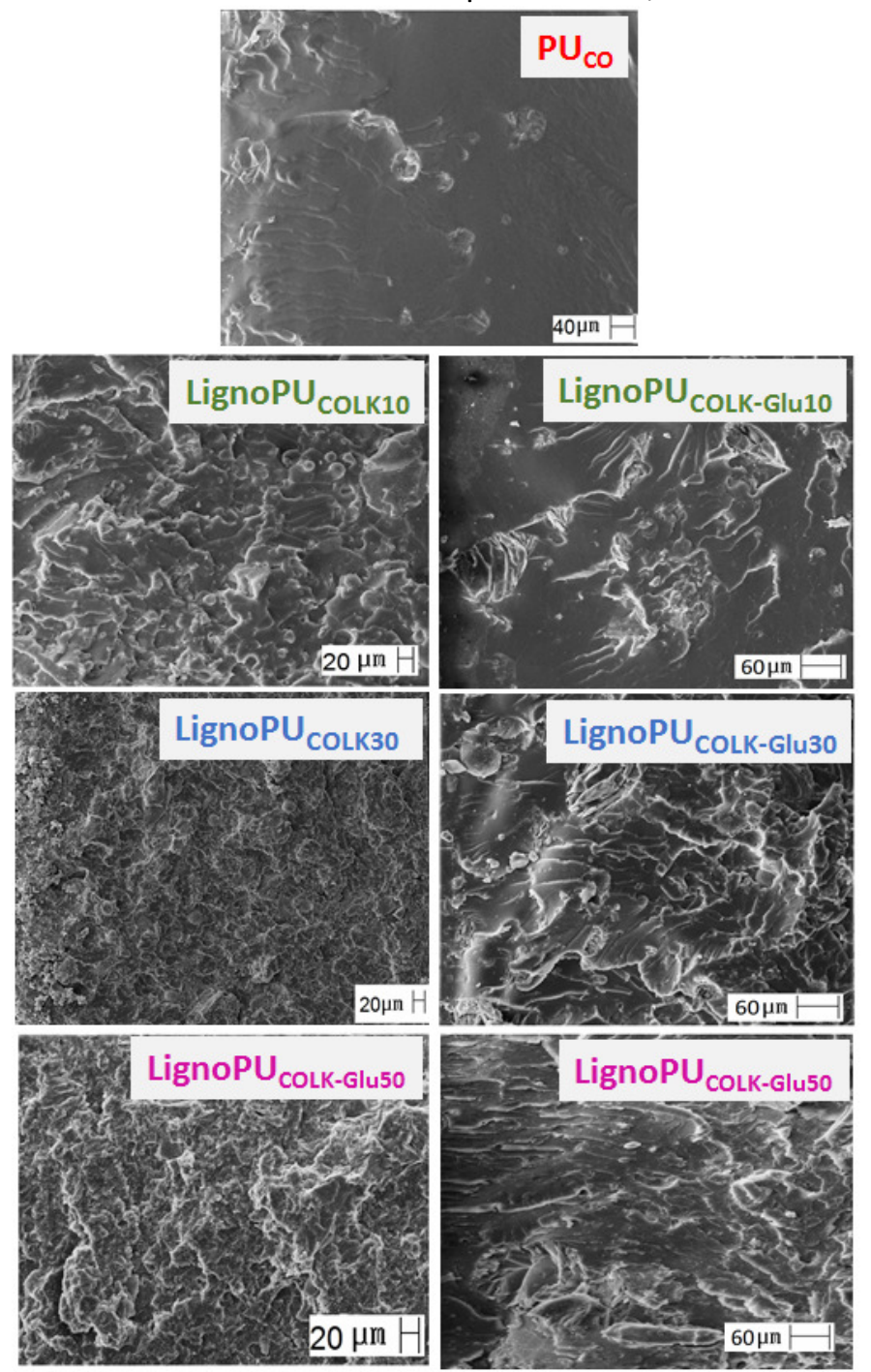

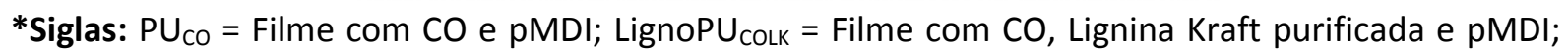
LignoPU $_{\text {COLK-Glu }}=$ Filme com CO, lignina modificada por hidroxialquilação e pMDI.

Enquanto o filme PUco apresentou uma superfície de fratura mais lisa, os filmes contendo LK e LK-Glu apresentaram uma superfície com ondulações e sulcos, sugerindo diferentes tipos de mecanismos de fratura nos filmes com e sem lignina (Figura 27).

Com relação à superfície da criofratura dos filmes formados nas sínteses em que LK e LK-Glu foram usados nas mesmas concentrações, também é possível notar diferenças. A superfície da criofratura dos filmes formados em sínteses usando LK aparentam conter mais 
sulcos e ondulações que a superfície da criofratura dos filmes formados em sínteses usando LK-Glu (Figura 27).

\subsubsection{Termogravimetria}

As curvas referentes a termogravimetria (TGA, DTG) dos filmes lignopoliuretânicos

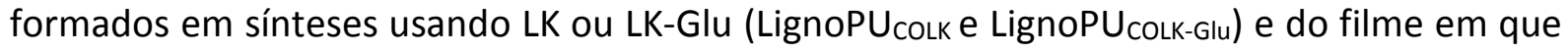
apenas CO foi utilizado (PUco) são apresentadas na Figura 28.

Figura 28 - Curvas de TGA (a) e (b) e DTG (c) e (d) dos filmes poliuretânicos preparados simultaneamente à síntese a partir de CO, LK ou LK-Glu e pMDI em atmosfera de N2, vazão de $50 \mathrm{~mL}$ $\mathrm{min}^{-1}$ e razão de aquecimento de $10{ }^{\circ} \mathrm{C} \mathrm{min}^{-1}$. Números 1,2 e $3 \mathrm{em}$ (c) e (d) correspondem ao 1ㅇ, 2 으 e 3o evento, respectivamente.

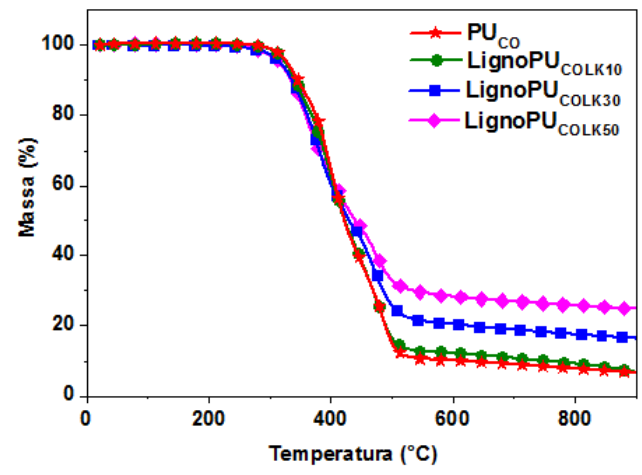

(a)

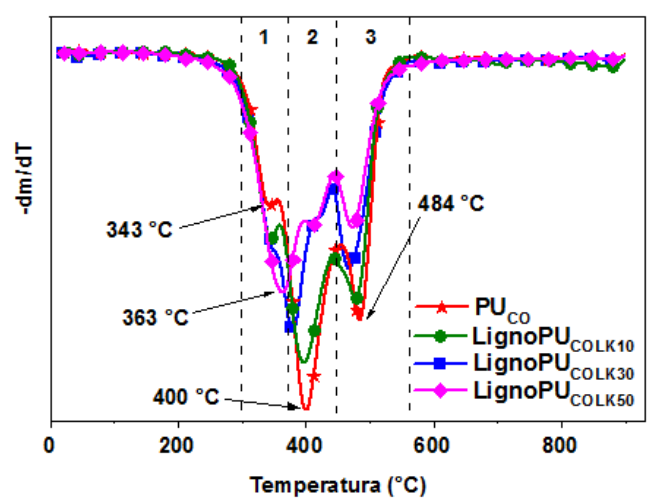

(c)

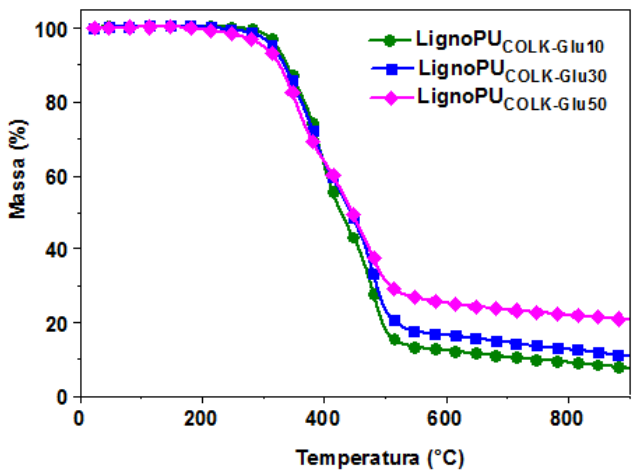

(b)

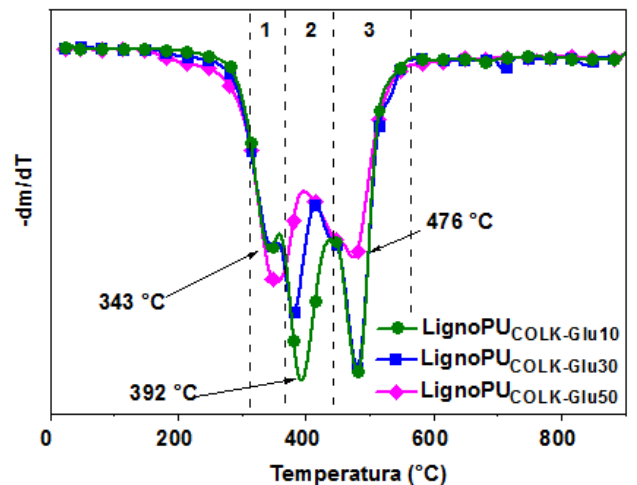

(d)

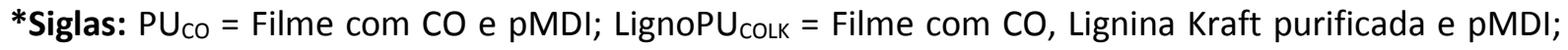
LignoPU CoLk-Glu $=$ Filme com CO, lignina modificada por hidroxialquilação e pMDI.

Em geral, a decomposição térmica das PUs ocorre em 2 ou 3 estágios, e a composição dos produtos de decomposição depende da estrutura da PU em questão (CHATTOPADHYAY; WEBSTER, 2009). A maioria dos filmes preparados no presente estudo apresentaram três 
estágios de perda de massa, com exceção dos filmes LignoPU colk50 e LignoPU $_{\text {colk-Glu50, que }}$ apresentaram 2 estágios de perda de massa (Figura 28 c e d). A Tabela 6 apresenta os dados obtidos a partir da Figura 26 para os filmes LignoPUs e para $\mathrm{PU}$ co.

Tabela 6 - Temperaturas dos eventos térmicos e massa residual encontrados nos filmes poliuretânicos formados simultaneamente à síntese realizada a partir de CO, LK ou LK-Glu e pMDI em atmosfera de $\mathrm{N}_{2}$

\begin{tabular}{|c|c|c|c|c|c|}
\hline \multirow[t]{2}{*}{ Filme } & \multicolumn{2}{|c|}{$\begin{array}{c}\text { Evento } 1 \\
\left(300-370^{\circ} \mathrm{C}\right)\end{array}$} & \multirow{2}{*}{$\begin{array}{c}\begin{array}{c}\text { Evento } 2 \\
\left(370-440{ }^{\circ} \mathrm{C}\right)\end{array} \\
T_{\text {Máx }}\left({ }^{\circ} \mathrm{C}\right)\end{array}$} & \multirow{2}{*}{$\begin{array}{c}\begin{array}{c}\text { Evento } 3 \\
\left(440-565^{\circ} \mathrm{C}\right)\end{array} \\
T_{\text {Máx }}\left({ }^{\circ} \mathrm{C}\right)\end{array}$} & \multirow{2}{*}{$\begin{array}{c}\begin{array}{l}\text { Resíduo } \\
\left(900{ }^{\circ} \mathrm{C}\right)\end{array} \\
\text { Massa (\% }\end{array}$} \\
\hline & $T_{\text {onset }}\left({ }^{\circ} \mathrm{C}\right)$ & $T_{\text {Máx }}\left({ }^{\circ} \mathrm{C}\right)$ & & & \\
\hline $\mathbf{P U} \mathbf{U}_{\mathrm{CO}}$ & 318 & 343 & 400 & 484 & 6,6 \\
\hline LignoPU & 315 & 347 & 398 & 477 & 7,1 \\
\hline LignoPU ${ }_{\text {COLK-Glu10 }}$ & 316 & 343 & 392 & 480 & 7,6 \\
\hline LignoPU & 315 & 343 & 380 & 468 & 16,4 \\
\hline LignoPU COLK-Glu30 & 309 & 343 & 380 & 480 & 10,9 \\
\hline LignoPU & 316 & 363 & -- & 473 & 24,7 \\
\hline LignoPU CoLK-Glu50 & 302 & 354 & -- & 476 & 20,7 \\
\hline
\end{tabular}

As curvas de DTG (Figura $28 \mathrm{c}$ e d) mostraram que o primeiro evento relacionado com a quebra das ligações uretânicas do tipo (- $\mathrm{HN}-\mathrm{CO}-\mathrm{O}-$ ) liberando $\mathrm{CO}, \mathrm{CO}_{2}$, aminas e aldeídos (SOMANI et al., 2003), apresentou um pico com temperatura em que a velocidade de perda de massa é máxima entre 343 e $347^{\circ} \mathrm{C}$ para os filmes formados a partir de PUs sintetizadas sem lignina (PUCO) e com 10 e 30\% de LK e LK-Glu (LignoPU CoLK10; LignoPU $_{\text {Colk-Glu10; }}$ LignoPU ${ }_{\text {CoLk30 e LignoPU }}$ CoLk-Glu3o). À medida que a lignina foi sendo adicionada a estrutura da $\mathrm{PU}$, esse pico foi sendo incorporado ao pico referente ao segundo evento (LignoPU CoLK50 $=363$ ${ }^{\circ} \mathrm{C}$; LignoPU $\mathrm{COLK}_{\text {Glu50 }}=354{ }^{\circ} \mathrm{C}$ ), o qual ocorreu no intervalo de temperatura de 370 a $440{ }^{\circ} \mathrm{C}$, e que está relacionado ao início da decomposição dos segmentos flexíveis presentes, principalmente oriundos do CO. Foi possível observar na Figura 28 c e d. Com o aumento de segmentos rígidos na estruturas das PUs, a intensidade do pico referente a decomposição dos segmentos flexíveis foi decrescendo (CORCUERA et al., 2010).

O terceiro e último evento, onde ocorre a quebra de ligações do tipo $C-C, C-O, C-H, C=C$ e C=O (CALLISTER, 1991; AZEVEDO, 2009), foi observado a temperaturas mais altas (de 440 a $565^{\circ} \mathrm{C}$ ), sendo que para o filme $\mathrm{PU}_{\mathrm{CO}}$ a temperatura em que a velocidade de perda de massa é máxima foi a maior $\left(484^{\circ} \mathrm{C}\right)$, o que pode estar relacionado a maior cristalinidade desse material, conforme mencionado a seguir, embora pequenas diferenças tenham sido observadas (Tabela 6). Uma maior quantidade de energia é necessária para decompor regiões 
com cadeias altamente ordenadas e unidas por forças intermoleculares mais intensas que no domínio não cristalino, o que pode ser detectado por termogravimetria (SEVERIAN, 2005; MORGADO; FROLLINI, 2011).

A curva TGA (Figura 28 a e b) mostra que os filmes apresentaram estabilidade térmica até em torno de $300{ }^{\circ} \mathrm{C}$, evidenciando o caráter hidrofóbico dos mesmos, pois não foi observada perda de umidade. A estabilidade térmica das PUs está relacionada à presença na estrutura química das mesmas de segmentos rígidos (anéis aromáticos do pMDI e da LK ou LK-Glu), de segmentos flexíveis (introduzidos pelas cadeias flexíveis do CO), assim como a razão molar de um segmento em relação ao outro (CORCUERA et al., 2010). A temperatura inicial ( $T_{\text {onset }}$ ) de decomposição dos filmes (Tabela 6) praticamente não foi alterada em função do uso de LK e LK-Glu na síntese das LignoPUs.

A curva de TGA (Figura 28 a e b) ainda revela que a incorporação de LK e LK-Glu nas PUs aumentou consideravelmente a porcentagem de massa residual dos filmes. Esse resíduo aumenta conforme a concentração de lignina aumenta na composição da PU, sendo essa massa residual referente principalmente à formação de carvão vegetal e uma alta fração de compostos aromáticos que não são decompostos em atmosfera inerte (BARTKOWIAK; ZAKRZEWSKI, 2004; VELDEN et al., 2010). Neste estudo, os filmes formados a partir 30 e 50 \% de LK-Glu apresentaram um valor de massa residual um pouco inferior aos formados $\mathrm{s}$ a partir de LK nas mesmas concentrações. Esse resultado provavelmente se deve ao fato de que, em uma mesma massa, LK possui maior teor de compostos aromáticos comparativamente a LK-Glu, devido aos grupos alifáticos introduzidos pela modificação química com glutaraldeído.

\subsubsection{Difração de raios $X$}

A cristalinidade dos filmes lignopoliuretânicos formados a partir de LK e LK-Glu

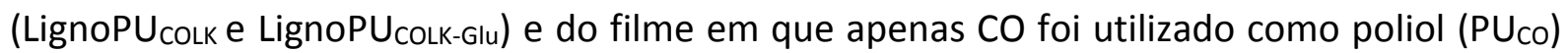
foi avaliada por difração de raios X (Figura 29). 
Figura 29 - Difratogramas de raios $X$ para os filmes poliuretânicos preparados simultaneamente à síntese realizada a partir de CO, LK ou LK-Glu e pMDI.

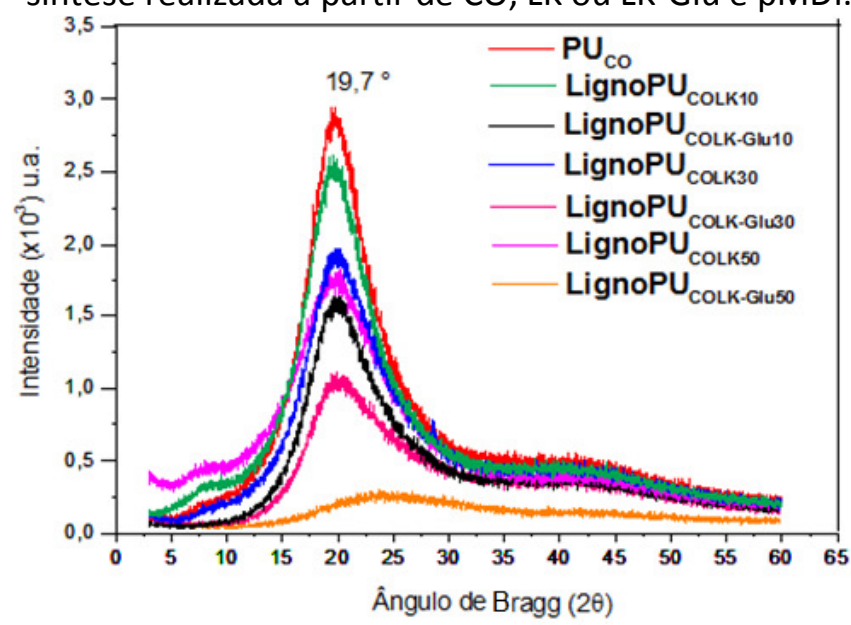

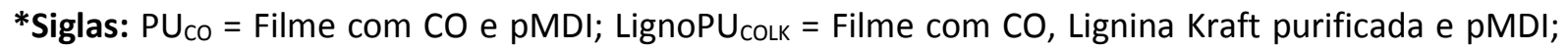
LignoPU $U_{\text {COLK-Glu }}=$ Filme com CO, lignina modificada por hidroxialquilação e pMDI.

O aparecimento de um pico bem definido em $2 \theta=19,7^{\circ}$, revela a formação de regiões ordenadas nos filmes produzidos (Figura 29). A Tabela 7 mostra os índices de cristalinidade (ICr \%) obtidos para os filmes. Eles foram calculados pela diferença na intensidade de picos específicos, correspondentes a domínios cristalinos, e da região não cristalina (KIM et al., 2016; ALEXANDER, 1969).

Tabela 7 - Índice de cristalinidade ( $\mathrm{ICr}$ ) dos filmes poliuretânicos preparados simultaneamente à síntese realizada a partir de CO, LK ou LK-Glu e pMDI

\begin{tabular}{|c|c|c|c|c|c|}
\hline Filme & $\operatorname{ICr}(\%)$ & $\mathrm{PU}_{\mathrm{cO}}$ & $\mathrm{ICr}=41 \%$ & Filme & $\operatorname{ICr}(\%)$ \\
\hline LignoPU & 40 & & & LignoPU CoLK-Glu10 & 37 \\
\hline LignoPU & 36 & & & LignoPU ${ }_{\text {CoLK-Glu30 }}$ & 28 \\
\hline LignoPU & 35 & & & LignoPU COLK-Glu50 & 13 \\
\hline
\end{tabular}

A cristalinidade de PUs é usualmente relacionada à ordenação dos segmentos rígidos, no caso de PUco correspondendo aos segmentos oriundos de PMDI (MISHRA; MAITI, 2011). A substituição de parte de CO por LK e LK-Glu na síntese das PUs promoveu a diminuição de domínios ordenados nos filmes lignopoliuretânicos, devido a não linearidade e a complexidade estrutural de LK e LK-Glu, o que dificulta a ordenação dos segmentos rígidos oriundos de LK/pMDI ou de LK-Glu/pMDI. A ordenação passa a ser praticamente dos segmentos rígidos provenientes de pMDI ligados aos segmentos flexíveis oriundos de $\mathrm{CO}$, os quais diminuem proporcionalmente com o aumento da proporção de LK ou LK-Glu usada. (Figura 29, Tabela 7). 


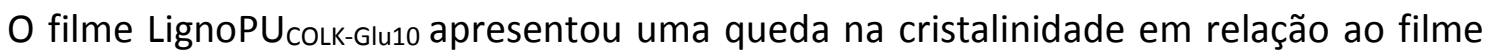

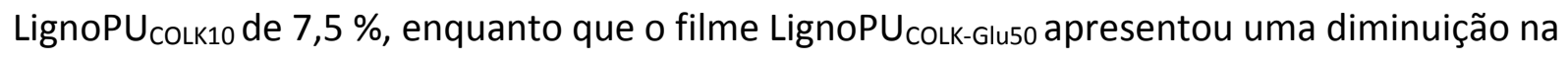

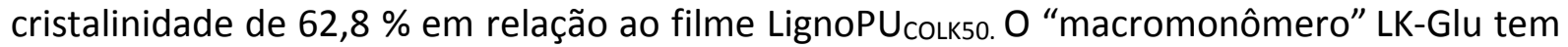
massa molar média superior à de LK (Tabela 1), assim como maior complexidade estrutural, o que dificulta ainda mais a ordenação de segmentos rígidos oriundos de LK-Glu/pMDI.

Ll et al (1996) sintetizaram uma série de PUs segmentadas a partir de policraprolactonas (PCL) com diferentes massas molares médias, 1,4 Butanodiol (BD) e MDI e observaram ICr's que variaram de 11 a $60 \%$, sendo essa avaliação feita pela técnica de calorimetria exploratória diferencial (DSC). Os Ic's observados no presente estudo (Tabela 7), encontram-se nessa faixa. No entanto, na comparação deve-se levar em conta a diversidade das variáveis que levam a formação de regiões cristalinas em cada tipo de PU, como matérias-primas usadas, temperatura, catalisador, técnica usada para avaliar cristalinidades.

\subsubsection{Teste de Intumescimento}

O teste de intumescimento foi realizado com o objetivo de avaliar a taxa de intumescimento $(S \%)$ dos filmes lignopoliuretânicos formados a partir de LK ou LK-Glu

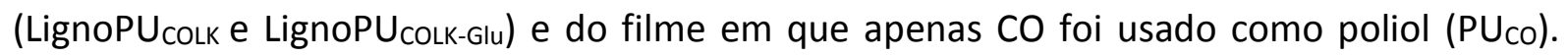

Diversos fatores devem ser levados em consideração durante a avaliação da taxa de intumescimento dos materiais, por exemplo, as condições reacionais (que podem ou não favorecer entrecruzamento), as estruturas dos reagentes envolvidos na polimerização, a cristalinidade do material, a intensidade da interação do solvente com o polímero que constitui o filme. A análise criteriosa desses fatores é importante, pois dependendo do contexto dos fatores citados, o valor obtido, pode não indicar entrecruzamento consequente de ligação química entre cadeias, mas pode ser um reflexo do volume livre existente entre cadeias individuais.

A Figura 30 mostra o gráfico de taxa de intumescimento dos filmes $(S \%)$, assim como a coloração das soluções de DMF após o término do teste. 
Figura 30 - (a) Taxa de Intumescimento (S\%) dos filmes formados e (b) Soluções de DMF após realização do teste de intumescimento, sendo: (1) $\mathrm{PU}_{\mathrm{CO}}$; (2) LignoPU $\mathrm{COLK10}_{10}$ (3) LignoPU $\mathrm{COLK-Glu10;}_{\text {; }}$ LignoPU ${ }_{\text {CoLK30; (5) LignoPU }}$ CoLK-Glu30; (6) LignoPU $_{\text {COLK50 e (7) LignoPU }}$ CoLk-Glu50.

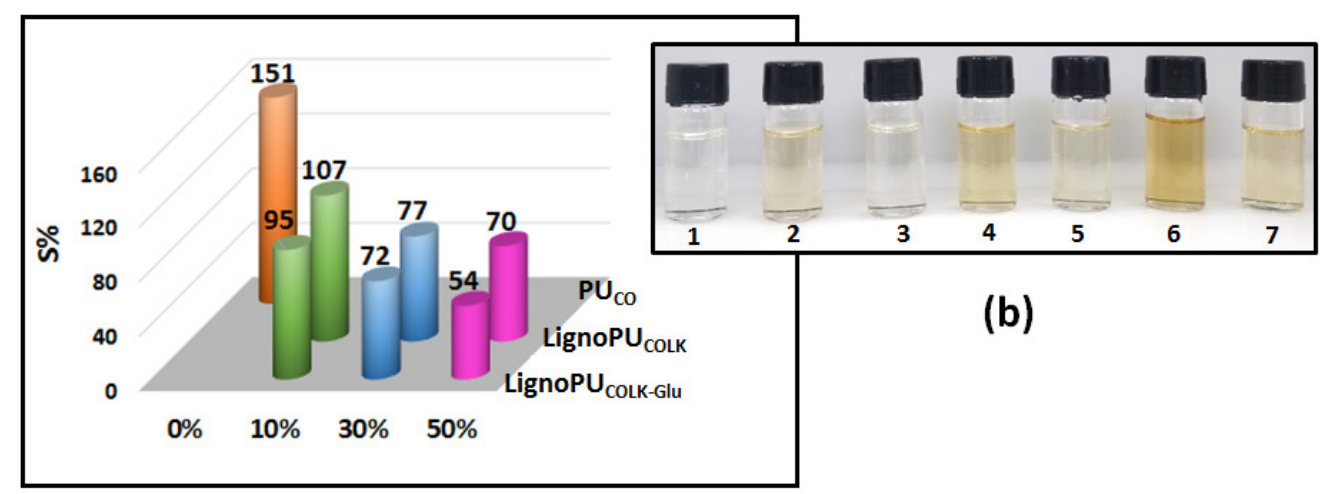

\section{(a)}

*Desvios-padrão: [De $\pm 0,6$ (LignoPU $\mathrm{COLK30}_{\text {) }}$ a \pm 6,8 (LignoPU COLK-Glu50)] $_{\text {. }}$.

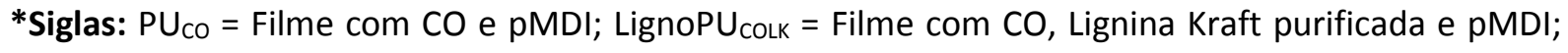

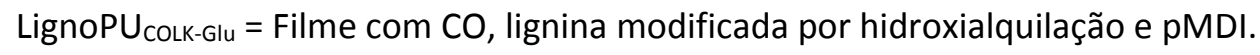

O filme $P U_{\text {co }}$ apresentou a maior taxa de intumescimento (151 $\pm 2 \%$ ) dentre os filmes avaliados, isso se deve ao fato de suas cadeias possuírem maior afastamento entre si e maior flexibilidade, o que viabiliza maior volume livre para acomodar moléculas de solvente (SOMANI et al., 2006), comparativamente aos outros filmes. LignoPU Colk10, LignoPU $_{\text {Colk30 e }}$

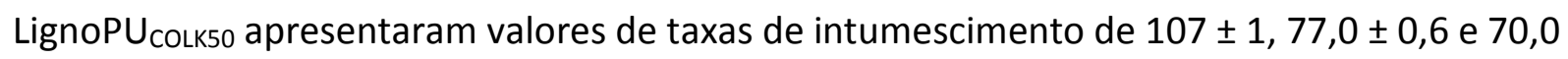
$\pm 3,6 \%$, respectivamente (Figura 30 a). Esse resultado mostra que a inserção de estruturas típicas de LK na estrutura química das PUs ocasionou uma diminuição na capacidade dos filmes de absorver o solvente DMF.

Levando em consideração que a temperatura em que ocorreu à síntese dessas PUs (25 ${ }^{\circ} \mathrm{C}$ ), em geral, não favorece o entrecruzamento de cadeias, o que se presente impacta o intumescimento, se tem como indicação que o decréscimo na taxa de intumescimento deve estar relacionado à inserção de estruturas volumosas, como as da LK ou LK-Glu, na estrutura química da PU, o que resulta em menos espaço para moléculas de solventes, como o DMF, se alojarem.

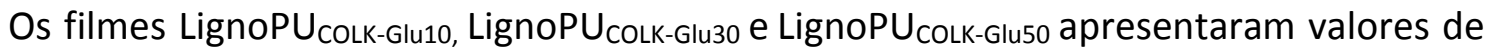
taxas de intumescimento de 95,0 $\pm 3,8,72 \pm 5$ e 54,0 \pm 6,8 \% respectivamente, ou seja, uma diferença de 11,2, 6,5 e 22,8 \% em relação à observada para LignoPU colk10, LignoPU $_{\text {colk30 }}$ e

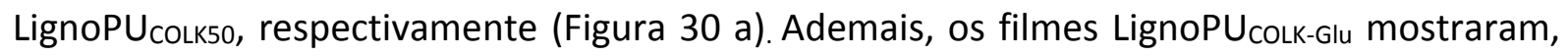
mesmo que próximos, menores ICr's (Tabela 7, Item 1.3.2.4) em comparação a LignoPU 


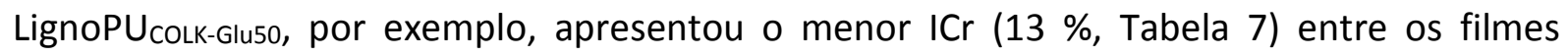
avaliados, e simultaneamente a menor $S \%(54,0 \pm 6,8 \%)$. Um decréscimo na $S \%$ foi observado conforme aumenta a cristalinidade, em função da ordenação das cadeias da região cristalina,o que dificulta a penetração do solvente (MILLER-CHOU; KOENIG, 2003).

A coloração das soluções de DMF após o término do teste de intumescimento, mostrada na Figura 30 b, revela um escurecimento da solução conforme o acréscimo da concentração de LK usado na síntese. Isto pode ter sido causado pela solubilização de PUs de menor massa molar média presentes no filme. Esse resultado também foi observado por JIA et al. (2015), ao produzir filmes poliuretânicos utilizando na síntese lignina extraída de madeira por solvente orgânico, MDI, 1,4 dioxano como solvente trietilamina (TEA) como catalisador.

As soluções de DMF dos filmes formados em sínteses utilizando LK-Glu são mais claras, comparativamente as soluções de DMF dos filmes formados a partir de LK nas mesmas concentrações, principalmente as soluções de DMF dos filmes formados a partir de 50 \% de LK e LK-Glu (Figura 30 b). A maior massa molar média de LK-Glu comparativamente a LK, leva a PUs de maior massa molar média, com menor solubilidade em DMF.

\subsubsection{6 Ângulo de contato}

Na Figura 31 estão apresentados os ângulos medidos no instante em que a gota se depositou nos filmes (ângulo de avanço - AA) e no final da análise (ângulo de recuo - AR). 
Figura 31 - Ângulo de avanço, AA e Ângulo de recuo, AR para os filmes poliuretânicos preparados simultaneamente à síntese realizada a partir de LK ou LK-Glu, CO e pMDI.

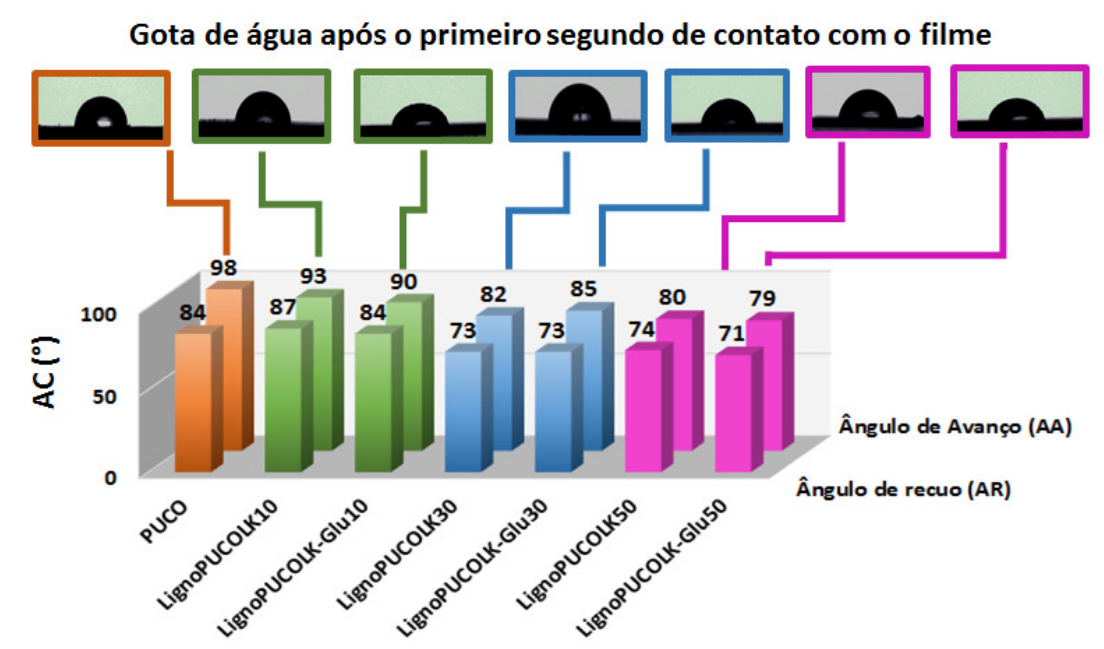

*Desvios-padrão: $A A=\left[\right.$ De $\pm 0,7\left(\right.$ LignoPU $\left._{\text {CоLкзо }}\right)$ a $\left.\pm 5,5\left(\mathrm{PU}_{\mathrm{CO}}\right)\right] ; A R=[$ Desvios padrão de $\pm 0,05$ (Lignopucosк10) a $\pm 5,7$ (LignoPU соцкзо $_{\text {) }}$ ]

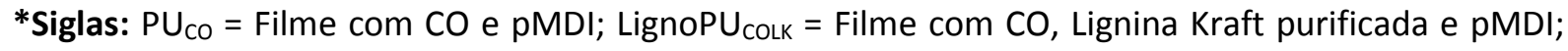

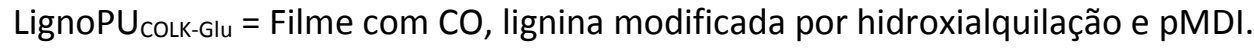

Quando o $A C(\theta)$ for maior que $90^{\circ}$, a superfície é considerada hidrofóbica, e quando $\theta$ for menor que $90^{\circ}$, é considerada hidrofílica. Quando o AC varia entre 30 e $90^{\circ}$, a superfície é hidrofílica, porém com um grau de hidrofilicidade considerado como intermediário. Os materiais que possuem $\theta$ superior a $140^{\circ}$ são chamados superhidrofóbicos, e os que possuem $\theta \approx 0^{\circ}$, são chamados superhidrofílicos (LUZ et al., 2008). O resultado do AA e AR (Figura 31) mostra que tanto a presença de estruturas típicas de LK quanto de LK-Glu na estrutura química da PU, conferiram um caráter menos hidrofóbico aos filmes, uma vez que conforme a concentração aumentou, o AA apresentou uma tendência a diminuição em relação à $P U_{c o}$, principalmente nos filmes formados concomitantemente a PUs sintetizadas a partir de 30 e 50 \% de LK e LK-Glu. Esse resultado indica a presença de um maior número de grupos polares voltados para a superfície dos filmes lignopoliuretânicos, possivelmente procedentes das estruturas típicas de lignina presentes. No entanto, em função do AA ser muito próximo de 90 , todos os filmes podem ser considerados como tendo superfície hidrofóbica.

Os filmes formados em sínteses em que LK-Glu foi usado como poliol não apresentaram diferenças significativas em relação aos filmes formados em sínteses em que LK foi usado, uma vez que tanto os valores de $A A$ quanto os de $A R$ foram semelhantes.

A histerese do $A C$, ou seja, a diferença entre $A A$ e $A R$, foi de $14^{\circ}$ para $P U_{C O}, 6^{\circ}$ para

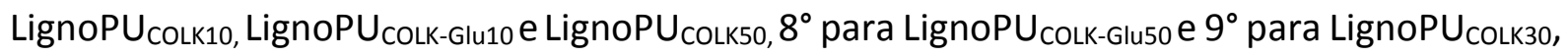


indicando que o uso de LK e LK-Glu como poliol na síntese das PUs levou a formação de superfícies mais lisas e homogêneas, comparativamente a PUco.

\subsubsection{Análise Dinâmico-Mecânica}

A análise dinâmico-mecânica (DMA) fornece informações a respeito do módulo de elasticidade ou armazenamento ( $\left.E^{\prime}\right)$, do módulo de dissipação viscosa ou perda ( $\left.E^{\prime \prime}\right)$, e do amortecimento mecânico ou atrito interno $\left(\operatorname{Tan}-\delta=E^{\prime \prime} / E^{\prime}\right)$ de um material, quando sujeito a uma solicitação dinâmica. As propriedades dinâmico-mecânicas dos filmes são determinadas pelas propriedades de seus componentes, pela morfologia e pela natureza da interação entre seus componentes (DE PAIVA; FROLLINI, 2001).

A Figura 32 apresenta as curvas Tan- $\delta$ versus temperatura para os filmes formados simultaneamente à síntese de PUs realizadas a partir de CO, LK e LK-Glu e pMDI.

Figura 32 - Curvas de (a) Tan- $\delta$ para os filmes poliuretânicos $\left(\mathrm{PU}_{\mathrm{CO}}\right.$, LignoPU $\mathrm{COLK10}_{\text {, LignoPU }}$ CoLk30, LignoPU ${ }_{\text {Colk50), (b) Tan- } \delta \text { para os filmes LignoPU }}$ colk30, LignoPU $_{\text {colk50 }}$ em escala Tan- $\delta$ reduzida, (c) Tan-

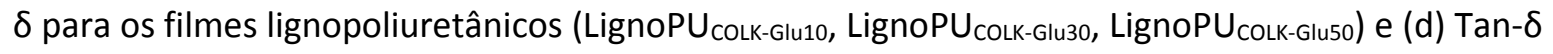

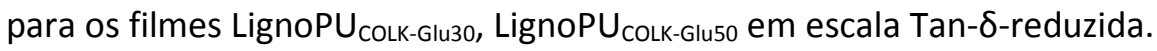

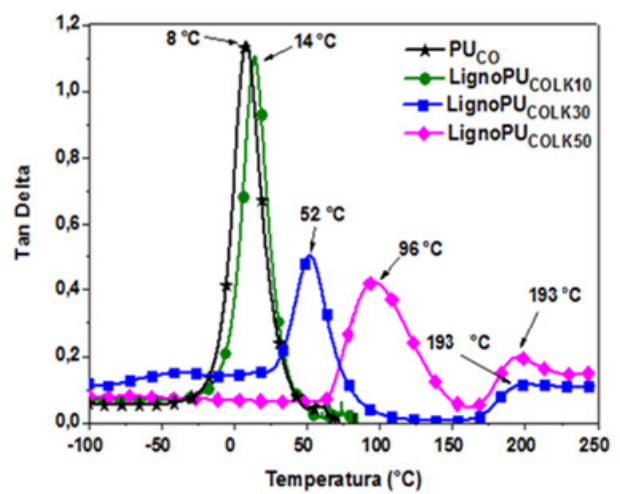

(a)

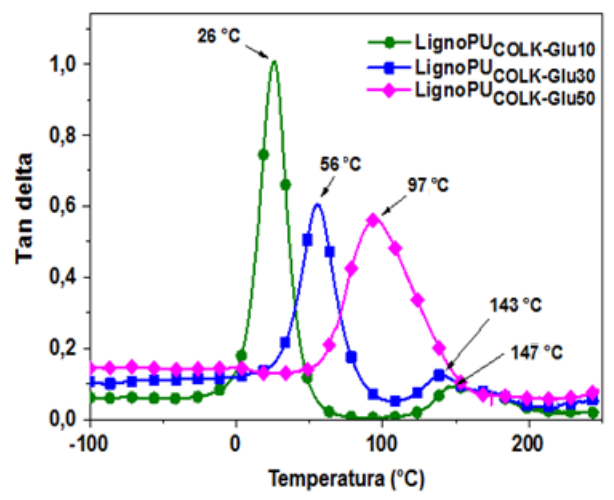

(c)

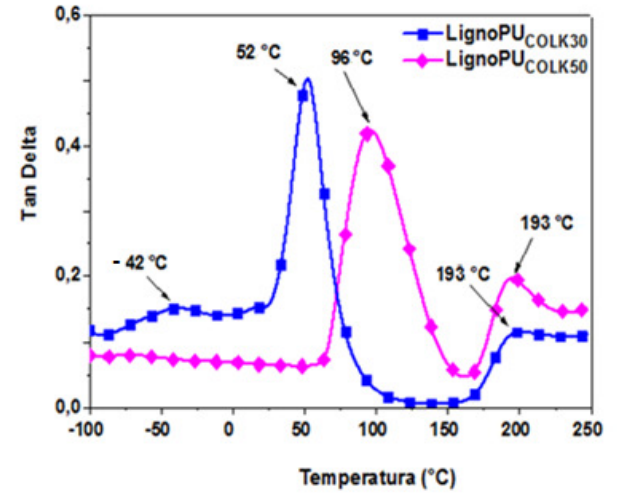

(b)

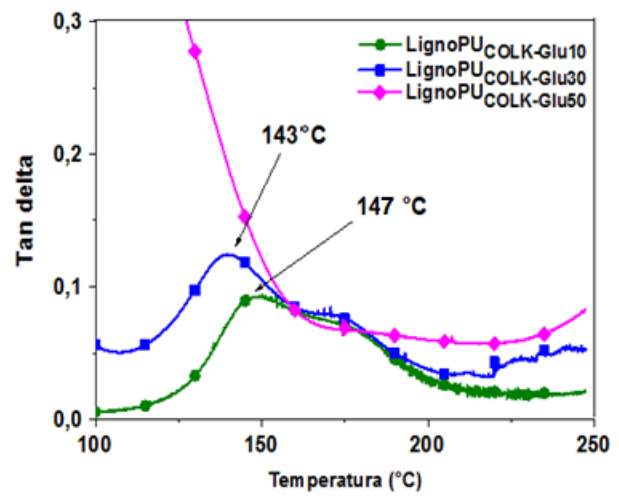

(d)

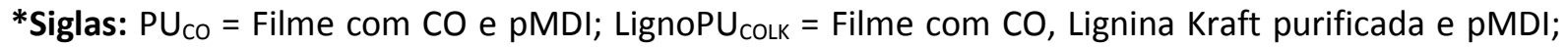

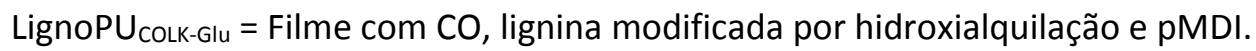


A Figura 32 a mostra na curva de Tan- $\delta$, a presença de apenas um pico nas amostras dos filmes formados a partir de PU $\mathrm{Co}_{\mathrm{C}}$ e LignoPU $\mathrm{CoLk10}_{10}$ os quais são relativamente estreitos, indicando que são decorrentes de relaxamento de segmentos com estrutura química relativamente similar. Já os filmes contendo 30 e $50 \%$ de LK apresentaram na curva de Tan- $\delta$ dois picos (Figura 32 b), porém menos intensos e mais largos que os observados para os filmes

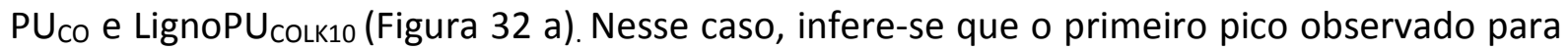
as amostras LignoPU ${ }_{\text {CoLk30 e LignoPU }}$ CoLk50, em 52,3 e 96,2 ${ }^{\circ} \mathrm{C}$, respectivamente, refere-se à primeira $T_{\mathrm{g}}$, proveniente de movimentos de rotação em torno de ligações simples nos segmentos flexíveis oriundos de CO, e que o segundo pico, em 193,3 e $192,7{ }^{\circ} \mathrm{C}$, para

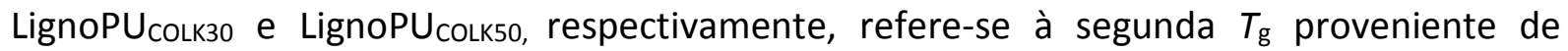
movimentos de rotação em torno de ligações simples nos segmentos rígidos oriundos de pMDI e LK (LOPES et al., 2012; ASENSIO et al., 2019). Ainda na Figura 32 b, a amostra LignoPU ${ }_{\text {COLK30 }}$ apresentou uma relaxação $\beta$ em torno de $-40^{\circ} \mathrm{C}$, ou seja, rotações em torno de ligações simples que ocorreram antes daquelas envolvendo segmentos, e que caracterizam a $T_{\mathrm{g}}$ (LORANDI et al., 2016). (LORANDI et al., 2016).

Com relação aos filmes formados simultaneamente a PUs sintetizadas com LK-Glu, é

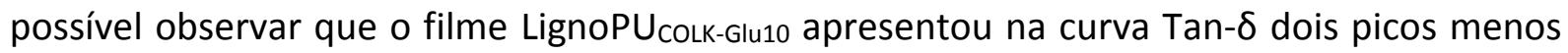

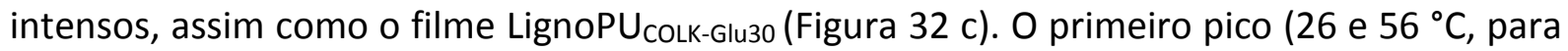
LignoPU $U_{\text {CoLK-Glu10 e LignoPU }}$ CoLk-Glu30, respectivamente) foi atribuído a $T_{\mathrm{g}}$ relacionada aos

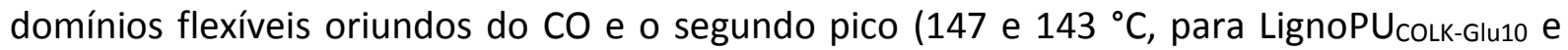

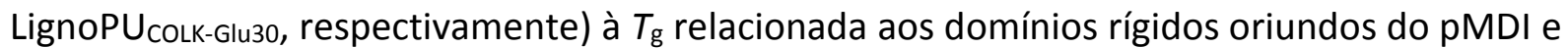
de LK-Glu. Os domínios flexíveis dos polímeros possuem $T_{\mathrm{g}}$ em temperaturas mais baixas que os rígidos, e conferem propriedades visco-elásticas, absorção e dissipação de energia para as poliuretanas. Já os domínios rígidos possuem $T_{\mathrm{g}}$ muito superior aos dos domínios flexíveis, em geral acima de $100^{\circ} \mathrm{C}$ (CINELLI et al., 2013). A presença de domínios rígidos em poliuretanas segmentadas é muito importante para suas propriedades mecânicas, uma vez que esses domínios agem como entrecruzamentos físicos para o segmento flexível, permitindo maior elasticidade para o material (LI et al., 1996). É importante salientar que a decomposição térmica dos filmes considerados inicia acima de $300{ }^{\circ} \mathrm{C}$ (Tabela 6) e que as curvas de calorimetria exploratória diferencial (DSC, não mostradas) não exibiram picos endotérmicos, o que poderia caracterizar a fusão de domínios cristalinos na faixa de temperatura em que os segundos picos apareceram nas curvas Tan- $\delta$ dos filmes LignoPU $U_{\text {colk }}$ e LignoPU $U_{\text {CoLk-Glu }}$ (Figura 
32). Sendo assim, pode-se afirmar que esse segundo pico se refere à transição vítrea das fases rígidas dessas LignoPUs.

A Tabela 8 apresenta os valores de $T_{\mathrm{g}}$ obtidos para filmes preparados neste estudo.

Tabela 8 - $T_{\mathrm{g}}$ (pico Tan- $\delta$ ) para os filmes poliuretânicos formados simultaneamente à síntese realizada a partir de CO, LK ou LK-Glu e pMDI

\begin{tabular}{|c|c|c|c|c|}
\hline \multirow{2}{*}{ Pico } & \multicolumn{4}{|c|}{$T_{\mathrm{g}}\left({ }^{\circ} \mathrm{C}\right)$} \\
\hline & $\mathrm{PU}_{\mathrm{co}}$ & LignoPU & LignoPU & LignoPU COLK50 \\
\hline $1^{\circ}$ & 8 & 15 & 52 & 96 \\
\hline $2^{\circ}$ & --- & --- & 93 & 193 \\
\hline & & LignoPU ${ }_{\text {COLK-Glu10 }}$ & LignoPU ${ }_{\text {coLk-Glu30 }}$ & LignoPU coLK-Glu50 \\
\hline $1^{\circ}$ & & 26 & 56 & 97 \\
\hline $2^{\circ}$ & & 147 & $\ldots 143$ & --- \\
\hline
\end{tabular}

A presença de estruturas típicas de ligninas, em substituição às do ácido ricinoleico presente no óleo de mamona, torna a movimentação de segmentos mais difícil, levando a filmes mais rígidos. À medida que aumenta o teor destas estruturas oriundas da lignina, pode ocorrer uma segregação de fases (soft e hard). A presença da fase rígida devido à introdução de LK e LK-Glu na formulação da poliuretana interferiu na $T_{\mathrm{g}}$ da fase flexível (10 pico), provocando um deslocamento para maiores temperaturas, comparativamente a PUco (Tabela 8).

Na Figura 32 a ainda é possível observar um alargamento no 10 pico das curvas

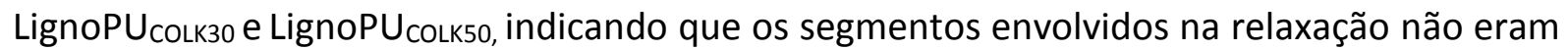

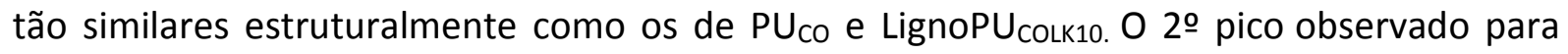

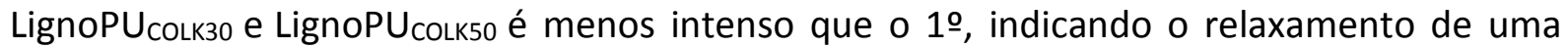
menor quantidade de segmentos rígidos, comparativamente aos segmentos flexíveis que geraram o 10 pico (Figura 32 b). Esta diferença de intensidades pode ser explicada pelos seguintes fatos: estes filmes apresentaram cristalinidade; os domínios cristalinos são principalmente constituídos por segmentos rígidos, ou seja, segmentos rígidos estão distribuídos entre regiões cristalinas e não cristalinas; o 20 pico foi gerado por segmentos rígidos presentes somente nos domínios não cristalinos.

SAITO et al. (2013) também observaram o aparecimento de duas $T_{\mathrm{g}} \mathrm{S}$ na síntese de lignopoliuretanas que geraram termoplásticos. Na síntese em questão foram usados solvente 
e catalisador, além de temperaturas acima da ambiente ( 80 e $100{ }^{\circ} \mathrm{C}$ ). As $T_{\mathrm{g}} \mathrm{s}$ encontradas foram em torno de -17 e $170^{\circ} \mathrm{C}$.

A Figura 32 c mostrou que a utilização de apenas $10 \%$ de LK-Glu, foi suficiente para

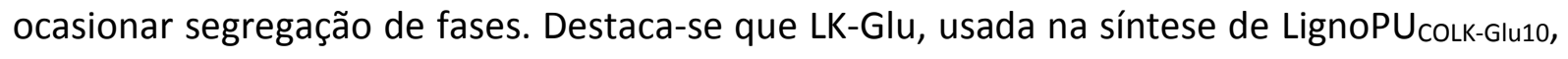
apresentou massa molar média superior a LK (Tabela 1, Item 1.3.1), usada na síntese de

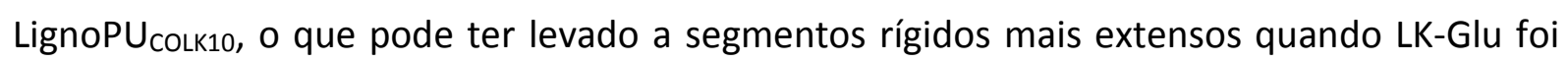
usada, favorecendo o surgimento de fase rígida.

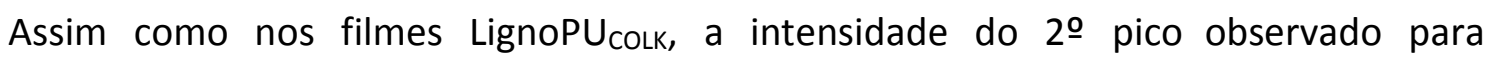

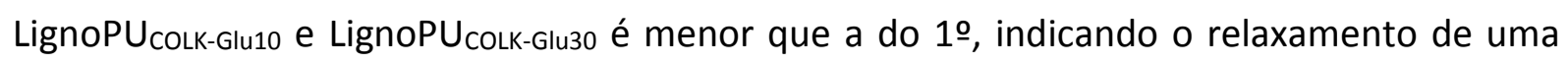
menor quantidade de segmentos rígidos, comparativamente aos segmentos flexíveis que geraram o 10 Pico (Figura 32 d). Essa diferença de intensidade, como explicado anteriormente, pode estar ligada ao fato de que parte dos segmentos rígidos desses filmes pode estar nos domínios cristalinos dos mesmos, uma vez que os domínios cristalinos são em sua maioria constituídos por segmentos rígidos (MISHRA; MAITI, 2011) e o 20 pico observado na curva de Tan- $\delta$, atribuído a transição vítrea, se refere apenas aos segmentos rígidos dos domínios não cristalinos dos filmes.

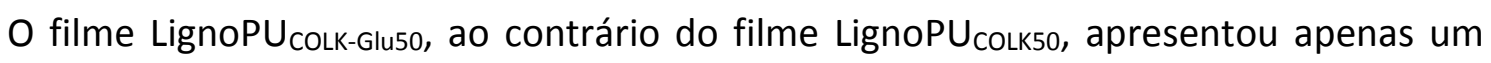
pico, largo, na curva de Tan- $\delta$ (Figura $32 \mathrm{c}$ ). Este resultado indica que as fases rígidas e flexíveis se misturaram neste filme, sendo a largura do mesmo decorrente da heterogeneidade estrutural dos segmentos rígidos e flexíveis cujos relaxamentos o originaram.

Os valores de $T_{\mathrm{g}}$ referentes aos segmentos flexíveis das PUs foram próximos nas proporções de 30 e 50 \% de lignina sendo ela modificada com glutaraldeído ou não (Tabela 8). Os filmes gerados simultaneamente à síntese de PUs realizadas a partir de $10 \%$ de LK e LK-

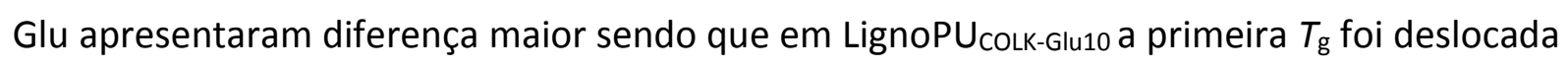
para temperatura superior $\left(26^{\circ} \mathrm{C}\right)$ comparada a LignoPU $\mathrm{COLK} 10\left(15^{\circ} \mathrm{C}\right)$ (Tabela 8). Já os valores de $T_{\mathrm{g}}$ referente aos domínios rígidos (2ำ pico) foram semelhantes entre os filmes formados a

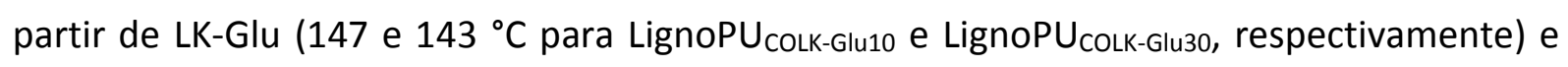
com LK (193 e $192^{\circ} \mathrm{C}$ para LignoPU ${ }_{\text {CoLK30 e LignoPU }}$ CoLk50, respectivamente).

A Figura 33 mostra E' para os filmes lignopoliuretânicos formados a partir de LK e LK-Glu em diferentes temperaturas $\left(-75^{\circ} \mathrm{C}\right.$ e $\left.25^{\circ} \mathrm{C}\right)$. 
Figura 33 - Módulo de armazenamento ( $\left.E^{\prime}\right)$ para os filmes poliuretânicos formados simultaneamente à síntese realizada a partir de CO, LK ou LK-Glu e pMDI nas temperaturas de -75 e $25^{\circ} \mathrm{C}$.
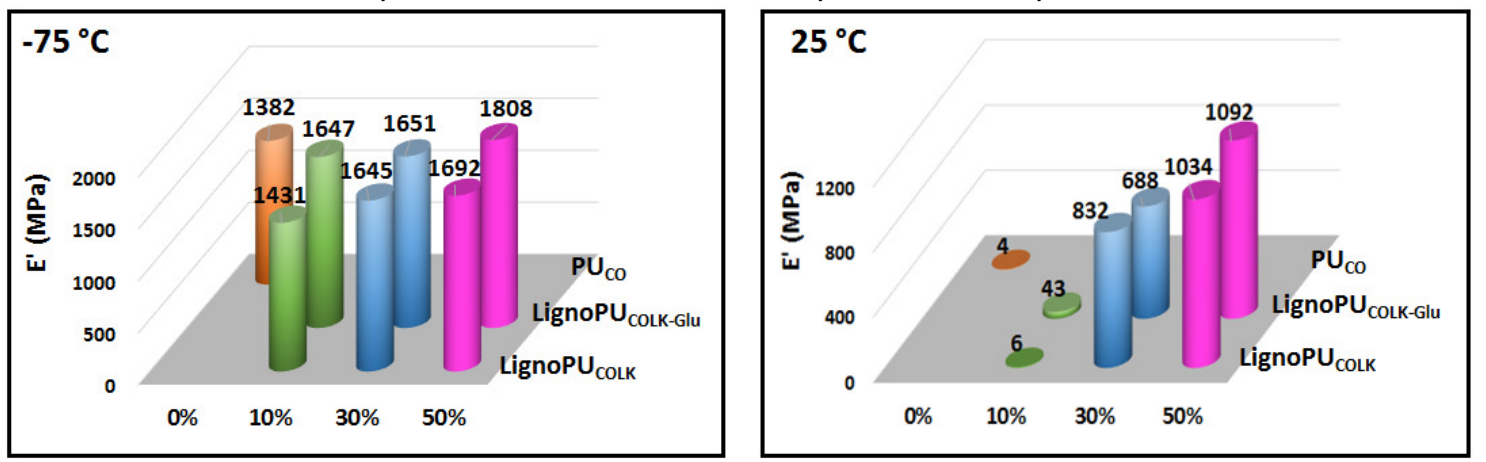

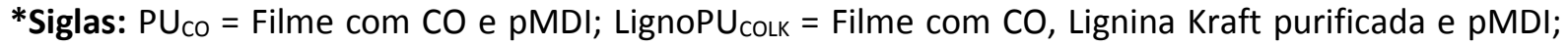

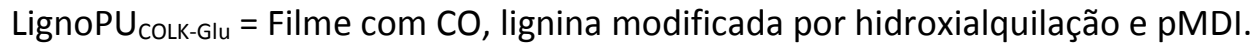

A introdução da LK e LK-Glu na estrutura das PUs, além de deslocar as $T_{\mathrm{g}}$ s referente aos domínios flexíveis, levou a um aumento no módulo de armazenamento ( $\left.E^{\prime}\right)$ dos filmes, tornando-os mais rígidos e dificultando a movimentação dos segmentos de cadeias, comparativamente a $\mathrm{PU}_{\mathrm{co}}$. Na temperatura de $-75^{\circ} \mathrm{C}$, ou seja, uma temperatura baixa $\mathrm{o}$ suficiente para esses materiais se encontrarem em seu estado vítreo, todos os filmes produzidos apresentaram valores de E' na ordem de $1000 \mathrm{MPa}$. Nessa temperatura, os filmes formados a partir de LK-Glu exibiram valores de E’ próximos e/ou superiores que os formados a partir de LK.

Na temperatura ambiente $\left(25^{\circ} \mathrm{C}\right)$, os valores de E' observados foram inferiores para os

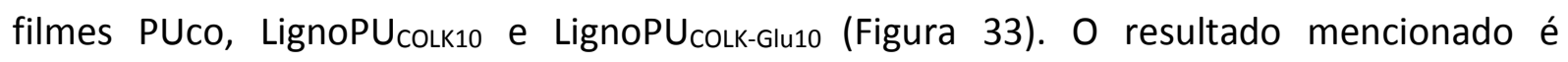
decorrente do fato que esses filmes já se encontravam no estado flexível, uma vez que os valores da $T_{\mathrm{g}}$ 1o pico observados para esses filmes estão abaixo ou próximas de $25^{\circ} \mathrm{C}$ (Tabela 8). Os filmes formados a partir de 30 e 50 \% de LK e LK-Glu apresentaram valores para a $T_{\mathrm{g}}$ 10 pico superiores a $25^{\circ} \mathrm{C}$ (Tabela 8), e, portanto, ainda estavam no estado rígido à temperatura ambiente, por isso os valores de $E^{\prime}$ observados para esses filmes foram mais altos. Isso evidencia o efeito de enrijecimento causado pela inserção de estruturas típicas de LK ou LKGlu na estrutura das PUs.

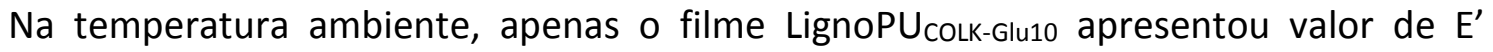
significativamente superior aos filmes formados a partir de LK (86 \%, Figura 33). Essas PUs estavam no estado flexível, como mencionado, sendo que nesse estado, onde existe rotação em torno de ligações simples presentes nos segmentos que constituem as cadeias dos domínios não cristalinos, foi possível perceber de forma mais acentuada o efeito do aumento 
da massa molar média e do volume de estruturas da LK-Glu, que resultou no aumento de $E^{\prime}$

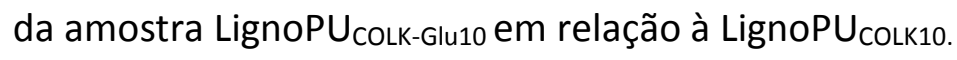

O módulo de armazenamento de filmes pode ser um indicativo de grau de entrecruzamento, uma vez que ligações cruzadas entre segmentos dificulta o movimento rotacional das ligações químicas simples que os constituem, tornando o material mais rígido. Conforme discutido no Item 1.3.2.5, a inserção de LK e principalmente, LK-Glu, na estrutura das PUs, ocasionou uma diminuição na taxa de intumescimento (\%S) dos filmes (Figura 30 a). Como citado anteriormente, diversos fatores, podem influenciar na avaliação de \%S, alguns exemplos são: a cristalinidade, a presença ou não de ligações cruzadas, a interação do polímero com o solvente em função do tipo de estruturas existentes, entre outros.

Os filmes LignoPU $U_{\text {CoLK-Glu10, LignoPU }}$ CoLK-Glu30 e LignoPU ${ }_{\text {COLK-Glu50 apresentaram uma }}$ redução no valor de $\%$ S de $11,2,6,5$ e $22,8 \%$ em relação à observada por LignoPU LignoPU $U_{\text {CoLK30 e LignoPU }}$ CoLK50, respectivamente (Figura 30 a). Com relação aos valores de $E^{\prime}$ observados para esses materiais a $25^{\circ} \mathrm{C}$, a mesma do teste de intumescimento, verificou-se que as amostras LignoPU COLK-Glu10 $_{\text {LignoPU }}$ COLK-Glu5o tiveram um aumento de 86 e $5 \%$ em

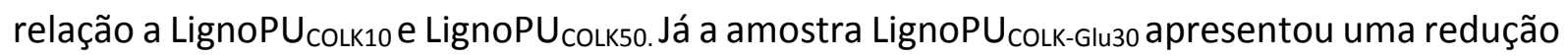
de $17 \%$ no valor de E' comparativamente a LignoPU

Os resultados obtidos para \%S e $\mathrm{E}^{\prime}$, indicaram que o resultado da \%S está relacionado a inserção de estruturas volumosas, como as da LK e LK-Glu, na estrutura da PU, resultando em menos espaço para moléculas de DMF se alojarem, independentemente de ter ocorrido entrecruzamento ou não.

O aumento na rigidez dos materiais pode modificar o mecanismo de fratura, e consequentemente o aspecto da superfície da mesma, deixando-a mais rugosa (NAIR et al., 2010). No item 1.3.2.2 (MEV), a superfície de fratura dos filmes em que LK e LK-Glu foram utilizados como reagentes em maiores proporções (30 e 50 \%, Figura 27) apresentaram mais sulcos e ondulações, em relação aos filmes em que LK e LK-Glu não foram utilizados ou foram utilizados em baixa proporção (10 \%). Esse resultado corrobora com o observado para os

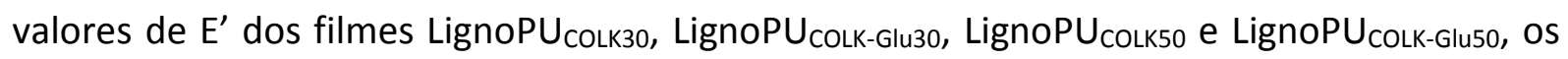
quais se mostraram superiores, principalmente a $25^{\circ} \mathrm{C}$, aos dos filmes PUco, LignoPU

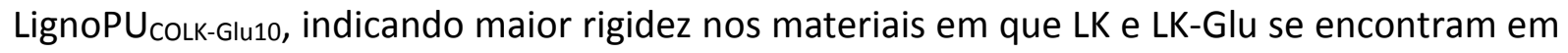
maior concentração (30 e 50 \%). 


\subsubsection{Propriedades de Tração}

A Figura 34 apresenta os resultados de resistência a tração, módulo de Young e alongamento na ruptura dos filmes lignopoliuretânicos preparados a partir de LK e LK-Glu (LignoPU Colk $_{\text {e LignoPU }}$ Colk-Glu) e do filme em que apenas CO foi utilizado como poliol $\left(\mathrm{PU}_{\mathrm{CO}}\right)$. É importante salientar que os filmes formados a partir de 30 e $50 \%$ de LK ou LK-Glu não romperam nas mesmas condições dos outros filmes, sendo assim, houve a necessidade de diminuir a largura desses filmes para conseguir avaliar as propriedades de tração (Item 1.2.5.6).

Figura 34 - (a) Resistência a ruptura, (b) módulo de Young e (c) alongamento na dos filmes poliuretânicos formados simultaneamente à síntese realizada a partir de CO, LK ou LK-Glu e pMDI.

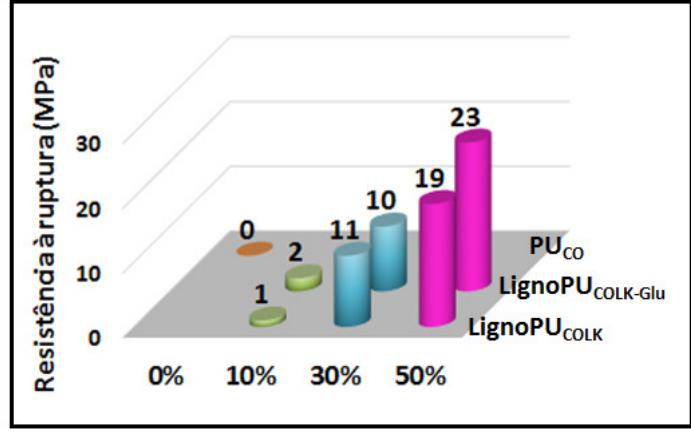

(a)

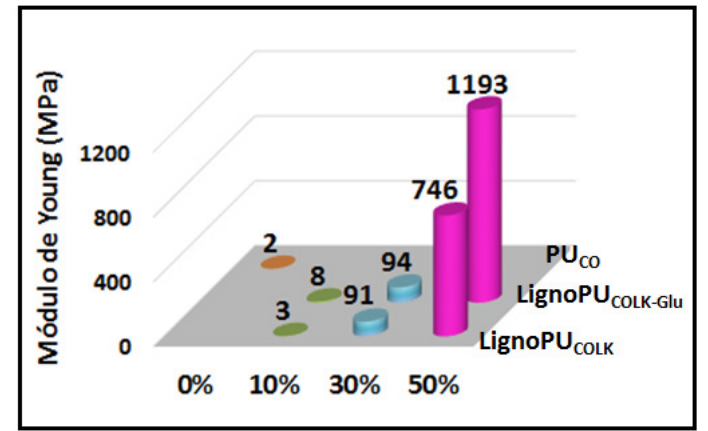

(b)

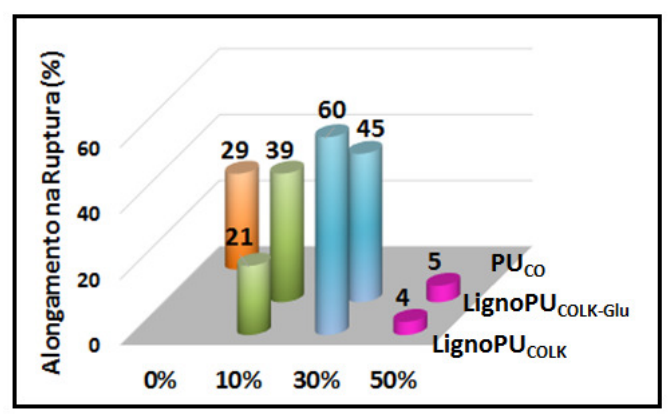

(c)

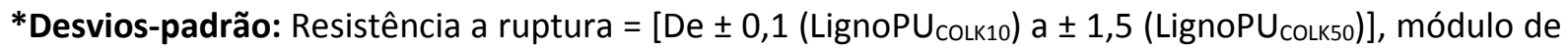
Young $=\left[\mathrm{De} \pm 0,1\left(\mathrm{PU}_{\mathrm{CO}}\right) \mathrm{a} \pm 34,6\right.$ (LignoPU $\left.\left.\mathrm{CoLk}_{\text {-Glu5o }}\right)\right]$ e alongamento na ruptura $=[\mathrm{De} \pm 0,1$ (LignoPU colkGluso) a $\pm 3,0$ (LignoPU $U_{\text {CoLK-Glu10) }}$.

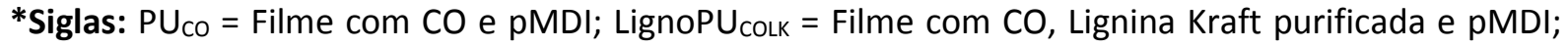

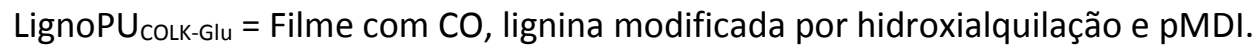

A presença de estruturas típicas da lignina na estrutura química da poliuretana impactou positivamente a resistência à tração. O filme $\mathrm{PU}_{\mathrm{C} O}$ apresentou resistência a tração extremamente baixa $(0,3 \pm 0,1 \mathrm{MPa})$, e para o filme LignoPUCoLK-Glu5o se obteve um resultado

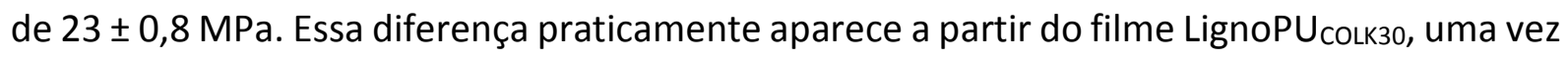




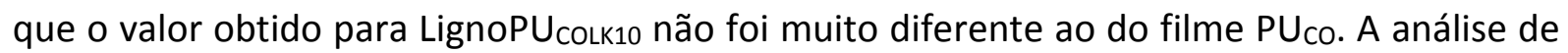
tração foi realizada à temperatura ambiente $\left(25^{\circ} \mathrm{C}\right)$, e nessa temperatura, conforme os resultados da análise de DMA, PU $U_{\text {co }}$ e LignoPU ${ }_{\text {colk10 }}$ estavam em seu estado flexível ( $T_{\mathrm{g}}$ 10 pico $\mathrm{PU}_{\mathrm{CO}}=8^{\circ} \mathrm{C} ; T_{\mathrm{g}}$ 10 pico LignoPU $\mathrm{COLK10}=15^{\circ} \mathrm{C}$, Tabela 8), enquanto que os filmes formados a partir de 30 e $50 \%$ de LK estavam em seu estado rígido $\left(T_{\mathrm{g}}\right.$ 1o pico LignoPU $\mathrm{CoLK} 30=52{ }^{\circ} \mathrm{C} ; T_{\mathrm{g}}$ 1o pico LignoPU ${ }_{\text {CoLk50 }}=96^{\circ} \mathrm{C}$, Tabela 8). Assim, os valores obtidos para resistência à ruptura para as amostras no estado flexível foram inferiores aos obtidos para as amostras no estado vítreo (Figura 34 a).

Com relação a resistência a tração dos filmes formados simultaneamente à síntese realizada a partir de LK-Glu, é possível observar na Figura 34 a, que os filmes LignoPU CoLK-Glu10 $_{\text {a }}$

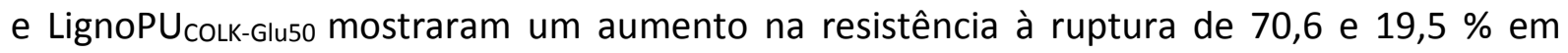
relação aos filmes formados nessas mesmas proporções, porém utilizando LK (Figura 34 a). As OH alifáticas inseridas na estrutura de LK-Glu, oriundas do glutaraldeído, levaram a reações dessas macromoléculas entre si, levando a "macromonômeros" de maior massa molar média, comparativamente a LK e, portanto, a PUs de maior massa molar média e enriquecidas com segmentos rígidos (ver discussão itens 1.3.1 e 1.3.1.2), o que pode justificar a maior resistência destes filmes.

Fatores como presença de cristalinidade e densidade de entrecruzamento também podem levar a um aumento na resistência a ruptura de materiais (TROVATI et al., 2010). Os

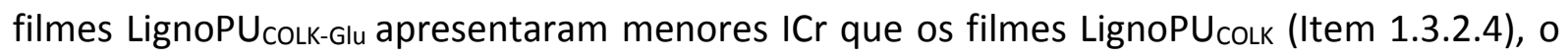
que indica que este fator não influenciou no aumento nos valores de resistência à ruptura dos

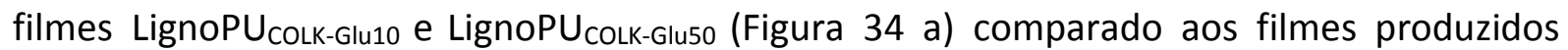
nessas mesmas proporções, porém com LK. O teste de intumescimento, mostrou uma

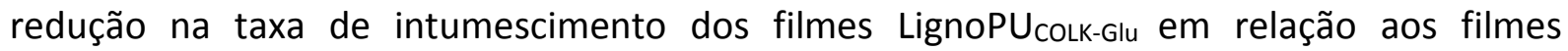
LignoPU $U_{\text {CoLK }}$ (Item 1.3.2.5), confirmando a menor disponibilidade de volume livre nos filmes

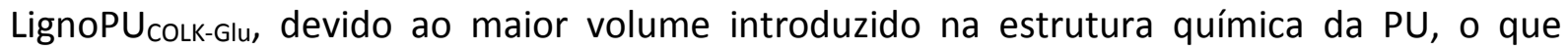
corrobora com os resultados de resistência à tração.

Novamente, é importante salientar que a análise de tração foi realizada à temperatura ambiente $\left(25^{\circ} \mathrm{C}\right)$ e que nessa temperatura nos domínios não cristalinos, o filme LignoPU ${ }_{\text {colk- }}$ Glu10 estava passando do estado vítreo para o flexível $\left(T_{\mathrm{g}}\right.$ 1o pico LignoPU $\mathrm{CoLK}_{\text {-Glu10 }}=26^{\circ} \mathrm{C}, \mathrm{Tabela}$ 8), enquanto que os filmes formados a partir de 30 e $50 \%$ de LK-Glu estavam em seu estado rígido ( $T_{\mathrm{g}}$ 10 pico LignoPU $\mathrm{COLK}_{\text {-Glu30 }}=56^{\circ} \mathrm{C}$ e $T_{\mathrm{g}}$ 1o pico LignoPU $\mathrm{COLK}-G l u 50=97^{\circ} \mathrm{C}$, Tabela 8). Isso explica 
os baixos valores encontrados para resistência a ruptura no filme LignoPU colk-Glu10 $(2,0 \pm 0,1$ $\mathrm{MPa})$, em relação aos filmes LignoPU $\mathrm{CoLK-Glu30}_{(10,0 \pm 0,4 \mathrm{MPa}) \text { e LignoPU }}$ COLK-Glu50 $(23,0 \pm 0,8$ $\mathrm{MPa}$ ). Além disso, LignoPU $\mathrm{COLK}_{\text {-Glu10 }}$ apresentou um grande aumento na resistência à tração na

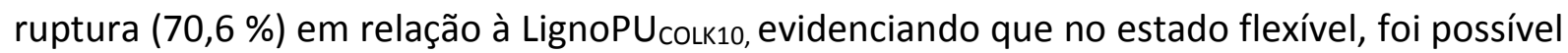
observar de forma mais acentuada, o efeito do aumento da massa molar média, do volume de estruturas e do número de hidroxilas ocorrido na LK-Glu. Esse resultado foi semelhante ao encontrado para o E' na análise de DMA a $25^{\circ} \mathrm{C}$ (Item 1.3.2.7).

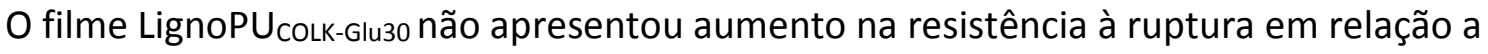

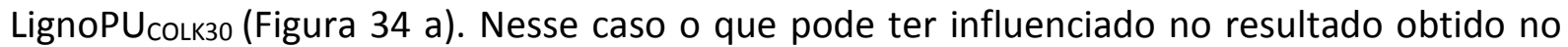
ensaio de tração foi a diminuição na cristalinidade, em aproximadamente $22 \%$, observada para LignoPU COLK-Glu30 em relação à LignoPU $_{\text {CoLK30. }}$

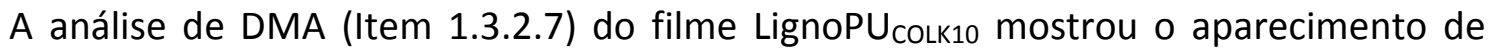
apenas um pico na curva de Tan- $\delta$, ou seja, uma $T_{\mathrm{g}}\left(15^{\circ} \mathrm{C}\right)$, indicando que não houve

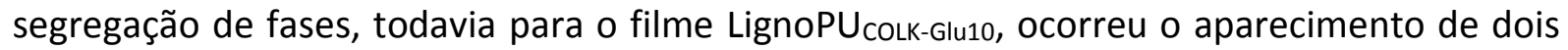
picos, ou seja, duas $T_{\mathrm{g}} \mathrm{s}$, evidenciando uma segregação de fases, em domínios soft $\left(T_{\mathrm{g}} 1^{\circ}\right.$ Pico $=$ $\left.26^{\circ} \mathrm{C}\right)$ e hard $\left(T_{\mathrm{g} 2^{\circ} \text { Pico }}=147^{\circ} \mathrm{C}\right)$, sendo o primeiro pico mais intenso que o segundo, ou seja, com maior número de segmentos flexíveis do que rígidos na porção não cristalina da PU, portanto, com maior possibilidade de movimentação dos segmentos e consequentemente de alongamento. Os domínios rígidos dessa PU, por sua vez, em função da modificação da LK com glutaraldeído, permitiram elevar a massa molar da PU, tornando-o mais resistente a ruptura que a LignoPU $U_{\text {colk10. }}$

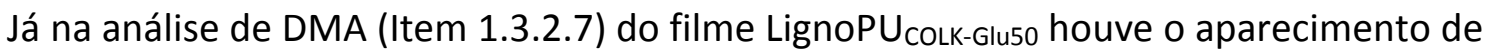
apenas um pico largo na curva de Tan- $\delta$, ou seja, uma $T_{\mathrm{g}}\left(97^{\circ} \mathrm{C}\right)$, ao contrário do filme LignoPU $U_{\text {CoLK50 que apresentou segregação de fases }\left(T_{\mathrm{g}} \text { 1o pico }\right.}=96{ }^{\circ} \mathrm{C}$ e $T_{\mathrm{g}} 2^{\circ}$ pico $\left.=193{ }^{\circ} \mathrm{C}\right)$. $\mathrm{O}$ aumento na resistência a ruptura de LignoPU CoLK-Glu50 em comparação a LignoPU $_{\text {CoLk50, }}$ provavelmente se deve ao aumento na massa molar média da PU, conforme citado anteriormente.

Para, o módulo de Young (Figura 34 b) também foi observado o mesmo perfil de aumento com a utilização tanto de LK quanto de LK-Glu, sendo que para as LignoPU colk esse efeito foi melhor observado nas concentrações de 30 e 50 \% e para as LignoPU colk-Glu principalmente nas concentrações de 10 e $50 \%$. 
Com relação ao alongamento na ruptura (Figura 34 c), para o filme $\mathrm{PU}_{\mathrm{co}}$, o qual contém maior número de segmentos flexíveis oriundos do $\mathrm{CO}$, se observou $29 \pm 1 \%$ de alongamento

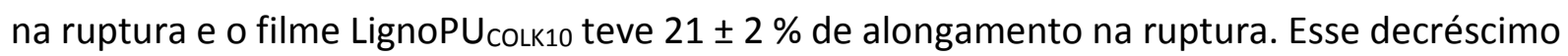
pode ser explicado pela inserção de segmentos rígidos contendo anéis aromáticos oriundos

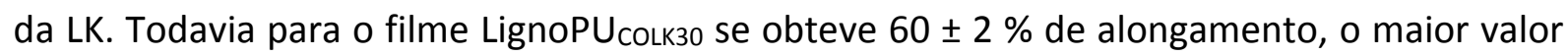
para esta propriedade dentre os filmes avaliados. Esse resultado indica que $30 \%$ de LK (macromolécula com massa molar ponderal média em torno de $2500 \mathrm{~g} \mathrm{~mol}^{-1}$ ), na formulação da poliuretana que gerou o filme, aumentou a massa molar média da PU de forma que o respectivo filme se tornou mais resistente à ruptura comparado aos filmes $\mathrm{PU}_{\mathrm{co}} \mathrm{e}$ LignoPU $U_{\text {CoLK10 }}$ (Figura 34 a), e permitiu que o filme atingisse maior alongamento na ruptura, devido a contribuição dos segmentos flexíveis do CO à estrutura química da PU (Figura 34 c). Estes resultados podem indicar que à síntese com produção simultânea de filme, à temperatura ambiente, na ausência de catalisador, leva a poliuretanas de menor massa molar média, quando LK não é usada como reagente $\left(P U_{C O}\right)$, ou é usada em baixa proporção

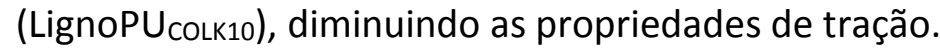

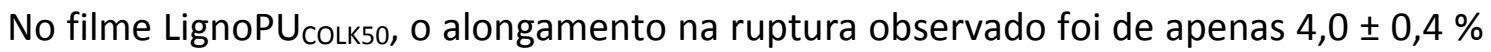
(Figura 34 c), indicando que uma proporção de LK de 50 \% na síntese da poliuretana leva a fases rígidas que diminuem o alongamento, devido a interação com os segmentos flexíveis provenientes de $\mathrm{CO}$, uma vez que, a proporção de segmentos flexíveis diminui, tornando a contribuição das fases rígidas predominantes.

Com relação ao alongamento na ruptura dos filmes formados a partir de LK-Glu, foi possível observar um acréscimo nessa propriedade de 46,6 e 35,8 \% para os filmes

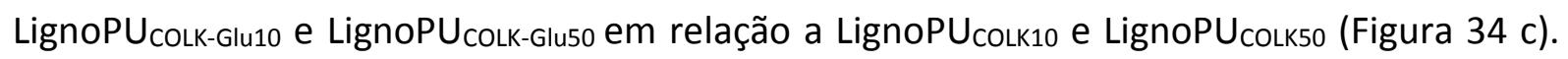
Esse resultado pode estar relacionado com a introdução das cadeias alifáticas (segmentos hidrocarbônicos), mais flexíveis que os anéis aromáticos, provenientes do glutaraldeído na LK, as quais permitiram juntamente com os segmentos flexíveis do $\mathrm{CO}$, que os filmes atingissem maior alongamento na ruptura.

Como mencionado anteriormente, o teste de tração foi realizado a aproximadamente $25^{\circ} \mathrm{C}$, portanto, na temperatura de transição vítrea do filme LignoPU CoLK-Glu10 $_{\text {g }}\left(T_{\mathrm{g}}{ }^{\circ}\right.$ pico $=26^{\circ} \mathrm{C}$, Item 1.3.2.7), ou seja, quando as cadeias começam a adquirir mobilidade, enquanto a amostra LignoPU $U_{\text {COLK-Glu5o }}\left(T_{\mathrm{g}}=97^{\circ} \mathrm{C}\right)$ ainda estavam em seu estado rígido. Isso explica a maior diferença no valor encontrado para o alongamento na amostra LignoPU $\mathrm{COLK}_{\text {Glu10 }}$ e também evidencia 
que no estado flexível, foi possível observar de forma mais acentuada o efeito do aumento da massa molar média e do volume de estruturas de LK-Glu.

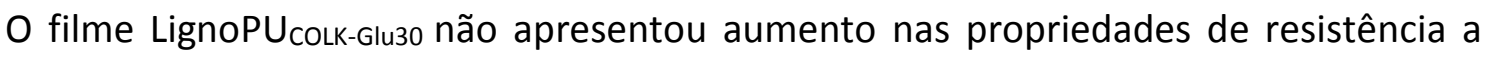
tração e alongamento na ruptura (Figura 34 a e c) em relação ao filme preparado com LK nesta mesma proporção.

De maneira geral, os resultados das propriedades de tração dos filmes formados a partir de LK e LK-Glu estão de acordo, ou superiores as propriedades de filmes adesivos poliuretânicos obtidos a partir de MDI e polióis derivados do petróleo, utilizando catalisador baseado em aminas e antiespumante (Resistência a ruptura: 11,5 até $40 \mathrm{MPa}$; Módulo de Young: 0,7 até 3,6 MPa e Alongamento na ruptura: 0,8 até 18,8 \%) (CLAU et al., 2011).

\subsubsection{Avaliação da influência da temperatura na síntese das LignoPUs sobre as propriedades dos filmes lignopoliuretânicos formados a partir de CO, LK ou LK-Glu como polióis e pMDI como isocianato}

Diferentes temperaturas acima da ambiente $\left(50,75\right.$ e $\left.100^{\circ} \mathrm{C}\right)$ foram consideradas após a deposição nas placas das misturas reacionais das LignoPUs sintetizadas com 30 e 50 \% de LK e LK-Glu (porcentagens selecionadas a partir dos resultados obtidos para filmes formados em reações ocorridas à temperatura ambiente), a fim de avaliar o impacto no tempo da reação de polimerização, assim como, nas propriedades dos filmes obtidos. A primeira etapa da reação, sob agitação, ocorreu à temperatura ambiente.

A mistura reacional logo após o depósito na placa foi avaliada por FTIR ( $t=0 \mathrm{~h}$ ), e os filmes foram retirados quando espectros obtidos de tempos em tempos indicaram ausência da banda isocianato, ou seja, total consumo de pMDI. Os filmes lignopoliuretânicos foram caracterizados por: TGA; DRX; DMA; Resistência à Tração; análise de ângulo de contato e teste de intumescimento.

\subsubsection{Espectroscopia na região do Infravermelho com Transformada de Fourier}

O aumento para temperaturas acima da ambiente $\left(50,75\right.$ e $\left.100{ }^{\circ} \mathrm{C}\right)$ após a deposição das LignoPUs nas placas de vidro foi realizado com o objetivo de acelerar a reação de polimerização. Os espectros das misturas reacionais (CO, 30 e 50 \% de LK ou LK-Glu e pMDI) 
imediatamente após deposição na placa $(t=0 h)$ e dos respectivos filmes formados nas diferentes temperaturas avaliadas pode ser observado no Apêndice D.

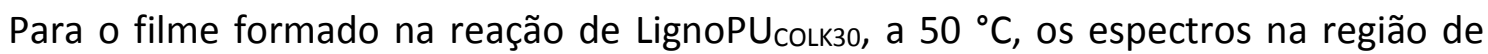
infravermelho mostraram consumo total de pMDI, com possibilidade de retirada do filme da placa, em um tempo (5 dias) cerca de $29 \%$ menor que o filme correspondente obtido à

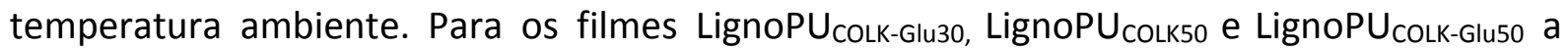
redução no tempo de retirada das placas foi de 20,20 e 12,5 \%, respectivamente.

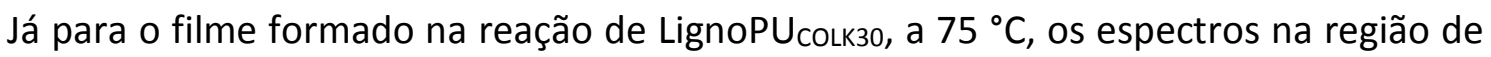
infravermelho mostraram consumo total de $\mathrm{pMDI}$, com possibilidade de retirada do filme da placa, em um tempo (4 dias) cerca de $43 \%$ menor que o filme correspondente obtido à

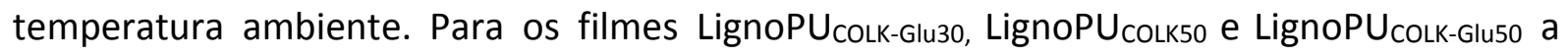
redução no tempo de retirada das placas foi de 20,30 e $12,5 \%$, respectivamente.

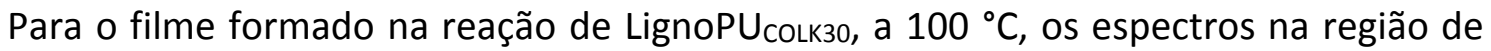
infravermelho mostraram consumo total de $\mathrm{pMDI}$, com possibilidade de retirada do filme da placa, em um tempo (2 dias) cerca de $70 \%$ menor que o filme correspondente obtido à temperatura ambiente. Para os filmes LignoPU CoLK-Glu30, LignoPU $_{\text {CoLK50 e LignoPU }}$ CoLK-Glu50 a redução no tempo de retirada das placas foi de 40,60 e $50 \%$, respectivamente.

O efeito da modificação química realizada na LK-Glu, em que $\mathrm{OH}$ alifáticas oriundas do glutaraldeído foram inseridas na estrutura de LK-Glu, com o objetivo de aumentar a reatividade da mesma frente ao grupo isocianato, foi observado principalmente a $100{ }^{\circ} \mathrm{C}$, uma vez que a redução do tempo necessário para retirada dos filmes das placas, tanto para as PUs sintetizadas com 30 \% quanto para as sintetizadas com 50 \% de LK-Glu, foi maior nessa temperatura (40 e $50 \%$ ) comparativamente as temperaturas de 50 e $75{ }^{\circ} \mathrm{C}$ (redução de 20 e $12,5 \%$, respectivamente).

Reações secundárias do grupo isocianato com as ligações uretânicas formadas podem ocorrer durante à síntese de PUs quando temperaturas acima de $60{ }^{\circ} \mathrm{C}$ são utilizadas, principalmente quando são utilizados isocianatos aromáticos, como o pMDI (DUSEK; SPIRKOVA, 1990; DUSEK et al., 1990). Os produtos dessas reações são chamados alofanatos (Figura 35). Os grupos alofanato formados ainda podem continuar a reagir com o grupo isocianato, resultando em biureto (Figura 35). 
Figura 35 - Reação de formação do grupo alofanato.

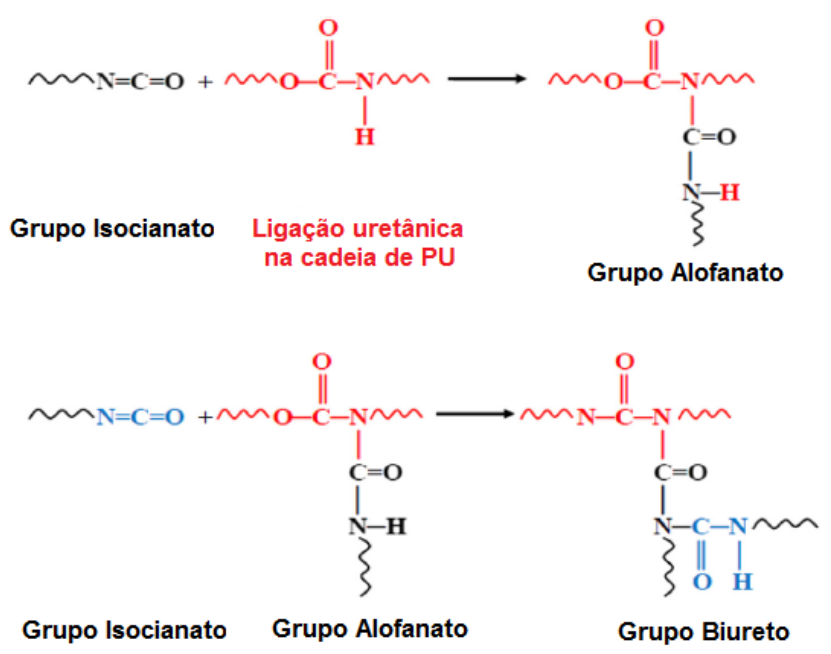

Fonte: Adaptado de YILGOR et al., 2015.

A frequência com que a banda referente a vibração da carbonila em PUs $\left(1650-1740 \mathrm{~cm}^{-}\right.$ $\left.{ }^{1}\right)$ aparece é indicativa de carbonilas $(\mathrm{C}=\mathrm{O})$ ligadas a grupos $\mathrm{N}-\mathrm{H}$ que estejam ligados por ligações hidrogênio ou que estejam livres. $O$ aparecimento dessa banda em frequências mais baixas (aproximadamente $1650 \mathrm{~cm}^{-1}$ ) no espectro de FTIR, é atribuída a vibração da carbonila ligada ao grupo N-H em alofanatos (WANG et al., 2017). A banda referente a $\mathrm{C}=\mathrm{O}$ dos filmes

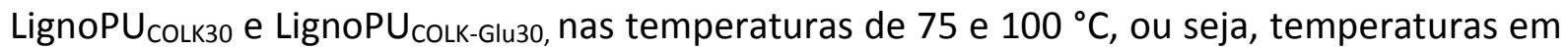
que há maior probabilidade de ocorrerem reações secundárias do tipo alofanato e biureto, apareceu em frequências superiores a $1650 \mathrm{~cm}^{-1}$, evidenciando a não formação destes compostos para essas amostras (Apêndice D). Todavia, nos filmes LignoPU $\mathrm{COLK50}_{0}$ e LignoPU $\mathrm{U}_{\text {colk- }}$ Glu5o, tanto formados a $75{ }^{\circ} \mathrm{C}$ quanto em $100{ }^{\circ} \mathrm{C}$, pode-se perceber um alargamento da banda referente as carbonilas e o aparecimento de um discreto pico em torno de $1670 \mathrm{~cm}^{-1}$ (Apêndice D). Essa banda pode estar relacionada a presença de grupos do tipo alofanato nas PUs produzidas com $50 \%$ de LK ou LK-Glu.

\subsubsection{Microscopia Eletrônica de Varredura}

A morfologia da superfície dos filmes formados em reações ocorridas em temperaturas acima da ambiente $\left(50,75\right.$ e $100{ }^{\circ} \mathrm{C}$ ) foi semelhante para todos os filmes (micrografias não mostradas). Em todos eles, a superfície se mostrou homogênea e sem a presença de bolhas ou sulcos, semelhante à observada para os filmes formados à temperatura ambiente e mostrados no Item 1.3.2.2. 
A Figura 36 apresenta as micrografias das criofraturas dos filmes LignoPU colk30;

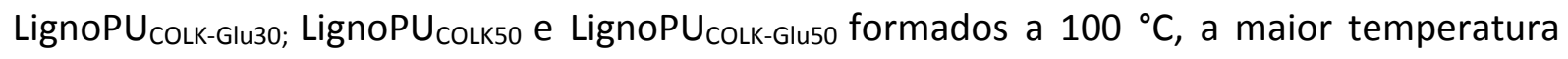
avaliada, e para fins de comparação, também apresenta micrografias dos respectivos filmes formados à temperatura ambiente, mostradas previamente no Item 1.3.2.2.

Figura 36 - Micrografias eletrônicas de varredura da criofratura dos filmes lignopoliuretânicos preparados simultaneamente à síntese realizada a partir de CO, LK ou LK-Glu (30 e 50 \%) e pMDI a 25
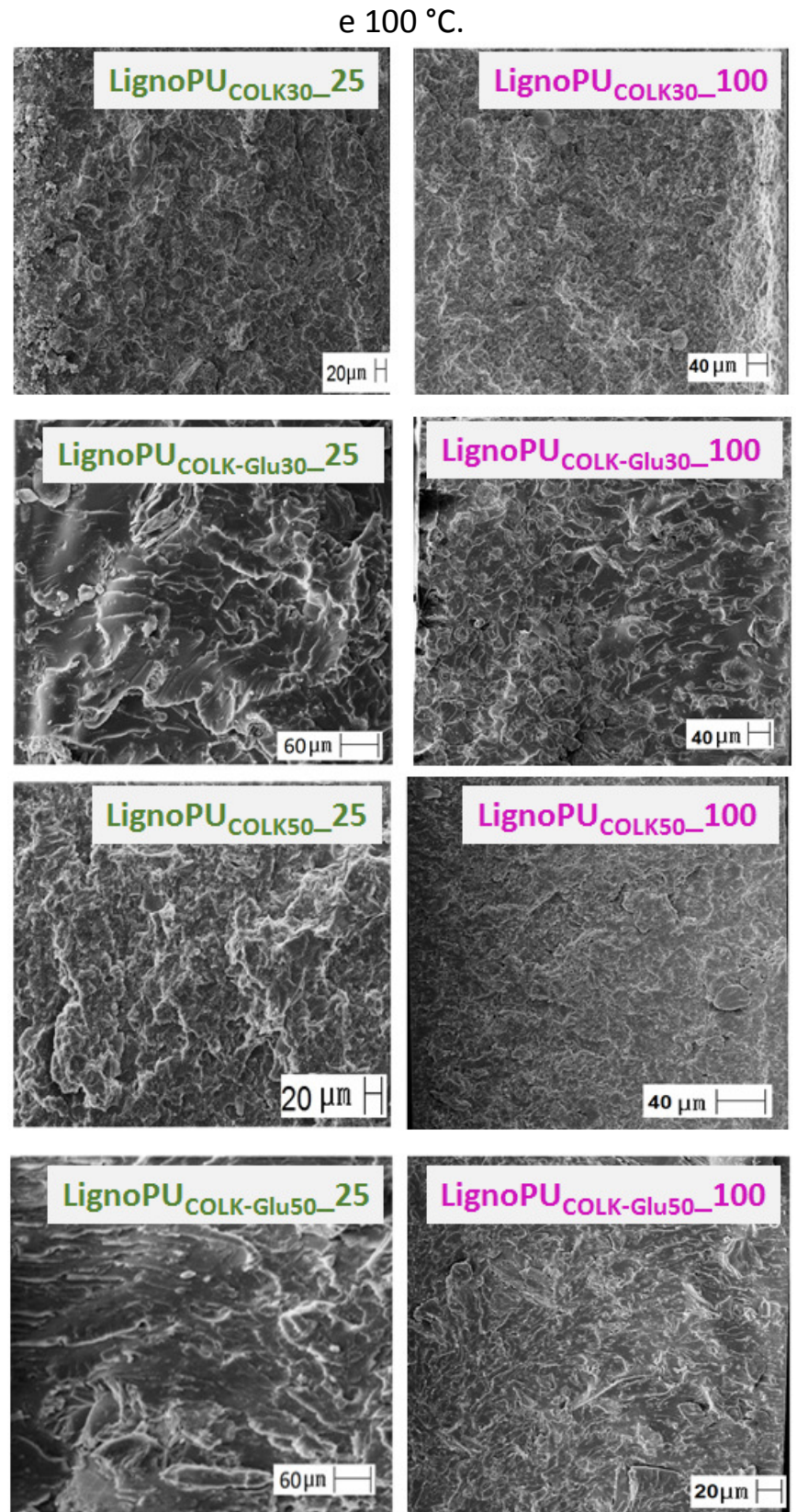

*Siglas: LignoPU ${ }_{\text {CoLK }}=$ Filme com CO, lignina Kraft purificada e pMDI; LignoPU ${ }_{\text {coLk-Glu }}=$ Filme com CO, lignina modificada por hidroxialquilação e pMDI.

De acordo ao observado na Figura 36, as superfícies de fratura dos filmes formados a $100^{\circ} \mathrm{C}$ apresentaram mais sulcos e ondulações do que os filmes correspondentes formados a 
$25^{\circ} \mathrm{C}$, indicando que o mecanismo de fratura desses filmes foi alterado com o uso de temperaturas acima da ambiente para as respectivas reações. Essa mudança na morfologia foi mais evidente nos filmes formados em sínteses em que LK-Glu foi usado como poliol $\left(100^{\circ} \mathrm{C}\right)$ comparativamente aos filmes formados em sínteses em que LK foi usado como poliol, na mesma temperatura.

\subsubsection{Termogravimetria}

O aumento para temperaturas acima da ambiente $\left(50,75\right.$ e $\left.100^{\circ} \mathrm{C}\right)$ durante a reação de polimerização das LignoPUs não alterou significativamente o perfil da decomposição térmica dos filmes formados, comparativamente ao dos filmes cujas reações de polimerização ocorreram à temperatura ambiente (Apêndice $E$ ).

As Tabelas 9 e 10 apresentam os dados termogravimétricos obtidos para os filmes

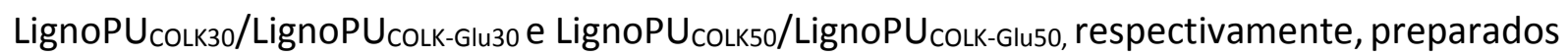
a $25,50,75$ e $100^{\circ} \mathrm{C}$.

Tabela 9 - Temperaturas dos eventos térmicos e massa residual encontrados para os filmes

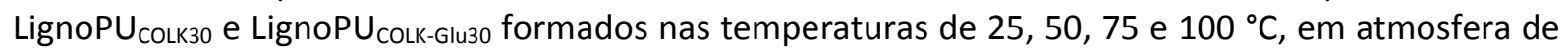
$\mathrm{N}_{2}$

\begin{tabular}{|c|c|c|c|c|c|}
\hline \multirow[t]{2}{*}{ Filme } & \multicolumn{2}{|c|}{$\begin{array}{c}\text { Evento } 1 \\
\left(300-360^{\circ} \mathrm{C}\right)\end{array}$} & \multirow{2}{*}{$\begin{array}{c}\begin{array}{c}\text { Evento } 2 \\
\left(360-415^{\circ} \mathrm{C}\right)\end{array} \\
T_{\text {Máx }}\left({ }^{\circ} \mathrm{C}\right)\end{array}$} & \multirow{2}{*}{$\begin{array}{c}\begin{array}{c}\text { Evento } 3 \\
\left(415-5655^{\circ} \mathrm{C}\right)\end{array} \\
T_{\text {Máx }}\left({ }^{\circ} \mathrm{C}\right)\end{array}$} & \multirow{2}{*}{$\begin{array}{c}\begin{array}{c}\text { Resíduo } \\
\left(900^{\circ} \mathrm{C}\right)\end{array} \\
\text { Massa (\%) }\end{array}$} \\
\hline & $T_{\text {onset }}\left({ }^{\circ} \mathrm{C}\right)$ & $T_{\text {Máx }}\left({ }^{\circ} \mathrm{C}\right)$ & & & \\
\hline LignoPU & 315 & 343 & 380 & 468 & 16,4 \\
\hline LignoPU & 311 & 341 & 376 & 481 & 13,6 \\
\hline LignoPU & 315 & 350 & 376 & 469 & 16,8 \\
\hline LignoPU & 312 & 345 & 377 & 473 & 16,4 \\
\hline LignoPU & 309 & 346 & 380 & 480 & 10,9 \\
\hline LignoPU CoLK-Glu30_50 & 310 & 346 & 382 & 476 & 12,8 \\
\hline LignoPU CoLK-Glu30_75 & 315 & 347 & 379 & 482 & 14,8 \\
\hline LignoPU COLK-Glu30_100 & 309 & 346 & 377 & 480 & 15,4 \\
\hline
\end{tabular}


Tabela 10 - Temperaturas dos eventos térmicos e massa residual encontrados para os filmes

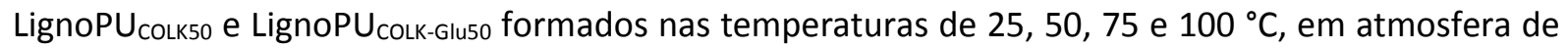
$\mathrm{N}_{2}$

\begin{tabular}{|c|c|c|c|c|}
\hline \multirow[t]{2}{*}{ Filme } & \multicolumn{2}{|c|}{$\begin{array}{c}\text { Evento } 1 \\
\left(300-400^{\circ} \mathrm{C}\right)\end{array}$} & \multirow{2}{*}{$\begin{array}{c}\begin{array}{c}\text { Evento } 2 \\
\left(400-565^{\circ} \mathrm{C}\right)\end{array} \\
T_{\text {Máx }}\left({ }^{\circ} \mathrm{C}\right)\end{array}$} & \multirow{2}{*}{$\begin{array}{c}\begin{array}{c}\text { Resíduo } \\
\left(900^{\circ} \mathrm{C}\right)\end{array} \\
\text { Massa (\%) }\end{array}$} \\
\hline & $T_{\text {onset }}\left({ }^{\circ} \mathrm{C}\right)$ & $T_{\text {Máx }}\left({ }^{\circ} \mathrm{C}\right)$ & & \\
\hline LignoPU ${ }_{\text {coLk50_25 }}$ & 316 & 363 & 473 & 24,7 \\
\hline LignoPU ${ }_{\text {coLk50_50 }}$ & 311 & 363 & 475 & 23,0 \\
\hline LignoPU & 312 & 369 & 478 & 22,7 \\
\hline LignoPU ${ }_{\text {Colk50_100 }}$ & 310 & 362 & 472 & 25,9 \\
\hline LignoPU & 302 & 354 & 476 & 20,7 \\
\hline LignoPU ${ }_{\text {COLK-Glu50_50 }}$ & 305 & 363 & 477 & 19,5 \\
\hline LignoPU_coLk-Glu50_75 & 306 & 345 & 462 & 22,8 \\
\hline LignoPU COLK-Glu50_100 & 310 & 358 & 453 & 26,0 \\
\hline
\end{tabular}

A temperatura inicial ( $T_{\text {onset }}$ ) de decomposição dos filmes (Tabela 9 e 10) praticamente não foi alterada em função do uso de temperaturas mais elevadas na reação das LignoPUs que levaram a formação dos filmes.

Também não foram observadas diferenças significativas no percentual de massa residual dos filmes formados a partir de 30 e $50 \%$ de LK e LK-Glu nas diferentes temperaturas avaliadas (Tabela 9 e 10), e isso se deve ao fato de que a composição dos reagentes não foi modificada entre os filmes, a única variável considerada foi a temperatura de síntese.

\subsubsection{Difração de raios $X$}

A cristalinidade dos filmes lignopoliuretânicos formados nas sínteses realizadas a partir de 30 e 50 \% de LK ou LK-Glu e pMDI, em diferentes temperaturas $\left(25,50,75\right.$ e $\left.100{ }^{\circ} \mathrm{C}\right)$ foi avaliada pela análise de difração de raios X (Figura 37). 


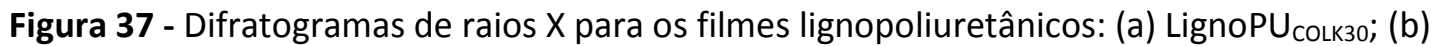
LignoPU $\mathrm{COLK-Glu30;}_{\text {(c) LignoPU }}$ COLK50 $_{\text {e (d) LignoPU }}$ COLK-Glu50, produzidos em diferentes temperaturas (25, 50,75 e $\left.100^{\circ} \mathrm{C}\right)$.

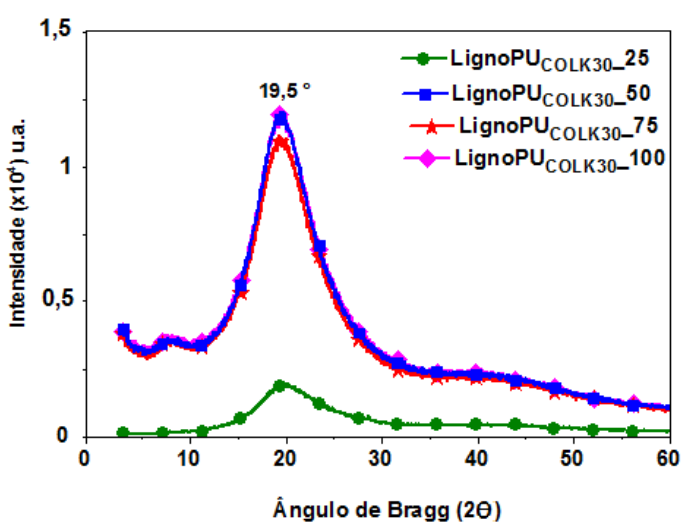

(a)

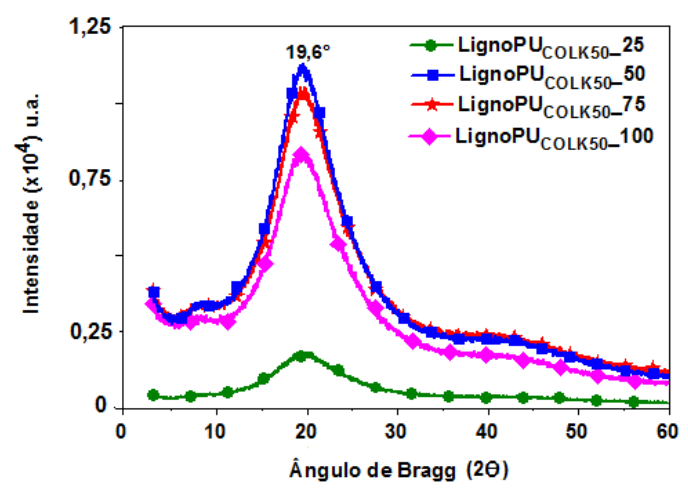

(c)

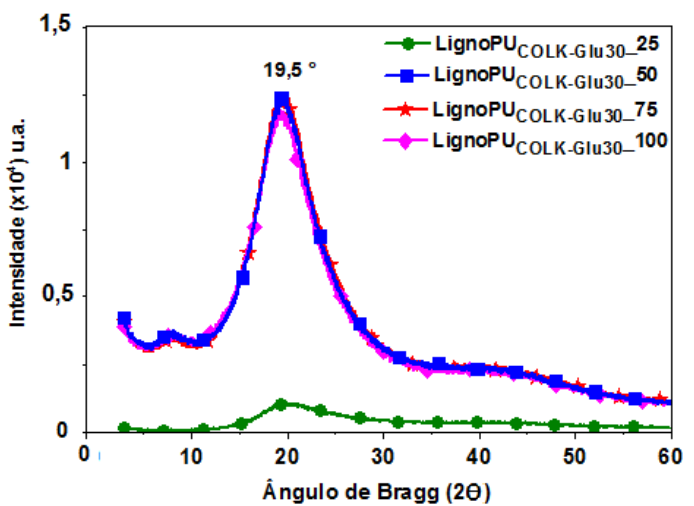

(b)

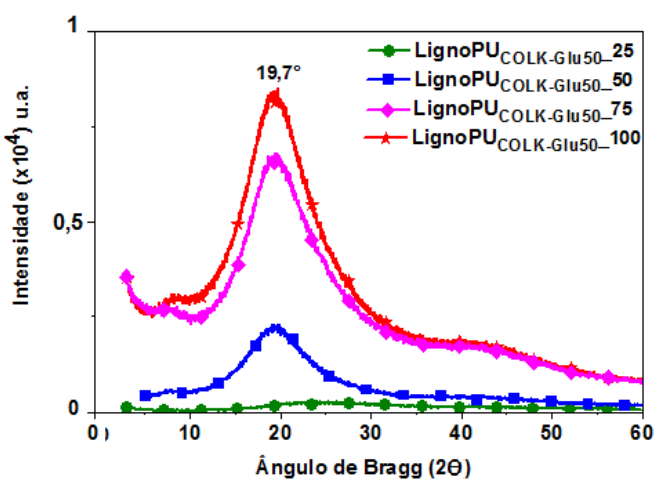

(d)

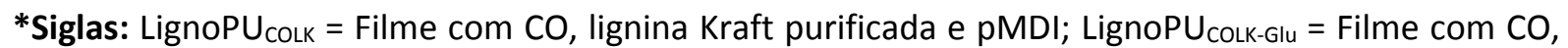
lignina modificada por hidroxialquilação e pMDI.

Em todos os filmes produzidos foi possível verificar o aparecimento de um pico intenso em aproximadamente $2 \theta=19,5^{\circ}-19,7^{\circ}$, evidenciando a formação de regiões ordenadas nos filmes. Os ângulos são próximos ao observado por TROVATI et al. $(2010)\left(2 \theta=19^{\circ}\right)$ em filmes produzidos a partir dà síntese de PUs com poliésteres derivados de óleo de mamona e MDI, em diferentes proporções de $\mathrm{NCO} / \mathrm{OH}$.

As curvas de difração de raios X (Figura 37), e a Tabela 11, revelam uma acentuada diferença na cristalinidade dos filmes formados a $25{ }^{\circ} \mathrm{C}$ em relação aos formados em temperaturas acima da ambiente. 
Tabela 11 - ICr dos filmes LignoPU ${ }_{\text {CoLK30, LignoPU }}$ CoLk-Gluзo, LignoPU $_{\text {CoLk50 e LignoPU }}$ COLK-Glu50, formados em diferentes temperaturas $\left(25,50,75\right.$ e $\left.100^{\circ} \mathrm{C}\right)$

\begin{tabular}{|c|c|c|c|c|}
\hline \multirow{2}{*}{ Filme } & \multicolumn{4}{|c|}{$\operatorname{ICr}(\%)$} \\
\hline & $25^{\circ} \mathrm{C}$ & $50^{\circ} \mathrm{C}$ & $75^{\circ} \mathrm{C}$ & $100^{\circ} \mathrm{C}$ \\
\hline LignoPU $U_{\text {CoLK30 }}$ & 36 & 62 & 61 & 61 \\
\hline LignoPU COLK-Gluзo & 28 & 64 & 63 & 62 \\
\hline LignoPU & 35 & 55 & 55 & 58 \\
\hline LignoPU COLK-Glu50 & 13 & 43 & 58 & 54 \\
\hline
\end{tabular}

Conforme a Tabela 11, a cristalinidade para todos os filmes foi maior quando formados em temperatura acima da ambiente. Cadeias mais extensas podem ter sido formadas nos filmes formados a 50, 75 e $100{ }^{\circ} \mathrm{C}$, aumentando a proporção de segmentos com capacidade de alinhamento com relação aos vizinhos.

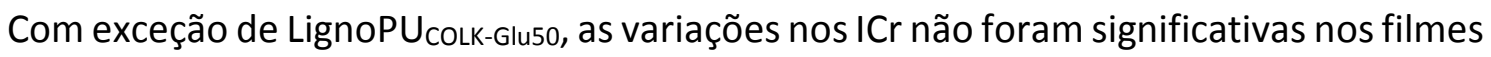
formados simultaneamente à síntese nas temperaturas entre 50,75 e $100^{\circ} \mathrm{C}$.

Considerando uma determinada temperatura, pode-se observar uma tendência de menor cristalinidade para LignoPU ${ }_{\text {COLK50 }}$ e LignoPU COLK-Glu50, comparativamente à LignoPU $_{\text {COLK30 }}$ e LignoPU CoLK-Glu3o, o que pode estar relacionado a maior concentração de LK e LK-Glu (50 \%),

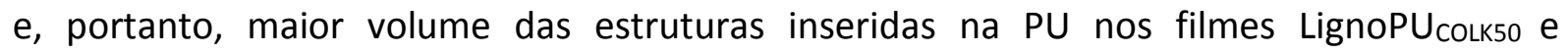

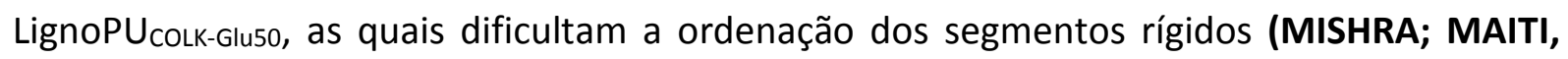
2011).

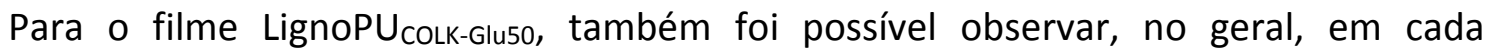
temperatura avaliada, o efeito da inserção do "macromonômero" LK-Glu, que possui massa molar média superior à de LK (LK $=2331 \mathrm{~g} \mathrm{~mol}^{-1} ; \mathrm{LK}-\mathrm{Glu}=4421 \mathrm{~g} \mathrm{~mol}^{-1}$, Item 1.3.1), assim como maior complexidade estrutural, o que dificulta ainda mais a ordenação de segmentos rígidos oriundos de LK-Glu/pMDI.

\subsubsection{Teste de Intumescimento}

A Figura 38 apresenta o gráfico da taxa de intumescimento dos filmes $(S \%)$, formados em $25,50,75$ e $100{ }^{\circ} \mathrm{C}$, utilizando DMF como solvente. 
Figura 38 - Taxa de Intumescimento $(\mathrm{S} \%)$ dos filmes formados simultaneamente à síntese realizada a partir de (a) $30 \%$ de LK e LK-Glu e (b) $50 \%$ de LK e LK-Glu nas temperaturas de $25,50,75$ e $100{ }^{\circ} \mathrm{C}$, utilizando DMF como sovente. Números $1,2,3,4,5,6$, 7 e 8 correspondem a LignoPU colk_25, $_{\text {, }}$ LignoPU COLK-Glu_25, LignoPU $_{\text {CoLK_50, LignoPU }}$ COLK-Glu_50, LignoPU $_{\text {COLK_75, LignoPU }}$ COLK-Glu_75,

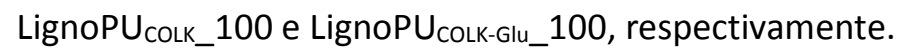

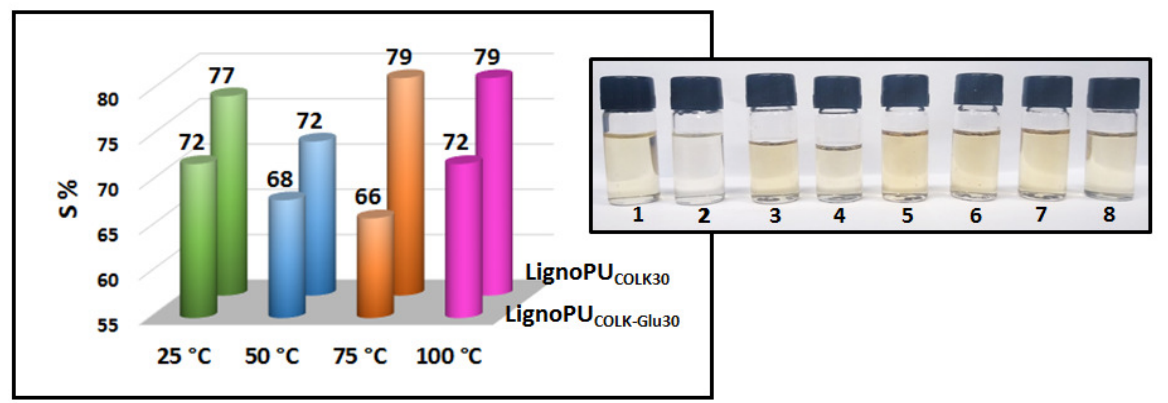

(a)

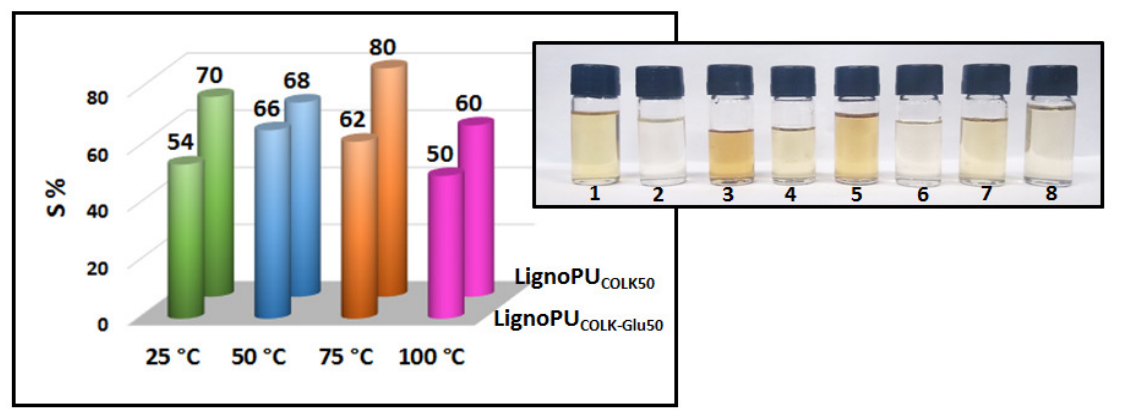

(b)

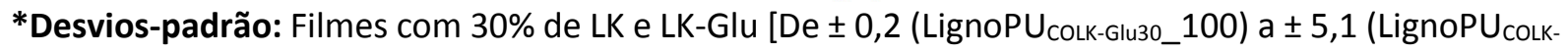
Glu30_25)]; Filmes com 50\% de LK e LK-Glu [De \pm 0,7 (LignoPU colk50_100) a \pm 5,6 (LignoPU $_{\text {colk50_50)] }}$

*Siglas: LignoPU $_{\text {CoLK }}=$ Filme com CO, lignina Kraft purificada e pMDI; LignoPU ${ }_{\text {COLK-Glu }}=$ Filme com CO, lignina modificada por hidroxialquilação e pMDI.

Conforme observado na Figura 38 a, os valores de S\% para os filmes formados a partir de $30 \%$ de LK e LK-Glu nas diferentes temperaturas foram próximos, indicando que nesses filmes o aumento da temperatura não influenciou o volume livre disponível para acomodar as moléculas de solvente.

A cristalinidade é um fator que impacta negativamente na $S \%$, em função da ordenação das cadeias da região cristalina, o que dificulta a penetração do solvente (MILLER-CHOU; KOENIG, 2003). Como reportado no Item 1.3.3.4, houve um acréscimo na cristalinidade de 41,9 e $56,2 \%$, respectivamente, nos filmes LignoPU CoLK30 $_{\text {e LignoPU }}$ COLK-Glu30 formados a $50{ }^{\circ} \mathrm{C}$ em relação à temperatura ambiente. Todavia, a $\mathrm{S} \%$ apresentou apenas uma tendência à redução nesses filmes (Figura 38 a), evidenciando que esse fator não impactou de maneira significativa o intumescimento. 
Já a Figura $38 \mathrm{~b}$ mostra que na temperatura de $100{ }^{\circ} \mathrm{C}$ os filmes LignoPU $\mathrm{COLK50}(60 \pm 1 \%)$ e LignoPU $U_{\text {CoLk-Glu50 }}(50 \pm 1 \%)$ apresentaram um tendência à diminuição na $S \%$. Reações paralelas, como as que formam alofanatos, podem ocorrer nessa temperatura, principalmente quando isocianatos aromáticos são utilizados (Figura 35) (DUSEK; SPIRKOVA, 1990; YILGOR et al., 2015). Essas ligações, se presentes, podem ocasionar a redução na S\% desses materiais.

A presença de ligações cruzadas influencia diretamente a morfologia e as propriedades de materiais, como filmes. Porém, a temperatura é apenas um dos fatores que leva a ocorrência de reações paralelas e entrecruzamentos na estrutura das mesmas. A extensão das reações secundárias também é fortemente dependente do tipo de isocianato (aromático ou alifático), da proporção NCO/OH usada, do solvente e do catalisador, se utilizados (KROL, 2007). No presente estudo, o conjunto de resultados indica que variações no volume livre parecem ser o fator que mais impacta o intumescimento dos filmes.

A coloração das soluções de DMF após o término do teste de intumescimento dos filmes formados a partir de $30 \%$ e 50 \% de LK e LK-Glu, mostrada na Figura 38 a e b, revela um escurecimento da solução conforme o acréscimo da temperatura em que os filmes foram formados, causado, provavelmente pela solubilização de PUs de menor massa molar média presentes nos filmes. Nos filmes formados a partir de $50 \%$ de LK e LK-Glu esse escurecimento se deu de forma mais intensa nas temperaturas de 50 e $75^{\circ} \mathrm{C}$. Entretanto as soluções de DMF dos filmes produzidos utilizando PUs sintetizadas com LK-Glu são mais claras, comparativamente as soluções de DMF dos filmes produzidos utilizando PUs sintetizadas com LK nas mesmas concentrações. Esse resultado deve ser consequência de menor proporção de PUs de menor massa molar média quando LK-Glu foi usada, devido ao fato que o "macromonômero" já possuía alta massa molar média.

\subsubsection{6 Ângulo de Contato}

Na Figura 39 estão apresentados os ângulos medidos no instante em que a gota se depositou nos filmes (AA) e ao final da análise (AR). 
Figura 39 - AA e AR para os filmes LignoPU coLk-Glu30, LignoPU $_{\text {Colk-Glu50, LignoPU }}$ CoLk30 $_{\text {e LignoPU }}$ CoLk50

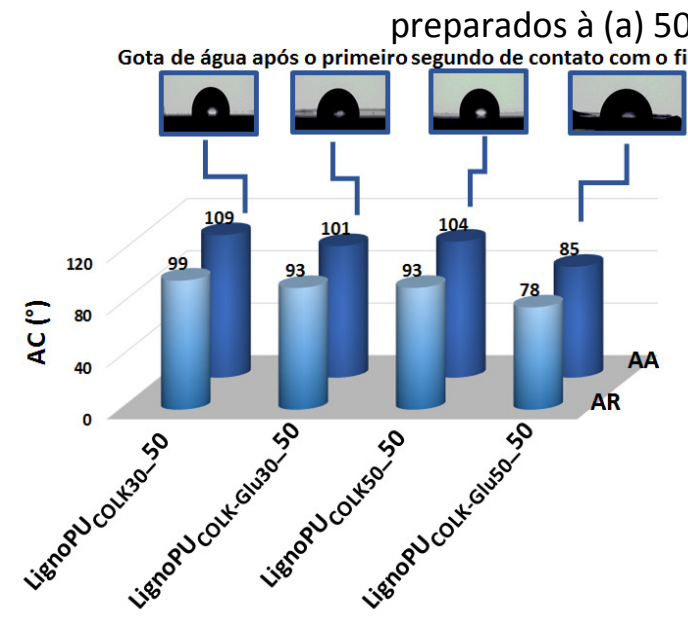

(a)

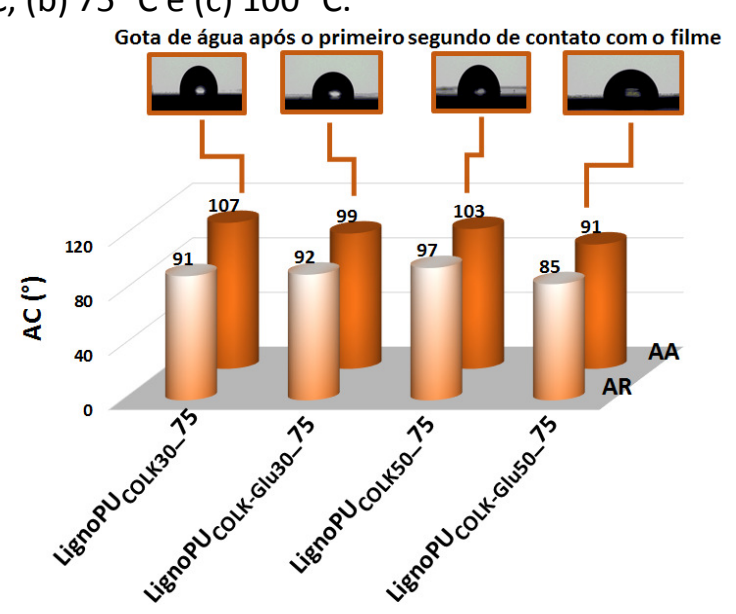

(b)

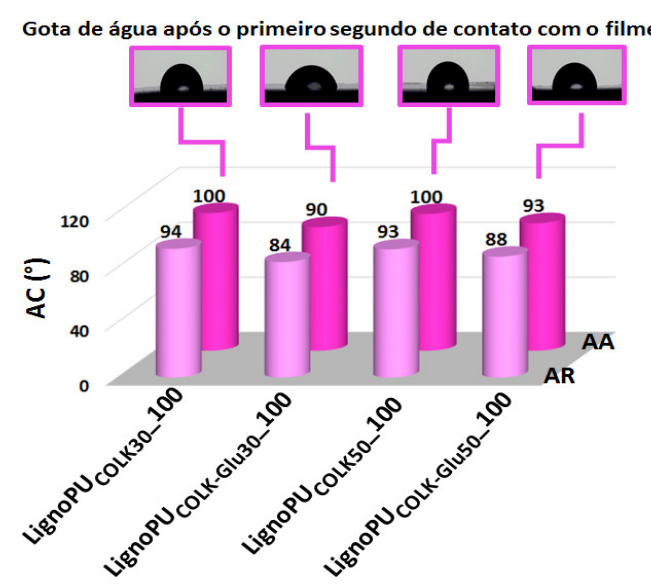

(c)

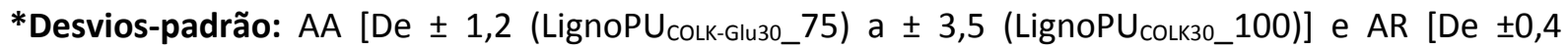
(LignoPU $U_{\text {colk-Glu30_75) a } \pm 4,5 \text { (LignoPU }}$ Colk30_75)].

*Siglas: LignoPU ${ }_{\text {CoLK }}=$ Filme com CO, lignina Kraft purificada e pMDI; LignoPU coLk-Glu $_{\text {Filme }}$ com CO, lignina modificada por hidroxialquilação e pMDI.

Os resultados para $A A$ dos filmes LignoPU CoLk30, LignoPU $_{\text {CoLk50, LignoPU }}$ COLK-Glu30 e

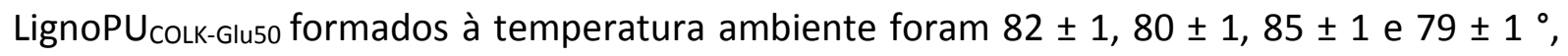
respectivamente. Os resultados de AA (Figura 39) mostraram que o uso de temperatura acima da ambiente na síntese dessas PUs, de maneira geral, conferiu um caráter mais hidrofóbico às superfícies dos filmes, uma vez que o AA ficou em média próximo dos $100^{\circ}$, enquanto para os mesmos filmes formados à temperatura ambiente o AA ficou muito próximo ou abaixo de $90^{\circ}$ (Figura 32, Item 1.3.2.6). Este resultado indica que em temperaturas acima da ambiente os filmes foram formados com maior proporção de domínios hidrofóbicos voltados para a superfície, comparativamente aos formados à temperatura ambiente. 
Os filmes LignoPU $U_{\text {CoLK30, LignoPU }}$ COLK-Glu30, LignoPU $_{\text {CoLk50 e LignoPU }}$ CoLK-Glu50 $_{\text {preparados a }}$ $50{ }^{\circ} \mathrm{C}$ apresentaram histerese de $10,8,11$ e $7^{\circ}$, respectivamente, enquanto os preparados a $100{ }^{\circ} \mathrm{C}$ apresentaram histerese de $6,6,7$ e $5^{\circ}$, respectivamente. Isso revela uma tendência ao decréscimo na histerese com o aumento da temperatura durante a reação de polimerização, indicando que o uso temperaturas mais altas na síntese das PUs levou a formação de filmes com superfícies mais lisas e homogêneas.

\subsubsection{Análise Dinâmico-Mecânica}

A Figura 40 apresenta as curvas Tan $\delta$ versus temperatura para os filmes formados a partir de PUs sintetizadas com $30 \%$ de LK ou LK-Glu nas temperaturas de $25,50,75$ e $100{ }^{\circ} \mathrm{C}$. Destaca-se que a decomposição térmica dos filmes considerados inicia acima de $300{ }^{\circ} \mathrm{C}$ (Tabela 9), ou seja, acima do intervalo considerado para DMA.

Figura 40 - Curvas Tan- $\delta$ para os filmes formados simultaneamente à síntese realizada a partir de (a) $30 \%$ de LK e (b) $30 \%$ de LK-Glu nas temperaturas de $25,50,75$ e $100^{\circ} \mathrm{C}$.

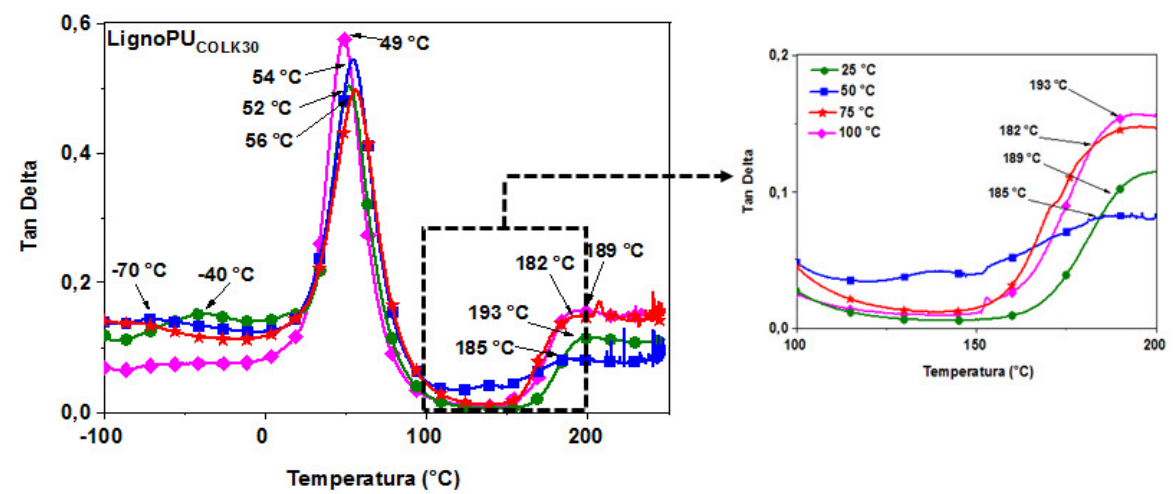

(a)
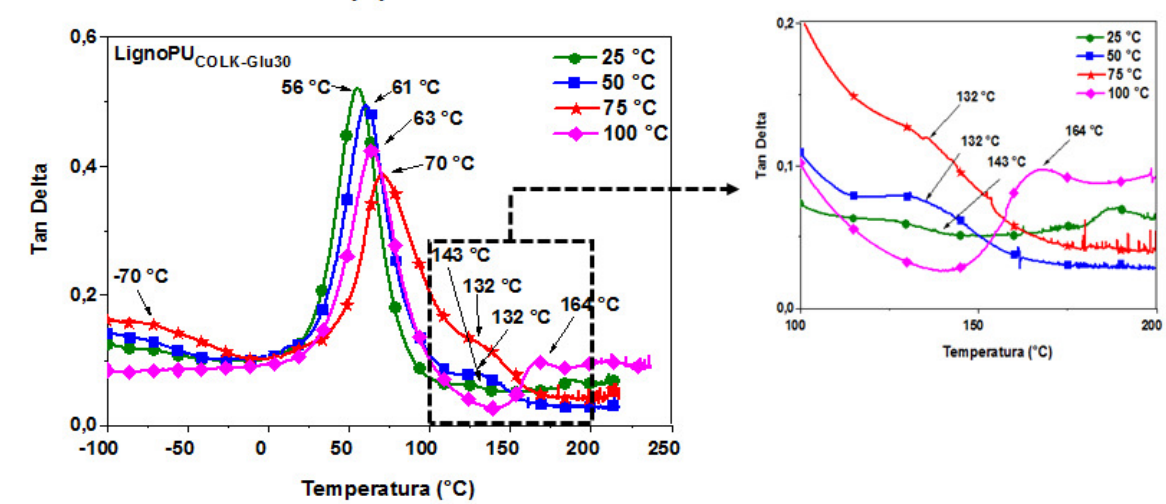

(b)

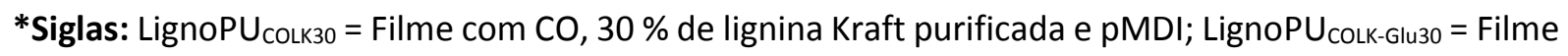
com CO, 30 \% de lignina modificada por hidroxialquilação e pMDI. 


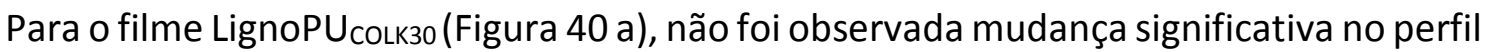
da curva Tan- $\delta$ e nos valores das $T_{\mathrm{g}}$ referentes aos domínios flexíveis ( $1^{\circ}$ pico) e rígidos $\left(2^{\circ}\right.$ pico) em função do aumento da temperatura da reação em que os filmes analisados foram formados, em relação aos formados à temperatura ambiente. A Tabela 12 apresenta os valores das $T_{\mathrm{g}}$ s referentes aos picos das curvas Tan- $\delta$ para os filmes formados a partir de $30 \%$ de LK ou LK-Glu, nas diferentes temperaturas em que os filmes foram formados $(25,50,75$ e $\left.100^{\circ} \mathrm{C}\right)$.

Tabela $12-T_{\mathrm{g}} \mathrm{s}$ (pico Tan- $\delta$ ) para os filmes formados simultaneamente as sínteses realizadas a partir de $30 \%$ de LK ou LK-Glu nas temperaturas de $25,50,75$ e $100{ }^{\circ} \mathrm{C}$

\begin{tabular}{|c|c|c|c|c|}
\hline \multirow{2}{*}{ Pico } & \multicolumn{4}{|c|}{$T_{\mathrm{g}}\left({ }^{\circ} \mathrm{C}\right)$} \\
\hline & LignoPU ${ }_{\text {COLK30_25 }}$ & LignoPU & LignoPU & LignoPU ${ }_{\text {CоLK30_100 }}$ \\
\hline $1^{\circ}$ & 52 & 54 & 56 & 49 \\
\hline \multirow[t]{2}{*}{$2^{\circ}$} & 193 & 185 & 182 & 189 \\
\hline & LignoPU $U_{\text {CoLK-Glu30_25 }}$ & LignoPU ${ }_{\text {CoLK-Glu30_50 }}$ & LignoPU COLK-Glu30_75 & LignoPU ${ }_{\text {COLK-Glu30_100 }}$ \\
\hline $1^{\circ}$ & 56 & 61 & 70 & 63 \\
\hline $2^{\circ}$ & 143 & 132 & 132 & 164 \\
\hline
\end{tabular}

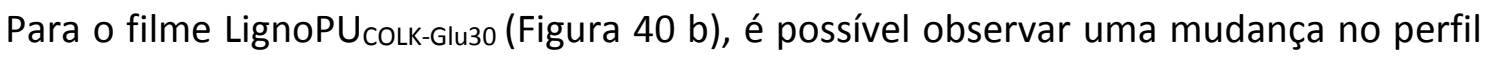
da curva de Tan- $\delta$ em função do aumento na temperatura de síntese. Na curva de LignoPU $U_{\text {colk- }}$ Gluzo formado a $75^{\circ} \mathrm{C}$ foi possível perceber o aparecimento de apenas um pico, indicando uma maior extensão da região onde os domínios rígidos e flexíveis da fase amorfa se misturaram

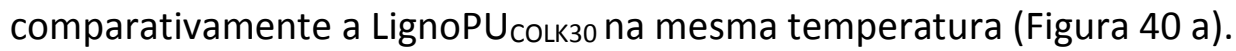

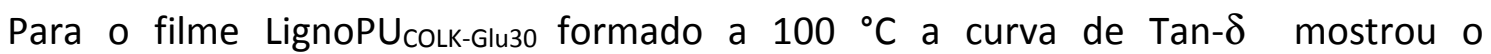
aparecimento de dois picos, sugerindo segregação das fases (soft e hard). Como a LK-Glu,

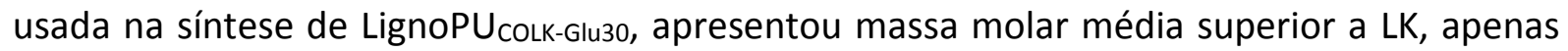
uma temperatura mais alta $\left(100{ }^{\circ} \mathrm{C}\right)$ favoreceu o surgimento de segmentos rígidos mais extensos que proporcionaram uma maior segregação de fases.

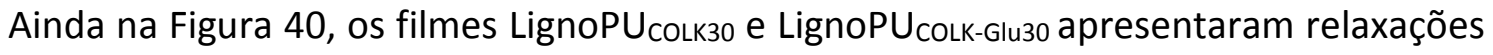
$\beta$, ou seja, rotações em torno de ligações simples de grupos, e que antecedem a $T_{\mathrm{g}}$ (LORANDI et al., 2016).

A Figura 41 apresenta as curvas Tan- $\delta$ versus temperatura para os filmes formados a partir de $50 \%$ de LK ou LK-Glu e pMDI nas temperaturas de $25,50,75$ e $100{ }^{\circ} \mathrm{C}$. Destaca-se 
que a decomposição térmica dos filmes considerados inicia acima de $300{ }^{\circ} \mathrm{C}$ (Tabela 10), ou seja, acima do intervalo considerado para DMA

Figura 41 - Curvas Tan- $\delta$ para os filmes formados simultaneamente à síntese realizada a partir de (a) $50 \%$ de LK e (b) $50 \%$ de LK-Glu nas temperaturas de $25,50,75$ e $100^{\circ} \mathrm{C}$.

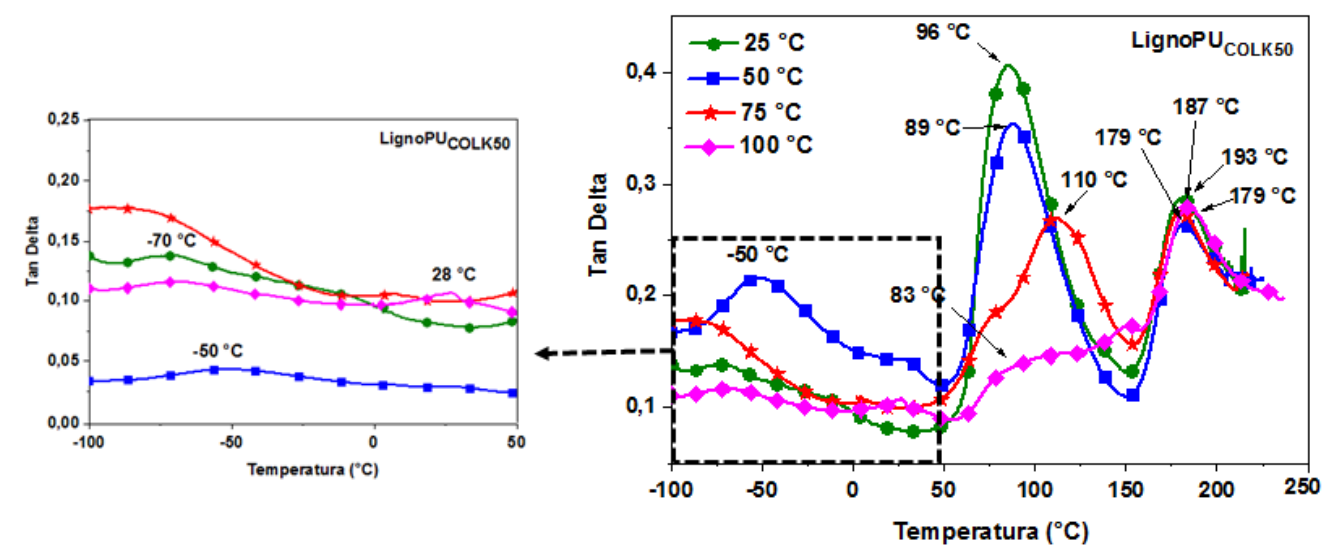

(a)
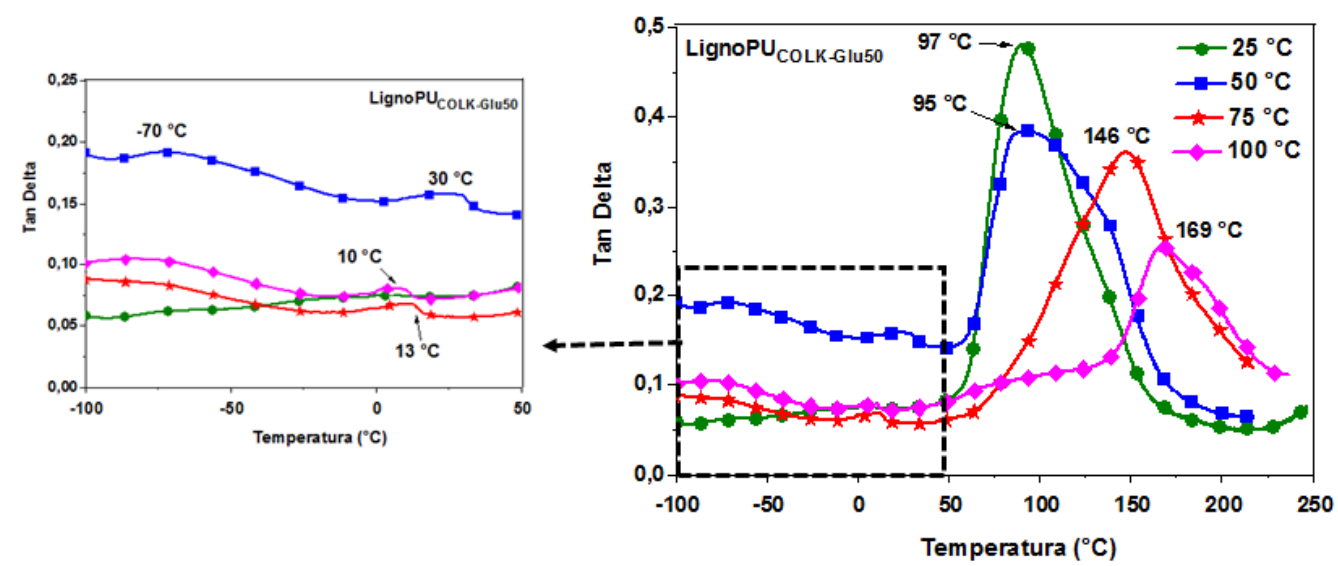

(b)

*Siglas: LignoPU CoLK50 $_{\text {= Filme com CO, } 50 \text { \% de lignina Kraft purificada e pMDI; LignoPU }}$ CoLK-Glu50 $_{\text {= Filme }}$ com $\mathrm{CO}, 50$ \% de lignina modificada por hidroxialquilação e pMDI.

A Figura 41 a mostra que o aumento da temperatura no preparo da LignoPU CoLk50 ocasionou uma diminuição na intensidade do $1^{\circ}$ pico $\left(1^{\circ} T_{\mathrm{g}}\right)$, ou seja, o relaxamento de uma menor quantidade de segmentos flexíveis. Também foi possível perceber o alargamento do $1^{\circ}$ pico, principalmente nas temperaturas de 75 e $100{ }^{\circ} \mathrm{C}$, indicando que os segmentos envolvidos na relaxação não eram tão similares estruturalmente. A Tabela 13 apresenta os valores de $T_{\mathrm{g}}$ referentes ao pico da curva Tan $\delta$ para os filmes formados em sínteses realizadas a partir de $50 \%$ de LK ou LK-Glu, nas diferentes temperaturas avaliadas $\left(25,50,75\right.$ e $\left.100{ }^{\circ} \mathrm{C}\right)$. 
Tabela 13 - $T_{\mathrm{g}}$ ( (pico Tan- $\delta$ ) para filmes formados simultaneamente à síntese realizada a partir de $50 \%$ de LK ou LK-Glu nas temperaturas de $25,50,75$ e $100^{\circ} \mathrm{C}$

\begin{tabular}{|c|c|c|c|c|}
\hline \multirow{2}{*}{ Pico } & \multicolumn{4}{|c|}{$T_{\mathrm{g}}\left({ }^{\circ} \mathrm{C}\right)$} \\
\hline & LignoPU ${ }_{\text {COLK50_25 }}$ & LignoPU $U_{\text {COLK50_50 }}$ & LignoPU ${ }_{\text {colk50_75 }}$ & LignoPU ${ }_{\text {Colk50_100 }}$ \\
\hline $1^{\circ}$ & 96 & 89 & 110 & 83 \\
\hline \multirow[t]{2}{*}{$2^{\circ}$} & 193 & 179 & 179 & 187 \\
\hline & LignoPU $_{\text {CoLK-Glu50_25 }}$ & LignoPU ${ }_{\text {CoLK-Glu50_50 }}$ & LignoPU CoLK-Glu50_75 $_{15}$ & LignoPU ${ }_{\text {COLK-Glu50_100 }}$ \\
\hline $1^{\circ}$ & 97 & 95 & 146 & 169 \\
\hline $2^{\circ}$ & -- & --- & --- & --- \\
\hline
\end{tabular}

Ainda na Figura 41, os filmes LignoPU CoLk50 e LignoPU $_{\text {CoLk-Glu50 }}$ apresentaram relaxações $\beta$, ou seja, rotações em torno de ligações simples de grupos, e que antecedem a $T_{\mathrm{g}}$ (LORANDI et al., 2016).

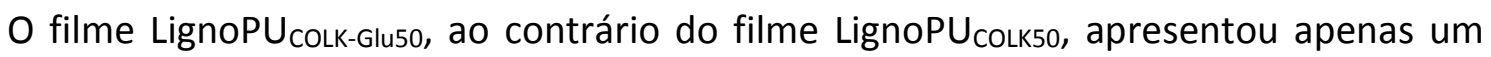
pico, largo, na curva de Tan- $\delta$ (Figura 41 b) em todas temperaturas avaliadas, indicando que as fases rígidas e flexíveis se misturaram neste filme, como discutido no Item 1.3.2.7. Observase que, a formação do filme LignoPU COLK-Glu50 $\mathrm{em}$ temperaturas mais altas (75 e $100{ }^{\circ} \mathrm{C}$ ) levou ao deslocamento das $T_{\mathrm{g} S}$ para valores maiores (146 e $169{ }^{\circ} \mathrm{C}$, respectivamente, Tabela 13), entretanto a intensidade dos picos foi inferior à das preparadas a 25 e $50^{\circ} \mathrm{C}$ ( 97 e $95^{\circ} \mathrm{C}$, Tabela 13), sugerindo menor número de segmentos flexíveis e rígidos misturados na fase não cristalina nos filmes formados nas mais altas temperaturas.

A Figura 42 apresenta o módulo de armazenamento $\left(E^{\prime}\right)$, a $25^{\circ} \mathrm{C}$, dos filmes LignoPU $U_{\text {CoLK30, LignoPU }}$ CoLK50, LignoPU COLK-Glu30 e LignoPU $_{\text {CoLK-Glu50 }}$ formados nas temperaturas de 50,75 e $100^{\circ} \mathrm{C}$.

Figura 42 - Módulo de Armazenamento $\left(E^{\prime}\right)$ a $25{ }^{\circ} \mathrm{C}$ dos filmes formados simultaneamente à síntese realizada a partir de (a) $30 \%$ de LK e LK-Glu e (b) $50 \%$ de LK e LK-Glu nas temperaturas de 50,75 e $100^{\circ} \mathrm{C}$.
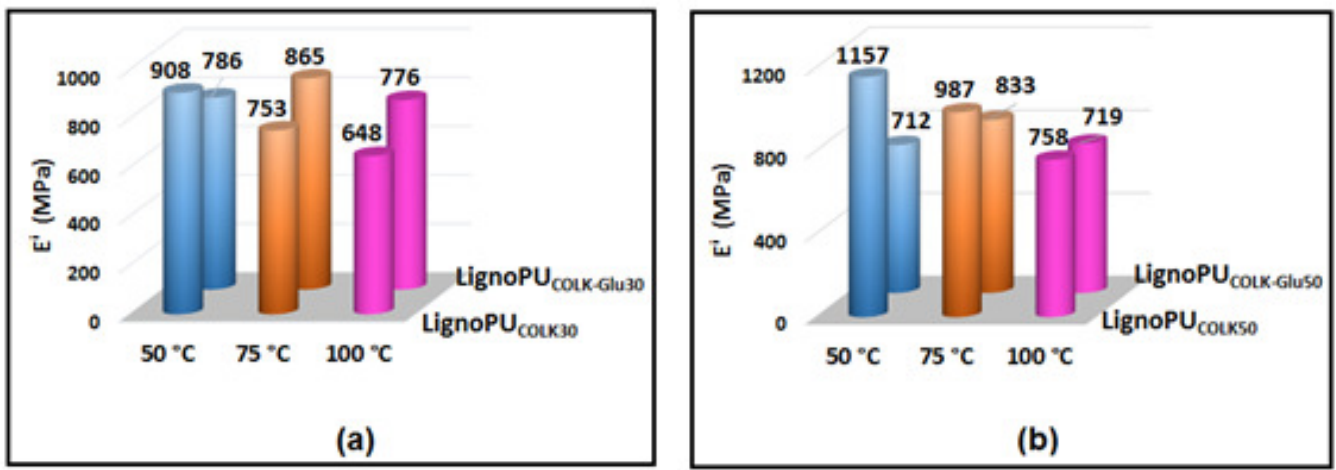

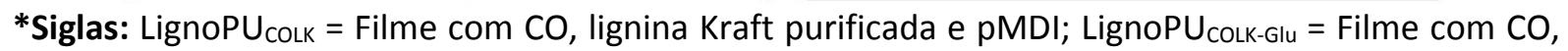
lignina modificada por hidroxialquilação e pMDI. 
Na temperatura ambiente $\left(25^{\circ} \mathrm{C}\right)$, na qual os valores de $\mathrm{E}^{\prime}$ estão apresentados, todos os filmes formados (30\% e $50 \%$ de LK e LK-Glu) nas temperaturas de $25,50,75$ e $100{ }^{\circ} \mathrm{C}$ se encontravam no estado rígido, uma vez que os valores de $T_{\mathrm{g}}$ observados para esses filmes estão acima de $25^{\circ} \mathrm{C}$ (Tabelas 12 e 13).

A Figura 42 a mostra que, de maneira geral, o aumento na temperatura durante à síntese das PUs realizadas a partir de $30 \%$ de LK ou LK-Glu não impactou de maneira significativa os valores de $E^{\prime}$ dos filmes, uma vez que os valores de $E^{\prime}$ dos filmes formados nas mais altas temperaturas, mantiveram-se no mesmo patamar dos filmes formados à temperatura ambiente (LignoPU ${ }_{\text {CoLk30_25 }}=833 \mathrm{MPa}$; LignoPU CoLK-Glu30_25 = $688 \mathrm{MPa}$ ).

Apesar da cristalinidade (Item 1.3.3.4), um fator que pode levar a um aumento no E' de

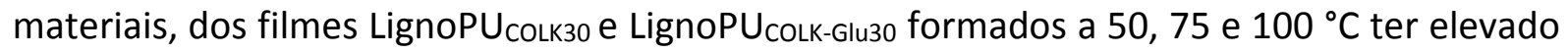

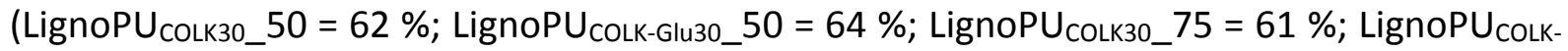
Glu30_75 = $63 \%$; LignoPU ${ }_{\text {CoLk30_100 = } 61 \% \text {; LignoPU }}$ CoLk-Glu30_100 = 62 \%) em relação aos

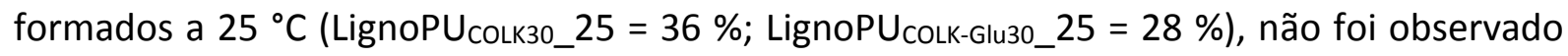
aumento significativo no $E^{\prime}$, inferindo que a cristalinidade não impactou nessa propriedade.

A Figura 42 b mostrou uma tendência ao decréscimo no $E^{\prime}$ dos filmes formados a partir

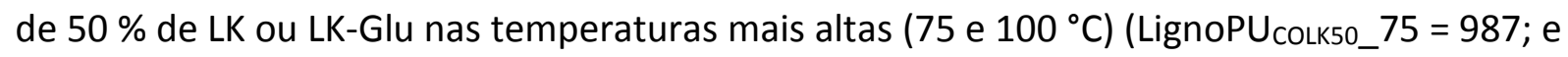
LignoPU COLK-Glu50_75 = 833 MPa; LignoPU $_{\text {COLK50_100 = } 758 \text { MPa e LignoPU }}$ CoLK-Glu50_100 = 719

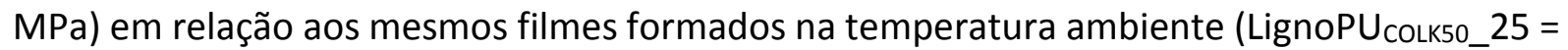
1034 e LignoPU CoLK-Glu50_25 = $1092 \mathrm{MPa}$ ), mesmo os valores estando todos no mesmo patamar. Novamente aqui, o aumento na cristalinidade (Item 1.3.3.4), de aproximadamente

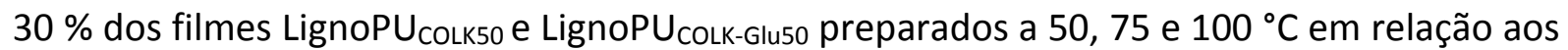
preparados a $25^{\circ} \mathrm{C}$ não pode ser correlacionado ao E' desses filmes.

As micrografias da superfície de fratura de LignoPU CoLk50_100 e LignoPU $_{\text {CoLK-Glu50_100 }}$ apresentaram maior rugosidade em relação aos filmes formados a $25^{\circ} \mathrm{C}$ (MEV; Item 1.3.3.2, Figura 36), entretanto, o resultado da análise de MEV não pode ser relacionado aos valores de $\mathrm{E}^{\prime}$, que foram inferiores para os filmes formados a $100^{\circ} \mathrm{C}$.

\subsubsection{Propriedades de Tração}

Previamente, no item 1.3.2.8 foram descritos os resultados obtidos para as propriedades de tração dos filmes formados simultaneamente às sínteses utilizando CO, LK ou LK-Glu $(0,10,30$ e $50 \%)$ e pMDI, $25{ }^{\circ} \mathrm{C}$. Com o objetivo de avaliar a influência da 
temperatura na reação de polimerização, neste item são descritos os resultados obtidos para as propriedades de tração dos filmes formados simultaneamente às sínteses utilizando CO e 30 e $50 \%$ de LK ou LK-Glu e pMDI, em temperaturas acima da ambiente $\left(50,75\right.$ e $\left.100^{\circ} \mathrm{C}\right)$.

A Figura 43 apresenta os resultados de resistência a tração, módulo de Young e alongamento na ruptura dos filmes lignopoliuretânicos formados a partir de 30 \% de LK ou LKGlu e pMDI (LignoPU ${ }_{\text {Colk e LignoPU }}$ CoLk-Glu) nas temperaturas de $25,50,75$ e $100{ }^{\circ} \mathrm{C}$.

É importante salientar que os filmes formados a partir de $30 \%$ de LK e LK-Glu a 25, 50, 75 e $100^{\circ} \mathrm{C}$ romperam todos nas mesmas condições, ou seja, possuíam as mesmas dimensões de corpo de prova (1,5 mm largura x $5 \mathrm{~mm}$ distância entre garras x 0,65 mm espessura).

Figura 43 - (a) Resistência a ruptura, (b) módulo de Young e (c) alongamento na ruptura dos filmes formados simultaneamente à síntese realizada a partir de $30 \%$ de LK e LK-Glu nas temperaturas de $25,50,75$ e $100{ }^{\circ} \mathrm{C}$.

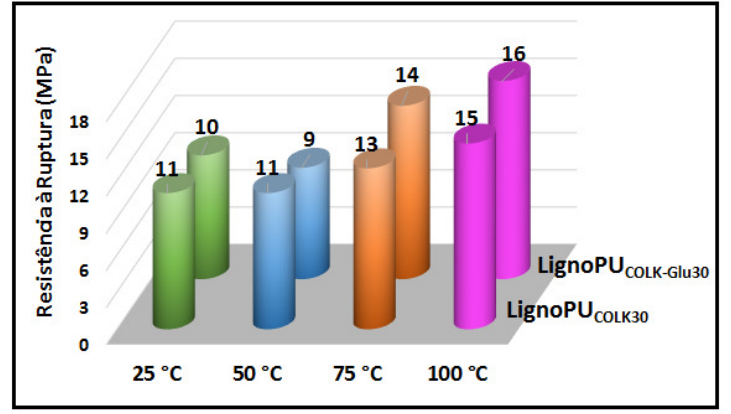

(a)

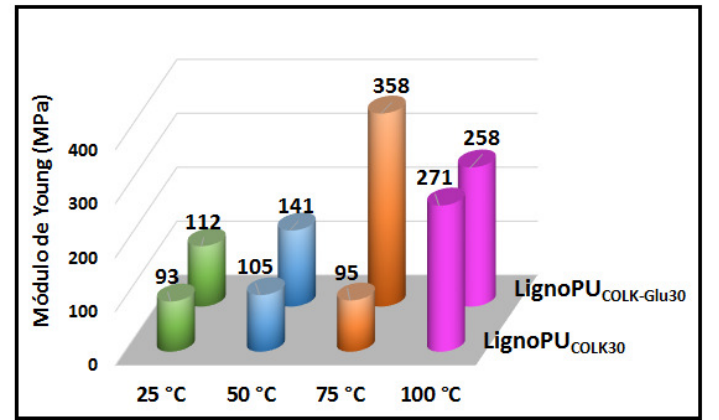

(b)

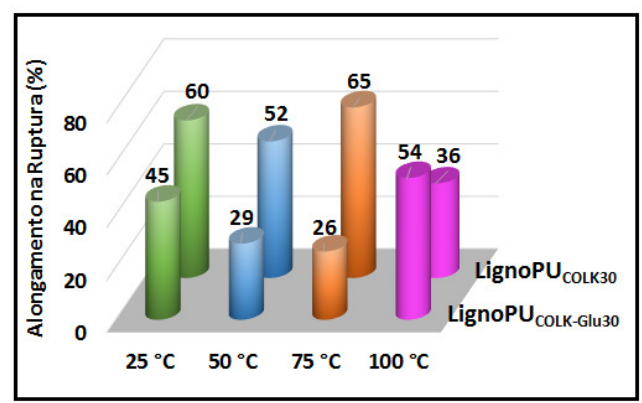

(c)

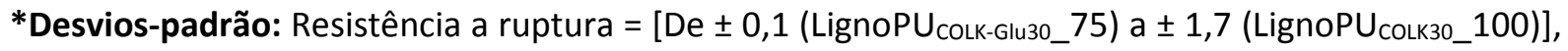
módulo de Young $=\left[\right.$ De $\pm 1,0$ (LignoPU $U_{\text {Colk-Glu30_100) a } \pm 10,0 \text { (LignoPU }}$ CoLk30_100)] e alongamento na ruptura $=\left[\right.$ De $\pm 0,3$ (LignoPU CoLK-Glu30_50) a \pm 3,5 (LignoPU $_{\text {CoLk30_100)] }}$.

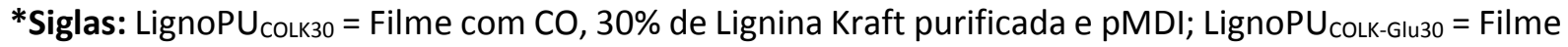
com CO, 30\% de lignina modificada por hidroxialquilação e pMDI.

O ensaio de tração foi conduzido a $25^{\circ} \mathrm{C}$, e nessa temperatura os filmes formados simultaneamente as sínteses realizadas a partir de $30 \%$ de LK ou LK-Glu nas temperaturas de 
$25,50,75$ e $100{ }^{\circ} \mathrm{C}$ ainda se encontravam no estado rígido, uma vez que os valores de $T_{\mathrm{g}}$ observados para esses filmes estão acima de $49^{\circ} \mathrm{C}$ (Tabela 12).

O gráfico de resistência à ruptura (Figura 43 a) mostra que para os filmes LignoPU COLK30 e LignoPU Colk-Glu30 $\mathrm{O}$ aumento da temperatura de síntese de $25^{\circ} \mathrm{C}$ para $50{ }^{\circ} \mathrm{C}$ não influenciou essa propriedade, já que os valores observados são semelhantes.

A cristalinidade é um fator que geralmente provoca um aumento na resistência a ruptura dos materiais, devido à organização das cadeias nos domínios cristalinos (TROVATI et al., 2010). Apesar de ter sido observado um acréscimo na cristalinidade dos filmes LignoPU ${ }_{\text {CoLK30 e LignoPU }}$ ColK-Gluzo preparados a $50{ }^{\circ} \mathrm{C}$ (LignoPU CoLK30_50 $=62 \%$; LignoPU $_{\text {COLK- }}$ Glu30_50 = 64 \%) em relação à temperatura ambiente (Item 1.3.3.4; LignoPU

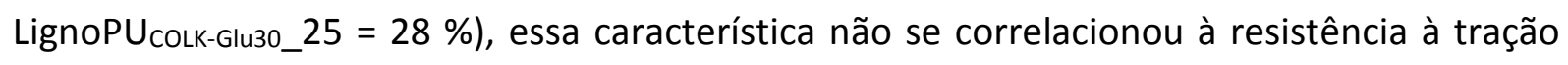
para essas amostras.

Considerando filmes formados simultaneamente as sínteses realizadas a 75 e $100{ }^{\circ} \mathrm{C}$, a

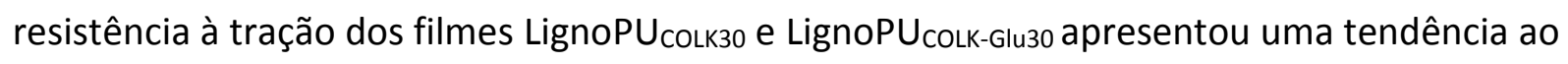
aumento (Figura 43 a) em relação aos formados em temperaturas mais baixas, principalmente nos filmes em que LK-Glu foi utilizada como reagente.

Os valores para módulo de Young observados para os filmes LignoPU CoLK30 e LignoPU $_{\text {COLK- }}$ Glu30 formados simultaneamente as sínteses realizadas a 75 e $100{ }^{\circ} \mathrm{C}$ também aumentaram, sendo que a amostra LignoPUCoLk-Glu30_75 apresentou o valor mais alto para esse parâmetro (358 $\pm 7 \mathrm{MPa}$ ) (Figura $43 \mathrm{~b}$ ). Considerando os resultados de cristalinidade, das $T_{\mathrm{g}}$ s obtidas via análise de DMA (Item 1.3.3.7) e teste de intumescimento (Item 1.3.3.5), os aumentos na resistência a ruptura e módulo de Young observados principalmente nas temperaturas mais altas avaliadas $\left(75\right.$ e $100^{\circ} \mathrm{C}$ ), provavelmente estão relacionados a formação de uma estrutura de domínios flexíveis e rígidos mais resistente nessas temperaturas do que nas temperaturas mais baixas.

O alongamento na ruptura para os filmes LignoPU CoLk30 e LignoPU $_{\text {COLK-Gluzo formados em }}$ diferentes temperaturas $\left(25,50,75\right.$ e $\left.100{ }^{\circ} \mathrm{C}\right)$ está apresentado na Figura 43 c. Os filmes formados a $50{ }^{\circ} \mathrm{C}$ mostraram um decréscimo no alongamento na ruptura em comparação aos formados à temperatura ambiente, que pode estar relacionado ao aumento no $\mathrm{ICr}$ desses

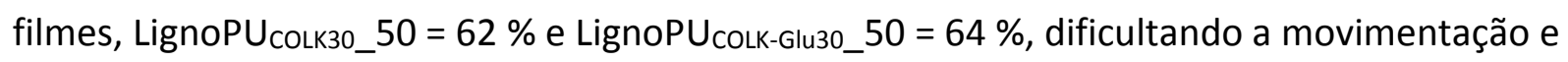

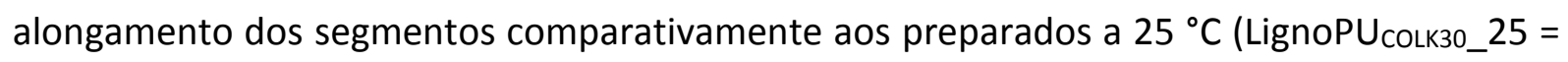
$36 \%$ e LignoPU COLK-Glu30_25 = $28 \%$ ) 


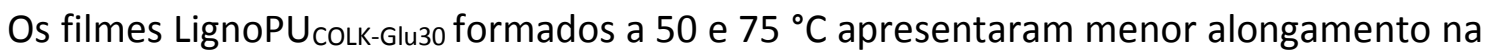

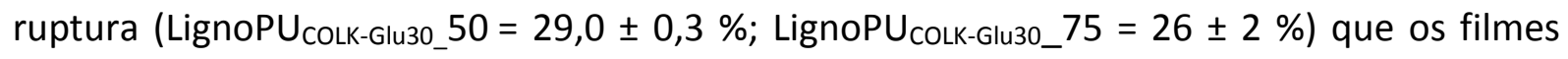

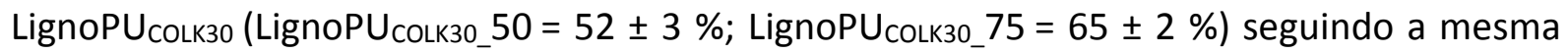
tendência observada para esse parâmetro nos filmes formados a partir dessa proporção de de LK ou LK-Glu a $25^{\circ} \mathrm{C}$. A análise de DMA (Item 1.3.3.7, Figura 40) dos filmes LignoPU mostrou o aparecimento de dois picos na curva Tan- $\delta$, ou seja, duas $T_{\mathrm{g}} \mathrm{s}$, evidenciando uma segregação de fases, em domínios soft e hard. Esses picos se encontravam em temperaturas bem distintas, indicando que esses domínios não estão misturados. Isso pode ter possibilitado que os segmentos flexíveis da PU se movimentaram mais livremente e consequentemente aumentarem o alongamento. É importante destacar que esses filmes ainda estavam em seu estado rígido durante esta análise, como mencionado.

Com relação aos filmes formados a $100{ }^{\circ} \mathrm{C}$, o alongamento na ruptura do filme LignoPU $U_{\text {CoLK-Gluзo foi superior (54 } \pm 2 \%) \text { ao encontrado para LignoPU }}$ COLK30 $(36,0 \pm 3,5 \%)$. Segundo a curva Tan- $\delta$ (DMA, Item 1.3.3.7, Figura 40), o filme LignoPU $U_{\text {CoLk-Glu30_100 }}$ apresentou a maior segregação de fases entre os filmes formados a partir de PUs sintetizadas com $30 \%$ de LK-Glu, ou seja, duas $T_{\mathrm{g}}$ s, em temperaturas bem distintas ( $T_{\mathrm{g}}$ 1ㅇ pico $=63{ }^{\circ} \mathrm{C}$; $T_{\mathrm{g} \text { 2o }}$ pico $=164{ }^{\circ} \mathrm{C}$ ). Como na LK-Glu foram introduzidas cadeias alifáticas provenientes do glutaraldeído (Figura 14), mais flexíveis que os anéis aromáticos, esse resultado indica que, apenas nos filmes formados simultaneamente à síntese realizada a $100{ }^{\circ} \mathrm{C}$, a modificação química realizada na LK-Glu possibilitou uma segregação dos domínios flexíveis e rígidos na PU que permitiram o aumento na resistência à ruptura necessário para promover o aumento no alongamento na ruptura em relação à LignoPU CoLk30_100.

A Figura 44 apresenta os resultados de resistência a tração, módulo de Young e alongamento na ruptura dos filmes lignopoliuretânicos formados simultaneamente à síntese

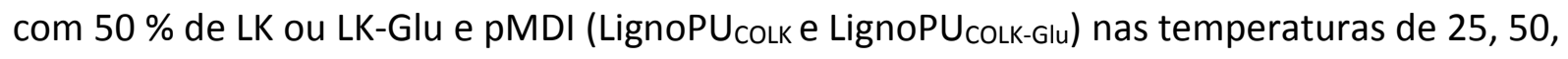
75 e $100{ }^{\circ} \mathrm{C}$.

Destaca-se que os filmes formados a partir de $50 \%$ de LK e LK-Glu a 25, 50, 75 e $100{ }^{\circ} \mathrm{C}$ possuíam a mesma medida dos corpos de prova para esse ensaio $(1,5 \mathrm{~mm}$ largura $\times 5 \mathrm{~mm}$ distância entre garras x 0,65 mm espessura). 
Figura 44 - (a) Resistência a ruptura, (b) módulo de Young e (c) alongamento na ruptura dos filmes formados simultaneamente à síntese realizada a partir de $50 \%$ de LK e LK-Glu nas temperaturas de $25,50,75$ e $100^{\circ} \mathrm{C}$.

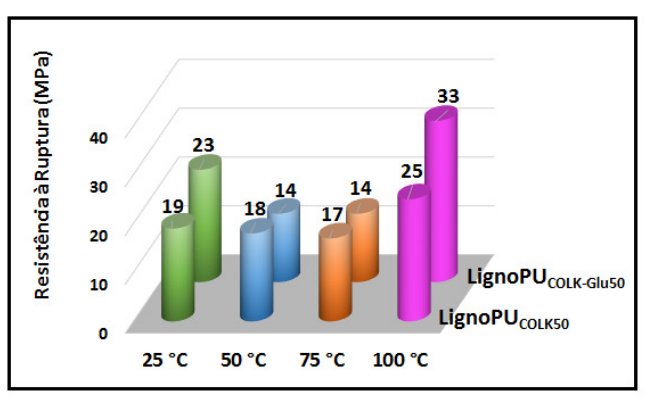

(a)

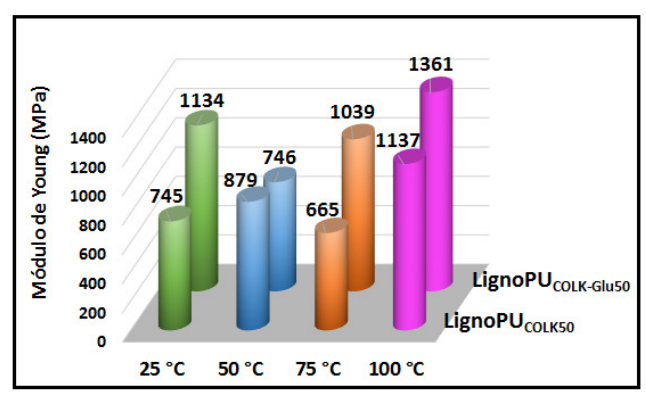

(b)

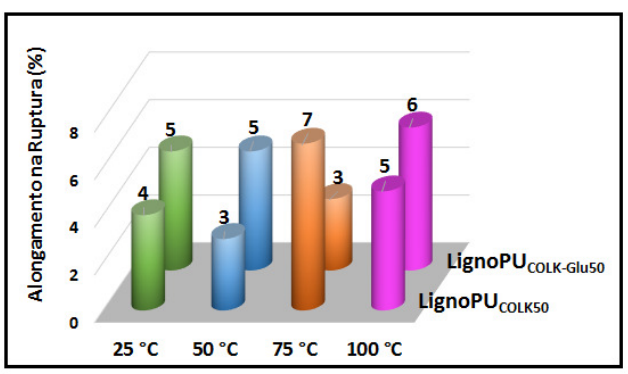

(c)

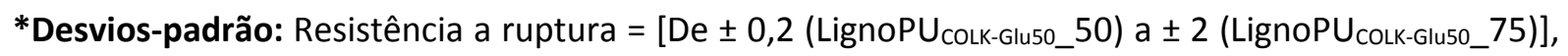
módulo de Young $=\left[\mathrm{De} \pm 3\right.$ (LignoPU COLK-Glu50_25) a \pm 36 (LignoPU $_{\text {COLK-Glu50_50) }}$ e alongamento na

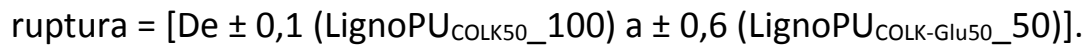

*Siglas: LignoPU CoLk50 $_{\text {= Filme com CO, } 50 \% \text { de Lignina Kraft purificada e pMDI; LignoPU }}$ CoLk-Glu50 = Filme com CO, 50\% de lignina modificada por hidroxialquilação e pMDI.

O ensaio de tração foi conduzido a $25{ }^{\circ} \mathrm{C}$, nessa temperatura os filmes formados simultaneamente as sínteses realizadas a partir de 50 \% de LK ou LK-Glu nas temperaturas de $25,50,75$ e $100{ }^{\circ} \mathrm{C}$, também se encontravam no estado rígido, uma vez que os valores de $T_{\mathrm{g}}$ observados para esses filmes estão acima de $80^{\circ} \mathrm{C}$ (Tabela 13).

A Figura 42 a mostra que os valores obtidos para resistência a ruptura dos filmes formados a partir de PUs sintetizadas a partir de $50 \%$ de LK ou LK-Glu, a 50 e $75{ }^{\circ} \mathrm{C}$, foram inferiores aos observados para os filmes formados à temperatura ambiente. Apesar de a cristalinidade dos filmes LignoPU ${ }_{\text {Colk50_50 (55 \%), LignoPU }}$ Colk-Glu50_50 (43 \%), LignoPU $U_{\text {COLK50_75 (55 \%) e LignoPU }}$ COLK-Glu50_75 (58 \%) ter aumentado significativamente nesses filmes em relação aos filmes formados à temperatura ambiente (LignoPUCoLk50_25 = 35 \%; LignoPUCOLK-Glu50_25 = 13 \%), Item 1.3.3.4 (DRX), esse fator aparentemente não influenciou de forma significativa a resistência a ruptura desses materiais.

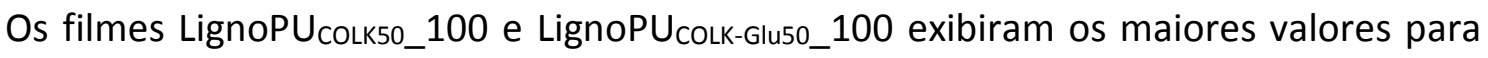
resistência à ruptura $(25,0 \pm 1,5$ e $33 \pm 1 \mathrm{MPa}$, respectivamente) e módulo de Young (1137 \pm 
29 e $1361 \pm 30 \mathrm{MPa}$, respectivamente), entre os filmes formados simultaneamente as sínteses realizadas a partir de $50 \%$ de LK ou LK-Glu avaliados (Figura 44 a e b). Esses filmes também foram os que apresentaram menores taxas de intumescimento (ver Item 1.3.3.5 LignoPU $_{\text {COLK50_100 }}=60,0 \pm 1,4 \%$; LignoPU ${ }_{\text {COLK-Glu50_100 }} 5 \pm 1 \%$ ), indicando a menor disponibilidade de volume livre. Como a cristalinidade desses filmes (Item 1.3.3.4 -

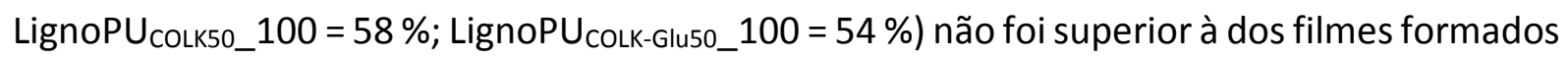

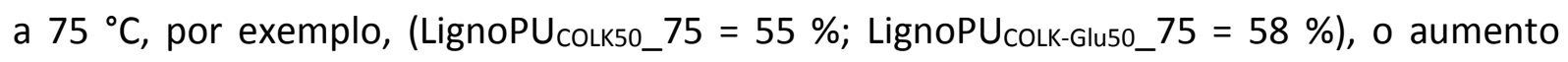
observado na resistência a ruptura e módulo de Young desses filmes provavelmente está relacionado, a formação de uma estrutura de domínios flexíveis e rígidos mais resistente nessa temperatura do que nas temperaturas mais baixas avaliadas.

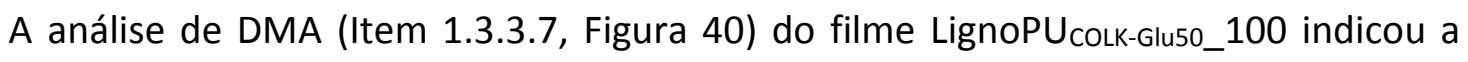
presença de dois picos na curva $\operatorname{Tan}-\delta$, o primeiro menor, decorrente de domínios estritamente flexíveis $\left(T_{\mathrm{g}}=83^{\circ} \mathrm{C}\right)$ e o segundo mais intenso em decorrência dos domínios rígidos não cristalinos da PU $\left(T_{\mathrm{g}}=187^{\circ} \mathrm{C}\right)$. Já o filme LignoPU ${ }_{\text {CoLK-Glu5o mostrou o aparecimento }}$ de um pico largo no gráfico de Tan- $\delta$ na temperatura de $169{ }^{\circ} \mathrm{C}$ (Tabela 13), a mais alta observada entre os filmes formados a partir de PUs sintetizadas com $50 \%$ de LK-Glu. Isso evidencia que as fases rígidas e flexíveis se misturaram neste filme, formando uma rede, sendo a largura do mesmo decorrente da heterogeneidade estrutural dos segmentos rígidos e flexíveis cujos relaxamentos o originaram. Vale ressaltar também que o filme LignoPU ${ }_{\text {colk- }}$ Glu50_100 foi o que apresentou a menor taxa de intumescimento entre os filmes avaliados (50 $\pm 1 \%$, ver Item 1.3.3.5), sugerindo menor disponibilidade de volume livre nesse filme.

Dessa forma pressupõe-se que, $100^{\circ} \mathrm{C}$ foi a temperatura em que foi possível verificar de forma mais acentuada a modificação química realizada na LK-Glu, a qual, elevou a reatividade e massa molar da mesma, proporcionando aumento na massa molar da PU, o que justificaria

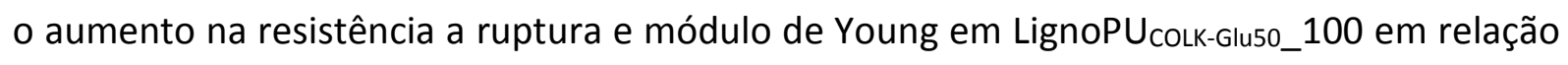
à LignoPU

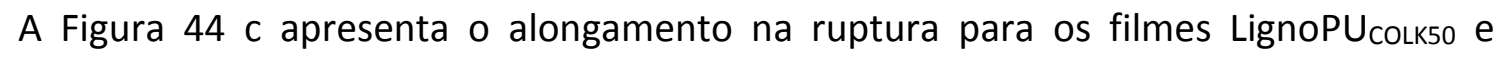

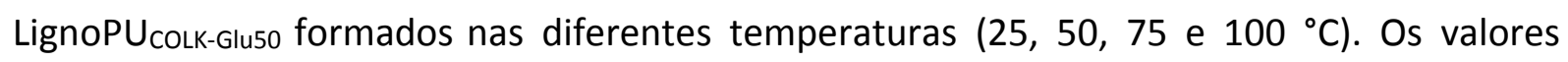
apresentados por esses filmes para esse parâmetro foram próximos, classificando-os como rígidos. 


\subsection{Conclusões Parciais}

A modificação da LK-Glu com glutaraldeído (reação de hidroxialquilação), em que cadeias contendo hidroxilas alifáticas foram inseridas na estrutura da LK-Glu, foi realizada com sucesso e confirmada pelo aumento da massa molar média e teor de hidroxila alifáticas, comparando-se LK-Glu com LK.

Filmes lignopoliuretânicos formados simultaneamente as sínteses utilizando LK e LK-Glu e isocianato do tipo aromático (pMDI), inicialmente à temperatura ambiente, sem utilização de solvente e catalisador, foram obtidos com êxito. Até onde se tenha conhecimento, a abordagem desse estudo e o uso de glutaraldeído na modificação de LK-Glu é inédita no que se refere à síntese de lignopoliuretanas com simultânea formação de filmes.

A formação de filmes concomitantemente à síntese das LignoPUs é importante do ponto de vista de processo, pois permite maior controle do mesmo, elimina outras etapas e gera um produto no formato final desejado, pronto para aplicação. Uma outra alternativa seria sintetizar o polímero, preparar uma solução a partir do produto, espalhar a mesma em uma superfície, e obter o filme por eliminação do solvente. Neste caso, seria necessário encontrar um solvente que dissolva o polímero, o que geralmente não é fácil, além de envolver uma etapa usualmente evitada, pois idealmente o solvente deveria ser recuperado e reciclado, dentre outros aspectos.

É importante destacar a ação do CO como agente dispersante de até 50\% de LK ou LKGlu na síntese das LignoPUs, uma vez que não há solventes orgânicos envolvidos nas sínteses, facilitando a interação entre todos os componentes da mistura reacional, além de atuar como reagente. A compatibilidade das regiões apolares e polares do ácido ricinoleico, o principal constituinte do óleo (Figura 9), com as respectivas regiões de LK e LK-Glu permitiram o aumento na mobilidade das moléculas, contribuindo para homogeneização do meio e subsequente reação com o pMDI.

A análise de FTIR mostrou que o tempo necessário para consumo total de grupos isocianato, e consequente retirada do filme da placa, para as PUs em que LK-Glu foi usado como poliol, a $25{ }^{\circ} \mathrm{C}$, foi menor que o apresentado pelos filmes formados a partir de PUs sintetizadas com LK nas mesmas proporções. Esse resultado mostra que a modificação química realizada na LK-Glu, atingiu o objetivo de aumentar a reatividade da mesma frente ao isocianato aromático pMDI. 
Em comparação ao que foi apresentado pelo filme $P U_{c o}$, as principais influências da presença de LK, e principalmente LK-Glu, foram no aumento na massa molar das PUs, o que levou a segregação de fases em domínios flexíveis e rígidos e consequente melhora nas propriedades mecânicas desses materiais, como aumento na resistência à ruptura, e nos módulos de armazenamento e de Young.

A influência do aumento na temperatura para valores acima da ambiente (50, 75 e 100 $\left.{ }^{\circ} \mathrm{C}\right)$ durante a reação de polimerização das LignoPUs realizadas a partir de 30 e $50 \%$ de LK e sobretudo LK-Glu, foi observada no aumento da reatividade (menor tempo para total consumo de grupos isocianato), e na melhora de propriedades térmicas e mecânicas dos filmes obtidos. Entre todas temperaturas avaliadas durante a polimerização das LignoPUs, 100 ${ }^{\circ} \mathrm{C}$ foi a temperatura que propiciou significativa melhoria nas propriedades mecânicas dos filmes, comparativamente aos filmes formados à temperatura ambiente.

Dessa forma, a lignina Kraft apresenta-se como uma excelente opção renovável de poliol, juntamente com o $\mathrm{CO}$, outro componente renovável, na síntese de lignopoliuretanas. A modificação da lignina com glutaraldeído (que pode ser obtido de fontes naturais) correspondeu a uma abordagem inovadora, e que propiciou o desenvolvimento de filmes lignopoliuretânicos com melhores propriedades térmicas e mecânicas, tornando-se uma melhor alternativa na síntese de LignoPUs quando comparada a LK, especialmente quando temperaturas altas como $100{ }^{\circ} \mathrm{C}$ são utilizadas em sua síntese.

Tanto o aumento na temperatura de síntese quanto a modificação química realizada para obter LK-Glu agregaram custos adicionais ao processo. No entanto, uma exploração mais ampla possível é desejável, pois as propriedades observadas podem indicar uma relação custo-benefício positiva.

Os filmes lignopoliuretânicos produzidos com CO, LK ou LK-Glu e pMDI, nas suas diferentes proporções e temperaturas de síntese, apresentaram características diferenciadas. Filmes com até $30 \%$ de LK ou LK-Glu em sua composição apresentaram flexibilidade e resistências mecânicas mais altas comparativamente aos filmes em que lignina não foi usada como reagente, com possíveis aplicações em áreas industriais como esteiras de produção e revestimentos de painéis de equipamentos, por exemplo. Já o uso de $50 \%$ de LK ou LK-Glu na composição das LignoPUs levou a formação de filmes rígidos, com maior resistentência mecânica e pouco flexíveis, que poderiam ser aplicados como materiais de revestimento proteção ao impacto e umidade, por exemplo, para superfícies planas (paredes, mesas). Essa 
diversidade de materiais com diferentes propriedades consiste em aspecto positivo, pois pavimenta o caminho para inúmeras possibilidades de aplicações. 


\section{Capítulo 2: Filmes poliuretânicos formados simultaneamente as sínteses realizadas a partir de óleo de mamona, Lignina Kraft/Lignina Kraft modificada com Glutaraldeído e Trímero de Hexametileno Di i socianato}

\subsection{Introdução}

No Capítulo 1, foi relatada a utilização de CO, LK e LK-Glu como polióis, e de pMDI como isocianato na reação de síntese de LignoPUs com simultânea formação de filmes.

Neste capítulo, com o objetivo de avaliar a influência da estrutura química do isocianato nos parâmetros de síntese e propriedades dos filmes formados, será abordada à síntese de poliuretanas (PUs) com formação simultânea de filmes utilizando como reagentes: CO, LK ou LK-Glu e isocianato de estrutura alifática, o trímero de hexametileno diisocianato (tHDI, Figura 8) (LignoPUHs).

Assim como no capítulo anterior, também serão mostrados resultados sobre o uso de temperaturas acima da ambiente durante a reação de polimerização sobre as propriedades dos filmes obtidos. No Capítulo 1 foram avaliadas três temperaturas acima da ambiente (50, 75 e $100^{\circ} \mathrm{C}$ ) durante à síntese das LignoPUs. Com base nos resultados obtidos no capítulo anterior, principalmente sobre resistência à tração, módulo de Young e DMA, foi considerada apenas a temperatura mais alta $\left(100^{\circ} \mathrm{C}\right)$, uma vez que as sínteses das LignoPUs que ocorreram nesta temperatura levaram a formação de filmes com melhores propriedades mecânicas.

As sínteses descritas neste capítulo, com a formação simultânea de filmes, assim como a caracterização detalhada de filmes lignopoliuretânicos, na ausência de solvente, usando lignina Kraft e óleo de mamona como polióis e tHDI como isocianato, até onde se tem conhecimento é uma abordagem inédita, assim como é considerada pioneira a utilização de lignina Kraft modificada via reação de hidroxialquilação com glutaraldeído na preparação de filmes lignopoliuretânicos preparados com tHDI. 


\subsection{Materiais e Métodos}

Os materiais utilizados foram os mesmos descritos no Item 1.2 do Capítulo 1, com exceção do isocianato utilizado na síntese dos filmes que correspondeu ao trímero de hexametileno diisocianato (tHDI) Desmodur ${ }^{\circledR}$ N3600, cedido pela indústria Covestro (São Paulo-SP).

\subsubsection{Síntese das Lignopoliuretanas usadas para preparar filmes}

Após ampla exploração de condições, as lignopoliuretanas foram sintetizadas utilizando CO, LK ou LK-Glu como polióis, e tHDI como isocianato (LignoPUHs), conforme a metodologia apresentada no diagrama da Figura 45.

Figura 45 - Diagrama da metodologia de síntese das lignopoliuretanas usadas para preparar filmes.

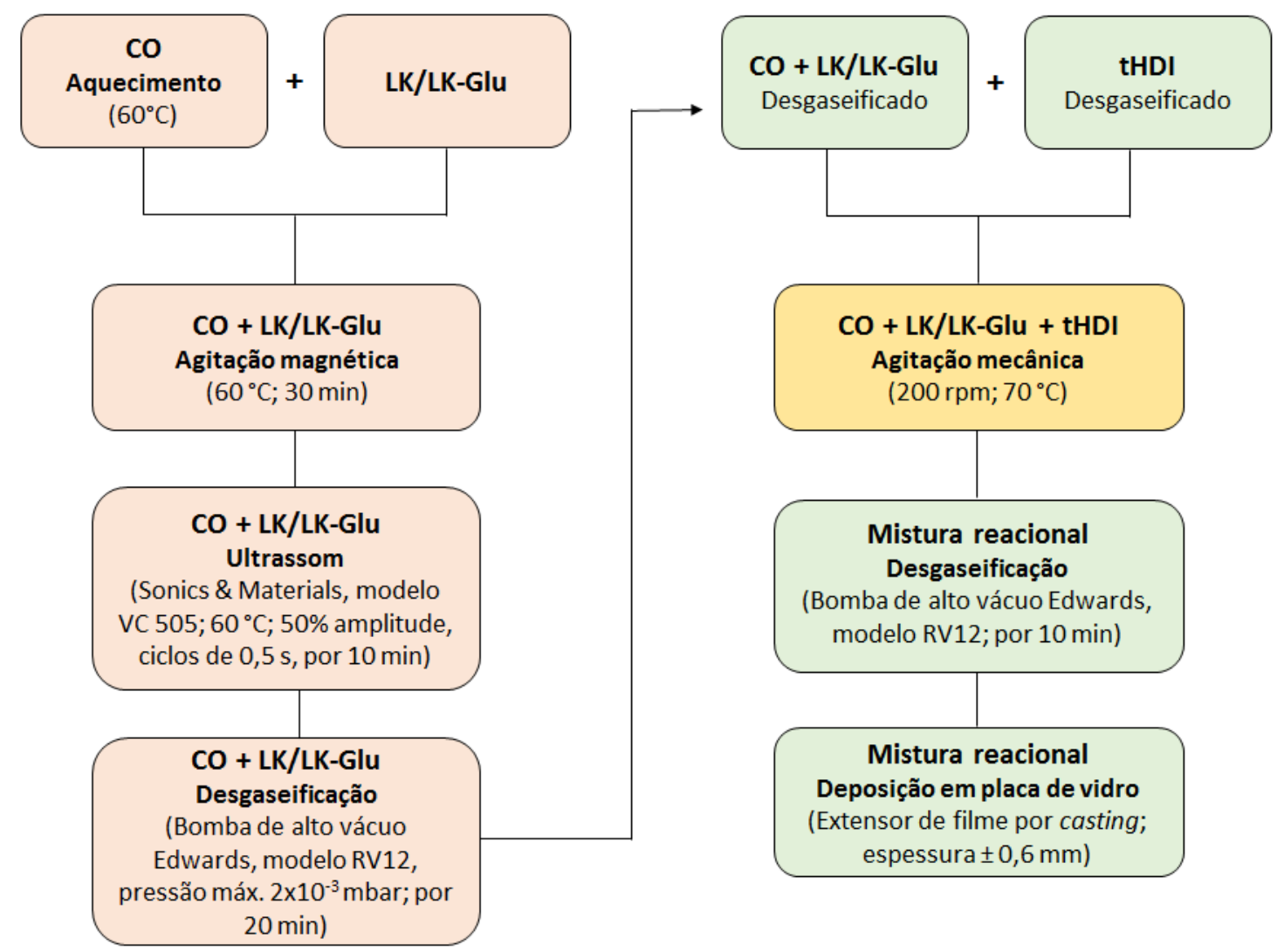

A mistura reacional espalhada na placa de vidro com o auxílio de um extensor foi colocada em uma sala a $(25 \pm 2)^{\circ} \mathrm{C}$ e umidade controlada (40\%), para dar prosseguimento à reação de polimerização da poliuretana, já nas condições de formação de filmes. Após o término da reação, o filme foi retirado da placa e armazenado em dessecador com sílica, sob 
vácuo, para análises posteriores. Um filme usando somente CO como poliol foi formado seguindo a mesma metodologia descrita previamente, para avaliar como a introdução da lignina na formulação impacta as propriedades do material, sendo assim, as propriedades dos filmes formados a partir de CO e LK ou LK-Glu foram comparadas as do filme em que apenas CO foi utilizado.

Os tempos de agitação mecânica da mistura reacional contendo LK ou LK-Glu, CO e tHDI (Figura 45), antes do espalhamento da mistura na placa de vidro, variaram dependendo das proporções dos reagentes considerados, e foram definidos em função da observação do aumento na viscosidade no meio reacional até adequação para espalhamento na superfície da placa. No Quadro 2 encontram-se as formulações, proporções dos reagentes, os tempos de agitação da mistura reacional, bem como o código utilizado para cada um deles.

QUADRO 2 - Condições de reação das LignoPUHs.

\begin{tabular}{|c|c|c|c|}
\hline Materiais & $\begin{array}{c}\text { Formulação e Proporção } \\
\text { dos reagentes }\end{array}$ & $\begin{array}{c}\text { Tempo de } \\
\text { Agitação (min) }\end{array}$ & Código \\
\hline Filme Poliuretânico & $\begin{array}{c}\text { CO/tHDI } \\
\text { Razão } 2: 1\end{array}$ & 60 & $\mathrm{PUH}_{\mathrm{CO}}$ \\
\hline \multirow{3}{*}{$\begin{array}{c}\text { Filmes } \\
\text { Lignopoliuretânicos } \\
\text { (LK) }\end{array}$} & $\begin{array}{c}\text { CO/LK10\%/tHDI } \\
\text { Razão 1,8 : 0,1 : } 1\end{array}$ & 60 & LignoPUH $_{\text {CоLK10 }}$ \\
\hline & $\begin{array}{c}\text { CO/LK30\%/tHDI } \\
\text { Razão 1,4 : 0,4 : } 1\end{array}$ & 40 & LignoPUH $_{\text {СоLкзо }}$ \\
\hline & $\begin{array}{l}\text { CO/LK50\%/tHDI } \\
\text { Razão } 1: 0,7: 1\end{array}$ & 75 & LignoPUH ${ }_{\text {CoLK50 }}$ \\
\hline \multirow{3}{*}{$\begin{array}{l}\text { Filmes } \\
\text { Lignopoliuretânicos } \\
\text { (LK-Glu) }\end{array}$} & $\begin{array}{l}\text { CO/LK-Glu 10\%/tHDI } \\
\text { Razão 1,5 : 0,1:1 }\end{array}$ & 55 & LignoPUH COLK-Glu10 \\
\hline & $\begin{array}{l}\text { CO/LK-Glu 30\%/tHDI } \\
\text { Razão } 1,2: 0,3: 1\end{array}$ & 30 & LignoPUH ${ }_{\text {COLK-Glu30 }}$ \\
\hline & $\begin{array}{c}\text { CO/LK-Glu 50\%/tTHDI } \\
\text { Razão } 0,8: 0,5: 1\end{array}$ & 60 & LignoPUH $_{\text {COLK-Glu50 }}$ \\
\hline
\end{tabular}

A razão molar $\mathrm{NCO} / \mathrm{OH}=1: 1$ foi mantida para todos os filmes, a qual, assim como a razão em massa dos reagentes, foram calculadas considerando os seguintes fatores:

a)

\begin{tabular}{ccc}
\hline Isocianato & $\begin{array}{c}\text { Teor de grupos NCO } \\
\text { (Informado pelo } \\
\text { fabricante) }\end{array}$ & $\begin{array}{c}\text { Mols de NCO } \\
\text { presente em 23 } \\
\text { g de tHDI }\end{array}$ \\
\hline $\begin{array}{c}\text { tHDI Desmodur N } \\
3600\end{array}$ & $23,0 \pm 0,5 \%$ & 0,5476 \\
\hline
\end{tabular}


b) $\quad \mathrm{Na}$ análise de $\mathrm{RMN}{ }^{1} \mathrm{H}$ (Capítulo 1, Item 1.3.1.2), foram detectados aproximadamente $4,1 \mathrm{mmol} \mathrm{OH} \mathrm{g}^{-1}$ na lignina Kraft (LK);

c) $\quad \mathrm{Na}$ análise de $\mathrm{RMN}^{1} \mathrm{H}$ (Capítulo 1, Item 1.3.1.2), foram detectados aproximadamente 5,8 mmol $\mathrm{OH} \mathrm{g}^{-1}$ na lignina Kraft modificada (LK-Glu);

d) A cada 977,22 g de CO tem-se 2,7 mols de hidroxilas (cálculo descrito no Item 1.2.4 do Capítulo 1).

Dessa forma, os mols de OH existentes na massa utilizada de CO e da LK e LK-Glu foram relacionados na razão 1:1 aos mols de NCO do tHDI, obtendo-se assim a massa em gramas de tHDI necessárias para reação.

\subsubsection{Espectroscopia na região do Infravermelho com Transformada de Fourier}

Imediatamente após a deposição da mistura reacional na placa de vidro foi retirada uma alíquota para análise (0h), e em períodos sequentes após a deposição do filme. A amostra referente ao tempo Oh foi analisada por deposição sobre pastilha de silício. Os outros espectros foram obtidos no modo de Reflectância Total Atenuada (ATR) descrito no Item 1.2.4.1 do Capítulo 1.

\subsubsection{Caracterização dos Filmes Poliuretânicos formados simultaneamente as sínteses realizadas a partir de CO, LK ou LK- Glu e tHDI}

Os filmes obtidos simultaneamente as sínteses foram caracterizados pelas mesmas técnicas descritas para os filmes formados tendo como reagentes CO, LK ou LK-Glu e pMDI, Item 1.2.5, Capítulo 1.

\subsubsection{Microscopia Eletrônica de Varredura}

As análises de MEV foram realizadas de acordo com o que foi descrito no Item 1.2.5.1 do Capítulo 1.

\subsubsection{Termogravimetria}

As análises de TGA foram realizadas de acordo com o que foi descrito no Item 1.2.5.2 do Capítulo 1. 


\subsubsection{Difração de raios $X$}

As análises de DRX foram realizadas de acordo com o que foi descrito no Item 1.2.5.3 do Capítulo 1.

\subsubsection{Teste de Intumescimento}

O teste de intumescimento foi realizado de acordo com o que foi descrito no Item 1.2.5.4 do Capítulo 1.

\subsubsection{Análise Dinâmico-Mecânica}

As análises de DMA foram realizadas de acordo com o que foi descrito no Item 1.2.5.5 do Capítulo 1.

\subsubsection{Análise de propriedades de Tração}

Os ensaios de resistência à tração foram realizados de acordo com o que foi descrito no Item 1.2.5.6 do Capítulo 1.

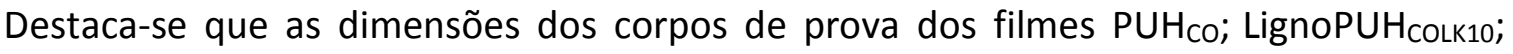

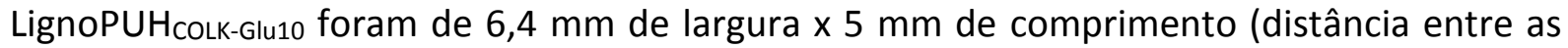
garras) x 0,65 mm de espessura. Em função do não rompimento dos filmes LignoPUH LignoPUH CoLk50; LignoPUH $_{\text {CoLk-Glu30; LignoPUH }}$ CoLk-Glu50 nas dimensões citadas, as dimensões dos corpos de prova desses filmes foram $1,5 \mathrm{~mm} \times 5 \mathrm{~mm} \times 0,66 \mathrm{~mm}$.

\subsubsection{Análise de Ângulo de Contato}

As análises de ângulo de contato foram realizadas de acordo com o que foi descrito no Item 1.2.5.7 do Capítulo 1.

\subsubsection{Avaliação da Influência da temperatura da reação de síntese das LignoPUHs sobre as propriedades dos filmes lignopoliuretânicos formados utilizando CO, LK ou LK-Glu como polióis e tHDI como isocianato}

Reações foram realizadas a $100{ }^{\circ} \mathrm{C}$ para LignoPUHs sintetizadas a partir de 30 e $50 \%$ de LK ou LK-Glu. As porcentagens mencionadas foram selecionadas a partir dos resultados 
obtidos para os filmes formados à temperatura ambiente. A metodologia seguida e as caracterizações realizadas foram as mesmas utilizadas para os filmes preparados com CO, LK ou LK-Glu e pMDI, e se encontram descritas no Item 1.2.5 do Capítulo 1.

\subsection{Resultados e Discussão}

\subsubsection{Filmes Poliuretânicos formados simultaneamente as sínteses realizadas a partir de CO, LK ou LK-Glu como polióis, e tHDI como isocianato}

\subsubsection{Espectroscopia na região do infravermelho com transformada de Fourier}

A Figura 46 mostra os espectros na região do infravermelho para as misturas reacionais (CO, LK ou LK-Glu e tHDI) imediatamente após a deposição na placa, e para o filme formado. A região de infravermelho apresentada vai de 4000 a $1600 \mathrm{~cm}^{-1}$ para melhor observação das principais regiões com as bandas características de PUs, ou seja, a $3050-3720 \mathrm{~cm}^{-1}$, referente à região da vibração de estiramento $\mathrm{N}-\mathrm{H}$; a $2800-3000 \mathrm{~cm}^{-1}$, referente a região de vibração de estiramento $\mathrm{C}-\mathrm{H}$ e a $1665-1780 \mathrm{~cm}^{-1}$, referente a vibração de estiramento da carbonila $(\mathrm{C}=0)$ em uretanas (amida I) (GURUNATHAN et al., 2015). 
Figura 46 - Espectros FTIR das misturas reacionais imediatamente após deposição na placa (CO, LK ou LK-Glu e tHDI) e dos filmes formados na região de 4000 a $1600 \mathrm{~cm}^{-1}$.
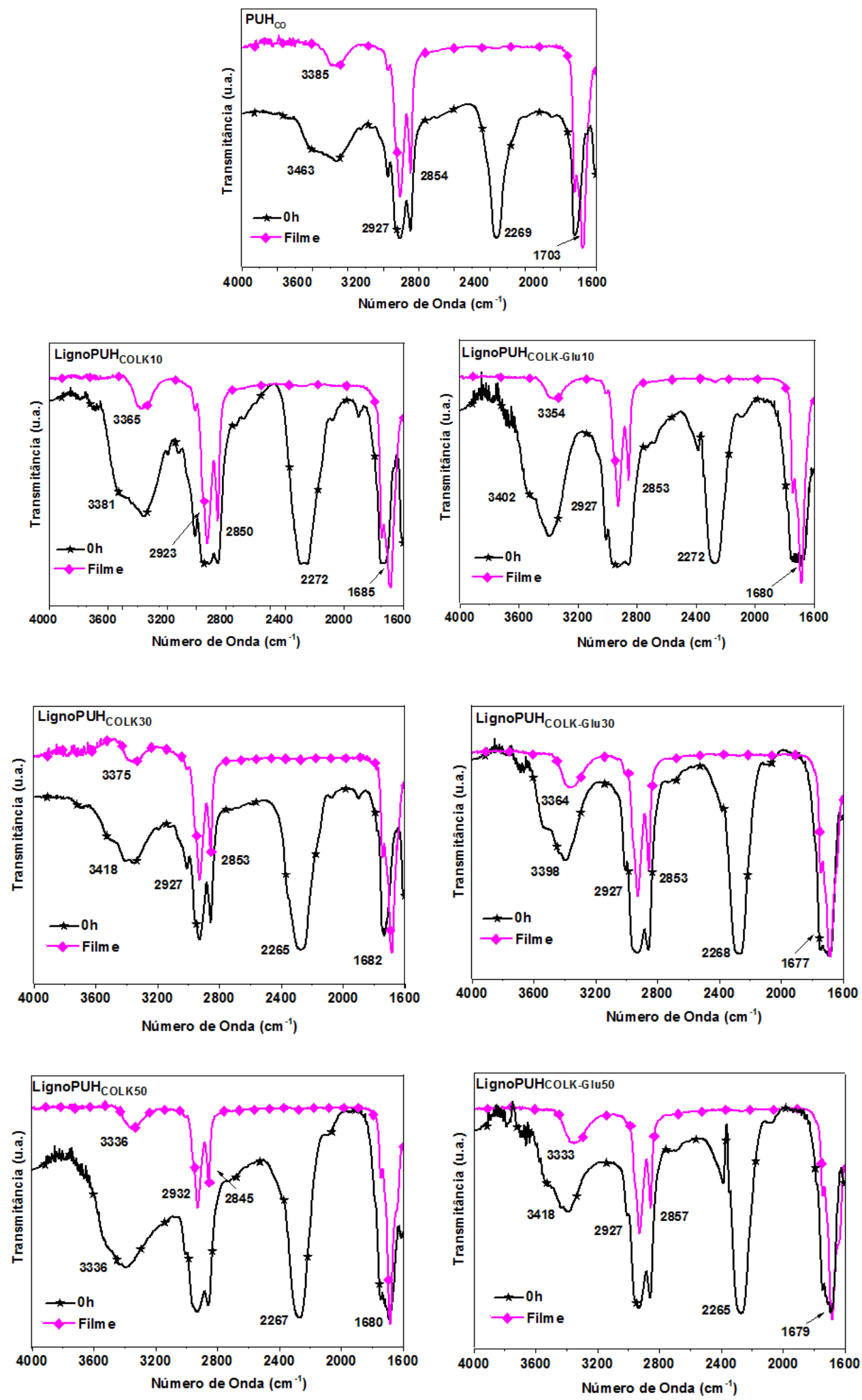

Os espectros da Figura 46 mostram que, da mesma forma que ocorreu com os filmes formados usando pMDI como isocianato (Capítulo 1), ao final da mistura dos reagentes (CO, 
LK ou LK-Glu e tHDI) e depósito na placa (tempo $0 \mathrm{~h}$ ), a banda referente ao grupo isocianato (NCO) (2272-2265 $\left.\mathrm{cm}^{-1}\right)$, proveniente do tHDI, era intensa. Nos filmes formados esta banda praticamente não foi observada, indicando que o isocianato reagiu com as hidroxilas do $\mathrm{CO}$ e da LK ou LK-Glu. Eventuais inflexões na linha base na região da banda referente ao grupo isocianato nos filmes formados pode ser decorrente da presença de grupos isocianato em pontas de cadeia (NASAR; LIBNI, 2017).

A banda em aproximadamente $3333-3385 \mathrm{~cm}^{-1}$ também mostrou-se intensa no tempo Oh, devido a presença dos grupos $\mathrm{OH}$ provenientes do $\mathrm{CO}$ e da LK ou LK-Glu que não haviam reagido durante a agitação da mistura reacional. A intensidade dessa banda no filme diminuiu consideravelmente, e pode ser atribuída a vibração de estiramento da ligação N-H do grupo uretana (-O-CO-NH-) em aproximadamente $3385-3333 \mathrm{~cm}^{-1}$, e as hidroxilas aromáticas de LK ou LK-Glu, que são menos reativas que as alifáticas.

Através da análise de FTIR, foi observado que o tempo para completar a reação aumentou conforme a concentração de LK (LignoPUH ${ }_{\text {COLK10 }}=7$ dias; LignoPUH $_{\text {COLK30 }}=10$ dias e LignoPUH ${ }_{\text {CoLK50 }}=11$ dias) e LK-Glu (LignoPUH CoLK-Glu10 $=5$ dias; LignoPUH $_{\text {CoLK-Glu30 }}=8$ dias e LignoPUH $_{\text {CoLK-Glu50 }}=10$ dias) aumentou como reagente, comparativamente a reação em que somente $\mathrm{CO}$ foi usado ( $\mathrm{PUH}_{\mathrm{CO}}, 5$ dias). Esse aumento no tempo de polimerização pode ser atribuído a um maior impedimento estérico das hidroxilas presentes em LK ou LK-Glu, o que retardaria a reação das mesmas com os grupos isocianato do tHDI (CHENG et al., 2012). Entretanto, LK-Glu mostrou-se mais reativa frente aos grupos NCO do tHDI, uma vez que o tempo de término de formação desses filmes foi menor, comparativamente aos preparados com LK na mesma concentração.

Novamente, destaca-se que no processo de obtenção de filmes via casting de soluções, no geral são usados solventes orgânicos apróticos, de alto ponto de ebulição, como DMF (PE $\left.=153^{\circ} \mathrm{C}\right)$ e $\mathrm{DMAC}\left(\mathrm{PE}=165^{\circ} \mathrm{C}\right)$ que agirão dissolvendo o polímero sintetizado (ALI et al., 2014; LUONG et al., 2016). Como mencionado anteriormente, a vaporização desses solventes é lenta, o que aumenta o tempo de obtenção de filmes. Adicionalmente, aumenta o custo, e reduz o aspecto de sustentabilidade do processo.

Uma diferença observada entre a utilização de isocianato aromático e alifático está no tempo necessário para completar a reação de polimerização, que a $25{ }^{\circ} \mathrm{C}$, foi superior nos filmes produzidos com tHDI (Ex. PUH CO $=5$ dias) em comparação aos produzidos com pMDI (Ex. PUco $=2$ dias). Os isocianatos aromáticos são mais reativos que os alifáticos, em função 
da conjugação do par de elétrons não ligado do grupo isocianato com o anel fenila (Figura 5), o que aumenta o caráter eletrofílico do átomo de carbono ligado ao nitrogênio.

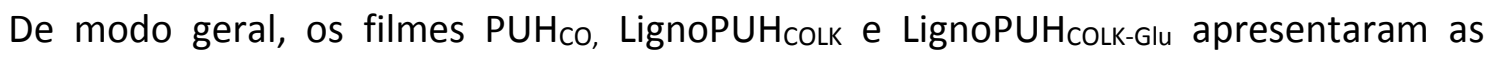
mesmas bandas de transmissão (Apêndice F).

\subsubsection{Microscopia Eletrônica de Varredura}

A análise de microscopia eletrônica por varredura foi feita com o objetivo de avaliar a morfologia da superfície (Figura 47) e da seç̧ão transversal (criofraturada) (Figura 48) dos filmes formados a partir de CO, LK ou LK-Glu, e tHDI.

A morfologia da superfície dos filmes foi semelhante para todos os filmes formados (Figura 47). Em todos eles, a superfície se mostrou homogênea e sem a presença de bolhas ou sulcos. A Figura 47, mostra como exemplo, as superfícies dos filmes formados usando somente

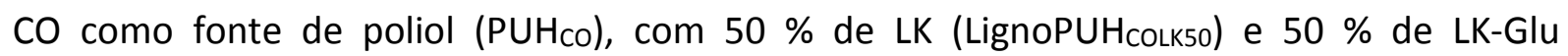

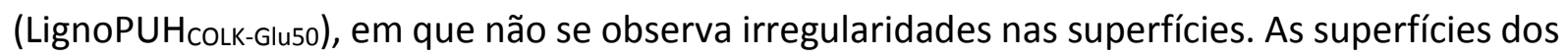
demais filmes são similares às mostradas.

Figura 47 - Micrografias eletrônicas de varredura da superfície dos filmes $\mathrm{PUH}_{\mathrm{co}}$, LignoPUH $\mathrm{P}_{\text {colk5o }} \mathrm{e}$ LignoPUH COLK-Glu5O.
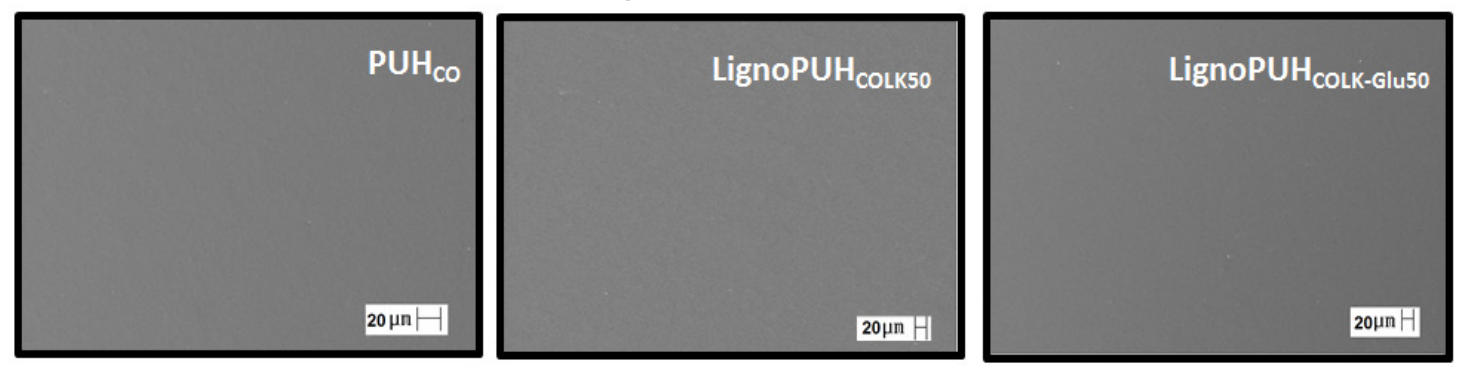

As micrografias das criofraturas dos filmes estão apresentadas na Figura 48. 
Figura 48 - Micrografias eletrônicas de varredura da criofratura dos filmes poliuretânicos preparados simultaneamente à síntese realizada a partir de CO, LK ou LK-Glu e tHDI.

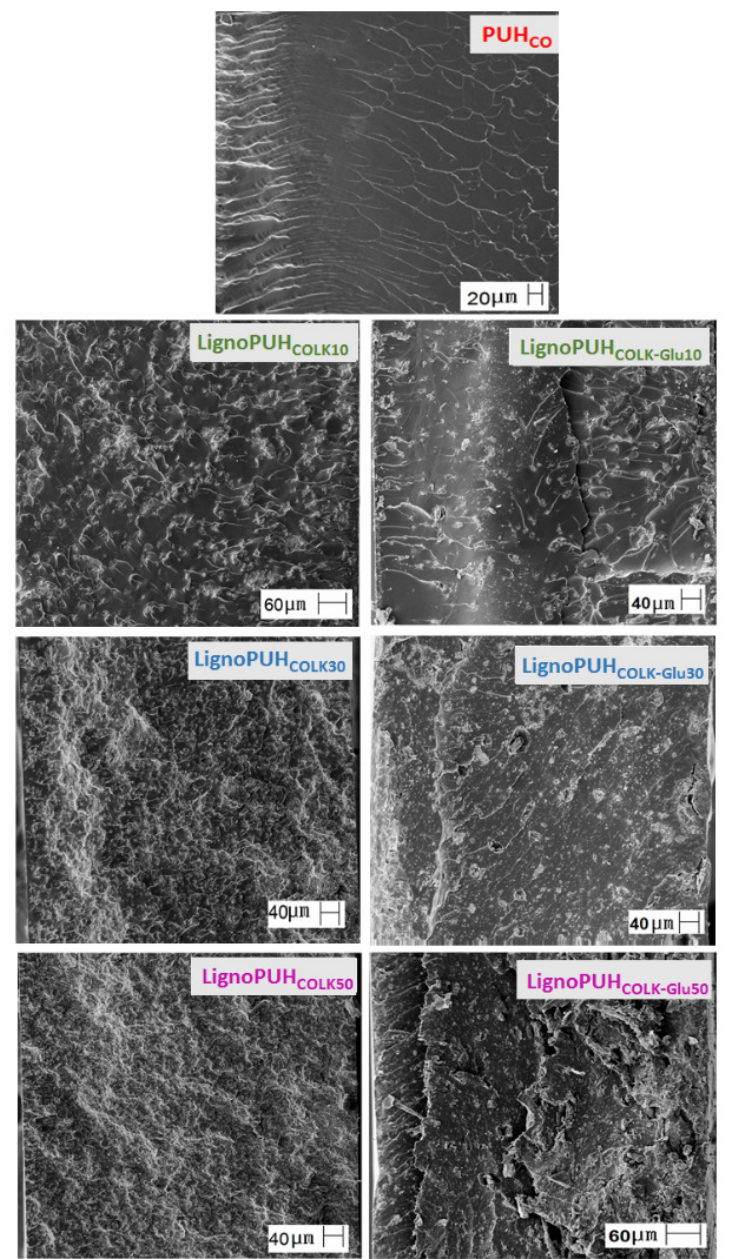

*Siglas: $\mathrm{PUH}_{\mathrm{CO}}=$ Filme com CO e tHDI; LignoPUH ${ }_{\text {COLK }}=$ Filme com Lignina Kraft purificada e tHDI;

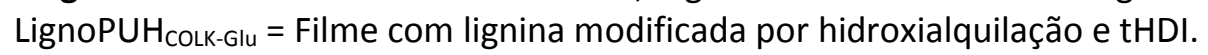

As micrografias da Figura 48, mostram que assim como ocorreu para os filmes formados simultaneamente as sínteses em que pMDI foi usado como reagente, a utilização de LK ou LKGlu como poliol nas sínteses usando tHDI também provocou uma mudança na morfologia da superfície de fratura dos mesmos, comparativamente a $\mathrm{PUH}_{\mathrm{co}}$.

O filme PUHco, apresentou uma superfície de fratura mais lisa, enquanto os filmes formados em reações realizadas a partir de LK ou LK-Glu apresentaram superfícies com ondulações e sulcos, as quais aumentaram conforme o aumento da presença de estruturas típicas de LK ou LK-Glu, sugerindo diferentes tipos de mecanismos de fratura nos filmes com e sem lignina (Figura 48).

Assim como nos filmes formados simultaneamente as sínteses em que pMDI foi usado como reagente, para os filmes formados a partir de tHDI, foi possível perceber diferenças 
entre os filmes formados a partir de LK e LK-Glu nas mesmas concentrações. A superfície da criofratura dos filmes formados a partir de LK-Glu aparentemente apresenta menos ondulações e sulcos que a superfície da criofratura dos filmes contendo LK (Figura 48). Esse resultado, provavelmente está relacionado a modificação química realizada em LK-Glu, que aumentou o número de segmentos alifáticos hidroxilados (Figura 14), proporcionando maior reatividade frente ao isocianato, resultando em uma estrutura lignopoliuretânica mais compacta e homogênea que a observada quando LK é usada como reagente.

\subsubsection{Termogravimetria}

As curvas referentes à termogravimetria (TGA) e termogravimetria derivada (DTG) dos filmes lignopoliuretânicos formados simultaneamente à síntese realizada a partir de CO, LK ou LK-Glu e tHDI (LignoPUHs) e do filme em que apenas CO foi utilizado como reagente (PUHCO) estão apresentadas na Figura 49.

Figura 49- Curvas de TGA (a) e (b) e DTG (c) e (d) dos filmes poliuretânicos formados simultaneamente à síntese realizada a partir de CO, LK ou LK-Glu e tHDI em atmosfera de $\mathrm{N}_{2}$, vazão de $50 \mathrm{~mL} \mathrm{~min}{ }^{-1}$ e razão de aquecimento de $10^{\circ} \mathrm{C} \mathrm{min}^{-1}$. Números 1 e 2 em (c) e (d) correspondem ao $1^{\circ}$ e $2^{\circ}$ evento, respectivamente.

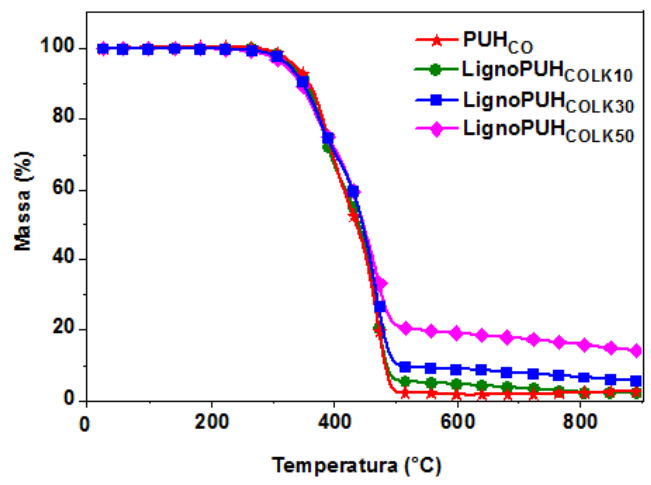

(a)

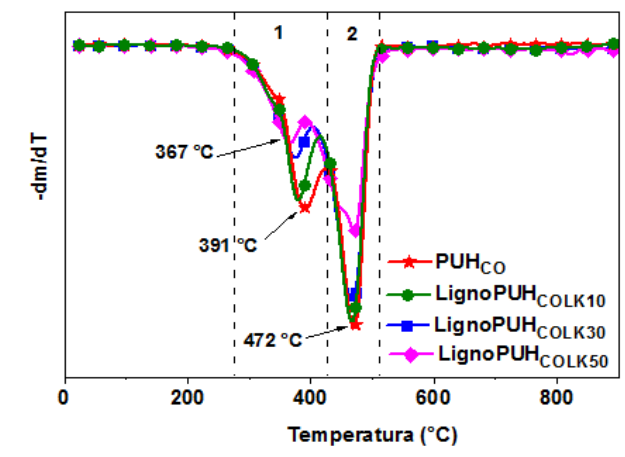

(c)

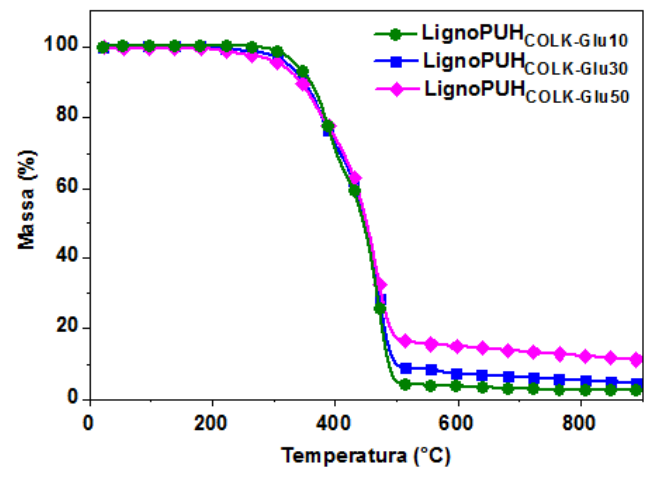

(b)

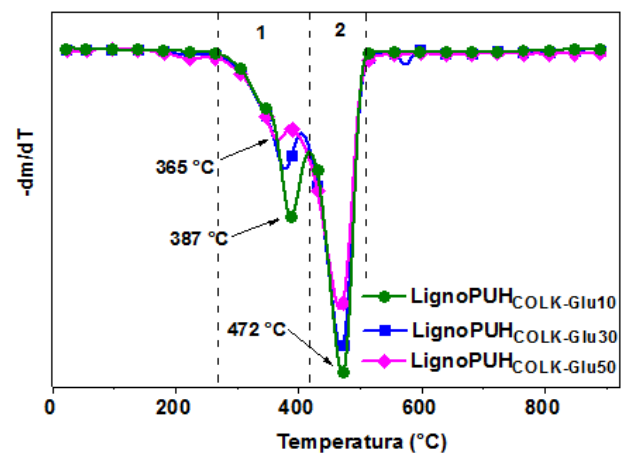

(d)

*Siglas: $\mathrm{PUH}_{\mathrm{CO}}=$ Filme com CO e tHDI; LignoPUH $\mathrm{H}_{\mathrm{Cok}}=$ Filme com Lignina Kraft purificada e tHDI;

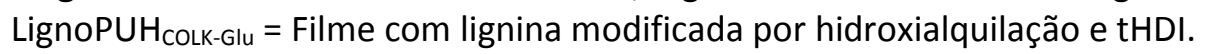


A Tabela 14 apresenta os dados obtidos a partir da Figura 49 para os filmes LignoPUHs e para $\mathrm{PUH}$ co.

Tabela 14 - Temperaturas dos eventos térmicos e massa residual encontrados para os filmes poliuretânicos formados simultaneamente à síntese realizada a partir de CO, LK ou LK-Glu e tHDI em atmosfera de $\mathrm{N}_{2}$

\begin{tabular}{|c|c|c|c|c|c|c|}
\hline \multirow{2}{*}{ Filme } & \multicolumn{3}{|c|}{$\begin{array}{c}\text { Evento } 1 \\
\left(300-406^{\circ} \mathrm{C}\right)\end{array}$} & \multicolumn{2}{|c|}{$\begin{array}{c}\text { Evento } 2 \\
\left(406-530^{\circ} \mathrm{C}\right)\end{array}$} & \multirow{2}{*}{$\begin{array}{c}\begin{array}{c}\text { Resíduo } \\
\left(900^{\circ} \mathrm{C}\right)\end{array} \\
\begin{array}{c}\text { Massa } \\
\text { (\%) }\end{array}\end{array}$} \\
\hline & $\begin{array}{l}T_{\text {onset }} \\
\left({ }^{\circ} \mathrm{C}\right)\end{array}$ & $\begin{array}{l}T_{\text {Máx }} \\
\left({ }^{\circ} \mathrm{C}\right)\end{array}$ & $\begin{array}{l}\text { Perda de } \\
\text { massa (\%) }\end{array}$ & $\begin{array}{l}T_{\text {Máx }} \\
\left({ }^{\circ} \mathrm{C}\right)\end{array}$ & $\begin{array}{l}\text { Perda de } \\
\text { massa (\%) }\end{array}$ & \\
\hline $\mathrm{PUH}_{\mathrm{CO}}$ & 352 & 391 & 38,5 & 472 & 51,3 & 2,6 \\
\hline LignoPUH $_{\text {COLK10 }}$ & 348 & 380 & 29,7 & 468 & 56,7 & 2,2 \\
\hline LignoPUH ${ }_{\text {CoLK-Glu10 }}$ & 351 & 387 & 28,3 & 472 & 59,8 & 2,7 \\
\hline LignoPUH $_{\text {COLKзо }}$ & 321 & 375 & 27,2 & 467 & 59,4 & 5,5 \\
\hline LignoPUH & 334 & 379 & 22,1 & 469 & 62,8 & 4,5 \\
\hline LignoPUH ${ }_{\text {CoLk50 }}$ & 323 & 367 & 21,3 & 471 & 53,5 & 14,1 \\
\hline LignoPUH ${ }_{\text {COLK-Glu50 }}$ & 328 & 365 & 16,3 & 467 & 62,6 & 11,1 \\
\hline
\end{tabular}

As curvas de DTG (Figura 49 c e d) mostraram que o primeiro evento ligado a quebra das ligações uretânicas e a decomposição dos segmentos flexíveis presentes, como os oriundos do CO e da cadeia acíclica do tHDI (CORCUERA et al., 2010), apresentou um pico com temperatura em que a velocidade de perda de massa é máxima entre 364 e $391{ }^{\circ} \mathrm{C}$ para os filmes obtidos. A temperatura em que a velocidade de perda de massa é máxima para o CO utilizado foi de $405^{\circ} \mathrm{C}$ (figura não mostrada), ou seja, próxima as encontradas para o primeiro evento nos filmes LignoPUHs, o que corrobora com a afirmação de que esse evento também está ligado a decomposição dos segmentos flexíveis das PUs. Conforme houve o aumento na concentração de LK e LK-Glu na composição dos filmes a perda de massa referente a esse evento diminuiu, provavelmente em função da diminuição dos segmentos flexíveis nos mesmos.

Já o segundo evento observado na curva DTG (Figura 49 c e d) ocorreu na faixa de temperatura de 430 a $520{ }^{\circ} \mathrm{C}$ e pode ser atribuído à decomposição das estruturas remanescentes após a primeira decomposição, dos anéis aromáticos da lignina e do anel de 6 membros do tHDI (TAVARES et al., 2016). A temperatura em que a velocidade de perda de massa é máxima para esse evento ficou entre 467 e $472{ }^{\circ} \mathrm{C}$ para os filmes formados, e a perda de massa apresentou uma tendência ao aumento nos filmes formados a partir de LK e, 
principalmente, LK-Glu em relação à PUHco, evidenciando o efeito da inserção de estruturas aromáticas na estrutura das Pus e da maior massa molar de LK-Glu comparativamente à LK.

Ainda é possível observar na Figura 49 c e d, que com o aumento de segmentos rígidos, oriundos de LK e LK-Glu, na estrutura das PUs, a intensidade do pico referente à decomposição dos segmentos flexíveis decresceu.

A curva TGA (Figura 49 a e b) mostra que os filmes apresentaram estabilidade térmica até em torno de $320^{\circ} \mathrm{C}$. A temperatura inicial ( $T_{\text {onset }}$ ) de decomposição dos filmes (Tabela 14) preparados com tHDI praticamente não foi alterada em função do uso de 10 \% de LK e LK-Glu na síntese das LignoPUHs, entretanto ao se utilizar 30 e 50 \% de LK e LK-Glu na síntese das mesmas foi possível observar uma diminuição na estabilidade térmica, principalmente nas LignoPUHs elaboradas com LK, embora as temperaturas ainda sejam altas.

A incorporação de 30 e 50 \% de LK nas PUs aumentou a massa residual dos filmes em 53 e 82 \%, respectivamente, em relação à $\mathrm{PUH}_{\mathrm{co}}$ (Tabela 14). Carvão vegetal e uma alta fração de compostos aromáticos que não são decompostos em atmosfera inerte são os principais contituintes dessa massa (BARTKOWIAK; ZAKRZEWSKI, 2004; VELDEN et al., 2010). Os filmes LignoPUH Colk-GluS apresentaram um valor de massa residual um pouco inferior às

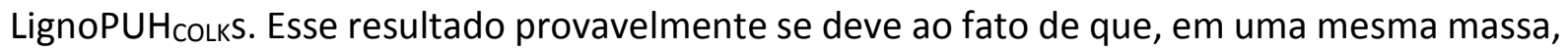
LK possui maior teor de compostos aromáticos comparativamente a LK-Glu, devido à inserção de grupos alifáticos durante a modificação química que levou à LK-Glu.

Comparando os filmes formados simultaneamente à síntese onde tHDI foi usado como reagente (LignoPUHs) com os filmes em que pMDI foi usado como reagente (LignoPUs), é possível perceber algumas diferenças no perfil da decomposição térmica. Além do pico referente à decomposição dos domínios rígidos ser mais intenso nas LignoPUs, devido a estrutura rígida aromática de LK ou LK-Glu e pMDI, as LignoPUs também apresentaram um terceiro estágio de decomposição referente a quebra de ligações C-C e segmentos remanescentes da estrutura (HABLOT et al., 2008).

A estabilidade térmica das PUs produzidas com pMDI $\left(\mathrm{PU}_{\mathrm{CO}}=318^{\circ} \mathrm{C}\right)$ foi inferior à das produzidas com tHDI $\left(\mathrm{PUH}_{\mathrm{CO}}=352^{\circ} \mathrm{C}\right)$, o que pode ser atribuído a maior cristalinidade desta última (Item 2.3.1.4, DRX). Como mencionado anteriormente no Item 1.3.2.3 (Capítulo 1), uma maior quantidade de energia é necessária para decompor regiões com cadeias altamente ordenadas e unidas por forças intermoleculares mais intensas que no domínio não cristalino, o que pode ser detectado via análise termogravimétrica. Em ambos os tipos de 
lignopoliuretanas (LignoPUHs e LignoPUs), o incremento de estruturas típicas de LK ou LK-Glu acarretou em menor estabilidade térmica. No entanto, os filmes em que LK-Glu foi usado como reagente apresentaram maior estabilidade térmica comparativamente aos em que LK foi usada como reagente na mesma concentração. A massa residual à $900{ }^{\circ} \mathrm{C}$ das LignoPUs mostrou-se superior à das LignoPUHs, o que já era esperado, em função do maior teor de compostos aromáticos das LignoPUs que não são decompostos em atmosfera inerte.

\subsubsection{Difração de raios $X$}

A cristalinidade dos filmes lignopoliuretânicos fomados a partir de tHDI foi avaliada pela análise de difração de raios X (Figura 50).

Figura 50 - Difratogramas de raios $X$ para os filmes poliuretânicos formados simultaneamente à síntese realizada a partir de CO, LK ou LK-Glu e tHDI.

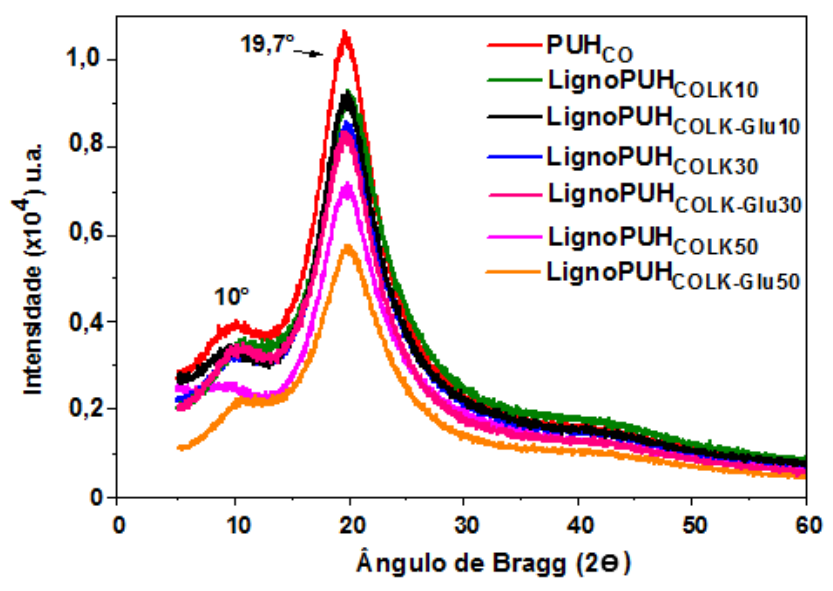

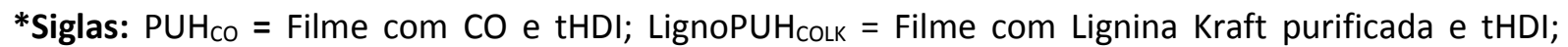

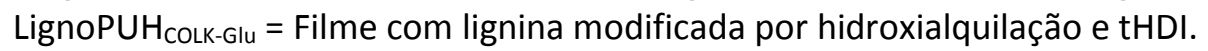

Na Figura 50, nota-se o aparecimento de dois picos, um de menor intensidade em $2 \theta=$ $10^{\circ}$ e outro de maior intensidade em $2 \theta=19,7^{\circ}$, demonstrando a formação de regiões ordenadas de diferentes tamanhos e geometrias nos filmes produzidos. Isso pode ter acontecido em função da utilização do isocianato tHDI no preparo dos mesmos, uma vez que a formação das regiões ordenadas nas PUs é usualmente relacionada à ordenação dos segmentos rígidos, oriundos do isocianato (MISHRA E MAITI, 2011). Como mencionado anteriormente, o tHDI contém um anel isocianurato de estrutura alifática (Figura 8), portanto, menos rígida que o pMDI (isocianato essencialmente aromático, Figura 6), o que pode ter levado a formação das regiões ordenadas de diferentes tamanhos e geometrias. A Tabela 15 
mostra os índices de cristalinidade (ICr \%) obtidos para os filmes. Eles foram calculados pela diferença na intensidade de picos específicos, correspondentes a domínios cristalinos, e da região não cristalina (KIM et al., 2016; ALEXANDER, L., 1969).

Tabela 15 - Índice de cristalinidade (ICr) dos filmes poliuretânicos formados simultaneamente à síntese realizada a partir de CO, LK ou LK-Glu e tHDI

\begin{tabular}{|c|c|c|c|c|c|}
\hline Filme & $\operatorname{ICr}(\%)$ & $\mathrm{PUH}_{\mathrm{CO}}$ & $\mathrm{ICr}=68 \%$ & Filme & $\operatorname{ICr}(\%)$ \\
\hline LignoPUH & 57 & & & LignoPUH ${ }_{\text {CoLK-Glu10 }}$ & 60 \\
\hline LignoPUH $_{\text {Соцкзо }}$ & 51 & & & LignoPUH ${ }_{\text {CoLK-Gluzo }}$ & 49 \\
\hline LignoPUH $_{\text {CoLK50 }}$ & 45 & & & LignoPUH ${ }_{\text {COLK-Glu50 }}$ & 40 \\
\hline
\end{tabular}

Os valores encontrados para os ICr (Tabela 15) revelam uma diminuição da cristalinidade nas PUs com o aumento da concentração de LK ou LK-Glu. Isso também pode ser observado na Figura 50, a qual mostra que à medida que LK ou LK-Glu foram incorporadas na estrutura das PUs, a intensidade dos picos localizados em $2 \theta=19,7$ e $10^{\circ}$ foi diminuindo. A diminuição de domínios ordenados nos filmes lignopoliuretânicos formados a partir de PUs sintetizadas com LK e LK-Glu, pode ser relacionada a não linearidade e a complexidade estrutural de LK e LK-Glu, o que dificulta a ordenação dos segmentos provenientes de tHDI, quando estruturas típicas de LK e LK-Glu estão próximas.

A Tabela 15 mostra ainda que os filmes formados simultanemante à síntese utilizando 30 e 50 \% de LK-Glu como reagente apresentaram uma tendência ao decréscimo na cristalinidade em relação aos produzidos com LK na mesma concentração. Esse resultado destaca o efeito da modificação química realizada em LK-Glu, em que segmentos alifáticos foram inseridos em sua estrutura, aumentando a massa molar média e o volume de estruturas nessa lignina, dificultando ainda mais a ordenação dos segmentos rígidos oriundos de LKGlu/tHDI.

A diminuição no $\mathrm{ICr}$ dos filmes lignopoliuretânicos em função do aumento na concentração de LK também foi observado nos filmes formados simultaneamente à síntese tendo como isocianato o pMDI (Item 1.3.2.4, Capítulo 1). Todavia, os valores dos ICr's obtidos para esses filmes $\left(\mathrm{PU}_{\mathrm{CO}}=41 \%\right.$; LignoPU $\mathrm{COLK10}=40 \%$; LignoPU $\mathrm{COLK}_{\text {-Glu10 }}=37 \%$; LignoPU $_{\text {COLK30 }}=$

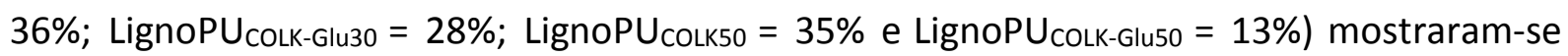
inferiores aos formados a partir de tHDI (Tabela 15). Nesse caso, o menor volume de estrutura molecular e menor rigidez do isocianato tHDI em comparação ao pMDI, contribuiu 
positivamente para a ordenação das cadeias poliméricas, aumentando o $\mathrm{ICr}$ desses filmes (Figura 50). Esse resultado também foi observado por ROGULSKA et al. (2007), em estudo de síntese e caracterização de poliuretanas segmentadas produzidas utilizando HDI e MDI como isocianatos, e derivados de difenil etano como polióis.

\subsubsection{Teste de Intumescimento}

O teste de intumescimento foi realizado nos filmes formados simultaneamente à síntese realizada a partir de CO, LK ou LK-Glu e tHDI à temperatura ambiente, utilizando DMF como solvente. A Figura 51 mostra o gráfico de taxa de intumescimento $(S \%)$ dos filmes formados tendo como reagentes CO, LK ou LK-Glu e tHDI à temperatura ambiente, assim como a coloração das soluções de DMF após o término do teste.

Figura 51 - (a) Taxa de Intumescimento (S\%) dos filmes preparados e (b) Soluções de DMF após realização do teste de intumescimento, sendo: (1) PUH CO; $_{\text {; }}$ (2) LignoPUH COLK10; (3) LignoPUH $_{\text {CoLk-Glu10; }}$

(4) LignoPUH CoLk30; (5) LignoPUH $_{\text {CoLk-Gluзo; (6) LignoPUH }}$ CoLk50 e (7) LignoPUH $_{\text {CoLK-Glu50. }}$

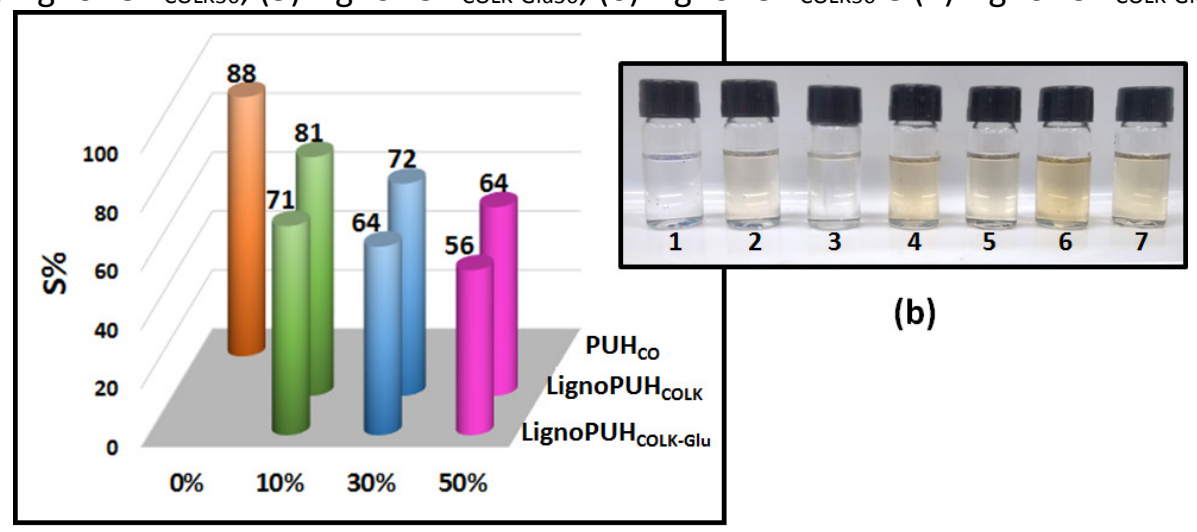

(a)

*Desvios-padrão: [De \pm 0,2 (LignoPUH CoLK10 $_{10}$ a $\pm 1,5$ (LignoPUH CoLK50) $_{\text {) }}$.

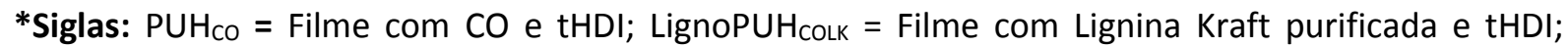

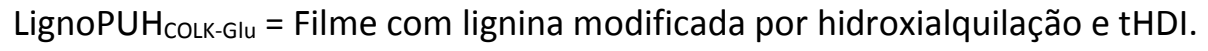

Igualmente ao resultado observado para os filmes formados utilizando pMDI como isocianato, entre os filmes formados a partir de tHDI, o formado usando somente CO como fonte de poliol ( $\mathrm{PUH}$ co) apresentou a maior taxa de intumescimento $(88 \pm 1 \%)$ dentre os filmes avaliados. Isso se deve ao fato de suas cadeias possuírem maior afastamento entre si e maior flexibilidade, o que viabiliza maior volume livre para acomodar moléculas de solvente (SOMANI et al., 2006), comparativamente aos outros filmes. Os valores de $S \%$ encontrados

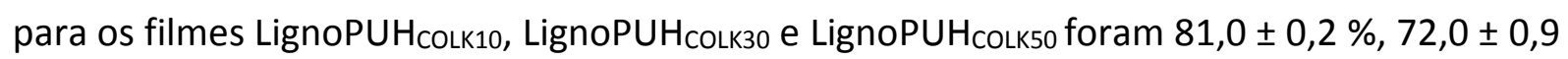


$\%$ e $64,0 \pm 1,5 \%$, respectivamente (Figura 51 a). Esse resultado evidencia que a inserção de LK na estrutura das PUs ocasionou uma diminuição na capacidade das mesmas de absorver o solvente DMF.

A análise dinâmico-mecânica e o teste de resistência à tração realizados para esses filmes e discutidos a seguir (itens 2.3.1.7 e 2.3.1.8, respectivamente) indicam que esses materiais não se comportam como termorrígidos ou elastômeros. A temperatura em que ocorreu à síntese dessas PUs $\left(25^{\circ} \mathrm{C}\right)$, em geral, não favorece o entrecruzamento químico de cadeias. Dessa forma, tem-se como indicação que o decréscimo na S\% provavelmente está relacionado a inserção das estruturas volumosas de LK e LK-Glu na estrutura da PU, que reduzem o espaço para as moléculas do solvente DMF se alojarem, sem necessariamente ter ocorrido entrecruzamento de cadeias.

Os filmes formados a partir de LK apresentaram uma diminuição da cristalinidade

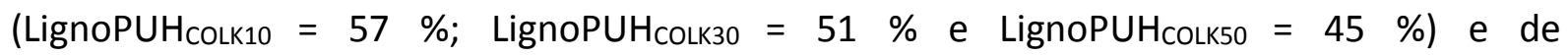
$S \%$ comparativamente a $\mathrm{PUH}_{\mathrm{CO}}(\mathrm{ICr}=68 \%)$, Item 2.3.1.4, Figura 51 a. Isso indica que principalmente na concentração de 50 \% de LK na estrutura da PU a absorção de DMF não está relacionada à cristalinidade mas sim ao menor volume livre devido o maior volume das estruturas de LK.

Com relação aos filmes formados tendo como polióis CO e LK-Glu, todos apresentaram um decréscimo de aproximadamente $12 \%$ na $S \%$ em relação aos formados tendo CO e LK

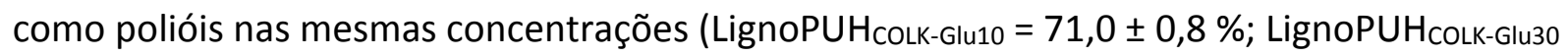
$=64 \pm 1 \%$ e LignoPUH ${ }_{\text {CoLK-Glu50 }}=56,0 \pm 0,9 \%$ ). Como a cristalinidade dos filmes formados a partir de 30 e $50 \%$ de LK-Glu foi inferior a observada para os filmes formados simultaneamente à síntese realizada a pertir de LK (LignoPUH CoLK30 $=51 \%$; LignoPUH CoLK-Gluзo $=49 \%$; LignoPUH COLK50 $=45 \%$ e LignoPUH ${ }_{\text {COLK-Glu50 }}=40 \%$ ), esse resultado provavelmente está ligado, como analisado anteriormente no Item 1.3.2.5 do Capítulo 1, ao menor volume livre dessas PUs devido o maior volume das estruturas de LK-Glu em relação as de LK.

A Figura 51 b apresenta a coloração das soluções de DMF após o término do teste de intumescimento. Assim como o observado anteriormente nos filmes formados simultaneamente à síntese utilizando pMDI como isocianato, observou-se um leve escurecimento das soluções conforme o acréscimo da concentração de LK e LK-Glu, atribuído à solubilização de PUs de menor massa molar média presentes no filme. As soluções de DMF dos filmes produzidos utilizando PUs sintetizadas com LK-Glu são mais claras, 
comparativamente as soluções de DMF dos filmes produzidos utilizando PUs sintetizadas com LK nas mesmas concentrações, provavelmente devido a massa molar média superior à de LK, que levou à formação de PUs com maior massa molar média, e menos solúveis em DMF.

De maneira geral, as $\mathrm{S} \%$ dos filmes formados simultaneamente à síntese com tHDI (Figura 51 a) foram inferiores as encontradas para os filmes formados simultaneamente à síntese utilizando pMDI como reagente, nas mesmas concentrações de LK e LK-Glu ou sem a presença da mesma $\left(\mathrm{PU}_{\mathrm{CO}}=151 \pm 2 \%\right.$; LignoPU ${ }_{\text {COLK10 }}=107 \pm 1 \%$; LignoPU ${ }_{\text {COLK-Glu10 }}=95,0 \pm 3,8$

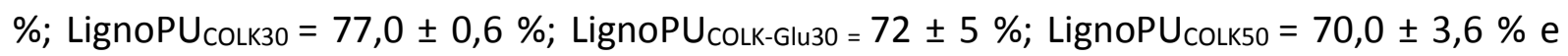
LignoPU CoLK-Glu50 $=54,0 \pm 6,8 \%$ ). Esse resultado pode estar associado aos maiores $\mathrm{ICr}$ encontrados nos filmes formados simultaneamente à síntese a partir de tHDI (Ver Item 2.3.1.4), em comparação aos encontrados nos filmes formados a partir de $\mathrm{pMDI}\left(P \mathrm{PU}_{\mathrm{CO}}=41 \%\right.$;

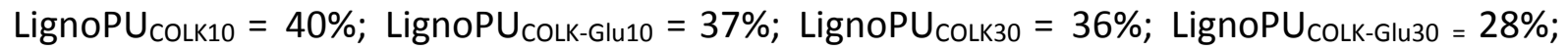
$\operatorname{LignoPU}_{\text {COLK50 }}=35 \%$ e LignoPU COLK-Glu50 $=13 \%$ ). A estrutura química aromática do pMDI provavelmente dificultou a organização das cadeias, como discutido no Item 2.3.1.4, o que impactou diretamente na $S \%$ destes filmes, fazendo com que ela aumentasse em relação aos filmes formados a partir de tHDI nas mesmas concentrações de LK e LK-Glu ou sem as mesmas.

\subsubsection{6 Ângulo de Contato}

Na Figura 52 estão apresentados os ângulos medidos no instante em que a gota se depositou nos filmes (ângulo de avanço - AA) e ao final da análise (ângulo de recuo - AR).

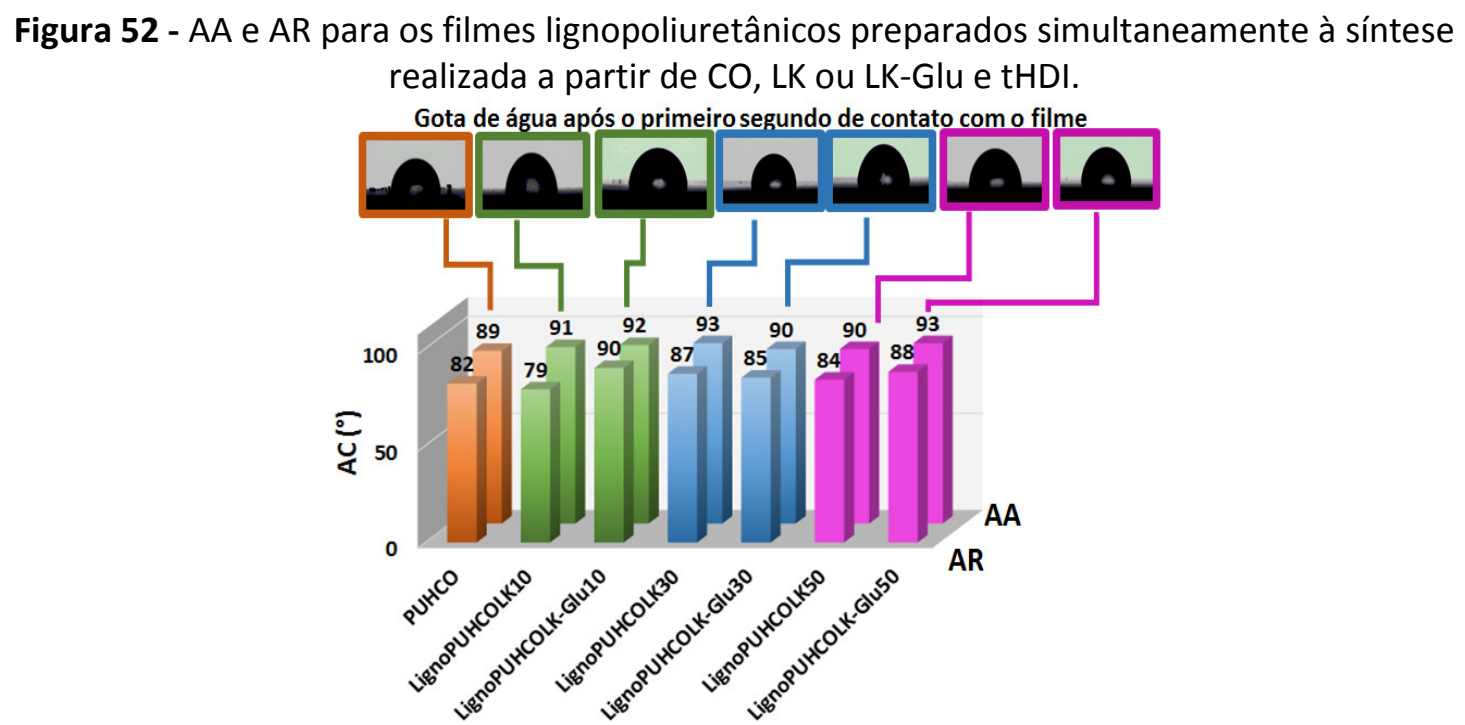

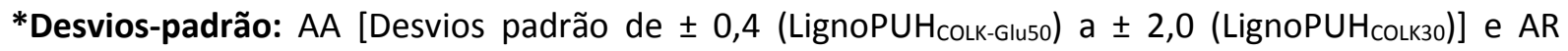
[Desvios padrão de $\pm 0,4$ (LignoPUH CoLk-Glu50) a $\pm 3,5$ (LignoPUH $_{\text {Colk-Gluзo) }}$ ). 
Para todos os filmes ocorre um pequeno decréscimo nos valores de ângulo de contato em função do tempo (Figura 52). Os valores dos ângulos de avanço observados para os filmes produzidos com tHDI, CO e LK ou LK-Glu foram em torno de $90^{\circ}$, que é considerado o valor limite na classificação entre superfícies hidrofóbicas $\left(\theta>90^{\circ}\right)$ e hidrofílicas $\left(\theta<90^{\circ}\right)$.

Conforme apresentado na Figura 52, o acréscimo de LK e LK-Glu na estrutura da PU aparentemente não influenciou a hidrofilicidade dos filmes, uma vez que os valores de AC observados mantiveram-se semelhantes à medida que as concentrações de LK e LK-Glu aumentaram. Nos filmes lignopoliuretânicos formados simultaneamente à síntese utilizando pMDI como reagente, a presença de estruturas típicas de LK ou LK-Glu na estrutura das LignoPUs conferiu um caráter menos hidrofóbico aos filmes $\left(A A\right.$ de: $P U_{C O}=98 \pm 5^{\circ}$; LignoPU $_{\text {COLK10 }}=93 \pm 1^{\circ} ;$ LignoPU $_{\text {COLK-Glu10 }}=90,0 \pm 2,7^{\circ} ;$ LignoPU $_{\text {COLK30 }}=82,0 \pm 5,7^{\circ} ;$ LignoPU $_{\text {COLK }}$ Glu30 $=85,0 \pm 1,4^{\circ} ;$ LignoPU $_{\text {COLK50 }}=80 \pm 1^{\circ}$ e LignoPU $\left.{ }_{\text {COLK-Glu50 }}=79,0 \pm 0,7^{\circ}\right)$. Os segmentos originados das reações entre CO, LK ou LK-Glu, com pMDI têm estruturas muito diferentes que aqueles formados considerando os mesmos polióis, mas tHDI como isocianato. Os resultados de AC mostraram uma leve tendência de aumento no caráter hidrofóbico das superfícies dos filmes quando tHDI foi usado (Figura 52), indicando maior presença de domínios apolares, comparativamente aos filmes formados a partir de pMDI.

A histerese nos filmes formados utilizando $\mathrm{CO}$ como único poliol $\left(7^{\circ}\right)$ a $25^{\circ} \mathrm{C}$ foi semelhante à dos filmes em que 30 e $50 \%$ de LK ou LK-Glu foram usados em conjunto como

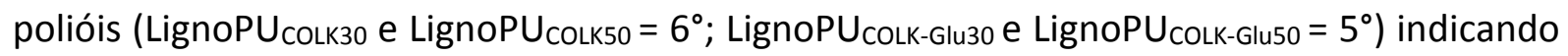
que nesses filmes, LK e LK-Glu não influenciaram na formação de superfícies mais lisas e homogêneas.

\subsubsection{Análise Dinâmico-Mecânica}

A Figura 53 apresenta as curvas Tan- $\delta$ versus temperatura para os filmes formados simultaneamente à síntese realizada a partir de LK ou LK-Glu, e tHDI. Destaca-se que a decomposição térmica dos filmes considerados inicia acima de $320^{\circ} \mathrm{C}$ (Tabela 14), ou seja, acima do intervalo considerado para DMA. 
Figura 53 - Curvas (a) Tan- $\delta$ para os filmes (PUH Co, LignoPUH $_{\text {colk10, LignoPUH }}$ CoLk30, LignoPUH $_{\text {colk50); }}$

(b) Tan- $\delta$ para os filmes apresentados em (a) escala reduzida; (c) Tan- $\delta$ para os filmes

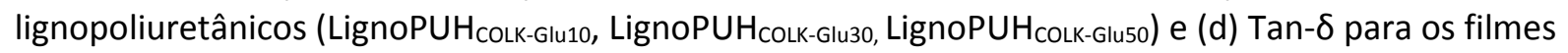
apresentados em (c) em escala reduzida.

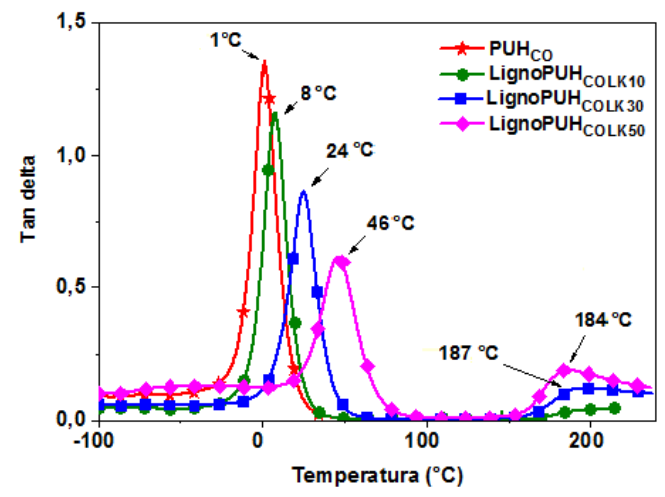

(a)

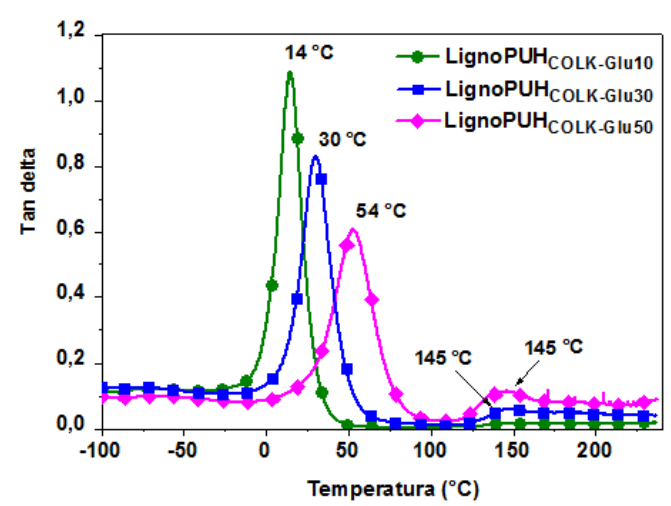

(c)

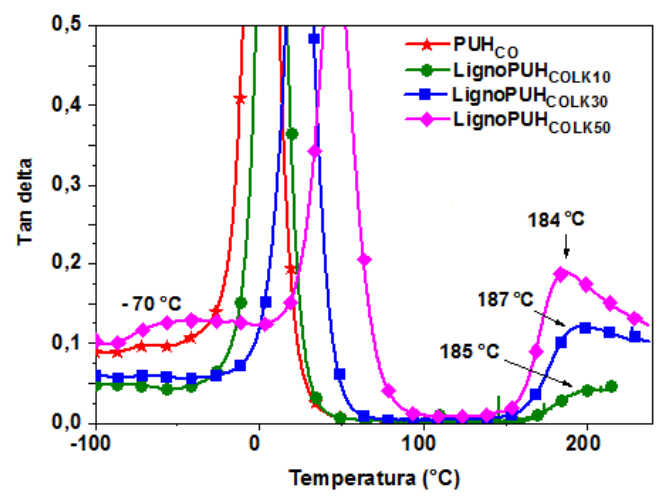

(b)

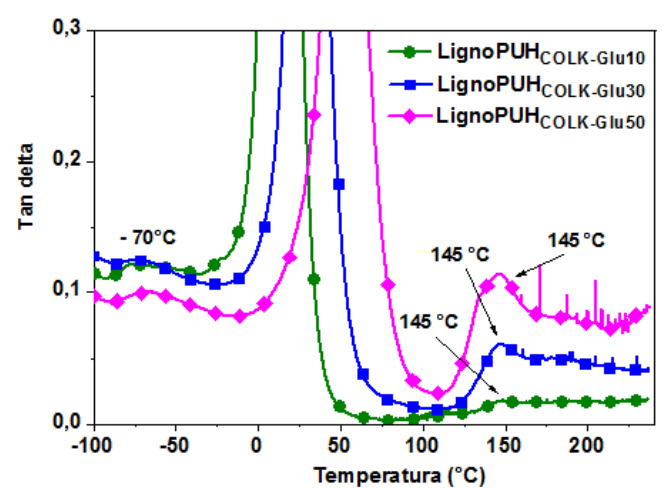

(d)

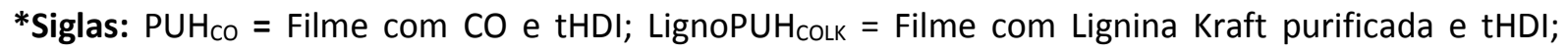

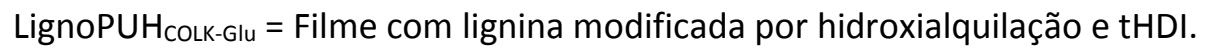

A Figura 53 a mostra na curva Tan- $\delta$, a presença de apenas um pico estreito para o filme $\mathrm{PUH}_{\mathrm{co}}$, indicando que são decorrentes de relaxamento de segmentos com estrutura química relativamente similar. Já os filmes contendo 10, 30 e 50\% de LK apresentaram dois picos (Figura 53 a), os primeiros menos intensos e mais largos que os observados para $\mathrm{PUH}_{\mathrm{CO}}$ (Figura 51 b). $O$ alargamento do $1^{\circ}$ pico sugere que havia uma heterogeneidade estrutural nos segmentos envolvidos na relaxação comparativamente à $\mathrm{PUH}_{\mathrm{CO}}$, e a baixa intensidade do $2^{\circ}$ pico indica o relaxamento de uma menor quantidade de segmentos rígidos, comparativamente aos segmentos flexíveis que geraram o 1‥ Esta diferença de intensidades pode ser explicada pelo fato que, como o $2^{\circ}$ pico foi gerado por segmentos mais rígidos presentes somente nos domínios não cristalinos, possivelmente, grande parte dos segmentos rígidos dessas PUs encontram-se nos domínios cristalinos, os quais são principalmente 
constituídos destes (MISHRA; MAITI, 2011). A análise de DRX (Item 2.3.1.4) mostrou que estes filmes apresentaram entre $40 \%$ e $68 \%$ de cristalinidade, reforçando essa hipótese.

O perfil das curvas Tan- $\delta$ dos filmes formados simultaneamente à síntese utilizando 10 , 30 e 50 \% de LK-Glu na composição (Figura 53 c) foi muito semelhante ao descrito acima para os filmes preparados com LK. A Figura 53 b e d, mostra ainda, que com exceção do filme

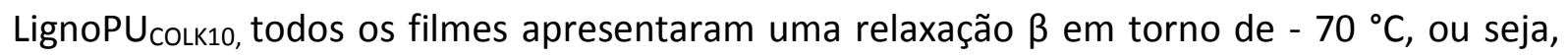
rotações em torno de ligações simples envolvendo grupos, que antecede a $T_{\mathrm{g}}$ (LORANDI et al., 2016).

A Tabela 16 apresenta os valores de $T_{\mathrm{g}}$ obtidos para os filmes obtidos neste estudo.

Tabela 16 - Valores de $T_{\mathrm{g}}$ (pico Tan- $\delta$ ) para os filmes poliuretânicos formados simultaneamente à síntese realizada a partir de CO, LK ou LK-Glu e tHDI

\begin{tabular}{|c|c|c|c|c|}
\hline \multirow{2}{*}{ Pico } & \multicolumn{4}{|c|}{$T_{\mathrm{g}}\left({ }^{\circ} \mathrm{C}\right)$} \\
\hline & $\mathrm{PUH}_{\mathrm{CO}}$ & LignoPUH & LignoPUH & LignoPUH \\
\hline $1^{\circ}$ & 1 & 8 & 24 & 46 \\
\hline \multirow[t]{2}{*}{$2^{\circ}$} & --- & 185 & 187 & 184 \\
\hline & & LignoPUH ${ }_{\text {CoLK-Glu10 }}$ & LignoPUH $_{\text {CoLK-Glu30 }}$ & LignoPUH $_{\text {coLK-Glu50 }}$ \\
\hline $1^{\circ}$ & & 14 & 30 & 54 \\
\hline $2^{\circ}$ & & 145 & 145 & 145 \\
\hline
\end{tabular}

Assim como o observado nos filmes formados simultaneamente à síntese utilizando LK ou LK-Glu, e pMDI como reagentes, a presença de estruturas típicas de ligninas, em substituição às do ácido ricinoleico presente no $\mathrm{CO}$, tornou a movimentação de segmentos mais difícil, levando a filmes mais rígidos quando formados a partir de tHDI. À medida que o teor destas estruturas oriundas da lignina aumentou, ocorreu a segregação de fases nos domínios não cristalinos (soft e hard). A presença da fase rígida devido à introdução de LK e LK-Glu na formulação da poliuretana interferiu na $T_{\mathrm{g}}$ da fase flexível (1ำ pico), provocando um deslocamento para maiores temperaturas, comparativamente a $\mathrm{PUH}_{\mathrm{co}}$ (Tabela 16).

A Tabela 16 mostra que a utilização de LK-Glu como matéria-prima na síntese das PUs, deslocou para valores maiores (aproximadamente 46, 19 e 14 \% para LignoPUHCoLk-Glu10, LignoPUH $_{\text {COLK-Glu30 e LignoPUH }}$ CoLK-Glu50, respectivamente) as $T_{\mathrm{g}} \mathrm{s}$ referentes aos segmentos flexíveis das PUs que constituíram os filmes, em relação aos filmes formados a partir de LK nas mesmas concentrações. Esse resultado enfatiza que a modificação química realizada em LK- 
Glu elevou sua reatividade e massa molar média, formando filmes mais rígidos que aqueles formados a partir de LK.

A Figura 54 apresenta o módulo de armazenamento $\left(E^{\prime}\right)$ a $25{ }^{\circ} \mathrm{C}$ para os filmes lignopoliuretânicos produzidos simultaneamente as sínteses utilizando CO, LK ou LK-Glu, e tHDI como reagentes (LignoPUHs) e para o filme em que apenas CO foi utilizado como poliol (PUHCO).

Figura 54 - Módulo de armazenamento $\left(E^{\prime}\right)$ a $25^{\circ} \mathrm{C}$ para os filmes poliuretânicos formados simultaneamente à síntese realizada a partir de CO, LK ou LK-Glu e tHDI.

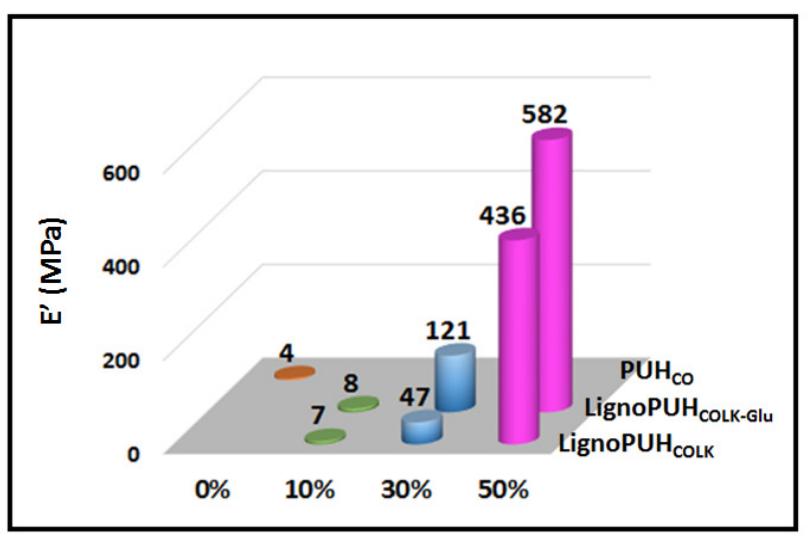

*Siglas: $\mathrm{PUH}_{\mathrm{CO}}=$ Filme com CO e tHDI; LignoPUH ${ }_{\text {colk }}=$ Filme com Lignina Kraft purificada e tHDI;

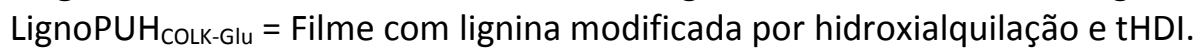

A introdução de estruturas típicas de LK ou LK-Glu nas estruturas das LignoPUHs, levou a um aumento no valor de $\mathrm{E}^{\prime}$ dos filmes, tornando-os mais rígidos devido à maior dificuldade na movimentação dos segmentos de cadeias, comparativamente à $\mathrm{PUH}_{c o}$, resultado semelhante ao observado para os filmes formados utilizando pMDI como isocianato (Item 1.3.2.7, Capítulo 1).

Na temperatura ambiente $\left(25^{\circ} \mathrm{C}\right)$, os valores de $\mathrm{E}^{\prime}$ observados para LignoPUH $\mathrm{HOLk50}_{\mathrm{e}}$

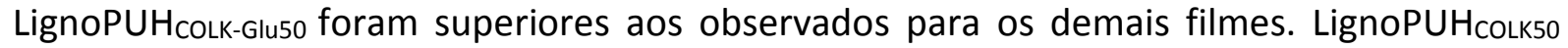

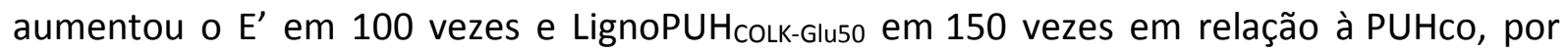
exemplo (Figura 54). Isto é decorrente do fato que os filmes formados simultaneamente as sínteses em que $50 \%$ de LK e LK-Glu foram usados, se encontravam no estado rígido ( $T_{\mathrm{g} s}$ acima de $25{ }^{\circ} \mathrm{C}$, Tabela 16), enquanto todos os outros filmes se encontravam no estado flexível ( $T_{\mathrm{g}} \mathrm{S}$ abaixo ou próximas a $25^{\circ} \mathrm{C}$, Tabela 16). Isso destaca o efeito de enrijecimento causado pela inserção de LK e LK-Glu na estrutura das PUs elaboradas com tHDI. 
O valor de E' de LignoPUH CoLK-Glu10, LignoPUH $_{\text {CoLK-Glu30 }}$ e LignoPUH ${ }_{\text {CoLK-Glu5o }}$ foi superior em 12,61 e $25 \%$, respectivamente, em relação aos filmes formados simultaneamente à síntese a partir de LK nas mesmas concentrações (Figura 54). Este resultado é consequência do efeito de enrijecimento exercido pela modificação química realizada na LK-Glu, em que segmentos alifáticos hidrocarbônicos e di-hidroxilados foram inseridos na estrutura da lignina, aumentando sua massa molar média e reatividade frente ao grupo isocianato.

$O$ resultado da taxa de intumescimento (\%S) pode ser correlacionado aos valores dos $\mathrm{E}^{\prime}$ dos filmes produzidos com LK ou LK-Glu e tHDI, uma vez que o aumento na rigidez dos segmentos, dificulta a penetração de solvente no meio. A inserção de LK e principalmente, LKGlu, na estrutura das PUs, além de aumentar o E', ocasionou uma diminuição na \%S dos filmes (Item 2.3.1.5; Figura 51). Esse decréscimo na \%S, assim como o aumento em E', pode ser influenciado pela presença de cristalinidade e ligações cruzadas, por exemplo. Todavia, conforme discutido no Item 2.3.1.5, as condições de síntese, os resultados do teste de tração discutidos a seguir (Item 2.3.1.8) e os valores de $E^{\prime}$ e $T_{\mathrm{g}}$ s obtidos para esses filmes, sugerem que o resultado da \%S está relacionado à inserção de estruturas volumosas, como as da LK e principalmente LK-Glu, na estrutura da PU, resultando em menos espaço para moléculas de DMF se alojarem, independentemente de ter ocorrido entrecruzamento ou não.

As micrografias dos filmes LignoPUH ${ }_{\text {CoLk30, LignoPUH }}$ CoLk-Glu30, LignoPUH $_{\text {CoLk50 e }}$

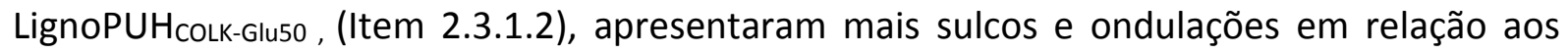
filmes em que LK e LK-Glu não foram utilizados ou foram utilizados em baixa proporção (Item 2.3.1.2). Essa mudança no mecanismo de fratura, conferindo aspecto mais rugoso, é considerado característico de materiais mais rígidos (NAIR et al., 2010), o que concorda com os valores superiores de $E^{\prime}$ observados nesses filmes, devido ao efeito de enrijecimento que estruturas típicas de LK e LK-Glu causaram nas PUs.

Os valores observados de $E^{\prime}$ para os filmes formados simultaneamente à síntese utilizando CO, LK ou LK-Glu e pMDI como reagentes foram majoritariamente superiores (PU $=4 \mathrm{MPa} ;$ LignoPU $_{\text {ColK10 }}=6 \mathrm{MPa} ;$ LignoPU $_{\text {CoLK-Glu10 }}=43 \mathrm{MPa} ;$ LignoPU $_{\text {CoLK30 }}=832 \mathrm{MPa}$; LignoPU $_{\text {CoLK-Glu30 }}=688 \mathrm{MPa}$; LignoPU CoLk50 $=1034 \mathrm{MPa}$ e LignoPU CoLK-Glu50 $=1092 \mathrm{MPa}$ ) aos encontrados para os filmes formados a partir de tHDI nas mesmas concentrações de LK e LKGlu (Figura 54). Esse resultado já era esperado, uma vez que a estrutura do isocianato pMDI é essencialmente aromática, portanto, mais rígida que a estrutura alifática do tHDI. Isso também se refletiu na $T_{\mathrm{g}}$ dos domínios flexíveis dos filmes formados simultaneamente à 
síntese realizada a partir de PMDI $\left(\mathrm{PU}_{\mathrm{CO}}=8^{\circ} \mathrm{C}\right.$; LignoPU $\mathrm{COLK} 10=15^{\circ} \mathrm{C}$; LignoPU COLK-Glu10 $=26^{\circ} \mathrm{C}$;

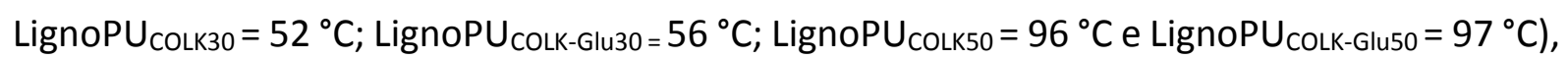
tanto que os filmes onde $30 \%$ de LK ou LK-Glu e pMDI foram utilizados como matéria-prima, ainda estavam no estado rígido à temperatura ambiente, diferentemente dos filmes em que foram usados 30 \% de LK e LK-Glu e tHDI na formulação e que se encontravam na transição vítrea. Todavia, o efeito da modificação química (aumento no $\mathrm{E}^{\prime}$ e $T_{\mathrm{g}} 1^{\circ}$ pico) realizada em LKGlu aparentemente foi mais evidente nos filmes em que tHDI foi usado como isocianato nas três concentrações avaliadas (10, 30 e 50 \%) de LK-Glu, enquanto que nos filmes onde pMDI

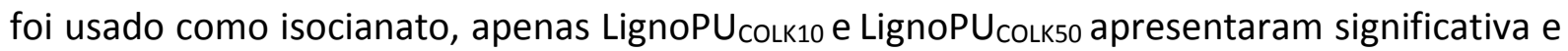
discreta melhoria, respectivamente.

\subsubsection{Propriedades de Tração}

A Figura 55 apresenta os resultados de resistência à tração, módulo de Young, e alongamento na ruptura dos filmes lignopoliuretânicos preparados simultamente à síntese utilizando CO, LK ou LK-Glu, e tHDI como reagentes, e do filme em que apenas CO foi utilizado como poliol ( $\mathrm{PUH}_{\mathrm{CO}}$ ). É importante salientar que os filmes formados nas sínteses a partir de 30 e 50 \% de LK ou LK-Glu não romperam nas mesmas condições dos outros filmes, sendo assim, houve a necessidade de diminuir a largura desses filmes para conseguir avaliar as propriedades de tração (Item 1.2.5.6). 
Figura 55 - (a) Resistência à ruptura, (b) módulo de Young e (c) alongamento na ruptura dos filmes poliuretânicos formados simultaneamente à síntese realizada a partir de CO, LK ou LK-Glu e tHDI.

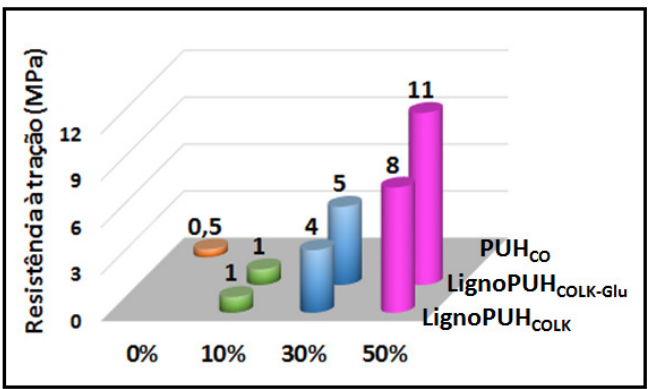

(a)

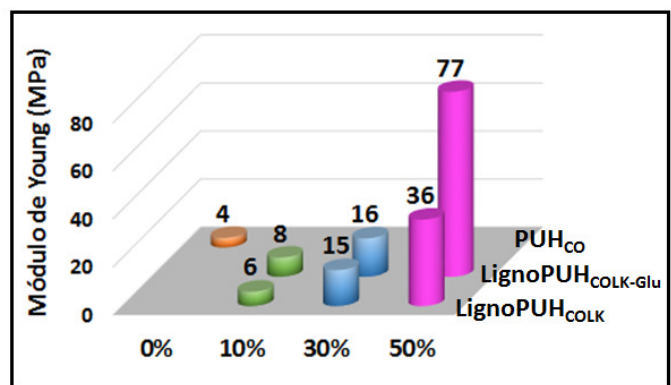

(b)

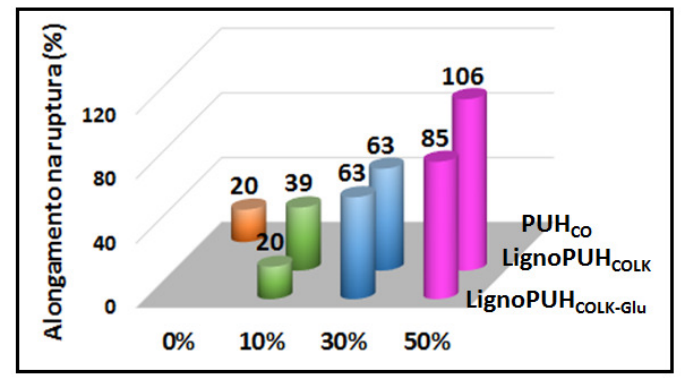

(c)

*Desvios-padrão: Resistência a ruptura $=\left[\mathrm{De} \pm 0,1\left(\mathrm{PUH}_{\mathrm{CO}}\right)\right.$ a $\pm 0,7$ (LignoPUH $\left.\mathrm{LOLk50}_{0}\right)$ ], módulo de Young $=\left[\mathrm{De} \pm 0,1\left(\mathrm{PUH}_{\mathrm{CO}}\right)\right.$ a $\pm 1,2\left(\right.$ LignoPUH $\left.\left._{\text {COLK50) }}\right)\right]$ e alongamento na ruptura $=\left[\mathrm{De} \pm 0,9\left(\mathrm{PUH}_{\text {COLK-Glu10 }}\right) \mathrm{a} \pm\right.$

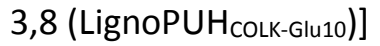

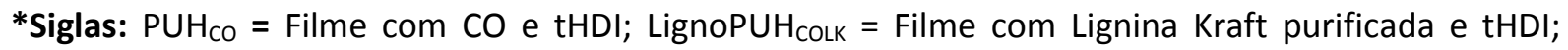
LignoPUH $_{\text {COLK-Glu }}=$ Filme com lignina modificada por hidroxialquilação e tHDI.

A Figura 55 a mostra que o filme PUHco praticamente não demonstrou resistência a

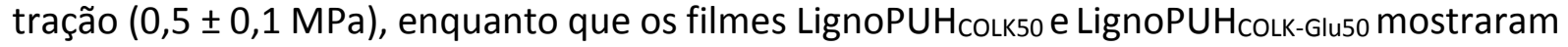
resultados de $8 \pm 1 \mathrm{MPa}$ e $11 \pm 1 \mathrm{MPa}$, evidenciando o impacto positivo nessa propriedade causado pela presença de estruturas típicas da lignina na estrutura química da poliuretana.

A análise de resistência à tração foi realizada à temperatura ambiente, ou seja, uma temperatura superior ou muito próxima as $T_{\mathrm{g}} \mathrm{s}$ referentes aos domínios soft presentes em regiões não cristalinas encontradas para esses filmes, de acordo com os resultados obtidos na análise de DMA $\left(T_{\mathrm{g}} 10\right.$ pico $\mathrm{PUH} \mathrm{CO}_{\mathrm{CO}}=1{ }^{\circ} \mathrm{C} ; T_{\mathrm{g}} 10$ pico LignoPU $\mathrm{COLK} 10=8{ }^{\circ} \mathrm{C} ; T_{\mathrm{g} 10 \text { pico LignoPUH }}$ CoLk-Glu10 $=$

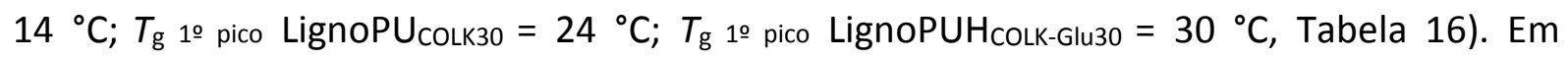

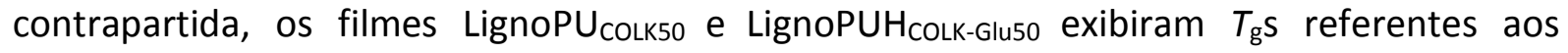
domínios flexíveis de regiões não cristalinas de 46 e $54{ }^{\circ} \mathrm{C}$ (2.3.1.7, Tabela 16), estando, portanto no estado rígido a $25^{\circ} \mathrm{C}$. Os valores obtidos para resistência à ruptura dos filmes que se encontravam no estado flexível foram inferiores aos obtidos para os filmes que se encontravam no estado vítreo (Figura 55 a). 
Ainda na Figura 55 a, a resistência à tração dos filmes formados simultaneamente à síntese utilizando LK-Glu como reagente foi superior à dos formados a partir de LK, principalmente nas maiores concentrações avaliadas (30 e 50 \%). Como discutido no Capítulo 1 (itens 1.3.1.3 e 1.3.1.4), as $\mathrm{OH}$ alifáticas inseridas na estrutura de LK-Glu, oriundas do glutaraldeído, levaram a reações dessas macromoléculas entre si, levando a "macromonômeros" de maior massa molar média, comparativamente a LK e, portanto, a PUs de maior massa molar média e enriquecidas com segmentos rígidos, o que pode justificar a maior resistência destes filmes.

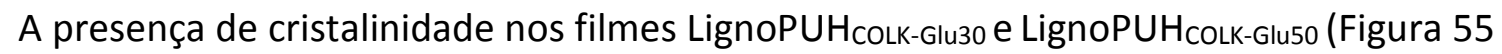
a) aparentemente não influenciou no aumento nos valores de resistência à ruptura desses

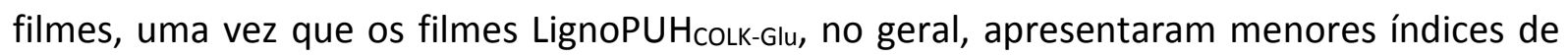
cristalinidade que os filmes LignoPUH

A análise de DMA (Item 2.3.1.7) mostrou que todos os filmes formados simultaneamente à síntese a partir de LK ou LK-Glu, e tHDI como reagentes, apresentaram segregação de fases em domínios soft ( $1^{\circ}$ pico) e hard $\left(2^{\circ}\right.$ pico) sendo o primeiro pico mais intenso que o segundo, ou seja, com maior número de segmentos flexíveis do que rígidos na porção não cristalina das PUs. A inserção de estruturas típicas de LK ou LK-Glu nas PUs proporcionou o aparecimento da fase rígida e, conforme a concentração de lignina aumentou nas lignopoliuretanas, aumentou também a intensidade da fase rígida (Figura 55 b e c). Isso mostra que as estruturas típicas de LK e LK-Glu permitiram elevar a massa molar dessas PUs, tornando os filmes mais resistentes à ruptura, especialmente as elaboradas com LK-Glu, que possui maior massa molar e $\mathrm{OH}$ comparativamente à LK em função de sua modificação química.

Para, o módulo de Young (Figura 55 b) também foi observado o mesmo perfil de

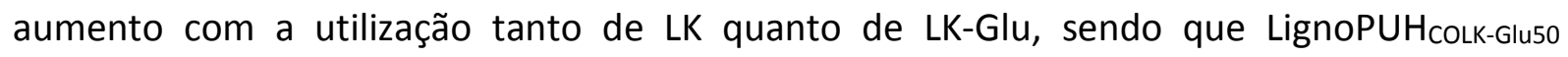
apresentou o maior valor para essa propriedade (77 $\pm 1 \mathrm{MPa}$ ) e a maior diferença (53 \%) no módulo de Young em relação à LignoPUHcoLk-Glu50.

Com relação ao alongamento na ruptura (Figura $55 \mathrm{c}$ ), o filme $\mathrm{PUH}_{\mathrm{co}}$, o qual contém maior número de segmentos flexíveis oriundos do CO apresentou $20 \pm 3 \%$ de alongamento na ruptura e os filmes LignoPUH $63 \pm 3$ e $106 \pm 2 \%$, respectivamente, de alongamento na ruptura. Esse acréscimo pode ser explicado pela inserção de LK (macromolécula com massa molar ponderal média em torno de 
$2500 \mathrm{~g} \mathrm{~mol}^{-1}$ ) na formulação das PUs que geraram os filmes que ocasionou o aumento na massa molar média das PUs de forma que os respectivos filmes se tornaram mais resistentes à ruptura comparado ao filme PUHCo (Figura 55 a), o que permitiu que os filmes atingissem maior alongamento na ruptura, devido a contribuição dos segmentos flexíveis do CO à estrutura química da PU (Figura 55 c). Estes resultados podem indicar que à síntese dos filmes com tHDI, à temperatura ambiente, na ausência de catalisador, leva a poliuretanas de baixa massa molar média, quando LK não é usada como reagente ( $\mathrm{PUH}$ Co) prejudicando as propriedades de tração.

Para os filmes formados simultaneamente à síntese realizada a partir de LK-Glu, em todas as concentrações avaliadas (10, 30 e 50 \%) não foi observado acréscimo nessa propriedade em relação a LignoPUH CoLk $_{\text {(Figura } 55 \text { c). Os filmes LignoPUH }}$ CoLk-Glu1o e

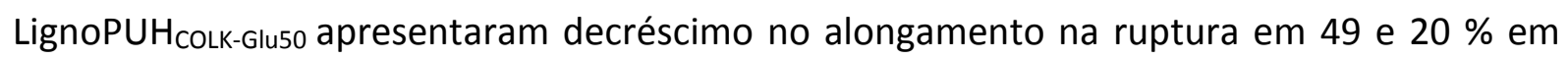
relação aos filmes formados a partir de LK nas mesmas concentrações.

A baixa resistência à ruptura de $\mathrm{PUH}_{\mathrm{CO}}$, LignoPUH $\mathrm{COLK10}_{10}$ e LignoPUH $\mathrm{COLK}_{\mathrm{C} \text {-Glu10 }}$ não permitiu que esses filmes alongassem muito comparativamente aos outros filmes A maior resistência

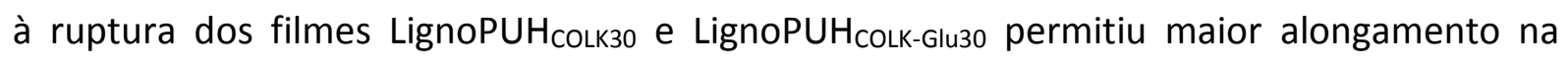
ruptura para os mesmos.

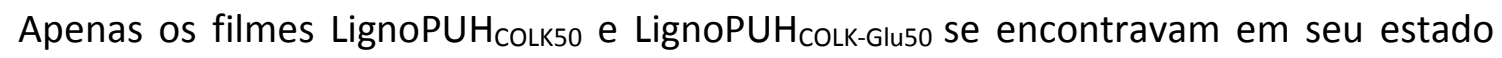
rígido a $25{ }^{\circ} \mathrm{C}\left(T_{\mathrm{gs}}=46{ }^{\circ} \mathrm{C}\right.$ e $\left.54{ }^{\circ} \mathrm{C}\right)$, e neles foi possível observar os maiores valores de alongamento na ruptura (106 $\pm 2 \%$ e $85 \pm 1 \%$ ) em relação aos demais filmes, o que infere que, para os filmes preparados com tHDI, a inserção de 50 \% de LK e LK-Glu foi importante para aumentar a resistência dessas PUs ao ponto de proporcionar melhor desempenho no parâmetro de alongamento na ruptura.

A Tabela 17 apresenta uma comparação dos resultados do ensaio de tração dos filmes produzidos com lignina, pMDI e tHDI a $25^{\circ} \mathrm{C}$. 
Tabela 17 - Comparação dos resultados do Análise de propriedades de Tração dos filmes preparados simultaneamente à síntese realizada a partir de pMDI e tHDI a $25^{\circ} \mathrm{C}$

\begin{tabular}{lcccccc}
\hline \multirow{2}{*}{ Amostra } & \multicolumn{2}{c}{$\begin{array}{c}\text { Resistência à Ruptura } \\
\text { (MPa) }\end{array}$} & \multicolumn{2}{c}{$\begin{array}{c}\text { Módulo de Young } \\
\text { (MPa) }\end{array}$} & \multicolumn{2}{c}{$\begin{array}{c}\text { Alongamento na } \\
\text { Ruptura (MPa) }\end{array}$} \\
\cline { 2 - 7 } & pMDI & tHDI & pMDI & tHDI & pMDI & tHDI \\
\hline CO & $0,3 \pm 0,1$ & $0,5 \pm 0,1$ & $2,0 \pm 0,1$ & $4,0 \pm 0,1$ & $29 \pm 1$ & $20 \pm 3$ \\
LK10 & $1,0 \pm 0,1$ & $0,9 \pm 0,2$ & $3,0 \pm 0,1$ & $6,0 \pm 0,5$ & $21 \pm 2$ & $39 \pm 4$ \\
LK-Glu10 & $2,0 \pm 0,1$ & $1,1 \pm 0,1$ & $8,0 \pm 0,2$ & $8,0 \pm 0,1$ & $39 \pm 3$ & $20 \pm 1$ \\
LK30 & $11,0 \pm 0,2$ & $4,0 \pm 0,4$ & $93 \pm 3$ & $15,0 \pm 0,5$ & $60 \pm 2$ & $63 \pm 3$ \\
LK-Glu30 & $10,0 \pm 0,3$ & $5,0 \pm 0,1$ & $112 \pm 4$ & $16,0 \pm 0,3$ & $45 \pm 2$ & $63 \pm 3$ \\
LK50 & $19 \pm 1$ & $8 \pm 1$ & $745 \pm 15$ & $36 \pm 1$ & $4,0 \pm 0,3$ & $106 \pm 2$ \\
LK-Glu50 & $23 \pm 1$ & $11 \pm 1$ & $1134 \pm 3$ & $77 \pm 1$ & $5,0 \pm 0,0$ & $85 \pm 1$ \\
\hline
\end{tabular}

O uso de LK e LK-Glu na síntese das PUs teve o mesmo efeito de enrijecimento das cadeias tanto nos filmes formados simultaneamente à síntese realizada utilizando isocianato do tipo aromático (pMDI) quanto alifático (tHDI) (Tabela 17).

De maneira geral, a Tabela 17, mostra que os valores de resistência à ruptura e módulo de Young dos filmes formados simultaneamente à síntese realizada a partir de LK ou LK-Glu, e pMDI a $25{ }^{\circ} \mathrm{C}$ são superiores aos encontrados para os filmes em que tHDI foi utilizado nas mesmas concentrações de LK ou LK-Glu. Esse resultado já era esperado uma vez que o isocianato pMDI possui uma estrutura essencialmente aromática, portanto mais rígida, que o isocianato alifático tHDI. Essa estrutura aromática do pMDI junto com o macromonômero igualmente aromático da LK e LK-Glu acarretou em maiores valores de resistência à ruptura e módulo de Young, assim como, alterou para temperaturas maiores às $T_{\mathrm{g}} \mathrm{d}$ dos domínios flexíveis das LignoPUs (Item 2.3.1.7).

As cadeias dos filmes formados a partir de 30 e $50 \%$ de LK e LK-Glu e pMDI ainda se encontravam no estado rígido à temperatura ambiente, enquanto que para os filmes em que tHDI foi utilizado como isocianato na síntese, apenas os filmes que continham $50 \%$ de LK e

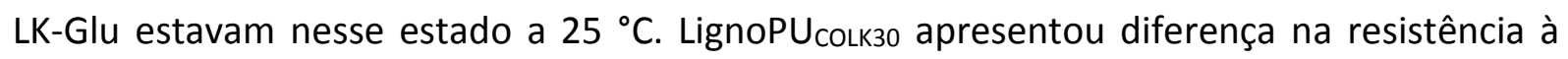

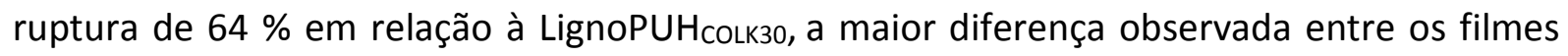
produzidos simultaneamente à síntese com pMDI e tHDI, e isso pode ser exlicado pelo fato 
dos filmes formados simultaneamente à síntese realizada a partir de tHDI estar na transição vítrea, enquanto o filme em que pMDI foi utilizado estava no estado rígido.

A utilização de LK-Glu, de maneira geral, elevou os valores de resistência à ruptura e módulo de Young em relação aos filmes em que LK foi utilizada, nas mesmas concentrações, na síntese, tanto nos filmes formados simultaneamente à síntese realizada a partir de pMDI quanto tHDI. Todavia os filmes formados a partir de LK-Glu e tHDI, de maneira geral, apresentaram maiores diferenças nesses parâmetros em relação aos filmes preparados com LK nas mesmas concentrações, do que os filmes cujas sínteses foram realizadas a partir de LKGlu e pMDI, indicando que LK-Glu interagiu melhor com o isocianato tHDI, provavelmente devido o menor impedimento estérico existente.

Para o alongamento na ruptura (Tabela 17), o acréscimo de até $30 \%$ de LK e LK-Glu provocou um aumento nessa propriedade nos filmes cuja síntese utilizou tHDI (LignoPUH colk30

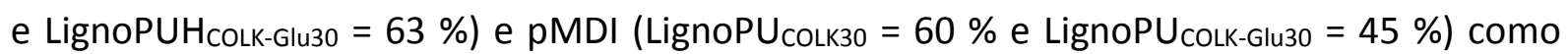
reagentes, entretanto o filme formado simultaneamente à síntese a partir de tHDI estava na transição vítrea durante a análise de tração, portanto com maior mobilidade das cadeias que os filmes cuja síntese utilizou pMDI nessa concentração. Já os filmes LignoPU ${ }_{\text {colk50 e }}$

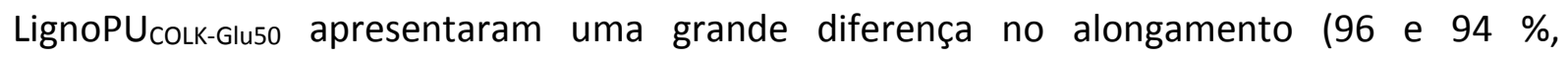

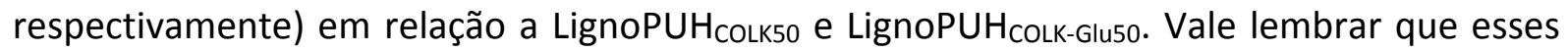
filmes se encontravam no estado rígido, logo na concentração de 50 \% de LK e LK-Glu, foi possível perceber a influência da estrutura alifática das PUs produzidas com tHDI, uma vez que nessa condição, elas estavam com resistência suficiente para permitir maiores alongamentos.

Outra observação importante é a de que os filmes em que LK-Glu e tHDI foram usados como reagentes na síntese, não obtiveram maiores alongamentos na ruptura em relação aos filmes em que LK e tHDI foram usados, diferentemente do que foi observado nos filmes formados simultaneamente à síntese a partir de 10 e $50 \%$ de LK-Glu e pMDI em relação aos filmes produzidos a partir de LK nessas concentrações. Sendo assim, infere-se que nos filmes em que à síntese foi realizada a partir de $\mathrm{pMDI}$, devido ao menor número de componentes flexíveis alifáticos na estrutura das PUs, a modificação química realizada em LK-Glu, que inseriu cadeias alifáticas hidrocarbônicas e di-hidroxiladas, permitiu juntamente com os segmentos flexíveis do $\mathrm{CO}$, que os filmes atingissem maior alongamento na ruptura em relação aos preparados com LK e pMDI. Já nos filmes em que tHDI foi utilizado como reagente, 
a introdução de cadeias alifáticas flexíveis em uma estrutura que já continha maior teor de componentes alifáticos não influenciou na propriedade de alongamento na ruptura em comparação aos filmes formados a partir de LK.

\subsubsection{Avaliação da Influência da temperatura na reação de síntese das LignoPUHs sobre as propriedades dos filmes lignopoliuretânicos formados utilizando CO, LK ou LK-Glu como polióis e tHDI como isocianato}

Com base nos resultados obtidos para os filmes formados simultaneamente à síntese realizada a partir de CO, LK ou LK-Glu, e pMDI descritos no Capítulo 1, apenas a temperatura de $100{ }^{\circ} \mathrm{C}$ foi considerada nas reações (após o espalhamento das LignoPUHs nas placas) realizadas a partir de CO, 30 e 50 \% de LK e LK-Glu, e tHDI. Os filmes foram caracterizados via TGA; DRX; DMA; Ensaio de Resistência a Tração; Ângulo de contato e Teste de intumescimento.

\subsubsection{Espectroscopia na região do infravermelho com transformada de Fourier \\ Os espectros das misturas reacionais (CO, 30 e $50 \%$ de LK ou LK-Glu e tHDI)} imediatamente após deposição na placa $(t=0 h)$ e dos respectivos filmes formados nas diferentes temperaturas avaliadas pode ser observado no Apêndice G.

O aumento da temperatura para $100{ }^{\circ} \mathrm{C}$ durante a reação de polimerização em todas as sínteses diminuiu o intervalo de tempo no qual não mais foi observada a banda referente ao grupo isocianato, confirmando consumo total de tHDI. A ausência da banda referente ao reagente foi considerada como indicador de condição apropriada para retirada do filme da placa. Os intervalos de tempo observados foram 4, 4, 5 e 4 dias para LignoPUH ${ }_{\text {Colkзo, }}$

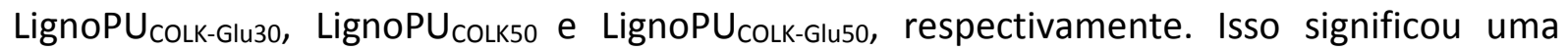
redução de 60, 50, 54 e 60 \% comparativamente aos filmes formados à temperatura ambiente.

Como reportado no Item 1.3.3.1 do Capítulo 1 , na temperatura de $100{ }^{\circ} \mathrm{C}$, reações secundárias do grupo isocianato podem ocorrer, levando a formação de, por exemplo, alofanatos (YILGOR et al., 2015). O aparecimento da banda referente à vibração da carbonila $\left(C=0\right.$ ) em PUs em frequências mais baixas (aproximadamente $1650 \mathrm{~cm}^{-1}$ ) no espectro de FTIR, é atribuída a vibração da carbonila ligada ao grupo N-H em alofanatos (WANG et al., 2017). 
Neste estudo, essa banda apareceu entre $1675-1679 \mathrm{~cm}^{-1}$ nos filmes formados a $100{ }^{\circ} \mathrm{C}$ (Apêndice $\mathrm{G}$ ), ou seja, valores de número de onda para vibração de $\mathrm{C}=0$ semelhantes aos dos

filmes formados à temperatura ambiente (LignoPUH CoLK30 $=1682 \mathrm{~cm}^{-1}$; LignoPUH $1677 \mathrm{~cm}^{-1}$; LignoPUH COLK50 $=1680 \mathrm{~cm}^{-1}$ e LignoPUH CoLK-Glu50 $=1679 \mathrm{~cm}^{-1}$ ), indicando que provavelmente não houve a formação de grupos alofanato, ou foram gerados em número insuficiente para detecção no espectro FTIR.

\subsubsection{Microscopia Eletrônica de Varredura}

$\mathrm{O}$ aumento da temperatura durante a reação de polimerização para $100{ }^{\circ} \mathrm{C}$ não alterou a morfologia da superfície dos filmes preparados com CO, 30 e 50\% de LK ou LK-Glu e tHDI. Em todos eles, a superfície se mostrou homogênea e sem a presença de bolhas ou sulcos (micrografias não mostradas), semelhantes às observadas no Item 2.3.1.2.

A Figura 56, apresenta as micrografias das criofraturas dos filmes formados simultaneamente às reações ocorridas a $100{ }^{\circ} \mathrm{C}$. Para fins de comparação, a Figura 56 , foram inseridas as micrografias obtidas para os filmes formados à temperatura ambiente $\left(25^{\circ} \mathrm{C}\right.$, 2.3.1.2). 
Figura 56 - Micrografias eletrônicas de varredura da criofratura dos filmes lignopoliuretânicos formados simultaneamente as sínteses ocorridas a partir de CO, 30 e $50 \%$ de LK ou LK-Glu, e tHDI, a 25 e $100^{\circ} \mathrm{C}$.
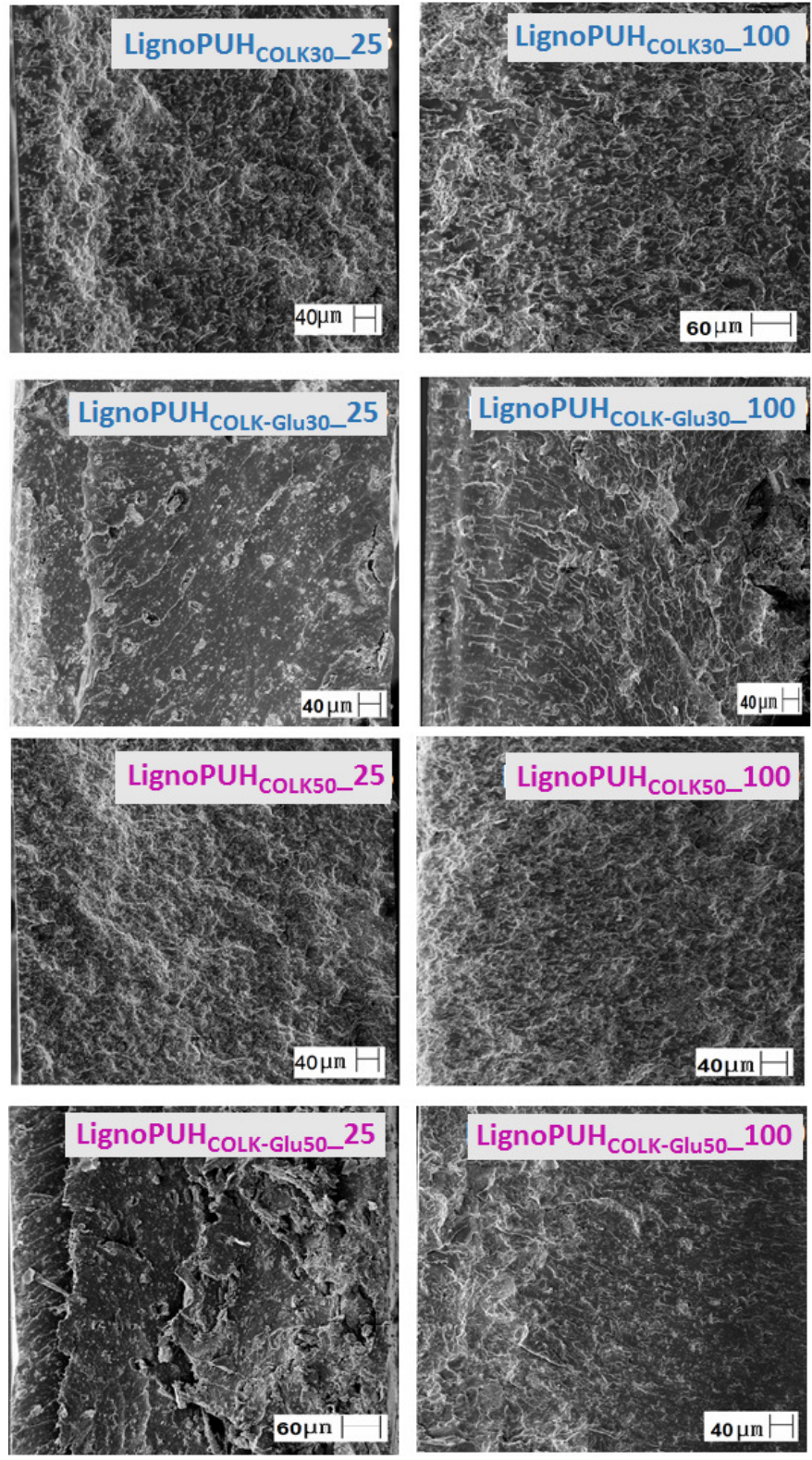

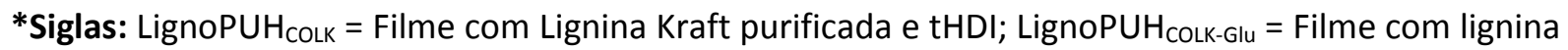
modificada por hidroxialquilação e tHDI.

A utilização de $100{ }^{\circ} \mathrm{C}$ durante a reação de polimerização das LignoPUHs, aparentemente tornou a superfície de fratura dos filmes, em geral, mais densas e principalmente, homogêneas que a dos filmes cujas sínteses ocorreram à temperatura ambiente (Figura 56). Os filmes formados simultaneamente à síntese realizada a partir de LK-Glu a $100{ }^{\circ} \mathrm{C}$ apresentaram maior homogeneidade na superfície de fratura comparativamente aos formados a partir de LK na mesma temperatura (Figura 56). 


\subsubsection{Termogravimetria}

O aumento para temperaturas $100{ }^{\circ} \mathrm{C}$ durante a reação de polimerização das LignoPUHs não alterou significativamente o perfil da decomposição térmica dos filmes formados, comparativamente aos filmes formados à temperatura ambiente. As curvas referentes à termogravimetria (TGA) e termogravimetria derivada (DTG) dos filmes formados a partir de CO, 30 e 50 \% de LK e LK-Glu e tHDI, $100^{\circ} \mathrm{C}$ são apresentadas no Apêndice $\mathrm{H}$.

As Tabelas 18 e 19 apresentam os resultados termogravimétricos obtidos para os filmes

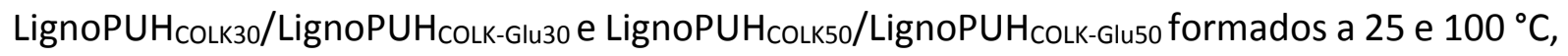
respectivamente.

Tabela 18 - Temperaturas e perdas de massa observadas nos filmes LignoPUH COLK30_25; LignoPUH $_{\text {CoLK- }}$ Glu30_25; LignoPUH ${ }_{\text {CoLk30_100 e LignoPUH }}$ CoLK-Glu30_100 em atmosfera de $\mathrm{N}_{2}$

\begin{tabular}{|c|c|c|c|c|c|c|}
\hline \multirow{2}{*}{ Filme } & \multicolumn{3}{|c|}{$\begin{array}{c}\text { Evento } 1 \\
\left(300-406^{\circ} \mathrm{C}\right)\end{array}$} & \multicolumn{2}{|c|}{$\begin{array}{c}\text { Evento } 2 \\
\left(406-530^{\circ} \mathrm{C}\right)\end{array}$} & \multirow{2}{*}{$\begin{array}{c}\begin{array}{c}\text { Resíduo } \\
\left(900^{\circ} \mathrm{C}\right)\end{array} \\
\text { Massa } \\
\text { (\%) }\end{array}$} \\
\hline & $\begin{array}{l}T_{\text {onset }} \\
\left({ }^{\circ} \mathrm{C}\right)\end{array}$ & $\begin{array}{l}T_{\text {Máx }} \\
\left({ }^{\circ} \mathrm{C}\right)\end{array}$ & $\begin{array}{l}\text { Perda de } \\
\text { massa (\%) }\end{array}$ & $\begin{array}{l}T_{\text {Máx }} \\
\left({ }^{\circ} \mathrm{C}\right)\end{array}$ & $\begin{array}{l}\text { Perda de } \\
\text { massa (\%) }\end{array}$ & \\
\hline LignoPUH_сокк30_25 & 321 & 375 & 27,0 & 467 & 59,4 & 5,5 \\
\hline LignoPUH_coLk30_100 & 324 & 376 & 27,3 & 465 & 54,6 & 9,2 \\
\hline LignoPUH_CoLK-Glu30_25 & 334 & 379 & 22,1 & 469 & 62,8 & 4,5 \\
\hline LignoPUH_coLk-Glu30_100 & 333 & 377 & 21,4 & 471 & 62,2 & 6,7 \\
\hline
\end{tabular}

Tabela 19 - Temperaturas e perdas de massa observadas nos filmes LignoPUH CoLK50_25; LignoPUH $_{\text {CoLk- }}$ Glu50_25; LignoPUH ${ }_{\text {CoLk50_100 e LignoPUH }}$ CoLK-Glu50_100 em atmosfera de $\mathrm{N}_{2}$

\begin{tabular}{|c|c|c|c|c|c|c|}
\hline \multirow{2}{*}{ Filme } & \multicolumn{3}{|c|}{$\begin{array}{c}\text { Evento } 1 \\
\left(300-406^{\circ} \mathrm{C}\right)\end{array}$} & \multicolumn{2}{|c|}{$\begin{array}{c}\text { Evento } 2 \\
\left(406-540^{\circ} \mathrm{C}\right) \\
\end{array}$} & \multirow{2}{*}{$\begin{array}{c}\begin{array}{r}\text { Resíduo } \\
\left(900^{\circ} \mathrm{C}\right)\end{array} \\
\begin{array}{c}\text { Massa } \\
(\%)\end{array}\end{array}$} \\
\hline & $\begin{array}{l}T_{\text {onset }} \\
\left({ }^{\circ} \mathrm{C}\right)\end{array}$ & $\begin{array}{l}T_{\text {Máx }} \\
\left({ }^{\circ} \mathrm{C}\right)\end{array}$ & $\begin{array}{l}\text { Perda de } \\
\text { massa (\%) }\end{array}$ & $\begin{array}{l}T_{\text {Máx }} \\
\left({ }^{\circ} \mathrm{C}\right)\end{array}$ & $\begin{array}{l}\text { Perda de } \\
\text { massa (\%) }\end{array}$ & \\
\hline LignoPUH_coLk50_25 & 323 & 367 & 21,3 & 470 & 53,5 & 14,1 \\
\hline LignoPUH_colk50_100 & 325 & 368 & 20,0 & 464 & 57,1 & 13,2 \\
\hline LignoPUH_coLK-Glu50_25 & 328 & 367 & 16,3 & 468 & 62,6 & 11,1 \\
\hline LignoPUH_CoLK-Glu50_100 & 332 & 375 & 22,8 & 478 & 60,8 & 11,7 \\
\hline
\end{tabular}

A temperatura inicial ( $T_{\text {onset }}$ ) de decomposição dos filmes (Tabela 18 e 19) praticamente não foi alterada em função do uso de temperaturas mais elevadas nas reações que levaram à formação dos filmes. 
Também não foram observadas diferenças significativas no percentual de massa residual dos filmes formados a partir de 30 e $50 \%$ de LK ou LK-Glu nà temperatura ambiente e $100{ }^{\circ} \mathrm{C}$ (Tabelas 18 e 19). Isso se deve ao fato de que a composição dos reagentes não foi modificada, a única variável considerada foi a temperatura de síntese. Pequenas diferenças nesses valores podem ser inerentes à técnica e a heterogeneidade da matéria-prima.

\subsubsection{Difração de raios $X$}

A cristalinidade dos filmes lignopoliuretânicos formados a partir de 30 e 50 \% de LK ou LK-Glu, e tHDI a $100{ }^{\circ} \mathrm{C}$ foi avaliada pela análise de difração de raios X (Figura 57). Para fins de comparação, a Figura 57, também apresenta as curvas de DRX obtidos para os respectivos filmes formados temperatura ambiente $\left(25^{\circ} \mathrm{C}\right.$; Item 2.3.1.4).

Figura 57 - Curvas de difração de raios $X$ para os filmes lignopoliuretânicos: (a) LignoPUH colk30 $\mathrm{e}$

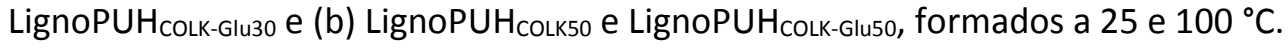

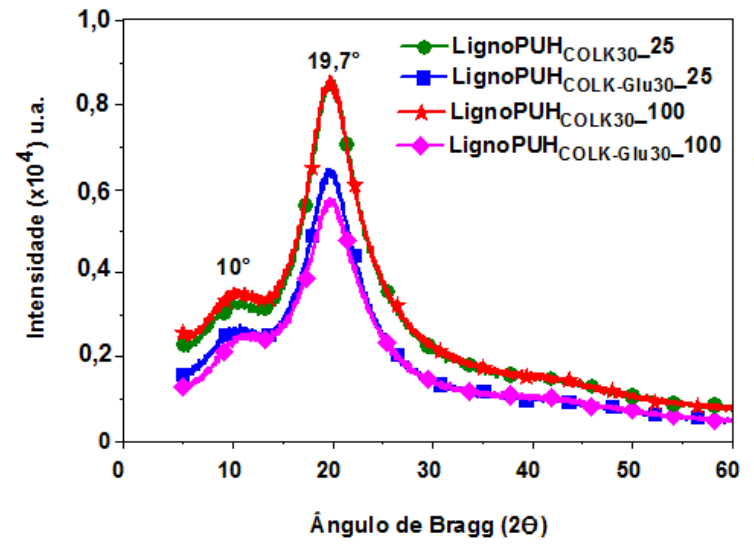

(a)

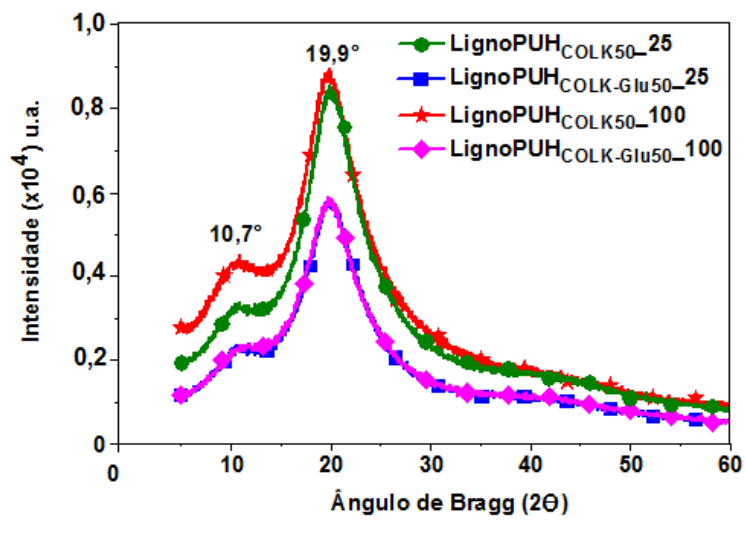

(b)

*Siglas: LignoPUH ${ }_{\text {coLK }}=$ Filme com Lignina Kraft purificada e tHDI; LignoPUH CoLK-Glu $_{\text {- Filme com lignina }}$ modificada por hidroxialquilação e tHDI.

Para todos os filmes observa-se um pico intenso em $2 \theta=19,7^{\circ}-19,9^{\circ}$, e outro de menor intensidade em $2 \theta=10,0^{\circ}-10,7^{\circ}$ (Figura 57), evidenciando a formação de regiões ordenadas de diferentes tamanhos e geometrias nos filmes produzidos, como comentado no Item 2.3.1.4. Os ICr calculados pela diferença na intensidade de picos específicos, correspondentes a domínios cristalinos e da região não cristalina (KIM et al., 2016; ALEXANDER, 1969), para os

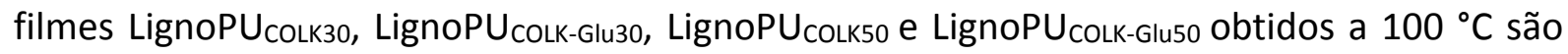


mostrados na Tabela 20. Para fins de comparação também são apresentados os resultados para os filmes formados à temperatura ambiente $\left(25^{\circ} \mathrm{C}\right.$; Item 2.3.1.4).

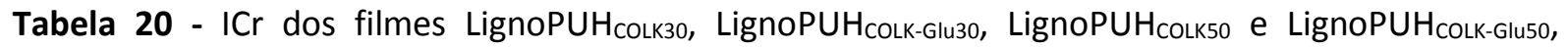
produzidos a 25 e $100^{\circ} \mathrm{C}$

\begin{tabular}{ccc}
\hline \multirow{2}{*}{ Filmes } & \multicolumn{2}{c}{$\mathrm{IC}_{\mathrm{C}}(\mathbf{\%})$} \\
\cline { 2 - 3 } & $\mathbf{2 5 ^ { \circ } \mathbf { C }}$ & $\mathbf{1 0 0}^{\circ} \mathbf{C}$ \\
\hline LignoPUH & 51 & 51 \\
CoLk30 & 49 & 44 \\
LignoPUH $_{\text {COLK-Glu30 }}$ & 45 & 45 \\
LignoPUH $_{\text {COLK50 }}$ & 40 & 40 \\
LignoPUH & \\
\hline
\end{tabular}

Conforme observado na Figura 57 e na Tabela 20, o aumento na temperatura durante a reação de polimerização das LignoPUHs não influenciou a cristalinidade dos filmes formados tanto a partir de LK quanto de LK-Glu.

Para os filmes formados simultaneamente à síntese utilizando LK e LK-Glu como polióis nas mesmas concentrações e pMDI como isocianato, o aumento na temperatura, de maneira

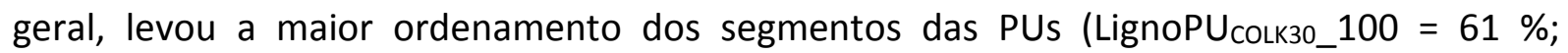
LignoPU $U_{\text {CoLK-Glu30_100 = } 62 \% \text {, LignoPU }}$ CoLK50_100 = $58 \%$; LignoPU CoLk-Glu50_100 = 54 \%), fato que não foi observado para os filmes em que tHDI foi usado como reagente (Tabela 20). Entretanto, os valores de cristalinidade observados para os filmes formados a partir de tHDI a $25{ }^{\circ} \mathrm{C}$ (ver Item 2.3.1.4) foram superiores aos encontrados para os formados a partir de pMDI

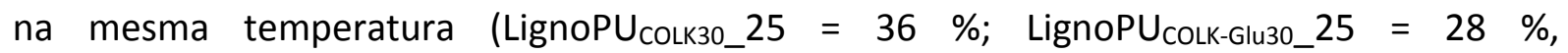
LignoPU ${ }_{\text {COLK50_25 = } 35 \text { \%; LignoPU }}$ COLK-Glu50_25 = $13 \%$ ), \%), provavelmente devido a menor estrutura molecular e menor rigidez do isocianato tHDI, que pode ter levado a um maior ordenamento dos segmentos rígidos.

\subsubsection{Teste de Intumescimento}

A Figura 58 apresenta o gráfico de taxa de intumescimento $(S \%)$ dos filmes formados a partir de PUs sintetizadas com 30 e $50 \%$ de LK ou LK-Glu e tHDI em $100{ }^{\circ} \mathrm{C}$, assim como, as soluções de DMF após a realização do teste de intumescimento. Para fins de comparação, os resultados dos respectivos filmes formados à temperatura ambiente também são mostrados (Item 2.3.1.5) 
Figura 58 - Taxa de Intumescimento $(\mathrm{S} \%)$ dos filmes formados simultaneamente à síntese a partir de: (a) CO, $30 \%$ de LK ou LK-Glu e tHDI a 25 e $100{ }^{\circ} \mathrm{C}$ e fotos das soluções de DMF após realização do teste de intumescimento, sendo: (1) LignoPUH CoLK30_25; (2) LignoPUH $_{\text {Colk30_100; (3) LignoPUH }}$ CoLk-

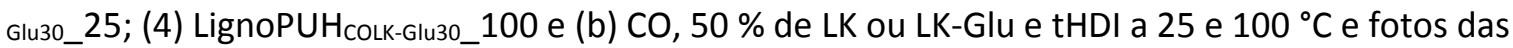

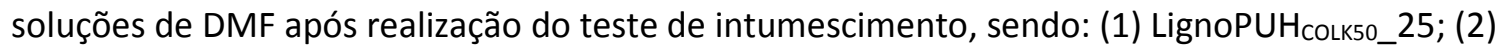

LignoPUH ${ }_{\text {colk50_100; (3) LignoPUH }}$ CoLk-Glu50_25; (4) LignoPUH

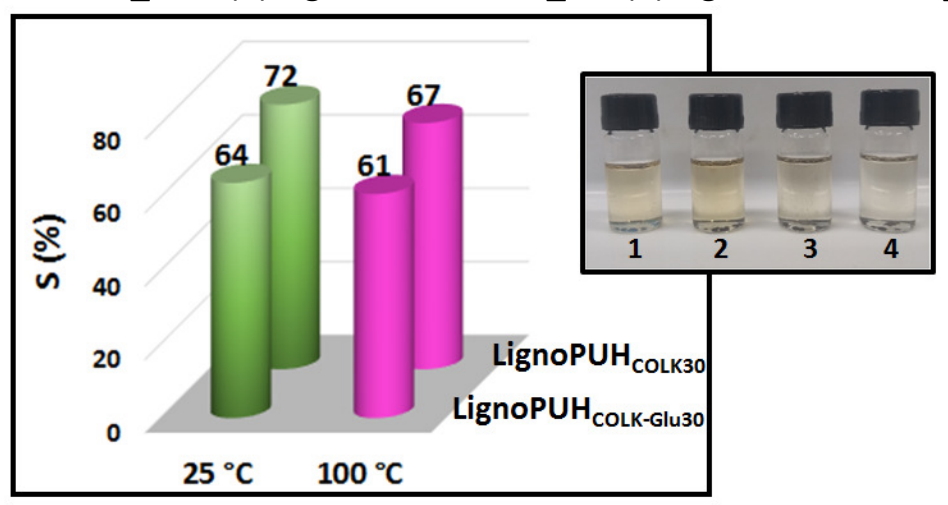

(a)

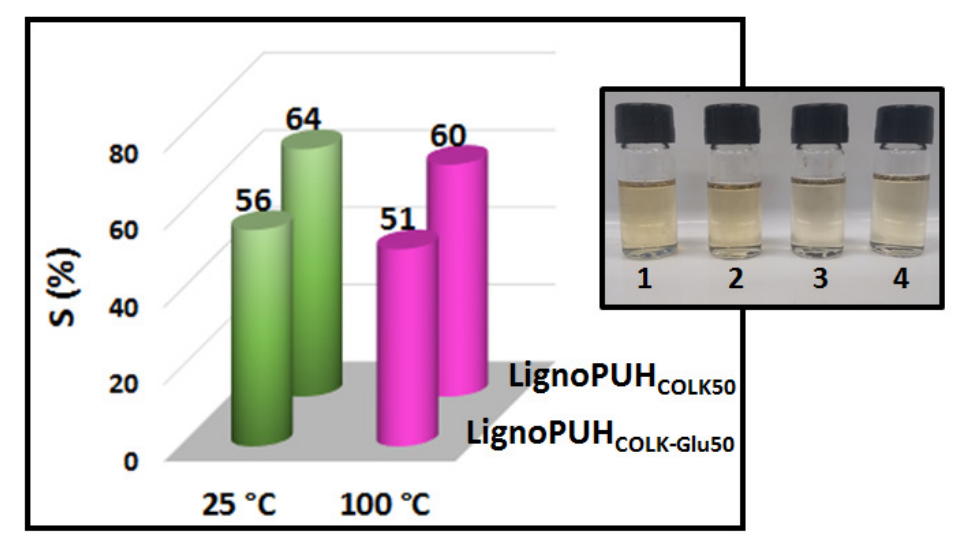

*Desvios-padrão: Filme com 30\% de LK e LK-Glu [De $\pm 0,7$ (LignoPUH ${ }_{\text {colk30_100) a } \pm 1,0 \text { (LignoPUH }}$ colkGlu30_25)]; Filme com 50\% de LK e LK-Glu [De $\pm 0,1$ (LignoPUH ${ }_{\text {colk-Glu50_100) a } \pm 1,5 \text { (LignoPUH }}$ colk50_25)]. *Siglas: LignoPUH ${ }_{\text {CoLK }}=$ Filme com Lignina Kraft purificada e tHDI; LignoPUH CoLK-Glu $=$ Filme com lignina modificada por hidroxialquilação e tHDI.

Conforme observado na Figura 58, os filmes formados a $100{ }^{\circ} \mathrm{C}$ apresentaram diminuição no valor da $S \%$ em relação aos formados à temperatura ambiente. A cristalinidade, um fator que pode impactar negativamente na $S \%$, neste caso, provavelmente não influenciou, uma vez que os valores de $\mathrm{ICr}$ dos filmes formados a $25{ }^{\circ} \mathrm{C}$ foi semelhante aos dos formados a $100^{\circ} \mathrm{C}$, Item 2.3.2.4. Isso pode ser consequência de ligações cruzadas em pequeno número, e não detectas na análise via FTIR, o que levaria a menor volume livre disponível.

Os filmes formados a partir de LK-Glu intumesceram menos que os formados a partir de LK nas duas temperaturas consideradas, evidenciando, novamente, o efeito da modificação química realizada, o que favoreceu reações das macromoléculas entre si, ocasionando o 
aumento da massa molar média e do volume de estruturas típicas desta macromolécula na estrutura química da PU, resultando em menos espaço para moléculas do DMF se alojarem.

A coloração das soluções de DMF após o término do teste de intumescimento (Figura 58), revela que as os filmes formados a partir de LK-Glu a $100{ }^{\circ} \mathrm{C}$ apresentaram cor mais clara, indicando menor volume livre para penetração de solvente. Esse resultado deve ser consequência de menor proporção de PUs de menor massa molar média quando LK-Glu foi usada, uma vez que o "macromonômero" possuía maior massa molar média comparativamente à LK.

\subsubsection{6 Ângulo de Contato}

Na Figura 59 estão apresentados os ângulos de avanço (AA) e recuo (AR) dos filmes formados simultaneamente à síntese realizada a partir de 30 e $50 \%$ de LK ou LK-Glu, a $100{ }^{\circ} \mathrm{C}$. Para fins de comparação, os resultados obtidos para os respectivos filmes formados à temperatura ambiente também são mostrados (Item 2.3.1.6).

Figura 59 - AA e AR para os filmes lignopoliuretânicos preparados simultaneamente à síntese realizada a partir de CO, LK ou LK-Glu e tHDI em diferentes temperaturas.

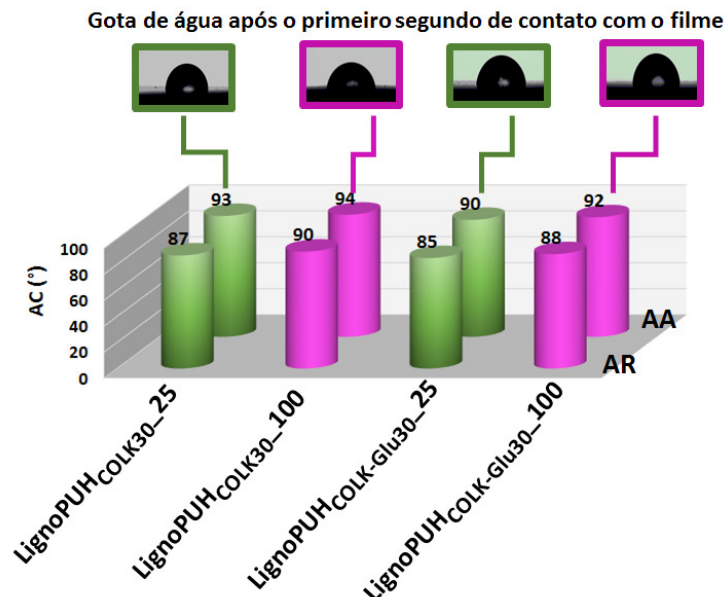

(a)

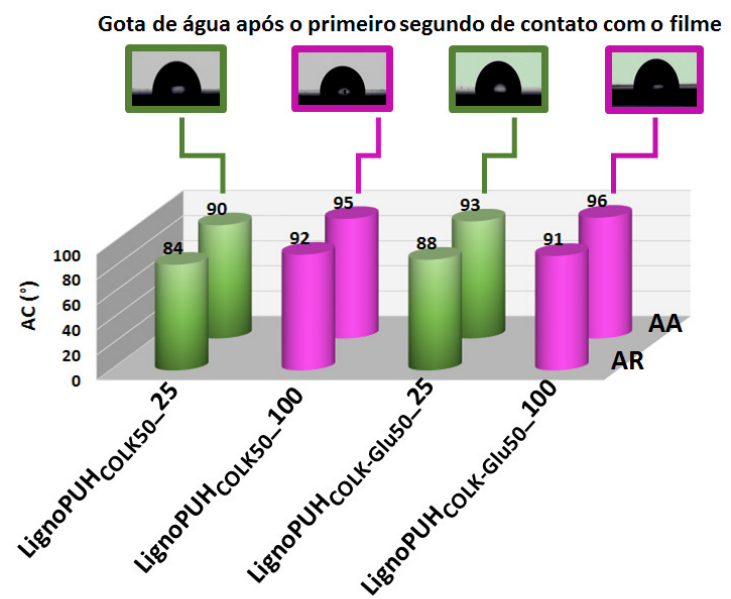

(b)

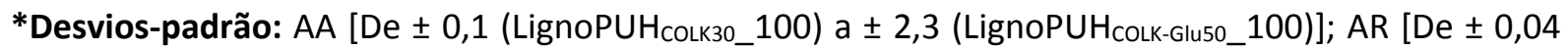
(LignoPUH CoLK30_100) a $\pm 3,5$ (LignoPUH $_{\text {CoLK-Glu30_25)]. }}$

*Siglas: LignoPUH coLK $_{\text {= Filme com Lignina Kraft purificada e tHDI; LignoPUH }}$ coLk-Glu = Filme com lignina modificada por hidroxialquilação e tHDI.

Conforme observado na Figura 59 , o acréscimo na temperatura para $100{ }^{\circ} \mathrm{C}$ durante a reação de polimerização não alterou significativamente os valores de AC tanto para os filmes formados a 30 quanto $50 \%$ de LK e LK-Glu. Todos os filmes apresentaram uma superfície com 
caráter hidrofóbico, uma vez que, os valores de AA observados foram discretamente superiores a $90^{\circ}$.

A diferença entre AA e AR (histerese), foi ligeiramente superior nos filmes formados a

$25{ }^{\circ} \mathrm{C} \quad\left(6\right.$ e $5^{\circ}$ para LignoPU CoLk30/LignoPU $_{\text {CoLK50 }}$ e LignoPU CoLK-Glu3o/LignoPU $_{\text {COLK-Glu50, }}$ respectivamente) em comparação aos formados a $100^{\circ} \mathrm{C}\left(4^{\circ}\right.$ para LignoPU $\mathrm{CoLk30}_{\text {LignoPU }}$ colkGlu30 e 3 e $5^{\circ}$ para LignoPU $U_{\text {Colk50 e LignoPU }}$ Colk-Glu50, respectivamente) indicando que o uso temperaturas mais altas na síntese das PUs levou a formação de filmes com superfícies mais lisas e homogêneas.

\subsubsection{Análise Dinâmico-Mecânica}

A Figura 60 apresenta as curvas Tan- $\delta$ versus temperatura para os filmes formados simultaneamente à síntese realizada a partir de 30 e $50 \%$ de LK ou LK-Glu, a $100^{\circ} \mathrm{C}$. Para fins de comparação, os resultados obtidos para os respectivos filmes formados à temperatura ambiente também são mostrados (Item 2.3.1.7). Destaca-se que a decomposição térmica dos filmes considerados inicia acima de $320{ }^{\circ} \mathrm{C}$ (Tabelas 18 e 19), ou seja, acima do intervalo considerado para DMA. 
Figura 60 - Curvas (a) Tan- $\delta$ para os filmes formados simultaneamente à síntese realizada a partir de $30 \%$ de LK e LK-Glu a 25 e $100{ }^{\circ} \mathrm{C}$ (b) Tan- $\delta$ para os filmes de (a) em escala Tan- $\delta$ reduzida; (c) Tan- $\delta$ para os filmes formados simultaneamente à síntese realizada a partir de $50 \%$ de LK e LK-Glu a 25 e $100{ }^{\circ} \mathrm{C}$ e (d) Tan- $\delta$ para os filmes de (c) em escala Tan- $\delta$ reduzida.

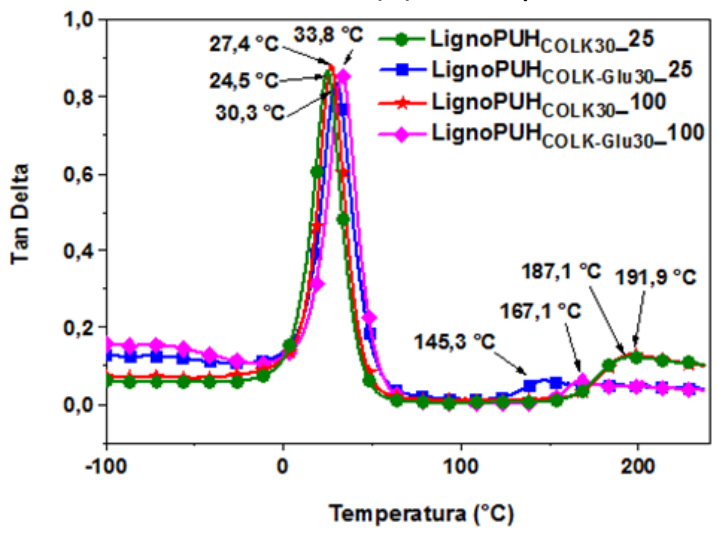

(a)

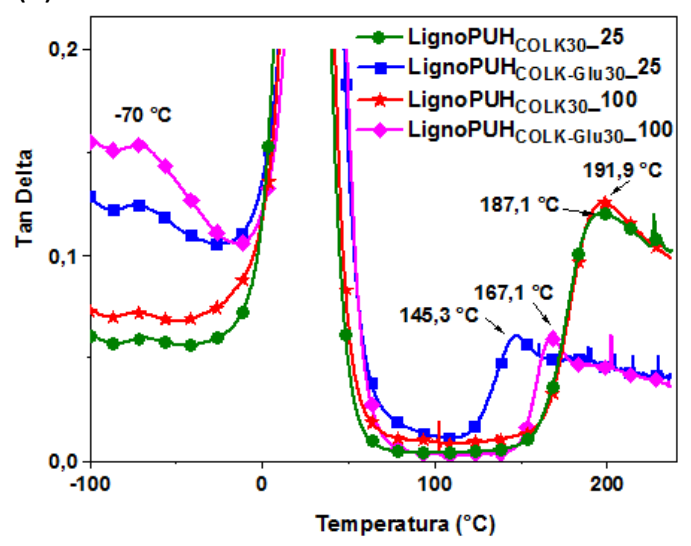

(b)

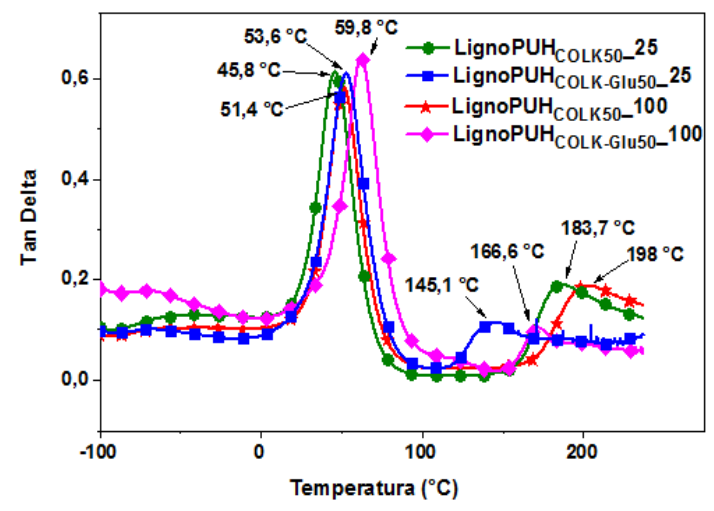

(c)

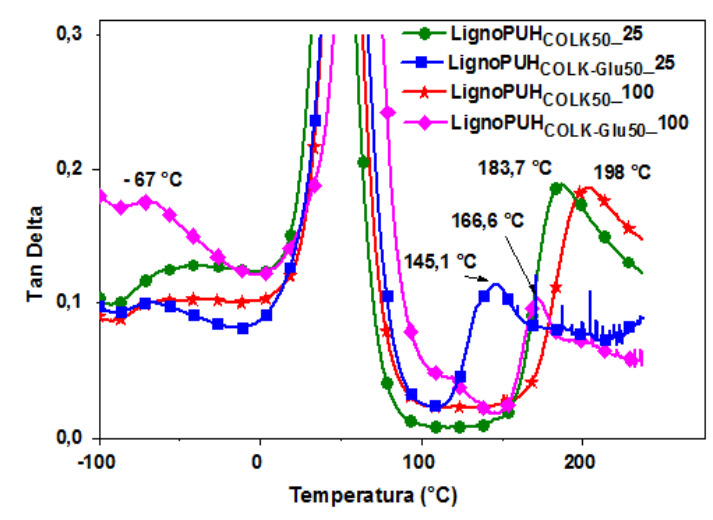

(d)

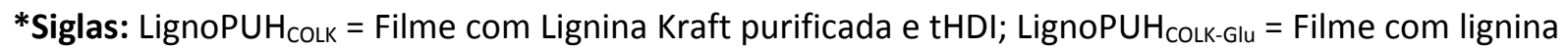
modificada por hidroxialquilação e tHDI.

Assim como nos filmes formados simultaneamente à síntese realizada a $25^{\circ} \mathrm{C}$, os filmes formados a $100{ }^{\circ} \mathrm{C}$, para ambas concentrações de LK ou LK-Glu, também apresentaram segmentação em domínios flexíveis e rígidos, sendo o primeiro pico $\left(1^{\circ} T_{\mathrm{g}}\right)$, em temperaturas mais baixas, referente aos domínios flexíveis, oriundos principalmente de CO e tHDI, e o segundo pico $\left(2^{\circ} T_{\mathrm{g}}\right)$, em temperaturas mais altas, referente aos domínios rígidos, oriundos de LK ou LK-Glu, e tHDI.

Os valores das $T_{\mathrm{g}}$ s referentes aos picos Tan- $\delta$ (Figura 60) encontram-se na Tabela 21. 
Tabela 21 - Valores de $T_{\mathrm{g}}$ (pico Tan- $\delta$ ) para os filmes formados simultaneamente à síntese realizada a partir de 30 e $50 \%$ de LK ou LK-Glu e tHDI a 25 e $100^{\circ} \mathrm{C}$

\begin{tabular}{|c|c|c|c|c|}
\hline \multirow{2}{*}{ Pico } & \multicolumn{4}{|c|}{$T_{\mathrm{g}}\left({ }^{\circ} \mathrm{C}\right)$} \\
\hline & LignoPUH & LignoPUH $_{\text {СоLк30_100 }}$ & LignoPUH & LignoPUH ${ }_{\text {CoLK50_100 }}$ \\
\hline $1^{\circ}$ & 24 & 27 & 46 & 51 \\
\hline $2^{\circ}$ & 187 & 192 & 184 & 198 \\
\hline & LignoPUHCoLK-Glu30_25 & LignoPUHCoLK-Glu30_100 & LignoPUHCOLK-Glu50_25 & LignoPUH \\
\hline $1^{\circ}$ & 30 & 34 & 54 & 60 \\
\hline $2^{\circ}$ & 145 & 167 & 145 & 167 \\
\hline
\end{tabular}

As Figuras $60 \mathrm{~b}$ e $\mathrm{d}$ mostram que as reações ocorrerem a $100{ }^{\circ} \mathrm{C}$ levou a um deslocamento para temperaturas maiores da $T_{\mathrm{g}}$ referente aos segmentos rígidos, principalmente nos filmes formados a partir de 30 e $50 \%$ de LK-Glu (cerca de $20{ }^{\circ} \mathrm{C}$, Tabela 21). Para os filmes formados a partir de LK, somente na concentração de 50 \% pode-se perceber esse deslocamento (cerca de $14{ }^{\circ} \mathrm{C}$, Tabela 21). Já o deslocamento para maiores temperaturas da $T_{\mathrm{g}}$ referente aos segmentos flexíveis mostrou-se mais evidente para os filmes formados a partir de 50 \% de LK ou LK-Glu, especialmente para o filme LignoPUHCoLK-Glu50_100 (Figura $60 \mathrm{c}$ ). Esse resultado demonstra que o aumento da temperatura na síntese das PUs causou o enrijecimento das mesmas, assim como, potencializou o efeito da modificação química realizada em LK-Glu. O que pode ter contribuído para isso pode ter sido a formação de ligações cruzadas em pequena extensão. Ainda nas Figuras 60 b e d, é possível verificar a presença de uma relaxação $\beta$ em torno de -70 e $-67^{\circ} \mathrm{C}$, respectivamente, ou seja, rotações em torno de ligações simples envolvendo grupos, que antecede a $T_{g}$ (LORANDI et al., 2016).

Os valores das $T_{\mathrm{g}}$ referentes aos domínios flexíveis ( $1^{\circ}$ pico) para os filmes formados a

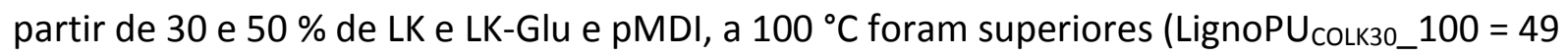

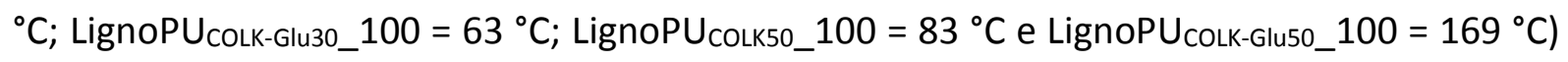
aos filmes em que tHDI foi usado na síntese, nas mesmas concentrações de LK ou LK-Glu, a $100{ }^{\circ} \mathrm{C}$ (Tabela 21). Como mencionado anteriormente, isso está ligado ao maior teor de componentes aromáticos nos filmes formados a partir de pMDI, os quais dificultam a movimentação dos segmentos. Outra constatação é que o aumento na temperatura para 100 ${ }^{\circ} \mathrm{C}$ nos filmes formados a partir de pMDI provocou mudanças no perfil de segregação dos domínios rígidos e flexíveis, por vezes misturando uma fase com a outra, como pode ser

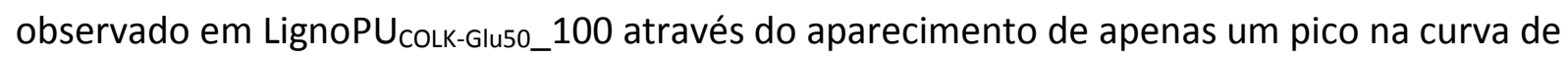
Tan- $\delta$ (Figuras 40 e 41, Capítulo 1). Para os filmes em que tHDI foi usado como reagente, o 
aumento de temperatura durante à síntese das PUs não acarretou em uma mudança desse tipo nas curvas de Tan- $\delta$, já que em todas as curvas foi possível observar o aparecimento de 2 picos distintos (Figura 60).

A Figura 61 apresenta o módulo de armazenamento $\left(E^{\prime}, 25^{\circ} \mathrm{C}\right)$, para os filmes

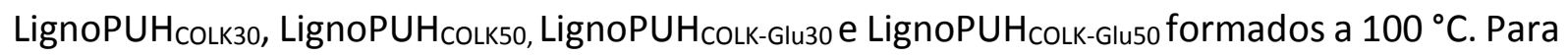
fins de comparação, os resultados obtidos para os respectivos filmes formados à temperatura ambiente também são mostrados (Item 2.3.1.7).

Figura $61-E^{\prime}\left(25^{\circ} \mathrm{C}\right)$ dos filmes formados simultaneamente à síntese realizada a partir de: (a) $30 \%$ de LK e LK-Glu e (b) $50 \%$ de LK e LK-Glu nas temperaturas de 25 e $100^{\circ} \mathrm{C}$.

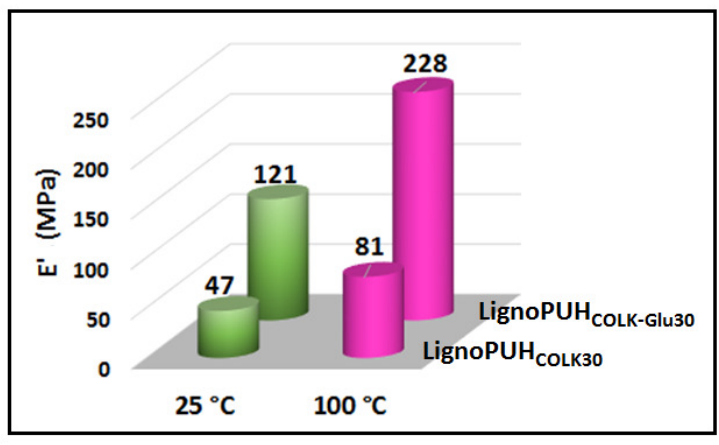

(a)

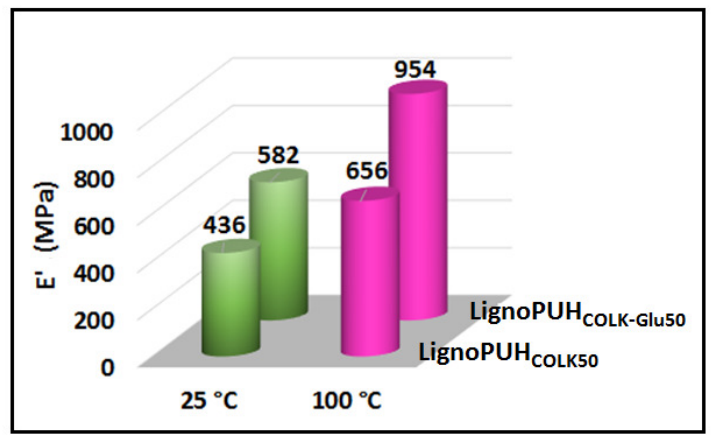

(b)

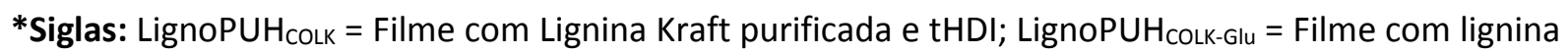
modificada por hidroxialquilação e tHDI.

O aumento na temperatura para $100^{\circ} \mathrm{C}$ durante à reação de polimerização claramente proporcionou o aumento nos valores de $E^{\prime}$ tanto nos filmes formados a partir de PUs sintetizadas com 30 quanto com $50 \%$ de LK e LK-Glu (Figura 61). Os filmes LignoPUH ${ }_{\text {COLK30_100, LignoPUH }}$ CoLk-Glu30_100, LignoPUH ${ }_{\text {CoLK50_100 e LignoPUH }}$ CoLk-Glu50_100 apresentaram um aumento nos valores de $E^{\prime}$ de 42, 47, 33 e $39 \%$, respectivamente, em relação aos filmes formados $25{ }^{\circ} \mathrm{C}$. Esse resultado evidencia o efeito do aumento da temperatura sobre as LignoPUHs, as quais tornaram-se mais rígidas devido ao aumento para $100{ }^{\circ} \mathrm{C}$ durante a reação de polimerização, observado pelo aumento no E'. Como mencionado anteriormente, ligações cruzadas podem ter se formado em pequena extensão, e não detectas na análise via FTIR, e a presença das mesmas acarreta em maior rigidez da cadeia polimérica (WANG et al., 2017).

Os valores de $\mathrm{E}^{\prime}$ a $25^{\circ} \mathrm{C}$, para os filmes formados a partir de $30 \%$ de LK e LK-Glu refletem o fato que esses filmes se encontravam na transição vítrea (Tabela 21), e, portanto, com 
segmentos presentes em regiões não cristalinas no estado flexível. Já os valores de $\mathrm{E}^{\prime}$ a $25^{\circ} \mathrm{C}$ para os filmes formados a partir de 50 \% de LK e LK-Glu refletem o aumento na concentração de LK/LK-Glu e o fato de que eles se encontravam no estado rígido a $25^{\circ} \mathrm{C}$ (Tabela 21).

Os filmes formados a partir de 30 e $50 \%$ de LK-Glu apresentaram maiores valores de $\mathrm{E}^{\prime}$ comparativamente aos filmes em que LK foi usado como reagente nas duas temperaturas avaliadas (25 e $100^{\circ} \mathrm{C}$; Figura 61).

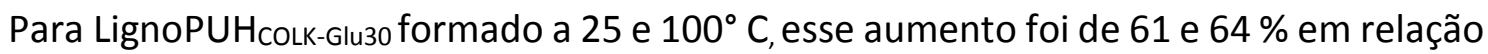
a LignoPUH CoLk30 formado nessas temperaturas. Enquanto que para LignoPUH $_{\text {CoLK-Glu50 }}$ formado a 25 e $100^{\circ} \mathrm{C}$, esse aumento foi de 25 e 31 \% em relação a LignoPUH coLk5o formado nessas temperaturas. A maior diferença observada para $E^{\prime}$ nos filmes LignoPUH colk-Gluzo se deve ao fato desses filmes estarem com segmentos presentes em regiões não cristalinas no estado flexível, permitindo perceber de forma mais acentuada o efeito do aumento da massa molar média e do volume de estruturas ocorrido na LK-Glu.

A cristalinidade desses filmes praticamente não se alterou em função da temperatura (Item 2.3.2.4), o que indica que este fator não influenciou no aumento de $E^{\prime}$ dos filmes avaliados. Entretanto, o teste de intumescimento, mostrou uma tendência à redução na S\% dos filmes formados a $100{ }^{\circ} \mathrm{C}$ em ambas concentrações de LK e LK-Glu (Item 2.3.2.5), o que poderia sugerir, por exemplo, a formação de ligações cruzadas, principalmente quando altas temperaturas são utilizadas durante à síntese dos polímeros, i.e. $100^{\circ} \mathrm{C}$. Como mencionado anteriormente, reações paralelas, como as que formam alofanatos, podem ocorrer nessas temperaturas e os grupos $\mathrm{N}-\mathrm{H}$ desses compostos são capazes eventualmente, de reagir com outras moléculas de isocianato e levar a formação de ligações cruzadas nas PUs (Figura 35, Capítulo 1) (DUSEK; SPIRKOVA, 1990; YILGOR ET AL., 2015).

As micrografias das fraturas dos filmes formados a $100{ }^{\circ} \mathrm{C}$ apresentaram maior rugosidade comparativamente aos formados a $25{ }^{\circ} \mathrm{C}$ (MEV; Item 2.3.2.2), sugerindo maior rigidez para estes filmes. Esse resultado concorda com o observado para os valores de $E^{\prime}$, que foram superiores nos filmes formados na temperatura acima da ambiente $\left(100^{\circ} \mathrm{C}\right)$.

Sendo assim, considerando que a estrutura do trímero de HDI composta por anel isocianurato (tHDI) pode ter favorecido o entrecruzamento de cadeias quando à síntese das LignoPUHs se deu a $100^{\circ} \mathrm{C}$, o aumento nos valores de E' nesses filmes, pode estar relacionado a formação de ligações cruzadas ainda que em pequena extensão. 
De maneira geral, os valores de E' para os filmes formados a partir de 30 e $50 \%$ de LK e

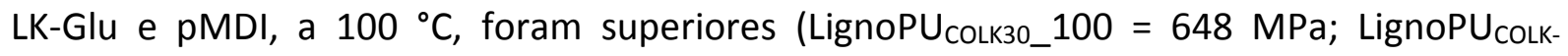

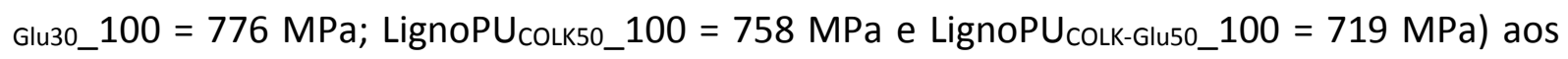
encontrados para os filmes preparados com tHDI (Figura 61). Isso pode ser explicado devido ao maior número de componentes rígidos aromáticos existentes nos filmes formados a partir de pMDI, o que os torna, de maneira geral, mais rígidos. Entretanto, os filmes

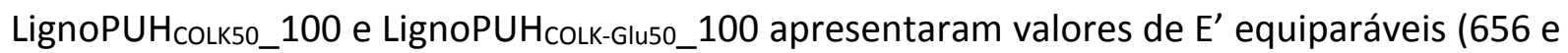
$954 \mathrm{MPa}$, respectivamente) aos preparados com pMDI, o que dependendo da aplicação utilizada pode se tornar uma boa alternativa, já esses filmes possuem maior rigidez que os demais filmes formados a partir de tHDI e outras propriedades, como maior elasticidade, devido o maior teor de componentes alifáticos comparado aos filmes preparados com pMDI.

\subsubsection{Propriedades de Tração}

A Figura 62 apresenta os resultados de resistência a tração, módulo de Young e alongamento na ruptura dos filmes lignopoliuretânicos formados a partir de $30 \%$ de LK ou LKGlu e tHDI a $100^{\circ} \mathrm{C}$. Para fins de comparação, os resultados obtidos para os respectivos filmes formados à temperatura ambiente também são mostrados (Item 2.3.1.8). Destaca-se que os filmes formados a partir de $30 \%$ de LK e LK-Glu a $100^{\circ} \mathrm{C}$ possuíam a mesma medida dos corpos de prova para esse ensaio $(1,5 \mathrm{~mm}$ largura $\times 5 \mathrm{~mm}$ distância entre garras $\times 0,65 \mathrm{~mm}$ espessura). 
Figura 62 - (a) Resistência a ruptura, (b) módulo de Young e (c) alongamento na ruptura dos filmes formados simultaneamente à síntese realizada a partir de $30 \%$ de LK e LK-Glu a 25 e $100{ }^{\circ} \mathrm{C}$.

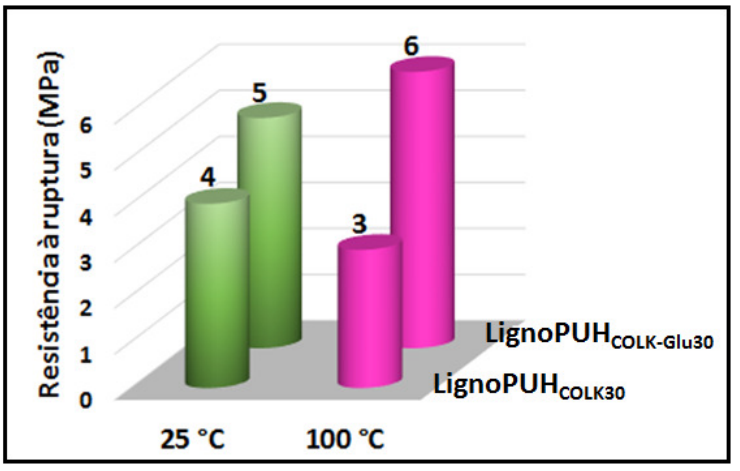

(a)

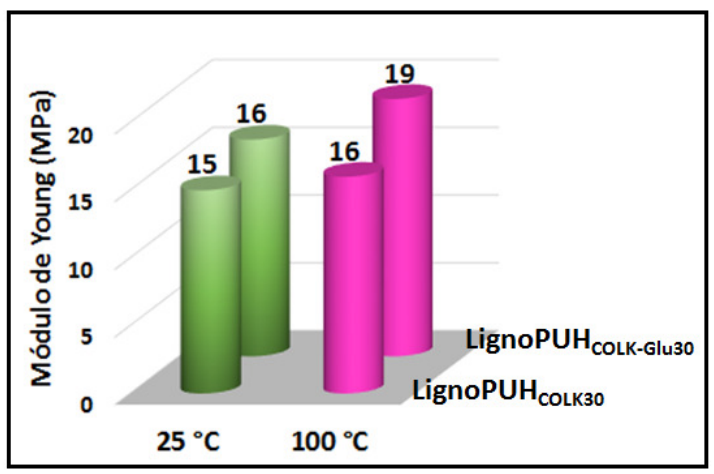

(b)

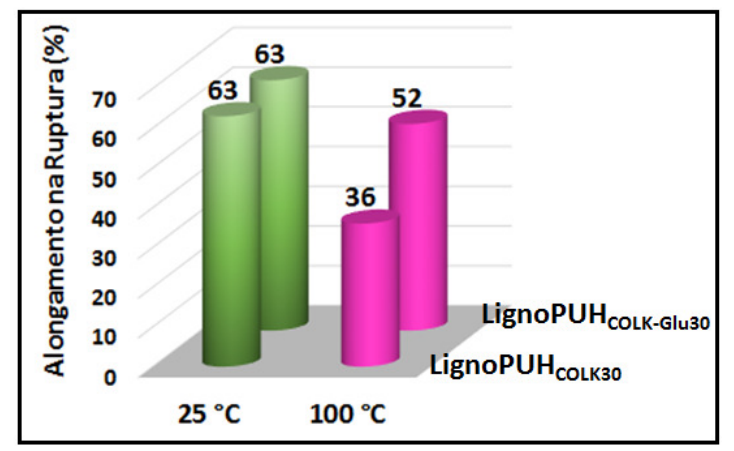

(c)

*Desvios-padrão: Resistência a ruptura $=$ [De \pm 0 (LignoPUH ${ }_{\text {соเк30_100) a } \pm 0,4 \text { (LignoPUH }}$ colk30_25)],

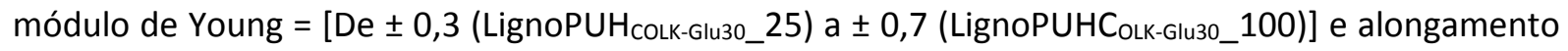
na ruptura $=\left[\right.$ De $\pm 1,1$ (LignoPUH CoLk30_100) a \pm 3,1 (LignoPUH $\left._{\text {CoLK30_25) }}\right]$

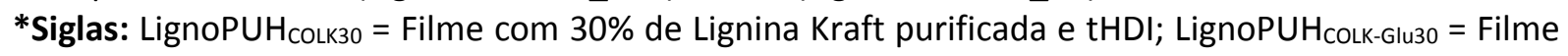
com $30 \%$ de lignina modificada por hidroxialquilação e tHDI.

O gráfico de resistência à ruptura (Figura 62 a) mostra que houve um discreto aumento nessa propriedade para o filme LignoPUH CoLk-Glu30_100 (6,0 \pm 0,3 $\mathrm{MPa})$ em relação à

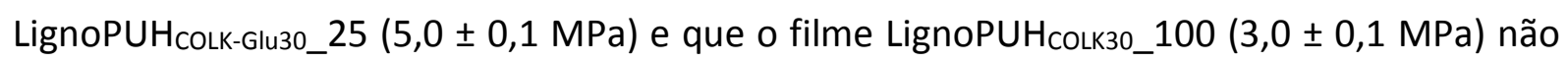

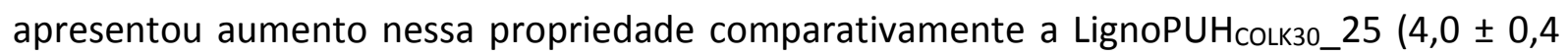
$\mathrm{MPa}$ ). É importante salientar que o ensaio de tração foi conduzido a $25{ }^{\circ} \mathrm{C}$, e nessa temperatura a maioria dos segmentos presentes em regiões não cristalinas dos filmes formados a partir de $30 \%$ de LK e LK-Glu a 25 e $100^{\circ} \mathrm{C}$ se encontravam no estado flexível, uma vez que as $T_{\mathrm{g}} \mathrm{s}$ referentes aos domínios flexíveis foram muito próximas à temperatura ambiente, como discutido previamente no Item 2.3.2.7 (Tan- $\delta$, Tabela 21). Isso explica as pequenas diferenças nos valores de resistência à ruptura encontrados para os filmes formados a partir de $30 \%$ de LK e LK-Glu a 25 e $100{ }^{\circ} \mathrm{C}$. 
Quanto ao módulo de Young (Figura 62 b), apenas LignoPUHCoLK-Glu30_100 apresentou um discreto aumento (19 $\pm 1 \mathrm{MPa}$ ) em relação aos demais filmes formados a partir de $30 \%$ de LK ou LK-Glu.

No gráfico de alongamento na ruptura (Figura 62 c) é possível observar que os menores valores para essa propriedade foram obtidos para os filmes preparados a $100{ }^{\circ} \mathrm{C}$, LignoPUH ${ }_{\text {Colk30_100 }}=36 \pm 1 \%$ e LignoPUHCoLk-Glu30_100 $=52 \pm 1 \%$, representando um decréscimo de 43 e 17 \% em relação aos filmes preparados na mesma concentração de LK e LK-Glu a $25^{\circ} \mathrm{C}$. Isso mostra o aumento na rigidez desses filmes com o aumento na temperatura durante à reação de polimerização, que propiciou menor alongamento dos mesmos. O filme

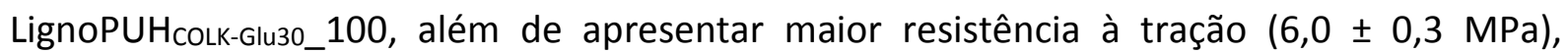

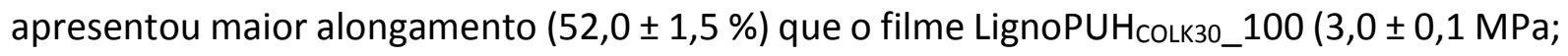
$36 \pm 1 \%$ ), destacando o efeito da inserção das cadeias alifáticas (segmentos hidrocarbônicos e também segmentos di-hidroxilados, como mencionado anteriormente) oriundas do glutaraldeído, que permitiram, juntamente com os segmentos flexíveis do CO, um maior alongamento na ruptura nesse filme.

A Figura 63 apresenta os resultados de resistência a tração, módulo de Young e alongamento na ruptura dos filmes lignopoliuretânicos formados a partir de 50 \% de LK ou LKGlu e tHDI a $100^{\circ} \mathrm{C}$. Para fins de comparação, os resultados obtidos para os respectivos filmes formados à temperatura ambiente também são mostrados (Item 2.3.1.8). Destaca-se que os filmes formados a partir de $30 \%$ de LK e LK-Glu a $100{ }^{\circ} \mathrm{C}$ possuíam a mesma medida dos corpos de prova para esse ensaio $(1,5 \mathrm{~mm}$ largura $\times 5 \mathrm{~mm}$ distância entre garras $\times 0,65 \mathrm{~mm}$ espessura). 
Figura 63 - (a) Resistência a ruptura, (b) módulo de Young e (c) alongamento na ruptura dos filmes dos filmes formados simultaneamente à síntese realizada a partir de $50 \%$ de LK e LK-Glu a 25 e 100 ${ }^{\circ} \mathrm{C}$.

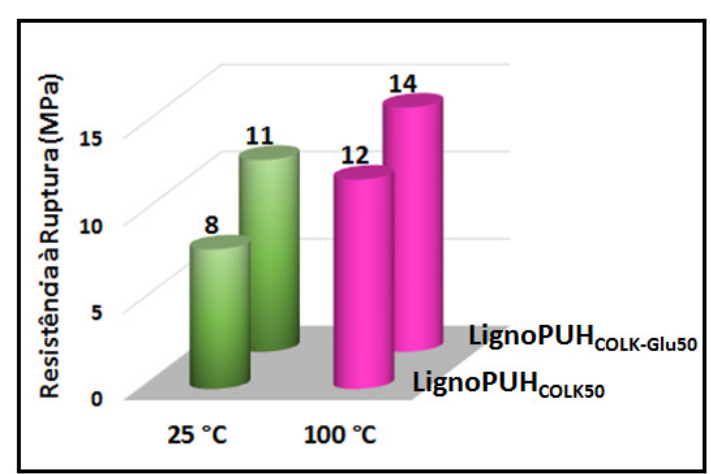

(a)

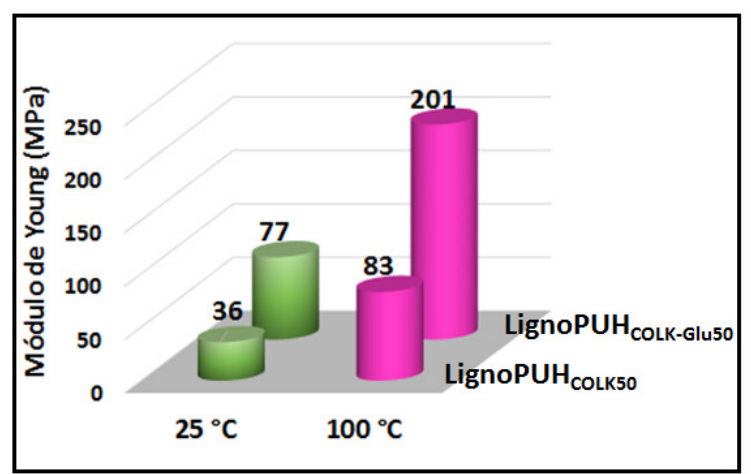

(b)

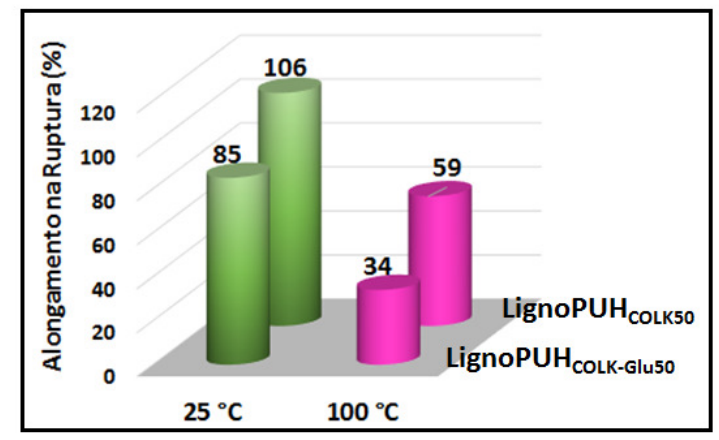

(c)

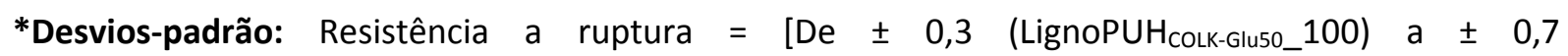

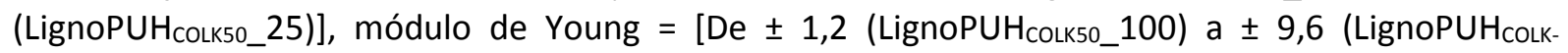

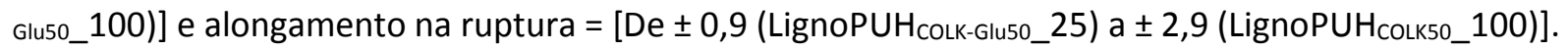
*Siglas: LignoPUH ${ }_{\text {CoLk50 }}=$ Filme com $50 \%$ de Lignina Kraft purificada e tHDI; LignoPUH coLk-Glu50 $_{\text {= Filme }}$ com $50 \%$ de lignina modificada por hidroxialquilação e tHDI.

O ensaio de tração foi conduzido a $25^{\circ} \mathrm{C}$. Nessa temperatura os segmentos presentes nos domínios não cristalinos dos filmes formados simultaneamente à síntese a partir de $50 \%$ de LK e LK-Glu a 25 e $100{ }^{\circ} \mathrm{C}$ se encontravam no estado rígido, uma vez que os valores de $T_{\mathrm{g}}$ dos domínios flexíveis ( $T_{\mathrm{g}}$ 10 Pico) observados para esses filmes estão acima de $25{ }^{\circ} \mathrm{C}$ como discutido no Item 2.3.2.7 (Tabela 21). Isso explica, os valores superiores observados para resistência à ruptura para esses filmes (Figura 63 a) em relação aos filmes formados a partir de $30 \%$ de LK e LK-Glu nas diferentes temperaturas avaliadas (Figura 62 a).

O aumento da temperatura para $100^{\circ} \mathrm{C}$ durante a reação de polimerização impactou positivamente na resistência à ruptura dos filmes formados a partir de $50 \%$ de LK e LK-Glu, promovendo aumentos de 33 e $21 \%$, respectivamente, em relação aos preparados a $25{ }^{\circ} \mathrm{C}$ (Figura 63 a). 
O módulo de Young apresentou o mesmo perfil da resistência à tração, com aumentos de 57 e 62 \% nessa propriedade para os filmes preparados a $100^{\circ} \mathrm{C}$ em relação aos preparados a $25^{\circ} \mathrm{C}$ (Figura $63 \mathrm{~b}$ ).

Os filmes LignoPUH ${ }_{\text {CoLk50_100 e LignoPUH }}$ CoLK-Glu50_100 obtiveram os maiores valores de E' (656 e $954 \mathrm{MPa}$, respectivamente) na análise de DMA (Item 2.3.2.7) entre todos filmes avaliados, portanto demonstraram ser mais rígidos, o que corrobora com os resultados obtidos para resistência à tração e módulo de Young.

Os filmes LignoPUH ${ }_{\text {CoLk50_100 e LignoPUH }}$ CoLk-Glu50_100 apresentaram 40 e 45 \% de cristalinidade (Item 2.3.2.4), respectivamente, todavia, os mesmos ICr foram observados para esses filmes preparados à temperatura ambiente, indicando que a cristalinidade não influenciou na resistência à tração desses filmes. Já as S\% (Item 2.3.2.5) apresentadas para esses filmes foram inferiores ( $60 \pm 1 \%$ e $51,0 \pm 0,7 \%$ ) as dos preparados a $25^{\circ} \mathrm{C}(64,0 \pm 1,5 \%$ e $56,0 \pm 0,9 \%$ ), confirmando a menor disponibilidade de volume livre nesses filmes. Esse resultado infere que o aumento para $100{ }^{\circ} \mathrm{C}$ durante a reação de polimerização influenciou na síntese das PUs, proporcionando a formação de ligações cruzadas ainda que em pequena extensão, ocasionando o aumento da resistência à tração desses filmes.

Ainda é importante salientar que o filme LignoPUHCOLK-Glu50_100 obteve resistência à

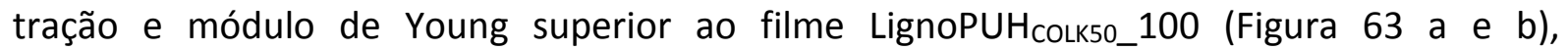
demonstrando novamente o efeito positivo que a temperatura exerce sobre a lignina modificada.

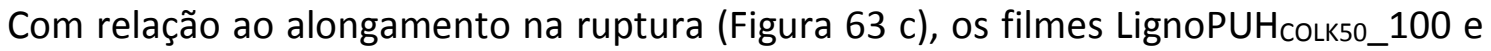
LignoPUHCoLK-Glu50_100 apresentaram um decréscimo nessa propriedade (44 e 60 \%, respectivamente) em relação às LignoPUHs preparadas a $25^{\circ} \mathrm{C}$. Essa queda no alongamento já era esperada devido ao enrijecimento das cadeias proporcionado pelo aumento da

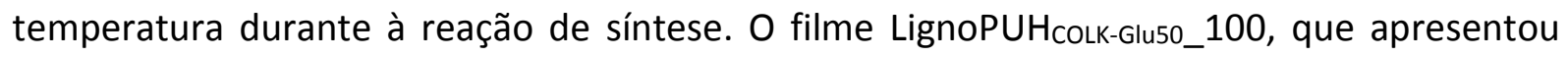
maior resistência à tração $(14,0 \pm 0,3 \mathrm{MPa})$ também apresentou menor alongamento $(34 \pm 1$ $\%)$.

Diferentemente do que ocorreu com os filmes formados a partir de com $30 \%$ de LK e LK-Glu a $100{ }^{\circ} \mathrm{C}$, onde LignoPUH COLK-Glu30_100 (52 $\left.\pm 1 \%\right)$ alongou mais que LignoPUH $_{\text {CoLK30_100 }}$ (36 $\pm 1 \%$ ), nos filmes formados a partir de $50 \%$ de LK e LK-Glu a $100{ }^{\circ} \mathrm{C}$, o alongamento na ruptura para LignoPUH ${ }_{\text {CoLK-Glu50_100 (34 } \pm 1 \%) \text { foi inferior ao de LignoPUH }}$ CoLk50_100 (59 \pm 3 \%). Esse resultado enfatiza que o efeito da modificação química realizado em LK-Glu é 
acentuado quando os materiais se encontram no estado flexível, como era o caso dos filmes formados a partir de $30 \%$ de LK ou LK-Glu (Tabela 22).

A Tabela 22 apresenta uma comparação dos resultados do ensaio de tração dos filmes formados simultaneamente à síntese realizada utilizando pMDI e tHDI a 25 e $100{ }^{\circ} \mathrm{C}$.

Tabela 22 - Comparação dos resultados da Análise de propriedades de Tração dos filmes formados simultaneamente à síntese realizada a partir de pMDI e tHDI a 25 e $100^{\circ} \mathrm{C}$

\begin{tabular}{lcccccc}
\hline \multirow{2}{*}{ Amostra } & \multicolumn{2}{c}{ Resistência à } & \multicolumn{2}{c}{$\begin{array}{c}\text { Módulo de Young } \\
\text { (MPa) }\end{array}$} & \multicolumn{2}{c}{$\begin{array}{c}\text { Alongamento na } \\
\text { Ruptura (MPa) }\end{array}$} \\
\cline { 2 - 7 } & pMDI & tHDI & pMDI & tHDI & pMDI & tHDI \\
\hline LK30_25 & $11,0 \pm 0,2$ & $4,0 \pm 0,4$ & $93 \pm 3$ & $15,0 \pm 0,5$ & $60 \pm 2$ & $63 \pm 3$ \\
LK-Glu30_25 & $10,0 \pm 0,3$ & $5,0 \pm 0,1$ & $112 \pm 4$ & $16,0 \pm 0,3$ & $45 \pm 2$ & $63 \pm 3$ \\
LK30_100 & $15 \pm 2$ & $3,0 \pm 0,1$ & $271 \pm 10$ & $16 \pm 1$ & $36 \pm 3$ & $36 \pm 1$ \\
LK-Glu30_100 & $16,0 \pm 0,1$ & $6,0 \pm 0,3$ & $258 \pm 1$ & $19 \pm 1$ & $54 \pm 2$ & $52 \pm 1$ \\
LK50_25 & $19 \pm 1$ & $8 \pm 1$ & $745 \pm 15$ & $36 \pm 1$ & $4,0 \pm 0,3$ & $106 \pm 2$ \\
LK-Glu50_25 & $23 \pm 1$ & $11 \pm 1$ & $1134 \pm 3$ & $77 \pm 1$ & $5,0 \pm 0,1$ & $85 \pm 1$ \\
LK50_100 & $25 \pm 1$ & $12 \pm 1$ & $1137 \pm 29$ & $83 \pm 1$ & $5,0 \pm 0,1$ & $59 \pm 3$ \\
LK-Glu50_100 & $33 \pm 1$ & $14,0 \pm 0,3$ & $1361 \pm 30$ & $201 \pm 10$ & $6,0 \pm 0,3$ & $34 \pm 2$ \\
\hline
\end{tabular}

De acordo com a Tabela 22, os valores de resistência à tração e módulo de Young dos filmes formados a partir de 30 e $50 \%$ de LK ou LK-Glu e pMDI a 25 e $100^{\circ} \mathrm{C}$ são superiores aos encontrados para os filmes formados nas mesmas concentrações de LK ou LK-Glu, porém, utilizando tHDI como isocianato. Esse resultado ilustra a diferença que o isocianato do tipo aromático (pMDI) exerce nessas propriedades. O uso de $100{ }^{\circ} \mathrm{C}$ durante a reação de polimerização contribuiu, de maneira geral, para o aumento nessas propriedades nos filmes formados a partir de tHDI e pMDI.

Diferenças significativas nos valores de resistência à ruptura e módulo de Young foram observadas nos filmes formados a partir de $30 \%$ de LK e LK-Glu a 25 e $100{ }^{\circ} \mathrm{C}$, utilizando tHDI e pMDI como isocianato. Isso se deve, principalmente ao fato dos domínios não cristalinos dos filmes formados a partir de tHDI estarem no estado flexível na temperatura em que o ensaio de tração foi realizado $\left(25^{\circ} \mathrm{C}\right)$, diferentemente dos filmes formados a partir de pMDI, que estavam no estado rígido. 


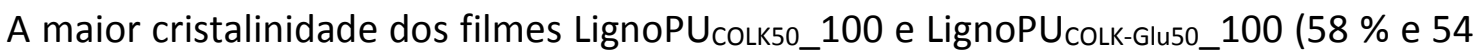
\%, respectivamente) em relação aos filmes LignoPUHCoLk50_100 e LignoPUH \% e $40 \%$, respectivamente) também pode ter contribuído para a maior resistência à tração observada para os primeiros.

Os valores obtidos para o alongamento na ruptura (Tabela 22), dos filmes formados simultaneamente à síntese realizada a partir de $30 \%$ de LK ou LK-Glu utilizando tHDI e pMDI foram semelhantes. Todavia, como mencionado anteriormente, os filmes formados a partir de tHDI já estavam no estado flexível, portanto com menor resistência devido à movimentação dos segmentos flexíveis, que limitaram o alongamento desses filmes. Para os filmes formados a partir de $50 \%$ de LK ou LK-Glu e pMDI a 25 e $100{ }^{\circ} \mathrm{C}$, os quais se encontravam todos no estado rígido, o alongamento na ruptura foi inferior aos formados a partir de tHDI. Provavelmente devido ao maior teor de componentes rígidos aromáticos que restringiram o alongamento dessas PUs. O uso de $100{ }^{\circ} \mathrm{C}$ durante a reação de polimerização impactou na diminuição do alongamento dos filmes formados a partir de tHDI. Todavia, para os filmes formados a partir de pMDI, o aumento na temperatura causou um discreto aumento nessa propriedade, principalmente quando $50 \%$ de LK ou LK-Glu foram utilizados como reagente.

\subsection{Conclusões Parciais}

O tempo necessário para consumo total de grupos isocianato, e posterior retirada do filme da placa, foi menor para as PUs em que LK-Glu foi usado como poliol, a $25{ }^{\circ} \mathrm{C}$, comparativamente ao apresentado pelos filmes preparados a partir de PUs sintetizadas com LK nas mesmas proporções. Esse resultado mostra que a modificação química realizada na LKGlu, atingiu o objetivo de aumentar a reatividade da mesma frente ao isocianato alifático tHDI, assim como o foi para o aromático, pMDI.

Em comparação ao que foi apresentado pelo filme $\mathrm{PUH}_{c o}$, as principais influências da presença de LK e principalmente LK-Glu foram na segregação de fases em domínios flexíveis e rígidos, e melhoria nas propriedades mecânicas desses materiais, como aumento na resistência à ruptura e alongamento na ruptura.

A influência do aumento na temperatura para $100^{\circ} \mathrm{C}$ durante a reação de polimerização das LignoPUHs formadas a partir de 30 e $50 \%$ de LK e sobretudo LK-Glu, foi observada no menor tempo para consumo total de grupos isocianatos, e na melhora de propriedades tais 
como módulo de armazenamento, Young e resistência à tração. Menores tempos de reação e ganhos em resistência e alongamento são propriedades desejáveis para filmes, pois aumenta o campo de aplicação dos mesmos.

O conjunto de resultados mostrou que lignina Kraft, uma matéria-prima abundante e de baixo custo, pode ser utilizada na síntese de PUs e formação simultânea de filmes, juntamente com $\mathrm{CO}$, utilizando o isocianato alifático tHDI. A utilização de lignina modificada através da reação de hidroxialquilação com glutaraldeído (LK-Glu) na síntese e formação simultânea de filmes lignopoliuretânicos preparados com tHDI, além de ser inovadora, propiciou o desenvolvimento de filmes com melhores propriedades térmicas e mecânicas, tornando-se, uma melhor alternativa quando comparada a LK, especialmente quando temperaturas altas como $100{ }^{\circ} \mathrm{C}$ são utilizadas na respectiva síntese.

Em função das diferentes propriedades obtidas para os filmes formados a partir de CO, LK ou LK-Glu e tHDI, como caraterísticas mais rígidas ou elastoméricas, por exemplo, vários usos podem ser dados a esses filmes na indústria em geral, principalmente na área de revestimentos, como mencionado anteriormente para os filmes preparados a partir de pMDI. 


\section{Capítulo 3: Filmes Poliuretânicos obtidos simultaneamente as sínteses realizadas a partir de óleo de mamona, e Lignina Kraft modificada com glutaraldeído ou não: adição de celulose nanocristalina}

\subsection{Introdução}

CNCs vem sendo utilizados como material de reforço de filmes baseados em uma extensa variedade de matrizes poliméricas (BAI et al., 2019; CHOWDHURY et al., 2019; VORONOVA et al., 2019; LUO et al., 2018; POPESCU et al., 2018), inclusive matrizes poliuretânicas (LEl et al., 2019; HUANG et al., 2018; KONG et al., 2018).

Uma boa adesão entre a matriz e o reforço em um compósito é importante, pois do contrário, pode levar a insatisfatórias propriedades mecânicas desses materiais (CHEN et al., 2016). As modificações químicas tanto da matriz, quanto do agente de reforço (TIAN et al., 2019; AUCLAIR et al., 2018) e o uso de compatibilizantes, especialmente aqueles de origem natural (CASTRO et al., 2017; DE OLIVEIRA SANTOS et al., 2014), são alternativas interessantes para melhorar a interação entre a matriz e o reforço nos compósitos.

CASTRO et al. (2015) utilizaram CO e outros óleos vegetais sem nenhuma modificação prévia como agentes dispersantes de CNCs obtidos de curauá na obtenção de filmes compósitos baseados em "polietileno verde". Nesse estudo foi observado que a presença de CO, na concentração de 3\% em massa, melhorou a dispersão dos CNCs na matriz polimérica, assim como contribuiu para maior resistência à tração dos materiais. Nesse contexto, no presente estudo, procurou-se avaliar o uso de CO não só como agente dispersante de LK e LKGlu, mas também de CNCs, e simultaneamente avaliar o efeito da modificação química da LKGlu, via reação de hidroxialquilação, na interação da matriz modificada com os CNCs. Destacase que o CO é constituído majoritariamente pelo ácido ricinoléico (Figura 9), o qual apresenta 
em sua cadeia grupos de caráter hidrofóbico/hidrofílico com afinidade tanto pela PU, quanto pelos CNCs.

Dessa forma, duas matrizes lignopoliuretânicas (LignoPUH Colk50_100 e LignoPUH $_{\text {colk- }}$ Glu50_100) foram selecionadas para adição de CNCs na mistura reacional. Essa escolha foi baseada na viscosidade do meio reacional e do tempo de reação que permitiriam melhor homogeneização dos CNCs, e também nos resultados das propriedades mecânicas, como resistência à tração, dos filmes formados a partir de CO, LK ou LK-Glu e tHDI a $100{ }^{\circ} \mathrm{C}$ (Capítulo 2).

Destaca-se que não foram consideradas sínteses com simultânea formação de filmes a partir de CO, LK ou LK-Glu, pMDI e CNCs, porque a viscosidade do meio reacional quando este isocianato polimérico foi usado, impediu que porcentagem maior que $5 \%$ de CNC fosse adicionada, sendo que para esta porcentagem não foram encontradas mudanças significativas nas propriedades dos filmes formados (resultados não mostrados).

Até onde se tenha conhecimento, a formação simultânea as sínteses, nas condições consideradas neste estudo, de filmes lignopoliuretânicos compósitos contendo CNCs não tem precedentes.

\subsection{Materiais e Métodos}

Os materiais utilizados foram os mesmos descritos no Item 2.2 do Capítulo 2, com exceção dos CNCs, os quais foram adquiridos em sua forma seca da University of Maine (Orono, EUA). As dimensões dos CNCs informadas pelo fabricante são: 5-20 nm largura x 150$200 \mathrm{~nm}$ comprimento.

\subsubsection{Síntese das LignoPUHs usadas para preparar simultaneamente filmes tendo como reagentes CO, LK ou LK-Glu, tHDI e CNCs como agente de reforço}

A metodologia de síntese das lignopoliuretanas produzidas utilizando CNCs como agente de reforço, com simultânea formação de filmes, está apresentada no diagrama da Figura 64. 
Figura 64 - Diagrama da metodologia de síntese das LignoPUHs sintetizadas utilizando tHDI como isocianato e CNCs como agente de reforço e usadas para preparar filmes.

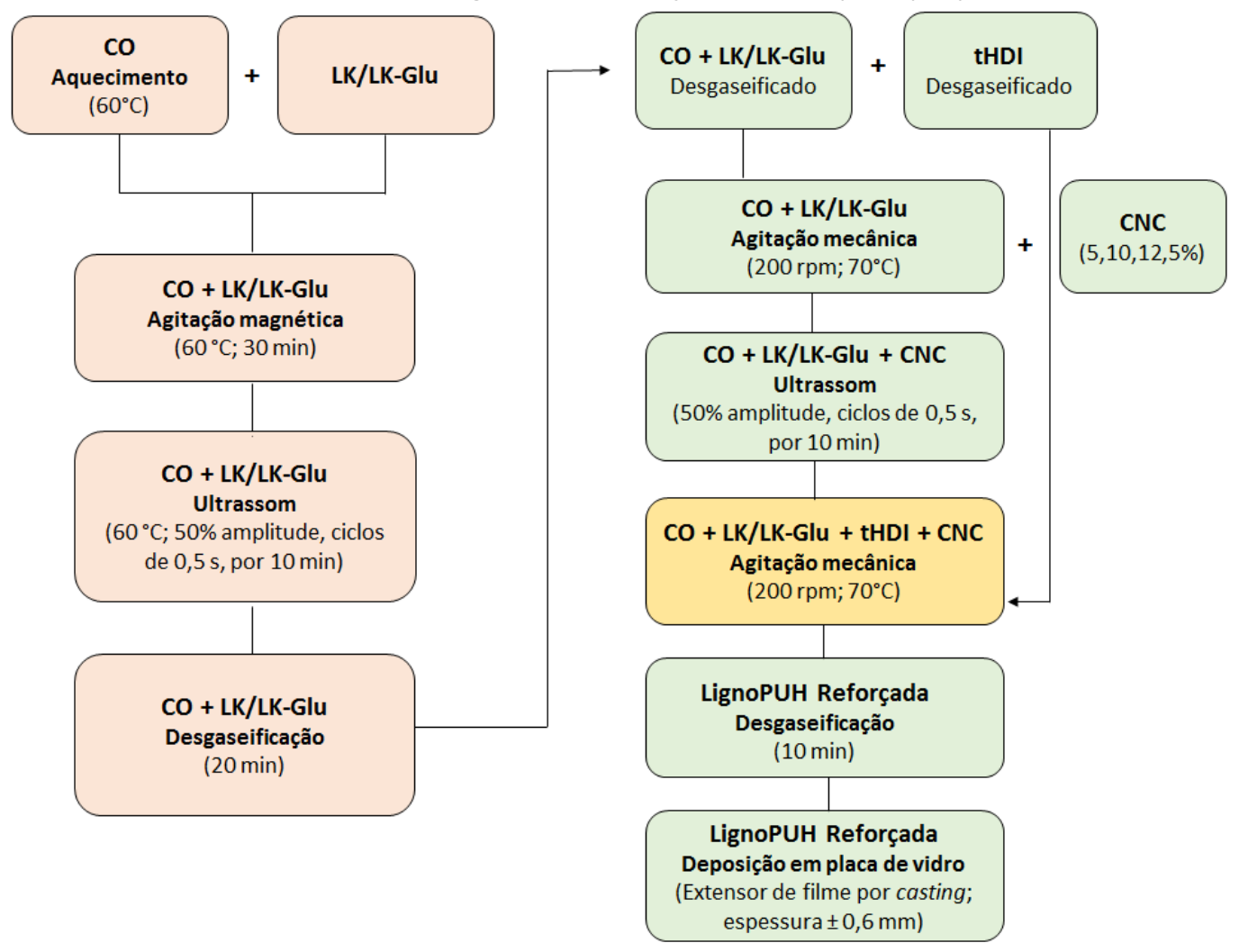

A mistura reacional espalhada na placa de vidro foi colocada em estufa de secagem a $100{ }^{\circ} \mathrm{C}$, para dar prosseguimento a reação de polimerização da poliuretana, com simultânea obtenção de filmes. O filme foi retirado da placa após o espectro FTIR indicar total consumo de tHDI, e armazenado em dessecador com sílica, sob vácuo, para análises posteriores.

Os tempos de agitação mecânica da mistura reacional contendo LK ou LK-Glu, CO tHDI e CNCs (Figura 64), antes do espalhamento da mistura na placa de vidro, variaram dependendo das proporções dos reagentes considerados, e foram definidos em função da observação do aumento na viscosidade no meio reacional. No Quadro 3 encontram-se as formulações, proporções dos reagentes, os tempos de agitação da mistura reacional, bem como o código utilizado para cada um deles. 
QUADRO 3 - Condições de reação das LignoPUHs reforçadas com CNCs.

\begin{tabular}{|c|c|c|c|}
\hline Materiais & $\begin{array}{c}\text { Formulação e Proporção dos } \\
\text { reagentes }\end{array}$ & $\begin{array}{c}\text { Tempo } \\
\text { de } \\
\text { Agitação } \\
\text { (min) }\end{array}$ & Código \\
\hline \multirow{3}{*}{$\begin{array}{c}\text { Filmes } \\
\text { Lignopoliuretânicos } \\
\text { (LK/CNCs) }\end{array}$} & $\begin{array}{l}\text { CO/LK50\%/tHDI/CNC5\% } \\
\text { Razão } 1: 0,7: 1: 0,13\end{array}$ & 75 & LignoPUH \\
\hline & $\begin{array}{l}\text { CO/LK50\%/tHDI/CNC10\% } \\
\text { Razão } 1: 0,7: 1: 0,26\end{array}$ & 60 & LignoPUHCOLK50_10\%CNC \\
\hline & $\begin{array}{l}\text { CO/LK50\%/tHDI/CNC12,5\% } \\
\text { Razão } 1: 0,7: 1: 0,33\end{array}$ & 50 & LignoPUHCoLK50_12,5\%CNC \\
\hline \multirow{3}{*}{$\begin{array}{c}\text { Filmes } \\
\text { Lignopoliuretânicos } \\
\text { (LK-Glu/CNCs) }\end{array}$} & $\begin{array}{l}\text { CO/LK-Glu50\%/tHDI/CNC5\% } \\
\text { Razão 0,8 : 0,5: } 1: 0,12\end{array}$ & 60 & LignoPUH \\
\hline & $\begin{array}{l}\text { CO/LK-Glu50\%/tHDI/CNC10\% } \\
\text { Razão 0,8 : 0,5: } 1: 0,24\end{array}$ & 50 & LignoPUH \\
\hline & $\begin{array}{l}\text { CO/LK-Glu50\%/tHDI/CNC12,5\% } \\
\text { Razão 0,8 : 0,5: } 1: 0,30\end{array}$ & 40 & LignoPUH ${ }_{\text {CoLK-Glu50_12,5\%CNC }}$ \\
\hline
\end{tabular}

A razão molar $\mathrm{NCO} / \mathrm{OH}=1: 1$ foi mantida para todos os filmes. Os cálculos feitos para obtenção das massas de CO, LK ou LK-Glu e tHDI utilizados na síntese das LignoPUHs reforçadas com CNCs consideraram os fatores descritos no Item 2.2.1 do Capítulo 2.

Os percentuais avaliados (5, 10 e 12,5 \%) foram selecionados de acordo com a previsão de possibilidade de dispersão de CNC no meio reacional. As massas de CNC utilizadas nos diferentes percentuais avaliados foram estimadas a partir da relação da massa total dos reagentes empregados na composição do filme. Os filmes obtidos nas mesmas condições citadas acima ( $50 \%$ de LK ou LK-Glu; tHDI; $100^{\circ} \mathrm{C}$ ), porém sem a presença de CNCs, foram denominadas LignoPUH ${ }_{\text {CoLk50_0\%CNC e LignoPUH }}$ CoLk-Glu50_0\%CNC.

\subsubsection{Espectroscopia na região do infravermelho com transformada de Fourier}

Imediatamente após a deposição da mistura reacional na placa de vidro foi retirada uma alíquota para análise (0h), e em períodos sequentes após a deposição do filme. A amostra referente ao tempo Oh foi analisada por deposição sobre pastilha de silício. Os outros espectros foram obtidos no modo de Reflectância Total Atenuada (ATR) descrito no Item 1.2.4.1 do Capítulo 1. 


\subsubsection{Caracterização dos Filmes Lignopoliuretânicos formados} simultaneamente as sínteses realizadas a partir de CO, LK ou LKGlu, e tHDI na presença de CNCs

Os filmes lignopoliuretânicos contendo CNCs e os filmes sem CNCs formados simultaneamente as sínteses realizadas a partir de $50 \%$ de CO, $50 \%$ de LK ou LK-Glu, e tHDI foram caracterizados pelas mesmas técnicas descritas para os filmes formados tendo como reagentes CO, LK ou LK-Glu e pMDI, Item 1.2.5, Capítulo 1.

\subsubsection{Microscopia Eletrônica de Varredura}

As análises de MEV foram realizadas de acordo com o que foi descrito no Item 1.2.5.1 do Capítulo 1.

\subsubsection{Termogravimetria}

As análises de TGA foram realizadas de acordo com o que foi descrito no Item 1.2.5.2 do Capítulo 1.

\subsubsection{Difração de raios $X$}

As análises de DRX foram realizadas de acordo com o que foi descrito no Item 1.2.5.3 do Capítulo 1.

\subsubsection{Teste de Intumescimento}

O teste de intumescimento foi realizado de acordo com o que foi descrito no Item 1.2.5.4 do Capítulo 1.

\subsubsection{Análise Dinâmico-Mecânica}

As análises de DMA foram realizadas de acordo com o que foi descrito no Item 1.2.5.5 do Capítulo 1.

\subsubsection{Análise de propriedades de Tração}

Os ensaios de resistência à tração foram realizados de acordo com o que foi descrito no Item 1.2.5.6 do Capítulo 1. As dimensões dos corpos de prova foram iguais para todos os filmes 
compósitos (1,5 $\mathrm{mm}$ de largura $\times 5 \mathrm{~mm}$ de comprimento - distância entre as garras $\times 0,65 \mathrm{~mm}$ de espessura).

\subsubsection{Análise de Ângulo de Contato}

As análises de ângulo de contato foram realizadas de acordo com o que foi descrito no Item 1.2.5.7 do Capítulo 1.

\subsection{Resultados e Discussão}

\subsubsection{Espectroscopia na região do infravermelho com transformada de Fourier \\ Os espectros das misturas reacionais (CO, 50 \% de LK ou LK-Glu, tHDI e CNCs)} imediatamente após deposição na placa $(\mathrm{t}=\mathrm{Oh}$ ) e dos respectivos filmes formados podem ser observados no Apêndice I.

O percentual de LK ou LK-Glu utilizados na síntese das PUs com simultânea formação desses filmes foi a mesma para todos (50\%), assim como a temperatura utilizada durante a reação de polimerização $\left(100^{\circ} \mathrm{C}\right)$. A diferença está no percentual de CNCs adicionado à mistura reacional $(5,10$ e $12,5 \%$ de $\mathrm{CNCs})$. Os espectros indicaram total consumo de isocianato para os filmes LignoPUH COLK50_5\%CNC, LignoPUH $_{\text {COLK50_10\%CNC e }}$

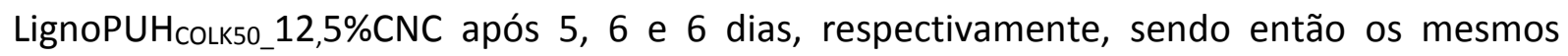
retirados da placa. Enquanto que para os filmes LignoPUH COLK-Glu50_5\%CNC, LignoPUH $_{\text {COLK- }}$

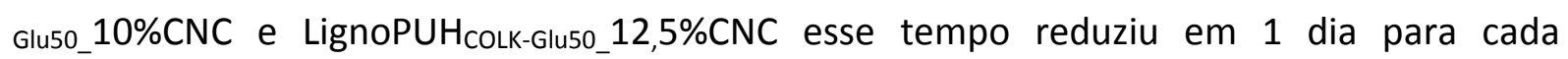

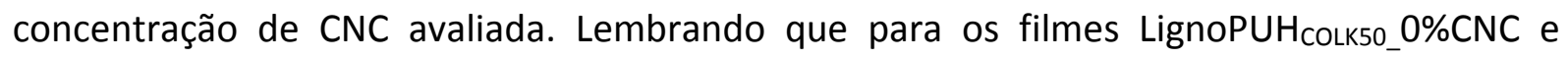

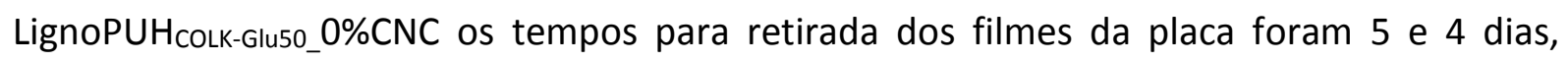
respectivamente. A presença de CNCs no meio reacional pode ter atuado como obstáculo para difusão dos reagentes no meio, retardando a reação de forma proporcional à concentração das nanopartículas presentes.

As bandas encontradas nos espectros na região do infravermelho dos filmes formados simultaneamente à síntese realizada a partir de CO, LK ou LK-Glu e tHDI sem a presença de CNCs (LignoPUHCoLk50_0\%CNC e LignoPUH CoLk-Glu50_0\%CNC), no geral, foram as mesmas

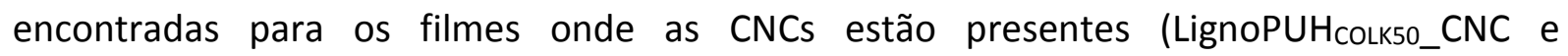
LignoPUH CoLk-Glu50_CNC) (Apêndice I). 


\subsubsection{Microscopia Eletrônica de Varredura}

A análise de microscopia eletrônica por varredura foi feita com o objetivo de avaliar a morfologia da superfície (Figura 65) e da seç̧ão transversal (criofraturada) (Figura 66) dos filmes produzidos com e sem a presença de CNCs.

A Figura 65, mostra como exemplo, a superfície dos filmes formados nas 2 matrizes sem a presença de CNCs (LignoPUH CoLk50_0\%CNC; LignoPUH CoLK-Glu50_0\%CNC), e com a presença de 10\% de CNCs (LignoPUH

Figura 65 - Micrografias eletrônicas de varredura da superfície dos filmes formados simultaneamente à síntese realizada a partir de CO, $50 \%$ LK ou LK-Glu e tHDI sem e com a presença de $10 \%$ de CNCs.

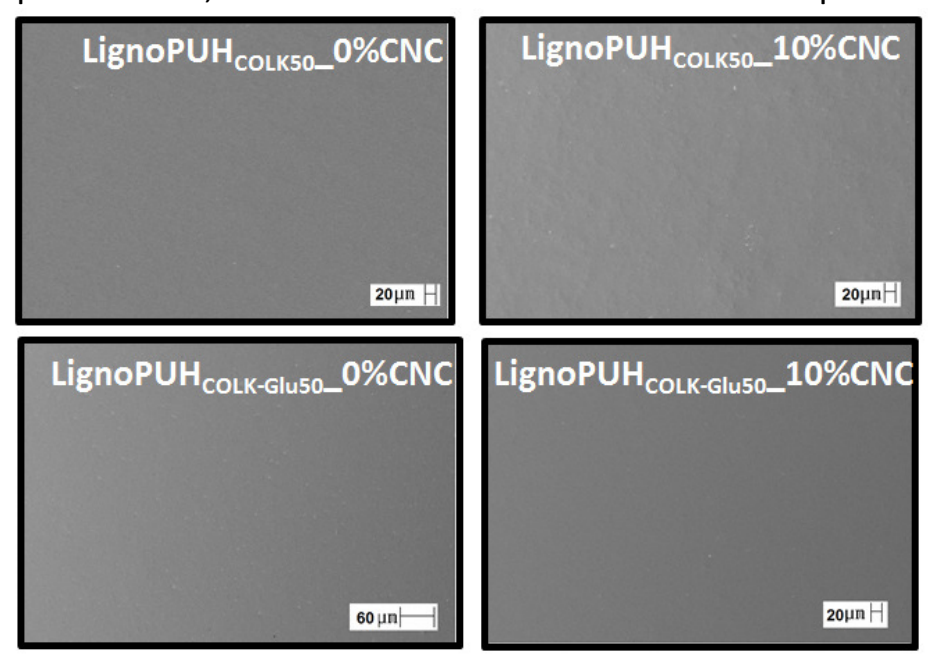

A morfologia da superfície dos filmes foi semelhante para todos os filmes produzidos. Em todos eles, a superfície se mostrou homogênea e sem a presença de bolhas ou sulcos (Figura 65).

A Figura 66 apresenta as micrografias das criofraturas dos filmes formados nas 2 matrizes sem a presença de CNCs (LignoPUHCoLk50_0\%CNC; LignoPUH a presença de 5, 10 e 12,5 \% de CNCs (LignoPUH Colk50_5\%CNC; LignoPUH

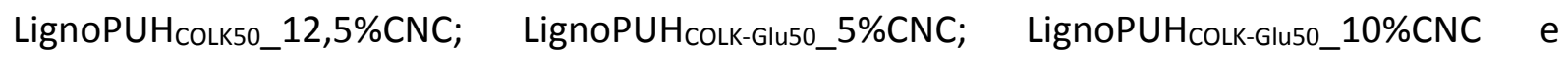

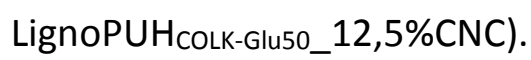


Figura 66 - Micrografias eletrônicas de varredura das criofraturas dos filmes formados simultaneamente à síntese realizada a partir de CO, 50 \% LK ou LK-Glu e tHDI sem e com a presença de CNC's.
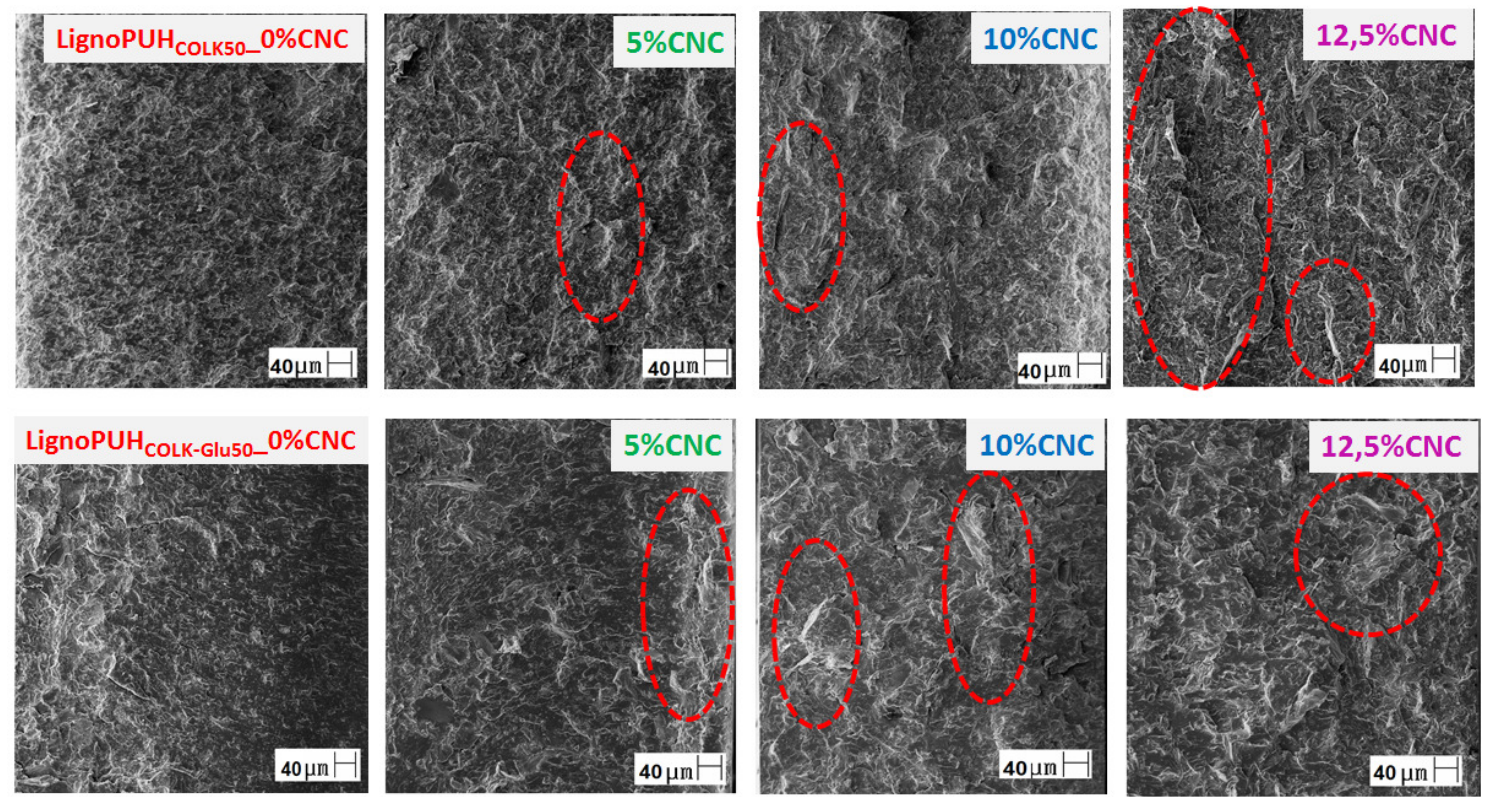

*Siglas: LignoPUH ${ }_{\text {colk50_CNC }=\text { Filme com } 50 \text { \% de Lignina Kraft purificada, tHDI e CNCs; LignoPU }}$ colkGluso_CNC = Filme com 50 \% de lignina modificada por hidroxialquilação, tHDI e CNCs.

Apesar da morfologia da superfície das criofraturas das amostras sem a presença de CNCs apresentarem rugosidade, ondulações e sulcos, é possível perceber uma mudança nessa morfologia com a presença dos mesmos nos filmes formados (Figura 66). Nas duas matrizes

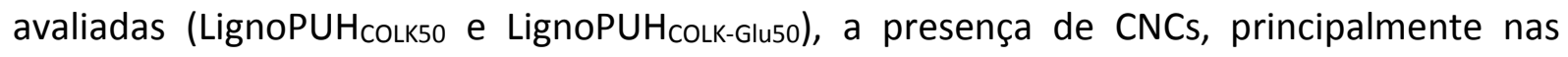
maiores concentrações de CNCs (10 e 12,5 \%), induziu a um aumento na deflexão. Como esse comportamento ocorreu de maneira uniforme em toda superfície dos filmes em que CNCs estavam presentes, conclui-se que houve uma boa dispersão dos CNCs na matriz. No entanto, não foi possível observar essa dispersão dos CNCs nas matrizes através da análise de MEV, em função das características da matriz e da limitação do equipamento para análise de partículas nanométricas. Outras técnicas, tais como, microscopia eletrônica de transmissão (MET) ainda serão realizadas visando verificar a dispersão dos CNCs nos filmes.

\subsubsection{Termogravimetria}

As curvas referentes à termogravimetria (TGA) e termogravimetria derivada (DTG) dos filmes lignopoliuretânicos preparados simultamente à síntese realizada a partir de CO, LK ou LK-Glu, tHDI e CNCs (LignoPUH ${ }_{\text {Colk50_CNC e LignoPUH }}$ Colk-Glu50_CNC) e dos filmes sem CNCs

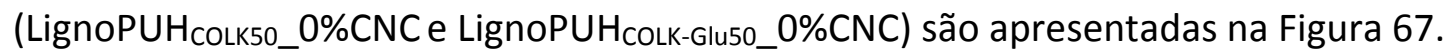


Figura 67 - Curvas de TGA (a) e (b) e DTG (c) e (d) dos filmes lignopoliuretânicos (CO, LK ou LK-Glu e tHDI) com e sem a presença de CNCs em atmosfera de $\mathrm{N} 2$, vazão de $50 \mathrm{~mL} \mathrm{~min}{ }^{-1}$ e razão de aquecimento de $10^{\circ} \mathrm{C} \mathrm{min}^{-1}$. Números 1 e 2 em (c) e (d) correspondem ao $1^{\circ}$ e $2^{\circ}$ evento, respectivamente.

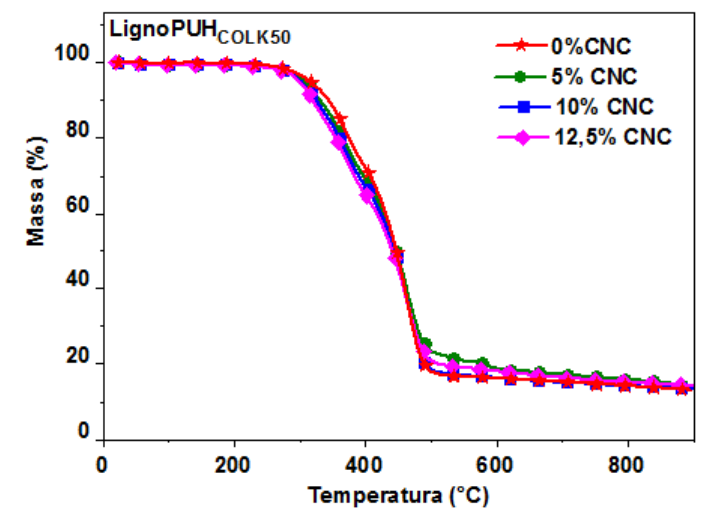

(a)

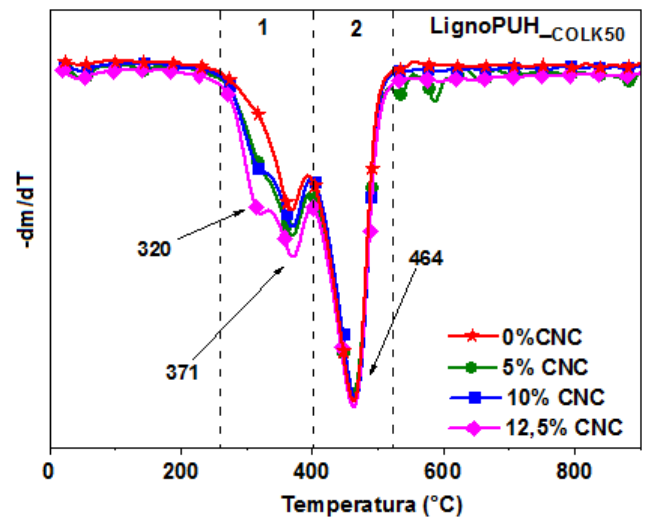

(c)

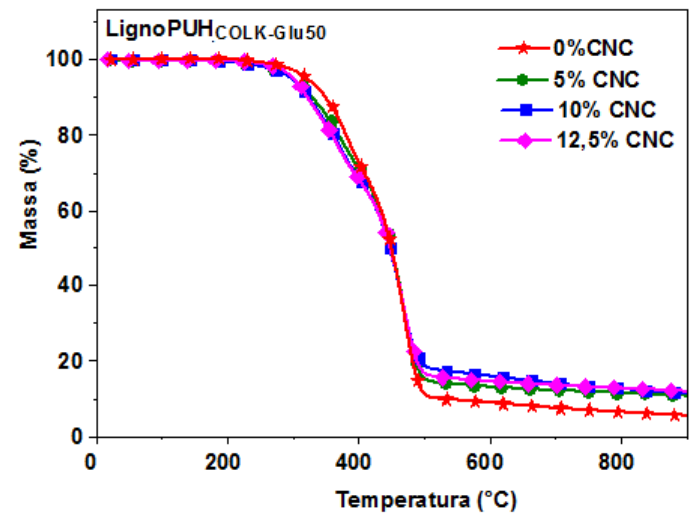

(b)

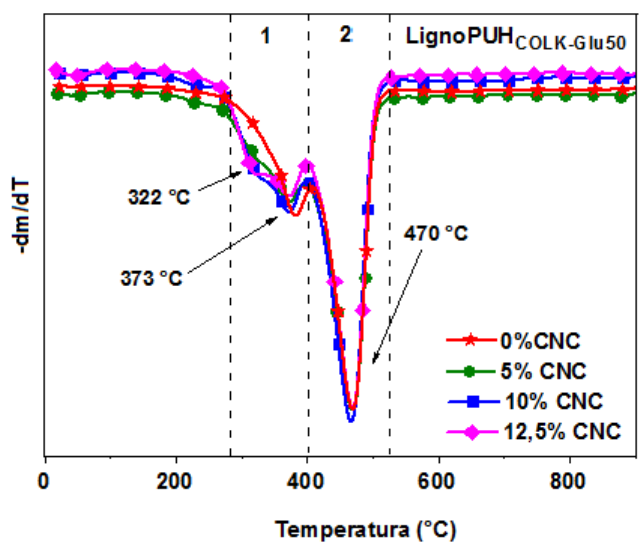

(d)

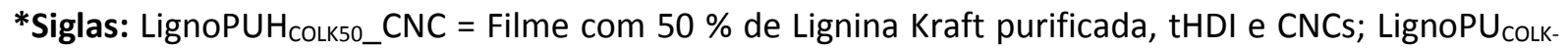
Glu5o_CNC = Filme com 50 \% de lignina modificada por hidroxialquilação, tHDI e CNCs.

A Tabela 23 apresenta os dados obtidos a partir da Figura 67 para os filmes LignoPUH Glu50_0\%CNC. 
Tabela 23 - Temperaturas e perdas de massa observadas nos filmes lignopoliuretânicos (CO, LK ou LKGlu e tHDI) com e sem a presença de CNCs em atmosfera de $\mathrm{N}_{2}$

\begin{tabular}{|c|c|c|c|c|c|c|}
\hline \multirow{2}{*}{ Filme } & \multicolumn{3}{|c|}{$\begin{array}{c}\text { Evento } 1 \\
\left(290-400^{\circ} \mathrm{C}\right)\end{array}$} & \multicolumn{2}{|c|}{$\begin{array}{c}\text { Evento } 2 \\
\left(400-530^{\circ} \mathrm{C}\right)\end{array}$} & \multirow{2}{*}{$\begin{array}{r}\begin{array}{r}\text { Resíduo } \\
\left(900^{\circ} \mathrm{C}\right)\end{array} \\
\begin{array}{c}\text { Massa } \\
(\%)\end{array}\end{array}$} \\
\hline & $\begin{array}{c}T_{\text {onset }} \\
\left({ }^{\circ} \mathrm{C}\right)\end{array}$ & $\begin{array}{l}T_{\text {Máx }} \\
\left({ }^{\circ} \mathrm{C}\right)\end{array}$ & $\begin{array}{l}\text { Perda de } \\
\text { massa (\%) }\end{array}$ & $\begin{array}{l}T_{\text {Máx }} \\
\left({ }^{\circ} \mathrm{C}\right)\end{array}$ & $\begin{array}{l}\text { Perda de } \\
\text { massa (\%) }\end{array}$ & \\
\hline LignoPUH & 325 & 368 & 20,0 & 464 & 57,1 & 13,2 \\
\hline LignoPUH ${ }_{\text {CoLK-Glu50_0\%CNC }}$ & 332 & 375 & 22,8 & 478 & 60,8 & 11,7 \\
\hline LignoPUH $_{\text {CoLk50_5\% CNC }}$ & 305 & 369 & 25,3 & 462 & 47,8 & 13,9 \\
\hline LignoPUH ${ }_{\text {CoLK-Glu50_5\% CNC }}$ & 309 & 372 & 23,2 & 470 & 57,9 & 10,8 \\
\hline LignoPUH & 300 & 368 & 27,4 & 468 & 50,9 & 13,4 \\
\hline LignoPUH & 302 & 373 & 25,5 & 467 & 51,6 & 11,3 \\
\hline LignoPUH & 291 & 371 & 31,3 & 463 & 45,8 & 14,1 \\
\hline LignoPUH ${ }_{\text {COLK-Glu50_12,5\% CNC }}$ & 294 & 371 & 27,6 & 468 & 52,9 & 11,9 \\
\hline
\end{tabular}

As curvas de DTG (Figura $67 \mathrm{c}$ e d) mostraram que o primeiro evento $\left(290-400{ }^{\circ} \mathrm{C}\right.$ ) relacionado com a quebra das ligações uretânicas e a decomposição dos segmentos flexíveis presentes, como os oriundos do CO e da cadeia acíclica do tHDI (CORCUERA et al., 2010) apresentaram para os filmes LignoPUH ${ }_{\text {CoLk50_CNC e LignoPUH }}$ CoLK-Glu50_CNC um pico com temperatura em que a velocidade de perda de massa é máxima entre 368 e $382{ }^{\circ} \mathrm{C}$, representando 20 e 22,8\% de perda de massa, respectivamente. À medida que os CNCs foram

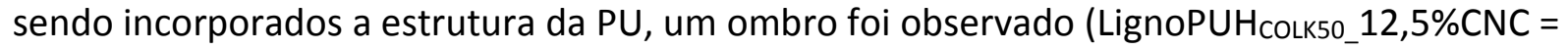

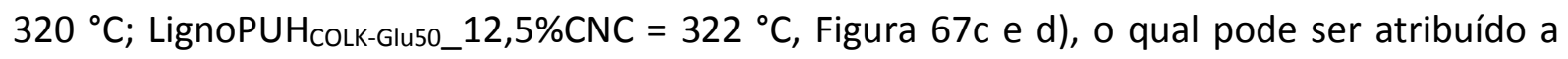
decomposição térmica de CNCs $\left(T_{\text {onset }}=295^{\circ} \mathrm{C}\right.$ com temperatura onde a velocidade de perda de massa é máxima em $314{ }^{\circ} \mathrm{C}$, Apêndice J) (Figura 67 c e d). Esse ombro mostrou-se mais proeminente nos filmes onde LK foi usado como reagente (Figura 67 c) em comparação aos filmes em que LK-Glu foi utilizado (Figura 67 d), sugerindo maior interação CNCs-matriz nos filmes LignoPUHCOLK-Glu50_CNC. Foi possível perceber um aumento na perda de massa referente a esse primeiro evento conforme houve aumento na concentração de CNCs nas PUs. Isso reforça a correlação do ombro presente nesse pico nas matrizes em que CNCs estavam presentes à decomposição térmica dos CNCs.

O segundo evento $\left(400-530{ }^{\circ} \mathrm{C}\right)$ se refere à decomposição das estruturas remanescentes após a primeira decomposição, dos anéis aromáticos da lignina e do anel de 6 membros do tHDI (TAVARES et al., 2016). 
A curva TGA (Figura 67 a e b) mostra que os filmes apresentaram estabilidade térmica até em torno de $290{ }^{\circ} \mathrm{C}$ e que conforme a incorporação de CNCs nas PUs aumenta, a porcentagem de massa residual dos filmes também aumenta, especialmente nos filmes formados a partir de PUs sintetizadas com LK-Glu. Todavia, os valores de massa residual para os filmes formados a partir de PUs sintetizadas com LK e CNC são superiores aos dos filmes formados a partir de PUs sintetizadas com LK-Glu e CNC (Tabela 23). Como mencionado anteriormente, essa massa residual se refere principalmente à formação de carvão vegetal e uma alta fração de compostos aromáticos que não são decompostos em atmosfera inerte (BARTKOWIAK; ZAKRZEWSKI, 2004; VELDEN et al., 2010) e em uma mesma massa, LK possui maior teor de compostos aromáticos comparativamente a LK-Glu, devido aos grupos alifáticos introduzidos pela modificação química.

\subsubsection{Difração de raios $X$}

A Figura 68 apresenta os difratogramas dos CNCs, dos filmes formados simultaneamente à síntese realizada a partir de CO, $50 \%$ de LK ou LK-Glu e tHDI sem a presença de CNCs e com a presença de 5,10 e $12,5 \%$ de CNCs em intervalo de $2 \theta$ que vai de 5 a $40^{\circ}$ para melhor visualização das regiões ordenadas cristalinas das amostras. 
Figura 68 - Curvas de difração de raios X para CNC; para os filmes lignopoliuretânicos preparados simultaneamente à síntese realizada utilizando (a) LK e (b) LK-Glu como polióis, tHDI como isocianato na presença ou não de 5, 10 e $12,5 \%$ de CNCs.

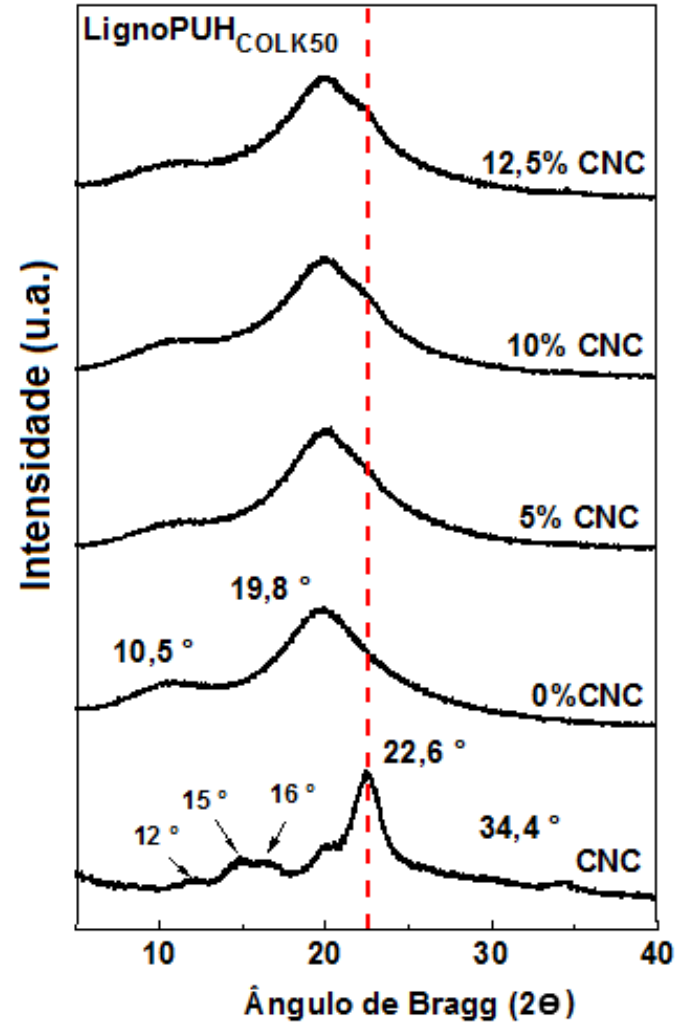

(a)

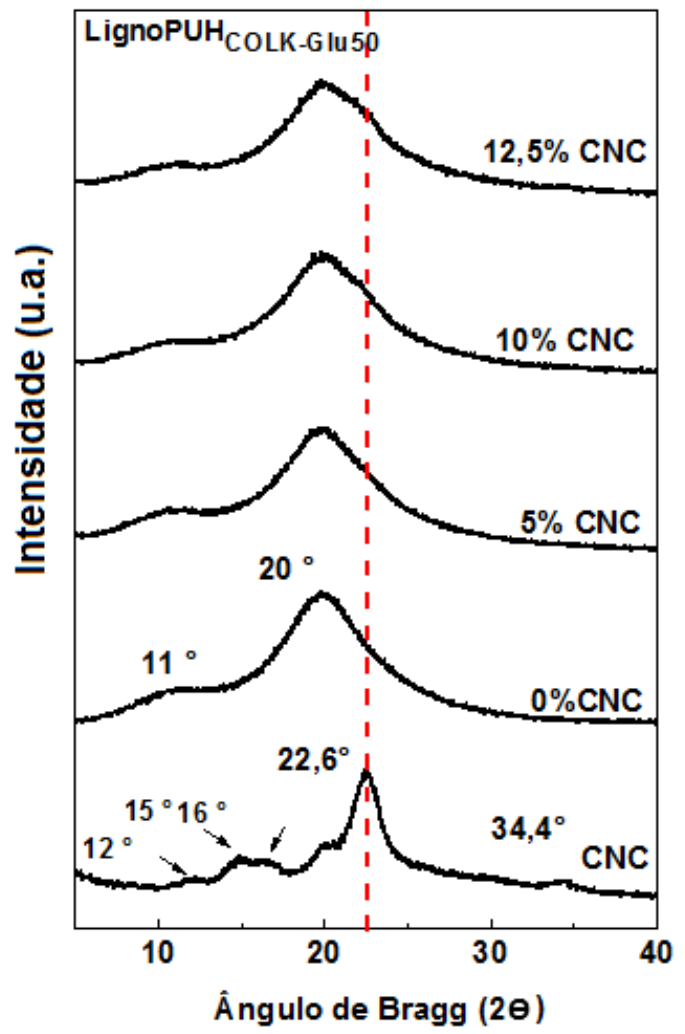

(b)

*Siglas: LignoPUH ${ }_{\text {COLK50_CNC }}=$ Filme com $50 \%$ de Lignina Kraft purificada, tHDI e CNCs; LignoPU colk- $_{\text {- }}$ Glu5o_CNC = Filme com 50 \% de lignina modificada por hidroxialquilação, tHDI e CNCs.

A Figura 68 a e b mostra que os filmes formados a partir de CO, LK ou LK-Glu, tHDI e 5, 10 e 12,5\% de CNCs apresentaram, igualmente aos respectivos filmes em que não há a presença de CNCs, dois picos, um de menor intensidade (LignoPUH CoLk50 $=10,5^{\circ} \mathrm{e}$ LignoPUH $\left._{\text {COLK-Glu50 }}=11^{\circ}\right)$ e outro de maior intensidade $\left(\right.$ LignoPUH $_{\text {COLK50 }}=19,8^{\circ}$ e LignoPUH ${ }_{\text {COLK- }}$ Glu50 $=20^{\circ}$ ), demonstrando a formação de regiões ordenadas nos filmes produzidos.

O difratograma dos CNCs apresenta os picos relacionados aos planos cristalográficos da celulose de acordo com os ângulos de Bragg (2Ө). Entre eles, o mais intenso é o que aparece em $2 \theta=22,6^{\circ}$ e juntamente com os outros picos caracterizam a chamada celulose cristalina do tipo I ou celulose nativa, que é sintetizada por plantas e algumas bactérias (ZHOU et al., 2009). A partir do acréscimo de $10 \%$ de CNCs nas LignoPUHs, as curvas de difração de raios $X$ apresentaram um aumento na área próxima ao ângulo $2 \theta=22,6^{\circ}$, o qual foi relacionado a celulose (Figura 68 a e b). Isso indica que a estrutura cristalina original da celulose I foi 
preservada nos filmes. Esse comportamento também foi observado por XUE et al. (2014) ao produzir filmes lignopoliuretânicos com lignina extraída de espiga de milho, polietileno glicol (PEG) e MDI e reforçá-los com CNCs obtidas a partir da hidrólise de línter de algodão.

A Tabela 24 mostra os índices de cristalinidade (ICr \%) obtidos para os filmes formados na presença ou não de CNCs.

Tabela 24 - ICr (\%)dos filmes lignopoliuretânicos (CO, LK ou LK-Glu e tHDI) com e sem a presença de CNCS

\begin{tabular}{|c|c|c|c|}
\hline Filme & $\operatorname{ICr}(\%)$ & Filme & $\operatorname{ICr}(\%)$ \\
\hline LignoPUH ${ }_{\text {COLK50_0\%CNC }}$ & 45 & LignoPUH ${ }_{\text {CoLK-Glu50_0\%CNC }}$ & 40 \\
\hline LignoPUH ${ }_{\text {COLK50_5\%CNC }}$ & 41 & LignoPUH ${ }_{\text {COLK-Glu50_5\%CNC }}$ & 44 \\
\hline LignoPUH ${ }_{\text {COLK50_10\%CNC }}$ & 47 & LignoPUH ${ }_{\text {COLK-Glu50_10\%CNC }}$ & 43 \\
\hline LignoPUH & 43 & LignoPUH ${ }_{\text {COLK-Glu50_12,5\%CNC }}$ & 43 \\
\hline
\end{tabular}

De acordo com a Tabela 24, a diferença entre os valores dos $\mathrm{ICr}$ observados para os filmes em que há presença de CNCs para os que não há, é próxima, indicando que a inserção de CNCs nas matrizes das LignoPUHs não influenciou significativamente nos $\mathrm{ICr}$ dos filmes LignoPUH ${ }_{\text {COLK50_CNC e LignoPUH }}$ COLK-Glu50_CNC.

\subsubsection{Teste de Intumescimento}

O gráfico das taxas de intumescimento $(S \%)$ filmes lignopoliuretânicos formados simultaneamente à síntese realizada a partir de CO, LK e LK-Glu e tHDI na presença ou não de CNCs estão apresentadas na Figura 69, assim como, as soluções de DMF após a realização do teste de intumescimento. 
Figura 69 - (a) S\% dos filmes lignopoliuretânicos (CO, LK ou LK-Glu e tHDI) com e sem a presença de CNCs e (b) fotos das soluções de DMF após realização do teste de intumescimento, sendo: (1) LignoPUH ${ }_{\text {CoLK50_0\%CNC; (2) LignoPUH }}$ CoLk-Glu50_0\%CNC; (3) LignoPUH ${ }_{\text {CoLk50_5\%CNC; (4) LignoPUH }}$ CoLkGlu50_5\%CNC; (5) LignoPUH ${ }_{\text {CoLk50_10\%CNC; (6) LignoPUH }}$ CoLk-Glu50_10\%CNC; (7) LignoPUH ${ }_{\text {CoLk50_12,5\%CNC e (8) LignoPUH }}$ CoLk-Glu50_12,5\%CNC.

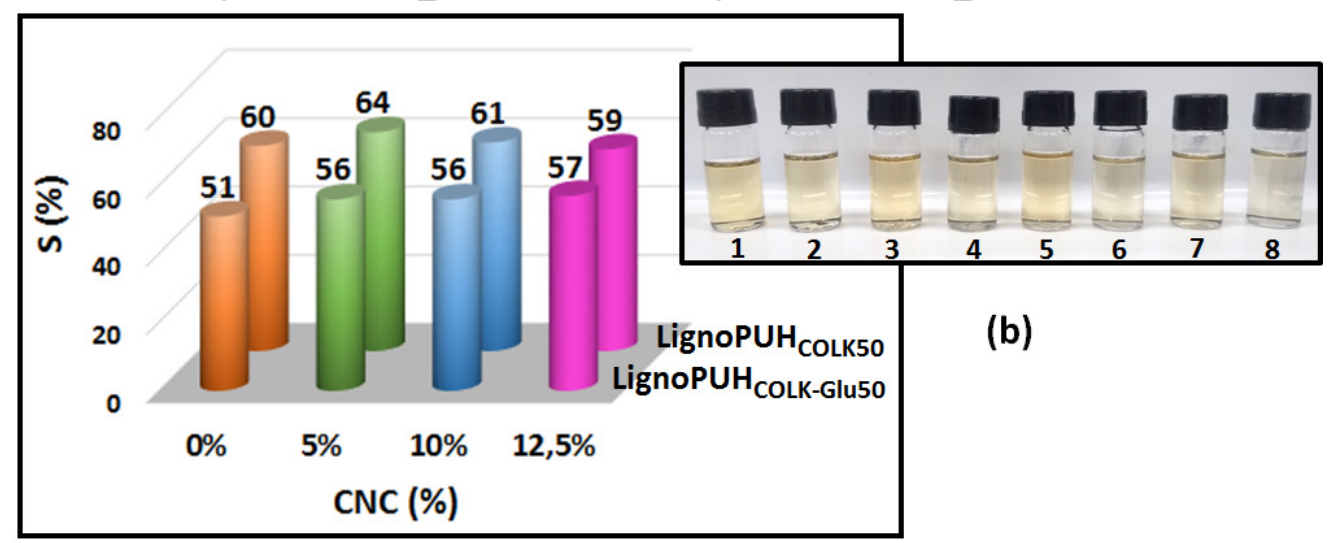

(a)

*Desvios-padrão: [De \pm 0,1 (LignoPUH ${ }_{\text {COLK-Glu50_5\%CNC) a } \pm 2,4 \text { (LignoPUH }}$ colk-Glu50_10\%CNC)].

*Siglas: LignoPUH ${ }_{\text {colk50_CNC = Filme com } 50 \text { \% de Lignina Kraft purificada, tHDI e CNCs; LignoPU }}$ colkGlu5o_CNC = Filme com 50 \% de lignina modificada por hidroxialquilação, tHDI e CNCs.

A Figura 69a mostra que os filmes em que CNCs estavam presentes na composição apresentaram uma tendência ao aumento na $S \%$, principalmente os preparados a partir de

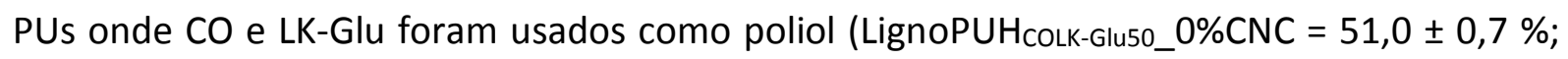
LignoPUH CoLk-Glu50_5\%CNC $=56,0 \pm 0,1 \%$; LignoPUH

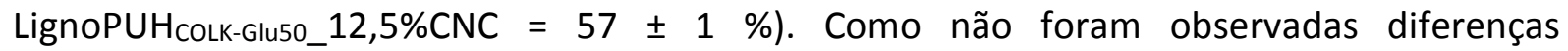
significativas na cristalinidade dos filmes em que CNCs estão presentes em relação aos que não estão, infere-se que esse fator não influenciou no resultado da $S \%$.

Dessa forma, considerando que houve um aumento no volume de estruturas das LignoPUHs em que CNCs estão presentes, especialmente as que foram preparadas a partir de LK-Glu, em função da modificação química realizada com glutaraldeído, em que segmentos alifáticos contendo hidroxilas ou não foram inseridos em sua estrutura (Figura 14), é possível inferir que a tendência ao aumento na S\% observada para os filmes em que CNCs estão presentes pode estar ligada a maior interação dos CNCs com o solvente utilizado, nesse caso o DMF, que facilitou a penetração do mesmo, principalmente através da interface da matriz poliuretânica com o reforço, devido sua afinidade. É importante ressaltar que o DMF é um solvente orgânico polar aprótico, miscível em água, e que os CNCs possuem grupos $\mathrm{OH}$ polares em sua cadeia passíveis de interações com o DMF (CHANG et al., 2016). 
A S\% nos filmes formados a partir de LignoPUHs sintetizadas com LK-Glu e CNCs foram menores em relação aos formados a partir de LignoPUHs sintetizadas com LK e CNCs (Figura 69 a). Como esse resultado também foi observado nas LignoPUHs que não continham CNCs, infere-se que esse resultado provavelmente está ligado ao menor volume livre dessas matrizes poliméricas, devido o maior volume das estruturas de LK-Glu em relação as de LK, conforme já mencionado em 1.3.2.5 Capítulo 1.

A coloração das soluções de DMF após o término do teste de intumescimento, visualizada na Figura 69 b, revelou um sútil clareamento da solução conforme o acréscimo da concentração de CNCs, sugerindo que a presença de CNCs no interior dos filmes dificultou a difusão de cadeias de baixa massa molar média para o solvente.

\subsection{6 Ângulo de Contato}

A Figura 70 apresenta os ângulos de avanço (AA) e recuo (AR) dos filmes formados simultaneamente à síntese realizada a partir de CO, 50\% de LK e LK-Glu, tHDI na presença ou não de CNCs.

Figura 70 - AA e AR para os filmes lignopoliuretânicos (CO, LK ou LK-Glu e tHDI) com e sem a presença de CNCs.

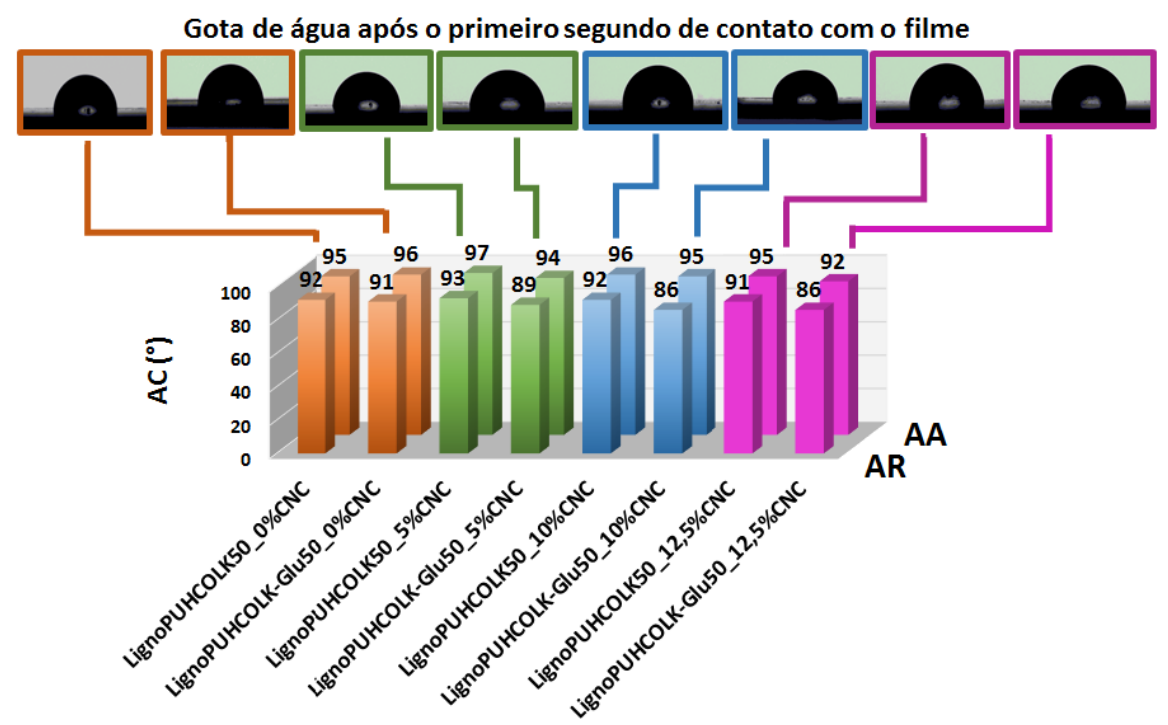

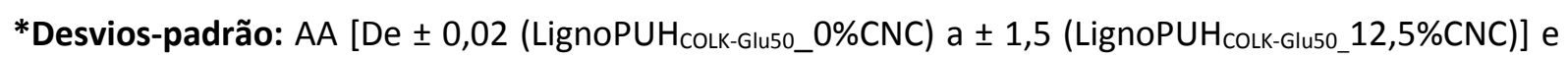

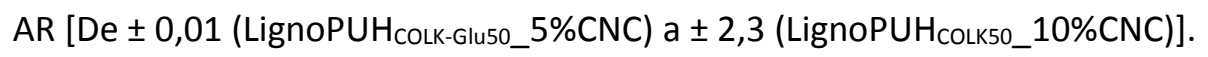

*Siglas: LignoPUH ${ }_{\text {Colk50_CNC }}=$ Filme com $50 \%$ de Lignina Kraft purificada, tHDI e CNCs; LignoPU colk- $_{\text {- }}$ Glu50_CNC = Filme com 50 \% de lignina modificada por hidroxialquilação, tHDI e CNCs. 
De acordo com a Figura 70, a adição de 5, 10 e 12,5 \% de CNCs aos reagentes usados nas sínteses das lignopoliuretânicas com simultânea formação de filmes praticamente não alterou os valores do AA e do AR em relação aos filmes formados nas sínteses em que CNCs não foram adicionadas. Todos os filmes apresentaram uma superfície de caráter hidrofóbico, uma vez que, os valores do AA observados são superiores a $90^{\circ}$, valor que delimita a classificação entre superfícies hidrofílicas e hidrofóbicas.

A celulose pode ser considerada como tendo caráter anfifílico (KONDO, 2007). O caráter hidrofílico é observado na direção equatorial de uma unidade anidroglicosídica (Figura 71), ou seja, paralelo ao plano do anel, pelo fato de todos os três grupos hidroxila estarem localizados nas posições equatoriais do anel (Figura 71). O caráter hidrofóbico é encontrado na direção axial da unidade anidroglicosídica, ou seja, perpendicular ao plano do anel, pois as ligações CH estão localizadas nas posições axiais do anel (Figura 71) (BERGENSTRÅHLE et al., 2010; MEDRONHO; LINDMAN, 2014a).

Figura 71 - Regiões hidrofílicas e hidrofóbicas da molécula de celulose.

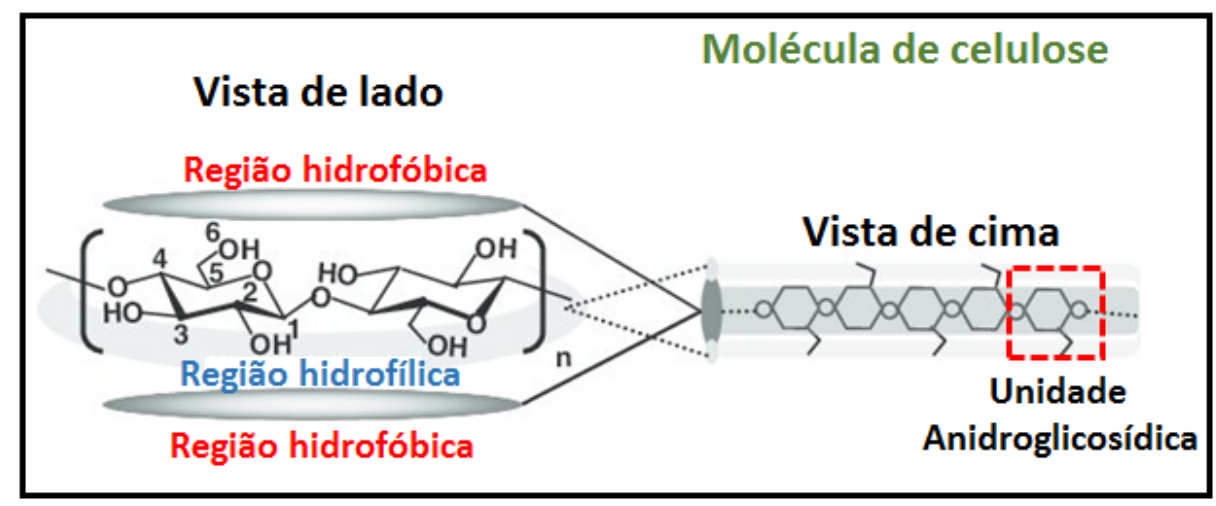

Fonte: Adaptado de KONDO (2007).

Os valores de AA não diminuíram significativamente conforme os CNCs foram acrescentados nas matrizes LignoPUHs e a histerese desses filmes foi pequena (entre 3 e 6, à exceção de LignoPUHCoLk50_12,5\%CNC que apresentou 9) sugerindo que os grupos hidroxila das CNCs estavam orientadas para o interior dos filmes, provavelmente interagindo com os grupos polares das estruturas das respectivas LignoPUHs, o que fez com que predominassem características hidrofóbicas na superfície dos filmes. 


\subsubsection{Análise Dinâmico-Mecânica}

A Figura 72 apresenta as curvas Tan- $\delta$ versus temperatura para os filmes lignopoliuretânicos formados simultaneamente à síntese realizada a partir de CO, 50 \% de LK

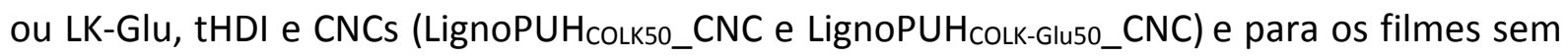
CNCs (LignoPUH ${ }_{\text {COLK50_0\%CNC e LignoPUH }}$ COLK-Glu50_0\%CNC).

Figura 72 - Curvas Tan- $\delta$ para os filmes lignopoliuretânicos formados simultaneamente à síntese a partir de CO, (a) LK e (b) LK-Glu e tHDI, na presença de 5, 10 e 12,5\% de CNCs e para os filmes sem CNCs $(0 \% \mathrm{CNC})$.

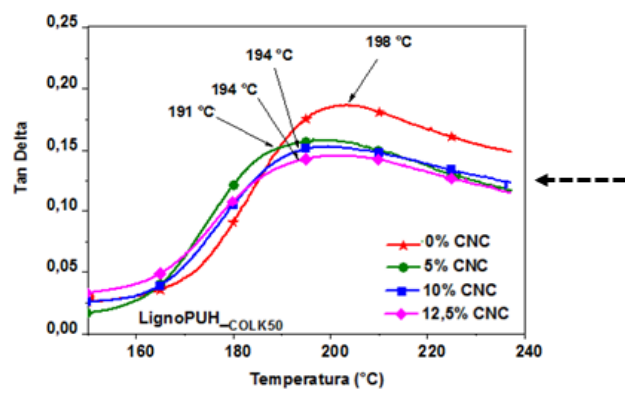

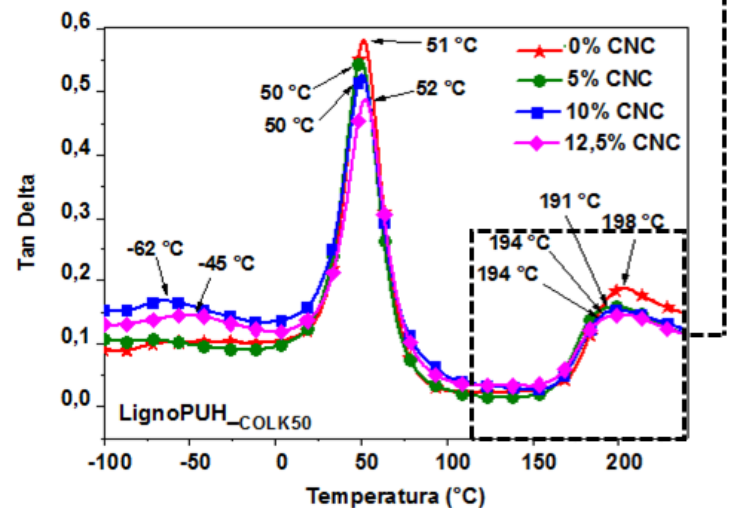

(a)
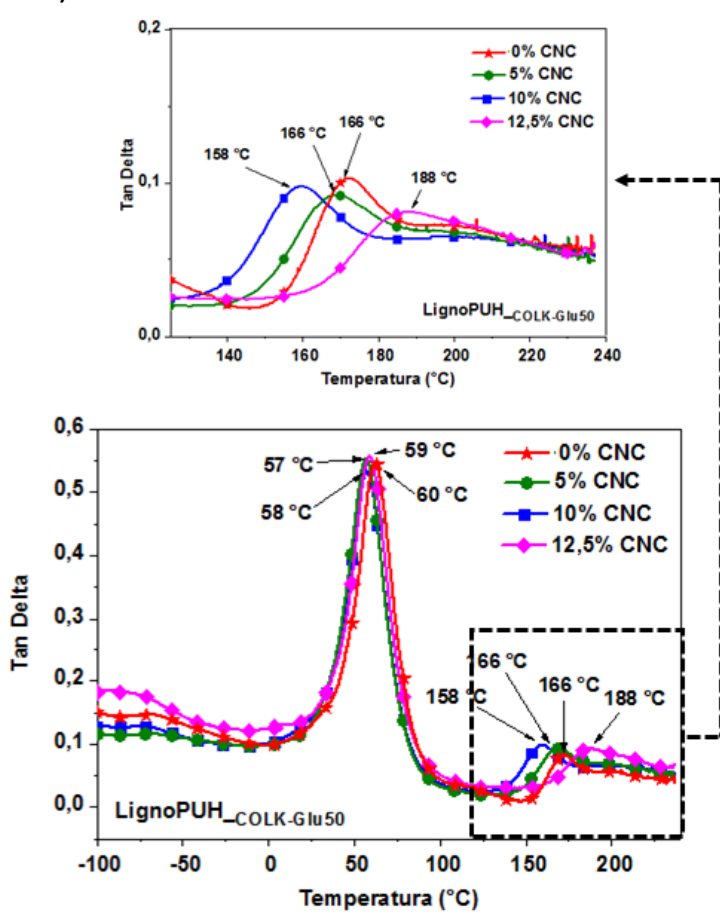

(b)

*Siglas: LignoPUH ${ }_{\text {Colk50_CNC }}=$ Filme com $50 \%$ de Lignina Kraft purificada, tHDI e CNCs; LignoPU colk- $_{\text {- }}$ Glu50_CNC = Filme com 50 \% de lignina modificada por hidroxialquilação, tHDI e CNCs.

Assim como para os filmes em que não há a presença de CNCs, as curvas Tan- $\delta$ para os filmes LignoPUHCoLk50_CNC (Figura 72 a) e LignoPUHCoLk-Glu50_CNC (Figura 72 b) mostram a segmentação dessas PUs, através do surgimento de dois picos de intensidade e temperaturas distintas. Como discutido anteriormente, o primeiro pico $\left(1^{\circ} T_{\mathrm{g}}\right)$ aparece em temperaturas mais baixas, é relativamente estreito, indicando que são transições decorrentes de relaxamento de segmentos com estrutura química relativamente similar e pode ser relacionado aos domínios flexíveis das PUs, provenientes principalmente do CO e das cadeias alifática do tHDI. Já o segundo pico $\left(2^{\circ} T_{\mathrm{g}}\right)$ aparece em temperaturas mais altas, é mais largo e 
menos intenso que o primeiro pico, sugerindo ser decorrente de relaxamento de segmentos com estrutura química não muito similar, e está relacionado aos domínios rígidos, oriundos principalmente de reações LK/tHDI ou LK-Glu/tHDI.

É importante salientar que as curvas TGA mostraram estabilidade térmica até aproximadamente $290{ }^{\circ} \mathrm{C}$ (Tabela 23), ou seja, não houve perda de massa na faixa de temperatura em que os segundos picos apareceram nas curvas Tan- $\delta$ dos filmes LignoPUH ${ }_{\text {COLK50_CNC e LignoPU }}$ CoLk-Glu50_CNC (Figura 72), o que poderia levar a modificações nas propriedades dos filmes, e por sua vez poderia gerar picos nas curvas Tan- $\delta$. O segundo pico foi então atribuído a transição vítrea das fases rígidas dessas LignoPUHs. Os valores dessas $T_{\mathrm{g}}$ s encontram-se na Tabela 25.

Tabela $25-T_{\mathrm{gS}}$ (pico Tan- $\delta$ ) para os filmes lignopoliuretânicos (CO, LK ou LK-Glu e tHDI) com e sem a presença de CNCS

\begin{tabular}{|c|c|c|c|c|}
\hline \multirow{2}{*}{ Pico } & \multicolumn{4}{|c|}{$T_{\mathrm{g}}\left({ }^{\circ} \mathrm{C}\right)$} \\
\hline & LignoPUH ${ }_{\text {CoLk50_0\%CNC }}$ & $5 \% \mathrm{CNC}$ & $10 \%$ CNC & $12,5 \% \mathrm{CNC}$ \\
\hline $1^{\circ}$ & 51 & 50 & 50 & 52 \\
\hline \multirow[t]{2}{*}{$2^{\circ}$} & 198 & 191 & 194 & 194 \\
\hline & LignoPUH ${ }_{\text {CoLk-Glu50_0\%CNC }}$ & $5 \% \mathrm{CNC}$ & $10 \%$ CNC & $12,5 \% \mathrm{CNC}$ \\
\hline $1^{\circ}$ & 60 & 57 & 58 & 59 \\
\hline $2^{\circ}$ & 167 & 166 & 158 & 188 \\
\hline
\end{tabular}

Para os filmes formados a partir de PUs sintetizadas com LK, na presença de CNCs, é possível perceber um decréscimo na intensidade do $1^{\circ}$ e $2^{\circ}$ pico (domínios flexíveis e rígidos, respectivamente) em decorrência do aumento na concentração de CNCs. Esse efeito pode estar relacionado às interações desses segmentos poliuretânicos com os CNCs. A intensidade das interações na interface da matriz com o reforço pode ser correlacionada com a diminuição na altura do pico de Tan- $\delta$, isso ocorre como consequência da diminuição da mobilidade das cadeias dos segmentos poliméricos, que por sua vez dissipam menos energia, ocasionando o decréscimo na altura do pico Tan- $\delta$ (DE OLIVEIRA SANTOS et al., 2014). Logo, quanto mais forte essa interação matriz-reforço, menor a intensidade dos picos de Tan- $\delta$. Esse efeito na altura do pico de Tan- $\delta$ depende da concentração de reforço utilizado na preparação do compósito (IDICULA et al., 2005). Assim, conclui-se que houve um aumento na intensidade das interações dos CNCs com os segmentos flexíveis e rígidos da matriz LignoPUHCoLk50_CNC conforme o aumento em sua concentração na mistura reacional (Figura 72a). Com relação aos 
valores das $T_{\mathrm{g} S}$ observados para os domínios flexíveis e rígidos dos filmes LignoPUHCoLk50_CNC, praticamente não houve alteração em função do aumento na concentração dos CNCs nos mesmos (Figura 72a, Tabela 25).

Ainda na Figura 72a, as amostras LignoPUH CoLk50_10\%CNC e LignoPUH_CoLk50_12,5\%CNC apresentaram uma relaxação $\beta$ em torno de -45 e - $62^{\circ} \mathrm{C}$, respectivamente, ou seja, rotações em torno de ligações simples envolvendo grupos, e que antecede a $T_{g}$ (LORANDI et al., 2016).

Para os filmes formados a partir de LK-Glu e CNCs (Figura 72b), o efeito na altura do pico em função da intensidade da matriz-reforço foi observado principalmente no pico referente aos segmentos rígidos, que sofreu um ligeiro decréscimo com o aumento na concentração dos

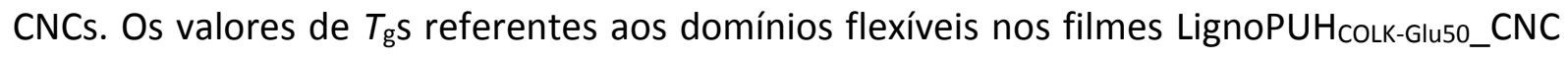
não apresentaram alteração em função do aumento na concentração de CNCs, todavia foram

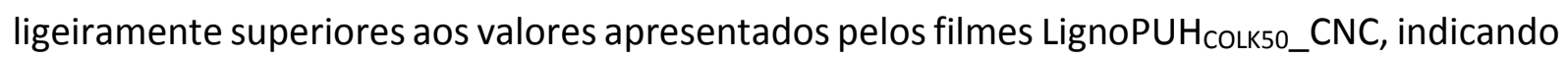
maior necessidade de energia para movimentar os segmentos flexíveis dos filmes formados a partir de LK-Glu (Tabela 25). Com relação aos valores de $T_{\mathrm{g}} \mathrm{S}$ dos domínios rígidos, a amostra

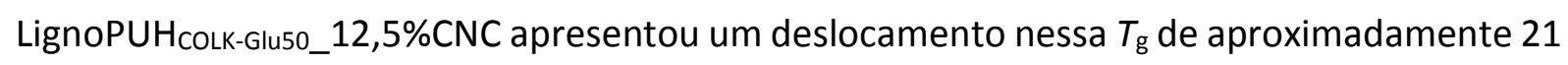
${ }^{\circ} \mathrm{C}$ em relação à LignoPUH CoLk-Glu50_0\%CNC, sugerindo maior rigidez nesse filme (Tabela 25).

A Figura 73 apresenta o módulo de armazenamento $\left(E^{\prime}\right)$, a $25^{\circ} \mathrm{C}$, dos filmes formados simultaneamente à síntese realizada a partir de CO, 50 \% de LK ou LK-Glu e tHDI com e sem a presença de CNCs.

Figura 73 - E' $\left(25^{\circ} \mathrm{C}\right)$ dos filmes lignopoliuretânicos (CO, LK ou LK-Glu e tHDI) com e sem a presença de CNCs.

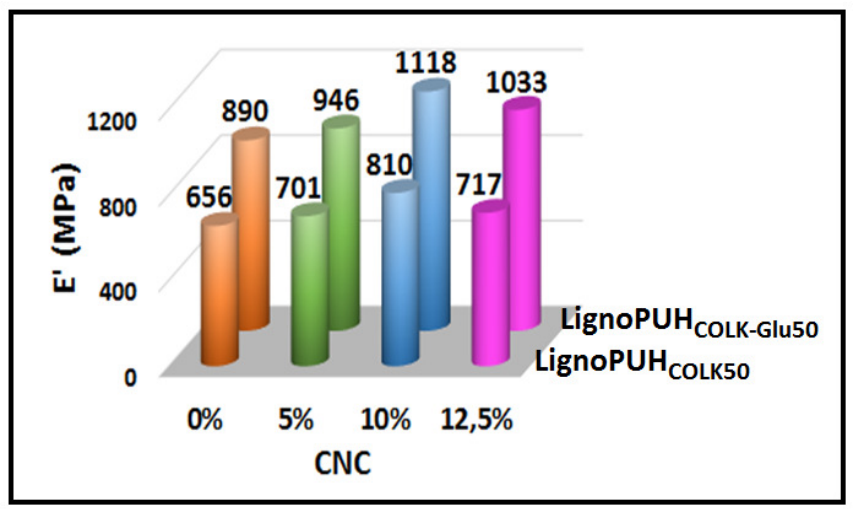

*Siglas: LignoPUH ${ }_{\text {Colk50_CNC = Filme com } 50 \% \text { de Lignina Kraft purificada, tHDI e CNCs; LignoPU }}$ colkGlu50_CNC = Filme com 50 \% de lignina modificada por hidroxialquilação, tHDI e CNCs. 
Na temperatura ambiente $\left(25^{\circ} \mathrm{C}\right)$, todos os filmes se encontravam no estado rígido, uma vez que os valores de transição vítrea $\left(T_{\mathrm{g}}\right)$ observados nos domínios não cristalinos para esses filmes estão acima de $25^{\circ} \mathrm{C}(\operatorname{Tan}-\delta$, Tabela 25$)$.

De acordo com a Figura 73, é possível verificar que a incorporação de até $10 \%$ de CNCS na mistura reacional dos filmes, tanto para os formados a partir de PUs sintetizadas com LK quanto LK-Glu, promoveu um aumento no E' dos compósitos em relação aos filmes não reforçados. A concentração de 12,5 \% de CNCs em ambas matrizes poliuretânicas ocasionou um pequeno decréscimo nos valores de $\mathrm{E}^{\prime}$ em relação as PUs reforçadas com $10 \%$ de CNCs, porém os valores ainda são superiores ao das matrizes em que não há a presença de CNCs. Isso pode indicar a ocorrência de início de aglomeração dos CNCs a partir de 12,5\%, devido à característica intrínseca dessas partículas de se auto-associarem através de ligações de hidrogênio, o que compromete a capacidade de reforço das nanopartículas (LEITE, 2015).

Existem diversos estudos na literatura que relatam o uso de CNCs como agentes de reforços em filmes poliuretânicos. A faixa de concentração de CNCs utilizada é bastante ampla (0,25 a 30\% em massa) (RUEDA et al., 2013; SARALEGI et al., 2014), sendo que a maioria relata o uso de até $10 \%$ de CNCs com ganhos nas propriedades mecânicas, a partir de $10 \%$ de CNCs a agregação das nanopartículas já pode prejudicar a ação como reforço das mesmas (BENHAMOU et al., 2015; BUFFA et al., 2018), concordando com o resultado observado para os valores de $E^{\prime}$ apresentados neste trabalho.

Para todas as concentrações de CNCs avaliadas (5, 10 e 12,5 \%; Figura 73) os filmes formados nas reações em que LK-Glu foi usado como poliol apresentaram maiores valores de E' comparativamente aos filmes formados a partir de LK. Os acréscimos de E' foram de 26, 27 e 31 \% para os filmes LignoPUH ${ }_{\text {CoLk-Glu50_5\%CNC, LignoPUH }}$ CoLK-Glu50_10\%CNC e LignoPUH CoLKGlu50_12,5\%CNC, respectivamente, em relação aos filmes formados nas reações em que LK foi usado como poliol, nas mesmas concentrações de LK-Glu. Esse resultado provavelmente está relacionado a uma maior interação dos CNCs com a matriz produzida com lignina modificada (LK-Glu). A inserção de segmentos alifáticos na LK-Glu, principalmente, os di-hidroxilados (Figura 14), através da reação da lignina com glutaraldeído, provavelmente, proporcionou melhor arranjo espacial e maior número de ligações hidrogênio dos CNCs com a matriz poliuretânica, promovendo o aumento de E'. 


\subsubsection{Propriedades de Tração}

A Figura 74 apresenta os resultados de resistência a tração, módulo de Young e alongamento na ruptura dos filmes lignopoliuretânicos preparados simultaneamente à síntese a partir de CO, LK ou LK-Glu e tHDI com e sem a presença de CNCs.

Destaca-se que os filmes formados a partir de $50 \%$ de LK e LK-Glu, tHDI na presença ou não de CNCs possuíam a mesma medida dos corpos de prova para esse ensaio (1,5 $\mathrm{mm}$ largura x $5 \mathrm{~mm}$ distância entre garras $\times 0,65 \mathrm{~mm}$ espessura).

Figura 74 - (a) Resistência a ruptura, (b) módulo de Young e (c) alongamento na ruptura dos filmes lignopoliuretânicos (CO, LK ou LK-Glu e tHDI) com e sem a presença de CNCs.

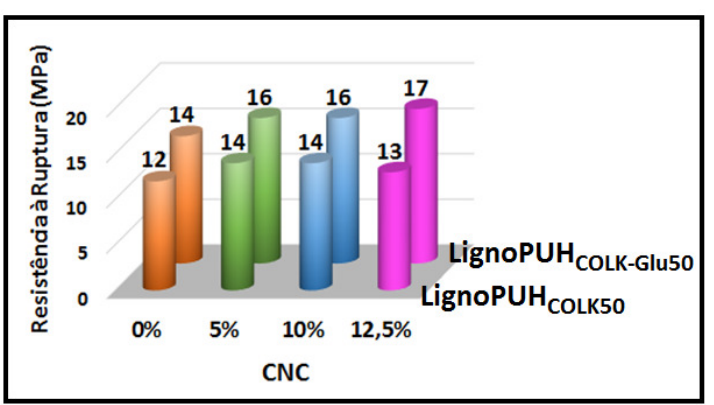

(a)

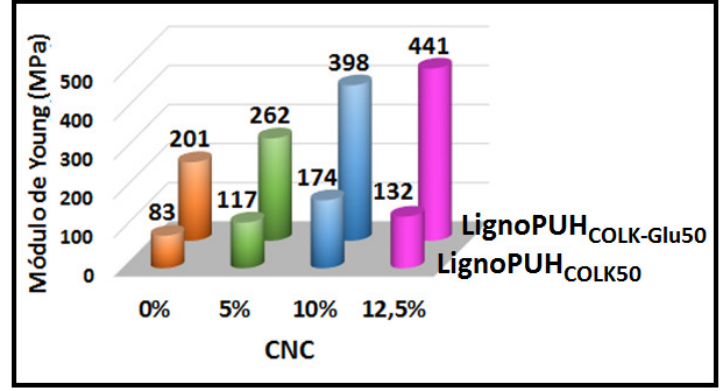

(b)

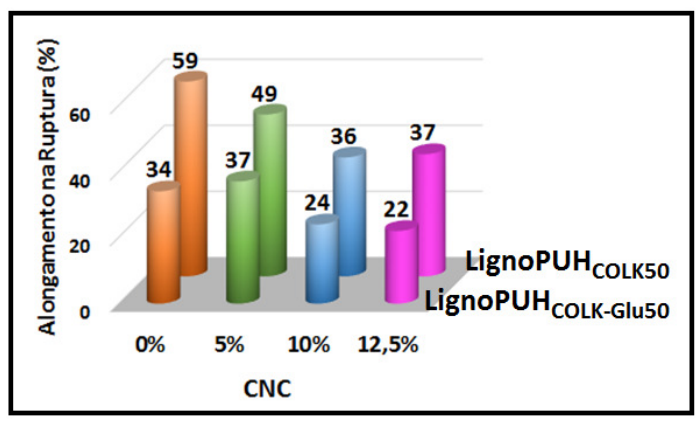

(c)

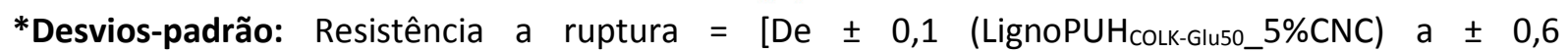
(LignoPUH ${ }_{\text {CoLk50_0\%CNC)], módulo de Young }=[\text { De } \pm 1,0 \text { (LignoPUH }}$ CoLk50_5\%CNC) a $\pm 11,6$

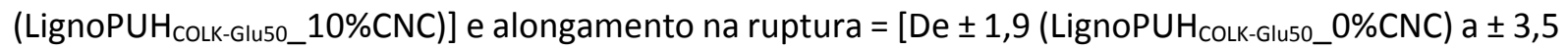
(LignoPUH ${ }_{\text {COLK50_12,5\%CNC)]. }}$

*Siglas: LignoPUH ${ }_{\text {Colk50_CNC }=\text { Filme com } 50 \% \text { de Lignina Kraft purificada, tHDI e CNCs; LignoPU }}$ CoLkGlu50_CNC = Filme com 50 \% de lignina modificada por hidroxialquilação, tHDI e CNCs.

O ensaio de tração foi conduzido a $25^{\circ} \mathrm{C}$, nessa temperatura os segmentos dos filmes formados a partir de 50 \% de LK ou LK-Glu e tHDI contendo ou não CNCs em sua composição se encontravam no estado rígido, uma vez que os valores de $T_{\mathrm{g}}$ observados para domínios não cristalinos para esses filmes estão acima de $25^{\circ} \mathrm{C}$ como discutido no Item 3.3.7 (Tabela 25). 
Para os filmes formados a partir de LK e CNCs, foi observado um aumento de $14 \%$ na resistência à tração dos filmes que contém 5 \% de CNCs em sua composição em relação ao filme sem CNCs (Figura 74a). A resistência à tração dos filmes que foram reforçados com 10 \% de CNCs $(14,0 \pm 0,4 \mathrm{MPa})$ manteve-se semelhante aos que foram reforçados com $5 \%$ de CNCs $(14,0 \pm 0,3 \mathrm{MPa})$ e ligeiramente superior ao filme reforçado com 12,5\% de CNCs $(13,0 \pm 0,2$ MPa) (Figura 74 a). Como comentado para os valores de $E^{\prime}$ na análise de DMA (Item 3.3.7), isso pode estar relacionado a aglomeração dos CNCs a partir de $12,5 \%$, interferindo negativamente na atuação dessas nanopartículas como agentes de reforço.

Para os filmes formados a partir de PUs sintetizadas com LK-Glu e CNCs, foi possível observar um aumento na resistência à tração de 18 \% para o filme LignoPUH colk-

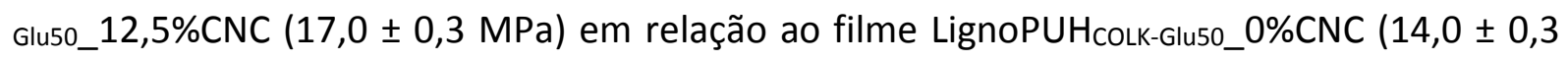
MPa). Os filmes reforçados com 5 e $10 \%$ de CNCs apresentaram o mesmo aumento $(16,0 \pm$ 0,1 MPa; 16,0 \pm 0,6 MPa, respectivamente) em relação ao filme não reforçado.

Com relação ao módulo de Young (Figura 74b), os filmes formados a partir de PUs sintetizadas com LK apresentaram aumento nessa propriedade até o acréscimo de $10 \%$ de CNCs (aumento de 52 \%) em relação ao filme não reforçado. Todavia, o filme

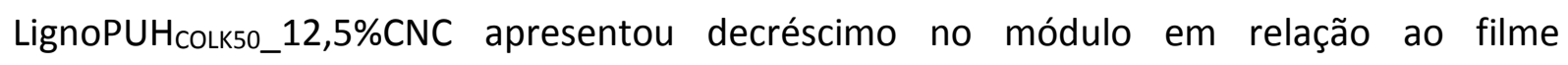

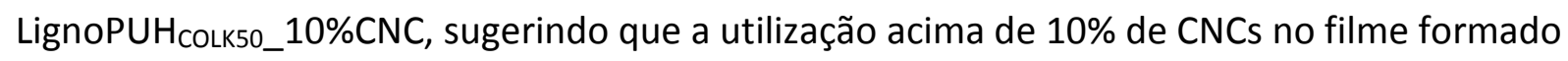
a partir de LK prejudica essa propriedade, corroborando com o resultado observado para resistência à tração, os quais foram justificados pela provável ocorrência de aglomerações dos CNCs. Nos filmes formados a partir de LK-Glu, o módulo de Young aumentou em todas as concentrações de CNCs avaliadas (23, 49 e 54 \% para LignoPUH Glu50_10\%CNC e LignoPUH CoLK-Glu50_12,5\%CNC, respectivamente) em relação ao filme LignoPUH com essa matriz, comparativamente a obtida a partir de LK.

A análise de DMA (Item 3.3.7, Figura 73) mostrou que o E' dos filmes formados a partir LK-Glu e 5, 10 e 12,5\% de CNCs foi superior ao dos filmes formados a partir de PUs sintetizadas com LK nas mesmas concentrações de CNCs, reforçando o resultado encontrado para resistência à tração e módulo de Young dos compósitos LignoPUHCoLk-Glu_CNC em comparação à LignoPUHCotk_CNC (Figura 74a e b).

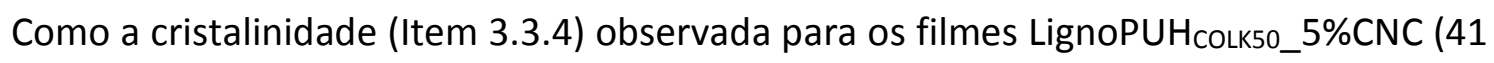
\%), LignoPUH ${ }_{\text {CoLk50_10\%CNC (47 \%) e LignoPUH }}$ Colk50_12,5\%CNC (43\%) foi semelhante à dos 
filmes LignoPUH ${ }_{\text {CoLk-Glu50_5\%CNC (44 \%); LignoPUH }}$ CoLk-Glu50_10\%CNC (43 \%) e LignoPUH COLKGlu50_12,5\%CNC (43\%), conclui-se que esse fator não contribuiu de forma significativa para os resultados obtidos para as propriedades mecânicas.

A Figura 74c apresenta os resultados para alongamento na ruptura dos filmes formados simultaneamente à síntese a partir de CO, LK ou LK-Glu e tHDI com e sem a presença de CNCs. Nela, foi observada uma redução de 17, 39 e 37 \%o alongamento na ruptura para os filmes LignoPUH ${ }_{\text {COLK50_5\%CNC, LignoPUH }}$ COLk50_10\%CNC e LignoPUH ${ }_{\text {CoLk50_12,5\%CNC, }}$

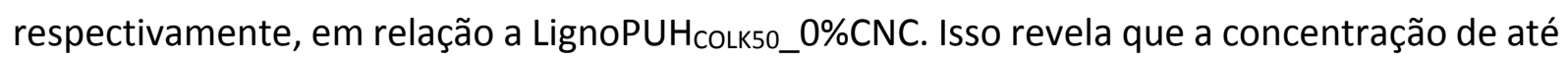
10 \% de CNCs nessa matriz atuaram aumentando a resistência a ruptura e diminuindo o alongamento dos filmes.

$\mathrm{Na}$ curva de Tan- $\delta$ (Item 3.3.7; Figura 72a) os filmes formados a partir de PUs sintetizadas com LK e CNCs apresentaram um decréscimo na altura dos picos referentes as $T_{\mathrm{g} S}$ dos domínios flexíveis e rígidos com o aumento da concentração de CNCs, o que foi correlacionado a intensidade na interação dos CNCs com a matriz lignopoliuretânica, devido a menor dissipação de energia ocasionada pela menor mobilidade dos segmentos. Essa intensificação das interações reforço-matriz em função do acréscimo de CNCs nos filmes

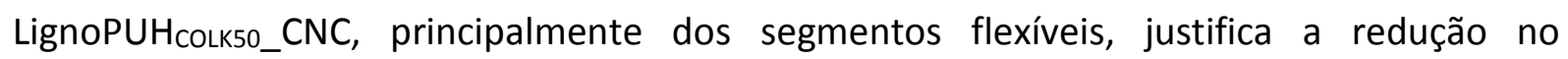
alongamento observada para esses filmes conforme o aumento na concentração de CNCs dos mesmos.

Os filmes formados a partir de PUs sintetizadas com LK-Glu e CNCs, no geral, alongaram menos que os filmes cuja síntese foi realizada a partir de LK e CNCs, corroborando com os resultados apresentados para resistência à ruptura e módulo de Young, que sugeriram maior

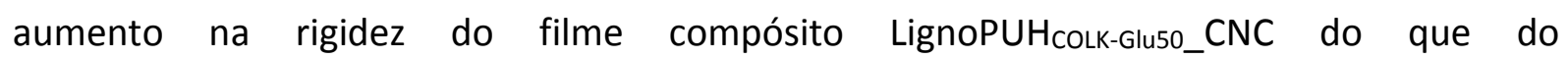

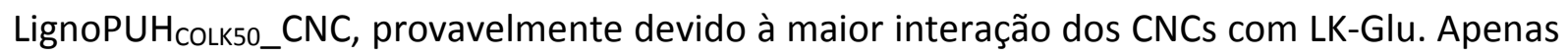

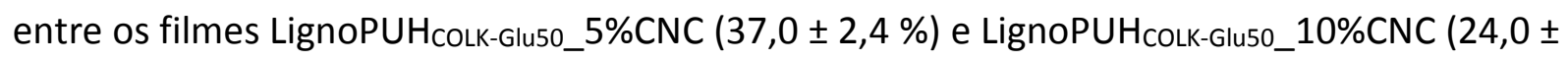
$2,7 \%)$, foi possível observar diferença significativa no alongamento na ruptura.

Os resultados mostrados na Figura 74 evidenciam que a presença de CNCs impactou de forma significativa o módulo de Young e o alongamento na ruptura, mas não a resistência à tração dos filmes.

Até onde se tenha conhecimento, o único artigo publicado envolvendo à síntese de filmes lignopoliuretânicos reforçados com CNCs foi o desenvolvido por XUE et al. (2014). Entretanto, a sua abordagem foi diferente a relizada neste estudo. No trabalho publicado por 
XUE et al. (2014), filmes poliuretânicos foram sintetizados usando THF como solvente, MDI como isocianato, PEG e lignina extraída de palha de milho como polióis e 5\% de CNCs extraídas de línter como reforço. A proporção PEG:Lignina e a razão molar NCO/OH utilizada foi igual a 1. Os resultados de resistência à tração, módulo de Young e alongamento na ruptura encontrados por eles para o filme não reforçado eo reforçado foram: 9 e $15 \mathrm{MPa}$; 9 e $25 \mathrm{MPa}$ e 144 e 67\%, respectivamente (erros ou desvios não informados). Sendo assim, foi observado 40 e $64 \%$ de aumento na resistência à tração e módulo de Young e queda de $54 \%$ no alongamento na ruptura. Comparando esses resultados com os obtidos neste estudo para o

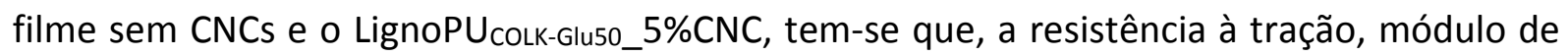
Young e alongamento na ruptura foram: 14,0 $\pm 0,3$ e 16,0 $\pm 0,1 \mathrm{MPa} ; 201 \pm 9$ e $262 \pm 10 \mathrm{MPa}$ e $34 \pm 2$ e $37 \pm 2 \%$, respectivamente. Portanto, houve um aumento de 14 e $23 \%$ na resistência à tração e módulo de Young e mesmo alongamento quando erros são considerados. Apesar do estudo realizado por XUE et al. (2014) ter obtido aumentos superiores na resistência à ruptura e módulo de Young em relação aos obtidos neste estudo, é importante considerar que a matriz não reforçada usada neste estudo já era consideravelmente mais rígida que a utilizada por XUE et al. Além disso, a ausência de solvente e a Mw do CO $\left(977,22 \mathrm{~g} \mathrm{~mol}^{-1}\right)$, superior à do PEG utilizado por eles $\left(400 \mathrm{~g} \mathrm{~mol}^{-1}\right)$, também podem ter contribuído para esses resultados. Sendo assim, comparações em diferentes sistemas se tornam complexos, em função das inúmeras variáveis e heterogeneidades, inclusive das matérias-primas utilizadas.

\subsection{Conclusões Parciais}

Foram preparados com êxito filmes lignopoliuretânicos utilizando como reagentes CO, LK ou LK-Glu, tHDI e até $12,5 \%$ de CNCs.

Destaca-se a ação do CO como agente dispersante não só de LK ou LK-Glu, mas também dos CNCs, promovendo a interação entre todos os componentes do sistema.

Os CNCs apresentaram uma ação efetiva como agentes de reforço, principalmente na matriz sintetizada a partir de LK-Glu, em relação à sintetizada a partir de LK. Isso se deu, provavelmente, por causa da maior reatividade e menor impedimento estérico existente em LK-Glu em comparação à LK.

Para a matriz sintetizada a partir de LK, foi observado que $10 \%$ de CNC's é a concentração limite para que se tenham ganhos nas propriedades mecânicas desses 
materiais. A partir dessa concentração de CNCs a formação de aglomerados pode ter prejudicado a capacidade de reforço das nanopartículas.

Para a matriz sintetizada a partir de LK-Glu, foi possível inserir até $12,5 \%$ de CNCs e ainda observar melhoras nas propriedades mecânicas, tais como acréscimo nos módulos de armazenamento (6, 20 e 14\%), Young (23, 49 e 54\%) e resistência à tração (12,5, 12,5 e 14\%) dos filmes LignoPUH ${ }_{\text {Colk-Glu50_5\%CNC; LignoPUH }}$ Colk-Glu50_10\%CNC e LignoPUH Glu50_12,5\%CNC, em relação aos não reforçados.

$\mathrm{O}$ reforço das LignoPUHs com CNCs em geral aumentou a rigidez dos filmes. Conforme o tipo de aplicação, isso pode ser considerado uma vantagem em relação aos filmes em que CNCs não são utilizados. Entretanto, estudos de viabilidade econômica e avaliações de propriedades específicas para o tipo de aplicação desejada são necessários para se decidir sobre a adequação do uso dos CNCs nessas matrizes. 


\section{Conclusões Gerais}

O presente estudo, como pretendido, levou a obtenção de forma inédita, até onde se tenha conhecimento, de diversos filmes poliuretânicos, formados simultaneamente as sínteses realizadas a partir de alto teor de matérias-primas de origem renovável, como o $\mathrm{CO}$, a LK e a LK modificada quimicamente, através da hidroxialquilação com glutaraldeído (LK-Glu) e dois tipos de isocianatos, um aromático (pMDI) e outro alifático (tHDI).

Também foram obtidos, com êxito e sem precedência, filmes compósitos formados em sínteses de lignopoliuretanas, na presença de CNCs.

De maneira geral, a utilização de LK-Glu na síntese dos filmes lignopoliuretânicos formados simultaneamente à síntese realizada tanto utilizando pMDI quanto tHDI como reagentes, influenciou positivamente, no que diz respeito, ao aumento da reatividade frente aos grupos isocianato e consequente diminuição no tempo para consumo total destes grupos.

Em comparação ao que foi apresentado pelos filmes em que apenas $\mathrm{CO}$ foi usado como poliol, para ambos tipos de isocianatos avaliados, as principais influências da presença de LK e principalmente LK-Glu (30 e $50 \%$ ), foram no aumento da massa molar das PUs, o que levou a segregação de fases em domínios flexíveis e rígidos, além de melhora nas propriedades mecânicas desses materiais, tais como aumento na resistência a ruptura e módulo de Young.

Pode-se concluir que a temperatura de $100{ }^{\circ} \mathrm{C}$ durante a reação de polimerização das PUs sintetizadas a partir de pMDI e tHDI, e 30 e 50 \% de LK, e sobretudo LK-Glu, influenciou no aumento da reatividade (menor tempo para consumo de grupos isocianato) e na melhora de propriedades mecânicas dos filmes obtidos, em relação aos filmes formados em reações ocorridas à temperatura ambiente.

A incorporação de 5 e 10\% de CNC's nos filmes lignopoliuretânicos previamente selecionados e formados a partir de PUs sintetizadas com CO, 50\% de LK ou LK-Glu e tHDI levou a acréscimos nos valores de módulo de armazenamento e módulo de Young desses filmes, especialmente os que continham estruturas típicas de LK-Glu em sua composição, devido à maior reatividade e menor impedimento estérico em comparação à LK, que permitiu maior interação com os CNCs e consequente ganho nas propriedades mecânicas dos materiais. Entretanto, a resistência à tração dos filmes reforçados com 10\% de CNCs foi igual a dos reforçados com $5 \%$, e superior aos reforçados com $12,5 \%$, sugerindo que pode ter 
ocorrido a formação de aglomerados de CNCs, os quais comprometeram o desempenho dos mesmos como agentes de reforço.

A lignina Kraft apresenta-se como uma excelente opção de matéria-prima abundante, de baixo custo e renovável, juntamente com o CO, outra matéria-prima renovável, na síntese de lignopoliuretanas. A modificação da lignina com glutaraldeído correspondeu a uma abordagem inovadora que propiciou o desenvolvimento de PUs com melhores propriedades térmicas e mecânicas, tornando-se uma melhor alternativa na síntese de lignopoliuretanas quando comparada a LK, especialmente quando temperaturas altas como $100^{\circ} \mathrm{C}$ são utilizadas em sua síntese.

Os diferentes tipos de isocianatos, as diferentes proporções de CO, LK ou LK-Glu utilizadas e a utilização de reforço como os CNCs, geraram filmes poliuretânicos com diferentes características e propriedades mecânicas, desde filmes mais flexíveis até filmes mais rígidos, o que permite que esses filmes sejam considerados para uma gama de possíveis aplicações. Exemplos dessas aplicações são: utilização em esteiras industriais ou painéis de equipamentos, embalagens ou revestimentos de superfícies, conferindo proteção mecânica, a radiação solar e a umidade. Processos como a modificação química da LK-Glu e aumento na temperatura de síntese podem gerar custos adicionais, todavia a ampliação do campo de aplicação para esses materiais pode trazer vantagens que superem esses custos.

Sendo assim, seguindo a premissa da necessidade do mercado por novos materiais que não impactem ou que diminuam o máximo possível o impacto sobre o meio ambiente, podese considerar que o presente estudo contribuiu substancialmente para a valorização do subproduto da indústria de papel e celulose, a lignina Kraft, e a síntese de filmes poliuretânicos seguindo rotas mais sustentáveis, utilizando matérias-primas de origem renovável. 


\section{Referências Bibliográficas}

ABNT. ABNT NBR NM ISO 287: papel e cartão: determinação do teor de umidade de um lote: método por secagem em estufa. Rio de Janeiro. ABNT, 2009.

ACHA, B. A.; MARCOVICH, N. E.; REBOREDO, M. M. Lignin in jute fabric-polypropylene composites. Journal of Applied Polymer Science, Hoboken, v. 113, n. 3, p. 1480-1487, 2009.

ACIK, G.; KAMACI, M.; ALTINKOK, C.; KARABULUT, H. R. F.; TASDELEN, M. A. Synthesis and properties of soybean oil-based biodegradable polyurethane films. Progress in Organic Coatings, Amsterdam, v. 123, p. 261-266, 2018.

ADLER, E. Lignin chemistry: past, present and future. Wood Science and Technology, Heidelberg, v.11, p. 169-218, 1977.

AKRAM, D.; HAKAMI, O.; SHARMIN, E.; AHMAD, S. Castor and Linseed oil polyurethane/TEOS hybrids as protective coatings: A synergistic approach utilising plant oil polyols, a sustainable resource.

Progress in Organic Coatings, Amsterdam, v. 108, p. 1-14, 2017.

ALEXANDER, L. X-ray diffraction methods in polymer science. New York: Wiley Interscience, 1969. p. 165-172.

ALI, A.; YUSOH, K.; HASANY, S.F. Synthesis and physicochemical behaviour of polyurethanemultiwalled carbon nanotubes nanocomposites based on renewable castor oil polyols. Journal of Nanomaterials, v. 2014, p. 1-9, 2014. DOI: 10.1155/2014/564384. Disponível em: http://dx.doi.org/10.1155/2014/564384. Acesso em: 17 jul. 2019.

ALLPORT, D. C.; GILBERT, D. S.; OUTTERSIDE, S. M. MDI and TDI usage: responsible risk management. In: ALLPORT, D. C.; GILBERT, D. S.; OUTTERSIDE, S. M. (ed.). MDI and TDI: safety, health and the environment. New York: John Wiley, 2003. p. 1-10.

AMERICAN POLYFILM. Disponível em: https://www.americanpolyfilm.com/about-american-polyfilmpolyurethane-manufacturer. Acesso em: 10 nov. 2019.

ARSHANITSA, A.; KRUMINA, L.; TELYSHEVA, G.; DIZHBITE, T. Exploring the application potential of incompletely soluble organosolv lignin as a macromonomer for polyurethane synthesis. Industrial Crops and Products, Amsterdam, v. 92, p. 1-12, 2016.

ASENSIO, M.; COSTA, V.; NOHALES, A.; BIANCHI, O.; GÓMEZ, Z.M. Tunable Structure and Properties of Segmented Thermoplastic Polyurethanes as a Function of Flexible Segment. Polymers, Oxford, v. 11, p. 1910, 2019.

AUAD, M. L.; CONTOS, V. S.; NUTT, S.; ARANGUREN, M. I.; MARCOVICH, N. E. Characterization of nanocellulose reinforced shape memory polyurethanes. Polymer International, Oxford, v.57, p.651659, 2008.

AUCLAIR, N.; KABOORANI, A.; RIEDL, B.; LANDRY, V.; HOSSEINAEI, O.; WANG, S. Influence of modified cellulose nanocrystals $(\mathrm{CNC})$ on performance of bionanocomposite coatings. Progress in Organic Coatings, Amsterdam, v. 123, p. 27-34, 2018. 
AUSTIN, A.; HICKS, D. A. A review of the global PU industry 2016 and outlook for 2017. PU MAGAZINE, Ratingen, v. 14, n. 1, 2017.

AZEVEDO, E.C.; CHIERICE, G.O.; NETO, S.C.; SOBOLL, D.S.; NASCIMENTO, E.M.; LEPIENSKI, C.M.; CHIERICE, G.O. Gamma radiation effects on mechanical properties and morphology of a polyurethane derivate from castor oil. Radiation Effects and Defects in Solids, London, v. 166, p. 208-214, 2011.

AZEVEDO, E. C. Efeito da Radiação nas propriedades mecânicas do adesivo de PU derivado do óleo de mamona. 2009. 134 f. Tese (Doutorado em Ciência e Engenharia de Materiais) - Setor de Tecnologia, Universidade Federal do Paraná, Curitiba, 2009.

BAI, L.; LIU, Y.; DING, A.; REN, N.; LI, G.; LIANG, H. Fabrication and characterization of thin-film composite (TFC) nanofiltration membranes incorporated with cellulose nanocrystals (CNCS) for enhanced desalination performance and dye removal. Chemical Engineering Journal, Amsterdam, v. 358, p. 1519-1528, 2019.

BARRIONI, B. R.; CARVALHO, S. M.; ORÉFICE, R. L.; DE OLIVEIRA, A. A. R.; PEREIRA, M. M. Synthesis and characterization of biodegradable polyurethane films based on HDI with hydrolyzable crosslinked bonds and a homogeneous structure for biomedical applications. Materials Science and Engineering C, Amsterdam, v. 52, p. 22-30, 2015.

BARTKOWIAK, M.; ZAKRZEWSKI, R. Thermal degradation of lignins isolated from wood. Journal of Thermal Analysis and Calorimetry, Oxford, v. 77, n. 1, p. 296-304, 2004.

BENHAMOU, K.; KADDAMI, H.; MAGNIN, A.; DUFRESNE, A.; AHMAD, A. Bio-based polyurethane reinforced with cellulose nanofibers: A comprehensive investigation on the effect of interface. Carbohydrate Polymers, Oxford, v. 122, p. 202-211, 2015.

BERGENSTRÅHLE, M.; WOHLERT, J.; HIMMEL, M. E.; BRADY, J. W. Simulation studies of the insolubility of cellulose. Carbohydrate Research, Oxford, v. 345, p. 2060-2066, 2010.

BOERIU, C. G.; BRAVO, D.; GOSSELINK, R. J. A.; VAN DAM, J. E. G. Characterisation of structuredependent functional properties of lignin with infrared spectroscopy. Industrial Crops and Products, Amsterdam, v. 20, p. 205-218, 2004.

BUfFA, J. M.; MONDRAGON, G.; CORCUERA, M. A.; ECEIZA, A.; MUCCI, V.; ARANGUREN, M. I. Physical and mechanical properties of a vegetable oil based nanocomposite. European Polymer Journal, Oxford, v. 96, p. 116-124, 2018.

CALLE, M.; LLIGADAS, G.; RONDA, J. C.; GALIA, M.; CÁDIZ, V. Non-isocyanate route to biobased polyurethanes and polyureas via $A B$-type self-polycondensation. European Polymer Journal, Oxford, v. 84, p. 837-848, 2016.

CALLISTER, W.D. Materials science and engineering: an introduction. New York: John Wiley, 1991.

CANETTI, M.; BERTINI, F. Supermolecular structure and thermal properties of poly(ethylene terephthalate)/lignin composites molecular structure and thermal properties of poly(ethylene terephthalate)/lignin composites. Composites Science and Technology, Oxford, v. 67, p. 3151-3157, 2007. 
CARRIÇO, C. S.; FRAGA, T.; PASA, V. M. D. Production and characterization of polyurethane foams from a simple mixture of castor oil, crude glycerol and untreated lignin as bio-based polyols.

European Polymer Journal, Oxford, v. 85, p. 53-61, 2016.

CASTRO, D. O.; PASSADOR, F.; RUVOLO-FILHO, A.; FROLLINI, E. Use of castor and canola oils in "biopolyethylene" curauá fiber composites. Composites Part A: applied science and manufacturing, Oxford, v. 95, p. 22-30, 2017.

CASTRO, D .O.; FROLLINI, E.; RUVOLO-FILHO, A.; DUFRESNE, A. "Green Polyethylene" and Curaua Cellulose Nanocrystal Based Nanocomposites: Effect of Vegetable Oils as Coupling Agent and Processing Technique. Journal of Polymer Science, Part B: polymer physics, Hoboken, v. 53, p. 10101019, 2015.

CASTOR OIL IN. Comprehensive castor oil report preview. Tamilnadu, 2016. Disponível em: http://www.castoroil.in/downloads/Preview_of_Comprehensive_Castor_Oil_Report.pdf. Acesso em 23 ago.2019.

CATETO, C. A.; BARREIRO, M. F.; RODRIGUES, A. E.; BROCHIER-SALON, M. C.; THIELEMANS, W.; BELGACEM, M. N. Lignins as macromonomers for polyurethane synthesis: a comparative study on hydroxyl group determination. Journal of Applied Polymer Science, Hoboken, v. 109, p. 3008-3017, 2008.

CHALLA, G. Polymer chemistry: an introduction. Harlow: Prentice Hall, 1993.

CHANG, H.; LUO, J.; DAVIJANI, A. A. B.; CHIEN, A-T.; WANG, P-H.; LIU, H.C.; KUMAR, S. Individually dispersed wood-based cellulose nanocrystals. ACS Applied Materials \& Interfaces, Washington, v. 8, p. 5768-5771, 2016.

CHATTOPADHYAY, D. K.; RAJU, K. V. S. N. Structural engineering of polyurethane coatings for high performance applications. Progress in Polymer Science, London, v. 32, p. 352-418, 2007.

CHATTOPADHYAY, D. K.; WEBSTER, D. C. Thermal stability and flame retardancy of polyurethanes. Progress in Polymer Science, London, v. 34, p. 1068 - 133, 2009.

CHEN, R. S.; AHMAD, S.; GAN, S.; SALLEH, M. N.; AB GHANI, M. H.; TARAWNEH, M. A. Effect of polymer blend matrix compatibility and fibre reinforcement content on thermal stability and flammability of ecocomposites made from waste materials. Thermochimica Acta, Amsterdam, v. 640, p. 52-61, 2016.

CHENG, S.; WILKS, C.; YUAN, Z.; LEITCH, M.; XU, C. C. Hydrothermal degradation of alkali lignin to biophenolic compounds in sub/supercritical ethanol and water-ethanol co-solvent. Polymer Degradation and Stability, London, v.97, p.839-848, 2012.

CHIERICE, G. O.; AZEVEDO, P.; FREIRE, V.; GUEIROS, G.; CHIERICE, G. Uso da Membrana de Polímero de Mamona em Regeneração Óssea Guiada em Defeitos ao Redor de Implantes Ósseointegrado Relato de Três Casos. Revista Brasileira de Implantodologia, Curitiba, v. 6, n.3, p. 8-12, 1997.

CHOWDHURY, R.A.; RAI, A.; GLYNN, E.; MORGAN, P.; MOORE, A.L.; YOUNGBLOOD, J.P. Superior, processing-dependent thermal conductivity of cellulose Nanocrystal-Poly(vinyl alcohol) composite films. Polymer, London, v. 164, p. 17-25, 2019. 
CINELLI, P.; ANGUILLESI, I.; LAZZERI, A. Green synthesis of flexible polyurethane foams from liquefied lignin. European Polymer Journal, Oxford, v. 49, n.6, p.1174-1184, 2013.

CLAU, S.; GABRIEL, J.; KARBACH, A.; MATNER, M.; NIEM, P. Influence of the adhesive formulation on the mechanical properties and bonding performance of polyurethane prepolymers. Holzforschung, Berlin, v. 65, p. 835-844, 2011.

CONSTANT, S.; WIENK, H. L. J.; FRISSEN, A. E.; DE PEINDER, P.; BOELENS, R.; VAN ES, D. S.; GRISEL, R. J. H.; WECKHUYSEN, B. M.; HUIJGEN, W. J. J.; GOSSELINK, R. J. A.; BRUIJNINCX, P. C. A. New insights into the structure and composition of technical lignins: a comparative characterization study. Green Chemistry, Cambridge, v. 18, p. 2651-2665, 2016.

CORCUERA, M. A.; RUEDA, L.; FERNADEZ D'ARLAS, B.; ARBELAIZ, A.; MARIETA, C.; MONDRAGON, I.; ECEIZA, A. Microstructure and properties of polyurethanes derived from castor oil. Polymer Degradation and Stability, London, v. 95, p. 2175 - 2184, 2010.

CORDERO, A. I.; AMALVY, J. I.; FORTUNATI, E.; KENNY, J. M.; CHIACCHIARELLI, L. M. The role of nanocrystalline cellulose on the microstructure of foamed castor-oil polyurethane nanocomposites. Carbohydrate Polymers, Oxford, v. 134, p. 110-118, 2015.

CORNILLE, A.; AUVERGNE, R.; FIGOVSKY, O.; BOUTEVIN, B.; CAILLOL, S. A perspective approach to sustainable routes for non-isocyanate polyurethanes. European Polymer Journal, Oxford, v. 87, p. 535-552, 2017.

CUNHA, F. O. V.; MELO, D. H. R.; VERONESE, V. B.; FORTE, M. M. D. C. Study of castor oil polyurethane - poly(methyl methacylate) semi-interprenetrating polymer networf (sipn) reaction parameters using a $2^{3}$ factorial experimental design. Materials Research, v. 7, n. 4, p. 539-543, 2004.

CZIONKA, S.; SIENKIEWICZ, N.; STRAKOWSKA, A.; STRZELEC, K. Keratin feathers as a filler for rigid polyurethane foams on the basis of soybean oil polyol. Polymer Testing, London, v. 72, p. 32-45, 2018.

D'ALMEIDA, A. L. F. S.; CALADO, V.; BARRETO, D. W.; D’ALMEIDA, J. R. M. Acetilação da fibra de bucha (Luffa cylindrica). Polímeros: ciência e tecnologia, São Carlos, v. 15, n. 1, p. 59-62, 2005.

DA SILVA, C. G. Bagaço de cana-de-açúcar como reforço de matrizes termorrígidas baseadas em macromoléculas de ligninas. 2011. Tese (Doutorado em Físico-química) - Instituto de Química, Universidade de São Paulo, São Carlos, 2011.

DA SILVA, C. G.; GRELIER, S.; PICHAVANT, F.; FROLLINI, E.; CASTELLAN, A. Adding value to lignins isolated from sugarcane bagasse and miscanthus. Industrial Crops and Products, Amsterdam, v. 42, p. 87-95, 2013.

DAS, S.; PANDEY, P.; MOHANTY, S.; NAYAK, S. K. Evaluation of biodegradability of green polyurethane/nanosilica composite synthesized from transesterified castor oil and palm oil based isocyanate. International Biodeterioration \& Biodegradation, London, v. 117, p. 278-288, 2017.

DEHNE, L.; BABARRO, C. V.; SAAKE, B.; SCHWARZ, K, U. Influence of lignin source and esterification on properties of lignin-polyethylene blends. Industrial Crops and Products, Amsterdam, v. 86, p. 320$328,2016$. 
DENCE, C. W. General structure features of lignins. In: LIN, E.S.; DENCE, C.W. (ed.). Methods in lignin chemistry. Berlin: Springer-Verlag, 1992. p. 3-6.

DE OLIVEIRA, F. Lignopoliuretanos: preparação, caracterização e aplicação em compósitos de sisal. 2014. 170 f. Tese (Doutorado em Físico-química) - Instituto de Química, Universidade de São Paulo, São Carlos, 2014.

DE OLIVEIRA, F., RAMIRES, E. C., FROLLINI, E., BELGACEM, M. N., Lignopolyurethanic materials based on oxypropylated sodium lignosulfonate and castor oil blends. Industrial Crops and Products, Amsterdam, v. 72, p. 77-86, 2015.

DE OLIVEIRA SANTOS, R. P.; CASTRO, D. O.; RUVOLO-FILHO, A. C.; FROLLINI, E. Processing and thermal properties of composites based on recycled PET, sisal fibers, and renewable plasticizers. Journal of Applied Polymer Science, Hoboken, v. 131, n. 12, p. 1-13, 2014.

DE PAIVA, J.M.F.; FROLLINI, E. Sugarcane bagasse reinforced phenolic and lignophenolic composites. Journal of Applied Polymer Science, Hoboken, v. 83, n. 4, p. 880-888, 2001.

DESIGN TECHNOLOGY. Plastics. [S.I.], [20--]. Disponível em:

www.designkmg.weebly.com/plastics.html. Acesso em 13 ago. 2019.

DIMIAN, A. C.; IANCU, P.; PLESU, V.; BONET-RUIZ, A. E.; BONET-RUIZ, J. Castor oil biorefinery: conceptual process design, simulation and economic analysis. Chemical Engineering Research and Design, London, v. 141, p. 198-219, 2019.

DOLEY, S.; DOLUI, S. K. Solvent and catalyst-free synthesis of sunflower oil based polyurethane through non-isocyanate route and its coatings properties. European Polymer Journal, Oxford, v. 102, p. 161-168, 2018.

DOHERTY, W.O.S.; MOUSAVIOUN, P.; FELLOWS, C.M. Value-adding to cellulosic ethanol: lignin polymers. Industrial Crops and Products, Amsterdam, v.33, p. 259-276, 2011.

DRIEST, P. J.; LENZI, V.; MARQUES, L. S. A.; RAMOS, M. M. D.; DIJKSTRA, D. J.; RICHTER, F. U.; STAMATIALIS, D.; GRIJPMA, D. W. Aliphatic isocyanurates and polyisocyanurate networks. Polymers for Advanced Technologies, Oxford, v. 28, p. 1299 - 1304, 2017.

DUSEK, K.; SPIRKOVA, M. Cross-linking and network formation in polyurethane systems with excess isocyanate. Cellular Polymers, Lancaster, v.9, n.2, p. 69-83, 1990.

DUSEK, K.; SPIRKOVA, M.; HAVLICEK, I. Network formation of polyurethanes due to side reactions. Macromolecules, Washington, v. 23, n. 6, p. 1774-1781.

DUVAL, A., LAWOKO, M. A review on lignin-based polymeric: micro- and nano-structured materials. Reactive and Functional Polymers, Amsterdam, v. 85, p. 78-96, 2014.

ELAZZOUZI-HAFRAOUI, S.; NISHIYAMA, Y.; PUTAUX, J.-L.; HEUX, L.; DUBREUIL, F.; ROCHAS, C. The shape and size distribution of crystalline nanoparticles prepared by acid hydrolysis of native cellulose. Biomacromolecules, Washington, v. 9, n. 1, p. 57-65, 2008.

EL MANSOURI N.; SALVADÓ, J. Structural characterization of technical lignins for the production of adhesives: Application to lignosulfonate, kraft, soda-anthraquinone, organosolv and ethanol process lignins. Industrial Crops and Products, Amsterdam, v. 24, p 8-16, 2006. 
FARIS, A.H.; RAHIM, A.A.; IBRAHIM, M.N.M.; HUSSIN, M.H.; ALKURDI, A.M.; SALEHABAD, A. Investigation of oil palm based Kraft and auto-catalyzed organosolv lignin susceptibility as a green wood adhesives. International Journal of Adhesion \& Adhesives, London, v. 74, p. 115-122, 2017.

FAIX, O. Fourier transformed infrared spectroscopy. In: LIN, S.Y.; DENCE, C.W. (ed.). Methods in lignin chemistry. Berlin: Springer-Verlag, 1992. p. 458-464

FENGEL, D.; WEGENER, G. Wood: chemistry, ultrastructure, reactions. Berlin, Walter de Gruyter, 1989.

FERNANDEZ, S. G.; UGARTE, L.; CALVO-CORREAS, T.; PENA-RODRIGUEZ, C.; CORCUERA, M. A.; ECEIZA, A. Properties of flexible polyurethane foams containing isocyanate functionalized kraft lignin. Industrial Crops and Products, Amsterdam, v.100, p. 51-64, 2017.

FLEXÍVEL TECNOLOGIAS EM POLIURETANO. O mercado brasileiro do poliuretano. Jaraguá do Sul, 2018. Disponível em: https://flexivelpu.com.br/blog/o-mercado-brasileiro-do-poliuretano/. Acesso em 23 ago. 2019.

GADHAVE, R. V.; MAHANWAR, P. A.; GADEKAR, P. T. Lignin-polyurethane based biodegradable foam. Open Journal of Polymer Chemistry, Irvine, v. 8, p. 1-10, 2018.

GAIKWAD, M. S.; GITE, V. V.; MAHULIKAR, P. P.; HUNDIWALE, D. G.; YEMUL, O. S. Eco-friendly polyurethane coatings from cottonseed and karanja oil. Progress in Organic Coatings, Amsterdam, v. 86, p. 164-172, 2015.

GAMA, N.V.; SILVA, R.; MOHSENI, F.; DAVARPANAH, A.; AMARAL, V. S.; FERREIRA, A.; BARROSTIMMONS, A. Enhancement of physical and reaction to fire properties of crude glycerol polyurethane foams filled with expanded graphite. Polymer Testing, London, v. 69, p. 199-207, 2018.

GARCIA, A.; TOLEDANO, A.; SERRANO, L.; EGÜES, I.; GONZALEZ, M.; MARIN, F.; LABIDI, J. Characterization of lignins obtained by selective precipitation. Separation and Purification Technology, Oxford, v. 68, p. 193-198, 2009.

GIERER, J.; SMEDMAN, L. A. The reactions of lignin during sulphate cooking. Part VIII. The mechanism of splitting of beta-arylether bonds in phenolic units by white liquor. Acta Chemica Scandinavica, Copenhagen, v. 19, p. 1103-1112, 1965.

GILLESPIE, G. D., EVERARD, C. D., FAGAN, C. C., MCDONNELL, K. P. Prediction of quality parameters of biomass pellets from proximate and ultimate analysis. Fuel, Oxford, v. 111, p. 771-777, 2013.

GOLDSCHMID, O. Ultraviolet spectra. In: SARKANEN, K. V.; LUDWIG, C. H. (ed.). Lignins: occurrence, formations, structures, and reactions. New York: Wiley-Interscience, 1971. p. 241-266.

GOLISZEK, M.; PODKOSCIELNA, B.; SEVASTYANOVA, O.; FILA, K.; CHABROS, A.; PACZKOWSKI, P. Investigation of accelerated aging of lignin-containing polymer materials. International Journal of Biological Macromolecules, Amsterdam, v. 123, p. 910-922, 2019.

GONÇALVES, A. R.; SCHUCHARDT, U.; BIANCHI, M. L.; CURVELO, A. A. S. Piassava fibers (Attalea funifera): NMR spectroscopy of their Lignin. Journal of Brazilian Chemical Society, São Paulo, v.11, n. 5, p. 491-494, 2000. 
GORDOBIL, O.; DELUCIS, R.; EGÜÉSA, I.; LABIDI, J. Kraft lignin as filler in PLA to improve ductility and thermal properties. Industrial Crops and Products, Amsterdam, v. 72, p. 46-53, 2015.

GORDOBIL, O.; MORIANA, R.; ZHANG, L.; LABIDI, J.; SEVASTYANOVA, O. Assesment of technical lignins for uses in biofuels and biomaterials: structure-related properties, proximate analysis and chemical modification. Industrial Crops and Products, Amsterdam, v. 83, p. 155-165, 2016.

GRAND VIEW RESEARCH. Polyurethane market analysis report by product (rigid foam, flexible foam, coatings), by application (furniture $\&$ interiors, construction automotive), and segment forecasts, 2019-2025. San Francisco, 2019. Disponível em: http://www.grandviewresearch.com/industryanalysis/polyurethane-pu-market. Acesso em 12 ago. 2019.

GUAN, J.; SONG, Y.; LIN, Y.; YIN, X.; ZUO, M.; ZHAO, Y.; TAO, X.; ZHENG, Q. Progress in study of nonisocyanate polyurethane. Industrial and Engineering Chemistry Research, Washington, v. 50, p. 6517-6527, 2011.

GURUNATHAN. T.; MOHANTY, S.; NAYAK, S. K. Isocyanate terminated castor oil-based polyurethane prepolymer: synthesis and characterization. Progress in Organic Coatings, Amsterdam, v. 80, p. 3948, 2015.

HABIBI, Y.; GOFFIN, A-L.; SCHILTZ, N.; DUQUESNE, E.; DUBOIS, P.; DUFRESNE, A. Bionanocomposites based on poly(3-caprolactone)-grafted cellulose nanocrystals by ring-opening polymerization. Journal of Materials Chemistry, Cambridge, v. 18, p. 5002-5010, 2008.

HABLOT, E.; ZHENG, D.; BOUQUEY, M.; AVÉROUS, L. Polyurethane based on castor oil: kinetics, chemical, mechanical and thermal properties. Macromolecular Materials and Engineering, Weinheim, v. 293, p. 922-929, 2008.

HOAREAU, W.; OLIVEIRA, F. B.; GRELIER, S.; SIEGMUND, B.; FROLLINI, E.; CASTELLAN, A. Fiberboards based on sugarcane bagasse lignins and fibers. Macromolecular Materials and Engineering, Weinheim, v.291, p.829-839, 2006.

$\mathrm{HU}, \mathrm{S}$; $\mathrm{LUO}, \mathrm{X}$; LI, Y. Polyols and polyurethanes from the liquefaction of lignocellulosic biomass. ChemSusChem, Weinheim, v. 7, p. 66-72, 2014.

HU, J.; CHEN, Z.; HE, Y.; HUANG, H.; ZHANG, X. Synthesis and structure investigation of hexamethylene diisocyanate (HDI)-based polyisocyanates. Research on Chemical Intermediates, Dordrecht, v. 43, p. 2799-2815, 2016.

HU, J., XIAO, R., SHEN, D., ZHANG, H. Structural analysis of lignin residue from black liquor and its thermal performance in thermogravimetric-Fourier transform infrared spectroscopy. Bioresource Technology, Amsterdam, v. 128, p. 633-639, 2013.

HUANG, X.; DE HOOP, C. F.; XIE, J.; WU, Q.; BOLDOR, D.; QI, J. High bio-content polyurethane (PU) foam made from bio-polyol and cellulose nanocrystals (CNCs) via microwave liquefaction. Materials \& Design, London, v. 138, p. 11-20, 2018.

HUIJGEN, W. J. J.; TELYSHEYA, G.; ARSHANITSA, A.; GOSSELINK, R. J. A.; DE WILD, P.J. Characteristics of wheat straw lignins from ethanol-based organosolv treatment. Industrial Crops and Products, Amsterdam, v.59, p. 85-95, 2014. 
IDICULA, M.; MALHOTRA, S. K.; JOSEPH, K. Dynamic mechanical analysis of randomly oriented intimately mixedshort banana/sisal hybrid fibre reinforced polyester composites. Composites Science and Technology, Oxford, v.65, p. 1077-1087, 2005.

IGNACIO, H.; MAZZER, N.; BARBIERI, C. H.; CHIERICE, G. O. Estudos Sobre a Aplicabilidade Médica da Poliuretana Derivada da Mamona. Resenha Ortopédica, São Paulo, v. 2, n.6, p. 10-11, 1996.

THE INTERNATIONAL LIGNIN INSTITUTE. About lignin. Orbe, [20--]. Disponível em: http://www.ililignin.com/aboutlignin.php. Acesso em 15 ago. 2019.

IONESCU, M. Chemistry and technology of polyols for polyurethanes. Shrewsbury: Rapra Technology, 2005. p. 602.

ISHIZU, A.; NAKANO, J.; OYA, H.; MIGITA, N. Occurrence of secondary condensation reaction in lignin. Mokuzai Gakkaishi, Tokyo, v.4, p.176-182, 1958.

ISLAM, M. T.; ALAM, M. M.; ZOCCOLA, M. Review on modification of nanocellulose for application in composites. International Journal of Innovative Research in Science, Engineering and Technology, Bangalore, v. 2, p. 5444-5451, 2013.

ISMAIL, E.A.; MOTAWIE, A.M.; SADEK, E.M. Synthesis and characterization of polyurethane coatings based on soybean oil-polyester polyols. Egyptian Journal of Petroleum, Cairo, v. 20, n. 2, p. 1-8, 2011.

JAKAB, E.; FAIX, O.; TILL, F.; SZEKELY, T. The effect of cations on the thermal decomposition of lignins. Journal of Analytical and Applied Pyrolysis, Amsterdam, v. 25, p. 185-194, 1993.

JANG, S.; KIM, D.; PARK, D.H.; KIM, O.Y.; WANG, S. Construction of sustainable polyurethane-based gel-coats containing poly $(\varepsilon$-caprolactone)-grafted lignin and their coating performance. Progress in Organic Coatings, Amsterdam, v. 120, p. 234-239, 2018.

JIA, Z.; LU, C.; ZHOU, P.; WANG, L. Preparation and characterization of high boiling solvent ligninbased polyurethane film with lignin as the only hydroxyl group provider. RCS Advances, Cambridge, v. 5, p. 53949-53955, 2015.

KALIA, S.; THAKUR, K.; CELLI, A.; KIECHEL, M. A.; SCHAUER, C. L. Surface modification of plant fibers using environment friendly methods for their application in polymer composites, textile industry and antimicrobial activities: a review. Journal of Environmental Chemical Engineering, Amsterdam, v. 1, n. 3, p. 97-112, 2013.

KANDA, D. H. F. ; NAGASHIMA, H. N. ; MALMONGE, J. A. ; SAKAMOTO, W. K. ; CHIERICE, G. O. . Effect of polyol excess on the electrical property of vegetable-polyurethane film. Journal of Materials Science, Storrs, v. 43, p. 5436-5440, 2008.

KARIMI, M. B.; KHANBABAEI, G.; SADEGHI, G. M. M. Vegetable oil-based polyurethane membrane for gas separation. Journal of Membrane Science, Amsterdam, v. 527, p. 198-206, 2017.

KLEMM, D.; PHILIPP, B.; HEINZE, T.; WAGENKNECHT, W. Comprehensive cellulose chemistry: functionalization of cellulose. Wiley Online Library, 1998.

KIM, S.; OH, S.; LEE, J.; ROH, H.; PARK, J. Changes of lignin molecular structures in a modification of kraft lignin using acid catalyst. Materials, Basel, v. 9, p. 1-15, 2016. 
KONDO, T. Nematic Ordered Cellulose: Its Structure and Properties. In: BROWN, R.M.; SAXENA, I.M. (eds.). Cellulose: Molecular and Structural Biology. Heidelberg: Springer, 2007. p. 285-305.

KONG, X.; LIU, G.; CURTIS, J. M. Novel polyurethane produced from canola oil based poly(ether ester) polyols: synthesis, characterization and properties. European Polymer Journal, Oxford, v. 48, n. 12, p. 2097-2106, 2012.

KONG, X.; WOLODKO, J.; ZHAO, L.; CURTIS, J. M. The preparation and characterization of polyurethane reinforced with a low fraction of cellulose nanocrystals. Progress in Organic Coatings, Amsterdam, v. 125, p. 207-214, 2018.

KONTOU, E.; SPATHIS, G.; NIAOUNAKIS, M.; KEFALAS, V. Physical and chemical cross-linking effects in polyurethane elastomers. Colloid \& Polymer Science, Heidelberg, v. 268, p. 636-644, 1990.

KOUTSKY, J. A.; HIEN, N. V.; COOPER, S. L. Some results on electron microscope investigations of polyether-urethane and polyester-urethane block copolymers. Journal of Polymer Science: Part B: polymer letters, Hoboken, v. 8, p. 353-359, 1970.

KROL, P. Synthesis methods, chemical structures and phase structures of linear polyurethanes. Properties and applications of linear polyurethanes in polyurethane elastomers, copolymers and ionomers. Progress in Materials Science, Oxford, v. 52, n. 6, p. 915-1015, 2007.

LAURICHESSE, S.; AVÉROUS, L. Chemical modification of lignins: towards biobased polymers. Progress in Polymer Science, London, v. 39, p. 1266-1290, 2014.

LEI, W.; ZHOU, X.; FANG, C.; LI, Y.; SONG, Y.; WANG, C.; HUANG, Z. New approach to recycle office waste paper: reinforcement for polyurethane with nano cellulose crystals extracted from waste paper. Waste Management, Oxford, v. 95, p. 59-69, 2019.

LEITE, L.S.F. Preparação e caracterização de compósitos de acetato de celulose e nanocristais de celulose. 2015. 135 f. Dissertação (Mestrado em Físico-química) - Instituto de Química, Universidade Estadual de Campinas, Campinas, 2015.

LEVCHIK, S. V.; WEIL, E. D. Thermal decomposition, combustion and fire-retardancy of polyurethanes: a review of the recent literature. Polymer International, Oxford, v. 53, p.1585-1610, 2004.

LIANG, D.; ZHANG, Q.; ZHANG, W.; LIU, L.; LIANG, H.; QUIRINO, R. L.; CHEN, J.; LIU, M.; LU, Q.; ZHANG, C. Tunable thermo-physical performance of castor oil-based polyurethanes with tailored release of coated fertilizers. Journal of Cleaner Production, Amsterdam, v. 210, p. 1207-1215, 2019.

LI, F.; HOU, J.; ZHU, W.; ZHANC, X.; XU, M.; LUO, X.; MA, D.; KIM, B. K. Crystallinity and morphology of segmented polyurethanes with different soft-segment length. Journal of Applied Polymer Science, Hoboken, v. 62, p. 631-638, 1996.

LI, J.; HE, Y.; INOUE, Y. Thermal and mechanical properties of biodegradable blends of poly(L-lactic acid) and lignina. Polymer International, Oxford, v. 52, p. 949-955, 2003.

LI, Y.; RAGAUSKAS, A.J. Ethanol organosolv lignin-based rigid polyurethane foam reinforced with cellulose nanowhiskers. RSC Advances, Cambridge, v.2, p. 3347-3351, 2012.

LI, Y., LUO, X., HU, S. Bio-based polyols and polyurethanes. Heidelberg: Springer, 2015. E-book. 
LOPES, G.H.; JUNGES, J.; FIORIO, R.; ZENI, M.; ZATTERA, A.J. Thermoplastic Polyurethane Synthesis Using POSS as a Chain Modifier. Materials Research, São Carlos, v. 15, p. 698-704, 2012.

LOPES, M. C.; TRIGUEIRO, J. P. C.; CASTRO, V. G.; LAVALL, R. L.; SILVA, G. G. Optimization of carbon nanotubes dispersion process in thermoset polyurethane. Polímeros, São Carlos, v.26, n.1, p. 81-91, 2016.

LORA, J. Industrial commercial lignins: sources, properties and applications. In: BELGACEM, M. N.; GANDINI, A. (eds.). Monomers polymers and composites from renewable resources. Amsterdam: Elsevier, 2008. p. 225-241.

LORANDI, N. P.; CIOFFI, M. O. H.; ORNAGHI JUNIOR, H. Análise dinâmico-mecânica de materiais compósitos poliméricos. Scientia Cum Industria, Caxias do Sul, v. 4, n. 13, p. 48-60, 2016.

LOURENÇON, T. V.; HANSEL, F. A.; DA SILVA, T. A.; RAMOS, L. P.; MUNIZ, G. I. B.; MAGALHÃES, W. L. E. Hardwood and softwood kraftlignins fractionation by simple sequential precipitation. Chemical Engineering Journal, Amsterdam, v. 157, p. 93-99, 2015.

LUO, J.; CHANG, H.; WANG, P-H.; MOON, R. J.; KUMAR, S. Cellulose nanocrystals effect on the stabilization of polyacrylonitrile composite films. Carbon, Oxford, v. 134, p. 92-102, 2018.

LUO, X.; XIAO, Y.; WU, Q.; ZENG, J. Development of high-performance biodegradable rigid polyurethane foams using all bioresource-based polyols: lignin and soy oil-derived polyols. International Journal of Biological Macromolecules, Amsterdam, v. 115, p. 786-791, 2018.

LUONG, N .D.; SINH, L. H.; MINNA, M.; JURGEN, W.; TORSTEN, W.; MATTHIAS, S.; JUKKA, S. Synthesis and characterization of castor oil-segmented thermoplastic polyurethane with controlled mechanical properties. European Polymer Journal, Oxford, v. 81, p. 129-137, 2016.

LUZ, A.P.; RIBEIRO, S.; PANDOLFELLI, V.C. Artigo revisão: uso da molhabilidade na investigação do comportamento de corrosão de materiais refratários. Cerâmica, São Paulo, v. 54, p. 174-183, 2008.

MALMONGE, J. A.; SANTOS, M. A.; MALMONGE, L. F.; KANDA, D. H. F.; CHIERICE, G. O.; SAKAMOTO, W. K. Characterization of Castor Oil Based Polyuretane Films Prepared With N-Methyl-2-

Pyrrolidinone as a Solvent. Journal of Applied Polymer Science, Hoboken, v. 98, p. 746-749, 2005.

MEDRONHO, B.; LINDMAN, B. Competing forces during cellulose dissolution: from solvents to mechanisms. Current Opinion in Colloid \& Interface Science, Oxford, v. 19, n. 1, p. 32-40, 2014.

MILLER-CHOU, B. A.; KOENIG, J. L. A Review of polymer dissolution. Progress in Polymer Science, London, v. 28, p. 1223-1270, 2003.

MISHRA, A. E MAITI, P. Aromatic polyurethanes: the effect of hard segment and chain structure on their properties. Journal of Polymer Engineering, Berlin, v. 31, p. 253-259, 2011.

MOGADHAM, P.N.; YARMOHAMADI, M.; HASANZADEH, R.; NURI, S. Preparation of polyurethane wood adhesives by polyols formulated with polyester polyols based on castor oil. International Journal of Adhesion and Adhesives, London, v. 68, p. 273-282, 2006.

MOHANTY, A. K.; MISRA M.; DRZAL, L. T. Natural fibers, biopolymers, and biocomposites. Boca Raton: CRC Press, 2005. 
MONTEIL-RIVERA, F.; PHUONG, M.; YE, M.; HALASZ, A.; HAWARI, J. Isolation and characterization of herbaceous lignins for applications in biomaterials. Industrial Crops and Products, Amsterdam, v. 41, p. 356-364, 2013.

MOON, J.; KWAK, S. B.; LEE, J.Y.; KIM, D.; HA, J.U.; OH, J.S. Synthesis of polyurethane foam from ultrasonically decrosslinked automotive seat cushions. Waste Management, Oxford, v. 85, p. 557562, 2019.

MOON, R. J.; MARTINI, A.; NAIRN, J.; SIMONSEN, J.; YOUNGBLOOD, J. Cellulose nanomaterials review: structure, properties and nanocomposites. Chemical Society Reviews, Cambridge, v. 40, n. 7, p. 3941-94, 2011.

MORGADO, D.L.; FROLLINI, E. Decomposição térmica de celulose de linter mercerizado e seus acetatos obtidos a partir de reação homogênea. Polímeros, São Carlos, v. 21, n. 2, 2011.

MOUBARIK, A.; GRIMI, N.; BOUSSETTA , N.; PIZZI, A. Isolation and characterization of lignin from moroccan sugar cane bagasse: production of lignin-phenol-formaldehyde wood adhesive. Industrial Crops and Products, Amsterdam, v. 45, p. 296-302, 2013.

MUTLU, H.; MEIER, M. A. R. Castor oil as a renewable resource for the chemical industry. European Journal of Lipid Science and Technology, Weinheim, v. 112, p. 10-30, 2010.

NAIR, M.N.R.; SUKUMAR, P.; JAYASHREE, V.; NAIR, M.R.G. Mechanical properties and fractography of block copolymers based on NR and MDI based polyurethanes. Polymer Bulletin, Berlin, v. 65, p. 8396, 2010.

NALI, E. C.; RIBEIRO, L. B. N. M.; HORA, A. B. Biorrefinaria integrada à indústria de celulose no Brasil: oportunidade ou necessidade? BNDES Setorial, Rio de Janeiro, v.43, p. 257-294, 2016.

NASAR, A.S.; LIBNI, G. Forward and reverse reactions of N-methylanilineblocked polyisocyanates: a clear step into double Arrhenius plots and equilibrium temperature of thermally reversible reactions. RSC Advances, Cambridge, v.7, p. 34149-34159, 2017.

NEVÁREZ, L. A. M.; CASARRUBIAS, L. B.; CELZARD, A.; FIERRO, V.; MUNOZ, V. T.; DAVILA, A. C.; LUBIAN, J. R. T.; SANCHEZ, G. G. Biopolymer-based nanocomposites: effect of lignin acetylation in cellulose triacetate films. Science and Technology of Advanced Materials, Abingdon, v. 12, p. 1-17, 2011.

NIAOUNAKIS, M. Recycling of biopolymers - The patent perspective. European Polymer Journal, Oxford, v. 114, p. 464-475, 2019.

NOREEN, A.; ZIA, K. M.; ZUBER, M.; TABASUM, S.; ZAHOOR, A. F. Bio-based polyurethane: an efficient and environment friendly coating systems: a review. Progress in Organic Coatings, Amsterdam, v. 91, p. 25-32, 2016.

NOTLEY, S.M.; NORGREN, M. Surface energy and wettability of spin-coated thin films of lignin isolated from wood. Langmuir, Washington, v. 26, n. 8, p. 5484-5490, 2010.

OGUNNIYI D.S.; FAKAYEJO W.R.O. Preparation and properties of polyurethane foams from toluene diisocyanate and mixtures of castor oil and polyol. Iranian Polymer Journal, Tehran, v. 5, p. 56-59, 1996. 
ÖHMAN, F. Precipitation and separation of lignin from kraft black liquor. 2006. (PhD-thesis) Chalmers Technical University, Gothenburg, 2006.

PARK, S. H.; OH, K. W.; KIM, S. H. Reinforcement effect of cellulose nanowhisker on bio-based Polyurethane. Composites Science and Technology, Oxford, v. 86, p. 82-88, 2013.

PASCAULT J.; SAUTEREAU H.; VERDU J.; WILLIAMS R. J. J. Thermosetting polymers. New York: Marcel Dekker, 2002.

PATIL, C. K.; RAJPUT, S. D.; MARATHE, R. J.; KULKARNI, R. D.; PHADNIS, H.; SOHN, D.; MAHULIKAR, P. P.; GITE, V. V. Synthesis of bio-based polyurethane coatings from vegetable oil and dicarboxylic acids. Progress in Organic Coatings, Amsterdam, v. 106, p. 87-95, 2017.

PEI, A.; MALHO, J.M.; RUOKOLAINEN, J.; ZHOU, Q.; BERGLUND, L.A. Strong nanocomposite reinforcement effects in polyurethane elastomer with low volume fraction of cellulose nanocrystals. Macromolecules, Washington, v. 44, p. 4422-4427, 2011.

PFISTER, D.P.; XIA, Y.; LAROCK, R.C. Recent advances in vegetable oil-based polyurethanes. ChemSusChem, Weinheim, v. 4, p. 703-717, 2011.

PHANTHONG, P.; REUBROYCHAROEN, P.; HAO, X.; XU, G.; ABUDULA, G.; GUAN, G. Nanocellulose: extraction and application. Carbon Resources Conversion, Beijing v. 1, p. 32-44, 2018.

POPESCU, M-C.; DOGARU, B-I.; GOANTA, M.; TIMPU, D. Structural and morphological evaluation of CNC reinforced PVA/Starch biodegradable films. International Journal of Biological Macromolecules, Amsterdam, v. 116, p. 385-393, 2018.

RAMIRES, E. C.; DE OLIVEIRA, F.; FROLLINI, E. Composites based on renewable materials: polyurethane-type matrices from forest byproduct/vegetable oil and reinforced with lignocellulosic fibers. Journal of Applied Polymer Science, Hoboken, v. 129, p. 2224-2233, 2013.

RAMIRES, E. C.; MEGIATTO, J. J. D.; GARDRAT, C.; CASTELLAN, A.; FROLLINI, E. Biobased composites from glioxal-phenolic resins and sisal fibers. Bioresource Technology, Amsterdam, v. 101, p. 19982006, 2010.

RIAZ, T.; AHMAD, A.; SALEEMI, S.; ADREES, M.; JAMSHED, F.; HAI, A. M.; JAMIL, T. Synthesis and characterization of polyurethane-cellulose acetate blend membrane for chromium (VI) removal. Carbohydrate Polymers, Oxford, v. 153, p. 582-591, 2016.

RISTIĆ, I. S.; BUDINSKI-SIMENDIĆ, J.; KRAKOVSKY, I.; VALENTOVA, H.; RADIČEVIĆ, R.; CAKIĆ, S.; NIKOLIĆ, N. The properties of polyurethane hybrid materials based on castor oil. Materials Chemistry and Physics, Lausanne, v. 132, n. 1, p. 74-81, 2012.

ROBERTS, J.; KHAN, S. Controlled black liquor viscosity reduction through salting-in. AIChE Journal, New York, v. 42, p. 2319-2326, 1996.

ROGULSKA, M.; KULTYS, A.; PODKOSCIELNY, W. Studies on thermoplastic polyurethanes based on new diphenylethane-derivative diols. II. Synthesis and characterization of segmented polyurethanes from HDI and MDI. European Polymer Journal, Oxford, v. 43, n. 4, p. 1402-1414, 2007.

ROSTRUP-NIELSEN, J.R. Chemistry: making fuels from biomass. Science, Washington, v.308, p. 1421, 2005. 
RUEDA, L.; SARALEGUI, B.A.; FERNÁNDEZ; D’ARLAS, ZHOU, Q.; BERGLUND, L.A.; CORCUERA, M.A.; MONDRAGON, I.; ECEIZA, A. Cellulose nanocrystals/polyurethane nanocomposites. Study from the view point of microphase separated structure. Carbohydrate Polymers, Oxford, v.92, p. 751-757, 2013.

SADEGHIFAR, H.; CUI, C.; ARGYROPOULOS, D. S. Toward thermoplastic lignin polymers. Part 1. Selective masking of phenolic hydroxyl groups in kraftlignins via methylation and oxypropylation chemistries. Industrial \& Engineering Chemistry Research, Washington, v. 51, n. 51, p. 16713-16720, 2012.

SAITO, T.; PERKINS, J. H.; JACKSON, D. C.; TRAMMEL, N. E.; HUNT, M. A.; NASKAR, A. K. Development of lignin-based polyurethane thermoplastics. RCS Advances, Cambridge, v. 3, p. 21832-21840, 2013.

SANNIGRAHI P.; PU, Y.; RAGAUSKAS, A. Cellulosic biorefineries-unleashing lignin opportunities. Current Opinion in Environmental Sustainability, Oxford, v. 2, p. 383-393, 2010.

SANTAN, H. D.; JAMES, C.; FRATINI, E.; MARTÍNEZ, I.; VALENCIA, C.; SÁNCHEZ, M. C.; FRANCO, J. M. Structure-property relationships in solvent free adhesives derived from castor oil. Industrial Crops and Products, Amsterdam, v. 121, p. 90-98, 2018.

SANTOS, P. S. B. D.; ERDOCIA, X.; GATTO, D. A.; LABIDI, J. Characterization of Kraft lignin separated by gradient acid precipitation. Industrial Crops and Products, Amsterdam, v. 55, p. 149-154, 2014.

SARALEGI, A.; GONZALEZ, M.L.; VALEA, A.; ECEIZA, A.; CORCUERA, M.A. The role of cellulose nanocrystals in the improvement of the shape-memory properties of castor oil-based segmented thermoplastic polyurethanes. Composites Science and Technology, Oxford, v 92, p. 27-33, 2014.

SARDARI, A.; ALVANI, A. S.; GHAFFARIAN, S. R. Castor oil-derived water-based polyurethane coatings: structure manipulation for property enhancement. Progress in Organic Coatings, Amsterdam, v. 133, p. 198-205, 2019.

SEVERIAN, D. Polysaccharides: structural diversity and functional versatility. New York: Marcel Dekker, 2005.

SEYMOUR, R. W.; COOPER, S. L. Viscoelastic properties of polyurethane block polymers. Advances in Urethane Science and Technology, Lancaster, v. 3, p. 66-80, 1974.

SETHI, J.; ILLIKAINEN, M.; SAIN, M.; OKSMAN, K. Polylactic acid/polyurethane blend reinforced with cellulose nanocrystals with semi-interpenetrating polymer network (S-IPN) structure. European Polymer Journal, Oxford, v. 86, p. 188-199, 2017.

SHARMA, A.; THAKUR, M.; BHATTACHARYA, M.; MANDAL, T.; GOSWAMI, S. Commercial application of cellulose nano-composites - a review. Biotechnology Reports, Amsterdam, v.21, p. e00316, 2019.

SHEN, D.K.; GU, S.; LUO, K.H.; WANG, S.R.; FANG, M.X. The pyrolytic degradation of wood-derived lignin from pulping process. Bioresource Technology, Amsterdam, v. 101, p. 6136-6146, 2010.

SILVA, B. B. R.; SANTANA, R. M. C.; FORTE, M. M. C. A solventless castor oil-based PU adhesive for wood and foam substrates. International Journal of Adhesion \& Adhesives, London, v. 30, p. 559$565,2010$. 
SJOSTROM, E. Wood chemistry: fundamentals and applications. 2. ed. New York: Academic Press, 1993. $223 \mathrm{p}$.

SOMANI, K. P.; PATEL, N. K.; KANSARA, S. S.; RAKSHIT, A. K. Effect of chain length of polyethylene glycol and crosslink density $(\mathrm{NCO} / \mathrm{OH})$ on properties of castor oil based polyurethane elastomers. Journal of Macromolecular Science, Part A: pure and applied chemistry, New York, v. 43, p. 797-811, 2006.

SOMANI, K. P.; KANSARA, S. S.; PATEL, N. K.; RAKSHIT, A. K. Castor oil based polyurethane adhesives for wood-to-wood bonding. International Journal of Adhesion and Adhesives, London, v. 23, p. 26975, 2003.

STATISTA. Market volume forecast of polyurethane worldwide from 2016 to 2021 (in million tons). Hamburg, 2019. Disponível em: https://www.statista.com/statistics/720341/global-polyurethanemarket-size-forecast/. Acesso em 12 ago. 2019.

SU, Q.; WEI, D.; DAI, W.; ZHANG, Y.; XI, Z. Designing a castor oil-based polyurethane as bioadhesive. Colloids and Surfaces B: biointerfaces, Amsterdam, v. 181, p. 740-748, 2019.

SUN, S.; LI, M.; YUAN, T.; XU, F.; SUN, R. Sequential extractions and structural characterization of lignin with ethanol and alkali from bamboo (Neosinocalamusaffinis). Industrial Crops and Products, Amsterdam, v. 37, p. 51-60, 2012.

SZYCHER, M. Szycher's handbook of polyurethanes. Boca Raton: CRC Press, 1999.

TAKIGAWA, T; ENDO, Y. Effects of Glutaraldehyde Exposure on Human Health. Journal of Occupational Health, Tokyo, v. 48, p. 75-87, 2006.

TAPPI. T 222 OM-02. Acid-insoluble lignin in wood and pulp. Peachtree Corners, 2002. p. 5.

TAPPI. T 412 OM-93. Ash in wood, pulp, paper and paperboard: combustion at 900 ㄷ. Peachtree Corners, 1993. p. 4.

TAVARES, L. B.; BOAS, C. V.; SCHELEDER, G. R.; NACAS, A. M.; ROSA, D. S.; SANTOS, D. J. Bio-based polyurethane prepared from Kraft lignin and modified castor oil. Express Polymer Letters, Budapest, v.10, n.11, p. 927-940, 2016.

TEJADO, A.; PEÑA, C.; LABIDI, J.; ECHEVERRIA, J. M.; MONDRAGON, I. Physico-chemical characterization of lignins from different sources for use in phenol- formaldehyde resin synthesis. BioResource Technology, Amsterdam, v. 98, p. 1655- 1663, 2007.

THRING, R. W.; NI, P.; AHARONI, S. M. Molecular weight effects of the soft segment on the ultimate properties of lignin-derived polyurethanes. International Journal of Polymeric Materials and Polymeric Biomaterials, New York, v. 53, p. 507-524, 2004.

TIAN, D.; WANG, F.; YANG, Z.; NIU, X.; WU, Q.; SUN, P. High-performance polyurethane nanocomposites based on UPy-modified cellulose nanocrystals. Carbohydrate Polymers, Oxford, v. 219, p. 191-200, 2019.

TOLEDANO, L. SERRANO, A. GARCIA, I. MONDRAGON, J. LABIDI. Comparative study of lignin fractionation by ultrafiltration and selective acid precipitation. Separation and Purification Technology, Oxford, v.154, p. 82-88, 2015. 
TRIBOT, A.; AMER, G.; ALIO, M. A.; BAYNAST, H.; DELATTRE, C.; PONS, A.; MATHIAS, J. D.; CALLOIS, J. M.; VIAL, C.; MICHAUD, P.; DUSSAP, C. G. Wood-lignin: Supply, extraction processes and use as biobased material. European Polymer Journal, Oxford, v.112, p. 228-240, 2019.

TROVATI, G.; SUMAN, M. V. N.; SANCHES, E. A.; CAMPELO, P. H.; NETO, R.B.; NETO, S.C.; TROVATI, L.R. Production and characterization of polyurethane castor oil (Ricinus communis) foam for nautical fender. Polymer Testing, London, v. 73, p. 87-93, 2019.

TROVATI, G.; SANCHES, E. A.; NETO, S. C.; MASCARENHAS, Y. P.; CHIERICE, G. O. Characterization of polyurethane resins by FTIR, TGA, and XRD. Journal of Applied Polymer Science, Hoboken, v. 115, p. 263-268, 2010.

VALE, M.; MATEUS, M. M.; DOS SANTOS, R.G.; DE CASTRO, C. N.; SCHRIJVER, A.; BORDADO, J. C.; MARQUES, A. C. Replacement of petroleum-derived diols by sustainable biopolyols in one component polyurethane foams. Journal of Cleaner Production, Amsterdam, v. 212, p. 1036-1043, 2019.

VALLEJOS, M. E.; PERESIN, M. S.; ROJAS, O. J. All-Cellulose composite fibers obtained by electrospinning dispersions of cellulose acetate and cellulose nanocrystals. Journal of Polymers and the Environment, New York, v. 20, n. 4, p. 1075-1083, 2012.

VAN DER KLASHORST, G. H. Lignin-formaldehyde wood adhesives. In: PIZZI, A. (ed.). Wood adhesives chemistry and technology. New York: Marcel Dekker, 1989. p. 155-190.

VELDEN, M. V.; BAEYENS, J.; BREMS, A.; JANSSENS, B.; DEWIL, R. Fundamentals, kinetics and endothermicity of the biomass pyrolysis reaction. Renewable Energy, Oxford, v. 35, n. 1, p. 232-242, 2010.

VILAR, W. Química e tecnologia dos poliuretanos. 3 ed. Rio de Janeiro: [s.n.], 2002.

VISHTAL, A.; KRASLAWSKI, A. Challenges in industrial applications of technical lignins. Bioresources, Raleigh, v. 6, p. 3547-3568, 2011.

VOLKOVA, E. R.; TERESHATOV, V. V.; KARMANOV, V. I.; MAKAROVA, M. A.; SLOBODINYUK, A. I. Polyurethane Adhesive Composition Cured at Room Temperature. Polymer Science, Series D. Glues and sealing materials, Moscow, v. 6, n. 2, p. 120-124, 2013.

VORONOVA, M. I.; SUROV, O.V.; RUBLEVA, N. V.; KOCHKINA, N. E.; AFINEEVSKII, A. V.; ZAKHAROV, A. G. Nanocrystalline cellulose composites with polyvinylpyrrolidone: self-assembly and dispersibility in water. Composites Communications, Amsterdam, v. 15, p.108-112, 2019.

WANG, C.; MA, C.; MU, C.; LIN, W. Tailor-made zwitterionic polyurethane coatings: microstructure, mechanical property and their antimicrobial performance. RSC Advances, Cambridge, v. 7, p. 2752227529, 2017.

WANG, X.; ZHANG, Y.; LIANG, H.; ZHOU, X.; FANG, C.; ZHANG, C.; LUO, Y. Synthesis and properties of castor oil-based waterborne polyurethane/sodium alginate composites with tunable properties.

Carbohydrate Polymers, Oxford, v. 208, p. 391-397, 2019.

WYMAN, C. E.; DALE, B E.; ELANDER,R. T.; HOLTZAPPLE, M.; LADISCH, M. R.; LEE, Y. Y. Coordinated development of leading biomass pretreatment technologies. Bioresource Technology, Amsterdam, v. 96, n. 18, p. 1959-1966, 2005. 
WON KIM, S. Prediction of product distribution in fine biomass pyrolysis influidized beds based on proximate analysis. BioResource Technology, Amsterdam, v. 175, p. 275-283, 2015.

WU, Q.; HENRIKSSON, M.; LIU, X.; BERGLUND, L. A. A High strength nanocomposite based on microcrystalline Cellulose and Polyurethane. Biomacromolecules, Washington, v. 8, n. 12, p. 36873692, 2007.

YANG, W.; FORTUNATI, E.; GAO, D.; BALESTRA, G.M.; GIOVANALE, G.; HE, X.; TORRE, L.; KENNY, J.M.; PUGLIA, D. Valorization of acid isolated high yield lignin nanoparticles as innovative antioxidant/antimicrobial organic materials. ACS Sustainable Chemistry \& Engineering, Washington, v. 6, p. 3502-3514, 2018.

YILGOR, I.; YILGOR, E.; WILKES, G. L. Critical parameters in designing segmented polyurethanes and their effect on morphology and properties: a comprehensive review. Polymer, London, v. 58, p. A1A36, 2015.

XUE, B. L.; WEN, J. L.; SUN, R. C. Lignin-based rigid polyurethane foam reinforced with pulp fiber: Synthesis and characterization. ACS Sustainable Chemistry \&Engineering, Washington, v. 2, n. 6, p. 1474-1480, 2014.

ZHANG, C., WU, H., KESSLER, M. R. High bio-content poly - urethane composites with urethane modified lignin as filler. Polymer, London, v. 69, p. 52-57, 2015.

ZHANG, Y.; WANG, J.; FANG, X.; LIAO, J.; ZHOU, X.; ZHOU, S.; BAI, F.; PENG, S. High solid content production of environmentally benign ultra-thin lignin-based polyurethane films: plasticization and degradation. Polymer, London, v. 178, 2019.

ZHANG, Y.; YAN, R.; NGO, T.; ZHAO, Q.; DUAN, J.; DU, X.; WANG, Y.; LIU, B.; SUN, Z.; HU, W.; XIE, H. Ozone oxidized lignin-based polyurethane with improved properties. European Polymer Journal, Oxford, v. 117, p. 114-122, 2019.

ZHAO, X.; CHENG, K.; LIU, D. Organosolv pretreatment of lignocellulosic biomass from enzymatic hydrolysis. Applied Microbiology and Biotechnology, Heidelberg, v. 82, p. 815-827, 2009.

ZHOU, Q.; MALM, E.; NILSSON, H.; LARSSON, P. T.; IVERSEN, T.; BERGLUND, L. A.; BULONE, V. Nanostructured biocomposites based on bacterial cellulosic nanofibers compartmentalized by a soft hydroxyethylcellulose matrix coating. Soft Matter, Cambridge, v. 5, n. 21, p. 4057-4340, 2009. 
APÊNDICE A - Cromatogramas de distribuição de massa molar da (a) Lignina Kraft Bruta Acetilada (LKB); (b) Lignina Kraft Purificada Acetilada (LK) e (c) Lignina Kraft Modificada com Glutaraldeído Acetilada (LK-Glu).

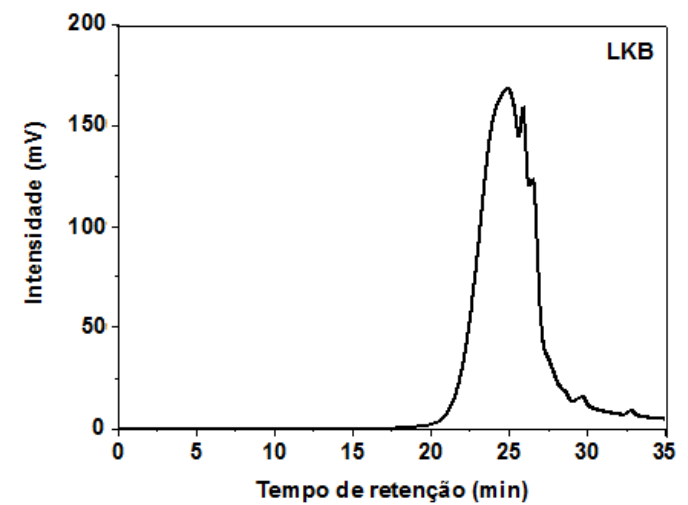

(a)

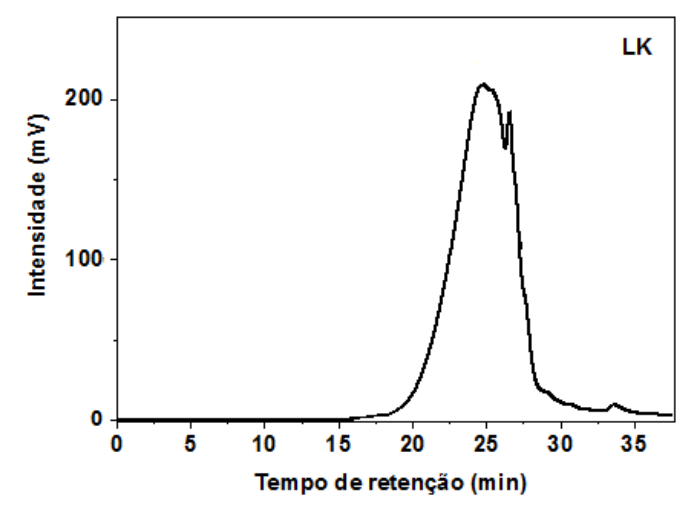

(b)

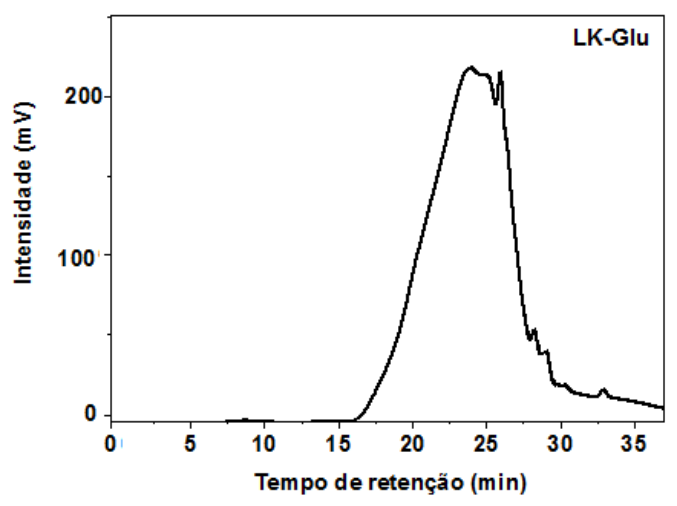

(c) 
APÊNDICE B - Espectros de FTIR para Lignina Kraft Purificada não Acetilada (LK), Lignina Kraft Purificada Acetilada (LK acetilada) e Lignina Kraft Modificada com Glutaraldeído e Acetilada (LK-Glu acetilada) na região de 4000 a $400 \mathrm{~cm}^{-1}$.

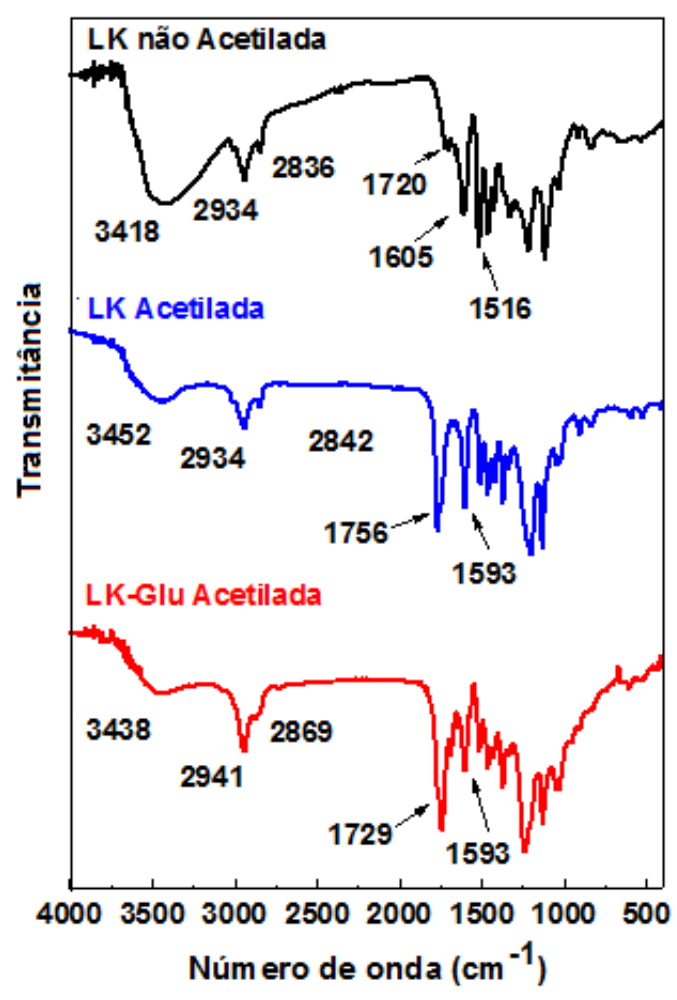


APÊNDICE C - Espectros de FTIR para os filmes $\mathrm{PU}_{\mathrm{CO}}$, LignoPU ${ }_{\text {соцкзо }}$

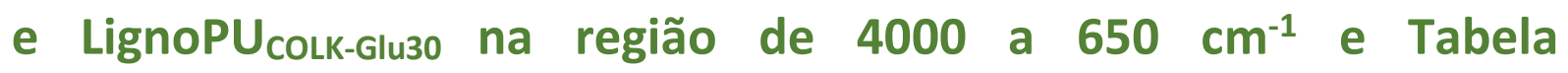
apresentando as principais bandas de transmissão observadas nos respectivos filmes.

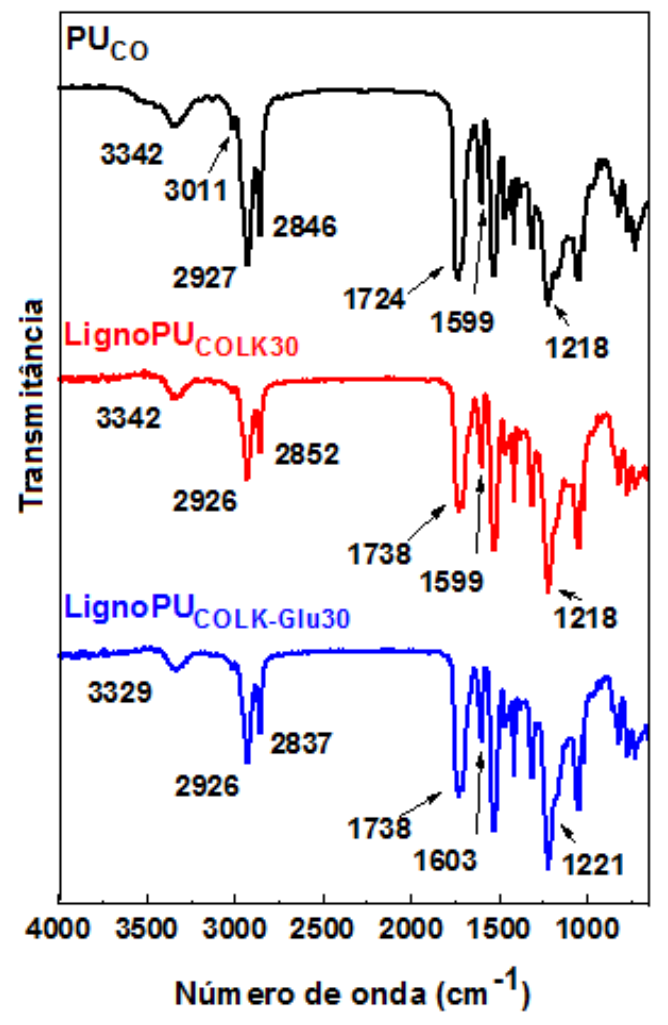

\begin{tabular}{cl}
\hline № de onda $\left(\mathbf{c m}^{-1}\right)$ & \multicolumn{1}{c}{ Possíveis Atribuiçães } \\
\hline $3342-3329$ & Vibração de estiramento da ligação N-H \\
\hline 3011 & $\begin{array}{l}\text { Deformação axial (=C-H) em dupla ligação no óleo de mamona } \\
\text { (óleo ricinoleico) }\end{array}$ \\
\hline $2927-2926$ & Deformação axial (C-H ${ }_{2}$ ) assimétrica \\
\hline $2852-2837$ & Deformação axial (C-H2) simétrica \\
\hline $2277-2266$ & Grupos isocianato (NCO) não reagidos \\
\hline $1738-1724$ & $\begin{array}{l}\text { Estiramento dos grupos carbonila da ligação uretânica (NH-CO- } \\
\text { O) (Amida I) }\end{array}$ \\
\hline $1603-1599$ & Vibração da ligação dupla dos anéis aromáticos (C=C) \\
\hline $1529-1521$ & Vibração N-H e C-N (Amida II) \\
\hline 1459 & Vibração N-H e C-N (Amida III) \\
\hline 1408 & Deformação axial C-N \\
\hline $1221-1218$ & Deformação axial assimétrica (C-O-C) \\
\hline 1039 & Deformação axial simétrica (C-O-C) \\
\hline $890-723$ & Deformação angular fora do plano C-H (anel aromático) \\
\hline
\end{tabular}

Fonte: Adaptado de RISTIC et al., 2012. 
APÊNDICE D - Espectros FTIR das misturas reacionais imediatamente após deposição na placa (CO, 30 e $50 \%$ de LK ou LK-Glu e pMDI) e para os filmes formados, na região de 4000 a $1550 \mathrm{~cm}^{-1}$. Temperaturas avaliadas: 50,75 e $100^{\circ} \mathrm{C}$.

$50{ }^{\circ} \mathrm{C}$

LignoPU $_{\text {CoLKзo }}$
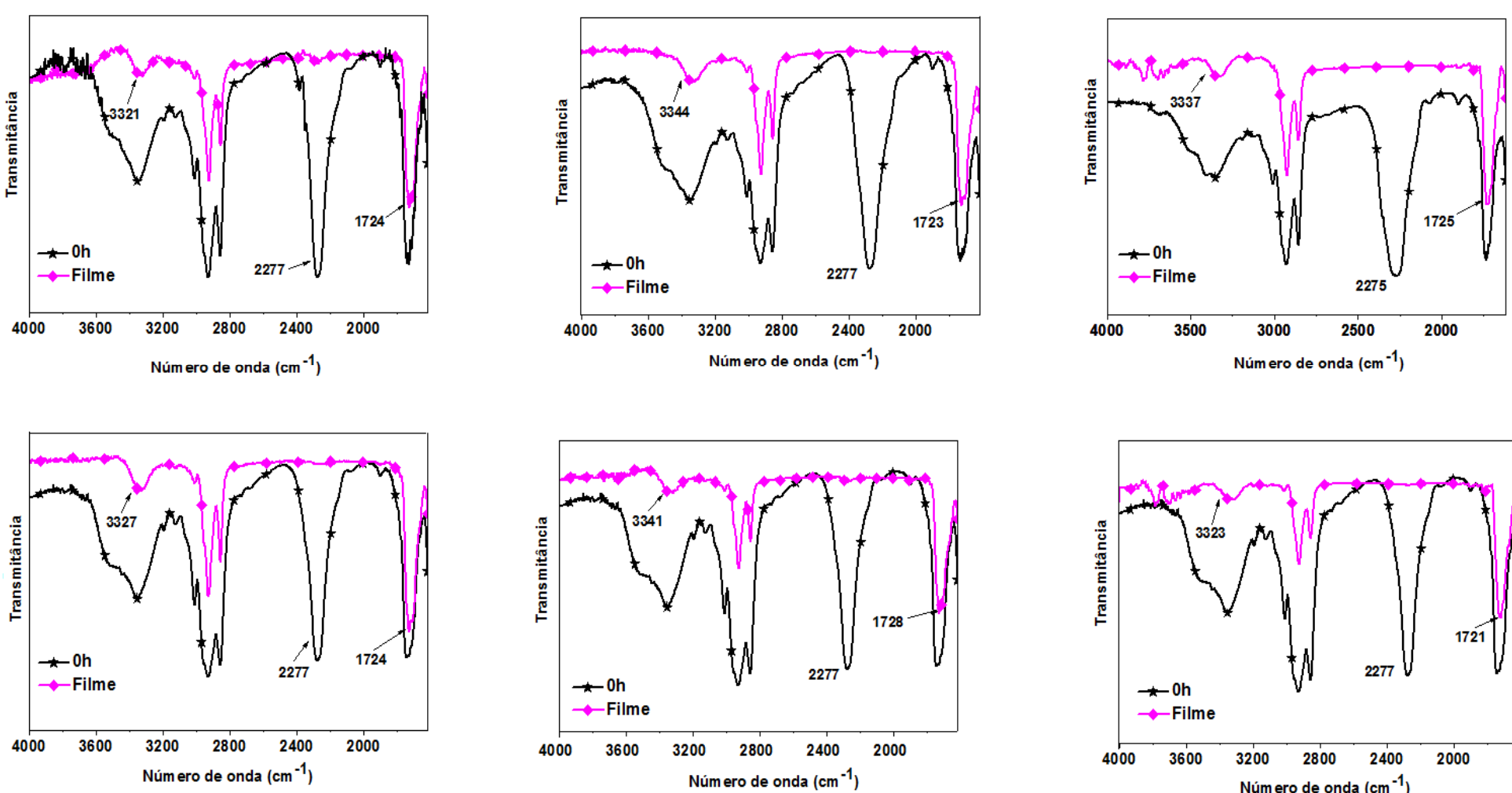

$75^{\circ} \mathrm{C}$

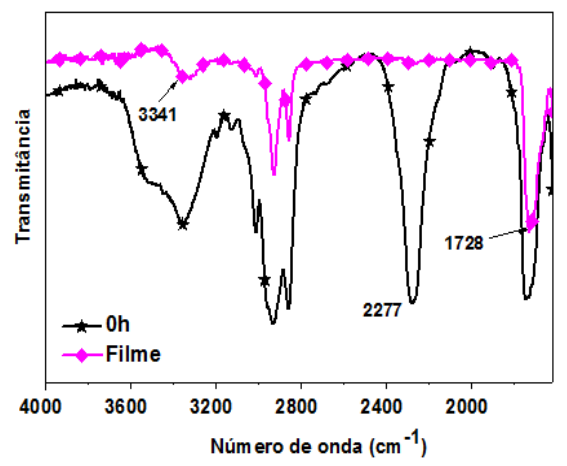

$100^{\circ} \mathrm{C}$

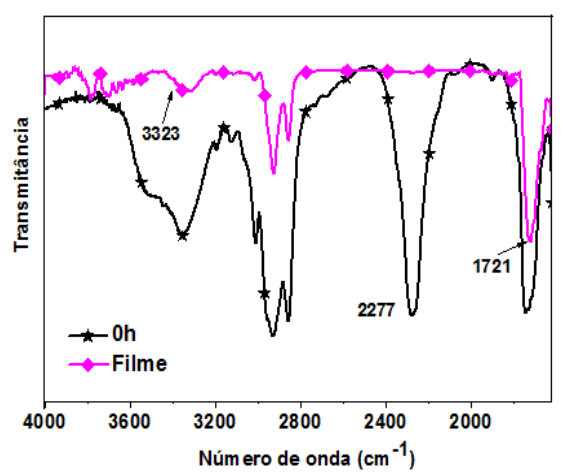


CONTINUAÇÃO APÊNDICE D - Espectros FTIR das misturas reacionais imediatamente após deposição na placa (CO, 30 e 50\% de LK ou LK-Glu e pMDI) e para os filmes formados, na região de 4000 a $1550 \mathrm{~cm}^{-1}$. Temperaturas avaliadas: 50,75 e $100^{\circ} \mathrm{C}$.

$50^{\circ} \mathrm{C}$

LignoPU $_{\text {CoLk50 }}$

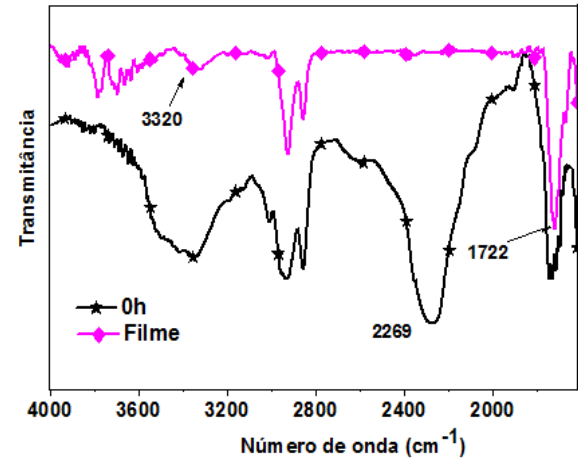

LignoPU COLK-Glu50

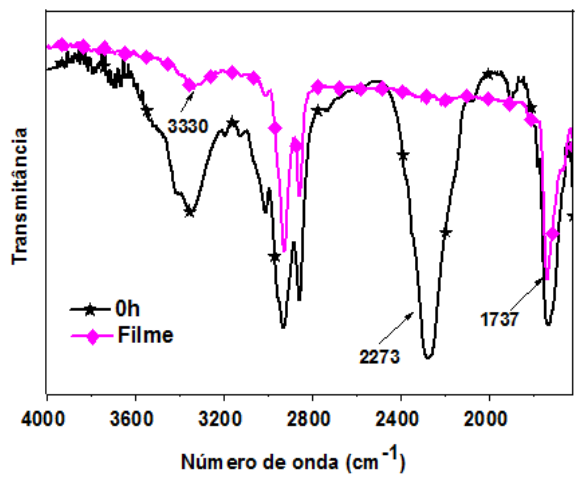

$75^{\circ} \mathrm{C}$
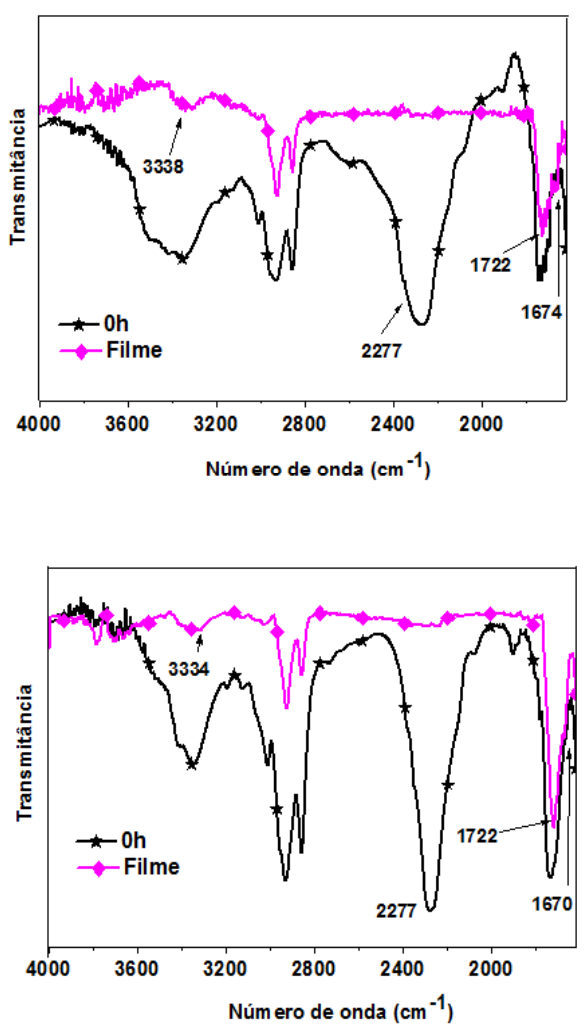

$100^{\circ} \mathrm{C}$
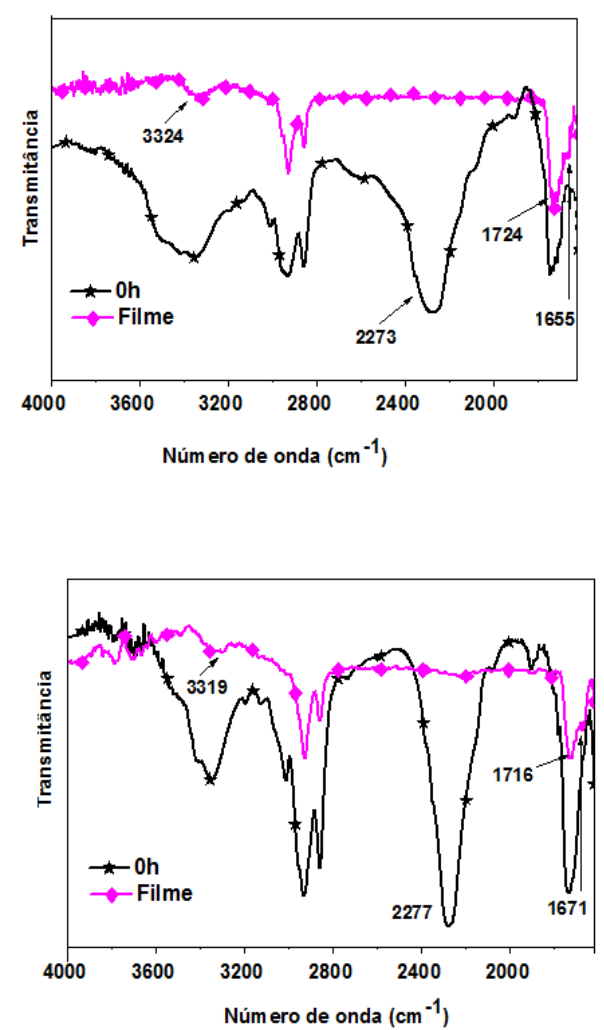
APÊNDICE E - Curvas TGA e DTG dos filmes (a) LignoPU соцкзо e

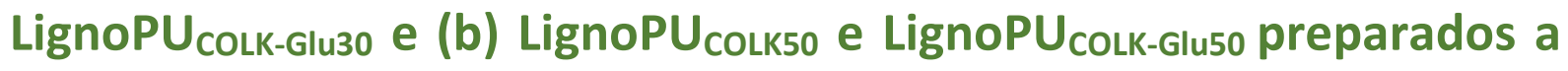
$25,50,75$ e $100^{\circ} \mathrm{C}$ em atmosfera de $N_{2}$, vazão de $50 \mathrm{~mL} \mathrm{~min}^{-1}$ e razão de aquecimento de $10^{\circ} \mathrm{C} \mathrm{min}{ }^{-1}$.
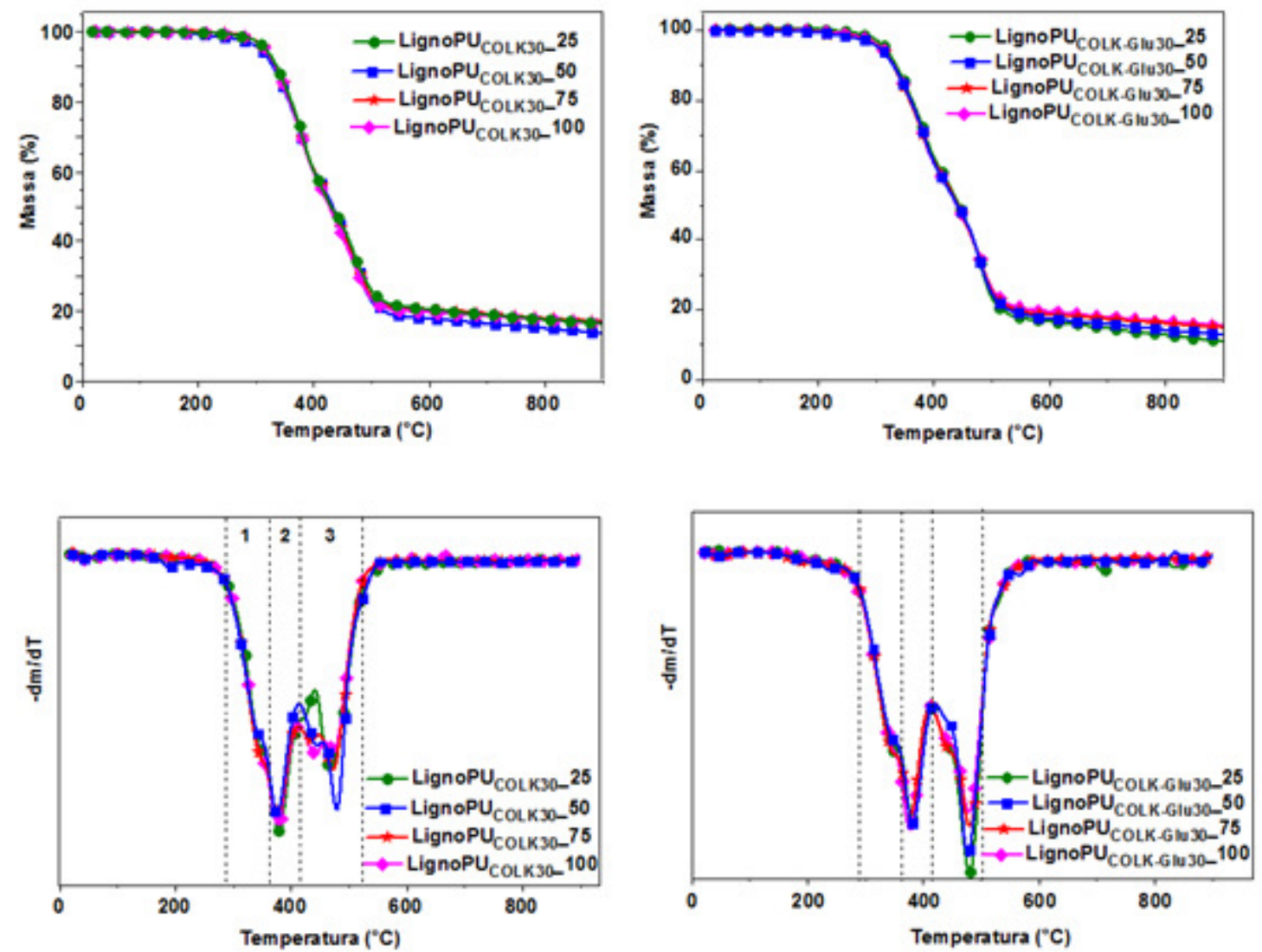

(a) 
CONTINUAÇÃO APÊNDICE E - Curvas TGA e DTG dos filmes (a)

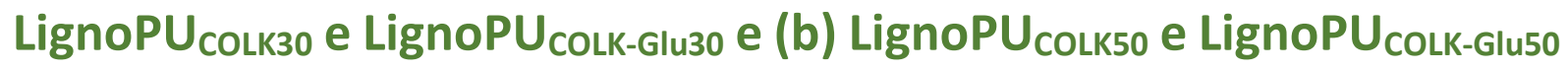
preparados a $25,50,75$ e $100{ }^{\circ} \mathrm{C}$ em atmosfera de $\mathrm{N}_{2}$, vazão de $50 \mathrm{~mL}$ $\mathrm{min}^{-1}$ e razão de aquecimento de $10{ }^{\circ} \mathrm{C} \mathrm{min}^{-1}$.
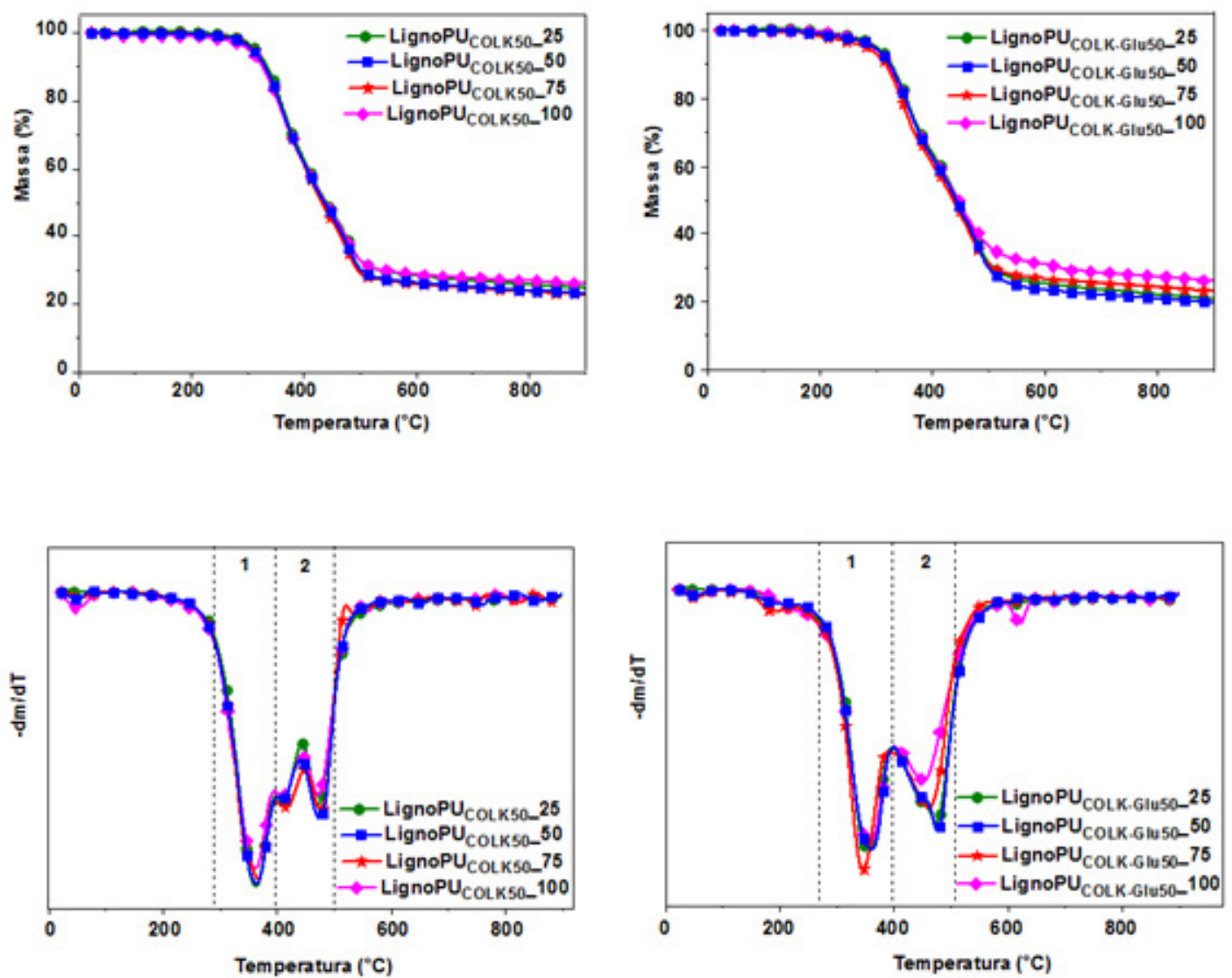

(b) 


\section{APÊNDICE F - Espectros de FTIR para os filmes PUHco,}

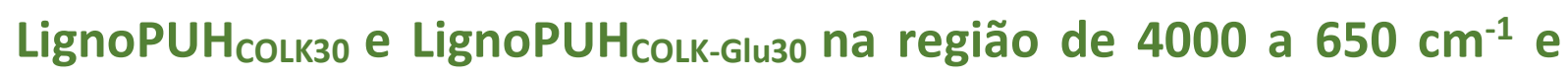
Tabela apresentando as principais bandas de transmissão observadas nos respectivos filmes.

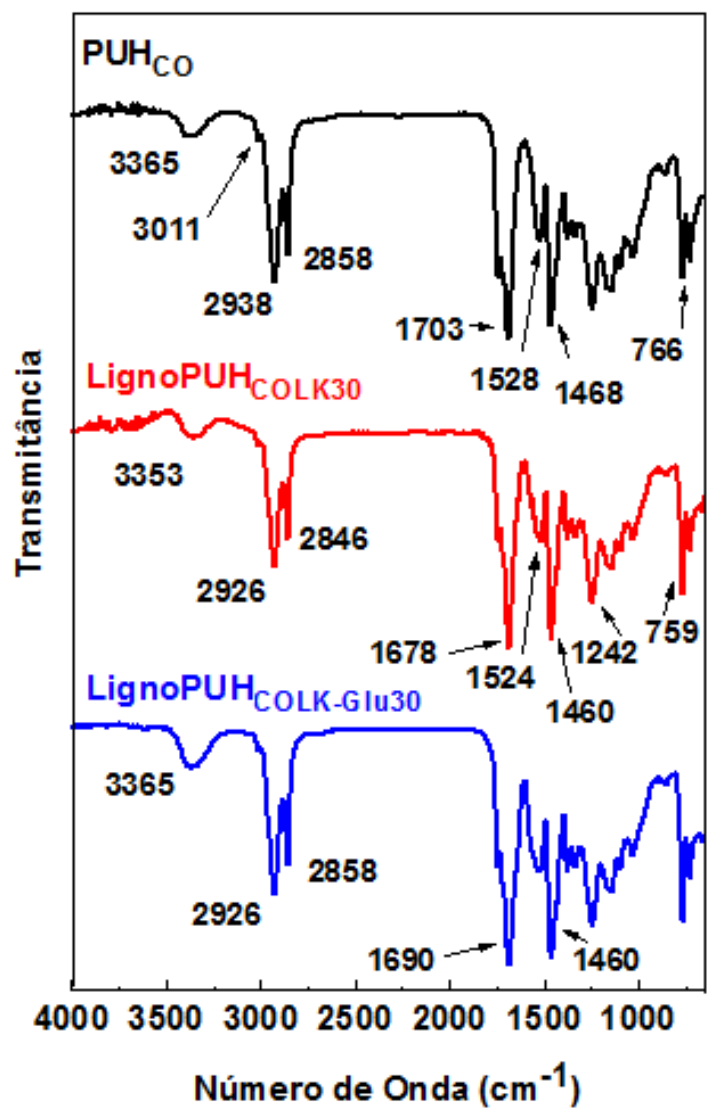

\begin{tabular}{cl}
\hline No de onda $\left(\mathbf{c m}^{-1}\right)$ & \multicolumn{1}{c}{ Possíveis Atribuições } \\
\hline $3365-3353$ & Vibração de estiramento da ligação N-H \\
\hline 3011 & $\begin{array}{l}\text { Deformação axial (=C-H) em dupla ligação no óleo de mamona (óleo } \\
\text { ricinoleico) }\end{array}$ \\
\hline $2938-2926$ & Deformação axial (C- $\mathrm{H}_{2}$ ) assimétrica \\
\hline $2858-2846$ & Deformação axial (C-H $)$ simétrica \\
\hline $2277-2266$ & Grupos isocianato (NCO) não reagidos \\
\hline $1703-1678$ & Estiramento dos grupos carbonila da ligação uretânica (NH-CO-O) \\
\hline $1518-1513$ & (Amida I) \\
\hline $1468-1460$ & Vibração N-H e C-N (Amida II) \\
\hline $1245-1242$ & Vibração N-H e C-N (Amida III) \\
\hline $766-759$ & Deformação axial assimétrica (C-O-C) \\
\hline
\end{tabular}

Fonte: Adaptado de RISTIC et al., 2012; HU et al., 2016. 
APÊNDICE G - Espectros FTIR das misturas reacionais imediatamente após deposição na placa (CO, LK ou LK-Glu e tHDI) e para os filmes formados, na região de 4000 a $1600 \mathrm{~cm}^{-1}$.
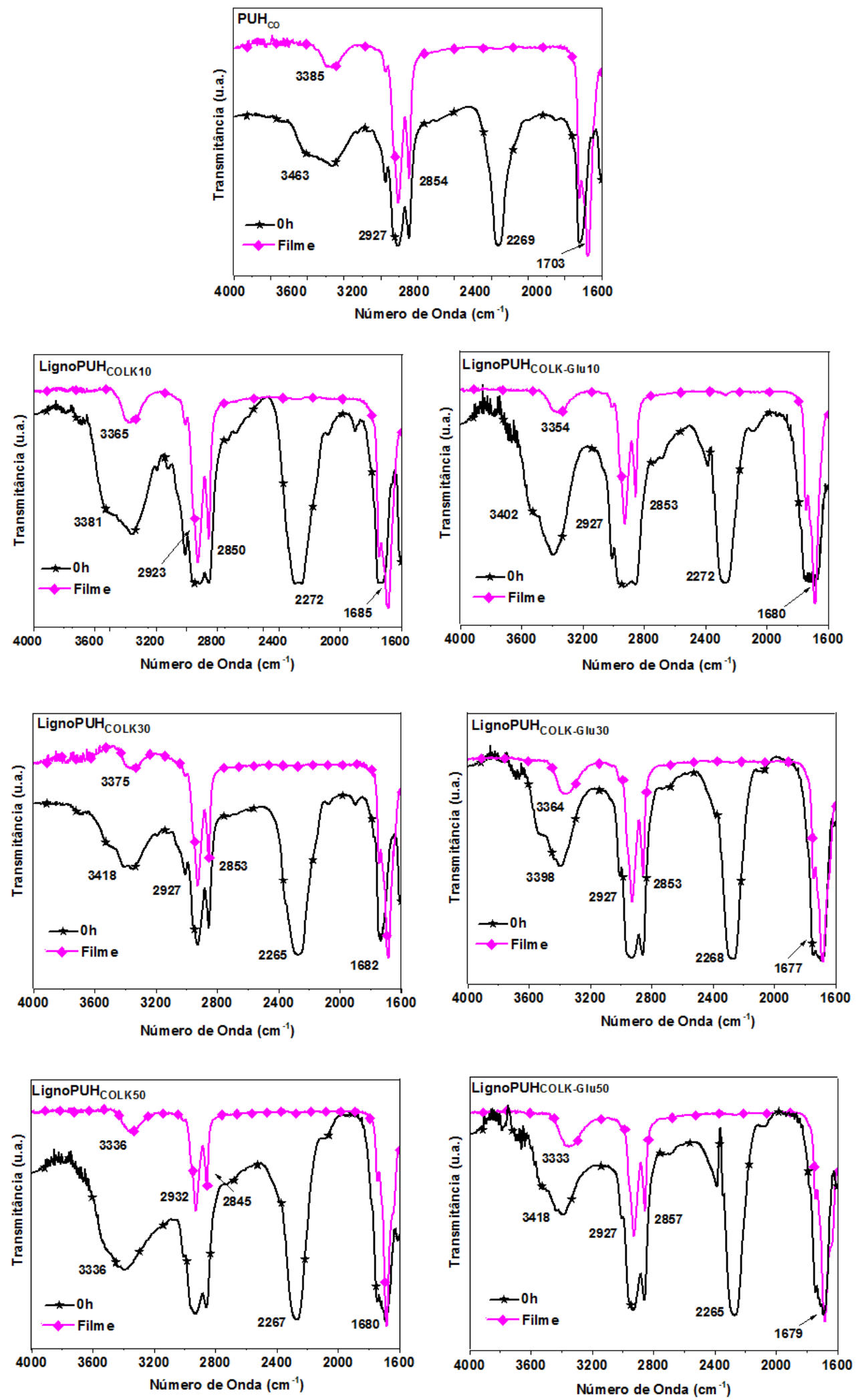
APÊNDICE H - Curvas TGA e DTG dos filmes (a) LignoPUH ${ }_{\text {соцкзо }} \mathrm{e}$ LignoPUH ${ }_{\text {CoLk-Glu30 }}$ e (b) LignoPUH CoLk50 $_{\text {e LignoPUH }}$ CoLk-Glu50 preparados a $25,50,75$ e $100^{\circ} \mathrm{C}$ em atmosfera de $\mathrm{N}_{2}$, vazão de $50 \mathrm{~mL}$ $\mathrm{min}^{-1} \mathrm{e}$ razão de aquecimento de $10^{\circ} \mathrm{C} \mathrm{min}^{-1}$.
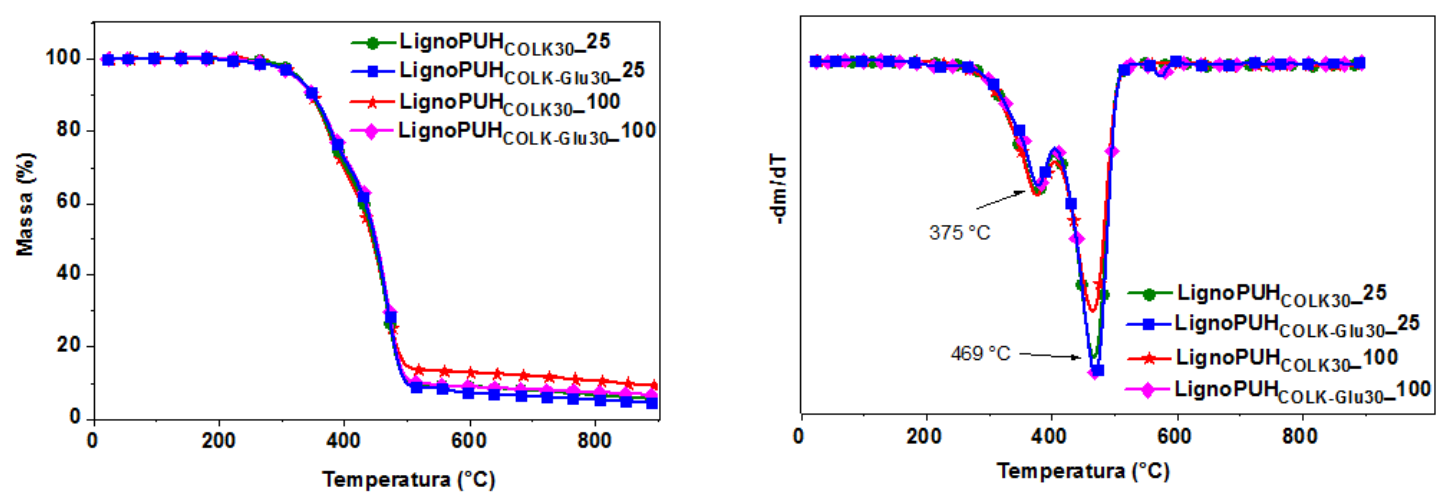

(a)
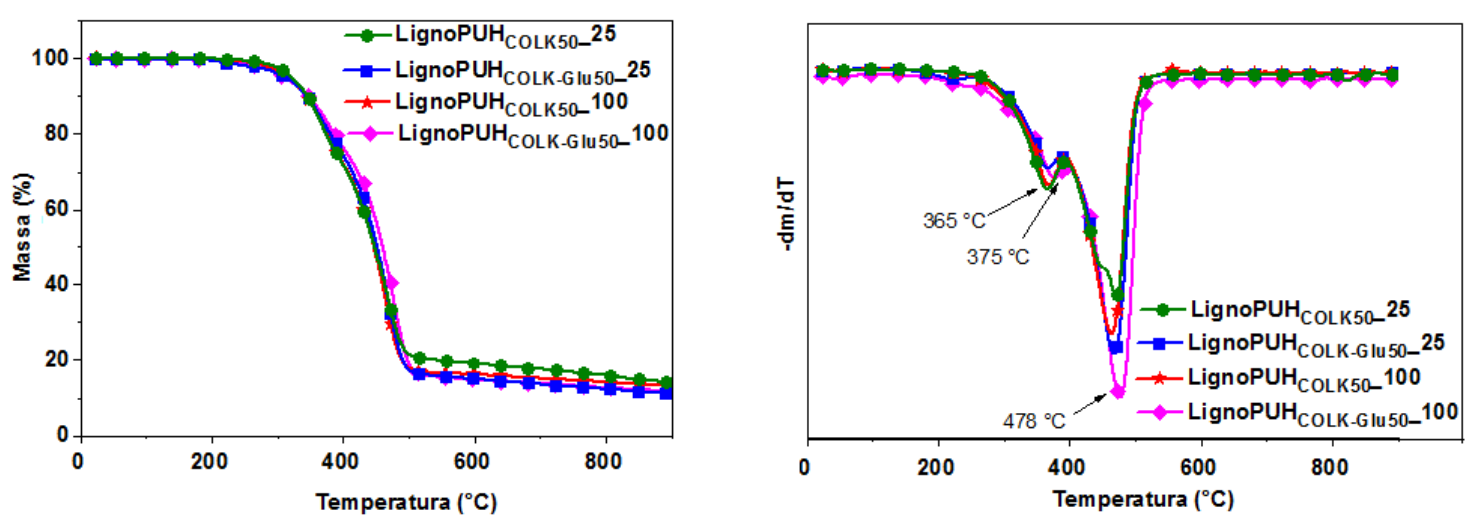

(b) 
APÊNDICE I - Espectros FTIR das misturas reacionais imediatamente após deposição na placa (CO, 50\% LK ou LK-Glu e tHDI) na presença ou não de CNCs e para os filmes formados, na região de 4000 a $1550 \mathrm{~cm}^{-}$ 1 .
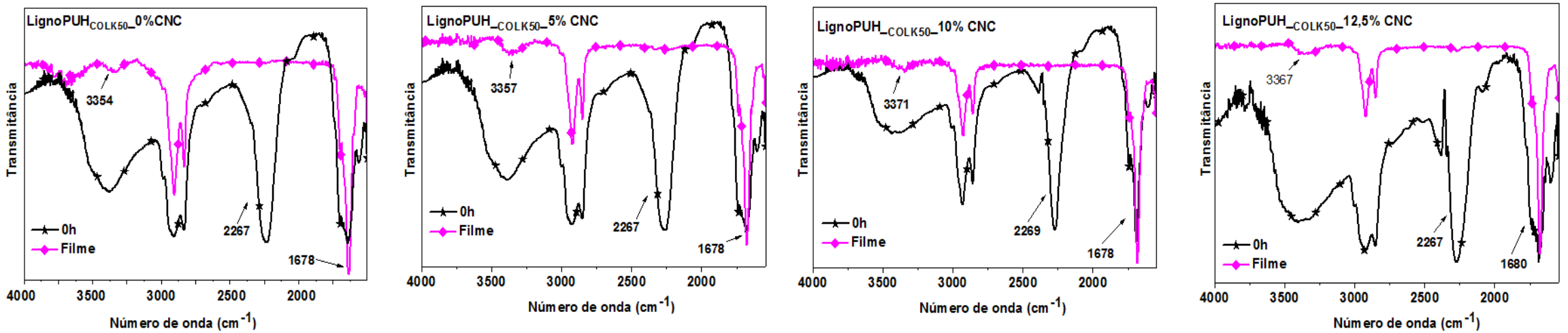

(a)
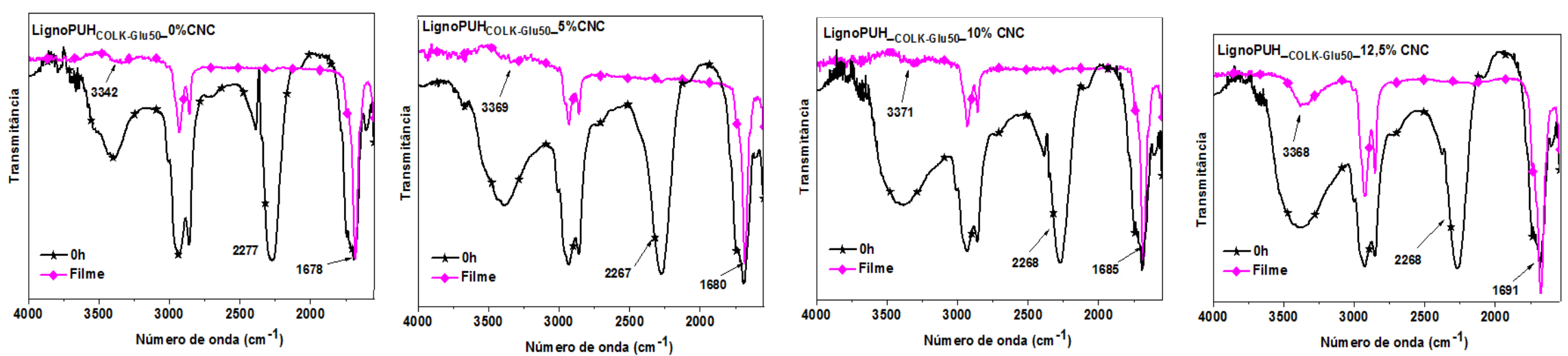

(b) 
APÊNDICE J - Curvas TGA e DTG dos CNCs em atmosfera de $\mathrm{N}_{2}$, vazão de $50 \mathrm{~mL} \mathrm{~min}^{-1} \mathrm{e}$ razão de aquecimento de $10^{\circ} \mathrm{C} \mathrm{min}^{-1}$.

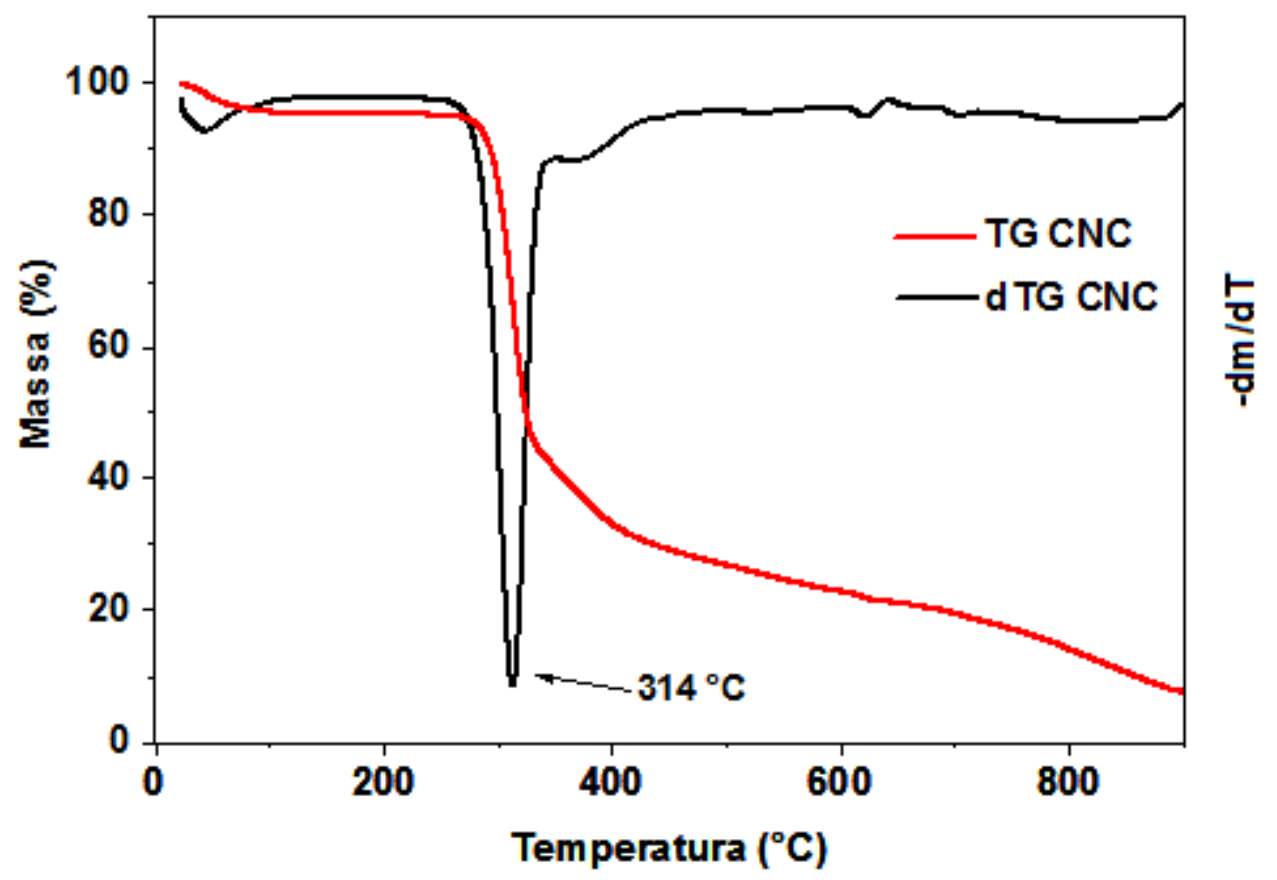

